\title{
Health and Environmental Effects of Oil and Gas Technologies: Research Needs
}

A Report to the Federal Interagency Committee on the Health and Environmental Effects of Energy Technologies 


\section{DISCLAIMER}

This report was prepared as an account of work sponsored by an agency of the United States Government. Neither the United States Government nor any agency Thereof, nor any of their employees, makes any warranty, express or implied, or assumes any legal liability or responsibility for the accuracy, completeness, or usefulness of any information, apparatus, product, or process disclosed, or represents that its use would not infringe privately owned rights. Reference herein to any specific commercial product, process, or service by trade name, trademark, manufacturer, or otherwise does not necessarily constitute or imply its endorsement, recommendation, or favoring by the United States Government or any agency thereof. The views and opinions of authors expressed herein do not necessarily state or reflect those of the United States Government or any agency thereof. 


\section{DISCLAIMER}

Portions of this document may be illegible in electronic image products. Images are produced from the best available original document. 


\section{Health and Environmental Effects of Oil and Gas Technologies: Research Needs}

\section{A Report to the Federal Interagency Committee on the Health and Environmental Effects of Energy Technologies}

Richard D. Brown

Project Manager

July 1981

MTR-81W77

Sponsor: The Federal Interagency Committee on the Health and Environmental Effects of Energy Technologies Contract No.: DEAC-01-79-EVInM18

The MITRE Corporation Metrek Division

1820 Dolley Madison Boulevard

McLean, Virginia 22102

DISCLAIMER

This book was prepared as an account of work sponsored by an agenev of the Unired States Government. weither the United Stales Government nor any agency thereot, nor ony of their employees, makes any

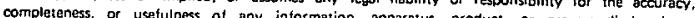

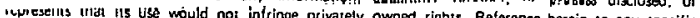
commercial product process, or service by trode name, trodemark. Re not necessarily constitute or imoly its endorsement, recommendation, or tor. or onemise. does 
THIS PAGE

\section{WAS INTENTIONALLY \\ LEFT BLANK}


FOREWORD

With the publication of this document, a wealth of information concerning all facets of the oil and gas industry is available under one cover. Prepared by The MITRE Corporation and subjected to review by knowledgeable individuals, this report focuses on topics of special interest to scientists, program planners, and industry officials concerned with the health and environmental issues associated with various facets of the oil and gas industry.

It is intended as a preliminary exploration, not as an assessment report. Its purpose is not to determine the precise nature or magnitude of any health or environmental problem, but instead to explore areas that may warrant further investigation.

Our understanding of the many problems discussed in this report is so limited that definitive statements cannot be made about their nature and magnitude. Where this is true, the report suggests research strategies that can increase our understanding--ultimately providing material for future assessments.

The numerous research needs identified are intentionally not ranked. Naturally they vary in significance--in the numbers of persons impacted, in the extent of environmental effects, and in the intensity of research that is required. However, a ranking would be meaningless because researchers and program managers utilize different criteria in establishing priorities. For this reason, the report provides basic information in a context that will permit individuals to set their own priorities with respect to their own research programs.

The report should be valuable to a wide range of individuals. It can be an important resource for the scientist engaged in topical research, for program planners in state and Federal agencies, and for industry, as we seek ways to make energy technologies safer for employees, the general public, and the environment. 


\section{ACKNOWLEDGMENTS}

The project manager wishes to acknowledge the contributions of certain individuals who were instrumental in the successful completion of this report. In addition to the primary author, Richard Brown, MITKE authors who contributed to various sections of the report were: Robert Small (Onshore Development); Michelle Leslie, Shashi Sood, and Alexis Taylor (Offshore Development); Ronald Rader (Refinery Operations); Ronald Rader and Robert Small (Transportation and Storage); Rajani Joglekar (End Use); and Rajani Joglekar, Ronald Rader, and Robert Small (Basic Effects Issues).

A thank you goes to the MITRE reviewers--Larry Andrews, Linda Duncan, Kit Krickenberger, Jan Sassaman, and Wade Smith--as well as to the peer reviewers outside of MITRE, including Robert Drew and Samuel Morris (Brookhaven National Laboratory); Vaun Newil1 (Exxon Corporation); Clint Cox, Susan Hern, and Richard Waxweiler (National Institute for Occupational Safety and Health); and Michael Chartock and Michael DeVine (the University of Oklahoma).

A special thank you is given to members of the Committee for the guidance and patience they provided throughout the development of this document. Finally, a special acknowledgment is given to the support staff for their technical, lngistioal, and elllurlal assisLance, including: Ruth Cooke (production), Charlotte London (coordination), Vivian Aubuchon (editing), and particularly, Ann Shreve and the others. who provided many hours of typing support. 


\section{OUTLINE OF REPORT}

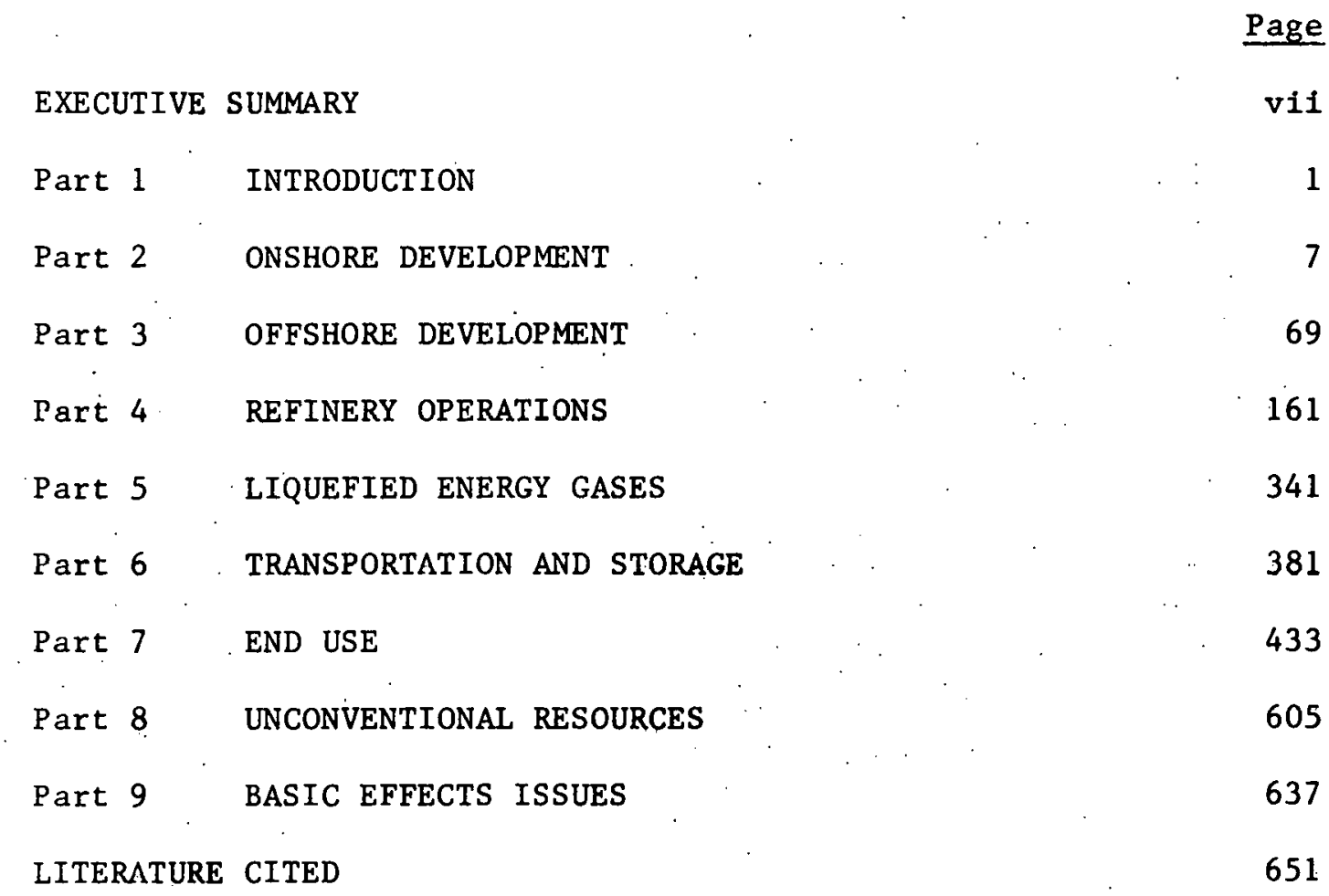


THIS PAGE

\section{WAS INTENTIONALLY LEFT BLANK}


Executive Summary 
This report discusses health and environmental issues associated with oil and gas technologies as they are currently perceived--both those that exist and those that are expected to emerge over the next two decades. The various sections of this report contain discussions of specific problem areas and relevant new research activities which should be pursued.

This is not an exhaustive investigation of all problem areas, but the report explores a wide range of issues to provide a comprehensive picture of existing uncertaintiss, trends, and other factors that should serve as the focus of future research.

The problem areas of major concerm include: effects of drilling fluids, offshore accidents, refineries and worker health, soil biota and petroleum spills, indoor air pollution, information transfer, and unconventional resources. These are highlighted in the Executive Summary because they pose serious threats to human health and the environment, and because of the sparcity of accumulated knowledge related to their definition.

\section{EFFECTS OF DRILLING FLUIDS}

There are over 1,000 trade name products available for drilling fluid formulations (see Table 18 in the offshore section for typical drilling fluid components). These are mixed as appropriate for a particular drizling activity in order to cool and lubricate the drilling bit and pipe, transport cuttings to the surface, act as a hydrostatic head against formation pressure, and to minimize corrosion.

These fluids, often termed "muds," have boon identifi.ed as highly toxic to aquatic biota under laboratory conditions. It is suspected that synergistic effects among components of driliing fluids could increase toxicity. Occupational health concems focus on dermal and inhalation exposure during formulation, handling, and disposal of the fluids. Environmental concerm focuses on the toxicity of the fluids with respect to long-term exposure of biota living on the seafloor adjacent to drilling rigs and within offshore drilling fields. The possibility of food chain contamination exists.

The issue of the effects of drilling muds on human health and aquatic biota should be defined. Information gathered in this area is applicable, not only to conventional onshore and offshore drilling, but also to enhanced oil recovery and the development of unconventional resources such as heavy crude, tar sands, eastern gas 
shales, western gas sands, gas-saturated brines, and gas in deep basins. This issue is discussed in both the Onshore and offshore sections of this report.

\section{OFFSHORE ACCIDENTS}

Recently, the news media and several trade joumals reported on tragic accidents associated with offshore drilling. These incidents have highlighted dangers, attracting the attention of the public and regulatory agencies to the industry's safety hazards.

One of the obstacles to assessing the extent of the problem is a lack of adequate data reporting. Currently, offshore and onshore accident data are comingled in a category termed "exploration and production." These should be segregated.

There is no comprehensive reporting program for offshore accidents. Publicly available data on offehore accidents relate only to mobile rigs and reflect a summary of press reports compiled by an industry consulting service. Offshore accident data should be divided into four categories: accidents involving tankers, fixed platforms, mobile rigs, and support vessels and structures.

\section{REFINERIES AND WORKER HEALTH}

A number of reports recently have appeared in the popular press concerning large numbers of brain tumor deaths among workers at Gulf Coast petroleum refineries and petrochemical complexes, but the significance of these findings is not clear. One conflicting study found no significant increase in the incidence of brain tumors at one of the refineries reported to have a high incidence. Similarly, other preliminary studies and analyses, most performed by affected industrial concerns, refute findings of high incidence and risk of brain tumor mortality.

The relative increased risk and any link between brain timors and employment in the petroleum refining and petrochemical industries require further examination, although there may be no resolution and the issue may not relate to current industrial hygiene practices. This is because most deaths involve workers who began employment more than 30 years ago, before petroleum refining and work practices changed in recognition of safety and health hazards.

A recent mortality study of workers at eight refineries in the United Kingdom found no significant increased risk for brain cancer, but an above-normal incidence of malignant melanoma (skin cancer). In addition, esophagal, stomach, intestinal, and rectal cancers were found. It is possible that a new workplace hazard akin to the threat 


\section{Part 1 \\ Introduction}


posed by vinyl chloride exposure may be recognized and defined through more research. Such research is discussed in the Refinery Operations section of this report under Summary of Research Needs, Occupational Health.

\section{SOIL BIOTA AND PETROLEUM SPILLS}

To date, except for effects related to tundra and cold climates associated with the Alaskan oil pipeline, research on the ecological effects associated with oil or product spills has focused on the aquatic environment. Research is needed that focuses equally on terrestrial ecosystems as these are expected to be impacted by the numerous gathering and transmission lines to be constructed in support of new oil and gas energy sources. The soil biota of the semiarid West and the Appalacian Basin have not been well studied with respect to oil and product spills. These areas are expected to be severely impacted by both conventional and unconventional oil and gas development. A listing of research needs related to soil biota is contained in the environment portion of Summary of Research Needs in the Transportation and Storage section.

INDDOR AIR POLLUTION

Recent research has shown that various harmful pollutants such as radon, nitrogen dioxide, and carbon monoxide have been found in the air of homes, offices, schools, and even recreational facilities. The severity of the impact of these pollutants on human health may be aggravated by government energy conservation programs which encourage the "weather-proofing" of buildings.

To date, attention on indoor radioactive emissions has focused on radon emanating from construction materials and on water supplies derived from aquifers located in sedimentary deposits rich in radioactive nuclides. Evidence suggests the posoibility of an equal amount of radon released from the combustion of natural gas in gas ranges and space heaters.

Nitrogen dioxide and other emissions from the indoor combustion of oil and gas also may compound the problems with and reactions of indoor air pollutants. Nitrogen dioxide levels have been found to be significantly higher (in some cases seven times higher) in homes with gas stoves than in homes with electric stoves. Gas appliances also have been cited as significant sources of carbon monoxide. However, research has focused on air pollutants associated with the infiltration of automotive exhausts and on volatile solvents. 
The nature, magnitude, and role of radioactive and chemical emissions from the indoor, energy-related use of oil and natural gas should be determined. Research in this area should be integrated with a comprehensive research program that addresses all facets of indoor air pollution.

\section{INFORMATION TRANSFER}

The techniques proposed for recovering oil from U.S. tar sands are also applied to recovery of deep light oils and heavy oils, and enhanced recovery of oil shale by in situ techniques. Some heavy oils are produced in Califomia and Texas by thermal methods (and are included in conventional oil reserve estimates). Gas from geopressured brines, easterm shales, western tight sands, and deep basins is expected to be extracted through the application of fracturing and the use of drilling muds--methods that are also employed to recover the resources named above.

These resources are classified by various Federal agencies under different programs, depending upon the agency's convenience and statutory mandates, pricing categories for the resource, and definition of conventional versus unconventional resources. As an example, research in support of heavy oit may be categorized as conventional crude oil research by one agency and as support of symthetic fuels development by another (the Eneray Serurity Act alaooifies undeveloped heavy crude as a synthetic fuel). As a result, many duplicative development and research strategies are taking place. often, identical generic and region-specific health and environmental research activities can apply to several technologies. An information transfer strategy is needed which will enable relevant generic, regional, and process-specific research to be brought to bear on solving similar oil and gas health and environmental effects problems. 


\section{INTRODUCTION}

The oil and gas industry is entering a new era in terms of the nature and diversity of resources and requirements of transportation and supply. The petroleum industry is directing more of its profits than ever before into the search for new energy supplies. In 1980, the industry spent more than $\$ 50$ billion on exploration and production inside the U.S. --26 percent more than the $\$ 40$ billion spent in 1979. About 60,000 wells were completed in 1980 (about 35 percent more than in 1979)--breaking the 1956 record of 58,160 .

With the additional emphasis on the extraction of oil and gas from unconventional sourccs and on the development of petroleum substitutes from coal and oil shale, the entire ofl and gas industry is likely to change. Now dependent upon imported gas and petroleum and on conventional domestic reserves, it is likely to become a diverse and complex industry within the next decade. The traditional association of the industry with fossil fuels (oil and gas related to biological decomposition and mineralization over the geologic time span) will be enlarged to include interaction with geothermal resources (gas saturated brines), synthetic fuels (in situ recovery of oll from tar sands and heavy crude), energy conservation (waste oll recovery), . and agriculture (oil and gas from blomass).

The character of the industry, both at present and in the future, is the subject of this report (Figure 1). Various facets of the industry are addressed in terms of potential health and environmental issues. The technology and research activities which should be undertaken to understand the issues are identified and a few broad research issues are discussed in the last chapter.

The changing character of the oil and gas industry creates the potential for new impacts on human health and the envirnnment. Consequently, changes in the industry are briefly discussed below.

\section{CONVENTIONAL ONSHORE AND OFFSHORE DEVELOPMENT}

The recent increases in energy prices have provided an incentive for accelerated o1l and gas development. In December 1980 the number of U.S. rotary drilling rigs exploring for new oil and gas reached $3,200--$ the highest number in 23 years. In the last year alone, the amount of drilling activity in the: Permian Basin of Texas incrcased by 50 percent. This new drilling follows a decade of declining exploration and production (Newsweek 1980). Accelerated oil and gas development is expected to continue and even markedly increase as the new administration focuses on increased production of domestic oil and gas reserves. 


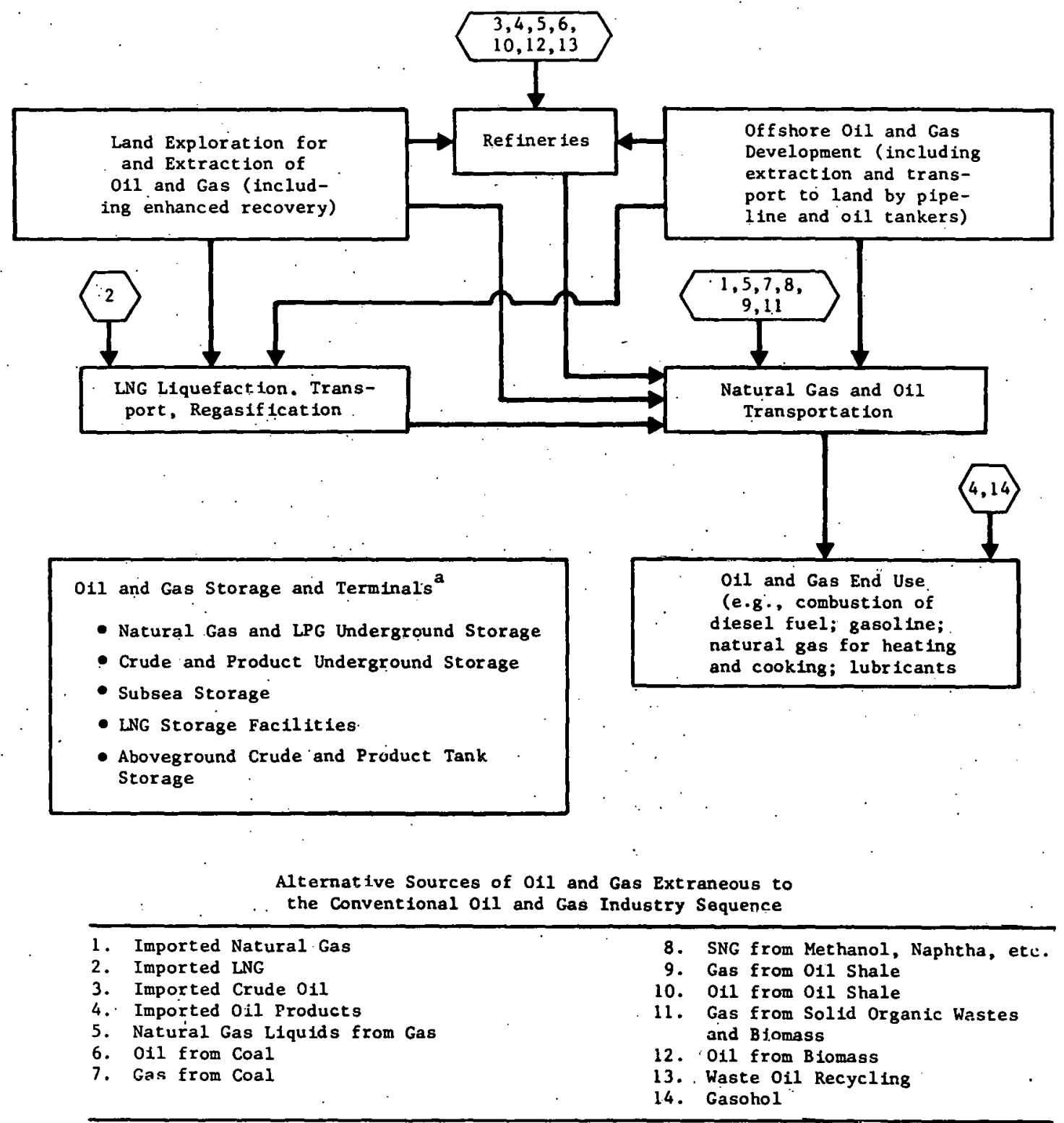

- a Storage is an integral part of each component.

\section{FIGURE 1}

\section{COMPONENTS OF THE OIL AND GAS ENERGY SEQUENCE}


Conventional development of eastern U.S. gas reserves focuses on tapping previously unexplored strata. One well recently tested at 1.6 million cubic feet a day (exceptional for Oh1o). In central Pennsylvania, an Amoco well tested at 20 million cubic feet a day (average daily consumption of natural gas in 1978 was about 52 bi1lion cubic feet a day) from a previously unexplored basin. In West Virginia, a well drilled into a shallow formation near Clarksburg tested at 7.5 million cubic feet a day. New findings related to the formation of the Appalachian Mountains suggest the possible existence of large amounts of untapped o11 and gas (Hodgson 1978; Technology Forecasts 1979).

offshore ofl and gas development is rapidly accelerating and undergoing dramatic changes. While rotary drilling began around 1900, offshore drilling started as recently as 1947. Drilling from floating platforms began in 1953 and the use of subsea wells began in 1962. In 1970, drilling in 1,300 feet of water was accomplished, followed by the development of dynamically stationed drillships in 1971. In 1980, 500 mobile rigs were operating. Exploration drilling has occurred in 5,000-foot depths. Some drilling units now are equipped to drill and produce oil in 6,000 feet of water, and equipment is avaflable for drilling and well completion in 8,000 feet of water.

Experience with deep ocean operations such as dredging seafloor muds at 8,000 feet, deep ocean mining in 16,000 feet of water, and ocean floor coring at 18,000 feet opens new horizons for offshore oil and gas development beyond the continental slope. The U.S. Geological Survey has found evidence from seismic data of a large carbonate reef extending along the entire U.S. East Coast and possibly around the Gulf of Mexico. This reef, underlying the continental slope at a water depth of 6,000 feet, is overlain by about 6,000 feet of clastic sedimenls which may bc porous and permeable to provide sizable hydrocarbon reserves (King 1980; Hammett 1980).

\section{REFINERY OPERATIONS}

Refinery operations traditionally have evolved slowly to meet new process demands. Rather than focusing on the construction of new plants, most reflueries undergo "modernizatinn," in which facilities are upgraded in certain ways to increase capacity and efficiency, to meet new pollution control requirements, and to produce a new product.

Refineries are facing new needs for expansion brought about, in part, by increased emphasis on the conventional development of domestic oil reserves. Some refineries designed to process imported 
Arabian light crudes may need to be altered in order to process certain heavier and high sulfur U.S. crudes. The new impact of synthetic liquids produced from coal and oil shale will require substantial changes in capacity and unit processes.

Production efficiency is expected to be Improved as a major step toward reducing U.S. dependence on imported crude oil. Refineries now consume 1/10th of the ofl they process (Maier et al. 1979). An example of an efficlency improvement was announced recently by Ashland 0i1, Inc.; which has developed a process to refine 25 percent more gasoline from a barrel of crude ofl than is now possible. This breakthrough, requiring a $\$ 70$ milition refinery addition in Kentucky, will use a reduced conversion process, which allows the production of more gasoline from the heavy, sludge-like portion of crude that normally has been sold as a low-priced boller fuel or made into asphalt (0'Toole 1980).

\section{LIQUEFIED ENERGY GASES}

Incentives for developing liquefied energy gases include: the recent uncertain availability of existing domestic gas supplies, questions regarding the timing of demand and explottation of new domestic supplies, and potential interruptions in the supply of 1mported LNG and natural gas. Liquefied energy gases used for peakshaving in a single 24-hour perlod during the 1980 winter season came from a varlety of sources, including 57 billion cublc feet from underground gas storage, 5 from propane-air plants, and 9 from LNG peak-shaving and satellite plants. Th1s represented 83 to 89 percent of the 1980 winter, peak-day sendout considered the maximum that would be required (Hale 1980). Clearly, liquefled energy gases, particularly LNG, play an important role in supplying gas for residential and industrial use. More storage units will be required as new conventional and unconventional sources of natural gas are developed.

\section{TRANSPORTATION AND STORAGE}

Transportation and storage networks are 1ndispensable, forming a link between production, refinement, and use of o1l and gas resources. With expansion of the oil and gas industry, geographic relationships between sites of supply and consumption will change dramatically. The development of unconventional sources of oil and gas, new conventional sources in the eastern Appalachian Basin and the western Rocky Mountain Overthrust Belt, and synthetic fuels will require thousands of miles of new gathering and transmission Iines. Many of these will be situated in relatively inaccessible areas and will be accompanied by extensive road construction. 
END USE

Even with economic recession, the demand for ofl in the industrialized world can likely rise by 300,000 to 500,000 barrels per day, and increased requirements of the developing world will add a daily average of about 100,000 barrels to this total (Energy Insider 1980). 011 and gas are the fossil fuels of cholce because of the have advantage over coal in terms of ease of handling, clean fuel attributes, and potential for petrochemical feedstocks. The demand for oil and gas will continue to grow. The role synthetic fuels and unconventional resources will play in filling this demand will depend upon future political and economic forces and decisions.

\section{UNCONVENTIONAL RESOURCES}

In the last 100 years, over 450 barrels of ofl have been discovered in the U.S. However, only about 115 billion barrels have been produced. Current advances in conventional drilling technology can allow only for the production of another 30 billion barrels from these flelds, leaving about 305 billion barrels. Another 26 billion barrels of oll are contalned within Utah's tar sands; 30 billion barrels of heavy, viscous barrels are located in California; and bilitions more are in shallow diatomite formations and tar sands elsewhere. Much of this oil is recoverable by the new techniques of oil mining and in situ extraction.

With respect to natural gas, only a small increase in production from new sources can more than quadruple the current estimate of recoverable reserves. These new sources include methane-saturated brines, eastern gas shales, western gas sands, methane from coal seams and mines, methane hydrates, gas in deep basins, and gas from blomass. Moderate gas recovery from these new reserves could extend the current 10-year supply of conventional natural gas (from convenclonal suurces at current consumption rates) to over 100 years. 
THIS PAGE

\section{WAS INTENTIONALLY LEFT BLANK}




\section{Part 2 \\ Onshore Development}


This section points to health research needs associated with onshore oil and gas development, with emphasis on the need for improved collection of health effects data, information on occupational health effects associated with the use of drilling fluids and chemicals and gases utilized in enhanced recovery methods, and the nesd for regional health assesements of the cumulative impact of airborme and waterborne contaminants associated with oil and gas production.

Research $i_{s}$ also needed on the environmental effects associated with onshore oil and gas development. Better methods should be developed to track the movement of pollutants through groundwater systems and information is needed on the transformation and fate of surfactants, solvents, and other groundwater contaminants related to oil and gas recovery.

Specific research needs in the above problem areas can be found within the Summary of Research Needs sections. These summary sections follow related discussions of health and environmental problems. Discussion of the effects of oil spilis on aquatic or terrestrial biota is presented within the Transportation and storage section of this report. 


\section{THIS PAGE WAS INTENTIONALLY \\ LEFT BLANK}


TABLE OF CONTENTS

$\underline{\text { Page }}$

LIST OF TABLES

TECHNOLOGY DESCRIPTION

Oil Extraction

Exploration and Site Preparation

Primary Production

Enhanced Oil Recovery

Secondary Recovery Methods

Tertiary Recovery Methods

Natural Gas Extraction

Enhanced Gas Recovery

HEALTH EFFECTS OF ONSHORE DEVELOPMENT

Occupational Health Hazards

Drilling

25

Petroleum Extraction

Public Health Hazards

Summary of Research Needs

Health Effects Data

Effects of Drilling Muds and Enhanced Oil

Recovery Agents

Exposure to Toxic Chemicals

40

Public llealth Considerations

40

Interactions of Toxic Agents

41

ECOLOGICAL EFFECTS OF ONSHORE DEVELUP̌MENT 
TABLE OF CONTENTS (Concluded)

Page

Petroleum Constituents

Effects of Petroleum Extraction Chemicals

51

Effects of Metals

5.1

Mobility of Organisms

55

Effects of Surfactants

55

Bioassay Testing

56

Sublethal Effects

57

Effects of Benzene

Detoxification and Bioaccumulation

Plankton

Benthic Organisms

61

Terrestrial Biota

61

Summary of Research Needs 62

TRANSPORT AND TRANSFORMATION

Water Medium 


\section{LIST OF TABLES}

Table Number

$\underline{\text { Page }}$

1 Some Chemical Agents Used in Oil Recovery

28

2 General Toxicity Data for Chemicals Used in Enhanced Oil Recovery

30

3

Effects on Selected Freshwater Biota

from Petroleum and Associated Constituents

Toxic Effects of Petroleum Extraction

Chemicals to Fish and Daphnia

52 


\section{THIS PAGE WAS INTENTIONALLY \\ LEFT BLANK}




\section{ONSHORE OIL AND GAS PRODUCTION}

\section{TECHNOLOGY DESCRIPTION}

\section{$011 \cdot$ Extraction}

Crude oil exists in and is extracted from underground rock formations, termed reservolis. These reservoirs may be composed of sandstone, limestone, or dolomite structures (American Petroleum Institute 1976). Within an oil reservoir, there may be varying amounts and kinds of naturally occurring energy resources in addition to crude ofl or natural gas. These are (National Petroleum Council 1976; American Petroleum Institute 1976):

- Dissolved gases within the crude oil,

- Dissolved gases within associated saltwater deposits that may coexist with the crude oil,

- Free (non-dissolved) gases that occur with the crude o11, and

- Free deposits of water (usually brine) associated with crude oil, in which gas may or may not be dissolved.

Recovering the oil and gas from these reservoirs is a multi-step process that begins with exploratory surveys, before proceeding to primary production, and then of ten to the use of enhanced recovery techniques.

\section{Exploration and Site Preparation}

Exploratory surveys to locate likely petroleum and gas bearing strata are the first step in 011 and gas production. Surface surveying methods involve using aerial and satellite photography in conjunction with on-site studies of the surface topography and geology. Subsurface analytical methods may include using gravimetric, magnetic, and seismic instruments. Seismic readings are obtained by recording shock waves that penetrate the earth's crust (Wilkins 1977). Shock waves can be generated by explosive charges planted on or in the earth's surface (Coffeen 1978). Such explosives have a limited potential. for polluting shallow streams when the selsmic shot is not properly cased (Wilkins 1977).

If instrument readings indicate a potential petroleum deposit, site preparation and preliminary core drilling may begin. This phase of preliminary operations involves using various types of land clearing and drilling equipment which can greatly modify the 
vegetation and soil surface of the affected area. In addition, the environment may be impacted by noise, dust, and combustion-related emissions from the equipment.

Perhaps the greatest potentlal danger associated with site preparation involves the initial driling procedure itself. A "blowout" (Britt et al. 1976), or uncontrolled flow of crude petroleum and associated components, can occur when an oil or gas formation is breached. Blowouts can spread large amounts of crude petroleum contalning many organics that are potentially toxic and not readily degradable, choking vegetation, destroying animal habitats, and covering workers. In addition to direct land and water poliution; fire associated with such blowouts results in release of gaseous and particulate air pollutants (e.g., hydrocarbons, nitrogen oxides, sulfur oxides, and carbon monoxide). These may pose additional safety hazards (Britt et al. 1976). Speclal drilling fluids and mechanical valves are generally employed to help prevent blowouts. Another hazard associated with drilling is land subsidence, which can occur accidentally in normal oll drilling and extraction procedures.

Primary Production

The utilization of naturally occurring gases and water to initiate oil movement from the reservoir to the earth's surface is termed primary production. After exploratory. and test procedures indirate the existence of an oil reservolr, the next step is primary production drilling, which requires the use of drilling equipment and complex chemical fluids. Modern methods of primary production primarily utilize rotary drilling. In this form of extraction, a rotating drill bit, connected by many hollow lengths of p1pe termed "the drill string," chips and gouges its way through soll and rock strata. The drill and its associated drill string are encased within a drill pipe. The hole (well bore) created by the rotary drill is constantly kept full of a chemical fluid called "drilling mud," composed of mixtures of clay, water, and various chemical compounds. (Sometimes compressed air is used in place of mud.) Mud is sent down the well bore through the hollow pipes forming the drill string and then is recirculated back to the surface through the space between the drill string and the large-diameter pipes forming the casing string which line the borehole. At the surface, rock cuttings and fines from the drilling are separated from the mud. This takes place through use of shakers, desanders, and desilters (Wilkins 1977). The purified mud can then be recycled. If the mud is too contaminated for cleaning, it may be disposed of in waste pits, along with the rock cuttings and other waste products (W1lkins 1977). 
The use of drilling mud is critical during the initial extraction stages and serves some of the following functions (Richards 1979):

- Lubricating the drill string,

o Cooling the rotary drill bit,

- Carrying the rock cuttings/fines from the well bore to the surface,

- Preventing parts of the penetrated formation from entering the well bore,

- Inhlbiting the entrance of undesirable formation fluids into the well bore, and

- Controlling excessive pressure in the well bore to prevent blowouts.

After the oil bearing stratum is reached, there is a shift of emphasis from drilling to the establishment of a production well (termed well completion). The two basic methods of well completion are termed. "open hole" and "perforated completion" (Allen and Roberts 1978). Both of these procedures involve cementing a string of connected pipes (casings) into the drilled hole. In open hole completion, the casing sits on top of the producling strata. In perforated completion, once the casing is in the producing level, steel bullets or shaped charges penetrate the casing and the cement in which it is set (Wilkins 1977). Holes are blown into the strata so that petroleum may seep into the casing. Ninety-five percent of all well completions are currently accomplished by the perforation method (Wilkins 1977). Regardless of which well completion method is ut111zed, a small production tube (or tubes) is installed within the perforated casing. It is through this production tube that the crude oll is brought to the surface.

Upon reaching the surface, crude ofl must be separated from other components with which it is associated. The two major components are brine (water containing, or saturated with sodium chloride and other salts) and natural gas. As a primary contaminant, brine must be removed on site before the crude petroleum is sent to the refinery for further processing (Wilkins 1977).

Mixtures of oil and water (usually brine) often occur as emu1stons elther as water in oil or ofl in water (Case 1970). The latter indicates a declining production situation in which the bulk ( 80 to 90 percent) of the fluid leaving the oil formation is water with 
colloidal oil droplets (Case 1970). The former is reflective of more desirable production situations in which water is not the primary component of the emulsion. In addition to emulsions, brine may also be associated with crude o1l as free water. In this situation, the water is gravimetrically separated from the oil. The water and oil mixture then enters large tanks in which baffles are inserted to minimize turbulence and to enhance the water and oil separation (Wilkins 1977). This procedure is known as free water knock-out.

Water and ofl emulsions require more elaborate treatment techniques to achieve separation of the two components. Heaters and electric dehydrators are used to physically separate the oil from the brine. Chemicals may also be added to destabilize emulsions. Once the mixture is broken into two separate phases, gravitational settling can occur and water can be drawn off and disposed of. The resulting crude oll is then sent to the refinery.

A considerable amount of brine may remain after crude oll separation. It is estimated that two to three cubic meters of brine are produced for every cublc meter of oil (Wilkins 1977). The majority ( 7.2 percent) of this brine is disposed of in underground formations or used for injection purposes during secondary recovery (Wilkins 1977). The remainder may be disposed of in non-potable water supplies, or in approved disposal areas, unlined pits, or rivers (Wilkins 1977).

In addition to brine, other by-products and emissions also may be produced in significant quantities. It has been estimated that 33 metric tons per day of hydrocarbon compounds can be collected in wastewater separators alone (Wilkins 1977). Some desirable components within crude ofl such as natural gas are extracted in the field. Hydrogen sulfide may be emitted from crude oil and brines where it has been held in solution under pressure.

Enhanced 011 Recovery

Enhanced oil recovery is the use of any technique to extract more oil than that which is obtained through primary production (Schumacher 1978): The various techniques are divided into two catégories, secondary and tertiary methods.

\section{Secondary Recovery Methods}

Secondary recovery techniques include the injection under pressure of either treated water or immiscible (natural) gas into an ofl formation to increase the petroleum flow. The injection of water, termed waterflooding, is by far the most important of these two techniques (National Petroleum Council 1976): It is estimated that, by 
1973, 1/2 of domestic oll was obtalned from reservolrs tapped elther in part or entirely through water flooding (Schumacher 1978). The use of natural gas injection to maintain reservolr pressure and augment declining well production has been steadily decreasing. One of the primary reasons for this is that waterflooding is far more efficient than gas for displacing oil (Office of Technology Assessment 1978; Schumacher 1978). The increasing value and price obtalned for natural gas in the commercial market is another factor limiting its use for secondary recovery.

Waterflood operations utilize two types of wells: production and injection wells. Treated water 18 pumped into the injection wells and down to the petroleum contalning formation. The injected water forces trapped petroleum held within the formation into the production wells where water pressure forces the ofl to the surface of the reservoir: The production fluid reaching the surface is a mixture of oil and injected water. This mixture is then separated using the same procedures described under primary production.

Common sources of injection water (usually brine) are: (1) water separated from o1l, (2) brine or fresh water obtalned from near the oil formation, (3) surface water (rivers, lakes, oceans), and (4) alluvial wells (Patton 1977). Whatever the source, the injected water usually requires treatment with various chemicals to prevent scale formation, inhibit corrosion, and prevent the growth of microorganisms. The nature and extent of the chemicals added to the injection water are of environmental importance, since surface and sub-surface contamination can result from spillage or seepage of either the mixed production fluid (treated water and o11) or the separated brine which requires disposal.

Brine and Its associated components are of ten disposed of in brine disposal wells. These are frequently old, depleted oil wells converted for other uses (Schumacher 1978). Usually, when the waste stream is injected into these wells, pressure is employed. This may cause fractures which can then result in seepage into freshwater aquifers.

\section{Tertlary Recovery Methods}

There are four major tertiary recovery techniques:

- Hydrocarbon-miscible flooding,

- $\mathrm{CO}_{2}$-miscible flooding,

- Micellar and polymer flooding, and

o Steam and in situ combustion. 
These methods fall into two basic classes: the first three reduce surface tension between oil and the driving fluid, while the last employs heat to reduce the viscosity of the oll (Schumacher 1978).

- Hydrocarbon-miscible flooding methods.

There are three basic extraction techniques that involve the use of gaseous hydrocarbons to move reservolr oil to the surface. The high-pressure gas technique uses gaseous hydrocarbons as the driving fluid under high pressure $(3,000$ psi) and is applicable to reservoirs that contain low viscosity oil. A prerequisite for this process is that the reservolr be able to sustain the use of such high pressures (Schumacher 1978). Th1s method makes use of the pressure to transfer the lighter hydrocarbon gases out of the ofl to form a leading gas front. The initlal gas front then evaporates more of the same light hydrocarbons from the remaining o11, thus forming a self-sustaining, miscible slug.

The enriched gas technique differs from the former method in that a miscible front is obtained by directly injecting gaseous hydrocarbons into the ofl reservoir, rather than by depending on high pressure to extract gas entralned within the reservolr ofl.

The third hydrocarbon flooding method, the miscible (LPG) slug process, involves injecting hydrocarbons of intermediate molecular weights into the reservoir. After this, gas injection may be employed (Schumacher 1978).

The use of hydrocarbon-miscible techniques is quite limited due to the high pressures required and the environmental hazards assoclated with blowing through the overlying structures. In addition, these methods suffer from a poor mobility ratio (Schumacher 1978). Finally, and most important, the hydrocarbons being used as driving fluids may have a greater value in the marketplace (National Petroleum Counc11 1976).

- Carbon dioxide-miscible flooding.

This method is analogous to that of the high pressure (hydrocarbon) gas technique previously described. $\mathrm{CO}_{2}$ is used to displace the gaseous hydrocarbons from the reservoir oil. These displaced components form the miscible zone. Besides the avallability of $\mathrm{CO}_{2}$, this method has other advantages. A much larger group of hydrocarbon components is vaporized from the oil than with the hydrocarbon technique. 
Also, this method may be employed in reservolrs under lower pressures than are required for some of the hydrocarbon recovery techniques (Rahme 1978).

- Water-miscible flooding methods.

These methods include both micellar (surfactant) and polymer flooding techniques. In micellar flooding, a spectified slug of surfactant solution, varying from 5 to 10 percent of the reservoir volume, is injected into the ofl formation (Rahme 1978). This solution causes the formation of of micelles or microemulsions (Schumacher 1978). The types of surfactants used include petroleum sulfonates, various hydrocarbons, alcohols, and inorganic salts (National Petroleum Counc11 1976). Whatever the nature of the detergent-11ke surfactants, they act to reduce the amount of oll-water tension and to solubilize and emulsify the o11, so that 1 t may be moved more readily from the formation.

Polymer flooding Involves the use of high-molecular-weight compounds added to the water that is infected into the ofl reservo1r. This method, in effect, is an augmented waterflooding technique. The polymers serve to increase the viscosity of the water being injected, thus enhancing the mobility ratio of the waterflood. In addition, they also decrease the permeability of the formation to the water being injected (National Petroleum Council 1976). The polymers used are generally either polyacrylamides or polysaccarides.

Due to the diverse chemicals employed in both surfactant and polymer flooding, these recovery methods may present a potential for environmental and health hazards, elther through direct use, as a result of an accident, or when they are disposed of.

Steam and in situ combustion techniques.

Steam and in situ combustion techniques are thermal methods which generate and apply heat to viscous crude olls to reduce the viscosity of oil, thus allowing it to flow more easily (Schumacher 1978). The use of steam injection is the most technologically advanced and widely used of any of the enhanced recovery methods (Office of Technology Assessment 1978).

There are two basic types of steam technologies: cyclic steam injection and steam drive. The former method is sometimes characterized as the "huff" (injection phase) and 
"puff" (production phase) technique. It uses the same well both for injecting the steam and obtaining the produced oll. Initially, high pressure steam is injected into the well for a specified period of time ranging from days to weeks, then the injection phase (huff) is stopped. The well is capped while the reservoir soaks up the injected steam. When the well is later reopened, the condensed water within the pressurized reservoir is converted back to steam. This occurs as a result of flashing and of a decrease in well pressure upon reopening (puff).

An alternative method involves the use of steam drives and a system of separate injection and production wells. Steam is continuously pumped down the injection wells. As the steam condenses. In the reservoir, a hot water zone is formed which pushes a mixed zone of ofl and water toward the production we11.

As with waterflooding and mlcellar-polymer flooding, there are potential environmental consequences with the steam technologies. Producing high pressure steam and pumping it down to the reservolr requires energy. The steam generators used in these thermal processes consume large amounts of o1l. As a result, significant amounts of combustion products may be vented to the atmosphere. With stoam gonerators it lias been est1mated that 40 lbs of hydrocarbons, 4,000 lbs of sulfur oxides, $8001 \mathrm{bs}$ of nitrogen oxides, and $280 \mathrm{lbs}$ of particulate matter could be emitted for every 1,000 barrels of oll produced (National Petroleum Council 1976). It is assumed that, of all the enhanced recovery techniques, the ones most likely to cause air quality impacts are those involving thermal processes.

The in situ combustion technique also makes use of heat to reduce ofl viscosity. In this method, heat is produced within the reservolr itself. Alr is injected into the formation and part of the crude ofl is lgnited and burned in place. This reduces the viscosity of the remaining ofl and the combined effect of vaporized oil, steam, and gas pushes the bulk of the oll to the surface. As with the steam methods, air quality may be compromised. Combustion products may be vented through surface fissures or cracks. In addition, various chemical pollutants may remain within the reservoir as a result of in situ burning. These may contaminate aquifers if the burn site is flooded. Measurement of some of the gaseous compounds emitted from in situ projects has shown that carbon dloxide, carbon monoxide, sulfur and nitrogen oxides, oxygen, and various hydrocarbons were produced. 
Natural Gas Extraction

Natural gas occurs in four types of reservoir situations: (1) dissolved gas within crude oil deposits; (2) associated (free) gas occurring with crude oil (e.g., in gas caps); (3) non-associated gas; and (4) gas dissolved within brines.

Natural gas is a desirable energy resource sometimes found associated with reservolrs of crude oil. It is removed from the petroleum at the production site before being sent for further processing. The gas is dissolved within oil, so the extraction process is basically one of using separators to remove the gas. There are two types of separators: two-phase unt ts that separate oll from gas, and three-phase units that separate o11, gas, and water. The configuration of the separators may be vertical, horizontal, or spherical, depending on the gas-to-oil ratio (Wilkins 1977 ).

Waste streams result from ofl and gas separation. Th1s may be especially true where relatively small amounts of gas are separated from crude or in remote areas where economlc incentives do not justify further gas processing steps. In this context, it has been estimated that 50 billion cubic feet of natural gas are lost each year to the atmosphere through venting, flaring (burning), and other fugitive losses (Wilkins 1977). In addition to these hydrocarbon emissions, there may be considerable amounts of sulfur-containing compounds associated with particular types of gas.

Whether dissolved in oil or found by itself, natural gas may contain hydrogen sulfide $\left(\mathrm{H}_{2} \mathrm{~S}\right)$, a hazardous substance which must be removed before further processing. The removal of hydrogen sulfide usually is carried out by passing the natural gas-hydrogen sulfide mixture through a monoethanolamine solution. This absorbs the $\mathrm{H}_{2} \mathrm{~S}$. Subsequently the monoethanolamine is stripped of the $\mathrm{H}_{2} \mathrm{~S}$ and recycled. The free $\mathrm{H}_{2} \mathrm{~S}$ can then be burned or sent to a sulfur recovery plant. If it is burned, there may be considerable amounts of $\mathrm{SO}_{2}$ released to the atmosphere (Leggett and Williams 1979).

In addition to $\mathrm{H}_{2} \mathrm{~S}$ removal, all natural gas having a water content greater than five to seven lbs per million cubic feet must have water eliminated before further processing. If this is not carried out, gas hydrates will form. Gas dehydration is usually accomplished by glycol absorption. Either di- or tri-ethylene glycol is used to absorb water from the gas and is then recycled with the free water vapor being vented to the atmosphere (Leggett and Williams 1979). 
Enhanced Gas Recovery

Enhanced gas production (gas stimulation) methods are now commonly used, especially in gas formation. These methods include hydraulic fracturing techniques, chemical explosive fracturing, and directionally controlled drilling. It should be emphasized that fracturing techniques are not unique to enhanced gas recovery, but also are used to stimulate oll production (Allen and Roberts 1978). All fracturing techniques involve increasing the reservoir area from which gas may be obtained and increasing the gas flow by breaking or fracturing the reservolr formation.

Hydraulic fracturing is a process whereby large quantitles of a fluid are pumped under pressure into a gas formation. This is exemplified in the single-well technique, with which a fluid injected through the wellbore initiates a fracture. Along with the fluid, a coarse sand or other material is injected to keep the fractures open for gas flow after fluid injection is stopped. The produced gas then flows up the same wel1 bore (U.S. Department of Energy 1979). This type of fracturing has a special use in "tight" gas-bearing formations, which include certain sand and shale formations. For example, in Amoco's Wattenburg Field in Colorado, hydraulic fracturing is used to increase production from certain tight bearing marine sands (Hanson et al. 1978). Various flulds, in addition to water, may be used for fracture induction. For example, foam, rryogens (low tomperature 11quids that expand), and gelled water have been utilized in some tight eastern sandstone and Devonian shale formations (Forrest and McKetta 1978).

In addition to hydraulic fracturing, explosive fracturing may also be utilized. There are two basic explosive techniques: (1) borehole shooting, which consists of lowering an explosive down the drilled hole and then opening a hole by detonation; and (2) pumping an explosive liquid slurry into the formation itself and then detonating the mixture (U.S. Department of Energy 1979).

Directionally controlled drilling is still another approach that is being investigated as an enhanced gas recovery technique. This takes advantage of the natural fractures existing in a formation and orients the direction of the drilling so the fractures will be intersected by the drill. This technique is used particularly for the extraction of gas from coal seams.

Whatever type of enhanced recovery technique is used, when the gas reaches the surface it will be separated from impurities such as water vapor and hydrogen sulfide and then will be sent for further processing, if needed. Hydrogen sulfide is a particular problem in the exploitation of the western overthrust belt and perhaps in deep 
basins. In certain deep basins, such as the Anadarko surrounding the Oklahoma panhandle, high pressures ( $1 . e ., 20,000$ psi) can cause casing failures. 
THIS PAGE

\section{WAS INTENTIONALLY \\ LEFT BLANK}




\section{HEALTH EFFECTS OF ONSHORE DEVELOPMENT}

The potential impact of ofl and gas production on occupational and public health is multifaceted both in scope and in the number of problems encountered. These problems may be specific to one technology or they may be present among a large number of technologies, but differ in the degree of associated impacts. This section presents an overview of potential health effects resulting from the production of oil and gas and offers directions for future research.

Occupational Health Hazards

\section{Driliing}

The major emphasis in this section is on reviewing the effects of exposure to materials used in production, the produced fluids, and their associated components. Where applicable, problems unique to specific technologies are addressed.

During exploration and drilling, health impalrment is 1ikely to be in the form of mechanical injury as a result of accidents. Workers are exposed to hazardous situations resulting from maintenance activities, equipment failure, oil rig set-up, and rig dismantling activities. In addition, high risk may be involved in geophysical or selsmographic exploration and testing, which often require extensive aerial surveys and the use of explosives to determine geological formation profiles.

The actual number of field accidents reported in 1978 that involved both injury and death may be divided into two categorles: exploration/production and drilling. Data from 109011 and gas companies (American Petroleum Institute 1979a) indicated that, of 72,749 employees in exploration and production, 2,758 (4 percent) were injured and 21 were killed. In drilling, there were 2,947 workers and 809 ( 3 percent) were injured, while 1 was killed. In the former category, the varied causes of death included: electrocutions, drownings, fatal falls, escaping gas, and helicopter or alrcraft crashes. (American Petroleum Institute 1979b).

These data reflect both onshore and offshore sites. There is no available breakdown of the relative number of deaths and types of injuries associated with either onshore or offshore production technologies. There is an apparent need to assess the relative hazards associated with each type of production technology and to identify: potential hazards that may be unique to different technologies. An obvious, but important, point of emphasis is that even the same extraction technology may present quite different degrees of danger depending on its location. For example, potential disposal and 
exposure hazards associated with production or waste products on the limited area of an offshore platform may be quite different from those on an onshore site--especially during emergency procedures that could necessitate rapid evacuation measures. In addition, climate affects the types of clothing workers may wear and the protective measures they use.

\section{Petroleum Extraction}

During the initial (primary) extraction of oil, large amounts of drilling muds are employed. It is estimated that a wel1 8,500 to 11,500 feet $(2,600$ to 3,500 meters $)$ deep requires 1,200 to 2,500 barrels of mud (Wilkins 1977). There are two basic types of drilling muds: water-based and oil-based. These terms. refer to the 11quid phase of the mud to which various chemical compounds are added (U.S. Environmental Protection Agency 1976). Onshore drilling usually employs freshwater muds, although saltwater- or oll-based muds may be employed for drilling through salt formations.

Drilling muds vary greatly with regard to their formulation. However, some of the more commonly used constituents in freshwater muds are: lignosulfonates, acrylonftriles, caustic lignin and tannin, emulsified asphalt, sodium polyacrylate, carboxymethyl-cellulose, and formaldehyde (Wilkins 1977). Several of these compounds have been shown to be carcinogenic in animals, including asphalt, tannins, formaldehyde, and acrylonitrite monomer. Although not generally used for onshore drilling operations, the ofl-based muds may contain various mixtures of oxidized asphalt, organic acids, alkalis, stabilizing agents, and diesel oil (U.S. Environmental Protection Agency 1976).

Due to their varied and unknown compositions, these mud formulations may introduce large amounts of potentially hazardous compounds into the work site. Workers and those in the immediate vicinity may be exposed to hazardous constituents through a number of routes-dermal exposure, percutaneous absorption, inhalation of volatile components and aerosols, and ingestion. 'In addition, workers' families may be exposed to compounds on clothing and the workers' personal effects, such as automobiles.

Information on the contents and toxicity of the various mud formulations is not readily available. Studies are needed to document the extent of worker exposures to drilling muds and assess potential health risks associated with occupational exposures to the various kinds of muds under diverse drilling operations.*

*For information on the offshore use and effects of drilling muds, the reader is referred to the offshore section of this report. A summary of bioassay information and ecological effects is provided. 
The drilling muds of ten contain formation cuttings that must be separated when they reach the surface. Drilling a 15,000-foot hole 8-1/2 inches in diameter produces 1,059 barrels of cuttings (Wilkins 1977). Often the mixture of cuttings and drilling mud is further contaminated with associated crude oll. The cuttings may contain hazardous materials, such as heavy metals, which may affect the environment and health.

In conjunction with drilling, a direct threat to the health and safety of workers may arise as a result of well blowouts, especially in the drilling of deep wells. In addition to causing direct injury, blowouts also cause direct cutaneous, aerosol, and vapor exposures to crude petroleum with its associated organics, polsonous gases (such as hydrogen sulfide), and drilling mud constitutents. If fire is associated with such an event, carbon monoxide, oxides of sulfur and nitrogen, and organic particulate matter also would be emitted (Lawrence 1976).

In other methods of oil extraction, such as waterflooding, potential health hazards may involve exposure to chemical constituents of the treated injection water as well as mixed production fluids. An important point of emphasis with respect to both secondary (waterflooding) and tertiary techniques is that the chemicals which become mixed with crude oil are of ten removed when the oll is recovered, which concentrates them and associated compounds (Antizzo and Lawrence 1976). The injection water used in a waterflood project usually requires chemical treatment prior to use; chemicals that may be employed include bactericides, scale inhibitors, anti-corrosives, anti-precipitants, and sequestering agents (Patton 1977).

A recent publication reviewed some of the toxicological properties and associated research needs for compounds used in enhanced oil recovery (Silvestro and Desmarais 1980). Some of these compounds are classed by use in Table 1. Toxicity values for many enhanced oil recovery compounds are presented in Table 2. Some generic and specific potential hazards are discussed below.

Surfactants used may pose significant occupational health hazards. Most surfactants act as irritants on contact with the skin and mucous membranes and when inhaled. Petroleum and aryl sulfonates have demonstrated carcinogenic activity in animals and yield sulfur oxides when heated. Sulfonation is generally performed on site, suggesting that high exposure potentials may occur. Synergistic actions and solubilization of other hazardous agents may compound the adverse effects of surfactants in oll recovery operations. 
TABLE 1

SOME CHEMICAL AGENTS USED IN OIL RECOVERY

Mobility Control Agents

Polyacrylamides

Xanthan gums

Carboxymethylcellulose

Hydroxyethylcellulose

Polyethylene glycol: monobutyl ether

Polyethylene oxide

\section{Cosurfactants}

1-hexanol

2-hexanol

1 -octanal

2-octanol

n-butanol (and tert-, sec-, and iso-isomers)

Cyclohexano1

Polyethoxyalkylphenol

\section{Blocides, Chelating Agents, Oxygen Scavengers}

Quaternary ammonium chloride

2,4,5-trichlorophenol

Pent achlorophenol

Phenol

2,2-dibromo-3-nitrilopropionamide

Copper sulfate

Glut araldehyde

Formaldehyde

Sodium hypochlorite

Acrolein

EDTA

1,6-hexandelamine

\section{Surfactants}

Alky aryl sulfonates

e.g., Alkyl benzene sulfonate Octadecyltoluene sulfonate Tridecyl benzyl sulfonate Decyl benzyl sulfonate Alkyl naphthenic sulfonates

Petroleum sulfonates 
TABLE 1 (Concluded)

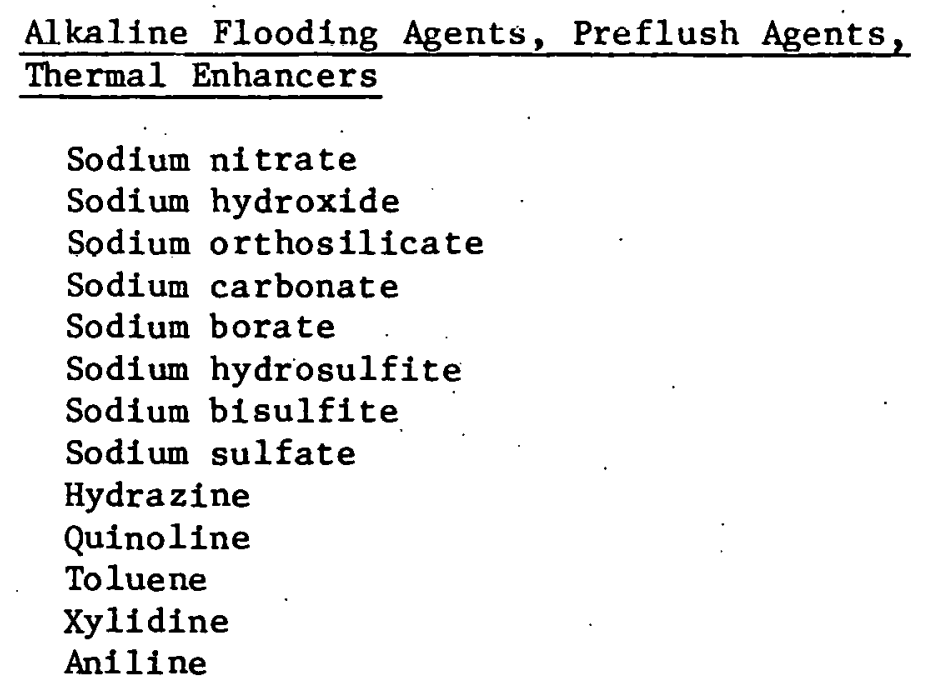


TA3LE 2

GENERAL TOXICITY DATA POR CHEMT JALS USED IN ENHANCED OIL RECOVERY

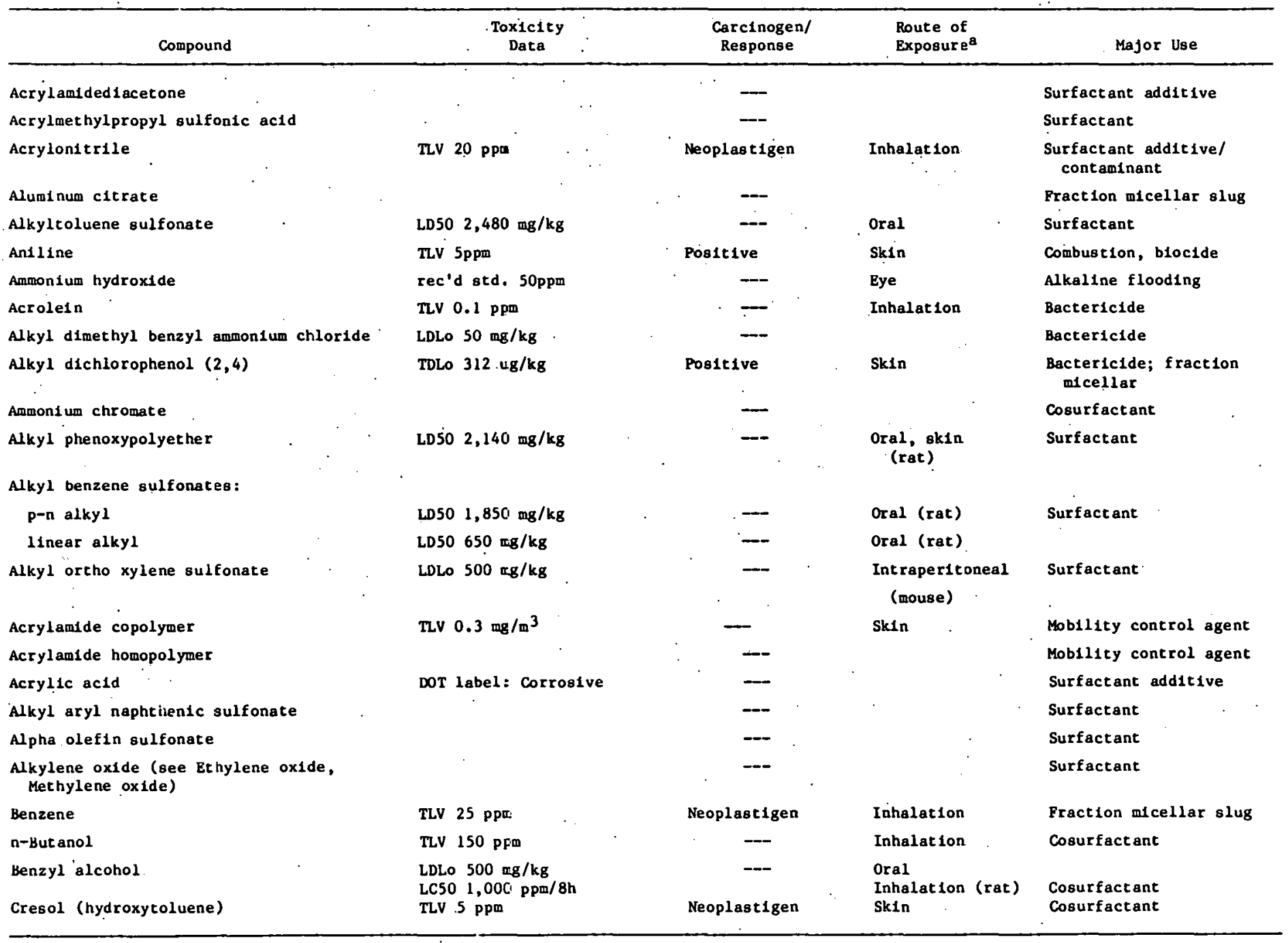


TABLE 2 (Cont 1nued)

\begin{tabular}{|c|c|c|c|c|}
\hline Compourid & $\begin{array}{c}\text { Toxicity } \\
\text { Data. }\end{array}$ & $\begin{array}{l}\text { Carcinogen/ } \\
\text { Response }\end{array}$ & $\begin{array}{l}\text { Route of } \\
\text { Exposure }\end{array}$ & Major Use \\
\hline Cyclohexanol & $\begin{array}{l}\text { TLV } 50 \mathrm{ppm} \\
\text { TCLO } 75 \mathrm{ppm}\end{array}$ & -- & Inhalation & Cosurfactant \\
\hline Calcium sulfate & $\begin{array}{l}\text { TLV } 10 \mathrm{gg} / \mathrm{m}^{3} \\
\text { TBLo } 194 \mathrm{~g} / \mathrm{m}^{3} / 10 y\end{array}$ & --- & Inhalation & Bactericide \\
\hline Cadmi um & $\operatorname{TLV} 0.05 \mathrm{mg} / \mathrm{m}^{3}$ & Positive & Innalation & Bactericide \\
\hline Carboxymet hylcel.lulose & (Nontoxic) $2,700 \mathrm{mg} / \mathrm{kg}$ & -- & Oral (rat) & Mob1lity control agent \\
\hline $\begin{array}{l}\text { Carboxypclymethylene (Cerboxyviny } 1 \\
\text { polymer) }\end{array}$ & (Nontoxic) $2,700 \mathrm{mg} / \mathrm{kg}$ & -- & Oral (rac) & Mobflity control agent \\
\hline Calcium chloride & $\mathrm{TLV} 10 \mathrm{mg} / \mathrm{m}^{3}$ & -- & Oral, Inhalation & Alkaline flooding \\
\hline Cyclohexenone & TLV $50 \mathrm{ppm}$ & --- & Inhalation & Eraction aicellar slug \\
\hline citric acid & $205011,700 \mathrm{mg} / \mathrm{kg}$ & -- & Ocal (rat) & Fraction Ificellar slug \\
\hline Cyclohexene & TLV $300 \mathrm{ppm}$ & -- & Oral & Fraction aicellar slug \\
\hline p-Chloroandline sulfate Laurate & & Positive & & Surfactant \\
\hline Cocodimelhylbenzyl ammonlum chloride & & -- & & Bactericide \\
\hline Vecane & & $-\cdots$ & & Fraction nicellar slug \\
\hline Vodecane & . & -- & & Fraction aicellar slug \\
\hline $\begin{array}{l}\text { Alkyl dinethyl quaterna=y ammon1um } \\
\text { chlorides }\end{array}$ & & -- & & Surfactant \\
\hline $\begin{array}{l}\text { Uieter-adecyl dimethyl ammonium } \\
\text { chlo:ide }\end{array}$ & · &.-- & . & Surfactan: \\
\hline Dodecyl trimerhyl ammonium chloride & & -- & & Surfactant \\
\hline Decyl be'zzyl sulfonlc acid & LD50 $2,000 \mathrm{mg} / \mathrm{kg}$ & --- & Oral (mouse) & Surfactant \\
\hline Diethyleneglycol sulfate & LD50 $1,000 \mathrm{mg} / \mathrm{kg}$ & --- & Oral (rat) & Surfactanc \\
\hline n-Dudecyl-diet hyleneglycol sulfate & LDSO $1,000 \mathrm{mg} / \mathrm{kg}$ & -- & Oral (rat) & Surfactant \\
\hline Lodecyl benzene sulfonate & $\mathrm{TLm} 96 \quad 100-10 \mathrm{ppm}$ & -- & & Surfactant \\
\hline Diphenoi plcrylhydrazine & & Positive & & Combustion \\
\hline Dimethyl hydrazine & TLV $5.5 \mathrm{ppd}$ & Neoplastigen & Sk1n & Combustion \\
\hline Diethylenetriarine & $\begin{array}{l}\text { TLV } 1 \mathrm{ppm} \\
\text { WLLO Sijo } \mathrm{mg} / \mathrm{kg}\end{array}$ & -- & Skin & Combustion; bactericide \\
\hline Decanol (nonyl carbinal) & $75 \operatorname{mos} / 3$ & Neoplastigen & skin & Cosurfactant \\
\hline $\begin{array}{l}\text { Di 1sobutylphencoxyethoxyethyl dimerhyl } \\
\text { benzyl ammon lum chloride }\end{array}$ & LDLO SD mg $/ \mathrm{kg}$ & Neoplastigen & Oral, eye & Surfactant \\
\hline $\begin{array}{l}\text { Uextrans } \\
\text { Deoxyritonucletec acid }\end{array}$ & $\begin{array}{l}(\text { Nontoxic) } \\
\text { (Nontoxic) }\end{array}$ & $\overline{--}$ & & $\begin{array}{l}\text { Mobility buffer } \\
\text { Mobility buffer }\end{array}$ \\
\hline
\end{tabular}


TABLLE 2 (Continued)

\begin{tabular}{|c|c|c|c|c|}
\hline curapuund & $\begin{array}{l}\text { Toxicity } \\
\text { Data }\end{array}$ & $\begin{array}{l}\text { Carcinogen/ } \\
\text { Response }\end{array}$ & $\begin{array}{l}\text { Route of } \\
\text { Exposure }\end{array}$ & Major Use \\
\hline Ethatud & $\operatorname{TLV} 1,000 \cdot \mathrm{ppm}$ & $\begin{array}{l}\text { Teratogen tests } \\
\text { in progress }\end{array}$ & Inhalation & Cosurfactant \\
\hline Eithylete uxide. & LCLO 4,000 ppm & Possible & Inhalation & Demulsification \\
\hline Vellutulatafiles & TLV 3 ppm; DUT: corrozive & -- & & Demulsification \\
\hline Leliyletuedi amblite & TCLO $200 \mathrm{ppm}, \mathrm{TLV} 10 \mathrm{ppm}$ & · - --- & Inhalation & $\mathrm{CO}_{2}$ removal \\
\hline EUTA & 2,000 ag $/ \mathrm{kg} 7-140$ & Teratogen & Oral (rat) & Preflushing agent \\
\hline Glycerul & LDSU $1,260 \mathrm{mg} / \mathrm{kg}$ & $\cdots$ & oral & $\begin{array}{l}\text { Mobility control agent; } \\
\text { fraction micellar slug }\end{array}$ \\
\hline Glyuxil (4U\%) & $\omega 507,070 \mathrm{mg} / \mathrm{kg}$ & - & Oral, skin & Surfactant \\
\hline Guar lium & LUSO $9,400 \mathrm{mg} / \mathrm{kg}$ & --- & Oral (rat) & Mobility buffer \\
\hline ilycerol disulfivalet ate munomyriscate & (Low) & - & & Surfactant \\
\hline Glutaraldeliyde & TLV 2 ppm & -- & Skin & Bactericide; cosurfactant \\
\hline Furfuryl alcoliol & $\operatorname{TuV} S \mathrm{ppm}$ & -- & Skin & Cosurfactant \\
\hline Fucl oll & $12,500 \mathrm{mg} / \mathrm{kg} 5 \mathrm{D}$ & Mutagen & $\begin{array}{l}\text { Oral, subcutaneous } \\
\text { (mouse) }\end{array}$ & Cosurfactant \\
\hline Furmaldeligue & TLV $2 \mathrm{ppm}$ & Neoplastigen & Inhalation & Bactericide; cosurfactant \\
\hline Fluoride solutions. & DOT: poition oxidizerz. & - & & Preflushing agent \\
\hline 1-hexanol & LDLO SUO $\mathrm{mg} / \mathrm{kg}$ & -- & Oral, akin & Cosurfactant \\
\hline $2-11 \times x a n u l$ & & - & . & Cosurfactant \\
\hline Heptanul & LDSO $3,250 \mathrm{mg} / \mathrm{kg}$ & -- & Oral, rat & Cosurfactant \\
\hline Hydruxyethylcel lu lose & & Implant tumors & Subcutaneous & Mobility control agent \\
\hline Hydrazine & TLV 1 PFm & Positive & Sk1n & $\mathrm{O}_{2}$ scavenger; combustion \\
\hline Hydrogell peroxide & TLV I ppm; vOT: oxidizer & -- & Inhalation & $\begin{array}{l}\text { Alkaline flooding; } \\
\text { combustion }\end{array}$ \\
\hline Hexidecyltribethyl amoonium chloride & & -- & & Surfactant \\
\hline llexadecyluaplithalene sulfonate & LD50 $2,320 \mathrm{mg} / \mathrm{kg}$ & -- & Oral, rat & Surfactant \\
\hline Hydroxyalkysultionate. & & -- & & Surfactant \\
\hline Heptane & & -- & & Fraction micellar slug \\
\hline L subut y 1 arethacrylate & $420 \mathrm{mg} / \mathrm{ks}$ & Teratogen & Ipr (rat) & Surfactant \\
\hline dsuquinutine & $350 \mathrm{mg} / \mathrm{kg}$ & -- & Oral, skin & Alkaline flooding \\
\hline Isobutanol & $500 \mathrm{mg} / \mathrm{kg}$ & Positive & Oral, skin & Cosurfactant \\
\hline Isopentanol & TLV $100 \mathrm{ppm}$ & Pooltive & Inhalation & Cosurfactant \\
\hline $\begin{array}{l}\text { Lsupropanol } \\
\text { Lauryl pulyethuxy sulfate }\end{array}$ & $\begin{array}{l}\text { TLV } 400 \text { ppm } \\
\text { (LOW). }\end{array}$ & -- & Inhalat Ion, sk1n & $\begin{array}{l}\text { Cosurfactant } \\
\text { Surfactant }\end{array}$ \\
\hline
\end{tabular}


TABLE 2 (Cont Inued)

\begin{tabular}{|c|c|c|c|c|}
\hline Jompound & $\begin{array}{c}\text { Toxicity } \\
\text { Data }\end{array}$ & $\begin{array}{l}\text { Carclnogen/ } \\
\text { Responge }\end{array}$ & $\begin{array}{l}\text { Route of } \\
\text { Exposure } \mathrm{a}^{\mathrm{a}}\end{array}$ & Major Use \\
\hline Lithium hydroxide & & --- & . & Steam flooding \\
\hline Magnesium & . & -- & · & Bactericide \\
\hline Manganese & & -- & & Bactericide \\
\hline Monusaccitaride & & --- & & Mobility centrol agent \\
\hline "-Methyl Laurille oleamide & & -- & & Surfactant \\
\hline Monubucyl:phenyl phenol sodium sulfate & & -- & & Surfactanc \\
\hline Morpholine steacate & . & --- & & Surfactant \\
\hline Methyl methylacrylate & TLV $100 \mathrm{ppm}$ & -- & Inhalation-Cus & Surfactant \\
\hline Methyl acrylate & $75 \mathrm{pps}$ & --- & Inialation & Surfactant \\
\hline p-Nunyl fhenod & LDSO $1,620 \mathrm{mg} / \mathrm{kg}$ & -- & Oral (rat) & Cosurfactant \\
\hline Nitrilotriacetic acid & WD50 $1,470 \mathrm{mg} / \mathrm{kg}$ & Neoplastigen & Oral (mouse) & Fraction of micellar slug \\
\hline Nitric.acid & $\begin{array}{l}\text { TLV } 2 \text { ppm; DOT: oxidizer } \\
\text { and corrosive }\end{array}$ & -- & & Combustion. \\
\hline NLtrogen oxide & $\begin{array}{r}\text { TLV } 25 \text { ppm; DOT: } \\
\text { anestietic gas }\end{array}$ & Teratogen & Inhalation (rat) & Combustior: \\
\hline Uctadectoluene sulfonate & & -- & & Surfactant \\
\hline Oetane & & -- & & Fraction of micellar slug \\
\hline Methyl nonyl kerone & LUSU $5,000 \mathrm{mg} / \mathrm{kg}$ & --- & . & \\
\hline $\begin{array}{l}\text { oxyerhyl echyl ke:one } \\
\text { oxyellulose }\end{array}$ & wosu $5,000 \mathrm{mg} / \mathrm{kg}$ & -- & & $\begin{array}{l}\text { Fraction of micellar slug } \\
\text { Mobility suf fer }\end{array}$ \\
\hline 1-octanol & LD50 $790 \mathrm{mg} / \mathrm{kg}$ & --- & Oral, skin & Cosurfactant \\
\hline 2-pentanol (amyl alcobol) & $500 \mathrm{ng} / 24$ hour & $\cdots$ & $\begin{array}{l}\text { Skin, eye, oral; } \\
\text { moderate to } \\
\text { severe ef fects } \\
\text { (rodents) }\end{array}$ & Cosurfactant \\
\hline $\begin{array}{l}\text { Fhenol } \\
\text { Pentadecyl pherol }\end{array}$ & TLV $\vec{\jmath} \mathrm{ppm}$ & Positive & Sxin & $\begin{array}{l}\text { Cosurfactant, biocide } \\
\text { Cosurfactant }\end{array}$ \\
\hline Pentane & $\operatorname{TLV} 1,000 \mathrm{ppm}$ & -- & Inhalation-CNS & Fraction of aicellat slug \\
\hline Propane & $\mathrm{TLV} 1,000 \mathrm{ppm}$ & --- & Inhalation & Fraction of micellar slug \\
\hline Potassicim permenganate & TDLo $2,400 \mathrm{~g} / \mathrm{kg} / \mathrm{D}$ & --- & & Fraction of micellar slug \\
\hline Yotassilm chronate & $\operatorname{rLv} 10 J \quad \mathrm{~g}$ & Possible & Oral, Inhalation & Fraction of micellar slug \\
\hline Pol yoxyethylene & L050 $7,460 \mathrm{mg} / \mathrm{kg}$ & . & $\begin{array}{c}\text { Cral (rat) } \\
\text {. }\end{array}$ & $\begin{array}{l}\text { Fraction of micellar } \\
\text { slug; cosurfactant; } \\
\text { mobility control } \\
\text { agent; demulsification }\end{array}$ \\
\hline
\end{tabular}




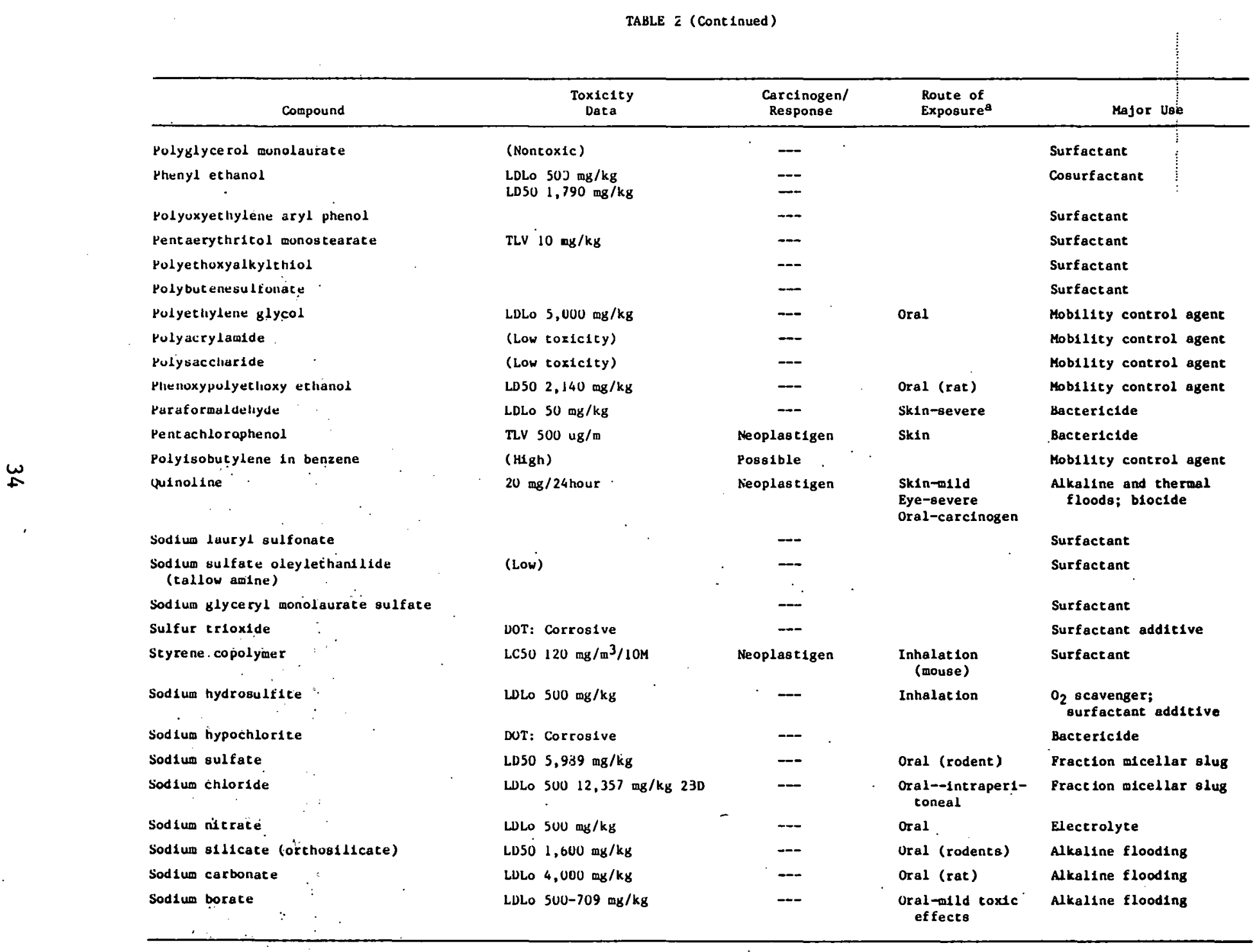


TABLE 2 (Concluded)

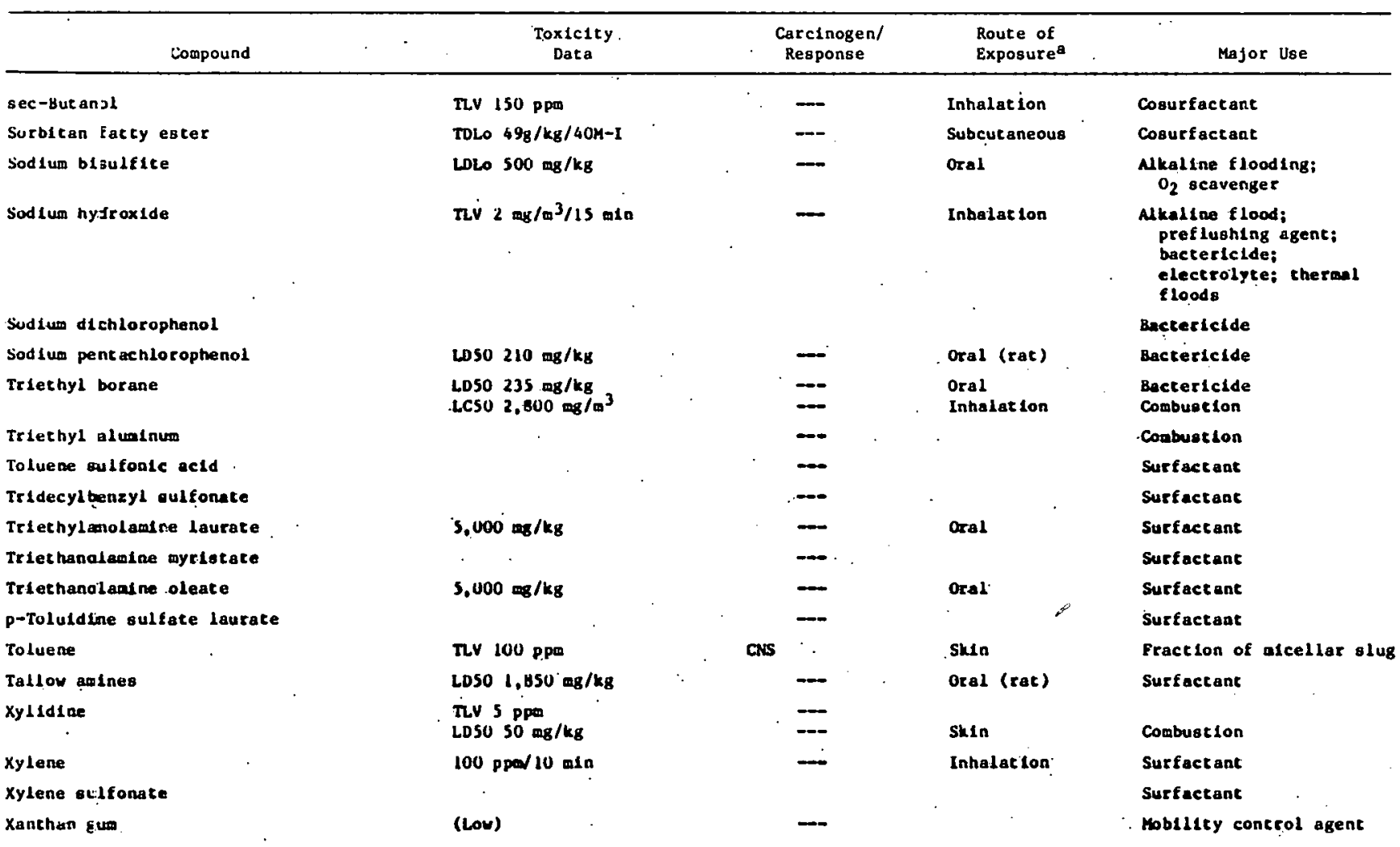

Notes: IVV = Threshold 11mit value.

$1050=$ The dose at which 50 pe :cent of the subject animals die.

LDLO - The dose at which less than 50 percent of the subject animals die.

XLO = Low threshold concentra:lon.

Tloo - Low threshold dose.

CNS - Dentral nervous systes.

anless otherwlise noted, in "Route of Ëkposure" column, data is human health data.

Source: Silvestro 1980. 
Biocides pose significant risks. Phenol toxicity is discussed in the Refinery Operations section of this report under Health Effects. Chlorinated phenols such as pentachlorophenol and 2,4,5trichlorophenol $(2,4,5-\mathrm{T})$ may be contaminated with chlorinated dioxins and dibenzofurans (also discussed in the Refinery Operations section). Glutaraldehyde, formaldehyde, and paraformaldehyde may act as sensitizers and carcinogens.

Polysaccharide-based and polyacrylamide agents pose significant inhalation hazards. Xanthan gums have been reported to cause disease similar to polymer and metal fume fevers. Hydrazine and quinoline employed in in situ combustion are carcinogenic in animal experiments and potential sensitizers. In significant quantities, chelating agents such as ethylenediaminetetracetic acid (EDTA) may sequester mineral cotactors in mucosal barriers, leading. to the enhanced absorption of other toxic agents.

Chemical reactions and synergistic toxic effects among the various compounds employed in oil extraction are largely unknown, as are those of their contaminants, crude o11 and 1 ts contaminants, and compounds encountered in drill cuttings. Drilling rig and other oil extraction workers' exposures to toxic agents and resulting adverse effects have received little study and remain largely uncharacterized.

A number of factors may be contributing to unassessed occupational health problems among oil $\mathrm{rig}$ and field workers. Domestic oil and gas drilling and extraction have recently experienced an upsurge in activity and this trend is expected to continue. Experienced and skilled field workers are in high demand worldwide, and it may be presumed that many $0 i 1 \mathrm{rig}$ and field workers lack extensive knowledge and experience with the mechanical, flammable, explosive, and toxic hazards they routinely encounter. Much drilling, especially exploratory drilling, is performed by small, independent operators. These factors, combined with the proprietary nature of drilling muds and enhanced oil recovery compounds, may contribute to unassessed occupational health problems among ofl rig and field workers. These problems may be difficult to assess, as these workers are highly mobile and often live and work. In isolated, undeveloped areas, lacking sophisticated medical facilities and expertise.

The use of miscible fluids to aid crude petroleum extraction entails occupational exposures distinct from those assoclated with waterflooding. Two such technologies are hydrocarbon and $\mathrm{CO}_{2}$ flooding, which use miscible gases as the driving fluids. There is a risk from fire and explosion assoctated with miscible hydrocarbon injection. The more widely used $\mathrm{CO}_{2}$ flooding entails risks of worker asphyxiation. This may occur elther through handling, on-site 
storage, or during the actual injection process (U.S. Department of Energy 1978). In addition to the direct use of $\mathrm{CO}_{2}$, hydrogen sulfide may become mixed with the injected gas in the reservoir formation. These mixed gases may then be recycled back into the reservoir. Should this occur, workers may be exposed to the toxic effects of $\mathrm{H}_{2} \mathrm{~S}$, as discussed in the Refinery Operations section of this report under Health Effects.

Water miscible (micellar/polymer) and thermal (steam and in situ) ofl extraction methods pose significant health hazards both for the worker and the public. The mfcellar/polymer technology ut 11 izes many different groups of chemicals, e.g., surfactants, cosurfactants, mobility buffers, electrolytes, pre-flushing compounds, bactericides, and various hydrocarbons that may be part of the micellar slug (Schumacher 1978). Within each of these groups there are many specific compounds that can be used (U.S. Department of Energy 1978). In general, it has been estimated that two pounds of chemicals are injected into a reservoir for each barrel of recovered oil (U.S. Department of Energy 1978).

011 extraction may result in significant fugitive emissions of crude ofl hydrocarbons and volatile crude ofl constituents, including potentially carcinogenic benzene. In addition, neurotoxic lower alkanes may evaporate from a number of sources. PAHs and other heavier compounds may be suspended in aerosols, condensed on particulates, or volatilized due to high temperatures. Volatile and liquid nitrosamines may form in extracted crude ofl and during treatment.

\section{Public Health Hazards}

Depending on how widespread the uses, amounts, and types of chemicals utilized and the pollutants produced, oil production technologies may have adverse impacts on public health. The llierimal technologies, especially steam injection, may result in hazardous exposures.

Currently, steam injection is the most widely used method for enhanced ofl recovery in the U.S. and is primarily centered in California (U.S. Department of Energy 1978). Approximately 15 gallons of crude o1l, containing up to 2 percent sulfur, must be burned In steam boilers to inject enough steam to produce 1 barrel (42 gallons) of ofl (U.S. Department of Energy 1978). Such combustion produces large amounts of airborne emissions. Among the pollutants produced are oxides of sulfur and nitrogen and particulate matter (U.S. Department of Energy 1978). Another study on emissions from such combustion showed that aldehydes, polycyclic aromatic hydrocarbons such as benzo(a)pyrene, carbon monoxide, hydrocarbons, and 
sulfur trioxide were produced (Schumacher 1978). In addition to any direct exposure effects from these compounds, indirect effects may occur as a result of atmospheric interactions or transformations. The indirect effects associated with airborne transport of organics and combustion products are not well understood, but it is known that specific alrborne organics, such as the polycyclic aromatic hydrocarbons, have induced a variety of cancers (Stokinger and Coffin 1968; Laskin et a1. 1970). Atmospheric oxidants have also been shown to initiate, or act as co-carcinogens for, the carcinogenic action of these hydrocarbons (Ayers and Buehler 1970; Altshuller and Bufalini 1971).

Other health impacts also have been studied. Hammer, et al. (1974) found coughing and chest discomfort to exist when healthy individuals were exposed to combustion-related oxidant concentrations between 0.25 and $0.39 \mathrm{ppm}$. In addition, the level of aldehydes has been linked with the degree of eye Irritation (Renzetti and Bryan 1961).

Although in situ combustion, another thermal recovery method, occurs deep within the oll reservolr, it also may produce emissions at the production well. In gaseous waste streams analyzed from 31 in situ combustion projects, carbon monoxide, carbon dioxide, oxygen, and 11ght hydrocarbons (methane, ethane, and propane) were detected.

A large potential for adverse impacts from enhanced recovery (excluding air pollution from the steam injection and in situ combustion processes) may reside in chemically-contaminated water that may infiltrate potable water supplies. The leaching and transport potential of various petroleum extraction chemicals or emission products into underground freshwater supplies are considered in the next section. The toxicity of crude oil constituents, driliing mud compounds, and o11 recovery agents may be significantly increased when water is chlorinated prior to public use. Carcinogenic halogenated methanes, chlorinated phenolics, and other compounds may be formed. The contamination of any freshwater source, especially if it is used as a source of drinking water, could have potentially serfous public health consequences. Health effects would depend on such factors as the amount and specific toxicity of the compounds in question. Fugitive emissions of hydrocarbons and other agents from used brine and fluids, crude oil, and leaking equipment may affect the health of those living near. oil wells. The health and environmental effects of fugitive emissions are discussed in the Refinery Operations section of this report. 
Health Effects of Natural Gas Production

The basic exploratory and drilling procedures utilized for natural gas do not differ substantially from those for oil (University of Oklahoma 1975). Thus, many potential health effects due to natural gas extraction have been discussed.

Potential health effects may result from separating dissolved natural gas from crude ofl at the production site. How the separated gas is further treated at the production site determines how potentially hazardous the operations may be to workers and the nearby public.

of direct concern from the standpoint of health impacts is the fact that natural gas may have varying concentrations of hydrogen sulfide associated with it. One study covering different geographical areas reported representative percent-by-volume data ranging from 0 to 35 percent (Leggett and Williams 1979). If the gas is processed rather than flared, the toxic hydrogen sulfide component will be 1solated and concentrated. Aside from any accidental release of gas, a major health concern is related to how the gas $1 s^{\prime}$ flared and its combustion products. The amounts of sulfur oxides and hydrogen sulfide emitted by flaring have been estimated. Assuming that natural gas contains an average of 0.5 mole percent of sulfur, approximately 250 million cubic feet per year of gaseous sulfur oxides and hydrogen sulfide are vented to the atmosphere from flares and fugitive losses (Wilkins 1977).

Potential health impacts from enhanced recovery methods, fracturing, and directional drilling must be considered in addition to those from conventional recovery techniques. These are new technologles for gas recovery lnvolving undefined health hazards related to the use of cryogenic and exotic fluids, and hazards associated with high pressures. At this point it would seem that many of the hazards associated with more conventional methods (e.g., hydrogen sulfide toxicity, hydrogen sulfide combustion, and oil combustion-related emissions) also apply to the new technologies.

Summary of Research Needs

Health Effects Data

Some health effects data for the petroleum industry are reported for the operations subject to recordkeeping requirements of the Occupational Safety and Heal th Administration (OSHA). The data include the number of employees, hours worked, recordable injuries and 111nesses, incident rates for fatalities, and information on lost workdays and restricted activity. These data are reported by Standard Industrial Classifications (SIC; U.S. Office of Management and Budget 
1972). With respect to drilling (SIC 1381) and exploration and production operations (SIC 1311), data from both onshore and of fshore drilling rigs are commingled and there is no separation of accident data from ancillary opeations such as brine injection systems and brine transport and disposal.

Both onshore and of fshore activities have diverged markedly over the last decade with respect to the nature and extent of risks. This is especially true as offshore exploration and production move into the deeper waters of the outer continental shelf.

An information gathering and reporting infrastructure is needed for collecting and processing health effects data. More explicit data also are needed.with respect to the nature and extent of 11lnesses and diseases. This information would be useful in retrospective epidemiological studies.

Effects of Drilling Muds and Enhanced 0il Recovery Agents

A study is needed concerning occupational exposure to drilling muds and enhanced o11 recovery agents. Documentation is needed on the frequency and duration of worker exposures. The study should include a retrospective epidemiological survey to assess potential health risks assoclated with operational handling and accidential exposures.

\section{Exposure to Toxic Chemicals}

Crude oil extraction and enhanced recovery methods involve worker exposure to many kinds of potentially toxic substances, including sequestering agents, anticorrosives, phenols, cosurfactants, bactericides, and various polycyclic hydrocarbons associated with crude petroleum. Although many basic research studies deal with the toxic effects of some of these materials, research has not focused on process-specific worker exposures to these substances. An in-depth assessment involving field study and measurements is needed, which focuses on identification of the toxic and carcinogenic chemicals utilized in secondary and tertiary recovery techniques and on an assessment of health risks associated with occupational exposure to these materials.

\section{Public Health Considerations}

Over the last decade, numerous health assessment studies have been performed which relate to potential risks to public health as a result of oll production. These generally have focused on production. near urban areas in Texas and southern California. Most of these have been conducted on the state level and have focused on conventional ofl and gas production. 
With the increasing use of sophisticated advanced recovery techniques, many new kinds and new combinations of gases and aerosols may be released to the atmosphere. The effects of these on adjacent communities and their interaction with urban pollutants should be addressed.

\section{Interactions of Toxic Agents}

Chemical interactions and synergistic reactions among the numerous substances encountered in crude ofl need study. Heat, pressure, and the complex chemical mixing that occurs during drilling may lead to the formation of unrecognized toxic substances. 
THIS PAGE

\section{WAS INTENTIONALLY LEFT BLANK}


ECOLOGICAL EFFECTS OF ONSHORE DEVELOPMENT

Aquatic Biota

This section focuses on the effects of petroleum on. freshwater biota, as well as the effects of compounds associated with petroleum production. ${ }^{\star}$ Among the factors to be addressed are:

- The source, composition, and relative toxicities of organic and inorganic petroleum components in the freshwater environment;

- The manner and degree by which such components may be taken up and transformed by organisms; and

- The various effects (or lack of effects) that petroleum or associated compounds may have on various organisms.

In petroleum production the pollutant of greatest potential concern, not only because of its volume, but also its toxicity, is the crude oll itself. Crude petroleum is a complex mixture of organic, inorganic, and metallic compounds, with the organics predominating. Some of its major organic groups are: the aliphatic hydrocarbons, cyclic paraffin hydrocarbons, aromatic hydrocarbons, naphthenearomatic hydrocarbons, resins, asphaltenes, and heteroatomic compounds (Bestougeff 1967). "Average" crude oll may also be characterized by the molecular size of its organic components. Gasolines $\left(C_{5}\right.$ to $\left.C_{10}\right)$ comprise 30 percent; kerosenes $\left(C_{10}\right.$ to $\left.C_{12}\right), 10$ percent; light distillate oils $\left(C_{12}\right.$ to $\left.C_{20}\right)$, 15 percent; heavy distillate oils $\left(C_{20}\right.$ to $\left.C_{40}\right), 25$ percent; and residuum o11, 20 percent (Valkovic, 1978). These relative proportions are helpful as an indicator of a particular crude ofl's toxicity to various types of freshwater organisms. For example, in the event of a spill, some of the lighter components of oil may evaporate rapidly, presenting a different length of exposure (but not necessarily of toxicity) than heavier components.

\section{Petroleum Constituents}

of all the organic fractions comprising petroleum, the aromatic hydrocarbons appear to be the most acutely toxic compounds (U.S. Environmental Protection Agency 1972). Such aromatics may exist in relative abundance; for example, benzene constitutes 20 percent or more of the total aromatics found in crude oil (Brockson and Bafley 1973).

\footnotetext{
*Effects on water quality are discussed below under Transport and Transformation.
} 
In addition to the organics, crude petroleum also has a large number of trace elements assoclated with it. The elements found in petroleum vary in number, concentration, and potential toxicity (Valkovic 1978). However, two metals--vanadium and nickel--exist in such high concentrations that their ratio to each other is often used to characterize crude petroleum (Valkovic 1978). Both of these metals can have toxic effects on freshwater biota which are discussed below.

The concentration of metals in crude oil may vary with both the geographic source and geological age of the petroleum. Vanadium is the element in greatest abundance, with levels as high as $1,100 \mathrm{ppm}$ reported (F11by and Shah 1975). Nickel is less abundant than vanadium, but its content is st111 high compared to other metals. Some crude ofl has been reported to contain $350 \mathrm{ppm}$ (Valkovic 1978). These metals are not uniformly distributed among the various classes of organic compounds with which they are associated, but usually reside in the higher-weight molecular compounds such as resins and asphaltenes (Filby and Shah 1975).

Consideration of all crude o11 components reveals a great variation in the fuel's potential effects on aquatic organisms. It has been suggested that the severity of petroleum's effects may increase in sequence, from mammals, which are highly tolerant; through finfish, plankton, and benthos; to birds, which are highly affected (American Institute of Mining Engineers 1975). A statement of this type is at best a generalization, and it should again be emphasized that different crude oils consist of varying amounts of light and heavy components of different molecular size. Consequently, the effects of crude oil components will differ in their toxicity to specific groups of organisms depending on many factors (e.g., amount of coating; rates of uptake, accumulation, elimination). For example, the low bolling, water soluble components of a crude ofl may be more acutely toxic due to their rapid uptake. This is especially true when refined oils, which contain a greater percentage of these low bolling compounds, are spilled (Brown, V.M., 1976). Although components of crude oil may be lethal to aquatic mammals and birds over a long period of time, many of these organisms die soon after an oll spill as a result of suffocation, exposure to cold, and drowning.

In the production of crude o1l, there are occasions when chemicals used in its production become mixed with it. In any discussion, therefore, of the ecological effects of crude petroleum, one must consider the potential effects of these "foreign" components. The problem of evaluating the toxicity of petroleum and any of these associated compounds is further complicated by the question of synergistic reactions, i.e., the combination of various components-whatever their source--may have greater, lesser, or differing effects than any of the components alone. 
Naturally occurring freshwater compounds could combine with various petroleum associated compounds to either mitigate or intensify potentially toxic reactions. Freshwater systems such as those affected by onshore oil and gas activities are excellent examples of both of these phenomena. There are wide variations in the levels of calcium and magnesium salts in freshwater, but whatever their concentration, they may affect the toxicity of forelgn elements such as crude oil organics and metals that may enter such systems. If such petroleum-derived materials enter freshwater in a spill, the natural hardness of the recelving water may be one determinant of potential toxictity. It appears that an inverse relationship exists between the toxicity of trace metal cations and water hardness. That is, the greater the hardness of the water, the less toxic are the cations of various trace metals to freshwater life.

In reality, the hardness of freshwater is often ascertained by measuring the calcium content of the water. It has been shown that in soft acid water (low calcium content) there is an observed toxicity to fish even when trace metals are at relatively low concentrations (Brown, V.M., 1976). It has also been reported that the rates and levels of uptake of various heavy metal radionuclides appear to be inversely related to the calcium concentration of the water (Brown, V.M., 1976). Concomitantly, any of a number of naturally occurring compounds within crude oil may combine with chemicals used to efther produce them, or clean them up in the event of a spill. Such chemical combinations may present different freshwater systems with differing degrees of toxic stress. Table 3 presents a synopsis of assorted effects on different groups of organisms caused by crude petroleum, some of its major constituents, and various associated compounds used in its production.

In an oll sp111, not all plants and animals are affected equally; some are impacted in different ways and by different mechanisms. For example, waterfowl may be killed quickly during the initial stages of an aquatic o1l spi.1. due to the loss of natural protective oils from thelr feathers (American Petroleum Institute 1976). Birds thus contaminated usually die from exposure, rather than from the uptake and accumulation of toxics in the oil.

Some constituents of crude oil also may affect waterfowl by inhibiting successful adult reproduction. Preliminary experiments on mallard eggs, to which microliter amounts of crude ofl were applied, have shown dose-related mortality (Alber and Szaro 1976). It is believed that such mortality results from toxic components within the crude oil, not embryo suffocation from oil covering the eggs. When the eggs were treated with a mixture of paraffins like those found in crude o1l, only a small decrease in reproduction resulted (Alber and Szaro 1976). It has therefore been suggested that the embryotoxic 
TABLB 3

EFFECTS ON SELRCTED FRESHWATER B=OTA FROM PETROLEUM AND ASSOCIATED CONSTITUENTS

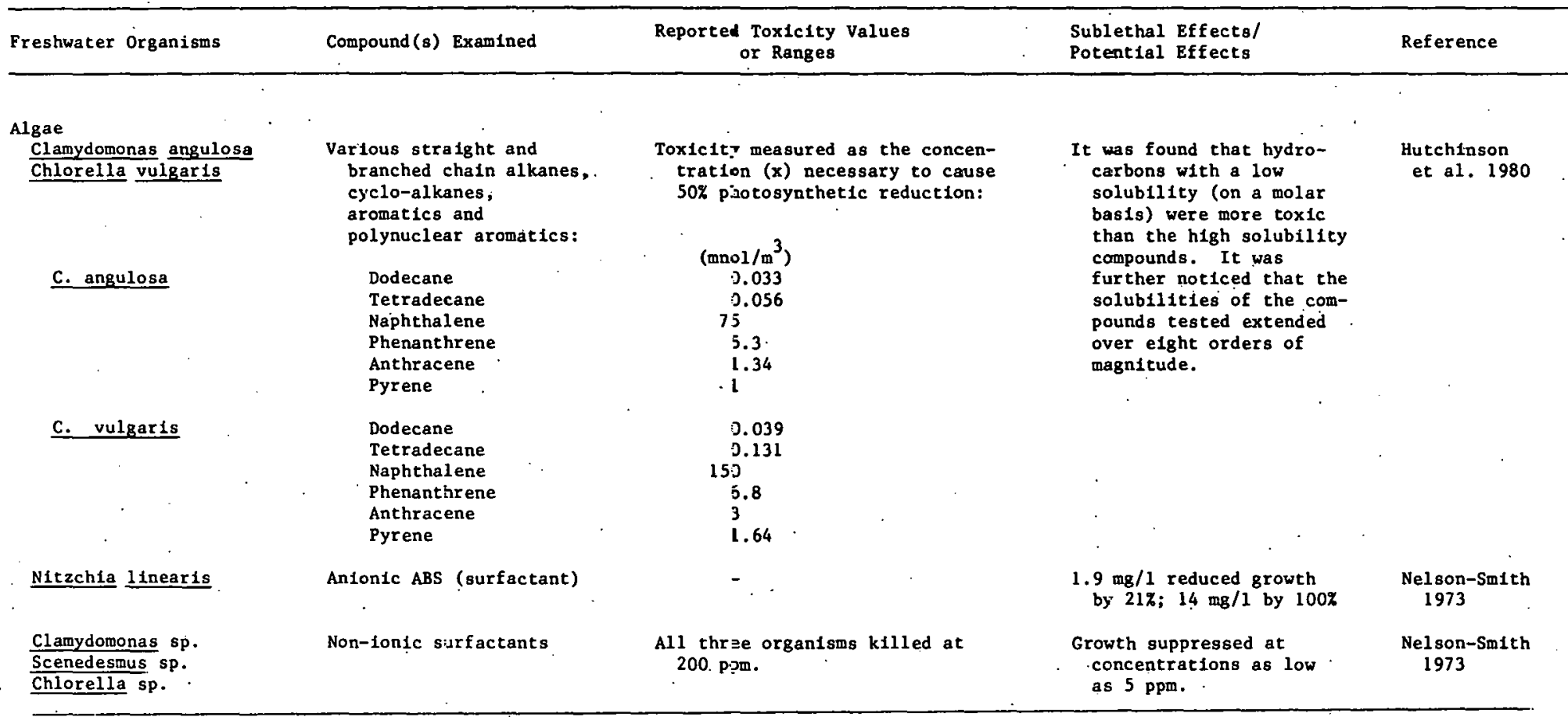


TABLE 3 (Continued)

\begin{tabular}{|c|c|c|c|c|}
\hline Freshwater Organisms & Compound (s) Examined & $\begin{array}{c}\text { Reported Toxicity Values } \\
\text { or Ranges }\end{array}$ & $\begin{array}{l}\text { Sublethal Effects/ } \\
\text { Potential Effects }\end{array}$ & Refererce \\
\hline Crustacea & & & . & · \\
\hline $\begin{array}{l}\text { Daphnids } \\
\text { Daphnia magna }\end{array}$ & $\begin{array}{l}\text { Linear alkylbenzene } \\
\text { Sulfonate (surfactant) }\end{array}$ & $\overline{-}$ & $\begin{array}{l}\text { Uptake of compound } \\
\text { occurred and was } \\
\text { found to be a function } \\
\text { of chain length and } \\
\text { exposure concentration }\end{array}$ & $\begin{array}{l}\text { Comotto et al. } \\
1979\end{array}$ \\
\hline Mollusca &. & . & . & \\
\hline $\begin{array}{l}\text { Fresh Water Mollusca } \\
\frac{\text { Cipangopalundina }}{\text { chinensis }}\end{array}$ & $\begin{array}{l}\text { The concentration of } \\
\text { polynuclear aromatic } \\
\text { hydrocarbons (PAHs) } \\
\text { in sediment and molluscs. }\end{array}$ & - & $\begin{array}{l}\text { Bloaccumulated concentra- } \\
\text { tions of some PAHs were } \\
\text { from is to } 200 \text { times } \\
\text { higher in the molluscs } \\
\text { than in the sediment. }\end{array}$ & Kalas et al. 1980 \\
\hline Fish & & . & & \\
\hline $\begin{array}{l}\text { Pink Salmon Fry } \\
\text { Oncorhynchus gorbusciza }\end{array}$ & Prudhoe Bay crude ofl & $\begin{array}{l}\text { Median tolerance } 11 \text { mit } \\
\text { (TLm) ranged from } 48-110 \text { ppr. }\end{array}$ & $\begin{array}{l}\text { Avoldance effects on } \\
\text { large fry at } 1.6 \mathrm{ppm} \\
\text { possibllity exists that } \\
\text { avoldance may disrupt } \\
\text { m1gration patterns. }\end{array}$ & Rice 1973 \\
\hline Freshwater fish & Crude ofl & $\begin{array}{l}\text { Concentrations as low as } 0.3 \mathrm{mg} / 1 \\
\text { found toxic. }\end{array}$ & - & $\begin{array}{l}\text { U.S. Department of } \\
\text { the Interiogr } 1972\end{array}$ \\
\hline $\begin{array}{l}\text { Chinook Salmor. } \\
\text { Oncorhynchus tschawyescha }\end{array}$ & Benzene & - & $\begin{array}{l}\text { Found } 86 \% \text { Increase in res- } \\
\text { p1ration rate over controls } \\
\text { af ter exposure time of } 48 \mathrm{hrs} \\
\text { to } 5 \mathrm{ppm} \text { benzene. Exposure } \\
\text { to } 10 \mathrm{ppm} \text { benzene for pertods } \\
\text { greater than } 48 \mathrm{hrg} \text { caused } \\
\text { narcosis resulting in respira- } \\
\text { tory decrease. }\end{array}$ & $\begin{array}{l}\text { Brockson and } \\
\text { Bailey } 1973 \\
-\end{array}$ \\
\hline
\end{tabular}


TABLE 3 (Cor.t1nued)

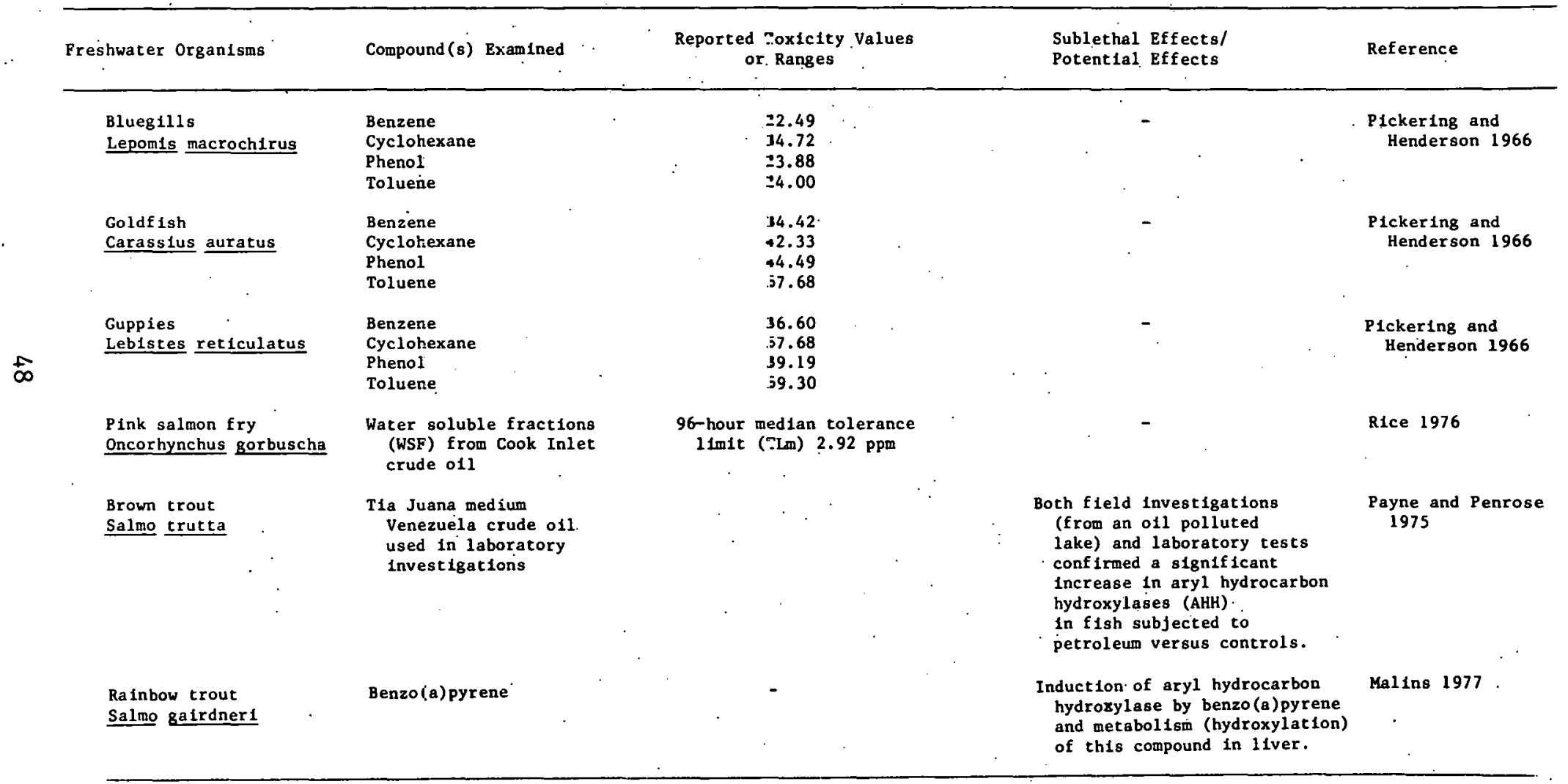


TABLE 3 (Continued)

\begin{tabular}{|c|c|c|c|c|}
\hline Freshwater Organi:jms & Compound (s) Examined & $\begin{array}{c}\text { Reported Toxicity Values } \\
\text { or Ranges }\end{array}$ & $\begin{array}{l}\text { Sublethal Effects/ } \\
\text { Potential Effects }\end{array}$ & Reference \\
\hline $\begin{array}{l}\text { Rainbow trout } \\
\text { Salmo galrdner1 } \\
\text { Carp } \\
\text { Cyprinus carplo }\end{array}$ & $\begin{array}{l}\text { 2-Methylnaphchalene, } \\
\text { Naphthalene }\end{array}$ & - & $\begin{array}{l}\text { Haif-lives of pollutants } \\
\text { In flsh exposed to pollu- } \\
\text { tants for } 9 \text { hours were less } \\
\text { chan } 24 \text { hours; but exposure } \\
\text { to compounds for } 4 \text { weeks } \\
\text { produced half-1lves (ellmi- } \\
\text { natlon) of hundreds of hours. } \\
\text { "Parent" compounds were of ten } \\
\text { found as metabolites: within } \\
\text { tissue. }\end{array}$ & $\begin{array}{l}\text { Melancoi and } \\
\text { Lech } 1979 \\
\end{array}$ \\
\hline $\begin{array}{l}\text { Blueg111s } \\
\text { Lepomis macrochdrus }\end{array}$ & $\begin{array}{l}\text { Varfous surfactants } \\
\text { Linear alkyl benzene } \\
\text { sulfonate, alkyl } \\
\text { ethoxylate sulfate, } \\
\text { amine oxide, trisodium } \\
\text { nitrilotrl-acetate }\end{array}$ & & $\begin{array}{l}\text { Some surfactants tested can } \\
\text { induce. Increases in ventila- } \\
\text { tion. (respiratory) rates. }\end{array}$ & Makf 1979 \\
\hline Trout & Anionic surfactants & - & $\begin{array}{l}\text { Iminobillzation of sperm } \\
\text { and reduced fertillzation } \\
\text { rate. }\end{array}$ & Nel son-Sanith 19.73 \\
\hline \multirow[t]{2}{*}{$\begin{array}{l}\text { Fathead Itinnows } \\
\text { P1mepligles pronelas }\end{array}$} & & $\begin{array}{l}\text { 96-hr. median tolerance } \\
\text { limit (Thm) } \mathrm{mg} / 1 \text { : }\end{array}$ & . & $\begin{array}{l}\text { Pickerting and } \\
\text { Henderson } 1966\end{array}$ \\
\hline & $\begin{array}{l}\text { Benzene } \\
\text { Cyclohexane } \\
\text { Pheno1 } \\
\text { Toluene }\end{array}$ & $\begin{array}{l}33.47 \\
32.71 \\
34.27 \\
34.27\end{array}$ & & \\
\hline
\end{tabular}


TABLE 3 (Concluded)

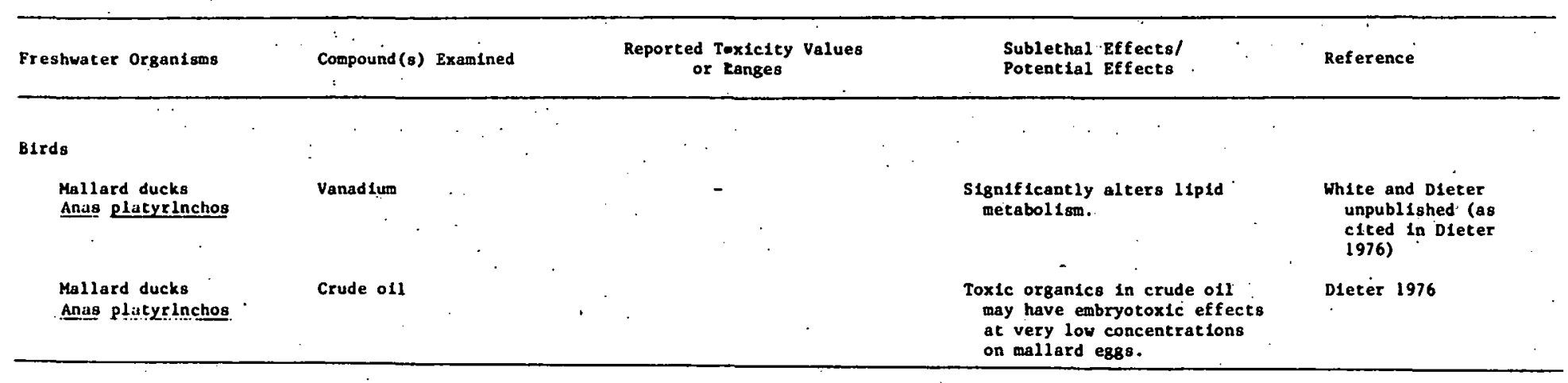


components in crude oil may reside in the aromatic rather than the paraffin portion of the petroleum. Studies on herring gulls from Lake Ontario may also implicate specific petroleum constituents as potential factors in the low reproductive rate noted there among the gulls. Investigations to determine the reasons for such low reproductive success led to an analysis of the gulls' body fat (11pids). Among 14 polynuclear aromatic compounds identified were 6 major aromatic compounds associated with petroleum: naphthalene, 2-methylnaphthalene, anthracene, benzo(a)fluorene, benzo(a)pyrene, and 9,10-diphenylanthracene (Fox et al. 1975).

\section{Effects of Petroleum Extraction Chemicals}

As discussed previously, chemical agents employed in drilling muds and enhanced oil extraction may be toxic to animals and humans. Toxicity values for many of these agents as they affect fish and daphnia are shown in Table 4. The aquatic toxicity of several hydrocarbons and other compounds is significantly increased when water is chlorinated for disinfection.

\section{Effects of Metals}

In addition to the diverse organic compounds in petroleum, there is a large and variable number of trace elements. For example, vanadium, varying in proportion from one crude oil to another, is usually. In the highest concentration relative to other trace metals. It has been shown that this element can significantly alter lipid (cholesterol and triglyceride) metabolism in specific waterfowl such as mallard ducks (White and Dieter, as cited in Dieter 1976). In these experiments, cholesterol values were measured for non-laying and laying mallard hens. The former averaged $119 \mathrm{mg}$ per dry liter and the latter, $38 \mathrm{mg}$ per dry liter. These values were determined to be normal, average values for these two conditions. In the ensuing experiments, the laying hens were fed $100 \mathrm{ppm}$ of vanadyl sulfate. Average concentrations of cholesterol were then measured at Intervals of $3,6,9$, and 12 weeks. It was found that there was no longer much of a difference between the laying hens and their non-laying counterparts, with cholesterol averaging $91 \mathrm{mg}$ per dry liter. In a simflar pilot study,the same alteration of lipid metabolism occurred when mallard hens were fed $10,000 \mathrm{ppm}$ of crude oil. In addition, they laid fewer eggs than normal (Dieter 1976).

It. is apparent that any such o11-induced changes could have profound effects on the reproductive capacity of freshwater waterfowl, especially when vanadium may occur in relatively high proportions. Since many waterfowl both live and reproduce in or around freshwater rivers, lakes, and marshes, the potential for direct kills or 
TABLE 4

TOXIC EFFECTS OF PETROLEUM EXTRACTION CHEMICALS TO FISH AND DAPHNIA

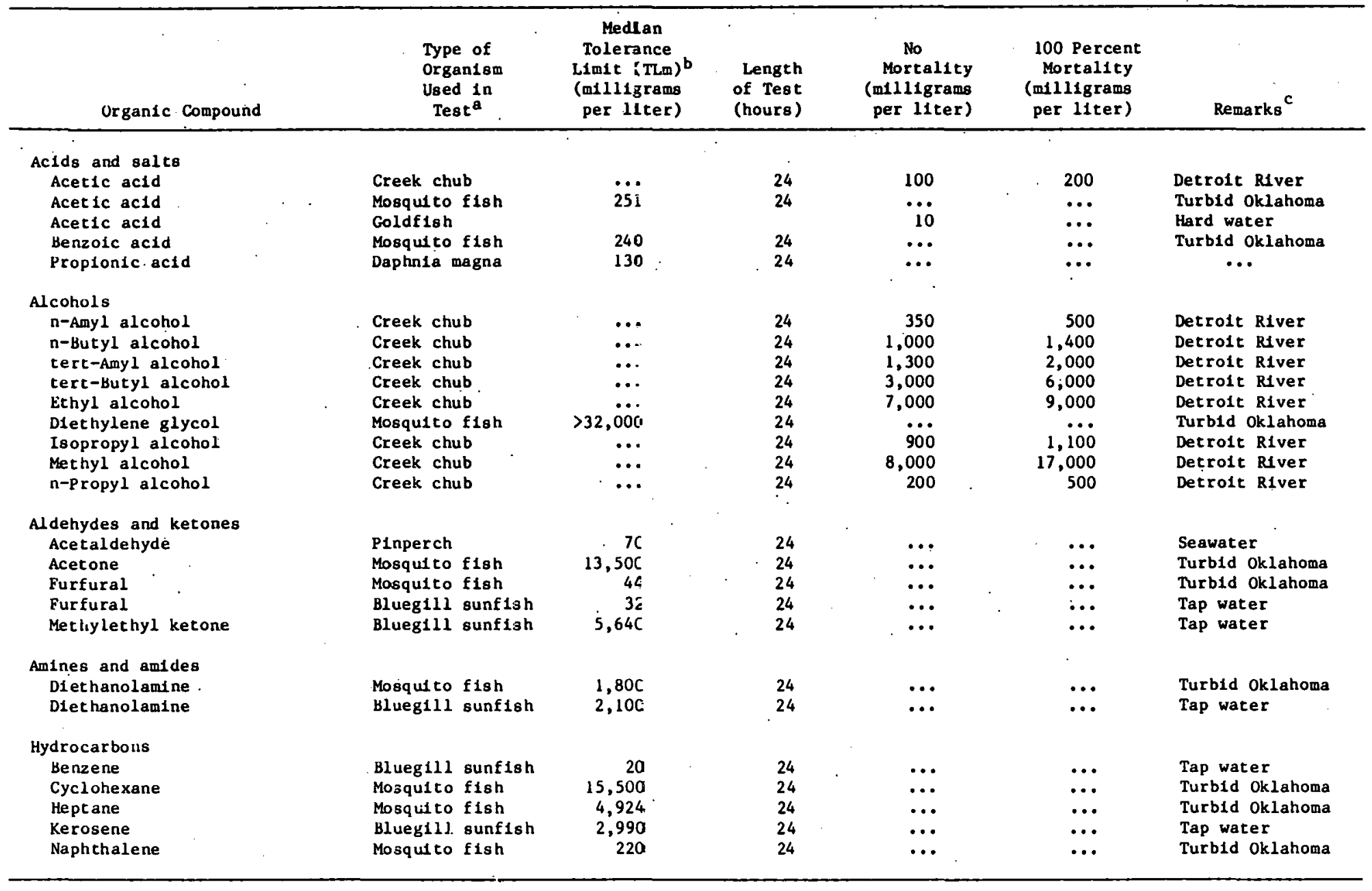


TABLE \& (Continued)

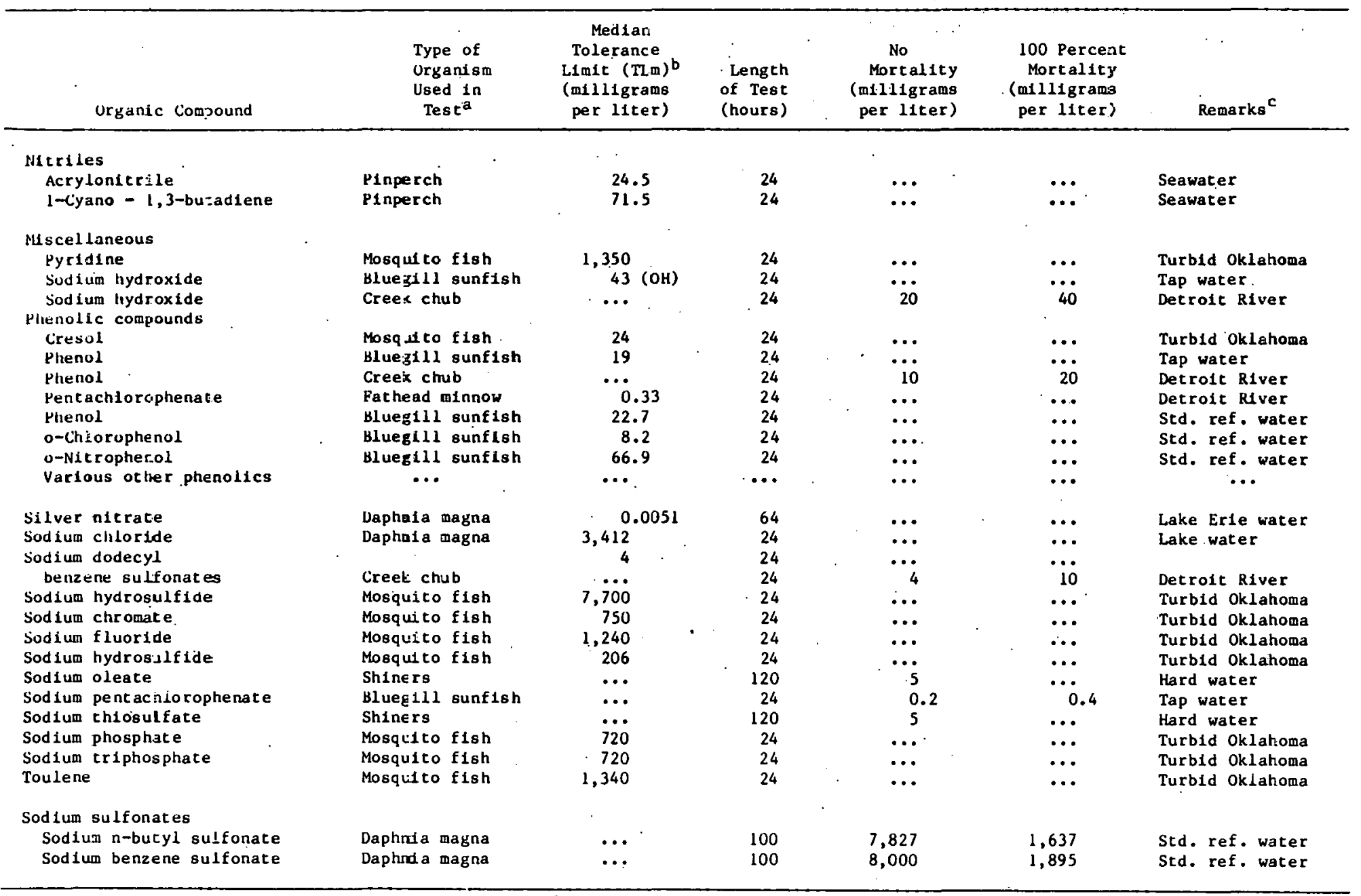


TABLE 4 (Cont 1nued)

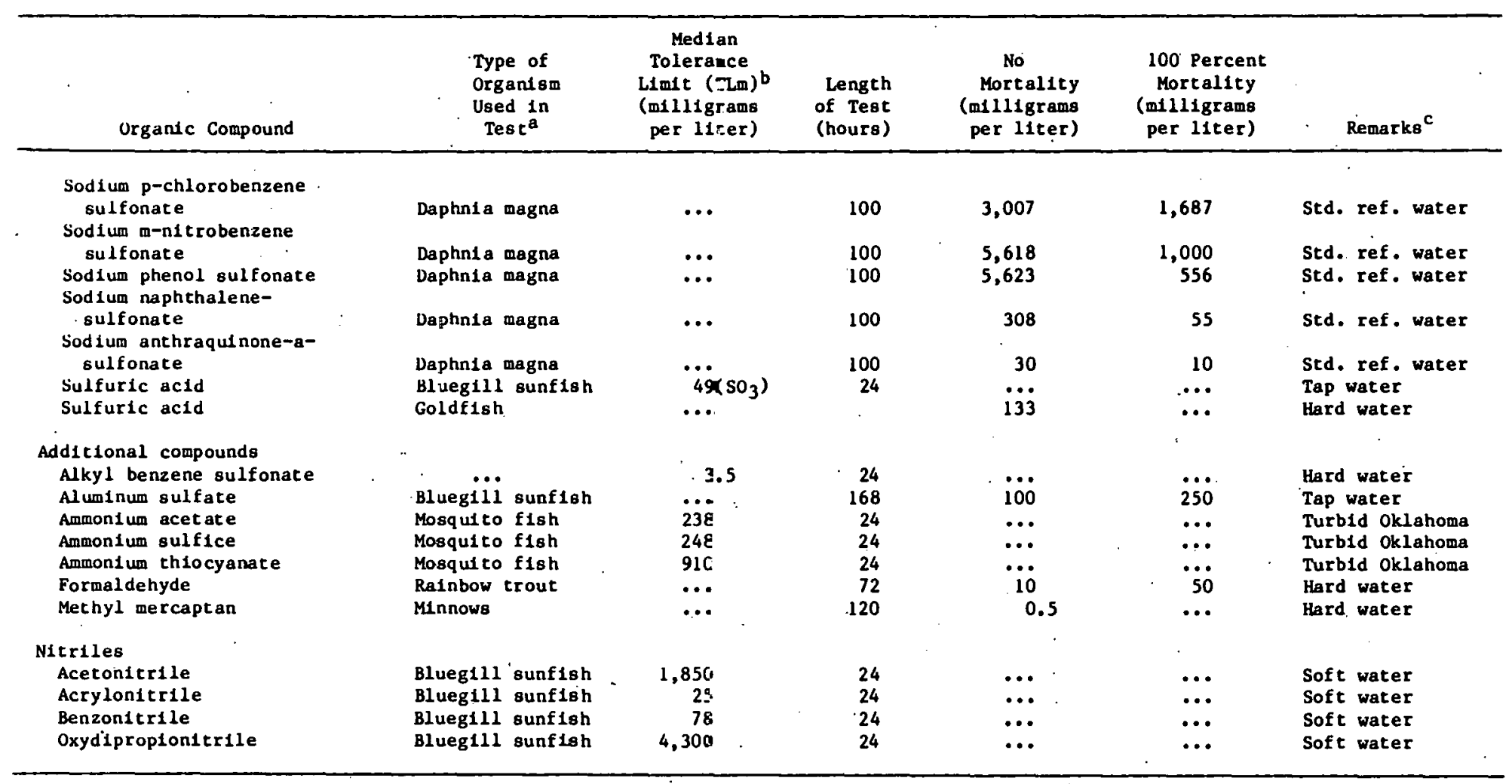

${ }^{a}$ Creek chub (Semolitus atromaculatus), mosquito f1sh (Gambusia affin1s), goldfish (Carassius auratus), bluegill sunfish (Lepomis macrochirus), rainbow trout (Salmo gairdneri1).

Median tolerance limit (TLm) is the concentration that will kill half the fish in the t1me shown.

For complete data, see test conditions described in the references cited on page 20-15 of silvestro 1980.

Source: Silvestro 1980. 
decreased reproduction from ofl spll1s could be large. This could especially be true along the major flyways which are the prime routes used by waterfowl during spring and autumnal migrations.

\section{Mobility of Organisms}

Organisms which spend their entire life cycle within aquatic systems (e.g., fish, plankton) and the benthic community may be impacted in different ways and to different degrees than other less habitat-restricted organisms such as waterfowl. Often the effect of spilled petroleum on wholly aquatic organisms is a function of their mobility. For example, fish may be able to avold the area of a spill before contamination occurs, but plankton and many members of the benthos (e.g., freshwater clams, gastropods, and other molluscs) are sessile or move very slowly. Groups such as these will be severely impacted if subjected to toxic petroleum compounds:

Even fish, which have a relatively high degree of mobility, may be severely impacted by an aquatic spill. One reason for this lies in the great divergence in physical characteristics of freshwater, as opposed to marine systems. Freshwater ecosystems vary in area, water depth, temperature, pressure, ion concentrations, and other parameters, espectally when compared to marine systems. Such physical and chemical variations may enhance the pollution stress placed on even mobile organtsms in a spill situation. Fish may experience interference with respiration when epithelial gill surfaces are covered with petroleum; aquatic oxygen depletion may occur from petroleum's organic constituents, and there can be more direct and rapid toxic effects due to the soluble compounds within oil (U.S. Department of the Interior 1972). In the general area of toxicity, the importance that various physical factors may have in augmenting toxic effects may not be adequately appreciated. Simple physical phenomena, such as winds, or the turbulence of flowing streams or rivers, may greatly increase the mixing or dispersion of ofl throughout the water column.

\section{Effects of Surfactants}

In severe spills, chemical dispersants or surfactants have been deliberately employed to disperse or solubilize the oil. Yet, the toxicity of oil and its degradation products are directly related to the awount of its dispereion throughout the water column. It is reported that, the greater the emulsification and dispersion of oil alone, the greater the toxicity (Tarzwe11 1971). Even in laboratory experiments, it has been shown that ofl which was mechanically emulsified by a homogenizer was far more toxic than oil that was manually mixed or stirred by aeration (Tarzwel1 1971). This may partially be due to the fact that oil treated with surfactants is more likely to cross skin and internal membrane barriers. 
The potential for toxic synergism between surfactants and crude oll is an important issue. Mixing dispersants with spilled oil to facilitate its cleanup and the use of surfactants to help extract it pose serious threats to aquatic systems. It is reported that, when dispersants were mixed with crude o1l, the differences (or spread) in toxicity of different dispersants to test organisms rose $187-$ fold (Tarzwell 1971). Mixing crude oil with these compounds, which are often used to help mitigate the ecological effects of an aquatic sp111, greatly increases the toxic effects on organisms such as fish by emulsifying and spreading crude petroleum constituents throughout the water column. The effects of such compounds were included above In Table 3.

Compounds such as surfactants are not only found mixed with water and crude petroleum in the event of a spill, but they are also used as an ald in producing crude oil in some tertiary recovery processes. Surfactants used for this purpose are 1nvolved with the formation of oil micro-emulsions within the ofl reservolr. The formation of such oll-surfactant emulsions helps solubilize the crude petroleum, facilitating its movement to the earth's surface. In addition to any direct toxicities that the various surfactants used in crude production have, they may facilitate the process of solubilizing toxic components present within the crude oil, making them more "avallable" to aquatic organisms, e.g., by easing their penetration through eplthelial barriers (Schumacher 1978). In effect, crude oll in a freshwater system may have different degrees of toxicity depending on the process used to extract it, especially if a particular extraction technology uses compounds that could intensify the normal effects of the crude o1l.

\section{Bioassay Testing}

In addition to synergistic reactions between crude oil and production-associated components, it is also important to consider the effects of individual compounds occurring naturally in crude oil. obtaining meaningful acute toxicity values for crude oil in laboratory procedures such as the 96-hour LC50 test, and for oil spills in the field is impossible without characterizing the specific petroleum compound. This is due to the large number of components present In crude oil (U.S. Environmental Protection Agency 1976). There is no "average" crude oll in regard to the concentration or proportion of the materials it contains. For this reason, individual chemicals and combinations of constituents of petroleum should be tested for both lethal and sublethal effects. 


\section{Sublethal Effects}

In addition to the more prevalent studies on acute toxic effects, some data on sublethal effects of petroleum and associated compounds on freshwater compounds are available. Sublethal effects include those which may not cause immediate death, but result in disruptions at the biochemical level or produce disruptions in normal feeding, reproductive, or behavioral patterns. It has been reported that sublethal effects from concentrations of crude oil as 1 ow as 10 to $100 \mathrm{ug}$ per liter can disrupt the normal behavior of various types of aquatic life (U.S. Environmental Protection Agency 1976). With experiments utilizing salmon fry, the response varied with the size of the fry. Small fry were found to be far more tolerant to crude oll than were larger fry at concentrations of less than $2 \mathrm{ppm}$ (Rice 1973). It has been postulated that avoldance reactions might have a disruptive effect on the migratory patterns of these fish. Such an effect could be extremely severe in the smaller rivers and creeks in which these fish orlginate and to which they must return to spawn.

\section{Effects of Benzene}

As mentioned earlier, benzene constitutes 20 percent or more of the total aromatic constituents in oil, and 1 t has a high degree of water solubility (Brockson and Bailey 1973). Tests on this compound with juvenile Chinook salmon indicate that benzene can have a profound effect on respiration. Juvenile salmon were exposed to concentrations of benzene equivalent to 5 and $10 \mathrm{ppm}$ over a total time period of 96 hours. Measurements of respiration were taken at 24 , 48,76 , and 96 hours. It was found that exposure to $5 \mathrm{ppm}$ caused an increase in the rates of respiration irrespective of the length of exposure time. However, the magnitude of the increase was related to length of exposure time, with the greatest percentage increase ( 86 percent) after 48 hours and less pronounced effects at 72 and 96 hours. The same relationshlp was found to exist at $10 \mathrm{ppm}$ as at $5 \mathrm{ppm}$, with respiration rates increasing at every exposure period except 96 hours. The investigators noted that the mean increase in respiration rate for $\mathrm{fish}$ exposed to $10 \mathrm{ppm}$ benzene for 48 hours was 115 percent (Brockson and Bailey 1973). Narcosis was another effect noted for flsh exposed to $10 \mathrm{ppm}$ benzene for longer time periods than described. This effect was accompanied by decreases in respiratory rate, and was found to be reversible when the animals were placed in fresh uncontaminated water. Similar increases in ventilation rates were observed in a series of diurnal tests using varlous surfactants (Maki 1979). 


\section{Detoxification and Bioaccumulation}

Another area which may have far reaching implications for freshwater organisms involves a specific metabolic response on the part of some organisms to the presence of petroleum or its constituents. Exposure to petroleum or benzo(a)pyrene activates an aryl hydrocarbon hydroxylase (AHH) enzyme system in various species of freshwater trout (Pedersen et a1. 1978; Ahokas et a1. 1974; Payne and Penrose 1975). This enzyme system appears to function as a detoxification mechanism in some species of freshwater fish (Payne and Penrose 1975).

The ecological and health significance of this pollution induced enzyme system may be great. It has been suggested that the catabolic intermediates of these detoxification reactions may produce metabolites that are more toxic than the compounds upon which they initially act (Rice et a1. 1976). Whether the effect of induction is on the activation or the detoxification of carcinogenic polycyclic aromatic compounds within petroleum remains to be fully elucldated (Payne and Penrose 1975). What has been demonstrated is that some aquatic organisms have the ability for pollutant biotransformation. Both experiments and field observations (Payne and Penrose 1975) using brown trout have demonstrated the induction of this biochemical mechanism. Fish were taken from two lakes, one clean and the other polluted with oil. In laboratory experiments, fish from the clean lake were placed in large recirculating tanks to which small amounts of a homogenized c.rude nil-water mixturc were added. Al the same time, in fleld experiments, flsh were taken from both the polluted and a clean lake for comparative purposes.

Fish from the clean lake that were exposed to o1l in the laboratory showed significant increases in AHH activity within 17 days. There was also a significant difference between the gill activity of exposed fish and controls. There was, however, no noticeable difference in mortality or behavior between the exposed fish and the controls (Payne and Penrose 1975). Fish taken from the clean and polluted lakes displayed significant differences in AHH activity, with fish from the polluted lake not only having significantly higher levels of activity, but also maintaining those levels over a period of 1 year in captivity.

Other investigations of petroleum constituents have focused on uptake, bioaccumulation, and rates of excretion. In this context, Melancon and Lech (1979) studied two ${ }^{14} \mathrm{C}$-labeled constituents of crude petroleum that are highly water soluble and that accumulate in some marine invertebrates. The compounds examined were ${ }^{14} \mathrm{C}$-labeled naphthalene and ${ }^{14} \mathrm{C}$-1abeled 2 -methylnaphthalene. The experimental flsh were ralnbow trout, carp, bluegill sunfish, and a marine 
species. The uptake and subsequent elimination of these compounds were examined after both short-term (8- or 24-hour) and long-term (4-week) exposure periods.

Rainbow trout exposed to ${ }^{14} \mathrm{C}-1$ abeled naphthalene rapidly accumulated it, but at the end of 24 hours, only 4 percent remained in the muscle tissue. When the trout were exposed to this compound for 4 weeks, the tissue levels rose slowly and were eliminated slowly over an ensuing 5-week period. Trout exposed to ${ }^{14} \mathrm{C}-2$-methylnaphthalene for a 4-week period showed a similar uptake pattern, but a different elimination pattern than with naphthalene. It was found that elimination of the 2-methylnaphthalene was a biphasic process, i.e., there was an initial rapid phase of elimination that had a half-life of less than 24 hours, and also a slow phase that had a half-life of hundreds of hours. Experiments with carp and bluegill sunfish exposed to this same compound for 4 weeks also exhibited a biphasic elimination pattern. Examination of muscle taken from the trout suggested that the difference in elimination rates (steady versus biphasic) for these compounds may depend on whether the compounds were accumulated and stored by the tissues as the parent compounds or as their metabolites. In this context, experiments were carried out by pretreating trout with B-napthoflavone before they were exposed to either of the ${ }^{14} \mathrm{C}-$ labeled compounds. The treated fish had a greater proportion of ${ }^{14} \mathrm{C}$ catalytic metabolites than did controls.

\section{Plankton}

The effects of petroleum have been studied not only with fish, but also with freshwater plankton and benthos. Information on these latter groups is extremely limited, however, especlally when compared to field and laboratory investigations on marine and estuarine species.

Fleld studies on freshwater plankton have tocused on petroleum's effects on gross population trends and on the chemical characteristics that help regulate populations. McCauley (1966) investigated the effects of a petroleum spill on river biota and associated chemical parameters. In the area of the spill there was an initial decline in the amount of dissolved oxygen found that was attributed to a partial exclusion of atmospheric oxygen caused by the oil film. This film gradually dissipated with time, with much of it being adsorped onto suspended matter, including petroleum-killed plankton. The material subsequently sank to the river bottom, forming an oily sludge in the sediment. Both high nitrate and phosphate levels were found. These nutrient levels were attributed to bacterial decomposition of plankton killed by the petroleum. Although limited in species diversity, large differences in abundance were found for the 
zooplankton present. Some of this abnormal variation was correlated with the ofl pollution. The major observation noted with the planktonic algae was that a spectrum of petroleum sensitivity existed; some groups tolerated the presence of oil during the entire 2-year study, while other groups were eliminated. Among the major freshwater algae found to be highly tolerant of the oil were species of Lyngbya, Oscillatoria, Euglena, and Scenedesmus.

In experiments using freshwater algae taken from lakes high in nickel (a major petroleum trace metal), the algae, rather than fish, were adversely affected. In other experiments, a major species of freshwater algae (Scenedesmus) was cultured from a lake that contained varying amounts of both copper and nickel. This particular organism was described as relatively metal tolerant. Experiments were conducted to determine if potential interactions might exist between these two metals, and how they might affect the algae. It was found that nickel alone was far less toxic then copper alone. However, even when low amounts of nickel were present together with low amounts of copper, toxicity was greatly increased (Stokes and Hutchinson 1976). The toxicity was not due to nickel, but was characterized as resulting from the copper. Evidently, the nickel, even in very small amounts, initiated a synergistic reaction that resulted in large amounts of copper being assimilated by the algae (Stokes and Hutchinson 1976).

Research dealing with effects of the more prevalent organic compounds in crude 011 also has ylelded data of potential significance to freshwater ecosystems. Hutchinson et al. (1980) examined the possible correlation between physical and chemical properties of various organics and their toxiclty to two representative freshwater algae: Chlorella vulgaris and Clamydomonas angulosa. Among the compounds examined were members of various straight and branched chain alkanes, cyclo-alkanes, aromatics, and polynuclear aromatics. Toxicity was measured as the concentration of a compound necessary to cause a 50 percent reduction in algal photosynthesis. The characteristics examined were solubility and the octanol-water partition coefficlent. A wide range of water solubilities existed among the tested organics. Solubilities extended over eight orders of magnitude. The range in octanol-water partition coefficients was almost as great, extending over six orders of magnitude. Test results for compounds in various organic classes showed a strong correlation between the degree of algal toxicity and the solubility and octanol-water partition coefficients of the 38 compounds tested. The toxicity to algae from representative compounds in various organic classes were shown in Table 3. Algal toxicity increased with the solubility of the pollutant, but hydrocarbons with a low solubility were generally more toxic (on a molar basis) than were high solubility compounds such as benzene (Hutchinson et al. 1980). 


\section{Benthic Organisms}

Limited data are available on the effects of petroleum and its constituents on freshwater benthos. McCauley (1966) examined the effects of a petroleum spill on both algal and benthic organisms in a freshwater river.* In the latter group, much the same situation was found to exist with benthic organisms as with planktonic algae, i.e., some groups were extremely tolerant of oll and others quite sensitive. Nematodes appeared to be highly tolerant of the petroleum. As many as 20 genera were identified in the worst area of pollution, and these thrived even when the pollution was at its maximum. Other organisms varied in their response, with "clean water" species such as Dugesia (a flatworm) being eliminated and forms such as Tublfex (an annelid worm) being very tolerant. This same pattern was seen for other benthic groups such as Crustacea and Hirudinea (leaches).

Another study (Kalas et al. 1980) examined the bioaccumulation potential for polynuclear aromatic hydrocarbons by a major and widespread benthic gastropod: Cipangopaludina chinensis. This organism has a long (6- to 15-year) life span, and during the winter it hibernates in pond and river sediments. Its intimate mode of existence on and in sediment, along with its widespread distribution, makes it a good indicator of specific types of pollution. In this study, both sediment and snails were compared for their concentrations of 18 different polycyclic aromatic hydrocarbons. Of these 18 compounds, 4 were below the detection limit in the snalls, but were found to be present in the sediment. With one exception, all of the remaining compounds were present at higher levels in the snall then in the sediment. The levels found in the snails were from 15 to 200 times those found in the sediment. These data suggest that some freshwater benthic organisms that are exposed to oll-contaminated sediment may concentrate some compounds far in excess of the levels found in the medium in which they exist.

\section{Terrestrial Biota}

In the Onshore section of this report, discussion of ecological effects has focused on the freshwater aquatic blota, which are more likely to be impacted by drilling activity than terrestrial biota.

An extensive discussion of the effects of spilled oil and air emissions from oil and gas activities on terrestrial biota is contained in the Transportation and Storage section. The transportation facet of the oil and gas industry threatens terrestrial biota with potential ail spills.

*In this study, ofl reached the bottom organisms in the form of an oily sludge. 
Summary of Research Needs

Knowledge of the effects of onshore petroleum production on freshwater blota covers a broad spectrum and is in-depth, as indicated in the above discussion. Water discharges from onshore drilling rigs are controlled and drilling mud wastes are recycled or disposed of in waste pits.

Research has focused within the last decade on developing procedures for dealing with spills. The U.S. Environmental Protection Agency (and the U.S. Coast Guard in near shore waters) is responding to accidental and intentional discharges and has developed measures for the control, removal, and safe disposal of these spills. Technology for detection, control, and removal is under development at the Industrial Environmental Research Laboratory's 011 and Hazardous Materials Spills Laboratory in Edison, New Jersey.

Thus, the focus of Federal research on freshwater oil spills has shifted from effects to the development of control strategies. Effects research is largely centered in academic institutions and focuses on basic research problems. 


\section{TRANSPORT AND TRANSFORMATION}

This section describes the movement and possible transformations in air and water media of pollutants that may be assoclated with petroleum production. A pollutant is considered to be any element or compound used in or produced by petroleum technologies that has or may have adverse effects on human health or the environment.

\section{Water Medium}

In primary and secondary petroleum production, large amounts of brine are associated with the produced oil. It has been estimated that 30 million barrels of such brine are produced daily in the U.S. (Meier 1978). After separation from the 011, this brine must be disposed of in some manner. The amount of brine and the manner of disposal may have a direct bearing on the movement of the brine (and other pollutants associated with $1 t$ ) into undesirable locations such as groundwater.

Brines associated with oll production are usually reinjected into the earth for one of two purposes: disposal or to increase ofl production, e.g., by waterflooding (U.S. Environmental Protection Agency 1977). When brine is reintroduced into the earth for disposal, it is often injected into deep saline aquifers through abandoned production wells, or it may be relnjected directly into the stratum of the oil formation from which it was withdrawn (U.S. Environmental Protection Agency 1977). When brine is disposed of through wells that use injection techniques, espectally if these wells are older production wells, there is the possibility of contaminating freshwater aquifers. These older production wells may. be poorly designed for use as waste injection systems. Also, ruptured or corroded casings may allow the movement of brine into freshwater strata (U.S. Environmental Protection Agency 1977).

The Lidustry makes an effort to prevent brine transport into freshwater strata when drilling or chemical waste injection procedures are begun. Engineering and design specifications to prevent such occurrences may be quite varied, but certain procedures are common among many extraction techniques. In any initial drilling operation, various types of geological strata are penetrated. Each strata may contain salt water, fresh water, gas, oil, or a mixture of gas, o11, and water. Both casings and extensive use of cement are employed to prevent brine transport between these strata. Each of the various geological strata above the oil or gas producing zone is cased and cemented to prevent such movement from occuring (Meier 1978). The actual surface casing string is set and cemented from 30 to 100 feet below the deepest freshwater layer that is capable of self-replenishment and which could be. used for various human 
activities (Meier 1978). Unfortunately, even with elaborate precautions, movement of pollutants, such as brine from saline strata, into freshwater zones can occur. Such pollutant movement may be from breaks or leaks in casing strings or associated structures. These, in turn, may be the result of such diverse causes as natural fault movement and subsidence or corroded and improperly plugged wells (Schumacher 1978). Pollution transport also may come about as a result of induced changes within the natural formation itself, resulting from oil recovery or waste disposal practices. For example, pressure is required to inject fluids or gases into the ofl or gas formation in various enhanced recovery techniques. Pressure is also employed to inject brines and other chemical wastes into disposal wells. Injection pressure from elther of the above causes can lead to fissures being created within the formation (Schumacher 1978). Such fissures could allow for movement of the brine or chemical wastes from saltwater strata into freshwater strata located within the same formation.

Other means by which brines, expended drilling muds, and cuttings may contaminate groundwater supplies are through surface waste disposal pits. These pits may be lined or unlined. Loss of the integrity of these pits occurs. Sometimes spills occur due to flooding and embankment failure. If surface leakage is indicated, various impervious materials such as gel, polymer, or plastics may be used to prevent leakage (Meier 1978). If brines, expended muds, or cuttings are placed in unlined waste pits, the real possibility. of transport to groundwater and subsequent contamination must then be considered. It should be emphasized that large amounts of cuttings are associated with drilling a well, and these cuttings may be contaminated with organics both from the oll-containing formation itself and from drilling fluids (Wilkins 1977). The types of chemicals used in formulating drilling fluids (muds) are large in number and contain many, varied types of inorganic and organic compounds. The ingredients have been variously listed as including everything from pH-control products, bactericides, calctum-removers, corrosion inhibitors, defoamers, emulsifiers, filtrate reducers, flocculants, foaming agents, lost circulation materials, lubricants, shale-control inhibitors, surface-active agents, thinners, dispersants, and viscosifiers, to weighting agents (Richards 1979).

Mud and brine pits are often bulldozed flat following evaporation and abandonment. As a long-term source of undesirable leachates, the discarded saline mud poses environmental problems with respect to land reclamation and agricultural use.

In general, there is little information avallable on the specifics of any reservolr transformation reactions occurring with chemicals that are initially injected into a formation. Since it is 
possible for various compounds in the ofl formation to move into freshwater aquifers, the potential exists for these original chemicals to be transformed within the formation, creating a toxic "reservolr" if released to external water supplies. This potential should be examined and there should be consideration of some of the potential mechanics of transformation that may occur once these, or other pollutants, actually reach aquatic systems.

Surfactants constitute a large group of chemicals widely used in ofl extraction techiques. The surfactants that are frequently used are composed of long chain alkyl- and aryl-sulfonates (Schumacher 1978). Many of these compounds are produced by a reaction requiring sulfonation. It has been reported that the sulfonation reaction is reversible and many compounds are sulfonated on site (Schumacher 1978). The stablifty of these, and perhaps other commonly used compounds, may thus be compromised under various conditions of reservolr temperature, $\mathrm{pH}$, and pressure.

Once pollutants have entered an aquatic system, they are subject to a large number of chemical transformations. The pollutants themselves or the chemical agents with which they react may be elemental, e.g., metals; inorganic or organic compounds, or ions. In addition to considering the movement of these pollutants, there is a concomItant need to analyze factors that may affect their transformation from one physical or chemical state into another. Among such factors are temperature, $\mathrm{pH}$, pressure, oxidation-reduction potential (redox), hydrolysis reactions, adsorption, and absorption.

One of the most important factors affecting pollutant transformations is the oxidation-reduction potential of the aquatic environment in which the pollutant 1s found (Tinsley 1979.). This, in turn, Is affected by the $\mathrm{pH}$ of the aquatic medium. Chemical reactions take place when electrons are lost from one compound or chemical species and gained by another. These are termed oxidation-reduction reactions and any system in which these reactions occur may be termed a redox system or environment. Water is a redox environment. The loss or gain of electrons by a pollutant in such an environment is important because, once a pollutant has become transformed (oxidized or reduced), it can possess radically different properties (Tinsley 1979). The change in properties may also change the biological and environmental effects of the pollutant. It 1 is important to note that different types of aquatic systems differ greatly in their relative oxidizing or reducing capacity. The same pollutant entering a stagnant lake may produce pollution degradation products quite different from those produced when it enters groundwater. 
The chemical behavior of a toxic metal in water demonstrates redox effects on toxicity. Mercury, a toxic metal, may exist under certain aquatic (redox) conditions in the form of a positive ion (differing in chemistry and appearance from the common silvery metal). Under these conditions, this electrically positive ion of mercury may chemically join with many types of electrically negative Ions to form any number of different compounds, or it may be ingested by microorganisms to form a methyl mercury complex (Tinsley 1979). (Methyl mercury is several times more toxic than metallic mercury.) Should the redox of this aquatic system change, that same initial positively charged ion of mercury could be converted into a thin film of the common metal and be volatilized from the water.

Organic compounds also may be directly affected by changes in aquatic redox systems. Unfortunately, these are not well characterized. It has been shown, however, that organic compounds do undergo chemtcal changes associated with the redox state of the water. This has been demonstrated for some of the chlorinated hydrocarbons, such as toxaphene and DDT. In the latter case, redox changes that favor the formation of a specific Ionic form of iron greatly increase the conversion of DDT to DDD (Tinsley 1979).

Also of importance in the transformation and/or degradation of organic or inorganic compounds in aquatic systems are hydrolysis reactions (Tinsley 1979), 1.e., direct reactions with water by various compounds, or the potential for these compounds to react with water. The study of hydrolysis reactions encompasses a huge body of chemical literature. A brief survey of a few of the Important classes of compounds that can be affected by hydrolysis may provide a perspective on the importance of this kind of reaction in the transformation of aquatic pollutants.

Esters, amides, carbamates, organophosphates, and various halogenated carbon compounds are representative of major classes of organlc groups. Esters and the halogenated hydrocarbons encompass large numbers of compounds used or produced in petroleum operations. These two groups can be used to 1llustrate some of the factors affecting hydrolysis. An ester is the product of a reaction between an alcohol and an organtc carboxylic acid. A halogenated hydrocarbon compound contains one or more of the halogen elements ( I, F, C1, Br).

Esters may be hydrolyzed by three different mechanisms that are termed acid catalyzed, base catalyzed, or neutral. These mechanisms, the rates of formation, and the amounts and types of degradation products that are formed may be affected by the $\mathrm{pH}$ of water, which can be altered by a spill. In addition to $\mathrm{pH}$, the position of various chemical groups attached to the ester molecule will also affect the compound's rate of degradation (Tinsley 1979). 
The halogenated hydrocarbons are also of interest due to the large number of these compounds that are in use. Like esters (some of which also are halogenated), these carbon compounds display a wide variety of characteristics that may affect their aquatic transformation. In some of these compounds, e.g., the chlorinated methanes, the rate of hydrolysis decreases as additional chlorine atoms are added to the compound. Furthermore, it is known that great variations exist in the rate of hydrolysis for these compounds with some, such as the chlorinated benzenes, being quite resistant to hydrolytic transformation (Tinsley 1979).

Chemical redox and hydrolysis reactions are major, but not the only determinants in aquatic pollutant transformations. Physical (adsorptive) phenomena also can occur. This may involve the adsorption of elements (e.g. metal lons onto aqueous sediment or various chemical compounds onto dissolved particulate matter). Adsorption 18 a complex phenomenon and most experimental work has been done on inorganic systems for which models have been developed. For example, one of the single most important parameters affecting a metal's adsorbability appears to be $\mathrm{pH}$. There appears to be a specific, and of ten narrow $\mathrm{pH}$ range for every metal over which that metal will be completely adsorbed and removed from solution (Leckie and James 1976).

The behavior of aquatic organics is poorly understood and much remains to be clarified.

\section{Air Medium}

Airborne pollutants associated with onshore production are not unique to the ofl and gas industry. A discussion of common transport, transformation, and fate problems, as well as research needs, is provided in the Basic Effects Issues section of this report.

Summary of Research Needs

Some research needs related to the general impacts of oil and gas activity on water quality are presented in the Basic Effects Issues section. Research needs that specifically concern onshore oll and gas production are discussed below.

011 and gas development has been excluded from many controls applicable tu uther industries, such as provisiono under the Safe Drinking Water Act intended to assure groundwater protection, despite the fact that petroleum can enter potable aquifers through cracks and fissures in strata adjacent to oil wells where spills or leaks may occur. Traditionally, tas te and smell have been used to detect petroleum in water. However, many of the more toxic and 
$\therefore \therefore$

carcinogenic components of crude ofl have no detectable odor or taste at potentially toxic concentrations. This factor, and the use of bactericides, pH-control substances, calcium-removers, defoamers, and emulsifiers require the development and use of sophisticated sampling and measurement devices to routinely detect these substances in ground and surface water.

The stability of surfactants, especially with respect to the reversibility of the sulfonation of surfactants, should be investigated. The conditions of reservoir and aquifer temperature, $\mathrm{pH}$, and pressure which affect the reactions should be studied.

The state of the art of tracking the movement of pollutants through groundwater systems is at an early stage of development. Dyes, Lycopodium spores, and other techniques have been used to trace and detect contamination of groundwater. With respect to the field production of 011 and gas, methods should be developed, including indicator "tracers," which can be used to detect and trace pollutants associated with onshore production through groundwater aquifer systems.

Many petroleum-related pollutants may undergo chemical transformation in the environment. These transformations and the toxic effects of their products require study to aid hazard assessments of the new and chemically complex extraction technologies. 


\section{Part 3 \\ Offshore Development}


OF FSHORE SUMMARY

This section observes that, with offshore oil and gas development, there is a need for adequate data reporting. Data on injuries, illnesses, and fatalities for onshore and offshore drilling rigs have been commingled. Onshore and offshore activities have diverged markedly over the last decade, leading to substantial differences with respect to the nature and extent of risks. A more appropriate and effective information gathering and reporting system should be developed.

A number of tragic offshore drilling and production rig accidents have recently focused attention on the need for greater under standing of the causal factors and potential mitigating measures which may be taken. A number of needed research and data collection activities are cited in this section.

Research is needed to define offshore oil and gas worker exposures and potential health risks related to the handling of the various formulations of drilling muds. The findings would also be applicable to onshore production. Retrospective epidemiological surveys, possibly focused on workers in the Gulf coast Basin would be useful in understanding the extent of this potential health problem.

The trend toward the greater use of offshore oil and gas transfer, loading, storage, and processing facilities may pose a significant problem with respect to air pollution. The effect of these airborne emissions and possible transformation reactions should be explored.

With respect to environmental effects, additional research is needed on the long-term effects associated with the release of drilling fluids in the marine snvironment, especially as a result of continuous loading within a developing field. Several reserarch areas associated with this subject (e.g., entrapment in trenches, effects of degradation products, effects in high energy environments) require clarification.

Research is also needed on the effects of exploratory techniques. During exploratory surveys in hostile environments, such as in the Beaufort Sea, a large seismic shock from the detonation of powerful explooives may be more desirable than repeated low-energy intensive shocks. The single, larger shock may hive lose impact on marine biota. Additional information is needed in this area to establish guidelines for exploratory activity in hostile marine environments. 
To date, oil and gas environmental studies have focused on the shallow waters of the continental shelf. With the use of modern mobile rigs and subsea completion systems, the deep ocean floor of the continental shelf, its trenches, and the continental slope can be exploited. The impact of such activity on this relatively stable environment and sensitive biota should be explored.

Many impacts have been postulated to occur as a result of chronic hydrocarbon discharges into the marine environment. The cumulative impacts of such discharges should be studied through the use of natural seeps as sources of oil discharges.

Specific research needs associated with the above mentioned problems can be found within the sumary of Research Needs sections. Discussion of the respective health and environmental problems may be found in sections preceding the research needs sumaries. 
OFFSHORE OIL AND GAS PRODUCTION

TABLE OF CONTENTS

$\underline{\text { Page }}$

$\begin{array}{lll}\text { LIST OF ILLUSTRATIONS } & 74\end{array}$

LIST OF TABLES $\quad 74$

TECHNOLOGY DESCRIPTION

Exploration $\quad \cdot 77$

Exploratory Surveys $\quad 77$

Exploratory Drilling $\quad 79$

Development Drilling and Well CompletIon $\quad 85$

Development Drilling $\quad 85$

Well Completion 91

Production $\quad 92$

Transportation $\quad \therefore \quad 94$

Pipelines $\quad 94$

Tankers and Barges . . . . 95

offshore Storage 95

Offshore 011 Ports--Complex Facilities $\quad 97$

Offshore Factlity $\quad 97$

Onshore Facilities $\quad$. . 98

System Supervisory Control 98

Future LOOP Phases 98

Other Deep Water Ports $\quad 98$

$\begin{array}{ll}\text { HEALTH EFFECTS OF OFFSHORE DEVELOPMENT } & 101\end{array}$

$\begin{array}{lr}\text { Occupational Health Cons1derations } & 101\end{array}$

Drilling Muds . 101

Hydrogen Sulfide 102

Health Statistics 102 
TABLE OF CONTENTS (Continued)

Page

$\begin{array}{ll}\text { Occupational Safety Considerations } & 102\end{array}$

Drilling Rig Accidents 107

Summary of Offshore Accidents 108

Offshore Safety Problems . 111

Tanker Accidents $\quad 112$

Pipeline Accidents $\quad 114$

Public Health and Safety Considerations 121

Summary of Research Needs . 127

Health Effects Data 127

Offshore Platform Information Needs . 127

Effects of Drilling Muds 129

Offshore Terminals 129

Coastal Pipelines $\quad . \quad . \quad \ldots \quad . \quad 129$

ECOLOGICAL EFFECTS OF OFFSHORE DEVELOPMENT 131

Exploratory Surveys 131

Esplusatury Ir1lingng . . 136

Drilling Muds 136

Laboratory Studies $\quad: \quad 142$

Field Studies 143

Production Drilling 144

Pipelines · ' 144

Tankers and Barges 145

Offshore Storage 146

Oil Spills 146

Summary of Research Needs 150

Effects of Drilling Muds . : 150

Description of Drilling Fluid Discharges .. 150

Fate and Transport 151

Biological Effects 151

Effects of Seismic Testing 152

Cumulative Effects $\quad 153$

Effects on Deep Water Environments

Impact of Natural Seeps 153 
TABLE OF CONTENTS (Concluded)

\section{Page}

TRANSPORT AND TRANSFORMATION

Atmos pheric

155

Aquat ic

155

Summary of Research Needs 
LIST OF ILLUSTRATIONS

Figure Number

Page

1

2

3

4

5

6

7

8

9

10

11

12

Seismic Operations

Positioning of Deep Water Drill Ship

80

Jack-Up Drilling Rig

81

Semisubmersible Drilling Rig

82

Floating Driliing System

84

Fixed-Pile (Production Drilling) Platform

86

Subsea Production System

88

Typical Directionally Drilled Wells

90

Typical Production Facility

93

Load on Top Technique

96

Ffferts of Drilling Fluid Dischargèd into the Marine Environment

Fate of 011 Spills

158

\section{LIST OF TABLES}

Table Number

$\underline{\text { Page }}$

1

Report of Occupational Injuries and Illnesses for 1978

103

Occupational Accidents for Crude 011 and Product Transport and Refining

Annual Deaths, Injuries, and Workdays Lost for Uncontrolled 0il-Fired Electricity

Sys tems

Fatalities by Functions and Causes 


\section{LIST OF TABLES (Concluded)}

Table Number

Page

Deaths and Injuries Resulting from Tankship Accidents

Extent of Tankship Los8 or Damage

Accident Sequence for 47 Tankship Losises

116

9 Description of Loss of Structural Integrity

for 47 Tankship. Losses

10 Liquid Pipeline Accident Summary

Pipeline Accident Summary by Commodity Involved

14 Yearly Emissions Estimates from Alaskan

15 Effects of Underwater Explosions on Aquatic Organis ms

Frequency of Reported Damage to Four Fish Organs 


\section{THIS PAGE \\ WAS INTENTIONALLY LEFT BLANK}


OFFSHORE OIL AND GAS PRODUCTION

\section{TECHNOLOGY DESCRIPTION}

\section{Exploration}

Exploratory activities are undertaken to locate geological formations which may contain ofl and gas accumulations. These activities usually progress through the following principal phases (Kash et al. 1973; University of Oklahoma 1975):

- Regional surveys to identify promising geological formations;

- Detalled surveys on which evaluations of specific areas are based; and

- Exploratory drilling to determine whether oil and gas are actually present in a given area.

\section{Exploratory Surveys}

Regional surveys involve passive reconnaissance techniques similar to those used for land exploration. Air and shipborne measurements are made of variations in the earth's magnetic and gravitational fields. Regional surveys are also conducted to detect natural seeps of hydrocarbons into the atmosphere. If the results of these passive reconnaissance techniques are promising, then more detailed, active surveying techniques such as selsmic analysis, bottom sampling, and coring are usually conducted.

Seismic surveying involves using an energy source to generate sound waves which are reflected and refracted from subsea geological formations (F1gure 1). The sound waves are picked up by hydrophones suspended from the research vessel. In the past, explosives were used to generate the sound waves; however, due to resulting adverse environmental impacts and the practicality of new techniques, the use of explosives has been replaced with alternate energy sources (Kash et al. 1973). Currently, contained detonations of a propane and oxygen mixture or high-powered oscillators are used to generate the sound waves.

Other active surveying techniques involve taking samples of the ocean floor and coring to obtain subsurface samples for geological exanination. These geophysical survey techniques and geological studies are useful to identify areas in which oil and gas may be found; however, exploratory drilling is necessary to determine whether commercial quantities of oil and gas are present. 


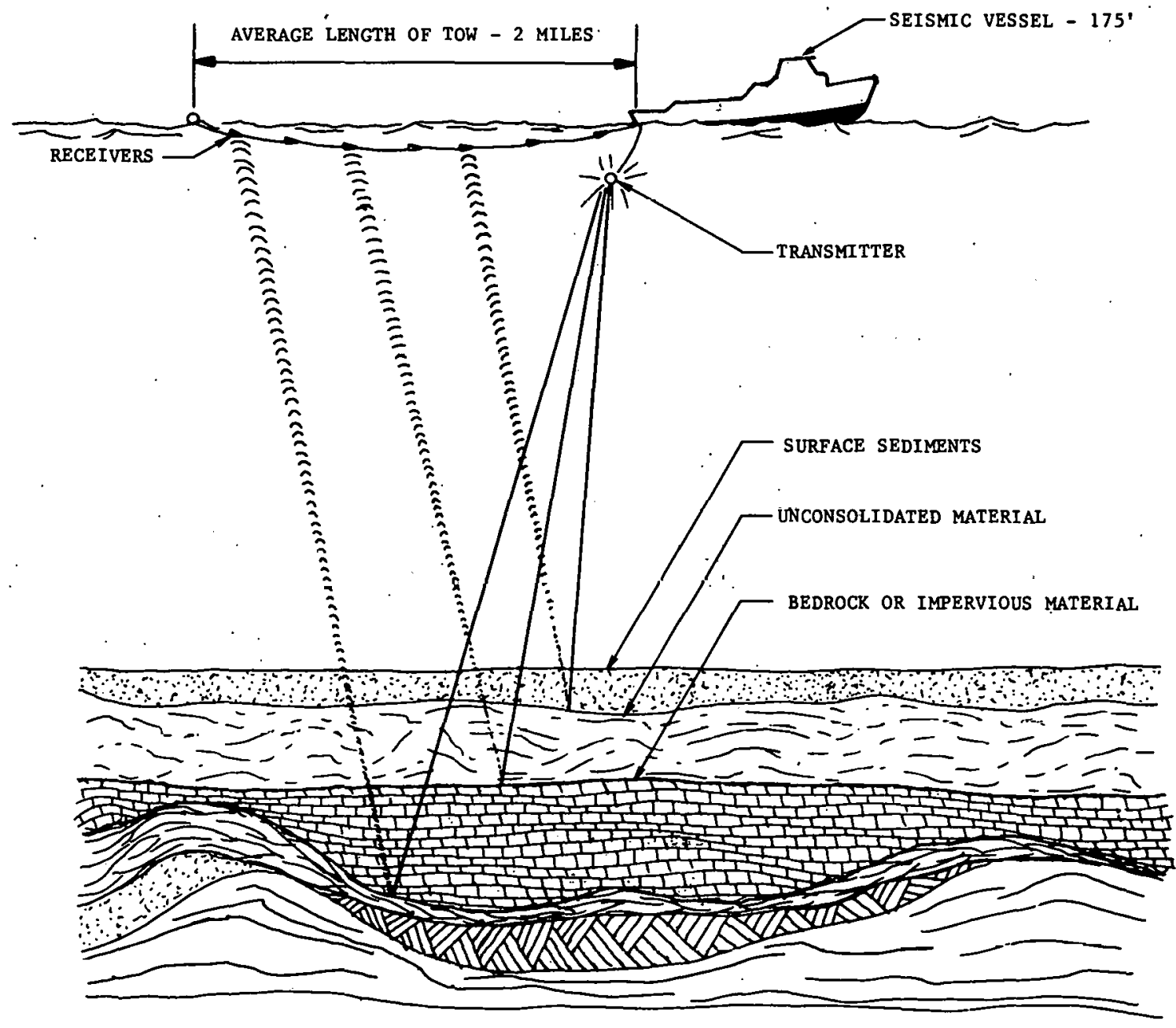

FIGURE 1

SEISMIC OPERATIONS 


\section{Exploratory Drilling}

The major difference between offshore exploratory drilling operations and those on land is that, offshore, a support system for the drilling rig and associated equipment is needed. Fixed platforms, due to their expense and the difficulty associated with moving them, are used primarily for production purposes (Clark et al. 1978). Four kinds of mobile platforms usually are used for offshore exploratory drilling: barges, drill ships, jack-ups, and semisubmersibles.

Barges are not self-propelled and must be towed from one drilling location to another (Harris 1972). Because of their lack of seaworthiness, barges are normally used in shallow, protected waters, although some have been built for drilling in water depths as great as 600 feet (University of Oklahoma 1975).

Drill ships, on the other hand, are self-propelled and are often used to drill in waters from 500 feet to 3,000 feet in depth (Council on Environmental Quality 1974). These vessels maintain their position over a well site by using either anchors or dynamic positioning propellers to compensate for movement (Figure 2). Drill ships may not be suitable for severe weather (University of Oklahoma 1975); however, modern drill ships (e.g., Glomar 40) are designed to maintain operations in winds of 60 miles per hour and waves of 50 feet (Clark et al. 1978).

A jack-up, or self-elevating drilling platform, has buoyant hulls that enable the rig to be towed to the drilling site (Figure 3). Upon reaching the drilling site, the legs, which are fitted vertically. through slots in the hull, are lowered either mechanically or hydraulically until they reach the ocean floor. The platform is then raised or "jacked-up" above the ocean surface until it is elevated above the height of anticipated waves. Jack-ups are extremely stable and provide a secure drilling position when used in the appropriate depths (Clark et al. 1978). They are designed to withstand severe weather conditions in shallow. water, and under calm conditions they can operate in depths up to 300 feet.

The semisubmersible (F1gure 4), the newest type of drilling rig available, has excellent stability in severe weather and can drill in water as deep as 2,000 feet (Kash et al. 1973; University of Oklahoma 1975). The platform deck may be supported by columns connected to large underwater displacement hulls, mounted on large vertical caissons, or supported by some combination of the two (Harris 1972). A semisubmersibles may be self-propelled or towed. When it reaches the drilling site, the columns, displacement hulls, or caissons are flooded, which reduces wave forces by locating the major buoyancy members (and the wave action) beneath the surface (Harris 1972). 


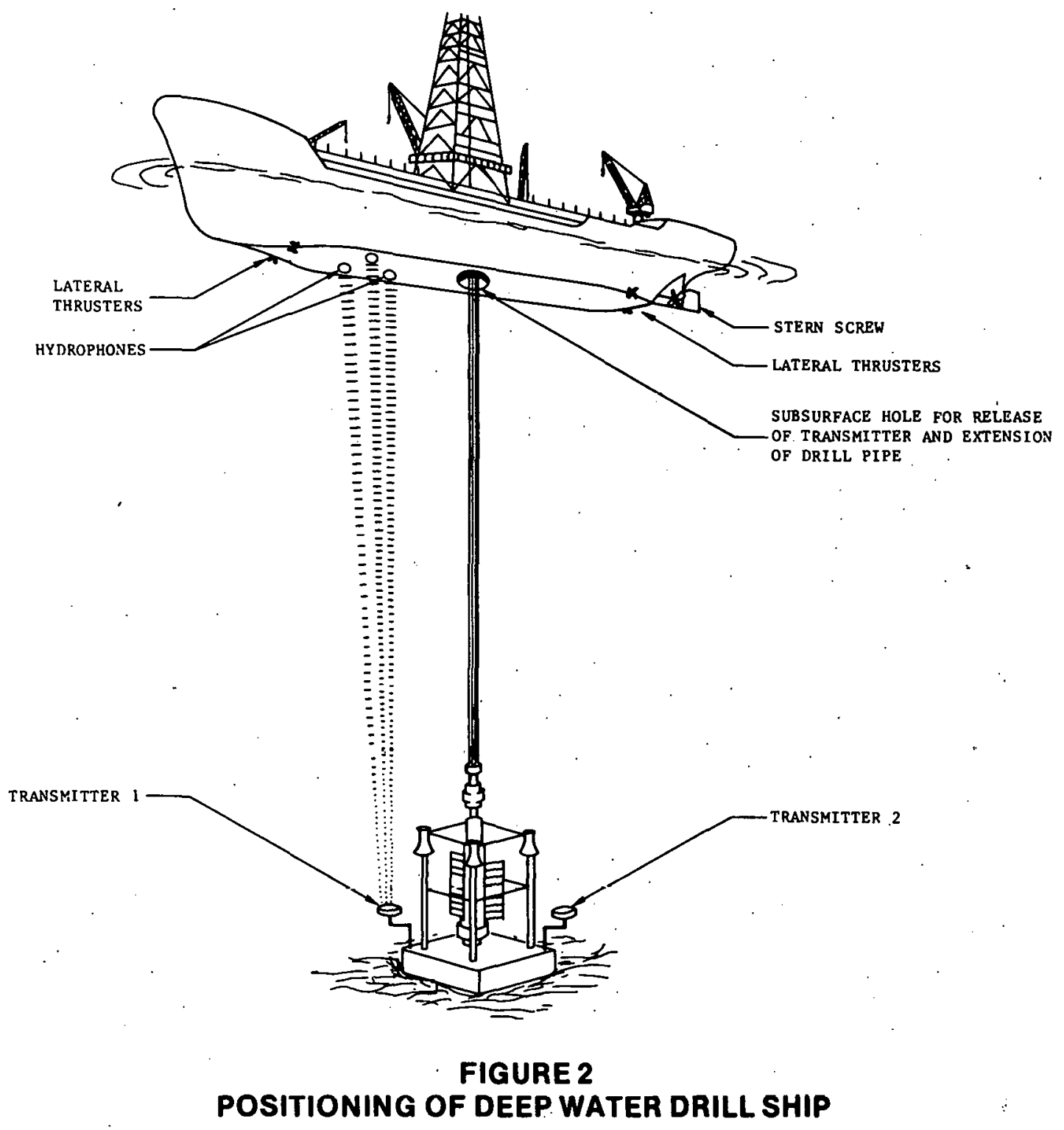




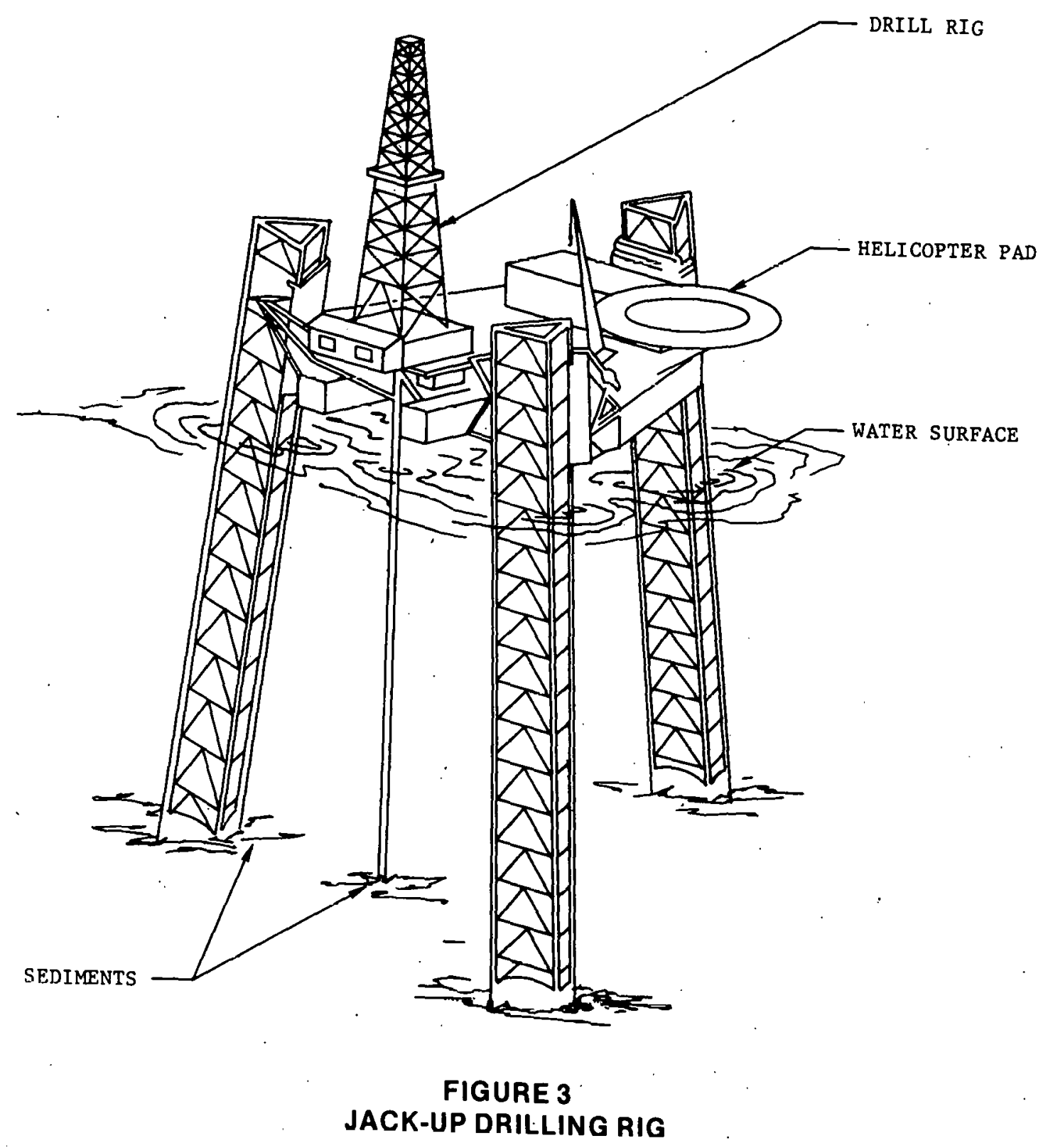




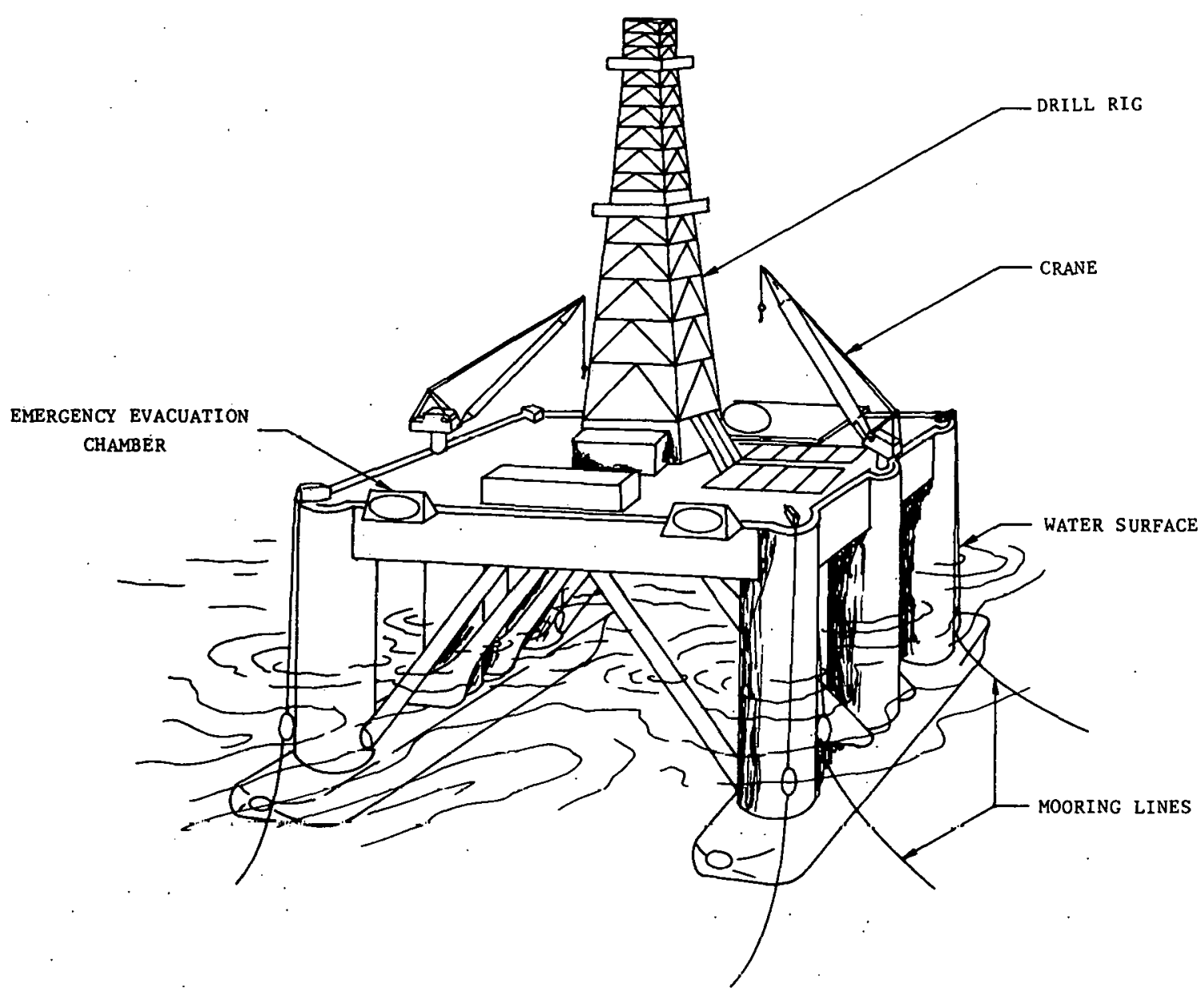

FIGURE 4

SEMISUBMERSIBLE DRILLING RIG 
Like drillships, semisubmersibles maintain their location with either anchors or a dynamic positioning system.

Jack-ups and semisubmersibles are most widely used for offshore exploratory drilling operations. $\ddot{A}$ recent survey of the world's mobile drilling rig fleet listed 271 jack-ups, 123 semisubmersibles, and $88 \mathrm{drillships}$ and barges (Tubb 1979).

Once the platform is positioned over the drill site, the drill stem is lowered to the ocean floor through a conductor pipe or a marine riser (Figure 5). : The methods and equipment used for offshore drilling are very similar to those used on land. Most wells, whether offshore or onshore, are drilled by rotary drilling methods which utilize (Sittig 1978):

- Machinery to turn the bit, to add sections on the drill pipe (i.e., drill string) as the hole deepens, and to remove the drill pipe and the bit from the hole; and

- A system for circulating a fluid (i.e., drilling mud) down through the drill pipe and back up to the surface.

The well bore is drilled by rotating the drill bit which is on the end of the string of drill pipe. Drilling mud is an important component of a drilling operation. It removes particles cut by the bit, cools and lubricates the bit, stabilizes the walls of the well bore, and controls any pressures that the bit may encounter in its passage through various formations (Sittig 1978).

The driling fluids that are discharged within the marine environment are typically water-based slurries containing clays and various chemical and mineral additives. Federal regulations prohibit the discharge of oil-based and oil-emulsion fluids. The specific formulations used in oil and gas exploration activities vary widely, although most contain barite (barium sulfate) for density control and low concentrations of sodium hydroxide, chrome lignosulfate, lignite, and other chemicals to control viscosity, fluid loss, corrosion, and other mud properties (Ayers 1980a; Petroleum Equipment Suppliers As sociation 1980).

These materials are released at drilling rig platforms both as relatively small-volume operational discharges and as infrequent large-volume bulk discharges. It is estimated that a total of 10,000 to 30,000 barrels of mud, containing 20 to 30 percent solids, is discharged over the life of a typical well (Ayers 1980a). From about 1,500 new wells drilled in U.S. offshore waters in 1979 (U.S. Geological Survey 1980), it is estimated that 15 million to 46 million barrels of drilling fluid were discharged into the marine environment. 


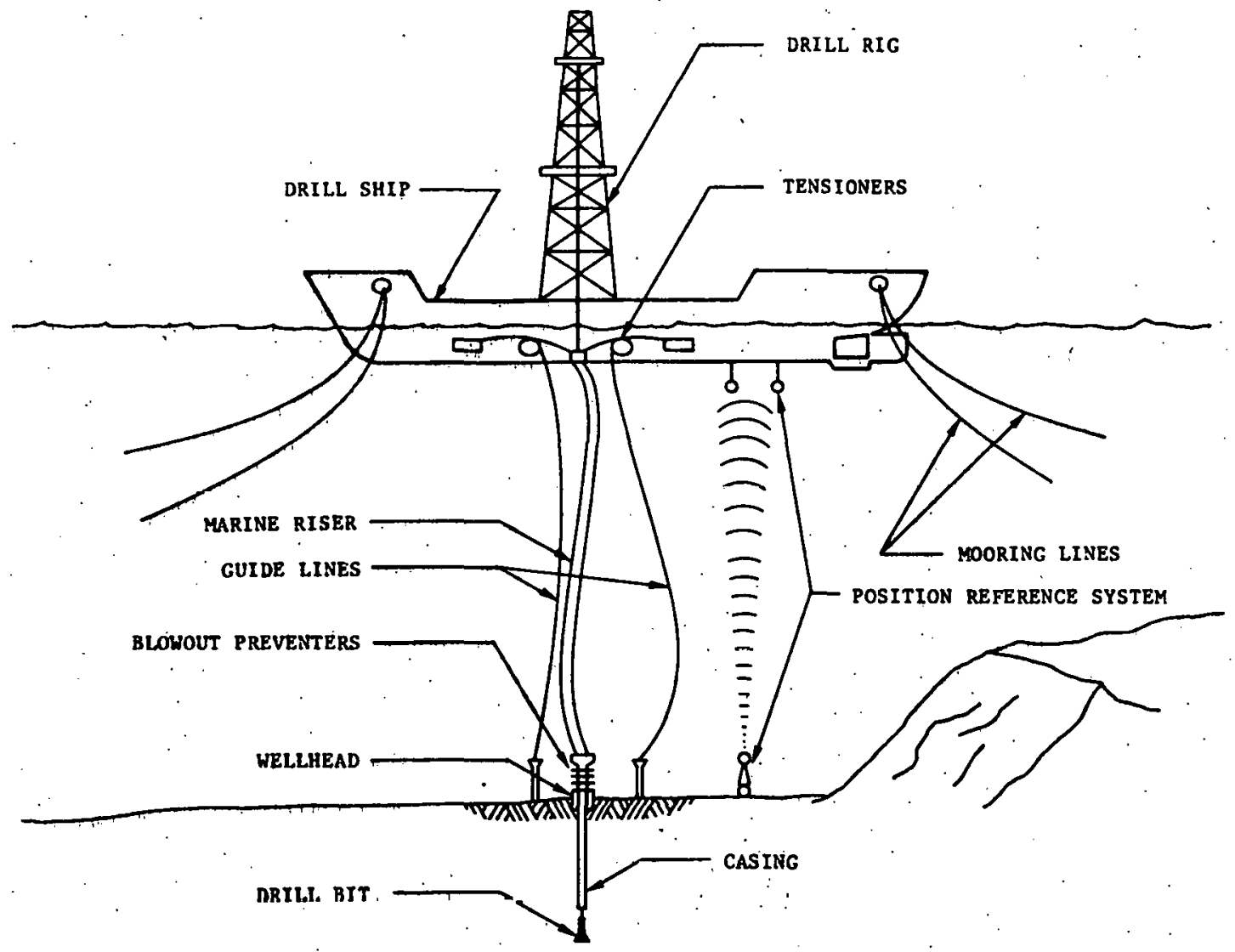

FIGURE 5

FLOATING DRILLING SYSTEM 
More than 90 percent of this. activity occurred within the Louisiana and Texas lease sale areas.

Exploratory drilling is one of the most hazardous steps in the development of offshore ofl and gas reserves due to the possibility of a blowout--the sudden surge of oil or gas pressure up the drill hole causing loss of control over the well (Council on Environmental Quality 1974). In addition to the drilling mud, safeguards used to minimize the possibility of a blowout include the setting of casing and installation of blowout preventers.

The casing usually consists of relatively large-diameter steel pipe and is used to line the bore hole (Kash et al. 1973). The type of casing used depends on the geological structures and pressures encountered during drilling. The surface casing provides an attachment site for the blowout preventer stack, which is a series of control valves that can close part or all of the drill hole in case of a blowout:

Development Drilling and Well Completion

\section{Development Drilling}

If exploratory drilling reveals commercially exploitable quantities of oil and gas, then preparations may be undertaken to begin production. Production operations are initiated by installing a platform to serve as a base for drilling development wells (Figure 6). In contrast to exploratory drilling, most offshore development drilling and production facilities utilize fixed platforms.

In shallow waters, platforms are usually constructed by first driving pilings of wood, steel, or concrete into the ocean floor and then constructing the platform or installing a prefabricated platform on Llie plliugs. In deeper waters, the platform 1o prefabricated onshore, floated or barged to the location, and sunk in place.

Platforms are not standardized, but are deslgned for each specific location. Components such as motors, derricks, cranes, and housing modules are standard items, but the structure on which they are housed may stand in waters ranging from 50 to 1,000 feet deep. Factors such as depth, sea floor soll conditions, wave action, winds, sea floor stability, and the weight of the structure must be considered (Clark et al. 1978). Platforms may be designed only for drilling and workover, or for a combination of driliing and production. Subsequent to drilling, some platforms may be converted to housing and recreational areas for field personnel. Many of the fields in the Gulf of Mexico and in the North Sea use a drilling platform for the development. wells and a satellite platform for the production 


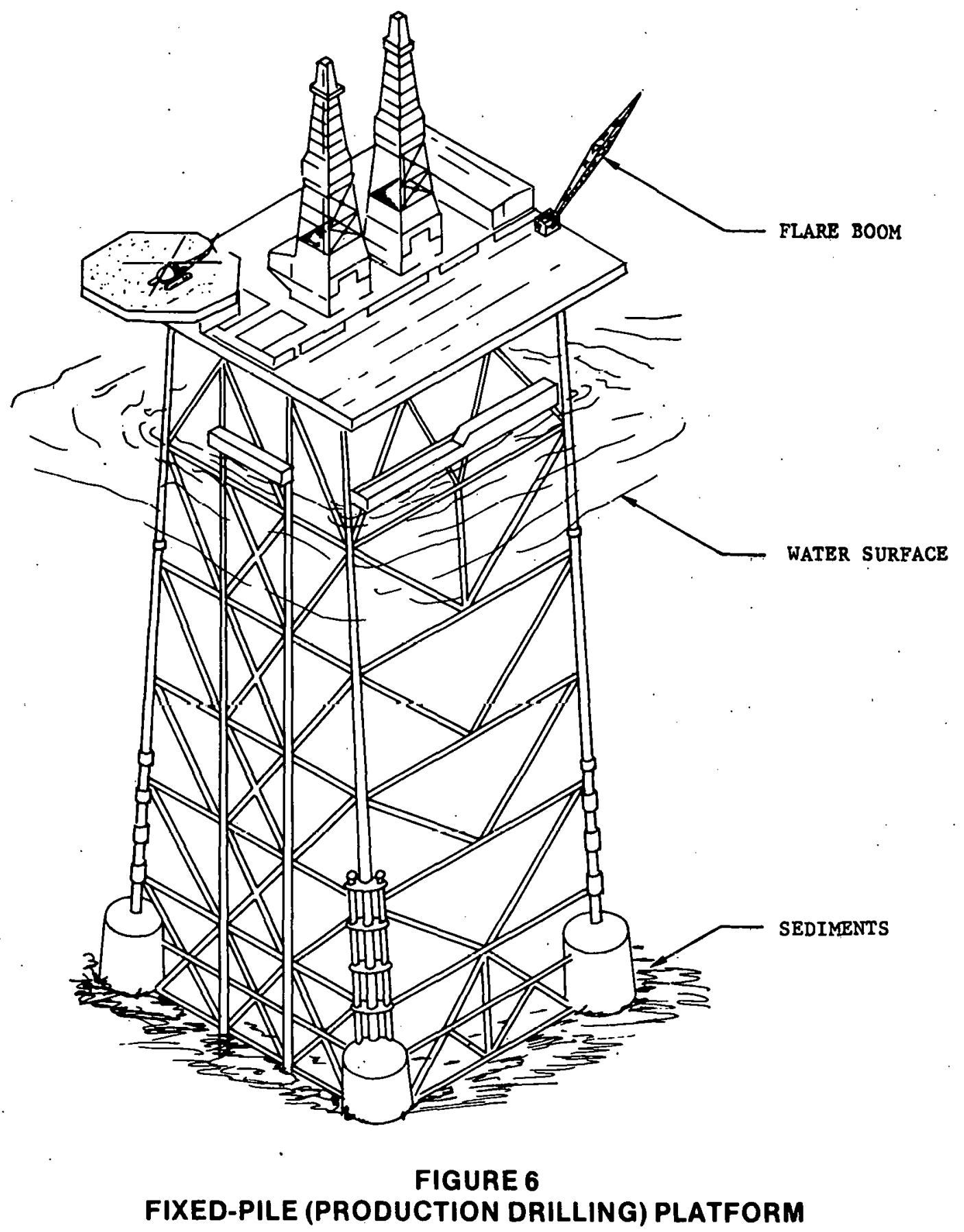


facilities. In deeper waters, the trend is toward combining platform functions since costs increase greatly with depth (U.S. Geological Survey 1976).

An emerging alternative to fixed production platforms is the subsea production system which involves placing the wellheads on the ocean floor rather than on platforms (Figure 7). The produced liquids or gases are transferred from the wellhead either to a nearby fixed platform or to a shore facility for processing (Kash et al. 1973). The subsea production systems exist in a variety of configurations, including: wet systems, in which the wellhead equipment is exposed to water; and dry systems which contain essentially conventional wellhead equipment within watertight chambers maintained at atmospheric pressure (Kash et al. 1973). However, there are three basic types of subsea systems under development: single subsea wells, encapsulated systems, and nonencapsulated mult1well systems. The encapsulated system involves the use of dry chambers to enclose dryland wellheads on the ocean floor. Workmen enter the oneatmosphere pressure chamber from a diving bell or submarine. The single subsea well and the nonencapsulated multiwell systems are both wet systems. Production equipment for the nonencapsulated multiwell system is located within the system and is serviced by a diving bell that can be either manned or unmanned (Kash et al. 1973; Council on Environmental Quality 1974).

Economic advantages that favor the increased use of subsea. production systems are (Ocean Industry 1978):

- Establishment of early production. The construction of an offshore platform and wells may take 5 years, whereas subsea systems can be completed within 1 year. This allows for early evaluation of a reservolr's production before heavy investments are made in permanent structures and provides an early cash flow supply.

- Utilization of exploratory wells as production units. Seafloor completions can be used to tap. exploratory wells that are ordinarily plugged. These units can be tied to a platform for operating.

- Kecovery and reuse of equiphent. In contrast to platformo, subsea equipment can be inexpensively recovered after production is cerminated.

- Production from marginal fields. The low cost of subsea systems permits their use in fields that would normally be abandoned due to low yields. 


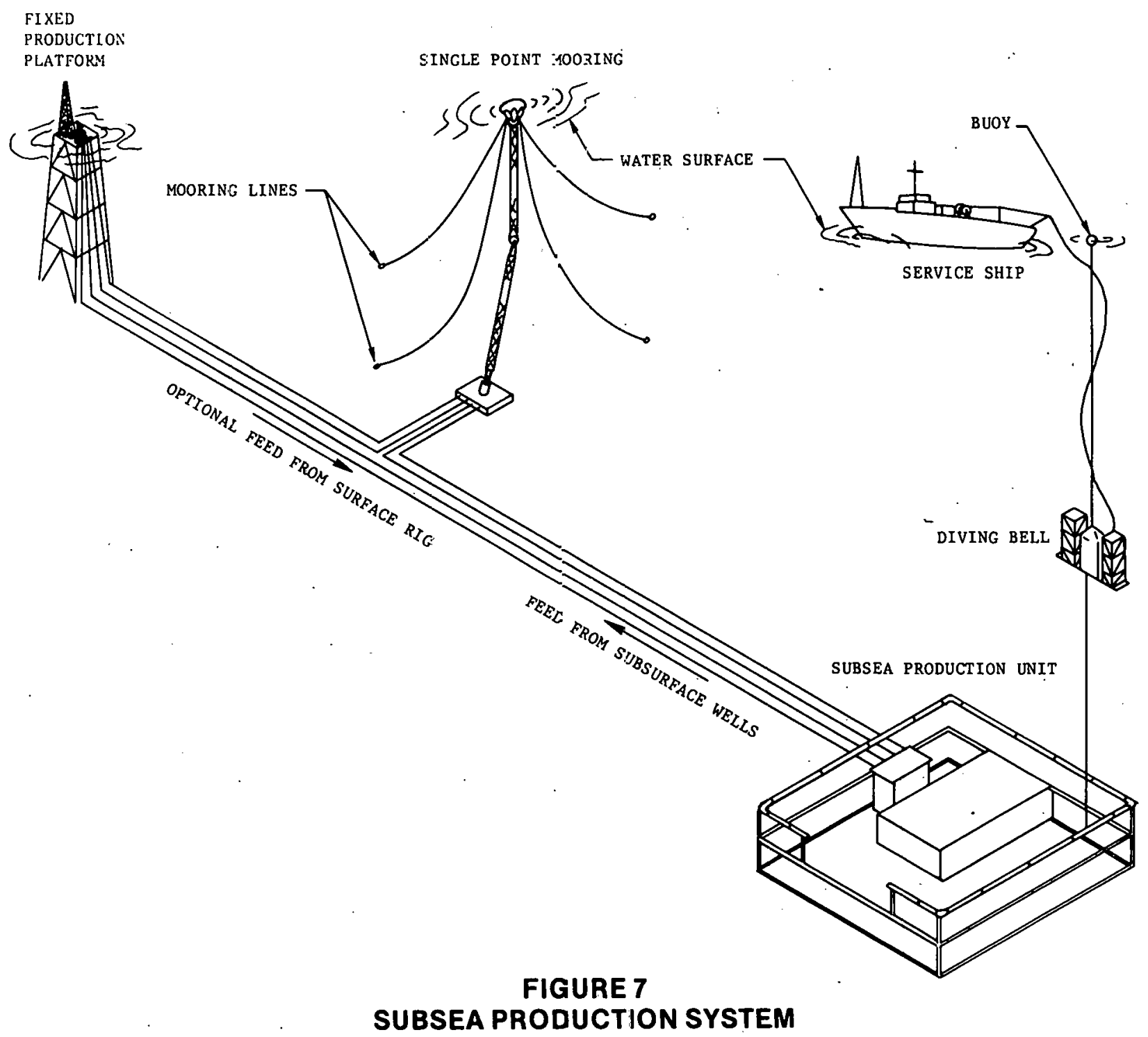


- Complete field use. Subsea systems can be used to tap areas where overburden is shallow and to service outer areas of a reservoir that cannot be reached with platform development wells.

- Deepwater production. A goal of the developers of subsea sys tems is to design equipment to operate at water depths below the economic operating depths of conventional platforms. Some subsea systems can be successfully installed and operated in water depths up to 3,000 feet.

- Unstable seafloors. Subsea systems can operate on sediments that cannot support a production platform.

- Avoldance of 1ce. Platforms erected through the a1r-sea interface in arctic regions may be damaged by wind and current-driven sheet ice and icebergs.

After the $f$ ixed platform or subsea system is assembled, development drilling, similar to exploratory drilling, commences. Development wells can be drilled vertically and individually, like exploratory wells, or they can be drilled directionally to cluster the wellheads in one location. With the latter method, the drill is directed off a vercical line to reach lateral sections of the ofl or gas reservoir, making the most economical use of expensive platform space (Figure 8). Directional drilling requires the use of special production rigs (mounted on the platform) which can rotate the drill strings through the drive or conductor pipe that may be set at an angle of up to $30^{\circ}$ with the ocean floor. Modern platforms accommodate as many as 60 wells (Clark et al. 1978).

The drilling procedures for development (production) wells are essentially Identical to those for exploratory wells (Kash et al. 1973; U.S. Geological Survey 1976). Alternatives to the rotary drilling process are being examined and include the use of a flexible. drill string, a jetted particle system, high fluid pressure drilling, and explosives.

Development drilling is generally less hazardous than exploratory drilling because the characteristics of the geological formations are bet ter known. However, there is still the potential threat of a blowout. The severity of a development well blowout increases significantly if oil and gas are being produced simultaneously from wells that have already been completed (Council on Environmental Qual1ty 1974). 


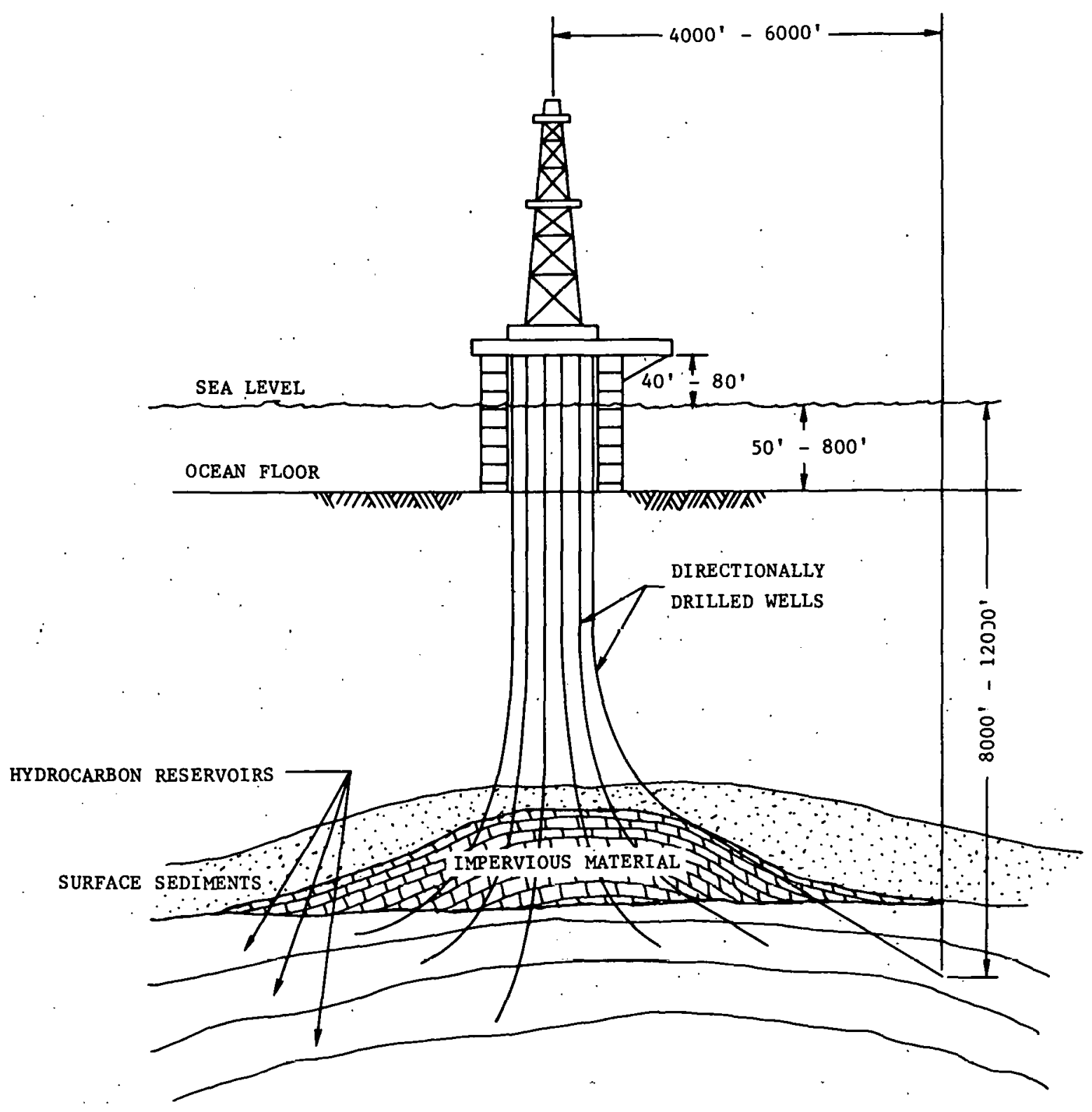

FIGURE 8

TYPICAL DIRECTIONALLY DRILLED WELLS 


\section{Well Completion}

If a well is dry, it is plugged with cement and abandoned. If commerclal quantities of oil or gas are found, the well 18 "completed"--a term that refers to the various activities required to transform a well into a producer of oil or gas. Kash et al. (1973) have described completion as incorporating the following activities:

o Setting and cementing casing;

- Perforating, or cutting holes in the casing that will permit oil or gas to flow from the formation into the well hole;

- Fracturing, or applying pressure or using explosives to increase permeability;

- Acidizing, or using acid to enlarge openings in the formation;

o Consolidating sand to keep sand from filling the well bore;

o Setting tubing, or a conduit for routing the oll or gas to the surface; and

o Installing downhole safety devices, or valves to prevent blowouts during production.

If any of these activities is performed after initial completion, it is considered a servicing or workover operation.

If well tests indicate that the well is productive, then production tubing string(s) is run inside the production casing. The tubing string serves to carry well production to the surface. Testing procedures are conducted through the blowout preventers (BOP) and the tubing 18 also run with the BOP stack in place. The BOP stack is removed after temporary plugs are set in the tubing. Finally, the well head control assembly, termed a "Christmas tree," is connected to the tubing (U.S. Geological Survey 1976).

After the pipes, tanks, and processing facilities are installed, seawater is pumped down the production casing of the well to flush out any remaining drilling mud (Clark et al. 1978). Downhole completion procedures vary greatly depending on reservolr conditions. The simplest completion technique is to perforate the production casing opposite productive intervals with gun (bullet) or jet (shapedcharge) perforations. 
Subsea completion operations differ from the above described normal surface completion operations only in that, upon completion, the wellhead control assembly (1.e., Christmas tree) is situated on the ocean floor (U.S. Geological Survey 1976).

\section{Production}

In their initial completion stage, most wells will flow naturally to the surface because their reservolr pressure is high enough to support the column of reservoir fluid in the production tubing and deliver it to the surface. If reservolr pressures are insufficient to lift oil to the surface, gas may be injected under pressure down the casing. Gas lift is not practical in all wells and is usually a temporary measure. It is practical only as long as reservoir pressure remains fairly high. Almost all wells, at some 8 tage in their productive lives, require artifical lift to bring production to the surface. Either submersible (1.e., rotary type) or hydraulic (1.e., piston type) pumps are usually used in offshore applications. Both pumping methods require little surface space and can be used in platform operations. Some models of the hydraulic pump are particularly suitable for subsea applications (U.S. Geological Survey 1976).

Once a well is completed and connected to production facilities, production may begin. If oll, gas, and other materials are produced, they must be separated (Figure 9).

The ofl is separated, metered, and pumped, either to shore by pipeline, to offshore storage tanks, or to a tanker. If water is produced with the oll, a "free water knock-out" tank is of ten used to remove water that is not contained in an oll-water emulsion. If water is produced as an emulsion with the oil or if the oil is mixed with sand, more sophisticated equipment is needed (Kash et al. 1973). Separated water may be discharged to the ocean; however, the maximum allowable oil content is 100 parts per million (ppm) and the average allowable oil content $1850 \mathrm{ppm}$ or less. Sand may be discarded into the ocean after the oil has been removed (Council on Environmental Quality 1974).

The gas is separated, pressurized, metered, and pumped to shore by pipeline. If there is no gas pipeline or if gas production is not economical, the gas may be pressurized and reinjected into the reservoir. If water is produced with the gas, the gas is dehydrated by contact with glycol.

When treatment facilities are mounted on production platforms, the equipment is similar, if not identical, to onshore production facilities (Kash et al. 1973). For subsea production, the processes 


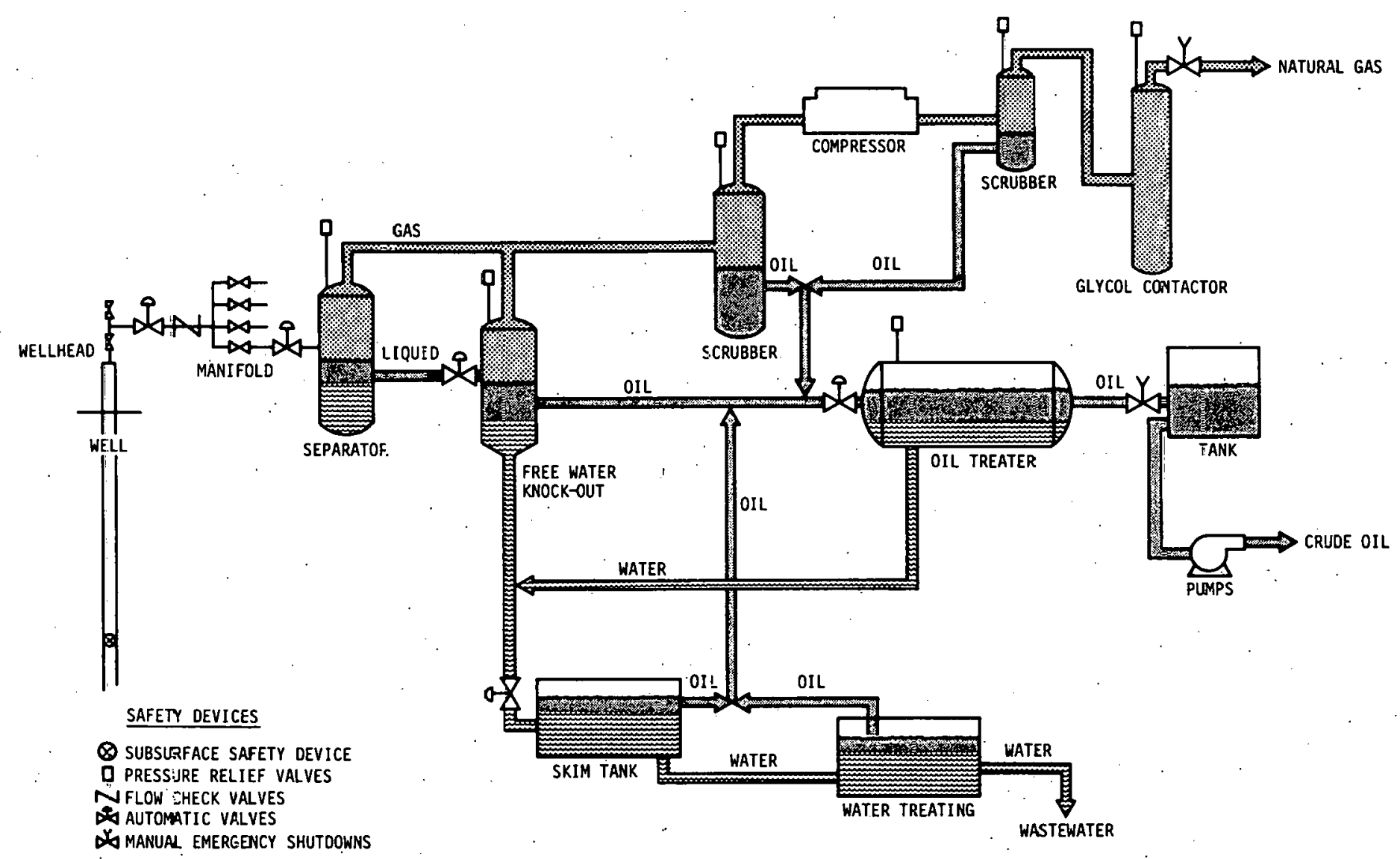

FIGURE 9

TYPICAL PRODUCTION FACILITY 
remain essentially the same, but the hardware becomes much more complex. The problems of extensive subsea operations may be so severe or expensive that it may be preferable to transport the produced materials ( $i . e .$, oil, gas, water, and sand) either to platforms or to onshore facilities for treatment (Kash et al. 1973).

Due to the potential for explosions, fire, storms, and earthquakes, many devices are installed to warn of impending or existing dangers and to control or stop the flow of oil and gas if trouble is sensed. Production platforms may be equipped with pressure, level, and combustible gas sensors; manual and automatic pressure rellef valves; and fire detection and fighting equipment. All wells also are equipped with a subsurface safety valve which can shut down the well in case of surface equipment failure.

Production activities are continuous and hardware is installed for the life of the fleld (Kash et al. 1973). However, it may be necessary to shut down and reenter a well to improve or restore production. A variety of operations may be involved in workover and servicing, including further drilling to deepen the well.

\section{Transportation}

011 and gas may be transported to onshore processing facilities either by pipeline or by bulk carriers such as tankers and barges. To date, natural gas has been transported only by pipeline. Durling the early stages of an oll fleld's development, small amounts of gas are sometimes vented or flared. All of the oil produced off the California coast and 98 percent of Gulf of Mexico o1l is transported to shore by pipeline (Kash et al. 1973). Nevertheless, barges and tankers are used as a temporary means of transportation during field development or to transport oil from fields with low production rates. Tankers are also used for supplemental transportation after pipelines are completed.

\section{Pipelines}

Pipelines transport large volumes of oll and natural gas. Once a pipeline route is selected and the volume to be pumped is determined, pipe size and strength are selected and line pressures calculated. Factors considered during the route selection process include: ocean bottom and subsurface foundations; current, wave, and tide conditions; and other uses of the area (e.g., fishing, shipping).

There are three primary techniques used to lay pipeline offshore: stove pipe, reel barge, and pipe pulling (Kash et al. 1973). In the stove pipe method, short sections of pipe are welded together 
on a pipelaying barge; then they are released into the water and lald on the ocean floor as the barge moves forward. There are several types of barges and several ways to lower the pipe. The vessel may have a barge or ship hull or it may be a semisubmersible. The barge hull is the most common, although its operation 18 limited to relatively calm seas. The main advantage to this method 18 that any diameter of pipeline can be laid, but laying proceeds at a relatively slow rate (Council on Environmental Quality 1974; U.S. Geological Survey 1976).

In the reel barge method, pipe 18 welded together onshore and 18 wound onto a large reel on the pipelaying barge. The pipe is latd as it unwinds. This technique is limited to plpe diameters of 12 inches or less (Council on Environmental quality 1974). The plpe pulling method uses barges and tugs to pull sections of welded pipe from an onshore launchway over the pipeline route. Th1s method is limited to use for distances of only 2 to 4 miles off shore (Kash et al. 1973).

Offshore pipelines may be burled for several reasons, the most important being to ensure that the line will not be damaged. Damage to pipelines may be caused by anchors, fishing operations, currents, and storm waves. A burial barge is used to sink the pipe beneath the surface, usually by displacing soll. with a high-pressure water jet (Kash et al. 1973; U.S. Geological Survey 1976).

\section{Tankers and Barges}

Tankers and barges transport less than 3 percent of the o11 produced in the Gulf of Mexico. However, in 1972 the Atlantic Coast states recelved 91 percent of thelr domestic crude oll supply by tanker and barge from the Gulf of Mexico, and 89 percent of their foreign crude oil imports by tanker and barge (Council on Environmental Quality 1974). Transportation by Very Large Crude Carriers (VLCC) or supertankers is economically advantageous only over great distances (e.g., from the Persian Gulf to the U.S.).

011 pollution from tankers and barges can occur either during transfer operations or as a result of collisions and groundings (Kash et al. 1973). Another major source of ofl pollution from tankers is intentional discharge--the pumping of ofly ballast water and tank wasliings lato the ocean (F1gure 10).

\section{Offshore Storage}

Offshore storage facilities can provide a buffer between the continuous production of wells and the discontinuitles of tanker operations (Kash et al. 1973). Bottom standing concrete gravity 


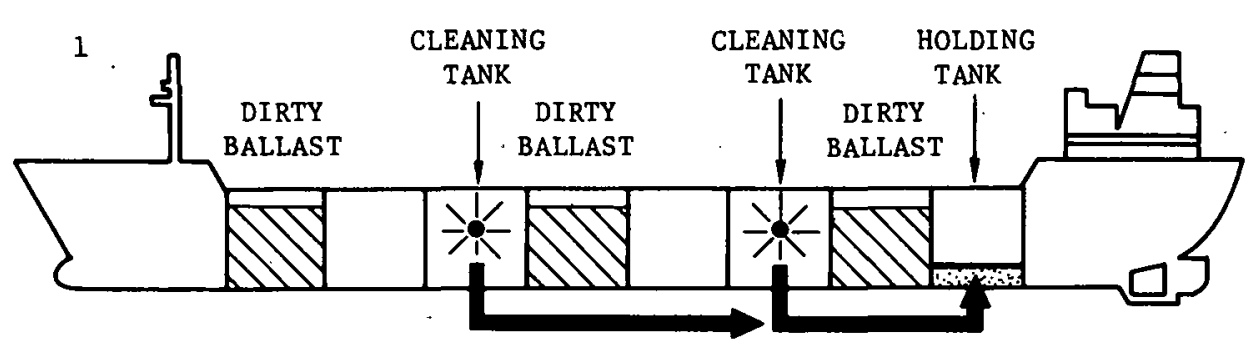

TANK WASHINGS TO HOLDING TANK

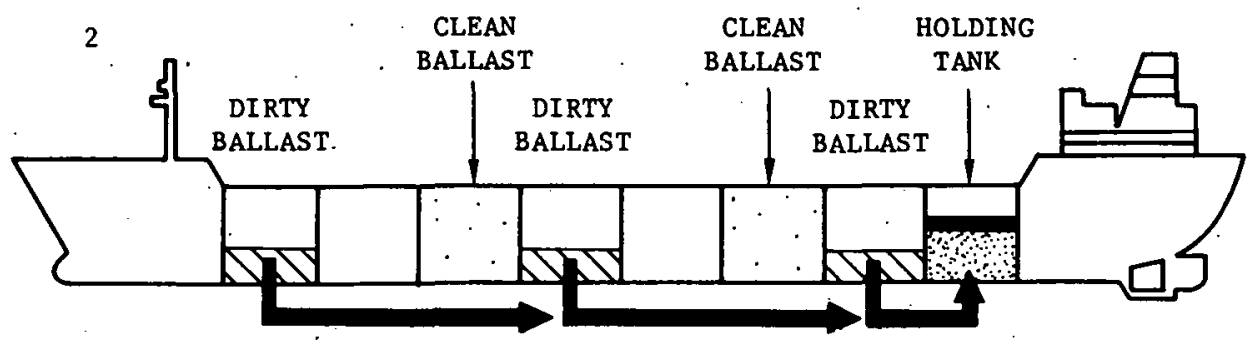

OIL AND OILY WATER TO HOLDING TANK

3

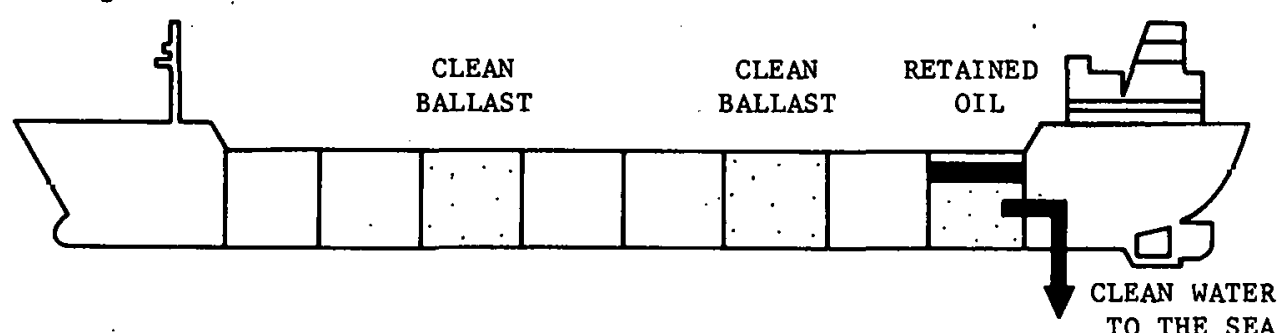

(1) After discharging its cargo, stability considerations require the tanker to take on ballast water in some of its empty cargo tanks. En route, the oil and water separate, and oil floats on top of the clean water. Meanwhile, other cargo tanks are cleaned and their oily residues pumped to a holding tank. (2) The cleaned tanks are filled with sea water, the orfginal ballast water, now separated from the oil, is pumped overboard, and the remaining oil and oily water go to the holding tank. (3) The oil and oily water are carried to the ship's destination, where the clean ballast water is pumped overboard, and the next cargo of crude is loaded on top of the retained residues. 
platforms and floating storage tanks with capacities of up to $1 \mathrm{mil}-$ lion barrels each are being used in the Persian Gulf and the North Sea. Offshore storage technology has been developed primarily in response to needs in other parts of the world. However, offshore storage will be necessary for subsea completion systems in very deep fields because of the economics of tanker transport versus pipelines (Ranney 1979).

Offshore 011 Ports--Complex Facilities*

Culminating over 6 years of planning, hearings, and preparation, the Louisiana offshore 011 Port (LOOP; the first American deepwater port capable of unloading supertankers) is under final construction. This may be the forerunner of a trend toward the greater use of the continental shelf for complex oil and gas storage and handling facilities. Initially, LOOP's operation will have a 1.4 million bbl-perday throughput capacity. About half of the crude will be transported to Louisiana refineries and the other half will be piped to refineries in the Midwest.

\section{Offshore Facility}

The LOOP Marine Terminal is located approximately 19 miles offshore, and will be operated as a common carrier system. The entire LOOP system includes 19 miles of offshore pipeline and 28 miles of pipeline through the marshland between the shoreline and the Clovelly Salt Dome, where crude oll will be temporarily stored. The LOCAP pipeline (pipeline connecting the LOOP to the Capline pipeline) will be constructed across 53 miles of marsh, swamp, forest, and agricultural land between the Clovelly Salt Dome and the St. James, Loulsiana, terminal, where the Capline pipeline will carry the ofl to the Midwest.

Arriving tankers of up to 700,000 dead weight tons (dwt) will be guided by a specially trained mooring master to one of three singlepoint mooring buoys, where they will be able to rotate 360 degrees around the buoy. This will enable the ship to maintain a heading of least resistance to wind and waves during offloading operations. The port is located in 110 feet of water in Grand Isle Block 59 in the Gulf of Mexico off the coastline of Louisiana.

All pipe entering and leaving the platform has a minimum of 10 feet of cover along a 500-foot section of line adjacent to the platform. The rest of the line has a minimum cover of 3 feet until the

\footnotetext{
*Information in this section is taken largely from Dietsch 1980.
} 
shoreline approach, where the line is burled to provide a minimum depth of 10 feet below mean low water.

\section{Onshore Facilities}

Connecting the platform with the onshore facilities is a 48-inch underwater pipeline that carries the ofl to the Fourchon Booster Station on the shore. Oil will then move through a 48-inch line to the Clovelly Salt Dome Storage Terminal containing eight subsurface cavities, each with a storage capacity of $4 \mathrm{million}$ barrels. The individual cavity system is essential because LOOP will be handling six different segregations of foreign crude. The crude is pumped into these storage cavities by 6,000-horsepower electrically powered pumps. These eight cavities have a total capacity of 40 million bbls. There will also be a 25 million-bbl brine storage reservoir, fire protection facilities, crude oll pumps, and power and communication facilities. In addition, the terminal provides space for originating pump stations for six future outgoing pipelines. This 48-inch line is about 29 miles long. Another 29 miles of 30 -inch brine line from the Clovelly Storage Facility extends 2 miles into the Gulf.

\section{System Supervisory Control}

The LOOP supervisory control and monitoring system is comprised of an integrated array of digital computers, peripheral devices, communications links, and programmable controllers. The system is designed to allow operational control and full monitoring of the entire LOOP facilities from the Operations Center at Galliano: The interface to the plpeline will be via the programmable controllers, which also function as the primary process control system. Local digital processors and associated man-machine interfaces will be located at three major facilities: the Marine Terminal, Fourchon Booster Station, and Clovelly Dome Storage Complex.

\section{Future LOOP Phases}

Possible future LOOP plans include phase II, when throughput would reach 2.4 million bbls per day with the addition of one single point mooring unit and connecting 56-inch line, one 48-inch line to shore, one 48-inch line to Clovelly, 10 million bbls of additional storage capactiy, and added pumping capacity at all pump stations.

\section{Other Deep Water Ports}

Recently the U.S. Army Corps of Engineers issued a dredging permit to the Port of Galveston and Pelican Terminal Corporation to proceed with construction and use of the deep channel and pipeline 
system to support the Gulf Coast's f1rst onshore deep-draft oll terminal. The Pelco (Northville Industries-Chicago Bridge \& Iron jolnt venture) crude oil terininal will be located on Pelican Island, sheltered from the Gulf of Mexico by the 1sland of Galveston, and have two tanker unloading berths capable of serving ships up to 250,000 dwt, lightened to a draft of $50 \mathrm{ft}$. Oil unloaded at the facility will be shipped by twin pipelines to a storage farm on the mainland at Texas City, from which delivery pipelines will fan out to refinerles near Houston, Port Arthur/Beaumont, and possibly Freeport, Texas. Construction is slated to begin in early 1981 and port operation is expected to begin in late 1982 (Pipeline and Gas Journal 1980). 


\section{THIS PAGE \\ WAS INTENTIONALLY \\ LEFT BLANK}




\section{HEALTH EFFECTS OF OFFSHORE DEVELOPMENT}

Offshore oil and gas production would have its greatest potential impact on human health within the workplace, although the general public could be affected if the industry causes contamination of the marine food chain leading to man and the emission of airborne pollutants from offshore production or port complexes. Federal agencies concerned with health and safety on offshore oil platforms include the Environmental Protection Agency, U.S. Geological Survey, Department of Energy, National Marine Fisheries Service, Food and Drug Administration, U.S. Coast Guard, Occupational Safety and Health Administration, and the National Institute for Occupational Safety and Health.

This section presents an overview of potential health and safety problems related particularly to offshore 011 and gas production and it provides directions for future research. The reader is referred to the Onshore section for discussions of health problems generally associated with exploration for and extraction of ofl and gas.

\section{Occupational Health Considerations}

Individuals involved in offshore oil and gas development operations may be subjected to potentially hazardous chemicals. It is expected that dermal exposure to driling muds and associated chemicals, and pulmonary exposure to air pollutants and flare gases are frequent:

\section{Drilling Muds}

Drilling mud is a chemically complex mixture of clay, water, and numerous chemical additives. Chemical ingredients used to formulate various muds can include $\mathrm{pH}$-control products, bactericides, calciumremovers, corrosion inhibitors, defoamers, emuleifiers, filtrate reducers, flocculants, foaming agents, lost circulation materials, lubricants, shale-control inhibitors, surface-active agents, thinners, dispersants, viscosifiers, and weighting agents (Richards 1979). The frequency of dermal exposure to these substances for offshore oil rig workers is not known and the effects of these substances on occupational health has not been thoroughly explored. On offshore plaforms, drilling muds are known to discolor the skin of workers and to present a safety. hazard when it coats surfaces, making them slippery. Additional information on the health effects associated with drilling fluids is contained in the Onshore section of this report under Health Effects. Research is needed to determine the extent and severity of adverse effects from exposure to these substances. For those found to represent hazards, methods should be developed to limit occupational exposure. 


\section{Hydrogen Sulfide}

A severe occupational health hazard on offshore drilling platforms is exposure to hydrogen sulfide. A few breaths of highly concentrated hydrogen sulfide escaping from the drill hole can result in paralysis of the diaphragm, causing a cessation in breathing. On most platforms, sensors designed to detect hydrogen sulfide in high concentrations trigger a walling siren to alert workers to move upwind, use walk-around air cylinders, or possibly, to embark on escape capsules. So deadly is the gas that prospective workers with poor hearing may not be allowed on the platform.

The hydrogen sulfide hazard may be compounded by another hazard--the impalred hearing of workers exposed to a high noise level on offshore drilling platforms. The noise 18 associated with the continuous use of diesel engines, metal striking metal, operation of cable and drum, and use of winches and chains. Communication by word of mouth is difflcult and workers usually watch each other's hands and eyes to avoid injury.

\section{Health Statistics}

Occupational Injuries and 11 lnesses for 1978 for various stages of ofl and gas development are listed in Table 1. This information was obtained by the American Petroleum Institute from $1 \cap 9,011$ and gas companies employing over 435,000 persons.with a total work experience of more than 890 million hours. The incidence rate (1.e., total recordable cases per 100 full time workers) was found to be 4.47 for 1978, compared with 4.52 for 1977 (American Petroleum Institute 1979a). Occupational accident data are summarized on an energy equivalent basis in Table 2 and in terms of supplying a 1,000-megawat power plant with fuel for 1 year in Table 3 .

Occupational Safety Considerations.

Accidents involved in the development of offshore oil and gas reserves can occur at any stage of development. These accidents can involve equipment fallure, human error, and natural phenomena. The consequences can include occupational injury or death. Workers may be injured by falling objects, swinging sections of pipe or block and tackle, uncontrolled torques in the drill stack, coupling pipe sections, blowouts, ofl platform fires, oll spills or pipeline leaks, and by transportation vehicles (e.g., helicopters).

For comparison purposes, a breakdown of fatalities for 1977 and 1978 is presented in Table 4 for 109 oll and gas companies employing 435,524 workers. There were only 75 on-duty fatal accidents during 1978. This is equivalent to one fatality for every 5,807 workers 
TABLE 1

REPORT OF OCCUPATIONAL INJURIES AND ILLNESSES FOR $1978^{\mathrm{a}}$

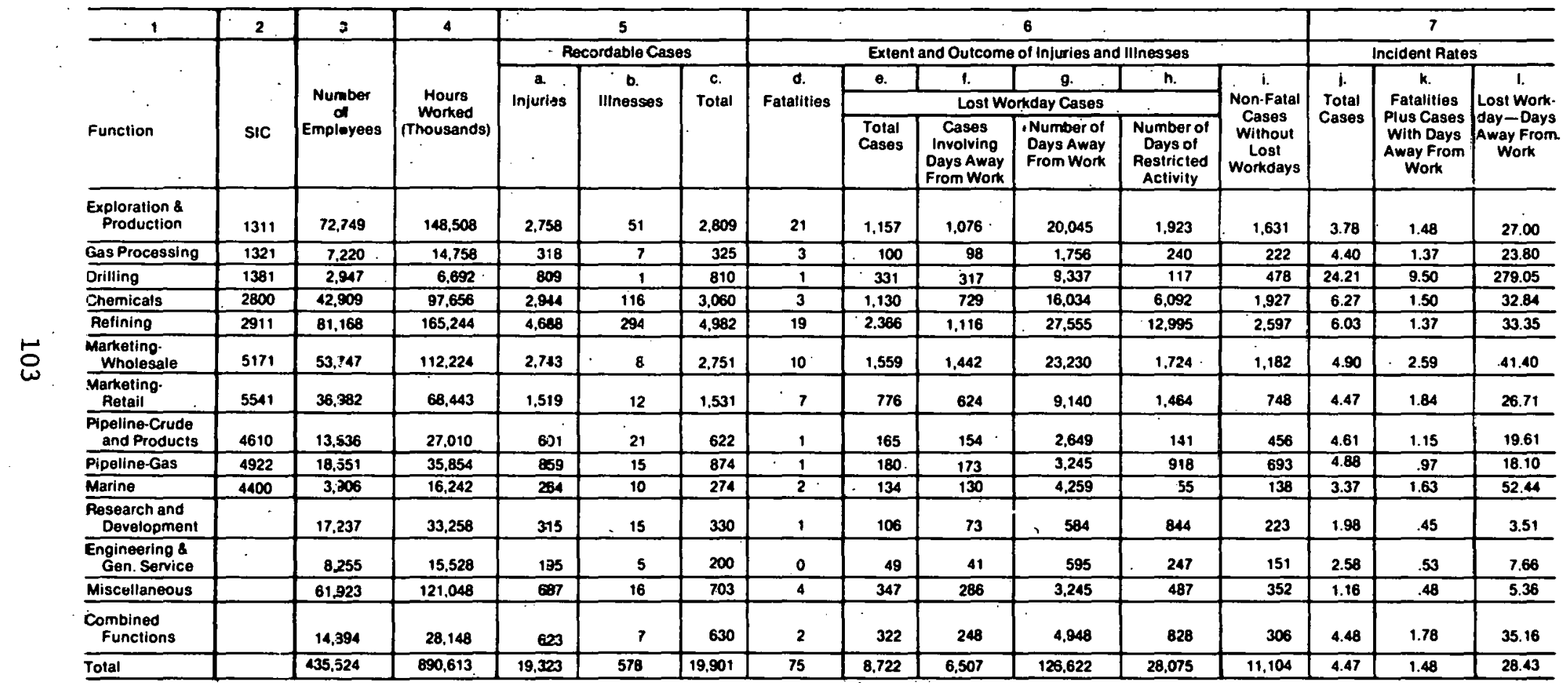

Incidence rates (column 7) are calculated as follows:

Column $7(0)=\frac{\text { Column } 5(c) \times 200,020}{\text { Column } 4 \times 1,000} \quad$ Column $7(k)=\frac{\text { Column } 8(d)+6(1) \times 200,000}{\text { Column } 4 \times 1,000}$

Column 70) $=\frac{\text { Column } 6(g) \times 200,000}{\operatorname{Column}(4 \times 1,000}$

${ }^{a}$ Covers operations subject to OSHA recordkeeping requirements only.

Source: American Petroleum Institute 1979a 
TABLE . 2

OCCUPATIONAL ACCIDENTS FOR CRUDE OIL AND PRODUCT TRANSPORT AND REFINING

\begin{tabular}{|c|c|c|c|}
\hline \multirow[b]{2}{*}{ System } & \multicolumn{3}{|c|}{ Accident Rate per $10^{12}$ Btu Equivalents } \\
\hline & Fatalities & Injuries & Man-Days Lost \\
\hline \multicolumn{4}{|l|}{ Crude 011} \\
\hline $\begin{array}{l}\text { Pipeline } \\
\text { Pipeline }\end{array}$ & $\begin{array}{l}6.9 \times 10^{-5} \\
0.009\end{array}$ & $\begin{array}{l}4.2 \times 10^{-3} \\
0.008\end{array}$ & $\begin{array}{r}1.0 \\
15.0\end{array}$ \\
\hline $0: 1$ tanker & 0.0009 & 0.008 & 15.0 \\
\hline 011 barge & 0.0009 & 0.008 & 15.0 \\
\hline $\begin{array}{l}\text { Product distribution } \\
\text { pipeline }\end{array}$ & $6.9 \times 10^{-5}$ & $4.2 \times 10^{-3}$ & 1.0 \\
\hline $\begin{array}{l}\text { Canadian crude/ } \\
\text { imported }\end{array}$ & $\cdot$ & & \\
\hline $\begin{array}{l}\text { Uncontrolled } \\
\text { Controlled }\end{array}$ & $4.4 \times 10^{-4}$ & $\begin{array}{l}0.0362 \\
0.0362\end{array}$ & $\begin{array}{l}2.05 \\
2.05\end{array}$ \\
\hline $\begin{array}{l}\text { Middle East. crude/ } \\
\text { imported }\end{array}$ & & . & \\
\hline $\begin{array}{l}\text { Uncontrolled } \\
\text { Controlled }\end{array}$ & $\begin{array}{l}4.4 \times 10^{-4} \\
4.4 \times 10^{-4}\end{array}$ & $\begin{array}{l}0.0362 \\
0.0362\end{array}$ & $\begin{array}{l}2.05 \\
2.05\end{array}$ \\
\hline \multicolumn{4}{|l|}{ Conventional refinery } \\
\hline Axablan crude & 0.0014 & 0.11 & 25.0 \\
\hline Kuwait crude & 0.0014 & 0.11 & 25.0 \\
\hline
\end{tabular}

Source: University of Oklahoma 1975. 


\section{TABLE 3}

ANNUAL DEATHS, INJURIES, AND WORKDAYS LOST FOR UNCONTROLLED OIL-FIRED- ELECTRICITY SYSTEMS

\begin{tabular}{|c|c|c|c|c|c|c|c|c|c|c|c|}
\hline \multirow[b]{3}{*}{ 官 } & & \multicolumn{2}{|c|}{ Extraction } & \multirow[b]{2}{*}{ Processing } & \multicolumn{3}{|c|}{ Transport } & \multirow[b]{2}{*}{ Conversion } & \multicolumn{3}{|c|}{ Total } \\
\hline & & Onshore & Offshore & & Onshore & offshore & Import & & Onshore & of fshore & Import \\
\hline & Deaths & 0.21 & 0.21 & 0.08 & 0.05 & 0.05 & 0.5 & 0.010 & 0.35 & 0.35 & 0.06 \\
\hline . & Injurles & 21 & 21 & 5.6 & 4.5 & 4.5 & 4.5 & 1.15 & 32.3 & 32.3 & 5.7 \\
\hline & $\begin{array}{c}\text { Workdays } \\
\text { lost }\end{array}$ & 2,135 & 2,135 & 785 & 562 & 562 & 562 & 127.2 & 3,609 & 3,609 & 689 \\
\hline
\end{tabular}

Source: Council on Environmental Quality 1973. 
TABLE 4

FATALITIES BY FUNCTIONS AND CAUSES

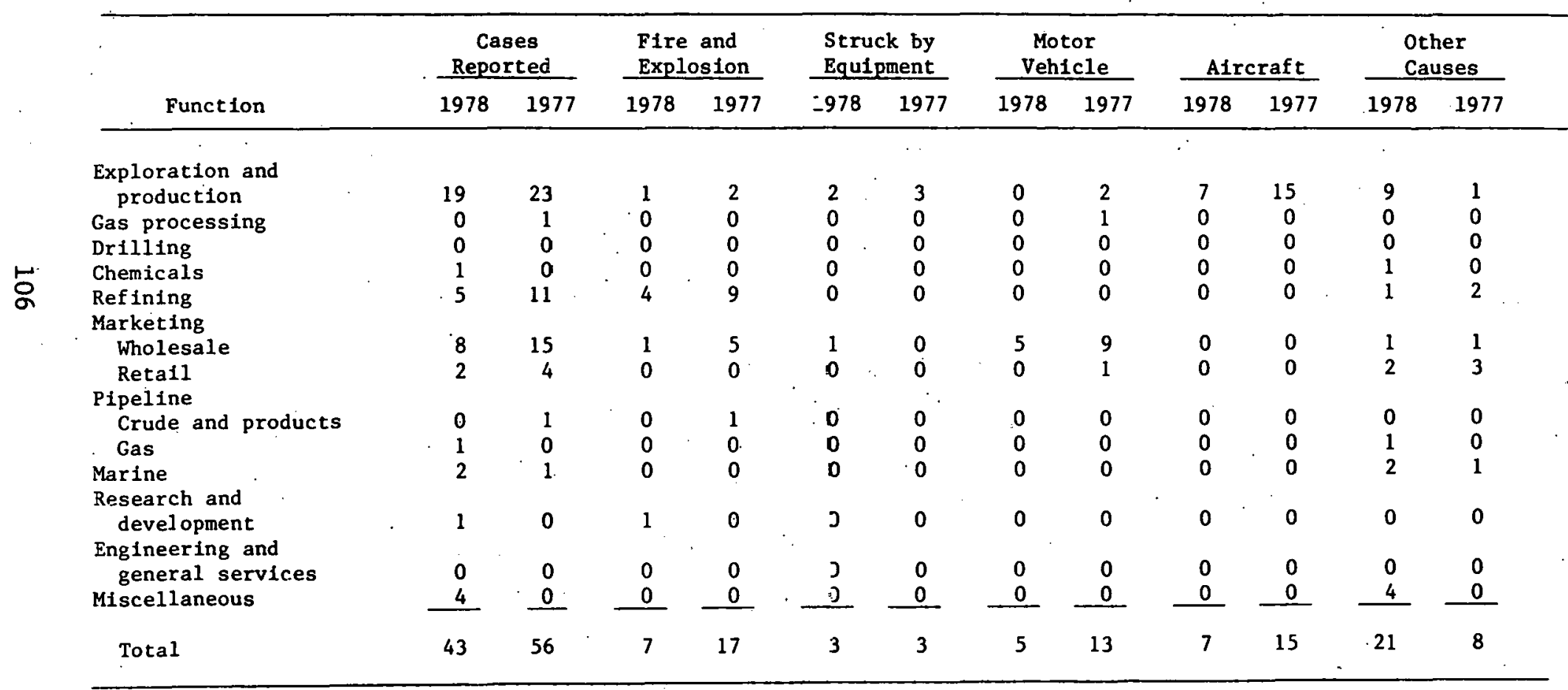

Source: American Petroleum Institute 1979b. 
employed--a slight increase over 5,995 in 1977 (American Petroleum Institute $1979 \mathrm{~b}$ ).

\section{Drilling Rig Accidents}

Recently the popular press and some trade journals reported on serlous accidents assoctated with offshore drilling (Downie 1980; The Washington Post 1980; U.S. News and World Report 1980; Mathews 1980). The reported incidents exposed the dangers of offshore drilling and attracted the attention of the public and regulatory agencies to the industry's safety hazards.

In a North Sea accident March 27, 1980, the o1l rig Alexander L. Kielland collapsed and 123 lives were lost (Downie 1980). Th1s semisubmersible rig with pontoon legs was considered to be almost incapable of capsizing. Consequently, most safety precautions against a large-scale disaster were designed for blowouts. Water safety precautions apparently did not anticipate a rig collapsing so quickly (Downie 1980). The builder and the owner of the rig are not sure what caused the accident and investigations are underway. Theories range from simple metal fatigue not discovered in routine inspections, to the snapping in a stormy sea of one of the anchor cables that secured the submerged pontoon legs to the ocean floor. The current and most likely theory is that a leg collapsed due to a crack originating from a hole created to hold a sensing device. Whatever the reason, the number killed in this single accident exceeded the 102 who have died in all deep-water oil exploration in the British sector of the North Sea since the mid-1960s (Downie 1980).

A gas drilling rig explosion about 100 miles southeast of Galveston took place just 3 days before the North Sea tragedy. Twenty-nine persons were injured and six were killed in this accident. Another rig explosion occurred recently about 110 miles southsoutheast nf Intercoastal City where a Marathon 0il Company drilling platform exploded and caught fire (The Washington Post 1980). There were no fatalitles, but several persons were injured. Although human error is blamed for most of these recent accidents, causal factors are still being investigated.

In July 1980 an offshore Chinese mobile oll rig exploded and collapsed in the Bohni. Gulf off China's east coast, killing 72 workers. The accident was attributed to failure to follow safety rules during movement of the rig in high winds. In addition, 1,043 other offshore accidents near China from 1975 to 1979 resulted in 105 deaths and 114 serious injuries (Mathews 1980).

U.S. offshore incidents have increased in recent years: In $1978,1,144$ wells were started in domestic waters and 58 incidents 
were reported. In contrast, 900 wells were started in 1970 and only 24 incidents were reported (Gillan 1980a). In spite of the recent increase, little is being done to collect data on offshore drilling rig accidents. Seeking information, MITRE contacted a number of private organizations--the American Petroleum Institute (API), International Association of Drilling Contractors (IADC), AFL-CIO, and the Offshore Rig Data Service--as well as government agencles, including the Occupational Safety and Health Administration (OSHA), Bureau of Labor Statistics (BLS), and the U.S. Coast Guard. Most of the private organizations do not segregate their data by drilling site, although the Coast Guard is making efforts in this direction. offshore RIg Data Service and IADC are the only organizations contacted that have some information in this area. Considering its data to be confidential, the latter makes its information available only to regulatory agencies or its own members. The former did supply some information which is summarized in the following section.

\section{Summary of Offshore Accidents}

In an attempt to comprehend the nature, type, and severity of accidents associated with offshore drilling rigs, a review of available data and information from various sources was conducted.

The data supplied by Offshore Rig Data Service (1980) covers 1955 to early 1980 and primarlly concens moblle rigs; few dara relate to fixed platforms. Five major types of accidents (based on their causes) are discernible from this data:*

- Blowouts/fires;

o. Structural/equipment fallure;

- Natural disaster damage (storms, hurricanes);

- Capsizings; and

- Miscellaneous (collisions, sinkings).

All types of accidents (except for blowouts) can occur in either of two operations: drilling or towing. However, capsizings and collisions seem to be more frequent during towing (capsizings also occur during preparations for towing) and most fires occur during drilling while the rig is still active. Generally, due to the necessity for frequent set-up, unfamillarity with the rig, and lack of ideal stability, mobile rigs are more susceptible to accidents than fixed platforms. During the drilling operation, the most disastrous

\footnotetext{
* This categorization is arbitrary and is designed to organize the available information. It should not, therefore, be considered a standardized classification.
} 
situation is a blowout, which can affect the rig and its occupants in several ways. Should the gas or product ignite after a blowout, the drilling rig could easily catch fire, resulting in total destruction. A blowout around a subsea wellhead could create sufficient aeration of the water to alter water density, causing the vessel to sink. An effect on jack-ups, or any rig permanently anchored to the bottom, would be scouring around mats, legs, or other bottom supports due to escaping gas, which could cause foundation fallure and subsequent rig damage. Table 5 shows the occurrence of these five types of accidents from 1955 to February 1980.

Over the 25-year period, 173 accidents were reported. The greatest percentage ( 38 percent) were attributable to natural disasters. About 27 percent resulted from blowouts or fires, and 22 percent from structural or equipment failure. Twelve injuries and 116 fatalities were reported during this period.

The data also reveal that accidents related to offshore mobile rigs have been steadily increasing since 1970. To a large extent this trend reflects an increase in activity by old and newly commissioned drilling rigs. Between 1949 and 1976 the offshore fleet grew from 1 to 345 operating rigs (Huff 1976). In September 1979 it had expanded to 512 vessels- -30 submersibles, 88 drillships and barges, 123 semisubmersibles and 271 jack-ups (Tubb 1979). By September 1980 this fleet has grown to 606 units (Trafford 1980).

Extrapolation of industry-wide accident rates from this information should be attempted with extreme caution because these data are for mobile rigs only. By nature of their activity, they are involved in accidents while moving off location or preparing to move.

The offshore fixed platform drilling industry can be a dangerous business, as indicated by a recent study that reported a high rate of fatalities for young men working on oil rigs in Louisiana. The study identified 205 occupational deaths among oil workers within a 6-year period (January 1973 to December 1978). Of those who died, about 1/3 were on land-based platforms, all were males, and a majority (about 57 percent) were under 30 years old. Around 66 percent of the deaths occurred on offshore platforms and 69 percent of the accidents took place during daylight hours. They occurred throughout the year with no seasonal or monthly predominance (Morbidity and Mortality Weekly Report 1980).

Trauma and drowning accounted for a majority of deaths ( 80 percent); $1 / 4$ th were attributable to workers belng struck by heavy objects; and about 21 percent resulted from tragic events such as explosions, fires, or helicopter crashes (Morbidity and Mortality Weekly Report 1980). 
TABLE 5

OFFSHORE RIG ACCIDENTS

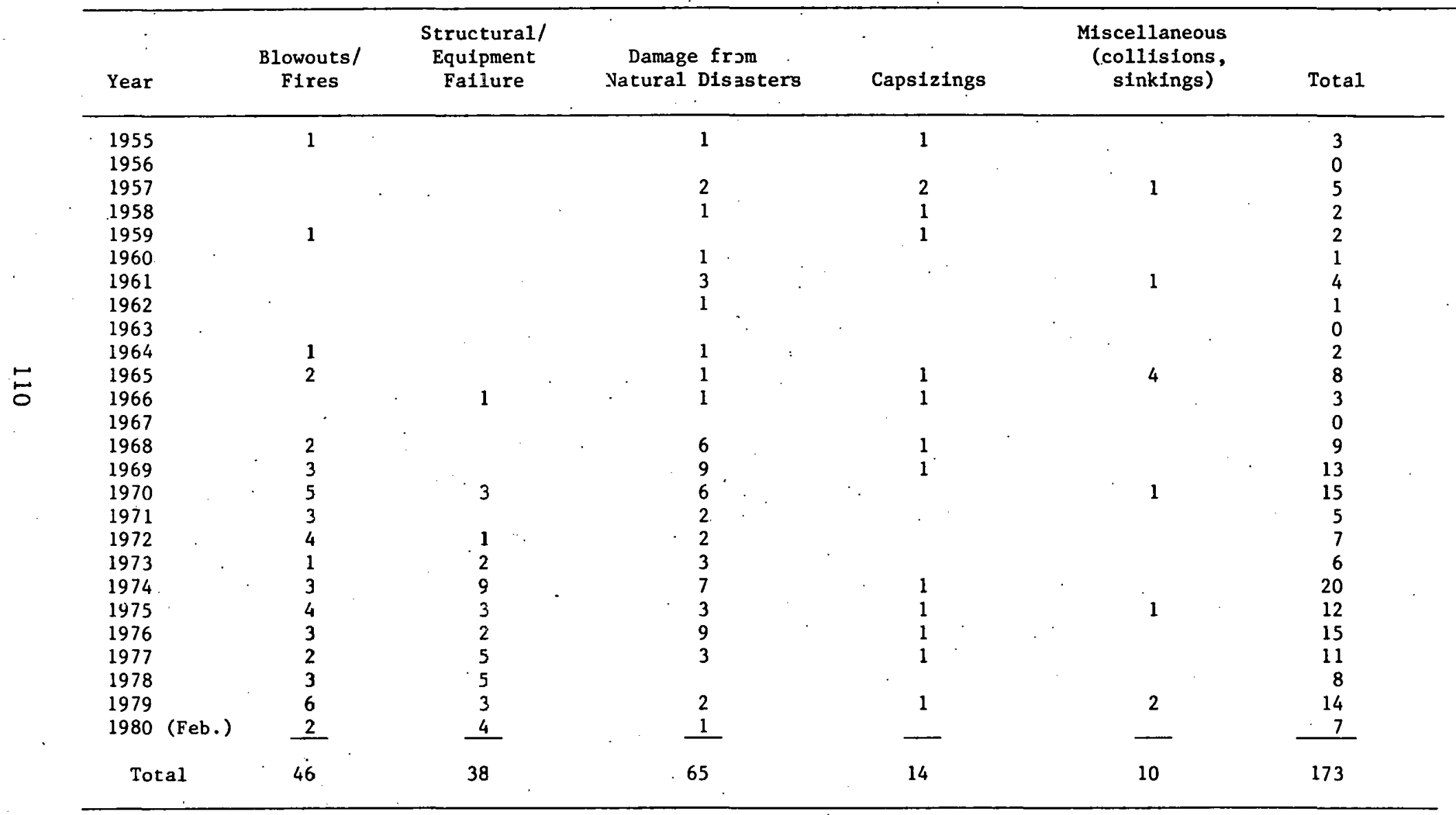

Source: Offshore Rig Data Service 1980, 
It is estimated that 25 percent of workers engaged 1 in o11 and gas. production in Loulsiana in 1978 worked full time on active oil rigs. The mortality rate for this group is estimated to be 188 to 235 per 100,000 workers per year. This compares to a mortality rate of 14 in 100,000 for all U.S. workers and 57 in 100,000 for those in construction, a relatively high risk industry (Morbidity and Mortality Weekly Report 1980).

\section{Offshore Safety Problems}

In the case of the North Sea accident involving the Alexander L. Kielland, the ofl companies spent millions of dollars installing safety precautions on the offshore rigs. Moreover, instructing workers in safety was a company priority (Boyne 1980). The Coast Guard, IADC, and the drilling industry attribute such accidents to human error. Most can be traced to people problems: lack of training, negligence, or a lapse in safety practices, even among workers who know better (Gillan 1980b). A preliminary analysis of the Loulsiana accidents indicated that factors contributing to a high rate of rig accidents include rapid turnover of personnel, lack of formal work training programs, and problems with regard to regulation of the industry (Morbidity and Mortallty Weekly Report 1980). Shell 011 Company statistics show that people problems were responsible for 75 percent of all lost-time accidents during offshore drilling and production. The other 25 percent resulted from a combination of personnel and equipment fallures. Even the causes of collapses are seldom beyond human control (Gillan 1980a).

Personnel turnover resulting from constant mobility of the rigs has been cited as one problem affecting personnel training. The accident rate is assumed to be higher with new employees. No hard data are available to substantlate this assumption, but records kept by the Ocean Drilling and Fxploration Company indicate that 68 percent of all lost-time injuries were sustalned by workers in their first 12 months of offshore duty (Gillan 1980a).

Illegal drug use by offshore workers 18 also considered to be responsible for accidents. Many petroleum and drilling companies have instituted ant 1-drug courses, conducted unannounced searches, and stalloned "sniffer" dogs on offshore rigs and platforms to seek out marijuana. After an anti-drug program was begun, some companies have reported 50 .percent declines in thelr accident rates, less employee turnover, and fewer losses from thefts. Use of alcohol 18 also believed to contribute to accidents (The Washington Post Magazine 1980).

Another factor contributing to poor safety records aboard drilling platforms is low morale. Freedom from boredom and good food can 
be expected to raise morale, while poor food, poor television reception and programming, and a lack of rapport with management could lower morale (The Washington Post Magazine 1980).

Irrespective of the human error factor and personnel training problems, both the Coast Guard and the International Association of Drilling Contractors have conceded that some drilling contractors have a poor safety record; however, because of high demand, they stay in business. The nation's energy crisis has forced operators to use drilling contractors they might ordinarily not use (Gillan 1980b). Drilling contractors are believed to have higher accident rates than company-owned rigs, but at present there is no way to check a contractor's safety record. Information can only be obtained from the firm or by listening to rumors in the petroleum industry. Nelther of these sources can offer dependable guidance in selecting the most crucial safety factor in offshore drilling--the drilling contractor.

Safety problems may be aggravated as countries with scant o11 exploration experience, such as those in Latin America and Africa, enter into the offshore drilling business. Experts caution that the underwater quest for petroleum may be accompanied by greater disasters before this decade is over (U.S. News and World Report 1980).

A change in the exploration environment has also been cited as a cause of offshore drilling accidents. Exploration now takes placé far from shore--a practice unheard of a few years ago. The North Sea disaster, for example, occurred 175 miles off the coast of Norway. Locating a rig that far from the coast makes rescue operations more difficult and places the rig in a harsher environment. Mobile rigs have drilled wells in water as deep as 4,876 feet (Smith 1979) and one fixed platform operates in 1,025 feet of water in the Gulf of Mexico (Ocean Industry 1980).

An emerging field of study relating to offshore safety is human factors engineering. This field concentrates on creating a workplace environment that is compatible with the entire spectrum of the workforce. The University of Oklahoma is examining the role of human factors engineering in drilling rig safety.

\section{Tanker Accidents*}

Tanker accidents may result not only in oil spills, but also in injuries, deaths, and property losses. Table 6 summarizes data

*In-depth coverage of transportation problems is provided in the Transportation and Storage section. 
TABLE 6

DEATHS $\Lambda$ ND INJURIES RESULTING

FROM TANKSHIP ACCIDENTS

\begin{tabular}{|lccc|}
\hline Accident Type & Number & Deaths & Injuries \\
\hline Breakdown & 4 & 5 & 53 \\
Collision & 26 & 259 & 130 \\
Explosion & 33 & 46 & 47 \\
Fire & 14 & 34 & 10 \\
Grounding & 0 & 0 & 0 \\
Ramming & 0 & 0 & 0 \\
Structura1 & 6 & 37 & 32 \\
failure & $\underline{0}$ & $\underline{381}$ & 0 \\
Other & 83 & 178 \\
Total & & 38 & 0 \\
\hline
\end{tabular}

Notes: For accidents involving vessels over 3,000 dwt. Deaths and injuries include those occurring on. other vessels or ashore as a result of the accident.

These data are from an analysis by the U.S. Coast Guard's Office of Merchant Marine Safety. They cover $3,71.5$ wnrl dwt.de tankship accidents from 1969 through 1973.

Source: Card et al. 1975. 
relating deaths and injuries to various types of accidents for 1971 to 1973. Most of the deaths and injuries were attributable to collisions and explosions (Card et al. 1975). The 381 deaths over a 3year period is not a large number compared to 1,500 persons killed in the U.S. each year in recreational boating accidents.

Data are presented in Table 7 which indicate the extent of damage to ships involved (Card et al. 1975). Of the 3,183 accidents, 73 percent caused only minor damage, while 15 percent resulted in no damage. Only 1.6 percent of the accidents resulted in total loss. The actual dollar amount of the damage or losses depends on repair or replacement costs, lost business revenues, increased insurance premiums, and other. factors for which no data were avallable.

Accident and damage descriptions for 47 of the 51 total losses are shown in Table 8. More than 1/3rd of the total losses were caused by structural failure and accounted for 44 percent of the oil outflow. Causes for the loss of structural integrity in the accidents are shown in Table 9 (Card et al. 1975).

\section{Pipeline Accidents *}

The occupational health hazards associated with pipeline accidents include fire and explosion with resulting injury and loss of life. Offshore oil and gas platforms are often connooted to shore by pipelines. These pipelines cross coastal. wetlands and uplands to connect with major transportation networks.

Liquid pipeline accidents caused approximately $\$ 3.2$ million in property damage, the loss of 7 lives, 15 injuries, and the loss of over 319,000 barrels of commodities during 1975 (offshore and onshore data are commingled). A summary of pipeline accidents for 1975 is shown in Table 10. A breakdown of accidents in terms of the commodity involved is shown in Table 11. It should be noted that, of the commodities lost as a result of accidents, crude oll represented 45.1 percent; gasoline, 28.3 percent; and liquified petroleum (LPG),

\footnotetext{
*In-depth coverage of oil and gas transportation is provided in the Transportation and Storage section.
} 
TABLE 7

EXTENT OF TANKSHIP LOSS OR DAMAGE

(1969-1973)

\begin{tabular}{|c|c|c|c|c|c|}
\hline Type of Involvement & $\begin{array}{l}\text { Total } \\
\text { Loss }\end{array}$ & $\begin{array}{l}\text { Heavy } \\
\text { Damage }\end{array}$ & $\begin{array}{l}\text { Light } \\
\text { Damage }\end{array}$ & $\begin{array}{c}\text { No } \\
\text { Damage }\end{array}$ & $\begin{array}{l}\text { Damage } \\
\text { Unknown }\end{array}$ \\
\hline Breakdown & 2 & 16 & 197 & 131 & 9 \\
\hline Collision & 7 & 64 & 570 & 78 & 25 \\
\hline Explosion & 11 & 30 & 52 & 10 & 1 \\
\hline Fire & 1 & 26 & 149 & 14 & 7 \\
\hline Grounding & 12 & 63 & 487 & 206 & 22 \\
\hline Ramming & 0 & 23 & 412 & 35 & 3 \\
\hline Structural failure & 15 & 39 & 445 & 2 & 14 \\
\hline Other & 3 & 1 & 1 & 0 & 0 \\
\hline Total & 51 & 262 & 2,313 & 476 & 81 \\
\hline
\end{tabular}

Source: Card et al. 1975. 
TABLE 8

ACCIDENT SEQUENCE FOR 47 TANKSHIP LOSSES ${ }^{\mathrm{a}}$.

(1969-1973)

\begin{tabular}{|c|c|c|c|}
\hline Accident Sequence & Number & $\begin{array}{l}\text { Oil Outflow } \\
\text { (long tons) }\end{array}$ & $\begin{array}{l}\text { Oil Outflow } \\
\text { (bbls) }\end{array}$ \\
\hline $\begin{array}{l}\text { Breakdown--structural } \\
\text { failure--sink }\end{array}$ & 1 & 16,350 & 123,933 \\
\hline $\begin{array}{l}\text { Breakdown--grounding-- } \\
\text { sink }\end{array}$ & 1 & 13,000 & 98,540 \\
\hline Collision--sink & 2 & 4,138 & 31,365 \\
\hline $\begin{array}{l}\text { Collision--explosion/ } \\
\text { fire--sink }\end{array}$ & 4 & 136,163 & $1,032,116$ \\
\hline Explosion/fire--sink & 12 & 90,030 & 682,427 \\
\hline $\begin{array}{l}\text { Grounding--explosion/ } \\
\text { fire--sink }\end{array}$ & 1 & 2,500 & 18,950 \\
\hline Grounding--sink & 9 & 134,726 & $1,021,223$ \\
\hline Flooding--sink & 2 & 54,669 & 414,391 \\
\hline $\begin{array}{l}\text { Structural failure-- } \\
\text { grounding--sink }\end{array}$ & 1 & 40,000 & 303,200 \\
\hline $\begin{array}{l}\text { Structural failure-- } \\
\text { sink }\end{array}$ & 14 & 282,519 & $2,141,494$ \\
\hline Total & 47 & 774,095 & $5,867,640$ \\
\hline
\end{tabular}

Note: Conversion factor--long tons $\times 7.85=\mathrm{bbls}$.

For tankships over 10,000 deadweight tons.

Source: Card et al. 1975. 
TABLE 9

DESCRIPTION OF T.OSS OF STRUCTURAL INTEGRITY FOR 47 TANKSHIP LOSSES $^{\mathrm{a}}$ (1969-1973):

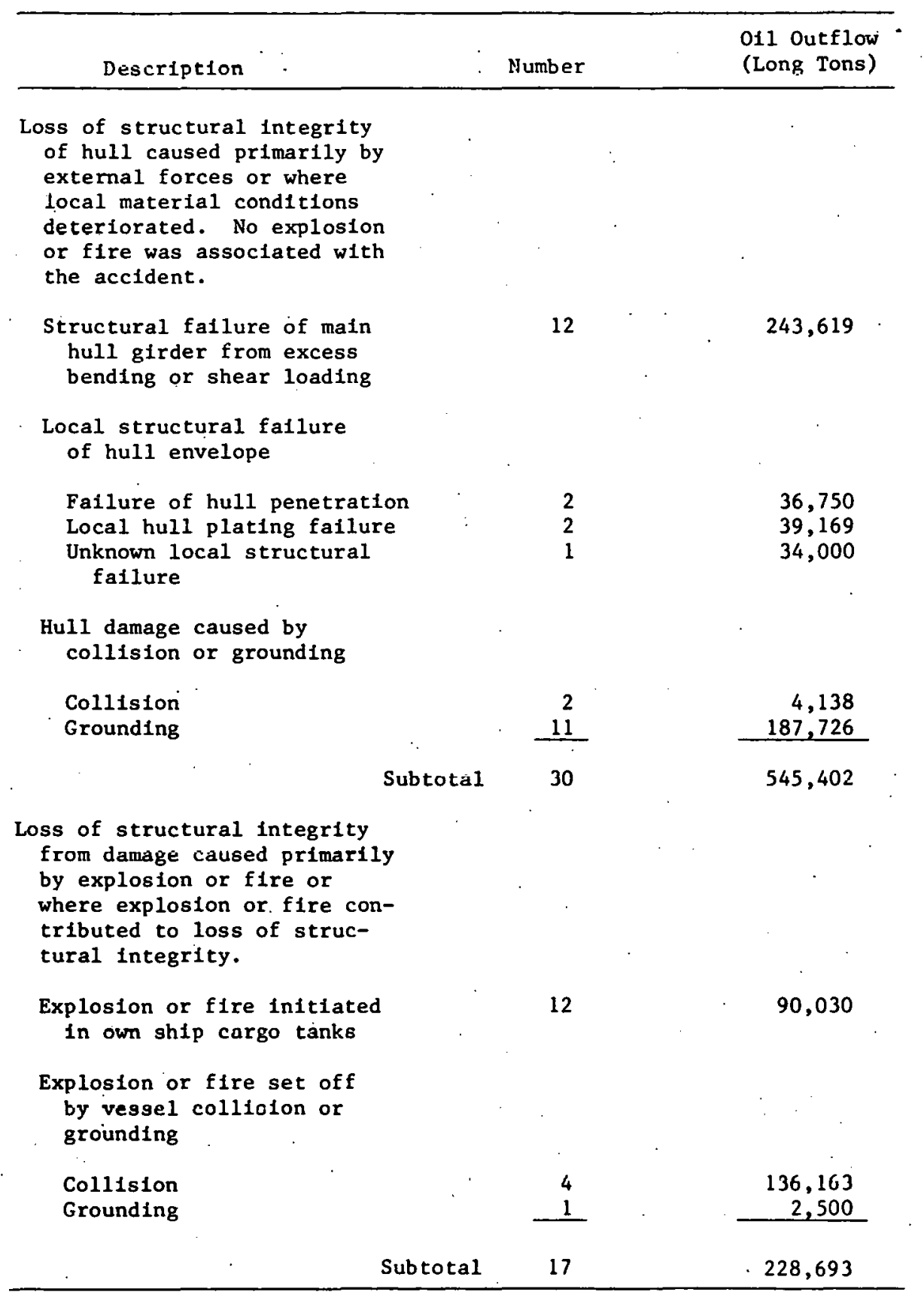

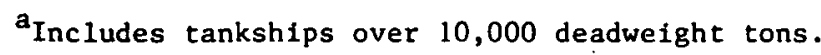

Sunice: Card ct al. 1975. 
TABLE 10

LIQUID PIPELINE ACCIDENT SUMMARY ${ }^{a}$

\begin{tabular}{|c|c|c|c|c|c|c|}
\hline \multirow{2}{*}{$\begin{array}{l}\text { Cause of } \\
\text { Accident }\end{array}$} & \multirow[b]{2}{*}{$\begin{array}{l}\text { Number of } \\
\text { Accidents }\end{array}$} & \multirow[b]{2}{*}{$\begin{array}{c}\text { Percent of } \\
\text { Total }\end{array}$} & \multicolumn{2}{|c|}{ Deaths } & \multicolumn{2}{|c|}{ Injuries } \\
\hline & & & $\begin{array}{l}\text { Carrier } \\
\text { Employees }\end{array}$ & $\begin{array}{c}\text { Non- } \\
\text { Employees }\end{array}$ & $\begin{array}{l}\text { Carrier } \\
\text { Employees }\end{array}$ & $\begin{array}{c}\text { Non- } \\
\text { Employees }\end{array}$ \\
\hline Equipment rupturing & & & & & & \\
\hline line & 75 & 28.6 & 0 & 0 & 0 & 1 \\
\hline Corrosion--external & 57 & 22.4 & 0 & 0 & 0 & 0 \\
\hline Equipment failure & 27 & 10.6 & 3 & 0 & 3 & 0 \\
\hline $\begin{array}{l}\text { Incorrect operation } \\
\text { by carrier personnel }\end{array}$ & 22 & 8.6 & 0 & 0 & 0 & 0 \\
\hline Corrosion--internal & 16 & 5.9 & 0 & 0 & 0 & 0 \\
\hline Defective pipe seam & 19 & 5.9 & 0 & 0 & 0 & 0 \\
\hline Defective girth weld & 5 & 2.0 & 0 & 0 & 0 & 0 \\
\hline $\begin{array}{l}\text { Failure of previously } \\
\text { damaged pipe }\end{array}$ & 4 & 1.6 & 0 & 4 & 0 & 9 \\
\hline Vandalism & 4 & 1.6 & 0 & 0 & 0 & 0 \\
\hline $\begin{array}{l}\text { Failure of previous } \\
\text { weld repair }\end{array}$ & 2 & 0.7 & 0 & 0 & 0 & 0 \\
\hline Lightning & 2 & 0.7 & 0 & 0 & 0 & 0 \\
\hline Miscellaneous & 29 & 11.4 & $\underline{0}$ & $\underline{0}$ & $\underline{0}$ & $\underline{2}$ \\
\hline Total & 262 & 100.0 & 3 & 4 & 3 & 12 \\
\hline
\end{tabular}

a For January 1, 1975 through December 31, 1975.

Source: U.S. Environmental Protection Agency 1977. 
TABĪE 11

PIPELINE ACCIDENT SUMMAZY BY COMMODITY INVOLVED

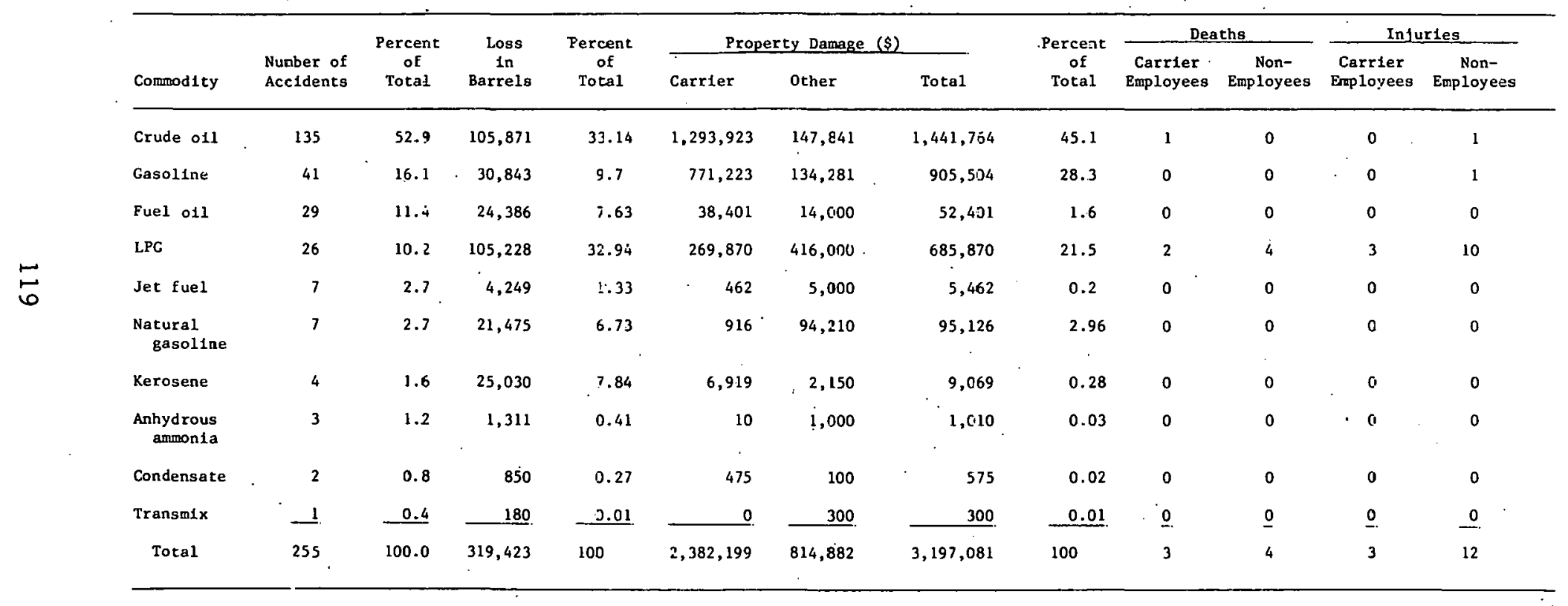

Source: U.S. Envidronmental Protection Agency 1977. 
21.5 percent. Accidents involving LPG accounted for 86 percent of the deaths and 87 percent of the injuries.*

Approximately 43 percent of the 78 accidents caused by equipment rupturing were the result of bulldozer, grader, and ditching machine operation. Of these 78 accidents, 47 percent involved the following activities :

- Pipeline and cable construction (12 accidents, 16.4 percent);

- Moving earth by commercial firms or local government (11 accidents, 15.1 percent); and

- Clearing or grading private land (11 accidents, 15.1 percent).

Although the bulk of these accidents relate to land-based ofl and gas transportation, hazards relating to these causes of accidents also exist for offshore pipelines crossing shallow bogs, coastal wetlands, and coastal upland areas. Often, longshore flatlands serve as transportation corridors, with railroads, gas and oil pipelines, water and sewage lines, electric lines, and burled telephone lines.

\footnotetext{
*Injury and fatality statistics are always subject to discrepancies due to non-uniform or incomplete reporting. Statistics quoted in this section come from the U.S. Department of Transportation (DOT). and are based on DOT 7000-1 forms filed during 1975. The American Petroleum Institute (API) also has published data for 1975 based on Information collected from 137 oil and gas companies and their subsidiaries. The API data are for the entire industry and are further divided by function (e.g., exploration and production, drilling, pipeline-crude, and products). Comparison of the appropriate API and DOT data for pipeline (crude and liquid) shows significant differences between the two sets of data:
}

$\begin{array}{lcc}\text { Injuries (108t-time) } & \frac{\text { API }}{\text { DOT }} & \begin{array}{c}15 \text { employee and } \\ \text { non-employee }\end{array} \\ \text { Fatalities } & 754 & \begin{array}{c}7 \text { employee and } \\ \text { non-employee }\end{array}\end{array}$

The API fatalities include tank truck accidents while the DOT figures apparently do not. 
The potential exists for compounding the dangers inherent in each of these transportation systems.

The DOT statistics also showed that 78 percent (57) of the corrosion-caused accidents were due to external corrosion. This would be expected to occur with old plpelines since newer ones generally have protective coatings and cathodic protection. Seventy-two percent were in equipment installed between 1920 and 1949 (Table 12). However, 75.5 percent involved lines with cathodic protection. External corrosion accidents accounted for approximately $\$ 115,800$ in property damage, but resulted in no deaths or injuries. Two-thirds of external corrosion accidents involved crude oil in the pipeline, while the remainder involved gasoline ( 15.8 percent); fuel o11 ( 12.3 percent); and jet fuel, furnace oil, and transmix (5.3 percent).

Pipeline spills were the second largest source of oll pollution in coastal waters (Boesch et al. 1974). In 1971, 1,436 leaks spilled 897,685 gallons. An evaluation of spill data indicates approximately 90 percent of offshore spills and 97 percent of all oll spilled comes from pipelines leading to wells less than three miles offshore. Most of the pipeline spillage results from the failure of old pipelines.

Pipeline accidents are caused by a number of factors, including equipment rupturing lines, internal and external corrosion, structural defects (seams, welds, repairs), human operating errors, vandalism, and natural causes. According to the U.S. Department of Transportation's office of Pipeline Safety Operations, equipment rupturing lines (28.6 percent) and external corrosion (22.4 percent) accounted for about half of the accidents during 1975 (U.S. Department of Transportation 1976). These accidents caused an estimated $\$ 757,500$ in property damage and a loss of 120,797 barrels of o1l, or 38 percent of the total oil lost in pipeline accidents.

Public Health and Safety Considerations

This section considers public health and safety issues which may result from the development of offshore oll and gas reserves. Under most circumstances, it can be assumed that any adverse human health ef fects associated with development drilling, well completion, and production operations were experienced primarily by workers involved with these operations. However, the potential does exist for the general public to be adversely affected by these operations. The location of offshore oll and gas activities, their proximity to urban areas, and local atmospheric transport processes must be considered.

Atmospheric emissions associated with offshore transportation operations may be considerable, although it is believed that the Impact can be greatly reduced with proper controls on tankers and 
TABLE 12

PIPELINE ACCIDENTS

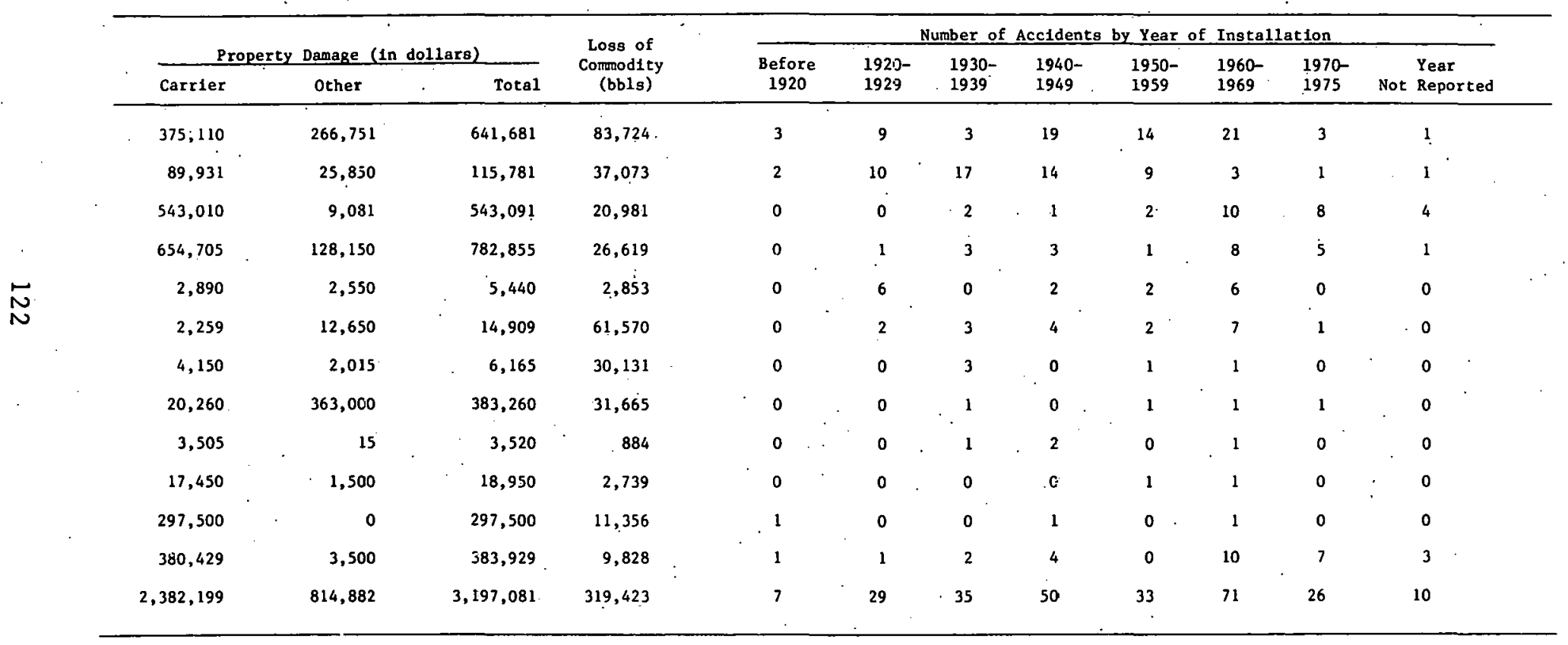

Source: U.S. Enví1ronmental Prutection Agency 1977. 
operational procedures (Brown 1977).* The majority of tanker emissions are escaping hydrocarbon ( $H C$ ) vapors from on-board storage tanks and nitrogen oxides $\left(\mathrm{NO}_{\mathrm{x}}\right)$, sulfur oxides $\left(\mathrm{SO}_{\mathrm{x}}\right)$, carbon monoxide ( $\mathrm{CO}$ ), and particulate matter from stack emissions during the offloading procedure. (The offloading procedure involves using a tanker's on-board engines at about 80 percent of full power to pump the crude to shore and lasts 10 to 12 hours for tankers in the 80,000 to 165,000 dwt class.)

Estimates based on the SOHIO project, a once-proposed major terminal for handling Alaskan crude (involving approximately 270 tanker visits per year), indicate that, on a yearly basis, $\mathrm{SO}_{\mathrm{x}}$ emissions could range from 220 tons per year to 880 tons per year. The ranges are based on differences in the sulfur content ( 0.5 to 2 percent) of the fuel. If transit time in the port vicinity is included, the range would be from 500 to 2,000 tons per year. It is evident that requiring low sulfur fuel to be burned near or in port greatly reduces these emissions. Emissions of nitrogen oxides are estimated to range from 120 tons per year to 210 tons per year, again depending on whether transit time is included. Carbon monoxide and particulate emissions are minimal and are not expected to result in serious public health problems (Brown 1977). Particulates are estimated to be 40 tons per year and Co emissions have not been calculated.

The outstanding issue is that of hydrocarbon emissions which, with $\mathrm{NO}_{\mathrm{x}}$, are precursors for the formation of oxidants. Generally, most hydrocarbon emissions in or near port are associated with tankers not containing segregated ballast systems. Most of these vessels are small (less than 75,000 dwt in size). Because of their shallow draft, these small tankers are the only ships that can serve many U.S. ports (Table 13).

The operations of ballasting in non-segregated ballast tankers and tank cleaning (purging) both may involve the release of large quantities of hydrocarbons. For tankers with fully segregated ballast, no hydrocarbon ballasting emisstons would occur. Similarly, if tank cleaning is not performed in port, no hydrocarbon effluents will. occur. The range of hydrocarbon estimates is, therefore, extremely large, reflecting different assumptions as to the operations to be performed and the types of tankers. For the soHIn project, the yearly estimates have run from essentially zero hydrocarbon emissions to as high as 10,000 tons per year. The lower figure represents

\footnotetext{
*Additional information on the health effects of deep water ports is provided in the Transportation and Storage section of this report.
} 
TABLE 13

CHARACTERISTICS OF MAJOR U.S. TANKER PORTS (1974)

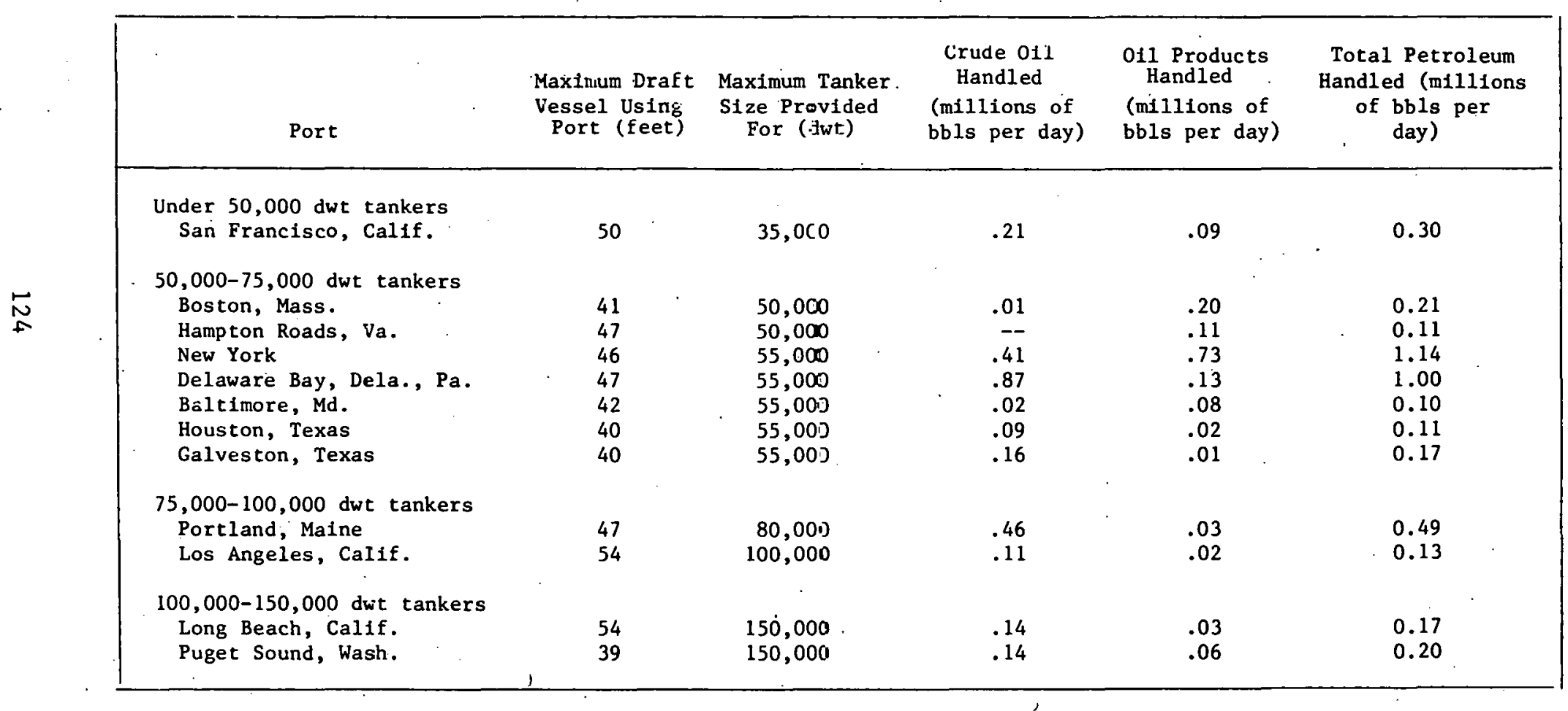


fully segregated ballast tankers and no release of hydrocarbons to the atmosphere from tank cleaning operations. The latter figure represents emissions that could occur if tank cleaning took place while in port and also along the coast near port. Table 14 compares the SOHIO estimated yearly emissions with emission rates that define new "major" air pollution sources--those that would be subject to emission offsetting requirements if they exacerbate a violation of a National Ambient Air Quality Standard. The State of California has been especially sensitive to these emissions as they would affect oxidant problems in southern California. In addition, all tanker stack emissions may contribute significantly to air quality degradation in or near ports.

The human health effects associated with photochemical oxidants $\left(\mathrm{e} . \mathrm{g} ., \mathrm{NO}_{\mathrm{x}}, \mathrm{SO}_{\mathrm{x}}\right.$ ) and airborne organics are not well understood, but it is known that photochemical oxidants in combination with specific airborne organics, such as the polycyclic aromatic hydrocarbons, have induced cancers and pulmonary adenomas (Stokinger and Coffin 1968; Laskin et al. 1970). Atmospheric oxidants also have been shown to initiate the carcinogenic action of this same class of hydrocarbons (Ayers and Buehler 1970; Altshuller and Beualini 1971). Thus, the development of offshore oil and gas reserves may result in atmospheric emissions that adversely affect public health.

In addition, potential adverse health effects may occur as a result of the separation of dissolved natural gas from crude o1l. If separation occurs at the offshore production site, the working and nearby general population may be affected since toxic hydrogen sulfide $\left(\mathrm{H}_{2} \mathrm{~S}\right)$ may be associated with natural gas. The percentage of $\mathrm{H}_{2} \mathrm{~S}$ by volume of gas has been reported as ranging from 0 percent to 35 percent (Leggett and Williams 1979). If the gas is processed rather than flared, the toxic $\mathrm{H}_{2} \mathrm{~S}$ component must be removed. In addition to accidental release of gas prior to $\mathrm{H}_{2} \mathrm{~S}$ removal, another public concern involyes disposal of $\mathrm{H}_{2} \mathrm{~S}$ after separation. An estimated 250 million $\mathrm{ft}^{3}$ per year of gaseous $\mathrm{SO}_{\mathrm{x}}$ or $\mathrm{H}_{2} \mathrm{~S}$ are vented to the atmosphere each year in the U.S. from flares and fugitive losses, assuming that natural gas contains 0.5 mole percent sulfur (Wilkins 1977).

0il spills resulting from offshore oil and gas operations may also present public health problems. Potentially carcinogenic compounds, such as polynuclear aromatic hydrocarbons, are released during an oil spill. In a volatile state these may be inhaled, or as a liquid they may be concentrated in the body tissues of fin fish and filter feeding organisms such as clams and oysters near the spill. The nearby human population may be adversely affected by consuming the oil-contaminated marine biota which have incorporated these potentially carcinogenic compounds (IMCO et al. 1977). 
TABLE 14

YEARLY EMISSIONS ESTIMATES

FROM ALASKAN CRUDE TANKERS AT PORT OF LONG BEACH

\begin{tabular}{|c|c|c|c|}
\hline & \multirow{2}{*}{$\begin{array}{l}\text { EPA Guidelines } \\
\text { (tons/year) }\end{array}$} & \multicolumn{2}{|c|}{$\begin{array}{c}\text { Estimates from SOHIO Project } \\
(270 \text { visits } / \text { year })^{b}\end{array}$} \\
\hline & & Port Only & Port \& Transit \\
\hline Particulates & 50 & 40 & 60 \\
\hline so $_{x}$ & 50 & $220^{c}-880^{d}$ & $500^{c}-2,000^{d}$ \\
\hline $\mathrm{NO}_{\mathbf{x}}$ & 50 & 120 & 210 \\
\hline $\mathrm{HC}$ & 50 & $0^{e}-7,000^{f}$ & $0^{e}-10,000^{f}$ \\
\hline $\mathrm{CO}$ & 500 & \multicolumn{2}{|c|}{ Negligible } \\
\hline
\end{tabular}

aGuidelines for defining a "major" source in effect at the time of SOHIO (Alaskan crude) environmental impact statement review.

bnly large tankers considered (100 visits, 80,000; 73 visits, 120,000; 9.7 visits, 165,000).

CAssumes a fuel sulfur content of 0.5 percent.

dAssumes a fuel sulfur content of 2.0 percent.

ENo ballasting or tank cleaning (purging) assumed.

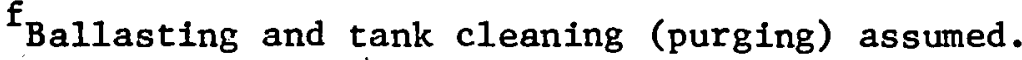


Another obvious effect of oil spills is the loss of aesthetic resources due to oil residue on beaches. Deposits of tar and other petroleum residues, whether from ofl spills or tanker cleaning operations, may present public health concerns. Acute toxicity may result from swallowing oil or, as mentioned, from inhaling petroleum fumes (National Academy of Sciences 1975). These problems tend to be local in nature, but may be significant in certain coastal urban areas.

The development of offshore oil and gas reserves is not expected to Interfere, to any great extent, with public safety. However, accidents directly affecting ofl and gas workers such as blowouts, toppling of platforms, and tanker collisions may also affect members of the general public who happen to be near the accident.

Summary of Research Needs

Health Effects Data

Some health effects data for the petroleum industry are reported for operations subject to OSHA recordkeeping requirements. The data include the number of employees, hours worked, recordable injuries and illnesses, incident rates for fatalities, and information on lost workdays and restricted activity. These data are reported by Standard Industrial Classifications (SIC; U.S. Office of Management and Budget 1972). With respect to drilling (SIC 1381) and exploration and production operations (SIC 1311), data from both onshore and offshore drilling rigs are commingled.

Onshore and offshore activities have diverged markedly over the last decade with respect to the nature and extent of risks. This is especially true as offshore exploration and production move into the. deeper waters of the outer continental shelf.

An information gathering and reporting infrastructure is needed for separation of the data. More explicit data are also needed with respect to the nature and extent of illnesses and diseases. This information would be useful in retrospective epidemiological studies.

Offshore Platform Information Needs

From the above discussion it is evident, not only that more rescarch is needed in the field of offshore drilling, but also that data collection activities should be streamlined. The U.S. Coast Guard has expressed its concern in this area by conceding that it is aware of a number of offshore oil and gas drilling companies with poor safety records, but a lack of documentation has prevented them from correcting potentially dangerous situations (Gillan 1980b). 
More stringent and explicit OSHA regulations dealing with worker safety on offshore drilling rigs would also be required to investigate the risks involved in the offshore drilling industry. The specific areas that need attention are:

- Offshore accident data should be segregated from onshore data.

- Offshore drilling rig accident data should be segregated from accidents involving tankers and platforms.

- More effective personnel and site-specific training programs should be devised.

- Effective anti-drug programs should be instituted. (Most companies are doing it on their own. These programs should be screened and made mandatory for all companies involved in offshore drilling.)

- Marijuana, unlike heroin and alcohol, leaves no telltale traces in urine. Experimental work is underway by American Medical Laboratories, Inc., Involving the use of radioisotopes for identification, but such analyses are costly and time consuming and the results are uncertain. Low cost tests should be developed that will quickly detect the presence of marijuana under field (drilling or production platform) conditions.

- Advanced research dealing with ocean bottom topography as related to pontoon anchors is needed.

- Research dealing with ocean weather forecasting should be accelerated.

- Research is needed in the design of safer, more rellable offshore drilling equipment. Of particular importance is the development of equipment that does not distract workers with undue noise.

- Increased research in human factors engineering with respect to minimizing accidents in offshore development that are caused by human error.

- Techniques should be devised for sharing U.S. knowledge and experience with relatively inexperienced countries.

- Last, but not least, standardized accident reporting procedures should be instituted. 
Concerned government agencies, industry, and trade associations should pool their resources and fund as much research as possible in these areas. As energy consumption rises, marine areas of the world are becoming prime exploration targets for the international oil. industry. In 1976, 20 percent of the western world's crude production came from offshore areas, but currently over 30 percent of production is derived from beneath the ocean,' largely in coastal waters. Since offshore drilling will be a major energy source in the years ahead, efforts should be made to make it as safe and efficient as possible. These efforts should include collecting detalled data and creating the infrastructure necessary for processing the information.

\section{Effects of Drilling Muds}

As is the case with onshore oil and gas development, a study is needed to define possible health effects associated with the use of drilling muds. Documentation is needed on the frequency and duration of worker exposures to the various formations of drilling muds. The study should include a retrospective epidemiological survey, possibly using data on workers in the Gulf Coast Basin, compared with bioassay information on the toxicity of various drilling muds, to assess the potential health risks. This information may be used to establish guidelines for handling and using drilling muds on offshore platforms.

\section{Offshore Terminals}

As oil and gas development moves farther offshore, complex terminals will be needed for production, storage, support, and/or loading and offloading. The effects that air emissions from such terminals have on occupational health and the health of the urban public are unknown. These are isolated sources of complex emissions, not subjecl to interactions with emission from other industries. In addition, the effect of possible transformation products from the interaction of these emissions and background environmental factors, including sea state and air-water interface conditions, should be explored.

\section{Coastal Pipelines}

As coastal ofl and gas development expands, pipelines will need to cross coastal areas to deliver crude to storage areas or distribution systems. Techniques should be developed and tested to minimize the negative impact of constructing and maintaining these pipeline systems. Finally, agents should be developed to decrease the volatility of oil spilled from pipeline breaks and during of floading. 


\section{THIS PAGE \\ WAS INTENTIONALLY \\ LEFT BLANK}


ECOLOGICAL EFFECTS OF OFFSHORE DEVELOPMENT

Environmental impacts will result from developing offshore oll and gas resources. Concerns related to fish and wildlife and their habitats are most significant for large offshore o1l and gas development projects, including exploration and production drilling, pipelaying, and oil transfer and transport.

\section{Exploratory Surveys}

The actual operation of an offshore oll and gas survey vessel is similar to that of a commercial fishing ship. Thus, the vessels are not expected to harm the aquatic system. However, seismic surveying techniques--using contained detonations of a propane and oxygen mixture or high-powered oscillators to generate sound waves-may result in adverse impacts on resident or migratory biota.

Clark et al. (1978) wrote that seismic surveys offshore in deep waters do not affect living resources, if they are conducted as specified in established regulations. Before modern techniques were perfected, surveyors frequently used dynamite, which caused fish kills; however, modern selsmic techniques have not caused any documented adverse impacts to living systems (Clark et al. 1978).

Experimental data on biological effects resulting from underwater explosions are summarized in Table 15. Mortality and injury of aquatic organisms depend primarily upon the charge weight, type of explosive, kind of organism, and the organism's proximity to the point of explosion. For example, a straight-line relationship was found between the percentage of fish fatalities and the distance from the charge (Chesapeake Biological Laboratory 1948). However, Fitch and Young (1948) reported an inverse relationship between injury to fish and the cube of the distance from the charge. They found that fish 10 feet from the explusiun could receive about eight timcs the force of shock as those 20 feet away. Hubbs and Rechnitzer (1952) reported that, in contrast to high explosives, black powder explosions (charges between 20 and 45 pounds) in the bottom sediments, on the bottom surface, or near the water surface had no adverse effects on fish.

It generally has been accepted that fish with swim bladders are more vulnerable to underwater explosions than those without swim bladders (Alpin 1977; Crutchfield 1969; Young 1973). The data presented in Table 16 show that the swim bladder is by far the most vulnerable organ for striped bass, trout, and croakers. 
TABLE 15

EFFECTS OF UNDERWATER EXPLOSIONS ON AQUATIC ORGANISMS

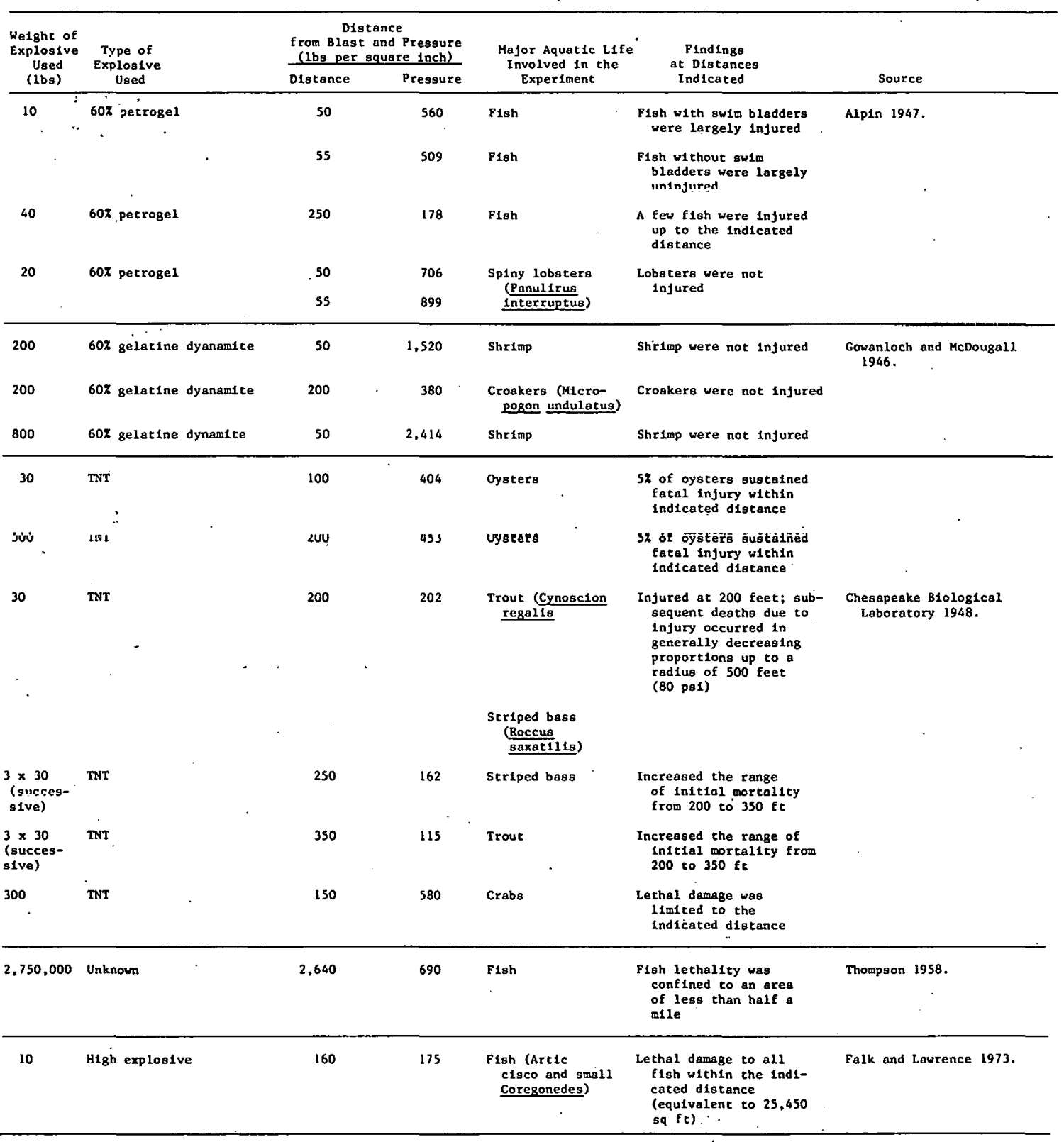


TABLE 16

FREQUENCY OF REPORTED DAMAGE TO FOUR FISH ORGANS

\begin{tabular}{|c|c|c|c|c|}
\hline \multirow[b]{2}{*}{ Species } & \multicolumn{4}{|c|}{ Organ } \\
\hline & Swim Bladder & Liver & Spleen & $\begin{array}{l}\text { Abdominal } \\
\text { Vein }\end{array}$ \\
\hline$\frac{\text { Rock }}{\text { (striped bass) }}$ & $\begin{array}{c}81 \text { of } 83 \\
(98 \%)\end{array}$ & $\begin{array}{c}11 \text { of } 83 \\
(13 \%)\end{array}$ & $\begin{array}{c}24 \text { of } 83 \\
(29 \%)\end{array}$ & $\begin{array}{c}33 \text { of } 83 \\
(40 \%)\end{array}$ \\
\hline Trout & $\begin{array}{c}135 \text { of } 145 \\
(93 \%)\end{array}$ & $\begin{array}{c}20 \text { of } 145 \\
(14 \%)\end{array}$ & $\begin{array}{c}19 \text { of } 145 \\
(13 \%)\end{array}$ & $\begin{array}{c}92 \text { of } 145 \\
(63 \%)\end{array}$ \\
\hline Croaker & $\begin{array}{c}12 \text { of } 13 \\
(92 \%)\end{array}$ & $\begin{array}{c}11 \text { of } 13 \\
(85 \%)\end{array}$ & $\begin{array}{c}6 \text { of } 13 \\
(46 \%)\end{array}$ & $\begin{array}{c}3 \text { of } 13 \\
(23 \%)\end{array}$ \\
\hline
\end{tabular}

${ }^{a}$ Includes all cases of fish injury.

Source: Chesapeake Biological Laboratory 1948. 
Benthic organisms also may be damaged when an explosion takes place on the ocean floor. It is estimated that the disturbed area is approximately equal to twice the width of the crater (Young 1973).

Plumes, composed primarily of fine-grained sediments, accompany most of the explosions taking place on or in the ocean floor. It has been reported that the turbidity produced by underwater explosions in the West Cove near Cross Cay Island, Puerto Rico, decreases to a normal level of transparency within 2 hours after the blasts (Brown and Smith 1972). The explosives consisted of 4,000 pounds of $\mathrm{C}-4$, which is 1.34 times more powerful than TNT on a welght-to-weight basis.

Searching for ways to minimize or eliminate harmful or irreversible environmental effects, several agencles have initiated firing programs. The Naval Ordnance Laboratory Field Branch (NOLFB), Solomons, Maryland, has performed underwater explosion tests since 1944 (Green and Davidson 1969). These experiments include tests with mines, torpedoes, depth charges, and phenomenological studies of special or new explosives. The laboratory uses three testing sites in the Patuxent River and one in the Chesapeake Bay. As a general rule, firings are prohibited in areas known to be favored fish habitats. For example, at the Patuxent River sites with a 40-foot water depth, firing is permitted during the entire year. In contrast, testing at shallower depths is permitted only hetwoen April and Nuvember. In the Chesapeake Bay, no firing is allowed during December, January, and February, and sometimes during March. These critical periods colncide with the maximum concentration of fish and, therefore, with maximum probable damage to them. The least probable damage would be caused by underwater explosions performed during June, July, and August, when fish are more dispersed.

Table 17 shows NOLFB data on mortalities resulting from underwater explosions between 1958 and 1972. In most instances, more nonedible $f i s h$ then edible $f$ ish were killed during the experiments (most fish in the bay are not utilized for food). The average fish mortality (in pounds) per pound of explosive ranged from 0.698 in 1960 to 0.027 in 1972. The averages recorded between 1966 and 1972 were considerably lower than those for the previous period (1958 to 1965). This would indicate that, when a smaller amount of explosive is used per shot, the damage to fish can be substantlally decreased.

Knowledge of the behavioral patterns of aquatic life is used in timing blasts to minimize impact. In addition, several methods have been suggested for driving fish away from the blast area. For example, radio broadcasts, pulsed electric currents, underwater sound, and underwater structures and lights are the methods most of ten used to attract fish to another location. Air bubble curtains, nets, 
TABLE 17

FISH MORTALITY DATA ${ }^{a}$

\begin{tabular}{|c|cc|rrr|rr|}
\hline \multirow{2}{*}{ Year } & Explosives Fired & \multicolumn{3}{|c|}{ Fish Killed } & $\begin{array}{c}\text { Average Mortality } \\
\text { Relative to } \\
\text { Explosions }\end{array}$ \\
\cline { 2 - 7 } & $\begin{array}{r}\text { Tota1 Welght } \\
\text { (1bs) }\end{array}$ & $\begin{array}{c}\text { Number of } \\
\text { Shots }\end{array}$ & $\begin{array}{r}\text { Edible } \\
\text { (1bs) }\end{array}$ & $\begin{array}{r}\text { Non-Ed1ble } \\
\text { (1bs) }\end{array}$ & $\begin{array}{c}\text { Total } \\
(1 \mathrm{bs})\end{array}$ & $\begin{array}{c}\text { (1bs/shot) } \\
(1 \mathrm{bs} / 1 \mathrm{~b})\end{array}$ \\
\hline 1958 & 19,000 & 44 & 613 & 7,107 & 7,720 & 175.0 & 0.406 \\
1959 & 9,000 & 70 & 247 & 4,003 & 4,250 & 60.7 & 0.472 \\
1960 & 22,000 & 65 & 807 & 14,553 & 15,360 & 236.0 & 0.698 \\
1961 & 12,000 & 195 & 312 & 6,218 & 6,520 & 33.4 & 0.543 \\
1962 & 14,000 & 45 & 561 & 2,069 & 2,630 & 58.4 & 0.188 \\
1963 & 13,000 & 42 & 291 & 1,529 & 1,820 & 43.3 & 0.140 \\
1964 & 16,000 & 82 & 290 & 5,070 & 5,360 & 65.4 & 0.335 \\
1965 & 36,000 & 272 & 640 & 11,470 & 12,110 & 44.5 & 0.336 \\
1966 & 34,000 & 53 & 556 & 2,304 & 2,860 & 54.0 & 0.084 \\
1967 & 35,000 & 178 & 275 & 995 & 1,230 & 6.9 & 0.035 \\
1968 & 42,000 & 209 & 1,200 & 100 & 1,300 & 6.2 & 0.031 \\
1969 & 27,330 & 279 & 991 & 6,583 & 7,574 & 27.1 & 0.277 \\
1970 & 17,107 & 151 & 1,036 & 1,064 & 2,100 & 13.9 & 0.123 \\
1971 & 5,928 & 143 & 575 & 1,001 & 1,576 & 11.0 & 0.266 \\
1972 & 18,505 & 70 & 170 & 337 & 507 & 7.24 & 0.027 \\
\hline
\end{tabular}

a Data from the Naval Ordnance Field Branch, Solomons, Maryland.

Source: Young 1973. 
chemicals, pulsed electrical currents, and radio broadcasts are commonly used to disperse or repel fish from the blast area.

In particularly hostile environments such as the Beaufort Sea and other areas of the Arctic Ocean, where it is difficult to obtain reliable acoustic measurements, it may be more environmentally desirable to use large dynamite charges to obtaln good selsmic readings. Repeated use of low intensity shocks by propane charges or electric oscillations to obtain good data may be more stressful on biota than a single large charge. This is an area which warrants additional research.

\section{Exploratory Drilling}

Offshore exploratory drilling operations for ofl and gas are normally conducted from mobile platforms (e.g., barges, drill.ships, jack-ups). The actual operation of the mobile unit 18 not expected to result in adverse environmental effects. However, impacts may result from the drilling process.

Direct environmental impacts, such as the removal of benthic substrate by floor sampling and corlng, and the addition of drill cuttings and other discharges from the drilling rig to the ocean floor, may result in adverse effects on indigenous biota. The removal of benthic substrate or the addition of drill cuttings may result in the destruction of benthic organisms' habitats. In general, the arditinn of drill cuttings and other anthropogenic material will increase turbidity, eutrophication, and toxification of the aquatic system. These types of impacts may interfere with either indigenous organisms (e.g., plankton, benthos, fish) or migratory fish.

During any drilling operation, there is also the potential for a blowout to occur. Blowouts, which cause loss of control over the well, are extremely hazardous and would result in adverse effects on the ecosystem.

\section{Drilling Muds}

Exploration and well completion activities in the marine environment utilize drilling fluids or "muds" (Table 18). The use of these materials can result in a range of physical, chemical, and biological effects (Figure 11). The areas of greatest concern are that: the muds may be acutely toxic or may produce deleterious sublethal responses in sensitive marine species; and metals and organic compounds present in some drilling fluids may accumulate in marine organisms to concentrations that would harm marine life or human consumers of fishery products (Neff 1980; Richards 1979). Federal agencies and industrial interests have sponsored many laboratory and 
TABLE 18

COMMON DRILLING FLUID COMPONENTS

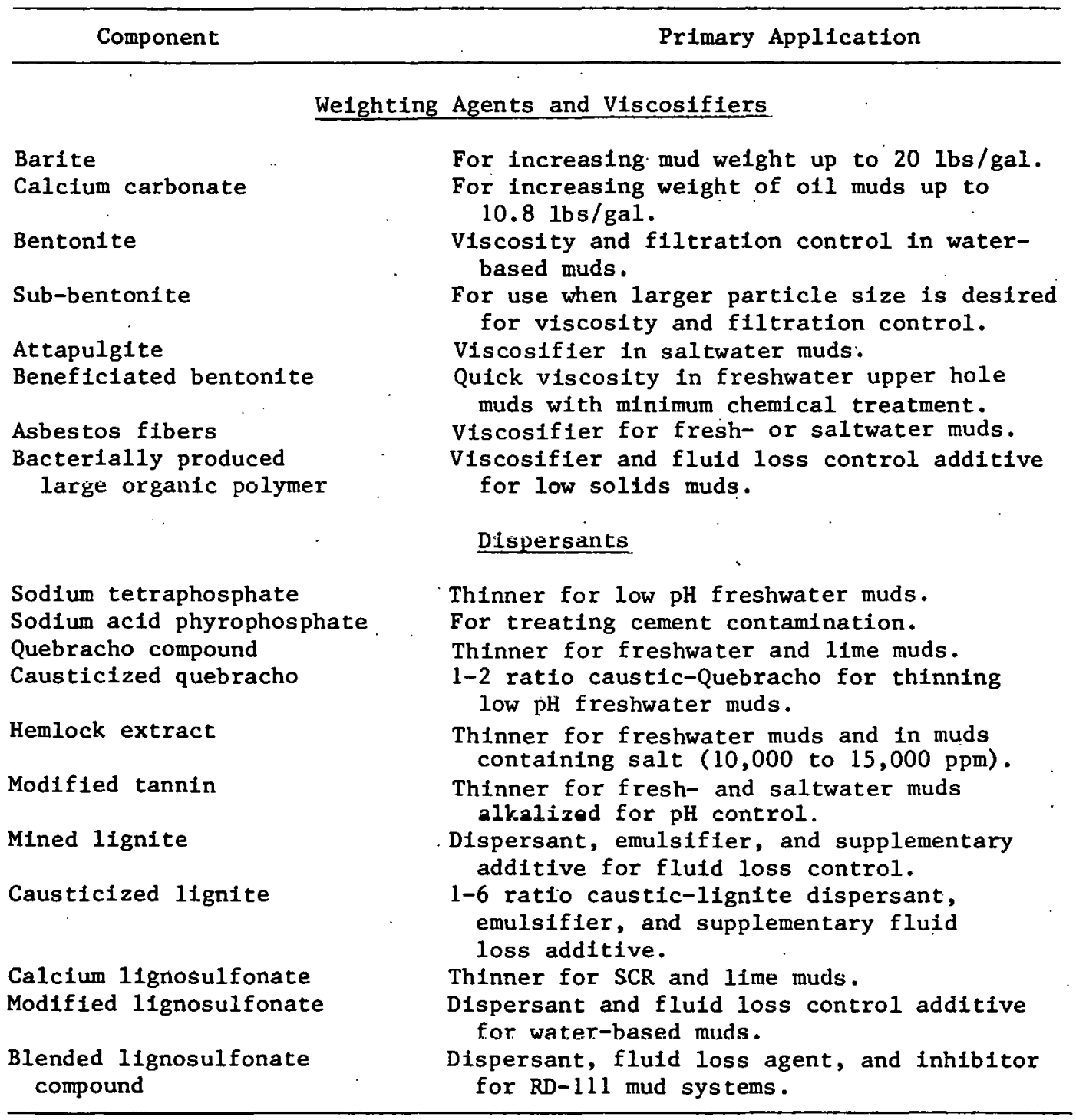


TABLE 18 (Continued)

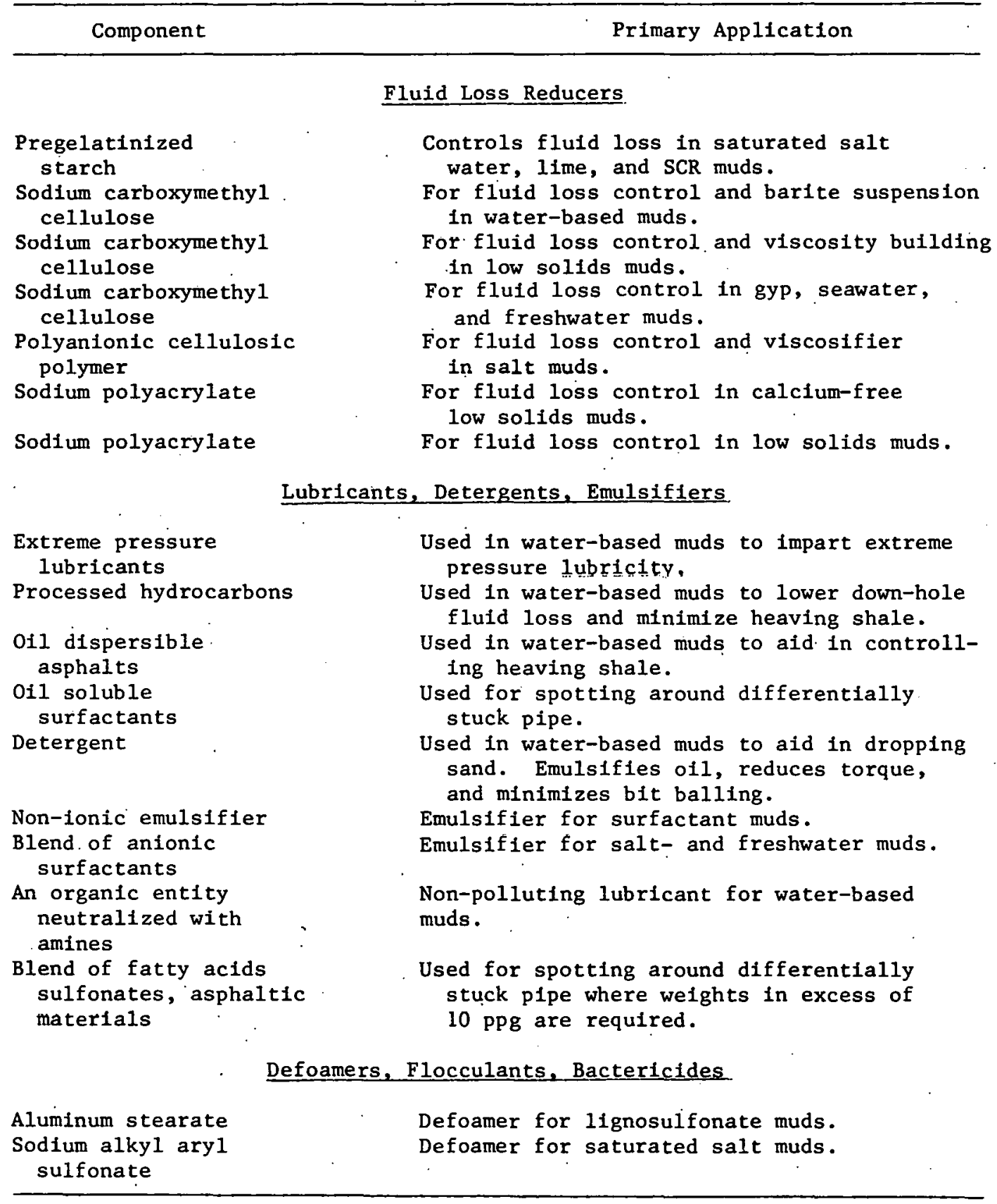


TABLE 18 (Continued)

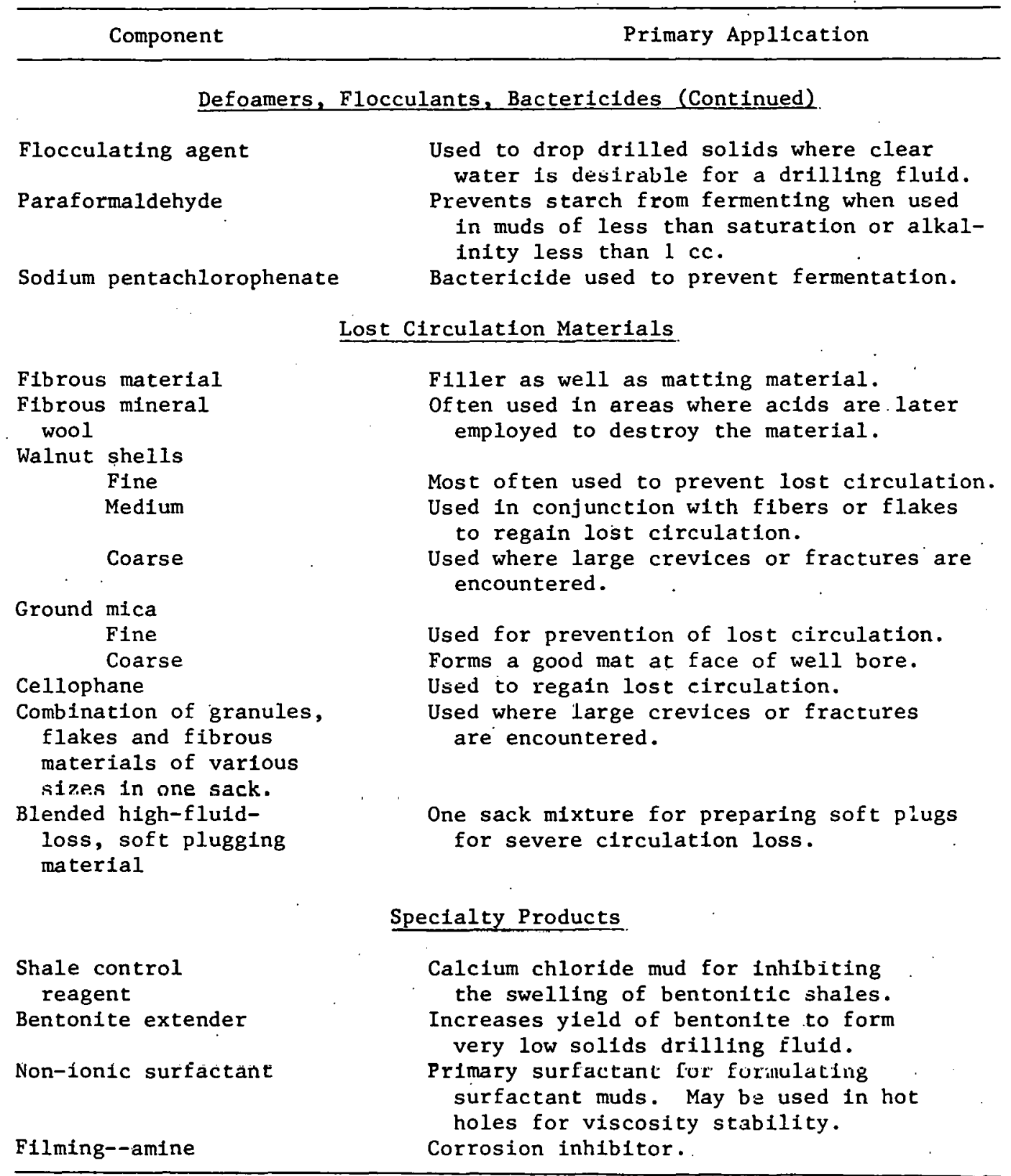


TABLE 18 (Continued)

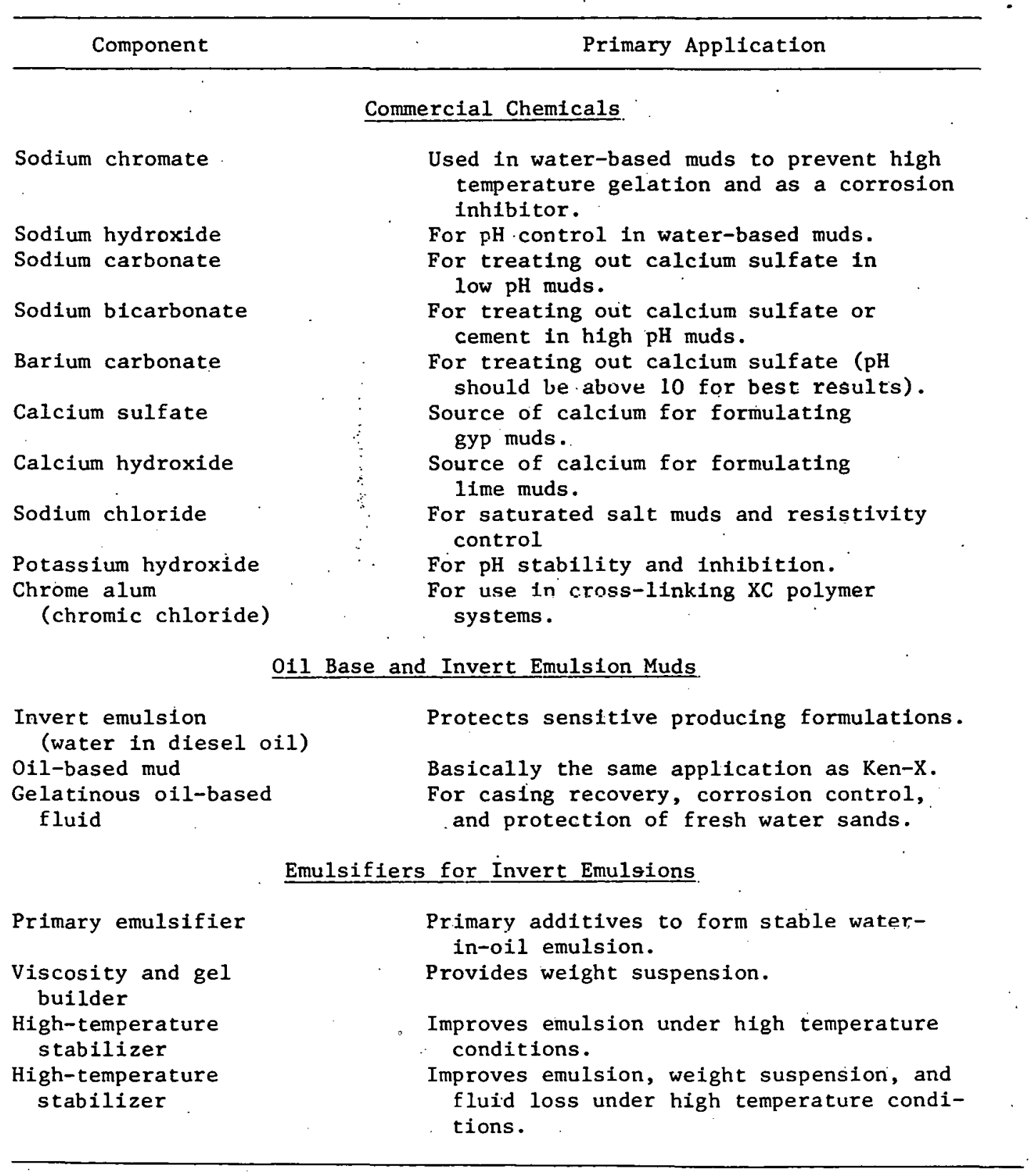

Source: U.S, Department of the Interior 1979 . 


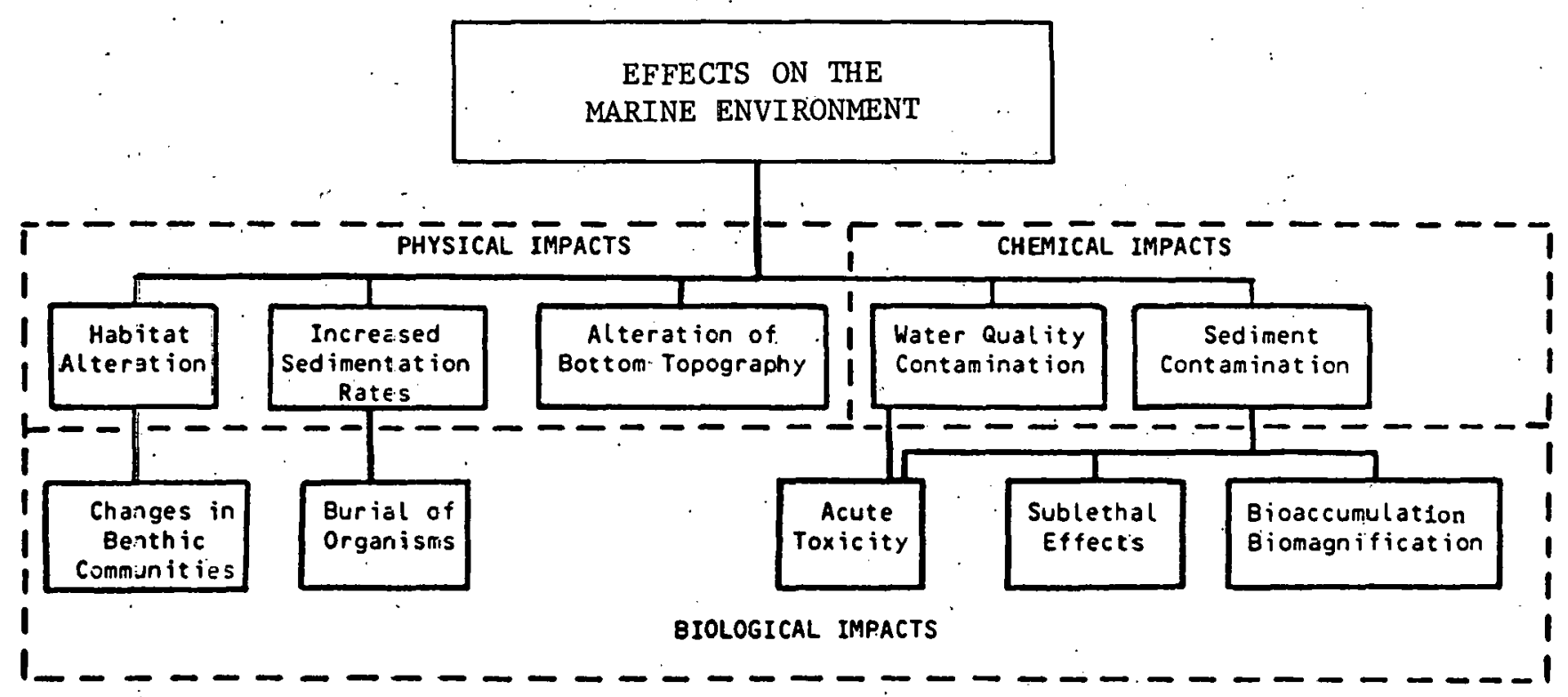

Source: Adapted from Neff 1980; U.S: Department of the Interior 19.79 .

\section{FIGURE 11}

EFF.ECTS OF DRILLING FLUID DISCHARGED INTO

THE MARINE ENVIRONMENT 
a few field studies to determine the nature and extent of these impacts. Research efforts are continuing, with activity concentrated in the Flower Garden Banks area of the Gulf Coast and the Georges Bank areas of the North Atlantic.

\section{Laboratory Studies}

Most laboratory studies related to drilling muds have been sponsored by the oil industry and by the Federal government, with a concentration of research effort at the U.S. Environmental Protection Agency's Environmental Research Laboratory at Gulf Breeze, Florida. Several general reviews of the status of laboratory research have been presented (Ayres 1980a; Neff 1980; Richards 1979). A number of recent studies were discussed at a symposium held in January 1980 (Steering Committee for the International Symposium on Drilling Fluids and Cuttings, In press). A complete review of all laboratory or controlled ecosystem studies on the effects of drilling fluld discharges has been sponsored by the National Oceanic and Atmospheric Administration (NOAA) in association with program effects on the Lower Cook Inlet of Alaska. A draft version of this report was scheduled for completion In October 1980 (Calder 1980).

Most of the laboratory studies on drilling fluid effects have involved the use of standard, 96-hour static bloassays to determine acute lethal toxicity. Testing has been undertaken using individual drilling fluid components and whole drilling flulds. A variety of test organisms have been used, including both freshwater and marine species. In general, these studies have found that most whole drilling fluids are "practically non-toxic," based on the classification scheme presented by Sprague (1973). Llowever, gome researchers, notably Richards (1980) and Conklin et al. (1980), ${ }^{*}$ reported bioassay results indicating that some drilling fluids may be highly toxic.

Fewer laboratory studies have been conducted to determine the sublethal effects of drilling fluid discharges. Ayers (1980a) notes that, in most studies, sublethal effects occurred at concentrations above the 100 to $1,000 \mathrm{ppm}$ range. Bioaccumulation of certain drilling fluid constituents (barium, chromium) has been documented, with depuration occurring in some cases but not in others (Brannon and Rao 1979; Liss et al. 1980; Page et al. 1980). Recent efforts also have included investigations of sublethal effects on corals (Shinn et al. 1980; Thompson 1979; Thompson and Bright 1977), and on

\footnotetext{
* Neff (1980) reported that the drilling fluid used in this study was a highly treated composition not intended for marine disposal.
} 
bivalve molluscs (McLeod et al. 1980). These studies generally indicate that effects are highly variable, depending upon the species studied, drilling fluid characteristics, and environmental conditions.

\section{Field Studies}

Several fleld studies have been conducted in the major U.S. oll and gas lease sale areas to determine the fate and effects of drilling fluid discharges in the marine environment. . Sponsored mainly by the Bureau of Land Management (BLM), the 011 industry, and most recently through the Federal Interagency Energy/Environment Research and Development Program, these studies range in complexity from diver observations to detalled monitoring of water column and benthic ef fects.

The major studies include:

- Tanner Bank Mud and Cuttings Study, which was carried out at a Shell oil Company exploratory. drill site about $160 \mathrm{kilome-}$ ters west of Los Angeles, California, and included analyses of drilling fluid plume dispersion, effects on water, and local bottom sediment chemistry (Ecomar, Inc. 1978; Ray and Meek 1980; Meek and Ray 1980).

- Lower Cook Inlet Study, which was. carried out at an Atlantic Richfield Company site about 56 kilometers west of Homer, Alaska, and included discharge dilution tests using a fluorescent dye, on-site bioassay testing, and bottom sediment sampling (Dames and Moore 1978).

- Mid-Atlantic Monitoring Program, which was carried out at an Exxon drilling site about $156 \mathrm{kilometers} \mathrm{east} \mathrm{of} \mathrm{Atlantic}$ City, New Jersey, and Included pre-drilling, drilling, and post-drilling monitoring of water chemistry, bottom sediments, and benthic communities (Ayers et al. 1980; Mariani et al. 1980; Menzle et al. 1980).

- Maximum Mud Discharge S.tudy, which was carried out at an Exxon drilling site about 80 kilometers south of Cameron, Loulsiana, and included intensive discharge plume monitoring at several depths (Ayers 1980a), accompanied by the use of a computer model to predict the short-term fate of the material (Brandsma et al. 1980).

- oCS Rig Monitoring Program, sponsored by BLM at various dri1ling site locations, which includes examinations of bottom topography, plume dispersion, and effects on bottom sediment 
conditions (Alexander et al. 1977; Bright and Rezak 1978a; Bright and Rezak 1978b; Groover 1977; T11lery 1980).

A review of these studies by Ayers (1980a) concludes that: (1) drilling fluids have a minimal local effect on ocean water quality, since they are dispersed rapidly and diluted within the area of the production field; and (2) effects on the benthic environment are localized and temporary. Richards (1979) notes that such conclusions have not been substantlated since most of the field studies have not been published in peer review journals. Careful review of these studies is an objective of the previously mentioned NOAA study that is underway.

Production Drilling

Production drilling 18 similar to exploratory drilling; however, it continues for a longer period of time and more drilling occurs at a single site. Therefore, there is a larger quantity of drill cuttings and mud to be disposed of. When this material is deposited overboard, the bottom topography 18 altered and benthic organisms may be smothered by 811 ts and sediments. This disposal practice may result in increased turbidity, eutrophication, and toxification of local waters. In addition, the increased activity (e.g., nolse from compressors) from boats, pumps, and other equipment associated with production drilling affects fish and other wildiffe. Some species avold an area that could have been occupled for feeding or reproduction, while other species are atracted to such activity.

As with exploratory drilling, the potential for blowouts exists and could lead to adverse impacts on the local environment and biota. 011 spills also would result in adverse environmental effects. This topic w111 be discussed in the following sections; however, it should be noted that spills are likely to occur prior to pipeline construction during the transfer of oil between production platforms and tankers or barges.

Pipelines

Adverse environmental impacts may be realized as a result of any of the following pipelaying processes: underwater excavation or dredging, subsea burial, corridor routing, and pumping station or landfall construction (Clark et al. 1978). The environmental effects of underwater excavation or dredging will probably be quite similar to the effects resulting from drilling operations. It is anticipated that the removal of benthic substrate during the excavation process will result in the loss of habitat for indigenous benthic organisms. The removal of substrate and the subsequent burial of pipeline will involve increased activity in the area. This type of environmental 
disruption could affect both indigenous and migratory biota; areas occupied for feeding, reproduction, and migration; and niches for other activities. Increased turbidity and sedimentation resulting from excavation and burial may also adversely affect biota.

Corridor routing through sensitive habitats or pipelaying in wetlands may result in both physical and biological impacts. Natural drainage and current patterns will be disrupted and erosion of soft and unconsolidated sediments in marshland areas may be markedly accelerated (Council on Environmental Quality 1974). This type of disturbance of the marsh environment may lead to changes in ambient turbidity, salinity, acidity, hydrogen sulfide toxicity, and biological oxygen demand.

Pipeline canals that are adequately backfilled or plugged may have temporary, localized effects on circulation patterns in marshes, but they do not result in permanent, continuous canals and spoil ridges. Water movement patterns remain essentially unchanged following restoration procedures. The effects of staggered borrow pits and discontinuous spoil deposits are localized and relatively small. of greater significance to the hydrological regime of the brackish marsh are: the construction of leveed access roads, the dredging of access and pipeline canals, and subsequent spoil deposition. Leveed roadways and open canals bordered by continuous spoil levees generate a complex of interactions which may facilitate changes in the marsh!s freshwater sheetflow from the uplands and facilitate rapid marsh drainage. The result may be a lower water table under the affected marsh surface, and eventually, drier conditions in high marsh areas (Longley and Jackson 1980).

Tankers and Barges

The actual operation of oll-carrying tankers or barges is not expected to result in adverse environmental effects. The effects would be similar to those resulting from the operation of any seagolng vessel (e.g., commercial fishing ships). However, oil spills may occur durling the transfer of oll between production platforms and tankers or barges.

Environmentally harmful impacts may result from tank cleaning and deballasting operations which are required when: a cargo is to be carried that will not tolerate residues from a previous cargo, a vessel is to undergo repair work, and clean ballast is to be taken on board (Clark et al. 1978). In the process of tank cleaning, the cleaning water sprayed into the dirty tanks will dislodge much of the oil adhering to structural members. Pumping this directly overboard will result in significant oil discharges. This practice is restricted by recent legislation limiting the quantities of oil 
pumped overboard (Clark et al. 1978). An emerging practice is to utilize the crude oil itself as a pressure spray to clean tank walls. This mintmizes the amount of water and detergent needed in the cleaning process.

The "load on top" technique recently adopted by industry reduces the amount of oil discharged to within the permissible limits of the present law (Clark et al. 1978). With this technique, ofl residue from the tank cleaning operation is pumped into an empty cargo tank. The mixture is then allowed to separate by gravity (the oil is normally on top since 1 ts density is lower than that of water). Water is pumped overboard until the interface approaches the suction line. The remaining fluid--a mixture of about 75 percent 011 and 25 percent water--1s transferred to a cargo tank in which new oil 18 loaded on top. Effectlve oll/water separation may be adversely influenced by the following: severe sea state conditions, insufficlent separation periods due to a short voyage, agitation due to the pumping operation itself, oll with a specific gravity close to that of seawater, inaccurate overboard discharge measuring devices, and human error (Clark et al. 1978). The adverse effects resulting from the discharge or spillage of oll will be discussed in the section below on oll spills.

\section{Offshore Storage}

As with pipelaying operations, adverse environmental effects may be realized from the construction of subsea storage facilities. Severe bottom currents may initiate ruptures in these systems, leading to oll contamination of seawater adjacent to the storage site. In addition, there is the potential threat of spills during oil transfers.

\section{Oil Sp111s}

The entire sequence in the development of offshore oil and gas reserves carries with it the potential for oil leaks and oil spills. The release of oil to the environment may result from blowouts or natural seeps during the drilling, well completion, or production processes; from the transfer of oil from platforms to tankers or tankers to storage facilities; from ofl pipeline leaks; or during tanker washing or ballasting operations. Between 1971 and 1975, an average of $18.4 \times 10^{9}$ gallons of ofl per year was reportedly spilled in U.S. waters (Council on Environmental Quality 1976).

Several policies have been initiated by the Federal government to prevent accidental oil spills (Brown 1977). In addition, methods are being developed and tested to contain and remove oil slicks. However, a correlation between the quantity of oil spilled and the 
level of oil imports and offshore drilling can be expected to continue.

An oil spill can harm wildlife that ingests petroleum or loses the insulating capacity of 1 ts feathers or fur. 011 spills have drastic implications for oceanic and diving birds (Clark et al. 1978). Generally, fish are able to avold the effects of an oil spill because they can swim beneath 1 t.

In addition to direct kills of organisms, the major adverse environmental effects of direct oll pollution of coastal waters are: disruption of feeding and reproductive activities of aquatic species; changes in physical and chemical habitat, causing exclusion of specles and reduction of populations; and stresses on the ecosystem from decomposition of liquid effluents, resulting in altered productivity, metabolism, system structure, and species diversity (Clark et al. 1978 ).

The effects of oll spills are complex, whether from tankers, platforms, or terminals. Some of the major components of f1sh and wildlife species and habitats that are affected include (Clark et al. 1978):

- Endangered birds. The known and suspected coastal foods of the American peregrine falcon, southern bald eagle, osprey, and other birds are sensitive to oll spills in any season.

- Migratory waterbirds. Areas along the shore have been identified as having significant concentrations of migratory birds during the winter, spring, and fall.

- Shellfisheries. Areas along the shore have been identifled as beds for surf clams, bay scallops, northern hard clams, oysters, and others. Both commercial and sports harvesting areas for these species would be affected in any season.

- Coastal finfish. A 25-mile strip of coastal waters along the entire length of the shore has been identified as critical during the summer and fall with respect to the egg and icthyoplanktonic stages of the scup, porgy, menhaden, and other species.

- Estuarine finfish. Estuarine areas and sounds have been identifled as important areas for weakfish, sea trout, whiting, striped bass, and other fish during the spring, summer, and fall. 
- Wetlands. All marsh areas have been identified as sensitive in any season.

- Wildlife refuges and management areas. All national wildlife refuges, wildlife management areas, wildlife areas, and natural areas have been identified as critical in any season.

- Beaches with high-intensity use. National recreation areas, including adjacent state and municipal beaches, have been identified as areas of high intensity usage in any seasons.

- Parks and recreation areas. The locations of all state parks and national recreation areas have been recorded as important in any season.

Marine ofl spills have involved both crude and refined olls (mostly no. 2 fuel o1l). Crude oil contalns water soluble components that are somewhat toxic to marine organisms, while no. 2 fuel ofl is highly toxic (Bell 1971). Spllled crude ofl is altered by weathering which involves evaporation, dissolution, microblal decomposition; and chemical oxidation. The processes of evaporation and dissolution lead to rapid depletion (in 2 to 4 days) of the low boiling, highly toxic fractions in an oil slick. Microbial and chemical oxidation of most higher bolling fractions is a relatively slow process and may take several years (Moore et al. 1973). Refined oils contain a greater percentage of low boiling substances and, therefore, are more toxic than crude oils. As an example, a no. 2 fuel ofl spill at West Falmouth, Massachusetts, produced a massive, Immediate kill of fish, clams, snails, crabs, lobsters, worms, and other invertebrates (Blumer and Sass 1972). O11 was incorporated into sediments and continued to inhibit repopulation 9 months after the spill. Normal functioning of benthic communities was profoundly affected for years after the spill (Jacoff 1979).

It is important to understand the fate of oil discharged or spilled in the marine environment. Rates for microblal degradation of o1l components and the role of photochemical reactions in altering or destroying the compounds must be identified and quantified in order to accurately predict the effects of oil spilis on biota.

Thus, a large ofl spill with a low recovery rate could be deleterious to aquatic fauna and flora. The degree of 1mpact would be contingent upon the amount and type of oil spilled and upon the extent of aquatic biota present. Should such a spill occur in a warm estuarine or marine area, the following general effects may occur:

- Direct lethal toxicity. Dissolved aromatic hydrocarbon derivatives could disrupt membrane activity in crustaceans 
and burrowing organisms and to a lesser extent in $\mathrm{fish}$ and mollusks, causing deaths (Moore 1973).

- Disruption of physiological and behavioral activity. Chemical communication is inhibited, leading to abnormal feeding, reproduction, orientation, and/or migration of marine organisms (Moore et al. 1973). In the case of most sp111s, this effect would persist at most only a matter of a few hours if it occurred at all. However, in certain rare instances, this effect could persist for several months, and in the most extreme case, for a year or more. This would be true if a highly toxic product such as no. 2 fuel oll spilled in unusually turbulent seas so that vertical mixing occurred and the sediments became saturated with the oll (Straunghan 1972).

- Direct coating by oil. 011 may smother or physically inhibit activities such as feeding and locomotion. Sessile organisms are most susceptible to coating.

- Incorporation of hydrocarbons in food chains. Polynuclear aromatic hydrocarbons, some of which are carcinogentc, are present in ofls generally in the range of a few parts per million. These components are easily absorbed and concentrated by marine animals. However, such marine animals quickly depurate these hydrocarbons once they have been removed from exposure (Anderson 1973; Battelle Pacific Northwest Laboratories 1973). Fin fish and filter feeding organisms such as clams and oysters concentrate hydrocarbons in body tissues, creating an objectionable taste.

o Habitat changes. Alteration of the physical-chemical environment, especially in the sediment, will cause shifts in the number and kinds of species present. The degree to which ofl contaminates sediments is a function of the absorptive capability of the sediment, depth of the water, vertical mixing, and the degree to which the slick has weathered and become more dense.

The acute blological effects of oll pollution, such as mass mortalities, require immediate remedial measures. However, the sublethal effects of persistent toxic substances or compounds that degrade to toxic substances on benthic organisms should be determined (Goldberg 1978). Since petroleum compounds have shorter residence times in water than in sediments, benthic organisms are subjected to greater exposure than pelagic organisms. 
Summary of Research Needs

The study of the effects of oll spills has recelved a great deal of Federal attention in the past decade. Current research focuses on monitoring long-term effects and on the recovery and enhancement of coastal wetlands affected by oll spills. Federal involvement in the oil spill arena has moved from the study of basic effects to regulatory control. The state of knowledge 18 diverse and 'In-depth, as indicated by the above discussions and voluminous reports on the subject. This section focuses on a few unresolved research problem areas.

\section{Effects of Drilling Muds}

As noted above, a variety of laboratory and field studies have been carried out on the effects of drilling fluid discharges in the marine environment. However, insufficient coordination of research efforts, attended by variability in experimental design and research results, has led to a lack of consensus on this 1ssue. Thus, there is a cruclal need for more efficient planning and management of research to identify and resolve the major questions pertaining to the nature of drilling fluid discharges, their transport and transformation, fate, and effects in the marine environment. As detalled below, each of these major research areas involves several specific research objectives.

\section{Description of Drilling Fluid Discharges}

It is well known that the composition of drilling flulds is highly variable (Petroleum Equipment Suppliers Association 1980), and that the toxicity of additives varies (Ayers 1980a). This undoubtedly accounts for much of the variability in the results of standard bioassay testing. Several recently initiated efforts will address some aspects of this research area:

- One objective of a literature survey being conducted under NOAA's guidance is to synthesize avallable information on the composition of drilling fluids and their use by the petroleum industry (Calder 1980).

- Several studies involving the chemical analysis of drilling fluid samples are being sponsored through EPA's Gulf Breeze Laboratory (U.S. Environmental Protection Agency 1980).

However, a more complete characterization of the range of chemical compositions in use is required. In addition, information is needed on the total volumes of the various types of drilling fluid discharges, the geographical distribution of these discharges, and methods of discharge. 
Fate and Transport

Many of the field studies that have been conducted have addressed the short-term transport and fate of discharged fluids. Fewer studies have been conducted on long-term fate and transport. Due to the diverse oceanographlc conditions of areas being drilled, it is difficult to form generalizations based on the available studies. Recently initiated research efforts are expected to meet some of the major information needs related to fate and transport. These studies include:

- A second objective of the literature survey being conducted under NOAA's guldance is to synthesize avallable information on the fate of drilling muds and cuttings in the marine environment (Calder 1980).

- The Bureau of Labor Management plans to sponsor an overview of its past rig monitoring efforts (Burke 1980).

- Two major projects, the Interagency Research and Monitoring Program on the Flower Garden Banks. (Burke 1980) and the Interagency Blological Task Force Monitoring Program for Georges Bank lease sale 42 (Bolton 1980) will include field studies on transport and fate.

- The ofl industry w1ll cont1nue to sponsor research such as the long-term study planned as part of Exxon's Mid-Atlantic Monitoring Program (Ayres 1980b).

In conjunction with these planned research projects, there is a need to delineate the differences between physical effects in lowenergy environments and those in high-energy environments. To f111 specific information gaps, additional research may be needed on plume behavior, the dispersion of drilling fluid constituents within the water column, and accumulation and long-term transport of settleable fractions. Additional field studies may also be necessary to identify any undesirable chemical transformations of drilling fluid constitutents that may result from weathering processes. Also of importance is the continued development, application, and verification of predictive models. Computer simulations, such as the model developed by Brandsma et al. (1980), can provide valuable guidance based on limited data (e.g., current structure, density profile, discharge, and drilling fluid characteristics).

\section{Biological Effects}

A major area of controversy has been the effects of discharged drilling fluids on marine communities. Difficulties have been 
encountered in the interpretation of bioassay results, in relating laboratory data to fleld data, and in assessing the limited information pertalning to any potential long-term effects. A broader question involves formulating a conceptual approach to predicting effects in different types of ecosystems or ecotypes (e.g., Gulf of Mexico, Mid-Atlantic, Northern Pacific).

Recently initiated research efforts should contribute substantially to an understanding of the blological effects of discharged drilling fluids. Key efforts Include:

- A third objective of the literature survey being conducted under NOAA's guidance is to synthesize avallable information on the biological and ecological effects of drilling fluids (Calder 1980).

- Continued acute toxicity and sublethal effects testing efforts on drilling fluid samples are part of the research program at EPA's Gulf Breeze Laboratory (U.S. Bnvironmental Protection Agency 1980).

- Two major projects, the Interagency Research and Monitoring Program on the Flower Garden Banks (Burke. 1980) and the Interagency Blological Task Force Monitoring Program for Georges Bank lease sale 42 (Bolton 1980) will include fleld studles telated to blological and ocologioal offects ( 9.8. , determining baseline conditions, trophic transfer of drilling fluid constituents, and effects on community dynamics).

In conjunction with these planned research projects, research must focus on: standardization of bioassay methods for lethal and sublethal effects, and the selection of appropriate test organisms; undertaking fleld investigations to verify laboratory findings; determining the physical impacts of mud discharges (e.g., burial, habitat alteration); and determining the areal extent of 1mpacts. Additional research should be directed toward identifying any potentially adverse effects on commercially important species. Over the long-term, the development or adaptation of ecological models may allow the synthesis of existing information for application in new drilling locations.

\section{Effects of Seismic Testing}

As discussed above, there is a controversy over whether it is environmentally advantageous to utilize a number of low-energy intensive seismic shocks in offshore oll exploration or a single large explosion, such as that propagated by dynamite, to obtain sufficient readings. This controversy is particularly relevant to 
hostile marine environments or sea-state conditions. Additional information is required focusing on behavior and mortality of marine biota exposed to repeated low-level seismic shocks.

\section{Cumulative Effects}

Habitat disturbance and the effects of drilling fluids are beginning to be studied with respect to offshore platforms. These field studies are largely directed toward a single platform and a single impact. Research 18 needed which will focus on the cumulative ef fects of large-scale development over a wide area (e.g., Georges Bank, Gulf of Mexico, Gulf of Alaska).

Overall large-scale programmatic studies have been conducted (e.g., Gulf of Alaska). These have largely focused on the characterization of indigenous blota, migration patterns, and bioassay analyses. Additional at tention should be placed on the interaction of offshore subsea and fixed platforms, thelir effects on the fauna inhabiting contiguous areas, and resultant long-term impacts. Attention may need to be placed on spacing platforms to avold environmental degradation and on habitat reclamation.

\section{Effects on Deep Water Environments}

With fixed offshore production platforms operating in as much as 1,025 feet of water (Gulf of Mexico) and mobile rigs in water as deep as 4,876 feet (205 nautical miles east-northeast of St. John's, Newfoundland), offshore drilling technology 18 entering a new era. Sea floor completion systems will begin to replace fixed platforms. With such a development, fauna inhabiting the deep ocean floor of the continental shelf and trenches will be disturbed. The potential effect of offshore development on these forms is relatively unknown. Many of these species have evolved in an environment that is relatively stable in terms of temperature, chemistry, and physical character and topography of sediments. More research is needed to fully characterize the impact of offshore development on fauna of the deep areas of the continental shelf.

\section{Impact of Natural Seeps}

For many years marine geologists have been aware of numerous active and quiescent seeps discharging into the environment. These include discharges of gas as well as oll. These seeps have important exploration implications.

Natural seeps have been observed in waters of the continental shelf off shore from California, Texas, and Louisiana. As much as 10 percent of all oil entering the marine environment is attributed to 
such seepage (Albright 1973; U.S. Environmental Protection Agency 1978).

In determining the cumulative impact of spllled crude ofl on the marine environment, the contribution of ofl from natural seeps must be assessed. Also, these seeps should be utilized to determine longterm chronic effects and the long-term adaption of marine biota to oil contaminated sediments. 


\section{TRANSPORT AND TRANSFORMATI ON}

This section describes the movement and possible transformations of pollutants associated with of fshore oll and gas operations in both atmospheric and aquatic environments. Observable discharges such as oil spills and drilling fluid effluents are discussed; however, future research emphasis should be placed on the fate and transformations of atmospheric emissions that reach the marine environment.

\section{Atmospheric}

The extent of airborne transport of offshore oll and gas pollutants is a function of both the physicochemical characteristics of the emissions and any extraneous alrborne conditions and elements. acting upon them. The interaction of these factors will determine how and to what extent emissions are transported. Complex chemical transformations between atmospheric emissions, various constituents, natural background levels of alrborne chemicals, and anthropogenic pollutants may result in pollutants differing from those intially emitted from offshore oll and gas operations.

The chronic loading of atmospheric emissions to the surrounding marine environment by both wet (1.e., rain) and dry deposition presents a potentially serious impact. It is important to realize that these emissions occur for the duration of offshore ofl and gas operatlons. Unlike an oil spill, there are no methods for "after-thefact" treatment and cleanup of atmospheric emissions.

Pollutants resulting from atmospheric emissions can settle on the surface film of the open ocean near the vicinity of offshore ofl and gas operations. These pollutants are subject to chemical transformation and may also reach and remain in the water column, settle into bottom sediments, or be transported into other areas. In the open ocean, the surface and the upper reaches (50 m from the surface) are excremely 1mportant to primary production, which is essential for the support of all other life forms (e.g., zooplankton, crustaceans, $f$ ish). Therefore, the extent and effects of atmospheric emissions from offshore oil and gas operations should be investigated with respert to such impacts.

\section{Aquatic}

0il discharged on the ocean surface undergoes physical, chemical, and biological alterations. Rapid physical and chemical processes include (McAuliffe 1977):

- Spreading and movement with wind and currents; 
- Evaporation of the volatile components;

- Solution, emulsification, and dispersion of small droplets Into the water;

- Sedimentation;

- Spray injection into the alr; and

- Chemical oxidation.

The transport and fate of oil is variable and influenced by conditions, such as location, winds, waves, currents, water depth, temperature, salinities, organisms, nutrients, and kind of oll (McAuliffe 1977). When added to calm waters, most olls spread in a thin, continuous layer that forms a circular pattern. As the ofl slick expands in size, it is not uniform--thicker patches within the slick appear (McAuliffe 1977).

Crude ofls and petroleum products may contain appreciable amounts of nitrogen, sulfur, and oxygen-contalning compounds, some of which are surface-active. These compounds and their concentrations determine the formation of o1l-in-water droplets or water-in-o1l masses on the surface. The general tendency is to form water-in-oll emulsions. However, under agitation by wind and waves, many oils break up, and small droplets disperse into the underlying waters (McAuliffe 1977). Such dispersion may be assisted by bacteriaproduced, surface-active compounds (Boehm and Quinn 1973), or by oil attachment to particulate matter in water.

Some crude olls have a tendency to form water-in-oll emulsions, frequently referred to as "chocolate mousse." These emulsions ultimately may become pelagic tar ( $t a r$ balls) that strand on beaches. However, crude oil spills probably contribute a minor amount of oil appearing as tar balls. Much of the tar stranded on beaches originates from washing tanker compartments, as evidenced by the viscous oils or waxy materials bound with sediment (McAuliffe 1977). As surface slicks break into ofl droplets or particles and disperse in near-surface waters, most remain suspended (Brown and Hufiman 1976) and move with the water. Some oll does sink, apparently through association with inorganic mineral matter suspended in water (McAuliffe et al. 1979).

The first compositional changes in oll spilled on water involve evaporation and solution of volatile components. These processes are simultaneous and competitive (McAuliffe 1977). The rates and extent of these changes depend upon the chemical and physical nature of the 
oil, wind velocitles, sea states, and water temperature. Each volatile hydrocarbon w1Il evaporate and also go into solution at rates that depend upon its vapor pressure (American Petroleum Institute 1953) and solubility (Button 1976).

011 discharged on a water surface is not in equilibrlum with reference to evaporation and solution of hydrocarbons. Wind constantly renews the air over the slick, and water movement (waves and currents) renews the underlying water. Hydrocarbons that dissolve in water evaporate quickly (McAuliffe 1977).

Concurrent with physical and chemical alterations are biological processes that operate most effectively after the physical processes have been initiated. Biological processes include degradation by microorganisms, and uptake (1f exposed) by larger organisms, followed by excretion, metabolism, or storage (McAuliffe 1977).

The rate of microbial degradation (e.g., bacteria, yeasts) will depend on many factors such as temperature; the concentrations of nitrate, phosphate, and dissolved oxygen in the water; the presence of other organtc compounds; and an area's history of previous exposure to ofl (Farrington 1977).

A basic understanding of the varlous transfer pathways and fates of oil has been derived. from laboratory studies, fleld studies, and the application of existing scientific knowledge (Farrington 1977). These potential pathways and fates are represented in Figure 12. Farrington (1977) identifies the following fundamental questions:

o What portions of oil inputs follow each of the various pathways of transfer?

- What are the rates of biochemical and chemlcal degradation of whole oll and components of oil during the various stages of movement through the marine environment?

- What are the final rates of oil removal by biochemical and chemical degradation, and by deep burial in sediments?

It is important to realize that these questions cannot be satisfactorily answered.

Unlike atmospheric deposition of pollutants, there are methods for treating and cleaning up oil spills. Farrington (1977) provides the following evaluation of oil spill cleanup methods.

The use of nontoxic emulsifiers of dispersants on an oil spill would result in increased dissolution of the oil 


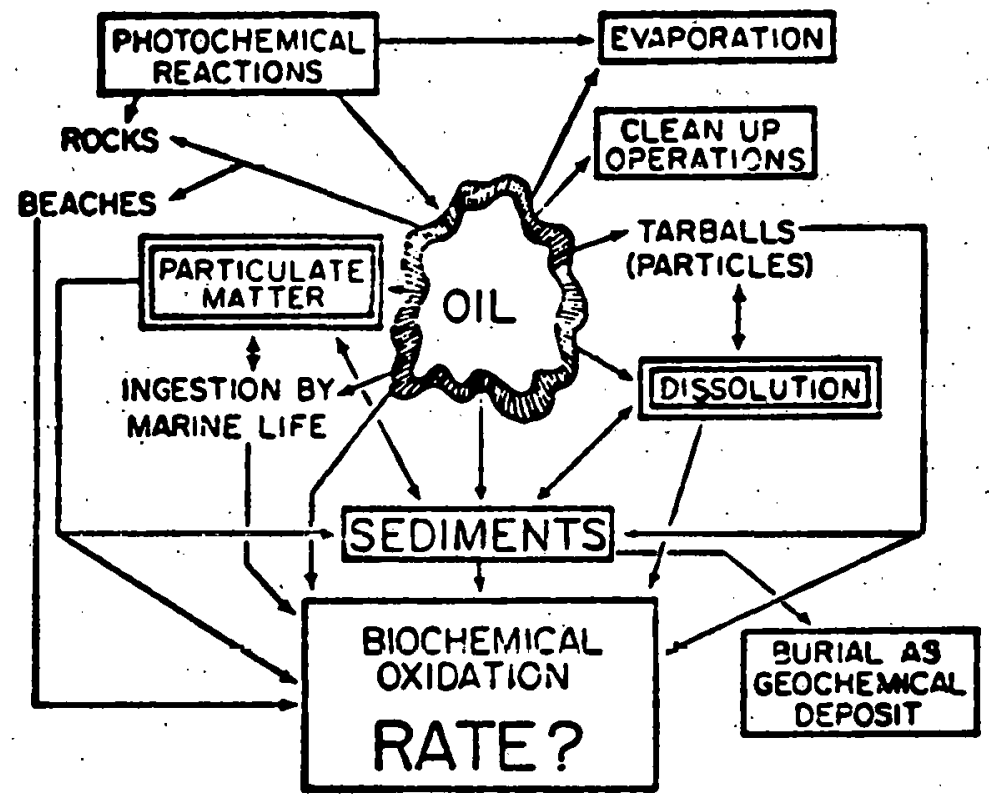

Source: Farrington 1977.

FIGURE 12

FATE OF OIL SPILLS 
and accommodation into the water column, adsorption into particulate matter, and incorporation into sediments. On the one hand, this might further the biodegradation of the oll by increasing mixing of oil, nutrients, oxygen, and naturally occurring microblal populations capable of degrading the oil. On the other hand, it would spread oil throughout the water column and sediments; possibly increasing the extent and severity of the toxic effects on organisms. The incorporation of significant quantities of oil into sediments could prolong the exposure of an area to the oil and adversely affect bottom dwelling organtsms. Resuspension of the sediment and transport to other areas would increase the size of the affected area. The use of sinking agents to remove the slick from surface waters would also result in the incorporation of the oil into sediments, which may not be advisable.

In addition to o1l, there are other substances used during of $f-$ shore drilling operations that might reach the aquatic environment. Drilling muds, cuttings, and formation water and 1ts dissolved, emulsified, and suspended solids are normally discharged to the surrounding aquatic environment during exploratory and development drilling.

Currently, little is known about the transport and transformation of drilling fluids. This is not surprising considering the chemical complexity of drilling fluids, the diverse geographical conditions of areas belng drilled, varying oceanographic conditions, and the fact that iftele is known about the basic biology of marine systems. Richards (1979) Identifies a research study which showed that a near-surface discharge of drilling fluid did not disperse untformly, but concentrated above the thermocline. Therefore, the potential for direct and/or indirect drilling fluid exposure via thermocline transport should be investigated under different hydrographic regimes.

Summary of Research Needs

- Information is needed on the extent and effects of the deposition (wet and dry) of atmospheric emissions from offshore o11 and gas operations. Emphasis should be placed on hydrocarbon species and their effect on surface films.

- The air-sea interface should be characterized, particularly with respect to intermedia transfer via resuspension (airborne) of evaporative hydrocarbons:

- Information is needed on the role of emulsified oil in terms of persistence, transformation products, and ultimate sinks. 
- Characterization is needed of transport and transformation of oll under deep sea pressures and chemical redox conditions.

- Information 18 needed on the long-term degradation of and ultimate products from the breakdown of drilling flulds in the marine environment. Research should focus on entrapment. of pollutants adjacent to the deep sea floors of the continental shelf and the merits of surface versus subsurface discharge of drilling fluids. 


\section{Part 4 Refinery Operations}




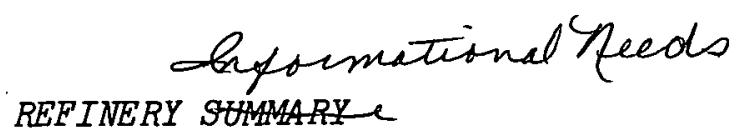

In discussing health research needs related to refinery activities, this section focuses on occupational and public health as it may be affected by exposure to airborne and surface-condensed toxic hydrocarbons. A voluminous amount of relevant data is available in the public domain. Wuch additional data exists as proprietary information relevant to catalysts, process chemicals, and in-plant, company sponsored emissions and ambient monitoring studies. An intensive effort is needed to bring all of this information together and conduct a migorous, well defined risk assessment.

Several reports have appeared recently concerning large numbers of brain tumor deaths among workers at Gulf Coast petroleum refineries and petrochemical complexes. A recent mortality study of refinery workers in the United Kingdom found no significant increased risk for brain cancer, but researchers noted an above normal incidence of malignant melanoma (skin cancer), esophagal, stomach, intestinal, and rectal cancers. Research is needed, especially epidemiological studies, to determine the extent and cause of these occupational illnesses.

Many. persons other than fulltime refinery workers, such as contractor employees, construction workers, part-time employees, railroad workers, and truck drivers, work within the boundaries of a refinery complex and may be exposed to hazardous chemicals. Normally, data collection with respect to morbidity and mortality studies does not include these workers. A reporting mechanism should be developed for the refinery industry which will include these individuals.

Dermal contact is a primary mechanism for exposure to hydrocar bons by refinery workers. A number of studies are needed to quantify this problem. These should include the development of a method for detecting polynuclear aromatic hydrocarbons on skin that is safer than using ultraviolet light.

This section notes that there are several research needs associated with occupational health. Studies are proposed as reeded in the areas of biological monitoring, epidemiology, and bioassays.

In addition, research concerning public health should be conducted. Incidenose of diseases in commmities adiacent to petroleum refineries should be assessed and significant variations from the norm should be followed by in-depth investigation. Sources of infor mation for review should include registries of prevalence of cancer, heart disease, birth defects, and neurological disorders. 
Research regarding ecological effects should focus on the effects of airborne ethylene and phenols on the growth of natural flora and crops, especially with respect to growth rate reduction, premature abcission, and breaking dormancy. More intense research should be conducted on the use of oily wastes in landfarming. Moreover, the roles of hydrogen chloride and hydrogen fluoride should be defined. Emitted fram refineries, these chemicals may have effects on the formation of acid rain, as well as other impacts on the ambient envirorment.

Low concentrations of potentially toxic hydrocarbons in refinery effluents and in. the envirorment should be monitored. Toward this end, relevant analyses need to be standardized and made more reliable in order to assure precision and reproducibility of results. 
REFINERY OPERATIONS

TABLE OF CONTENTS

Page

LIST OF ILLUSTRATIONS

World Petroleum Refining

Refinery Types and Configurations

171

U.S. Refineries and Feedstocks

174

Refinery Feedstocks

174

Sulfur in Crude Oil Feedstocks

183.

Refinery Process Stream Nomenclature

183

Petroleum Refining Processes and Technology

Crude Desalting

Crude 0 il Fractionation

Drying and Sweetening

188

Solvent Refining and Dewaxing . 189

Hydrotreating $\quad 190$

Hydrocracking $\quad 191$

Alkylation

193

Isomerization

Catalytic Reforming

Thermal Cracking

Catäycic Ciacking

Polymerization

Deasphalting

Asphalt Blowing

Grease Manufacture

Wax Manufacture

Hydrogen Manufacture

Process Heaters and Steam Production 204

Pressure Relief and Flare Systems . 206

Blending and Packagling . . . 207

Crude 011 and Product Storage . 207

Wastewater Treatment 
TABLE OF CONTENTS (Continued)

$\underline{\text { Page }}$

HAZARDS OF REFINERY OPERATIONS

Occupational Health

Trends in Petroleum Refining Affecting Safety and Health

Workers Employed in Refineries

Recognition of Refinery Occupational Hazards

Hazardous Exposure Monitoring

Carcinogens in the Refinery

Other Refinery Hazards

Hot Environments

Catalysts

Dyes

Asbestos

Refinery-Associated Skin Disorders 228

Skin Diseases--General Incidence 228

Chemically-Induced Skin Disorders 228

Occupational Safety $\quad 229$

Safety in Design and Operation 229

Fires and Explosions 231

The Canvey Island Investigation . . 233

Refinery Deterioration 235

Health Effects of Refinery Chemicals 237

Hydrocarbons

Acyclic Hydrocarbons

Hydrocarbon Neuropathy

Alicyclic Hydrocarbons

246

Aromat 1c Hydrocarbons 
TABLE OF CONTENTS (Continued)

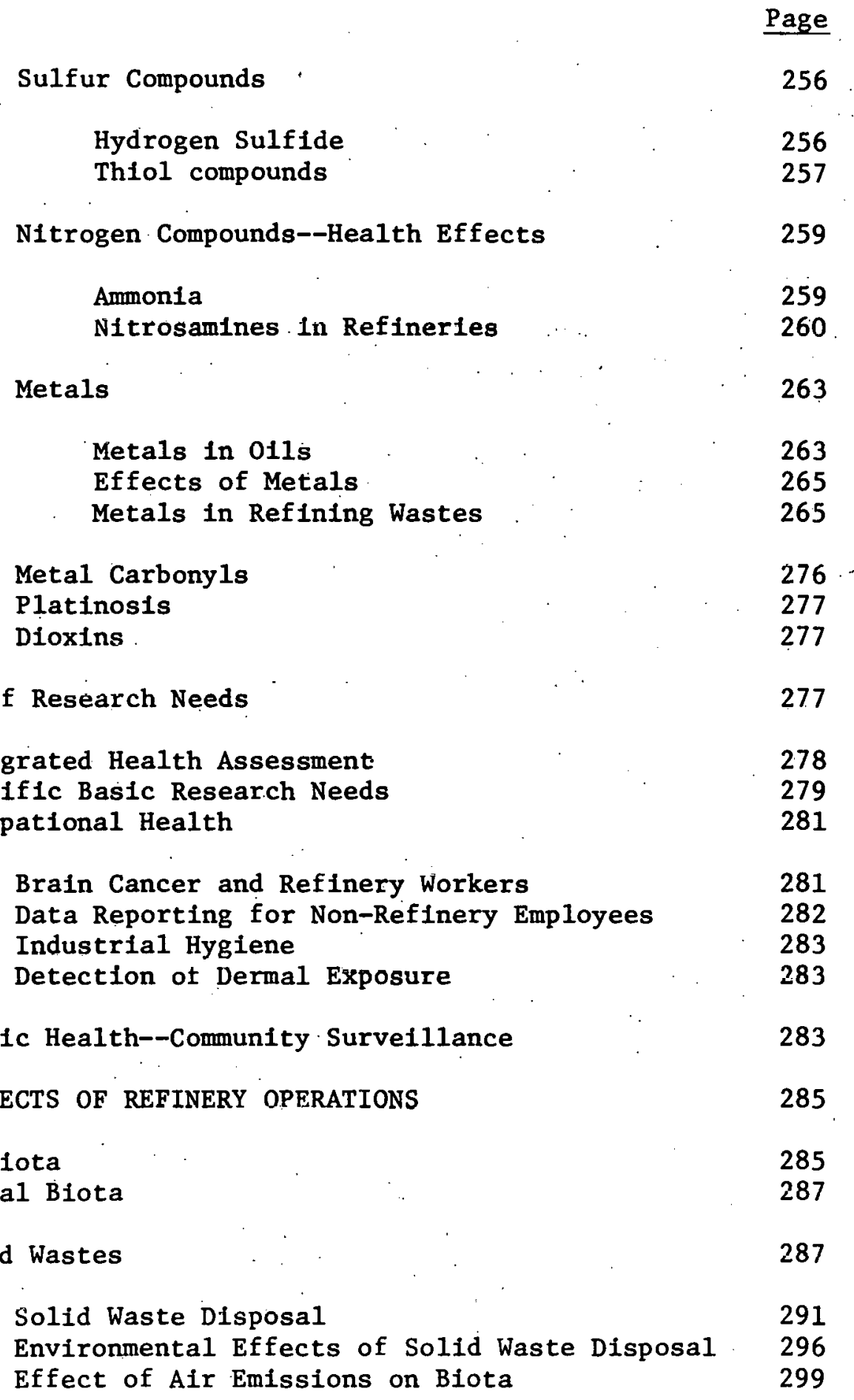


TABLE OF CONTENTS (Concluded)

Page

Summary of Research Needs : $\quad 300$

Aquatic Effects 300

Terrestrial Effects 300

Solid Wastes . . . 300

TRANSPORT AND TRANSFORMATION · 301

Air Medium 301

Environmental Transport: $\quad 301$

Source Characterization. 303

Hydrogen Sulfide 303

Carbon Monoxide. : 306

Hydrogen Cyanide 306

Sulfur Dioxide and Sulfur Oxides. 306

Thiols 307

Phenolic Compounds $\quad 307$

Aldehydes $\quad 307$

Ammonia $\quad 307$

Hydrogen Chloride . 307

Ilydrogen Fluviride $\quad 308$

Particulate Matter . 308

Organic Sulfides and Nitrogen Bases . 308

Hydrocarbon Emissions . . . 309

Fugitive Hydrocarbon Emissions 311

Polycyclic Aromatic Hydrocarbons (PAHs) : 313

Fluidized Catalytic Cracking (FCC) 315

Other Sources of PAHs

Odors from Refineries 317

Refinery Contributions to Smog 319

Emissions from Petrochemical Operations 320

Air Emissions $\quad 320$

Water Medium $\quad 320$

Summary of Research Needs $\quad 334$

Acid Rain 338

Toxic Hydrocarbon Emissions 338

Toxic Hydrocarbon Effluents 338

Precision and Reproducibility of Analyses 338

Characterization of Refinery Wastes and Emissions 339 


\section{LIST OF ILLUSTRATIONS}

Figure Number

Page

1

Topping Refinery (Subcategory A)

173

2

Cracking Refinery (Subcategory B)

175

3

Petrochemical Refinery (Subcategory C)

176

4

Lube Refinery (Subcategory D)

177

5

Integrated Refinery (Subcategory E)

178

6

Distribution of the Petroleum Refining Industry

180

\section{LIST OF TABLES}

Table Number

Page

$i$

Refinery Output Volume for 1978

$\mathbf{1 7 2}$

2

Processing at U.S. Refineries.

179

3

Represent at Ive Crudes and Their Residua

181

4

Crude 011 Quality Ranges in Major Production Area 8

182

5

Rofinery Feedstocks, 1980 Entimates

184

6

EPA Priority Pollutant Chemicals

217

EPA-Designated Carcinogens Likely to Occur in Refineries

8 Polynuclear Aromatics on a Refinery Worker's Apron 


\section{LIST OF TABLES (Continued)}

Table Number

Page

11

Societal Risks Due to Facilities on Canvey Island, United Kingdom

236

Acute Toxicity of Aliphatic Hydrocarbons

239

Effects of Alkane Vapor Exposure on Humans

243

14 Toxicity of Alicyclic Hydrocarbons 247

15. Toxicity of Benzene 250

16 Toxicity of Toluene and Xylenes $\quad 252$

17 Metal Content in Crude 0118. 264

18. Some Metallic Lubricant Additives and Their Uses

19 Physiological Effects of Metals Found in Petroleum Products

Toxiclty of Soluble Aromatic Hydrocarbons

21 Refinery Effluent Components That Can Cause Tainting of the Flesh of Aquatic Organisms

Annual Solid Waste Generation of the U.S. Petroleum Refining Industry

Waste Constituents Generated by Refineries

292

Estimates of Refinery Waste Generation

293

Estimates of Refinery Waste Disposal

Methodologies

Refinery Alr Emissions

302

27 Potential Sources of Atmospheric Emissions within Refineries

Module Atmospheric Emissions from a Gasoline Refinery 
Table Number

Hazardous Hydrocarbons Emitted from FCC Unit Generators

Distribution of Approximate Leak Rates for Two Refineries of S1milar Throughput

Petroleum Refinery Process Streams Likely to Contain Significant Potentially Hazardous PAHS

Hydrocarbons Emitted from FCC Unit Regenerators

Odors of Compounds Found in Refinery Emissions

318

Petrochemical Processes as Waste Sources

Evaluation of Wastewater Flow and Characteristics

Organic Priority pollutants in Refinery

Organic Priority Pollutants in Refinery Wastewater Feeds to Blotreatment

Organic Priority Pollutants in Refinery Final Effluents

Frequency and Concentration Range of Trace Elements in Refinery Intake Waters 


\section{THIS PAGE \\ WAS INTENTIONALLY \\ LEFT BLANK}


REFINERY OPERATIONS

\section{TECHNOLOGY DESCRIPTION}

\section{World Petroleum Refining}

World output of refined petroleum products in 1978 was estimated at 22.9 billion barrels (U.S. Department of Energy 1978e). Refinery production for the U.S. and the world, excluding Sino-Soviet countries for which data are unavallable, is presented in Table 1. SinoSoviet output is estimated at 4,849 million barrels, or 21.2 percent of world output. The 5,647 million barrels produced by U.S. refinerles represents 24.7 percent of the world total, or 31.3 percent of the non-Sino-Soviet world total. The world's largest refining countries, excluding the Sino-Soviet areas, were (in billion barrels) the United States (5.6), Japan (1.7), France (0.9), Italy (0.9), and West Germany $(0.9)$.

\section{Refinery Types and Configurations}

Petroleum refineries are usually classified into general groupIngs based on their primary product slate or processing performed. U.S. Environmental Protection Agency. (EPA) effluent regulations for petroleum refineries recognize five basic categories based on primary products and associated processing:

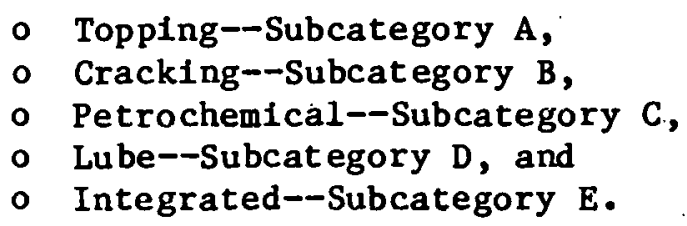

The topping refinery is the simplest of the basic refinery types. Topping refers to the use of simple fractionation (distillation) processes to obtain straight run fractions such as naphtha, middle distillate, and fuel oils from crude olls. Catalytic reforming, hydrotreating, and sweetening processes may be used. Since chemical cracking or cleavage processes are not directly involved, the properties of topping refinery products and pollution are directly related to the crude feedstocks used.' A sluplified flow diagram of a topping refinery is shown 1n Figure 1. The topping refinery's basic processes are essentially duplicated in the other categories of refineries.

A cracking refinery performs catalytic or thermal cracking, besides the basic topping refinery operations. Cracking significantly increases the proportion of lighter aromatics fractions. 
TABLE 1

REFINERY OUTPUT VOLUME FOR $1978^{\mathrm{a}}$

(millions of barrels)

\begin{tabular}{|lcc|}
\hline \multicolumn{1}{|c}{ Product } & U.S. & World \\
\hline Gasoline & $2,630(46.6 \%)$ & $4,813(26.6 \%)$ \\
Kerosene and jet fuel & $410(7.3 \%)$ & $1,353(7.5 \%)$ \\
$\begin{array}{l}\text { Distillate fuel ofl } \\
\text { Residual fuel oil }\end{array}$ & $1,147(20.3 \%)$ & $4,073(2.3 \%)$ \\
$\begin{array}{l}\text { Lubricants (including } \\
\text { grease) } \\
\text { Refinery fuel consumption } \\
\text { and loss) } \\
\text { Other products }\end{array}$ & $5.59(9.9 \%)$ & $4,670(25.9 \%)$ \\
Total refined products & $158(2.8 \%)$ & $171(0.9 \%)$ \\
. & $673(1.2 \%)$ & $2,134(11.8 \%)$ \\
\hline
\end{tabular}

a Data reflect output for the U.S. and the world, excluding the Sino-Solviet countries--the U.j.S.R., China (People's Republic), Germany (East), Poland, Hungary, Romania, Bulgaria, and Albania.

Source: Energy Information Administration 1980. 


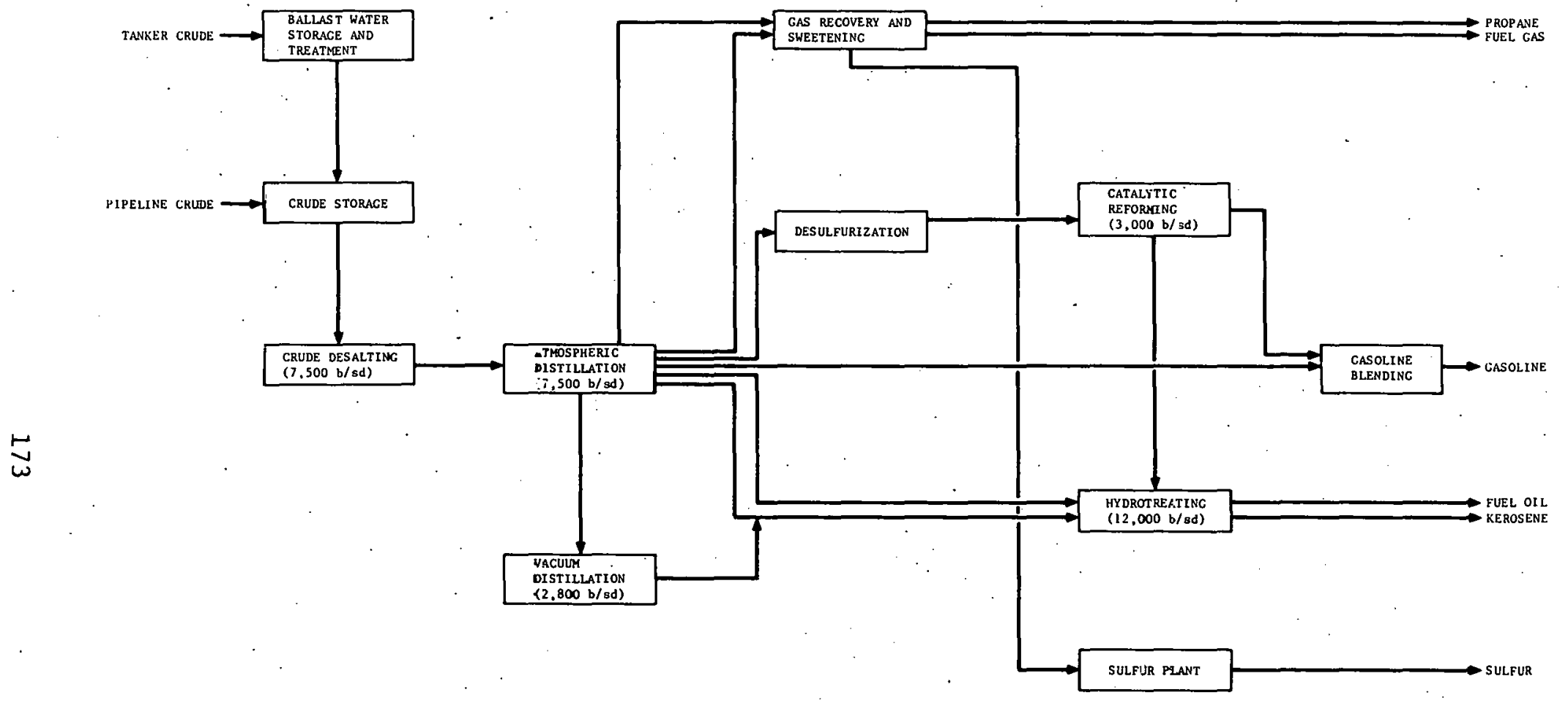

Source: S1tc18 1978

MEDIAN REFINERY FLOW SHEET

FIGURE 1

TOPPING REFINERY (SUBCATEGORY A) 
Heavy and middle distillates are cracked to produce lighter hydrocarbons with a higher octane rating for blending into gasoline, kerosene, jet fuel, and fuel oils, which are in high demand. A simplified flow diagram of a cracking refinery 18 shown in Figure 2.

The petrochemical refinery adds petrochemical operations to those of the topping and cracking categories. Petrochemical feedstocks, such as olefins and BTX (benezene, toluene, and xylene) fractions, are included among major products for subsequent on-site petrochemical manufacture. Petrochemical processing is not considered a refinery operation in this report since it is not primarily related to energy generation or use. A simplified flow diagram of a petrochemical refinery is shown in Figure 3.

The lube refinery adds lubricating oil manufacturing processes as a major activity to those performed by topping and cracking refineries. A simplified flow diagram of a lube refinery 18 shown in Figure 4.

The Integrated refinery includes all the major refinery operations: topping, cracking, lube oll manufacturing, and petrochemical processing. A simplified flow diagram of an integrated refinery is shown in Figure 5 .

\section{U.S. Refineries and Feedstocks}

The approximately 297 U.S. refineries had a capacity of about 18 million barrels per day as of January 1980 (Aalund 1980a). Refinery processing outputs usually are expressed as barrels per calender day (b/cd) or averaged barrels per day and as barrels per stream day (b/sd) or barrels per days in operation. U.S. refinery output by processing operation is shown in Table 2. The states with the largest total refining capacity, in decreasing order, are: Texas, California, Louisiana, Illino1s, Pennsylvania, New Jersey, Indiana, Oh1o, and Oklahoma. Each of these 8 tates has over $500,000 \mathrm{~b} / \mathrm{cd}$ total operating capacity. Figure 6 depicts the approximate locations of most U.S. refineries.

\section{Refinery Feedstocks}

Characteristics and constituents of crude oil and residuals (heavy fractions remaining after distillation) vary greatly. Table 3 presents some of the characteristics of major feedstock crude olls and their residual fractions. Additional information showing the relative proportions of distilled fractions obtainable from feedstocks in various regions of the world is shown in Table 4 . 


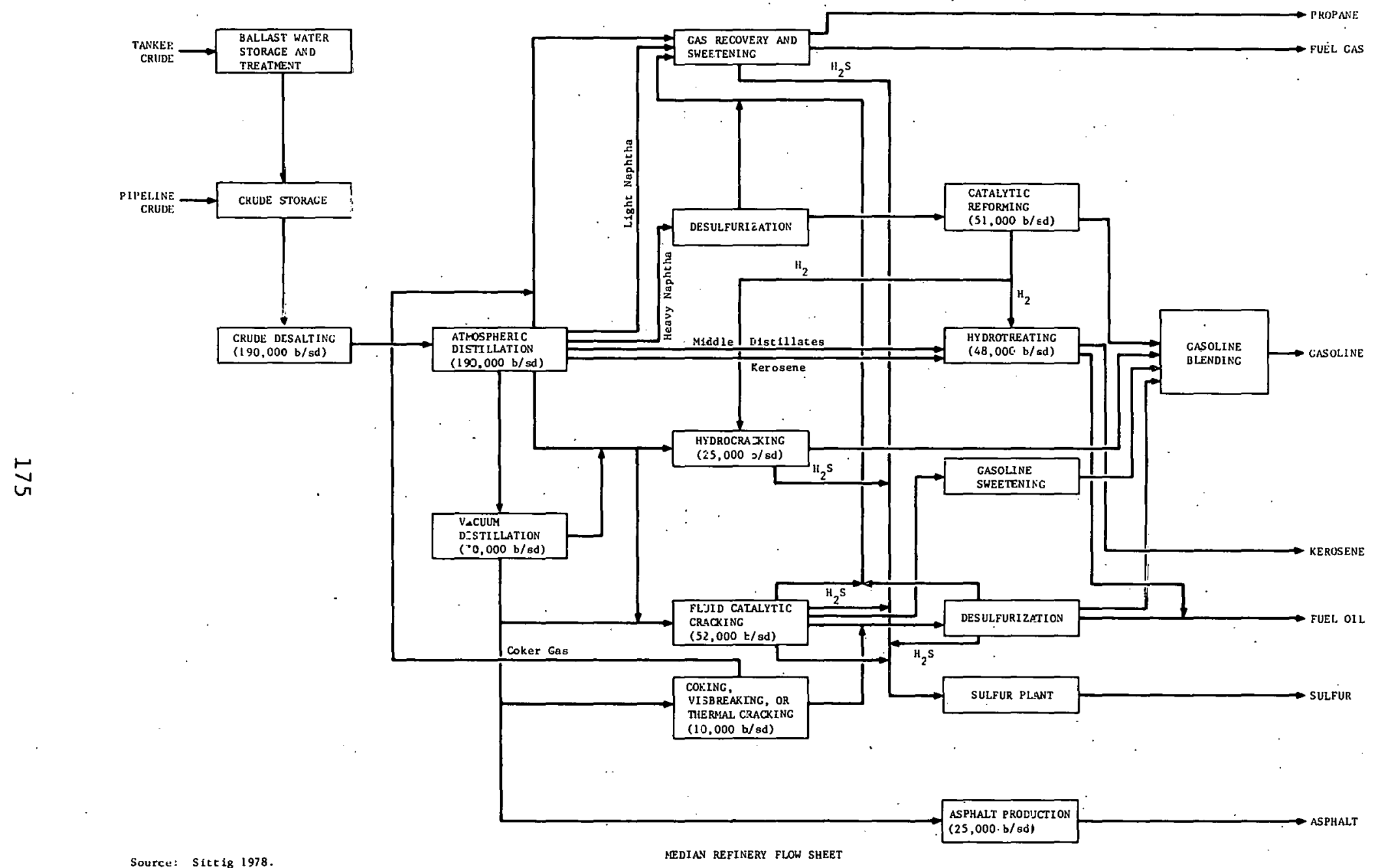

Source: Sittig 1978.

\section{FIGURE 2}

CRACKING REFINERY (SUBCATEGORY B) 


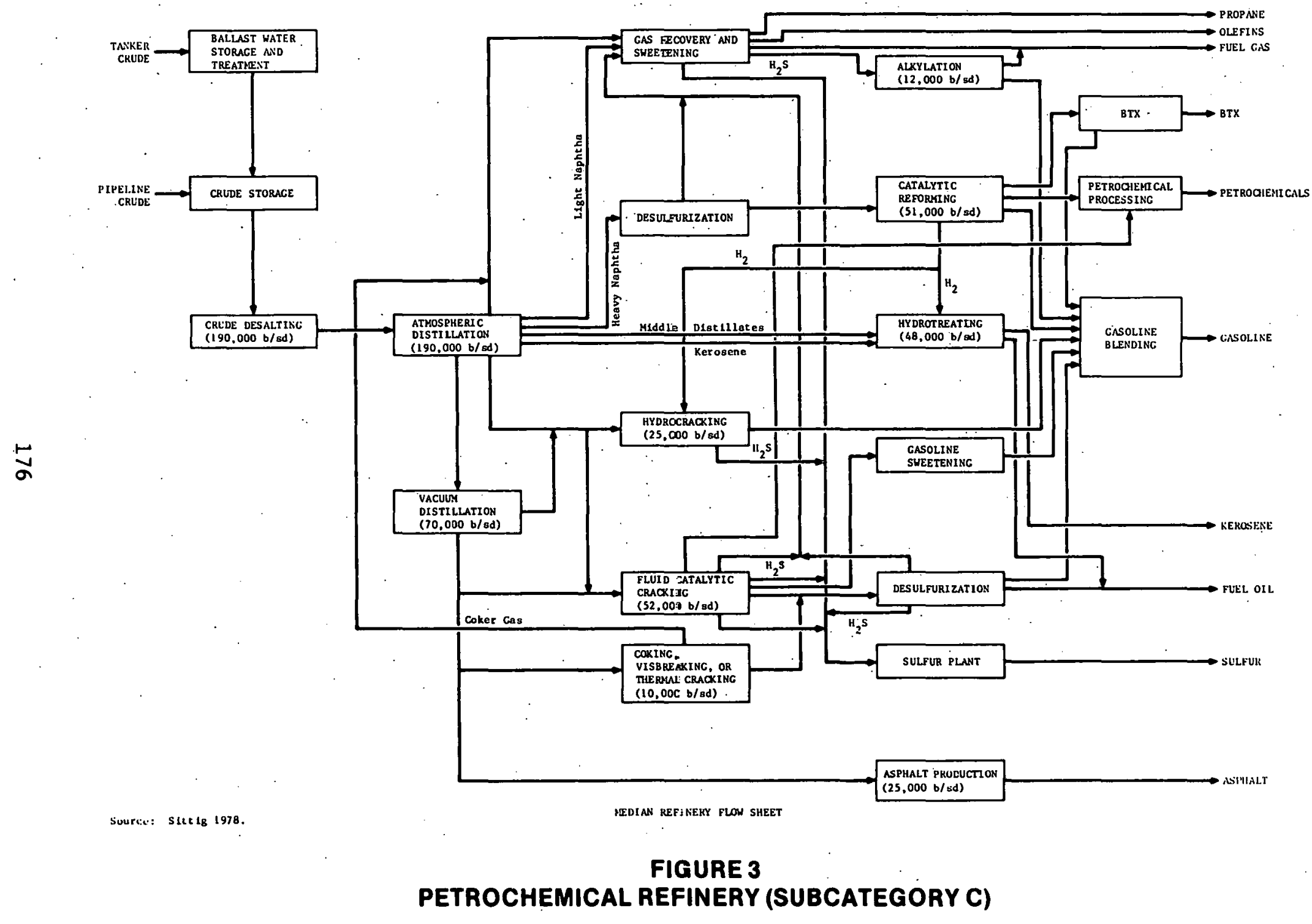




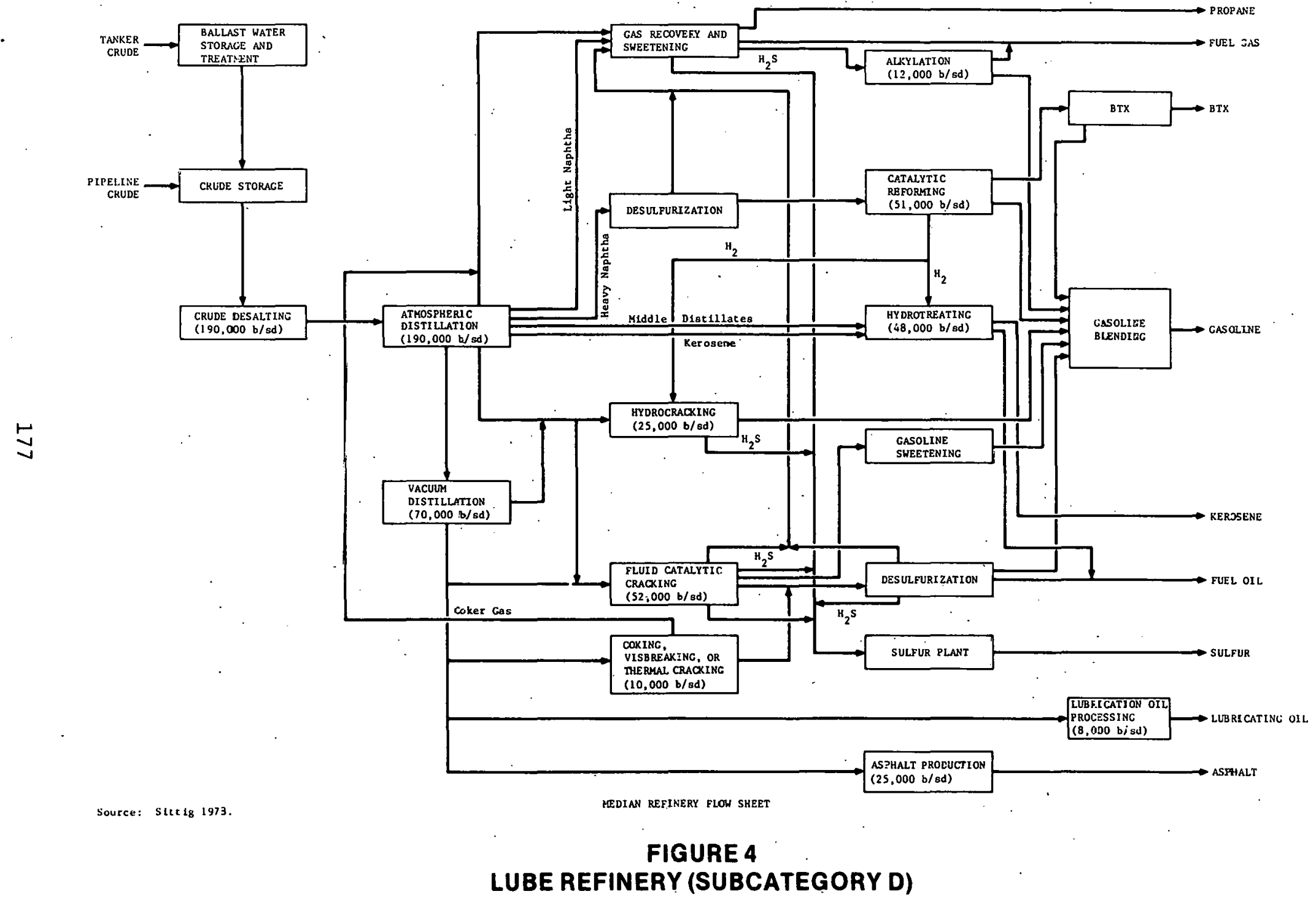




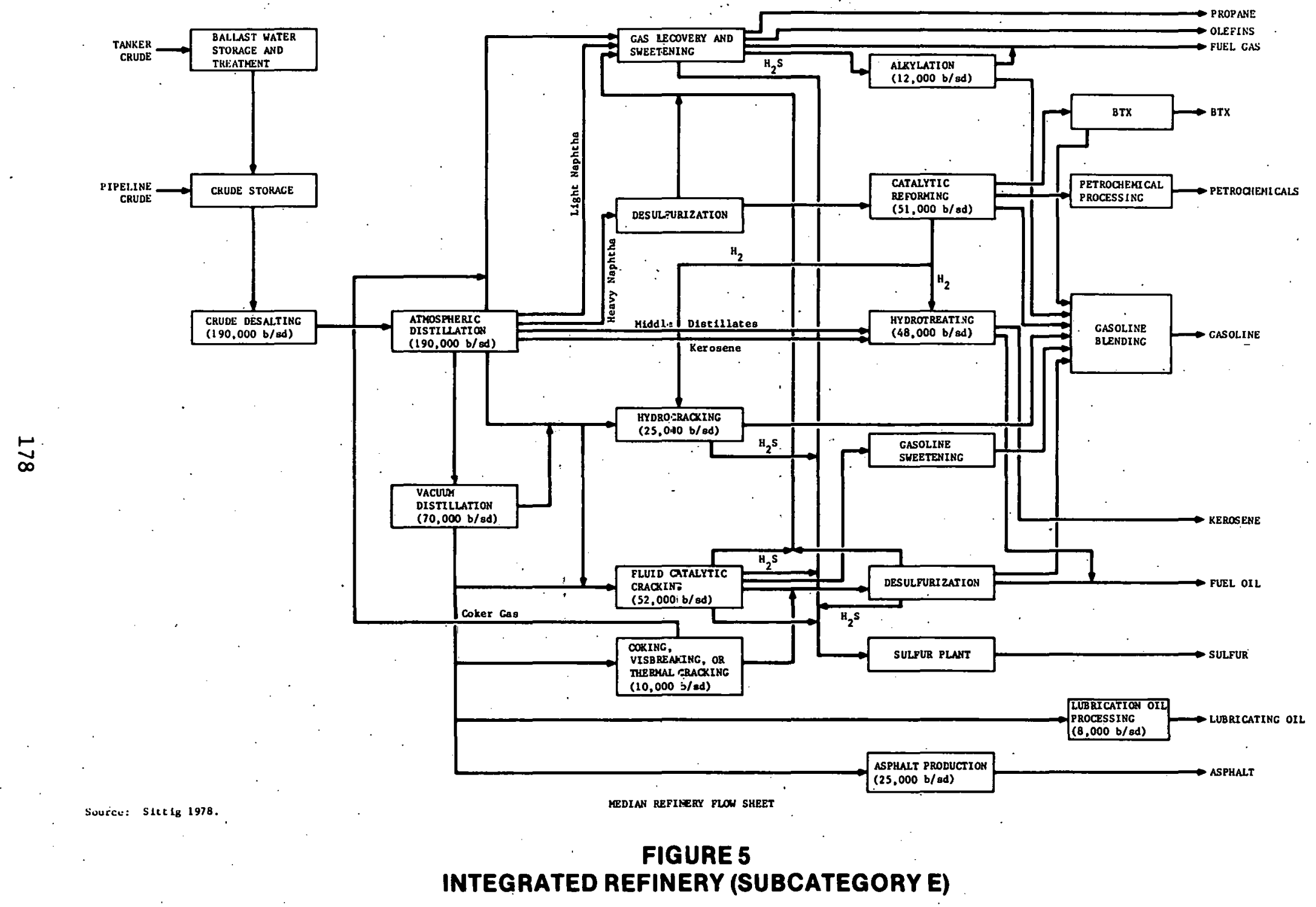


TABLE 2

PROCESSING AT U.S. REFINERIES ${ }^{a}$

\begin{tabular}{|c|c|}
\hline Proces 8 & $\begin{array}{c}\text { Production Volume } \\
(\ln \cdot b / s d)\end{array}$ \\
\hline Vacuum distillation & $6,685,862.0$ \\
\hline Thermal operations & $1,556,425.0$ \\
\hline Catalytic cracking & \\
\hline $\begin{array}{l}\text { Fresh feed } \\
\text { Recycled feed }\end{array}$ & $\begin{array}{r}5,304,906.0 \\
817,194.0\end{array}$ \\
\hline Catalytic reforming & $3,924,469.0$ \\
\hline Catalytic hydrocracking & $888,278.0$ \\
\hline Catalyt1c hydrorefining & $1,956,384.0$ \\
\hline Alkylation production & $1,007,311.0$ \\
\hline Aromatics/18omerization $b$ & $463,800.0$ \\
\hline Lubrication oilsb & $233,252.0$ \\
\hline Asphalt production $b$ & $753,699.0$ \\
\hline Hydrogen production $(\operatorname{mmcfd})^{b}$ & $1,609.2$ \\
\hline Coke production (tons/day) & $48,200.0$ \\
\hline 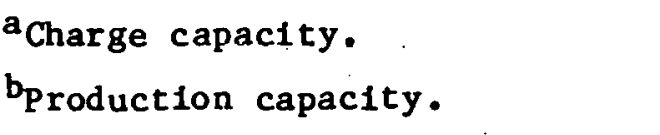 & \\
\hline Source: Aalund 1980a; Cantrell & 1980. \\
\hline
\end{tabular}




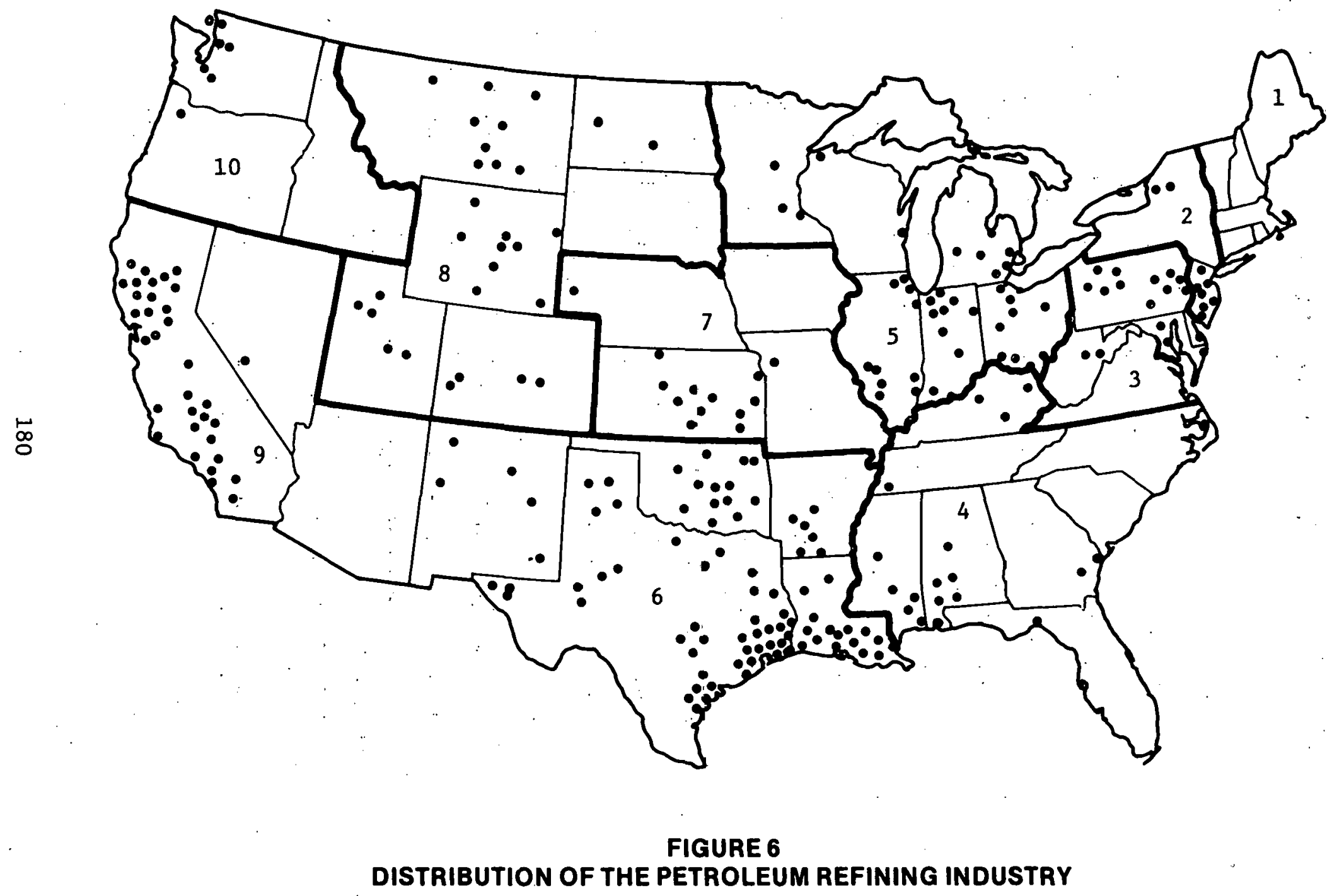


TABLE 3

REPRESENTATIVE CRUDES AND THEIR RESIDUA

\begin{tabular}{|c|c|c|c|c|c|c|c|c|c|c|}
\hline Crude & & $\begin{array}{c}\text { Arabi- } \\
\text { an } \\
\text { Light }\end{array}$ & $\begin{array}{l}\text { Arabi- } \\
\text { an } \\
\text { Heavy }\end{array}$ & Kuwait & $\begin{array}{l}\text { Irani- } \\
\text { an } \\
\text { Heavy }\end{array}$ & $\begin{array}{l}\text { Su- } \\
\text { matra } \\
\text { Light }\end{array}$ & $\begin{array}{l}\text { Vene- } \\
\text { zuelan }\end{array}$ & $\begin{array}{l}\text { Alaskan } \\
\text { North } \\
\text { Slope }\end{array}$ & $\begin{array}{l}\text { North } \\
\text { Sea } \\
\text { Ninian }\end{array}$ & California \\
\hline Gravity ( $\left.{ }^{\circ} \mathrm{API}\right)$ & & 33.3 & 28.1 & 31.3 & 30.8 & 35.3 & 33.3 & 26.3 & 35.1 & 20.9 \\
\hline Sulfur (wt \%) & & 1.8 & 2.9 & 2.5 & 1.6 & 0.07 & 1.2 & 1.0 & 0.41 & 0.94 \\
\hline Nitrogen (wt \%) & & 0.16 & 0.19 & 0.09 & 0.18 & 0.08 & 0.12 & 0.22 & 0.07 & 0.56 \\
\hline Vacuum residua $\left(1,000^{\circ}+\right.$ & $+\mathrm{F})$ & & & & & & & & & \\
\hline Gravity ( $\left.{ }^{\circ} \mathrm{API}\right)$ & & 8.0 & 4.6 & 7.4 & 6.3 & 20.1 & 10.9 & 7.4 & 13.0 & 5.4 \\
\hline Sulfur (wt \%) & & 3.7 & 5.6 & 5.1 & 3.2 & 0.18 & 2.8 & 2.1 & 1.3 & 1.6 \\
\hline Nitrogen (wt \%) & & 0.49 & 0.67 & 0.38 & 0.83 & 0.33 & 0.56 & 0.64 & 0.42 & 1.33 \\
\hline Asphaltenes (wt \%) & & 11.3 & 20.6 & 12.0 & 14.7 & 7.9 & 16.0 & 8.1 & 6.9 & 12.0 \\
\hline $\mathrm{Fe}(\mathrm{p} p \mathrm{~m})$ & & & 10.0 & 0.9 & 9.0 & 13.0 & 5.0 & 15.0 & $<1.0$ & 90.0 \\
\hline
\end{tabular}

Source: Aalund 1980b. 


\section{TABLE 4}

CRUDE OIL QUALITY RANGES IN MAJOR PRODUCTION AREAS

\begin{tabular}{|c|c|c|c|c|c|c|c|c|c|c|c|c|c|c|c|}
\hline \multirow{2}{*}{$\frac{\text { Region }}{\text { Gravity Range }}$} & \multicolumn{3}{|c|}{ Middle East } & \multicolumn{3}{|c|}{ Africa } & \multicolumn{3}{|c|}{ Latin America } & \multicolumn{3}{|c|}{ Western Europe } & \multicolumn{3}{|c|}{ Other E. Hemisphere } \\
\hline & $\operatorname{Max}$ & Av & Min & $\operatorname{Max}$ & Av & Min & Max & Av & $\operatorname{Min}$ & $\operatorname{Max}$ & $\mathbf{A v}$ & Min & $\operatorname{Max}$ & Av & Min \\
\hline Gravity ( $\left.{ }^{\circ} \mathrm{API}\right)$ & 41.0 & 33.2 & 19.0 & 45.0 & 36.3 & 24.3 & 34.0 & 27.8 & 17.0 & 44.0 & 36.7 & 35.0 & 44.0 & 34.8 & 29.0 \\
\hline Sulfur (wt \%) & 1.3 & 1.6 & 4.6 & 0.1 & 0.2 & 0.5 & 0.2 & 1.4 & 2.4 & 0.2 & 0.3 & 1.0 & 0.1 & 0.1 & 0.1 \\
\hline Yields (vol \%) & & & & & & & & & & & & & & & \\
\hline Gasoline & 23.0 & 22.0 & 8.0 & $30: 0$ & 26.0 & 14.0 & 14.0 & 16.0 & 7.0 & 33.0 & 26.0 & 22.0 & 43.0 & 22.0 & 7.0 \\
\hline Middle distillate & 38.0 & 33.0 & 28.0 & 39.0 & 37.0 & 24.0 & 56.0 & 30.0 & 24.0 & 34.0 & 36.0 & 37.0 & 46.0 & 42.0 & 21.0 \\
\hline Residue & 35.0 & 43.0 & 64.0 & 27.0 & 34.0 & $61 . C$ & 29.0 & 53.0 & 68.0 & 28.0 & 35.0 & 38.0 & 8.0 & 35.0 & 71.0 \\
\hline
\end{tabular}

Source: Cuddington 1980. 


\section{Sulfur in Crude 011 Feedstocks}

The removal of sulfur from crude ofl during the production of refinery products is a major task performed by refining processes. Combustion of sulfur-containing petroleum products leads to the formation of sulfur dioxide $\left(\mathrm{SO}_{2}\right)$, an objectionable pollutant. Table 5 presents data concerning sweet (low sulfur) and sour (high sulfur) crude oils and other feedstocks used by U.S. refineries. The type of feedstocks a refinery can process depends largely on the types and configuration of processing equipment it employs. Sulfur compound removal is primarily performed by sweetening and hydrotreating processes. Many U.S. refineries, especially older and smaller refineries, can only handle crude oil feedstocks with a limited aggregate sulfur content. Many of these refineries must use imported sweet (low sulfur) in crude oil as their major or supplemental feedstock.

Sulfur in crude oil occurs as malodorous hydrogen sulfide $\left(\mathrm{H}_{2} \mathrm{~S}\right)$ and as thiols (mercaptans), thiophenes, sulfides, and polysulfides. The nature and concentration of sulfur compounds varies with each crude oll. Sulfur compounds are removed by general refining processes, but, in general, sulfur compounds tend to remain distributed in crude ofl fractions and in their final products in proportions that increase with increasing molecular weight and boiling point.

Sulfur content, usually expressed in terms of percent by weight of sulfur, may not appear high. However, the percentage of sulfurcontaining molecules can be very high, perhaps exceeding half the total crude oll constituents. The sulfur may be incorporated in large molecules comprising crude oll. This sulfur may be removed by catalytic hydrogenation processes such as hydrotreating (hydrodesulfurization). These processes release the sulfur as gaseous hydrogen sulfide and, to a lesser extent, volatile thiols. Resultant potentially toxic and malodornis process streams are usually processed to reclaim elemental sulfur. Crude ofl and fractions are of ten washed with caustic solutions or further fractionated to remove. these sulfur compounds from the liquid phase. The proportion, complexity, and stability of sulfur compounds are higher in heavier residual crude oil fractions. More intense pressures, temperatures, and high purity hydrogen are required to yleld low sulfur residual fuel oils. Low sulfur fuels for power generation and industrial use (as required by Federal regulations) are produced by these energy-intensive methods.

Refinery Process Stream Nomenclature

Petroleum refinery process streams are complex mixtures for which precise definitions and chemical constitution-based nomenclature are lacking. The composition of process streams may vary 
TABLE 5

REFINERY FEEDSTOCKS

(1980 estimates)

\begin{tabular}{|c|c|c|}
\hline Type of Feedstock & $\begin{array}{c}\text { Input } \\
\text { (barrels/day) }\end{array}$ & $\begin{array}{c}\text { Crude and } \\
\text { Field } \\
\text { Condensate } \\
\text { (percent) }\end{array}$ \\
\hline $\begin{array}{l}\text { Sweet crude oll } \\
\text { (less than } 0.5 \% \text { welght sulfur) }\end{array}$ & $8,004,000$ & 50.5 \\
\hline $\begin{array}{l}\text { Medium light crude oil } \\
\text { (0.5-1.0\% weight sulfur) }\end{array}$ & $2,210,000$ & 14.0 \\
\hline $\begin{array}{l}\text { High sulfur crude oil } \\
\text { (greater than } 1 \% \text { welght sulfur) }\end{array}$ & $5,513,000$ & 34.8 \\
\hline Total crude o11 & $15,747,000$ & 99.3 \\
\hline Field condensate & 115,000 & 0.7 \\
\hline Ücher feedistóčks & $1,320,000$ & $=$ \\
\hline Total refinery Input & $17,182,000$ & 100.0 \\
\hline
\end{tabular}

-- Represents zero or rounds to zero.

Source: Aalund $1980 \mathrm{~b}$. 
greatly depending on a multitude of factors, including the crude oil source, process conditions and sequence, and chemicals used.

To aid development of the Toxic Substances Control Act (TSCA) Inventory, EPA is sued an addendum to the Candidate List of Chemical Substances concerning the nomenclature to be used for reporting petroleum refinery intermediates and products (U.S. Environmental Protection Agency 1978). Refinery process streams are generically defined according to their source (process), general hydrocarbon composition, predominant carbon numbers and hydrocarbon types, and boiling range or other physical characteristics. Refinery by-products, waste products, proprletary names, impurities, and additives are not included in this publication. Chemical Abstracts Service (CAS) Reg1stry Numbers are associated with all process streams. The adequacy of these definttions, their acceptance and use by refiners, and the degree to which process streams are considered proprietary information by many refiners will be evident after the inftial TSCA Inventory is published.

Petroleum Refining Processes and Technology

The following are descriptions of major refinery processes. Information was obtained from several sources (Sitt1g 1978; Gulf Publishing Company 1978; U.S. Environmental Protection Agency 1974; and Dickerman et al. 1977).

Crude Desalting

- Application: Inorganic salts, water, suspended solids, and certain water soluble compounds must be removed from crude olls to prevent equipment fouling, corrosion, and catalyst poisoning in downstream processing units.

- Input materialo: Crude ofl; oil bearing water.

o Products: Desalted crude oils for fractlonation processing.

- Process description: Crude desalting is essentially a solvent extraction process using water as the extracting medium. In chemical desalting, chemical deemulsifiers (surfactants) are added to the crude oil, water is added, and the resulting emulsion. is heated to 150 to $350^{\circ} \mathrm{F}$ and held in a settling tank. Salts and other lmpurittes dissolve in or attach to the water globules which settle out and coagulate.

Electrical desalting differs from chemical desalting; electrical differentials are applied and deemulsifiers are used only for crude oils with a high suspended solids content. Suspended water globules 
are concentrated in the bottom portion of the settling tank under the influence of a high voltage electrostatic field.

In both types of processing, desalted crude is continuously drawn off the top of the settling tank and the wastewaters are continuously drawn off the bottom. Ammonia may be added to reduce corrosion.

- Ope rating parameters: Temperature, 150 to $350^{\circ} \mathrm{F}$ (66 to $177^{\circ} \mathrm{C}$ ); and pressure, $2.8+\mathrm{kg}$ per $\mathrm{cm}^{2}(40+\mathrm{ps} 1)$.

- Wastes: Approximately 1.5 to 2.5 gallons of wastewater per barrel of crude ( 35 to 60 liters per $\mathrm{m}^{3}$ ) 18 discharged to the wastewater treatment or sewer system. Water discharge contalns extracted chlorides, sulfides, bicarbonates, free o1l, ammonia, phenol, and suspended solids. This wastewater has a relatively high blological oxygen demand (BOD) and chemical oxygen demand (COD), and contains chlorides and other dissolved materials that may cause adverse effects if discharged untreated into water bodies.

- Trend8: Electrical desalting 18 replacing chemical desalting. Two-stage electrical desalting and supplemental chemical desalting may be used as dirtier crude oils are processed in refineries.

\section{Crude 0il Fractionation}

- Applications: Crude oil is distilled using single or multiple fractionating columins and processes to separate it into intermediate product streams.

- Input materials: Crude oll (desalted).

- Products: Crude oll fractions differentiated by bolling point ranges.

- Process description: Many combinations of equipment configurations and distillation products are encountered, depending on the crude oil used and the desired product mix. Usually, crude oil is preheated using recovered process heat, charged to a direct-fired furnace, and charged to an atmospheric fractionation (distillation) column at about 650 to $700^{\circ} \mathrm{F}$ (344 to $371^{\circ} \mathrm{C}$ ).

The vaporized oil condenses in the vertical fractionation column, with lighter (higher boiling point) fractions diffusing and condensing toward the top of the column and heavier (lower bolling 
point) fractions condensing or remaining at the bottom. Fractions are continously drawn of $f$ and diverted for further processing or distribution.

Residual, high boiling point materials are usually withdrawn into a vacuum fractionation column for separation into lubricants, residual oil fractions, and/or catalytic cracking feedstocks. Heavy asphalt residual base stock is withdrawn from the bottom of the column. Light fractions may be further fractionated and degassed to produce stralght-run gasoline. Gases removed during fractionation Include ethane, methane, propane, and butane.

Steam distillation may be used for stripping (extracting) sulfur-containing compounds.

- Operating parameters: Process takes place at atmospheric pressure or in a partial vacuum; temperature is approximately $248^{\circ} \mathrm{F}\left(120^{\circ} \mathrm{C}\right)$ at the top of the fractionation column and $698^{\circ} \mathrm{F}\left(370^{\circ} \mathrm{C}\right)$ at the bottom. Typical installations are energy-intensive, requiring about $100,000 \mathrm{Btu}$ 's per barrel of crude oll for process heat, $17 \mathrm{~kg}$ of steam per barrel $\left(143 \mathrm{~kg} \mathrm{per} \mathrm{m}^{3}\right)$ of crude oil for stripping, and 82 liters of cooling water per bbl (690 liters per $\left.\mathrm{m}^{3}\right)$ of crude oil.

- Wastes: Condensed water-containing sulfides occur in high concentrations when sour (high sulfur) crudes are processed. They are usually discharged to the wastewater treatment or sewer system. The wastewater also contains ammonia, phenols, ofl, chlorides, thiols (mercaptans), and other watersoluble compounds. Barometric condensers that use water jets to reduce pressure for vacuum distillation may contribute to the formulation of ofl emulsions. However, the use of surface condensers in which oil does not come into contact with water does not lead to this waste. Fraction sampling may. produce some wastes.

Distillation is essentially a closed process, in terms of atmospheric releases. Fugitive hydrocarbon emissions and process heaters are the major sources of atmospheric emisslons,

o Trends: Larger and more complex fractionation systems reflect the general industry treud toward larger, more complex, refineries. Multiple atmospheric and vacuum distillation unit configurations with increased sidestreams and products represent another trend. Surface condensers for vacuum distillation are replacing barometric condensers. 


\section{Drying and Sweetening}

- Application: Sweetenting processes remove sulfur compounds, primarily hydrogen sulfide, thiols (mercaptans), and thiophenes, to improve odor, color, and oxidation stability; to lower fuel sulfur content to comply with environmental regulations; and to lower the amount of tetraethyl lead required to boost gasoline octane ratings. Drying removes water and both processes lower concentrations of carbon dioxide and other impurities.

- Input materials: A wide varlety of intermediate and final products are dried and sweetened. Usually middle distillate liquids, such as gasoline, kerosene, jet fuels, home heating oils, and sometimes sour gases, are processed.

- Process description: Most sweetening processes involve the use of a caustic (basic) regenerable- sorbent liquid, usually diethanolamine, to extract sulfur compounds. Washing solutions are regenerated by heating and air or steam stripping. Electrical fields may be applied to facilitate separation. Drying is performed using sand filters, absorptive clay beds, or other water adsorptive or absorptive media.

Chemical sweetenting processing involves three major activities: (1) oxidation of thlols (mercaptans) to less objectionable disulfides; (2) removal of thiols; and (3) destruction or removal of other sulfur compounds including hydrogen sulfide and elemental sulfur (also performed through hydrotreating). Processes that convert thiols into disulfides include Doctor Sweetening, copper sweetening, Bender, and Merox.

Inhibitor sweetening uses a caustic solution and a substituted phenylenediamine substance to catalytically oxidize thiols to disulfides in gasoline and related products. The phenylenediamine substance acts as an inhibitor, reducing the amounts of oxidation inhibitors normally added later to final gasoline blends.

- Operating parameters: Dependent on process(es) used.

- Wastes: Spent caustic solutions are the most common wastes from drying and sweetening. Spent caustics may be characterized as sulfidic or phenolic, depending on the oil treated. Spent sulfidic caustics contain high sulfide concentrations. Spent phenolic caustics contain high concentrations of phenol., cresols, xylenols, and sulfur compounds. Spent caustics have very high BOD and COD. When diethanolamine is used, a 
small amount--about one gallon per 100 barrels (four liters per $159 \mathrm{~m}^{3}$ )--of waste must continually be replaced.

Water washing of treated products and regeneration of treating agents, such as sodium plumbite $\left(\mathrm{Na}_{2} \mathrm{PbO}_{2}\right)$ used in Doctor Sweetening and copper chloride, may cause small amounts of these substances to be discharged in aqueous waste streams.

Sweetening of sour gases results in an $\mathrm{H}_{2} \mathrm{~S}-\mathrm{rlch}$ gas stream that may be flared, burned as fuel, or processed to recover elemental sulfur.

No atmospheric emissions, other than fugitive emissions, are associated with these processes.

- Trends: Air pollution standards to control sulfur emissions have resulted in a strong trend toward replacing sweetening processes with hydrotreating, because hydrotreating removes almost all, not just select, sulfur compounds. Sweetening w111 continue to be used because it is effective and economical. Sweetening processes producing toxic or high waste loads, such as Doctor Sweetening, will tend to be replaced by lower waste-producing processes.

\section{Solvent Refining and Dewaxing}

- Applications: Solvent refining includes a multitude of processes that extract desired and undesired components from feedstocks on the basis of differential solubilities. Most frequently, the processes are used to separate aromatic from non-aromatic components, dewax lubrication oils, deoil waxes, and to remove undesired unstable, acidic, sulfur, organometallic, naphthenic, and/or nitrogen compounds. Removal of aromatics improves diesel fuel combustion and increases gasoline octane ratings.

- Input materials: A wide variety of feedstocks are used, including fractionated crude oils, deasphalted oil, naphtha, and catalytic reforming products. Feedstocks vary with the processes and desired products.

- Process description: Hydrocarbons and other substances are separated on the basis of their relative solubilities in different solvents. Solvents used in the various processes include acetone, benzene, dichloroethane, diglycolamine, formy lmor pholine, furfural, methyl-ethylketone, methyl-isobutylketone, n-methylpyrrolidone, methylene chloride, pentane, 
phenol, propane, propylene, sulfolane, sulfur dioxide, sulfuric acid, tetraethylene glycol, toluene, urea, and water.

Processing usually involves:

(1) Drying and/or deaeration of the feedstock;

(2) Using countercurrent solvent extraction techniques;

(3) Separation of the bulk of the solvent from the product by heating and fractionation or evaporation;

(4) Removal of solvent traces from the product by steam stripping or vacuum flashing (exposure to high vacuum); and

(5) Solvent purification for reuse.

- Products: refined olls, fuels, and waxes; high octane blending components; and high-purity aromatics.

- Operating parameters: Solvent extraction processes may involve heating or refrigeration of feedstocks and/or products. Electrostatic precipitation may be used to separate inorganic compounds.

- Wastes: The solvents themselves are the major potential pollutants from solvent refining. Many of the solvents such as phenol, glycols, and amines have high BOD. Solvents are nearly always recycled, but leaks and spilis may occur. Water from the bottom of fractionation towers containing oil and solvent is the main aqueous waste stream.

- Trends: Solvent refining will increase as quality requirements for refinery products increase and as demand for extracted aromatics for petrochemical production increases.

\section{Hydrotreating}

- Applications: Like hydrocracking, hydrotreating involves the catalytic combination of hydrogen with feedstock hydrocarbons. However, in hydrotreating, the degree of saturation is not as severe. Hydrotreated feedstocks may be used as blending stocks for final products, or they may be used as feedstocks for additional processing, especially catalytic reforming which requires hydrotreating as pretreatment to malntain catalyst viability and to yield a better product. 
Hydrotreating causes sulfur-bearing compounds to form hydrogen sulfide and nitrogen-bearing compounds to form ammonia. Approximately 90 percent of the sulfur and nitrogen are removed from the feedstock. Catalyst regeneration associated with subsequent catalytic cracking will release less sulfur dioxide to the atmosphere.

- Input materials: Many processes using practically all possible feedstocks are employed. Naphthas, Including gasolines, account for the largest share of hydrotreated feedstocks.

- Process description: Catalysts and feedstocks used account for the major differences among the available processes. In most processes, the feedstock is mixed with hydrogen, heated, and charged under pressure to catalytic reactor units. Reactor products are cooled, hydrogen separated and recycled, and desired and undesired fractions separated. The degree of hydrogenation increases with pressure, temperature, and contact time. Excessive contact time and temperature lead to coke formation. Most hydrotreating processes require constant hydrogen input from a hydrogen generation unit.

- Products: Feedstocks with low sulfur, nitrogen, and olefin contents, and improved stability.

o Operating parameters: Pressures at 100 to $3,000 \mathrm{psig}$, depending on the process; temperatures at 350 to $850^{\circ} \mathrm{F}$ ( 176 to $454^{\circ} \mathrm{C}$ ), depending on the process, but usually at 600 to $800^{\circ} \mathrm{F}$ ( 315 to $426^{\circ} \mathrm{C}$ ); and hydrogen consumption, usually at less than 200 scf per barrel of charge.

- Wastes: The concentration and quantity of wastes depend on the process used. Wastewater streams come from steam strippers, sour water stripper bottoms, and accumulators on fractionation columns. Sulfides and ammonia are the major pollutants. Phenols may be present if a high bolling point feed is used.

- Trends: Hydrotreating has primarily been used to treat light materials, such as naphthas and gasolines; but with continued developments heavier fractions are being processed. Hydrotreating is increasing, because it can be applied to most feedstocks, is flexible, and reduces gross air and water pollution. Hydrotreating and hydrocracking units are being installed at faster rates than other refining process units.

\section{Hydrocracking}

- Applications: Hydrocracking is probably one of the most economically important processes in modern U.S. refineries. 
Heavy sour feedstocks may be converted into sweeter, lighter, more profitable products, especially gasoline, other light fuels, and petrochemical feedstocks.

Hydrocracking combines catalytic cracking of hydrocarbons with catalytic hydrogenation under high pressures. Cracked hydrocarbons are hydrogenated to yield totally saturated products with lower aromatic contents.

Sulfur and nitrogen compounds are usually removed in the process. Most hydrocracked fractions do not require additional sweetening.

- Input materials: A wide range of feedstocks, including most distillate fractions, gas o1ls, heavy sour crude o11s, and residuals, may be hydrocracked. Hydrocracked fractions may be further processed. Prectous metal compounds may be employed as catalysts.

- Process description: The process is much like hydrotreating, but takes place in a hydrogen atmosphere at higher pressures and lower temperatures. Reactor outputs are separated, and fractionated; hydrogen is recycled to the reactor, and heavier-than-desired fractions are recycled to the reactor. olefins. (alkenes) formed during cracking are saturated with hỳdröogen.

o. Products: Gasoline, high octane 1soparaffins, jet fuels, diesel fuels, and low-sulfur fuel oll.

- Operating parameters: Temperature at 780 to $1,500^{\circ} \mathrm{F}$ (400 to $800^{\circ} \mathrm{C}$ ), pressure at 100 to $2,000 \mathrm{psig}$.

- Wastes: Aside from the process heaters, atmospheric emissions result from catalyst regeneration operations and fugitive hydrocarbon emissions. Large quantities of carbon monoxide may be released from catalyst regeneration.

A sour water and ammonia-containing waste stream forms from steam condensation during catalyst steam stripping and regeneration.

Catalys ts usually have a life of about 2 years, after which they may be reclaimed or disposed of as solid waste.

o Trends: Hydrocracking capacity is growing because it allows for adjusting refinery intermediates and products to meet market demands. More profitable products such as high-octane 
unleaded gasoline may be produced than can be obtained through other processes.

\section{Alkylation}

- Applications: Alkylation is used to convert normally gaseous hydrocarbons to high-octane gasoline components. Isoparaffins (secondary alkanes), usually isobutane, are catalytically combined (condensed) with olefins (alkenes), such as propylene, butylene, and pentylene, using a strong acid catalyst to form longer chain hydrocarbons. When butylene undergoes alkylation with 1sobutane, the major product is isooctane $(2,4,4-t r i m e t h y l p e n t a n e)$, the reference material for octane ratings having an octane number of 100 .

- Input materials: The process uses petroleum gases (e.g., isoparaffins, usually 1sobutane; and olefins, usually propylene, butylenes, and pentylenes).

- Process description: A dry, olefinic gaseous feedstock is mixed with excess isobutane and reacted with an acid catalyst in a reaction vessel. The catalysts may be hydrofluoric acid $(\mathrm{HF})$, aluminum chloride $\left(\mathrm{ALCl}_{3}\right)$, or sulfuric acid $\left(\mathrm{H}_{2} \mathrm{SO}_{4}\right)$. Reactor output is separated, the acid phase recycled to. the reactor, and hydrocarbons are passed through a caustic and water wash and fractionated. Excess isobutane is recycled to the reactor and by-products (normal butane and propane) are removed.

When sulfuric acid 18 used as the catalyst, acid and organtcally combined sulfur are removed by caustic scrubbing prior to fractionation. The reactor temperature may be maintained through refrigeration.

- Operating parameters: Temperature at about $120^{\circ} \mathrm{F}\left(48^{\circ} \mathrm{C}\right)$ for $\mathrm{AlCl}_{3}$, about 50 to $61^{\circ} \mathrm{F}\left(10\right.$ to $\left.16^{\circ} \mathrm{C}\right)$ for $\mathrm{H}_{2} \mathrm{SO}_{4}$, and about 81 to $90^{\circ} \mathrm{F}\left(27\right.$ to $32^{\circ} \mathrm{C}$ ) for $\mathrm{HF}$; pressure at 100 to $150 \mathrm{psig}$ ( 7 to $10 \mathrm{~kg}$ per $\mathrm{cm}^{2}$ ) reported for $\mathrm{HF}$ and $\mathrm{H}_{2} \mathrm{SO}_{4}$.

- Wastes: Catalytic alkylation processes are generally closed systems with no process vento to the atmosphere, except for those from fired heaters. HF units are generally closed systems. However, any leaks or spills involving fluorides are hazardous health and safety problems. Alkaline (caustic) scrubbers remove any fluorides that could be incidentally discharged in process streams. HF acid regeneration units 
usually produce a sludge material that is efther incinerated or alkaline washed to produce solid waste fluorides. Fluorides removed from the output are also disposed of as solid wastes.

Wastewaters from sulfuric acid process product scrubbing are usually processed by the refinery's water neutralization and wastewater treatment systems to recover the acid or to neutralize other wastes. Waste streams from scrubbing usually contain sulfides, suspended and dissolved solids, oils, and other contami nants.

- Trends: Alkylation capacity may be expected to increase to satisfy demands for high-octane gasoline. However, feedstock olefins may be routed to make more profitable petrochemicals. Alkylation is replacing polymerization as the means of converting olefins to gasoline because its products have higher octane ratings.

\section{Isomerization}

- Applications: Isomerization is used to convert normal $\mathrm{C}_{4}$ to $\mathrm{C}_{6}$ primary alkanes (butane, pentane, and hexane) into their respective isoparaffins (secondary alkanes). Isobutane formed may be used as a feedstock for alkylation processes. Isopentane and 1sohexane have suffioiently high octane ralings to be used directly as blending components for gasoline.

- Input materials: Normal butane, pentane, and hexanecontaining fractions from a number of process streams.

- Process description: Sweet, dry feedstock is mixed with hydrogen and organtc chlorides as a promoter; then it is heated, and passed over a catalyst. The use of chlorinated platinum-aluminum oxide catalys ts has been reported. Hydrogen is separated from the product and recycled. Liquids are fractionated to separate normal parafins from isoparafins and isoparafin product $s$ treams are neutralized with alkaline materials. Normal parafins are recycled, isobutane is sent on to alkylation units, and 1sopentane and 1sohexane are used for gasoline blending. Hydrogen 18 used in the process to hydrogenate side-reaction unsaturated compounds and to prevent polymertzațion.

- Operating parameters: Temperature at 464 to $491^{\circ} \mathrm{F}$ (240 to $255^{\circ} \mathrm{C}$ ), and pressure at 300 to $400 \mathrm{psig}(21$ to $28 \mathrm{~kg}$ per $\mathrm{cm}^{2}$ ). 
- Wastes: Isomerization is essentially a closed process. The neutralization step produces some aqueous wastes that would probably be relatively low in sulfide, ammonia, phenolics, and BOD.

Catalysts are generally replaced after 2 years and reprocessed for platinum and precious metal recovery at plants that are separate from the refinery.

Catalytic Reforming

- Applications: Reforming is primarily used to increase the octane rating or antiknock qualities of naphtha-rich fractions used as gasoline blending stock. Although a number of reactions take place, the predominant reactions are the dehydrogenation and aromatization of naphthenes (cyclic alkenes) to form stable C6 to C8 aromatics, such as benzene, toluene, xylenes, and others. These aromatics have a higher Research Octane Number (RON) than their precursors and are usually used for gasoline blending. Catalytic reforming also causes other reactions to occur: paraffin hydrocracking, paraffin dehydrocyclization, and paraffin isomerization. Hydrogen from dehydrogenation reactions is a major by-product of catalytic reforming. Some hydrogen may be recycled to sustain reactor pressure and to suppress coke formation caused by polymerization. Most of the hydrogen is used for other processes, such as hydrocracking, hydrotreating, isomerization, and petrochemical processing.

Bi-metallic and multi-metallic catalysts containing platinum and other metal promoters, such as rhenium, are used in most processes.

- Input materlals: Feedstocks are desulfurized (sweetened) naphthas and naphthene-rich fractions. Usually the feedstock has been hydrocracked. Removal of sulfur, nitrogen, arsenic, and other metals from feedstock is required to prevent catalyst polsoning (deactivation).

- Process description: Platforming is the most widely used catalytic reforming process. The charge and recycled gases are heated and passed through a series of catalytic reactors. Reactor oucput is separated into liquid and gas streams, the gases are compressed for recycling, and liquids are stabillzed to the desired vapor pressure. Catalysts may be continuously withdrawn, regenerated, and returned to the top of the reactor units. Alternatively, the catalyst may be 
periodically regenerated by taking the reforming units off stream, or one reactor may be regenerated at a time.

- Products: High-octane gasoline fractions; benzene, toluene, xylenes, and other aromatics; and isobutane. Hydrogen is a significant by-product.

- Operating parameters: Temperature varies with installation, feedstock, and desired products. Pressure is the most important parameter and controls the relative amounts of dehydrogenation and hydrocracking reactions.

o. Wastes: This is essentially a closed system process. Slight atmospheric emissions may occur from catalyst regeneration, mostly as carbon monoxide.

- Trends: Catalytic reforming processing has increased to supply increased amounts of high-octane gasoline.

Thermal Cracking

- Application: Thermal cracking involves the breaking down of heavy ofl fractions, usually residuals from vacuum fractionation processes, Into lighter (lower-molecular-weight) middle distillate and heavy fuel oil fractions. Heat and pressure are used, rather than catalysts. Heat breaks the honds withln hydrocarbon chains and, to a lesser extent, may cause recombination (polymerization) to form larger molecules. Coking processes yield coke, which is widely used as a fuel in industry.

- Input materials: Residual crude oil fractions, asphalts, and unfractionated crude olls.

- Process description: Visbreaking is a mild form of thermal cracking that causes little reduction in bolling point range, but signtficantly lowers the viscosity of the feed. The feed is heated in the visbreaking heater, vapors are removed, and the heavier fractions are recycled. The output mav be fractionated for gasoline, fuel olls, gas oil, and gases.

Coking is a severe form of thermal cracking, often using a residual feedstock that has resisted other cracking processes. Feed is heated and held at a high temperature. The vapor phase undergoes further cracking, and the liquid phase undergoes successive cracking and polymerization to form vapors and coke. Vapor phases are fed into fractionation units. Coking units usually have at least two drums--one 
in service while the coke from the other is removed with high-pressure water jets.

- Products: Coke, fuel oils, gas oll, naphtha, gasoline, and gases.

- Operating parameters: Coking heater outlet temperatures are about 900 to $950^{\circ} \mathrm{F}\left(482\right.$ to $\left.510^{\circ} \mathrm{C}\right)$, and pressures are about 20 to $60 \mathrm{psig}\left(1.4\right.$ to $4.2 \mathrm{~kg}$ per $\left.\mathrm{cm}^{2}\right)$. In general, an increase in temperature increases light hydrocarbon yields and decreases coke production, while higher pressures have the opposite effect.

Visbreaking inits use steam at about $575^{\circ} \mathrm{F}\left(302^{\circ} \mathrm{C}\right)$ and 300 psig (21 kg per $\left.\mathrm{cm}^{2}\right)$.

o Wastes: Water, usually contalning various oll fractions and high in BOD, COD, ammonia, phenol, and sulfides, results from thermal cracking fractionation units. Wastewater may be highly alkaline.

- Trends: Visbreaking and coking are the two major forms of thermal cracking in the U.S. Older thermal cracking processes have been practically eliminated.

\section{Catalytic Cracking}

- Applications: Catalytic cracking is used to increase the yield and quantity of gasoline and other desirable lighter products, while minimizing the yield of residual or heavier products.

- Input materials: A wide variety of feedstocks are used, including naphthas, gas o1ls, coke distillates, deaspha1tized oils, and sometimes unfractionared crude o1ls.

- Process description: Catalytic cracking involves the use of at least four chemical reactions--thermal decomposition, primary catalytic reactions at the catalyst surface, secondary catalytic reactions between the primary products, and polymerization and removal of products from reactions by absorption on catalyst surfaces as coke.

Catalysts include synthetic and natural'silica-alumina, treated bentonite clay, fuller's earth, aluminum hydrosilicates, zeolites, and bauxite. Catalyst forms include beads, pellets, and powders, and they are used in fixed, moving, or fluidized beds. Fluidized-bed catalytic cracking (FCC) uses 
finely powdered catalysts that, when mixed with a gas, have physical properties similar to liquids. This fluid catalytic cracking accounts for most of the catalytic cracking capacity in the U.S.

In fluid catalytic cracking, hot powdered catalyst is lifted by the incoming feed which vaporizes upon contact. Reactor vapors pass through cyclone separators that separate powdered catalyst from gaseous reaction products. Vapors enter a fractionation column where desired products are removed and heavier fractions are usually recycled to the reactor. Spent catalyst passes to a steam stripper to remove residual hydrocarbons, and then to a regenerator where coke deposited on the catalyst 18 burned off through combustion with preheated a1r. The degree of combustion, by design, may vary from complete combustion, to $\mathrm{CO}_{2}$ or any $\mathrm{CO}_{2}$-to-CO rat1o. The hot regenerated catalyst is fed back to the reactor.

Flue gases from catalyst regeneration pass through cyclone separators and/or electrostatic precipitators to remove catalyst. Flue gases containing appreclable quantities of $\mathrm{CO}$ may be burned in a $\mathrm{CO}$ boller. The energy content of pressure, flue gas heat, and heat from Co combustion are frequently recovered to drive equipment or generate steam.

F1xed-bed catalytic cracking employs stationary catalyst beds. Moving-bed catalytic processing uses catalyst beads which fall through the reaction chambers.

o. Products: Gases (alkanes), gasoline, middle dist1llates, and petrochemical feedstocks.

- Operating parameters: Fluidized-bed catalytic cracking reactor temperatures are 887 to $1,022^{\circ} \mathrm{F}\left(475\right.$ to $\left.550^{\circ} \mathrm{C}\right)$, and pressures are 10 to $30 \mathrm{psig}\left(0.7\right.$ to $2.1 \mathrm{~kg}$ per $\left.\mathrm{cm}^{2}\right)$. With catalyst regenerators, the temperatures are 1,247 to $1,400^{\circ} \mathrm{F}$ $\left(675\right.$ to $760^{\circ} \mathrm{C}$ ), and pressures are 15 to $35 \mathrm{psig}$ ( 1 to $2.5 \mathrm{~kg}$ per $\mathrm{cm}^{2}$ ). Moving- and fixed-bed units operate under similar onditions.

- Wastes: Catalytic cracking is a major source of refinery pollution. Catalyst regeneration, involving steam stripping and decoking, results in fluid waste streams containing oil, sulfides, phenols, ammonia, and other substances. The catalyst steam stripper has been reported to use five gallons of water per barrel of feed ( 120 liters per $\left.\mathrm{m}^{3}\right)$, which is routed to wastewater treatment systems. Atmospheric emissions from generators with no emission controls include: 
(1) Particulates --32 to $116 \mathrm{gr}$ per bbl $(0.267$ to $0.976 \mathrm{~kg}$ per $\mathrm{m}^{3}$ ) fresh feed;

(2) Sulfur oxides--107 to $185 \mathrm{gr}$ per bbl $(0.898$ to $1.505 \mathrm{~kg}$ per $\mathrm{m}^{3}$ ) fresh feed;

(3) Carbon monoxide--4,677 $\mathrm{gr}$ per bbl (39.2 $\mathrm{kg}$ per $\left.\mathrm{m}^{3}\right)$ fresh feed;

(4) Hydrocarbons--75 $\mathrm{gr}$ per bbl $\left(0.630 \mathrm{~kg}\right.$ per $\left.\mathrm{m}^{3}\right)$ fresh feed;

(5) Nitrogen oxides- -13 to $50 \mathrm{gr}$ per bbl $(0.107$ to $0.416 \mathrm{~kg}$ per $m^{3}$ ) fresh feed;

(6) Aldehydes $-6.44 \mathrm{gr}$ per bbl $\left(0.054 \mathrm{~kg}\right.$ per $\left.\mathrm{m}^{3}\right)$ fresh feed; and

(7) Ammonia--18 gr per bbl $\left(0.155 \mathrm{~kg}\right.$ per $\left.\mathrm{m}^{3}\right)$ fresh feed.

Atmospheric emissions controlled bý Co bollers yield negligible amounts of carbon monoxide, a quantity of particulates ranging from 4.3 to $21 \mathrm{gr}$ per barrel $(0.036$ to $0.175 \mathrm{~kg}$ per $\mathrm{m}^{3}$ ) of fresh feed, and somewhat lesser amounts of other emissions. The co boiler has too low a temperature (about $700^{\circ} \mathrm{C}$ ) to consume the other combustible emissions.

Aqueous wastes, primarily condensed steam from catalyst stripping, contain hydrogen sulfide, mercaptans, ammonia, and phenols. These wastewaters are alkaline and have high COD and BOD. Sulfide and phenols concentrations may vary greatly, depending on the feedstock fractions or crude ofls.

- Trends: Industry is turning increasingly to catalytic cracking and larger sized units because of the demand for high-octane gasolines and petrochemical feed stocks. Fluid catalytic cracking is more competitive than flxed-or movingbed catalytic cracking. However, many existing units may be expected to remain in operation for several years.

\section{Polymerization}

- Applications: Polymerizatinn is used to convert olefin (alkene) feedstocks into higher-octane gasoline blends. Polymerization is much like catalytic alkylation. However, two olefins are combined, rather than an olefin and an isoparaffin, as in alkylation. Polymerization is decreasing 
In use because olefins yleld a higher return when used as feedstocks for petrochemicals.

- Input materials: Any combination of olefins, such as ethylene, propylene, butylene, and/or pentylene.

- Process description: Olefin gases are passed over catalysts where polymerization occurs. Phosphoric acid catalyst is usually used, but sulfuric acid is used in some older units. The reaction is exothermic, requiring the use of cooling water and injection of cold feed into the reactor. Vapor products are fractionated, acid catalysts are recycled, and acid in products is removed by caustic washing.

- Operating parameters: Temperature at 300 to $435^{\circ} \mathrm{F}$ (149 to $223^{\circ} \mathrm{C}$ ), and pressure at 150 to $1,200 \mathrm{psig}(10.5$ to $84 \mathrm{~kg}$ per $\mathrm{cm}^{2}$ ).

- Wastes: Polymerization is a closed process with no purposeful atmospheric emissions. Alkaline solutions from caustic washing and acids washed out during maintenance are liquid wastes. Acid catalysts adhering to solids yleld solid waste when periodically removed.

- Trends: Polymerization does not increase octane ratings as much as alkylation and required olefin feedstocks may be more profitably used in petrochemical processing. The polymerization capacity has been decreasing in U.S. refineries.

Deasphalting

- Applications: Deasphalting, or the removal of asphalt residues, is used to upgrade several intermediates and products. Deasphalting improves lubricating oil qualities and deasphaltized oils are among preferred feedstocks for catalytic cracking and hydrocracking processes. Extracted asphalt may be utilized by blending with other products or the asphalt output may be marketed. Deasphalting removes some sulfur and nitrogen compounds, metals, carbon residues, and parafins from the feedstock.

- Input materials: The feedstock is usually a vacuum fractionation or other residual o1l. Lubricating o1ls and asphalts may be processed.

o Process description: Deasphalting is usually performed by solvent extraction using propane or other light hydrocarbons. Resulting deasphaltized oil and asphalt phases are processed 
through evaporation and steam stripping to separate and recover propane, oil, and asphalt products. 011 and asphalt products may be further vacuum or atmospheric fractionated.

- Products: Asphalt or heavy fuel blending stocks and deasphalted o1ls.

- Operating parameters: Temperature at 160 to $220^{\circ} \mathrm{F}$ (70 to $105^{\circ} \mathrm{C}$ ), pressure at 450 to $600 \mathrm{psig}$ ( 32 to $43 \mathrm{~kg}$ per $\mathrm{cm}^{2}$ ), and steam at 30 to $140 \mathrm{lbs}$ per bbl ( 86 to $400 \mathrm{~kg}$ per $\mathrm{m}^{3}$ ) of feed. Typical units have operating capacities of 2,700 to 4,400 bbls per day $\left(17,000\right.$ to $28,000 \mathrm{~m}^{3}$ per day $)$.

About 300 gallons of feed per bbl $\left(7,250\right.$.11ters per $\left.\mathrm{m}^{3}\right)$ of cooling water are required.

- Wastes: Atmospheric emissions are process heater flue gases and fugitive emissions from high-pressure equipment. Condensed steam contaminated with hydrocarbons is usually routed to the refinery wastewater treatment facility.

- Trends: Deasphalting may be expected to increase as product quality requirements become more stringent, as demand for lubrication oll increases, as crude ofl supplies become heavier, and as demand for petrochemical feedstocks increases. Solvent refining feedstocks often require deasphalting and the future of deasphalting is thus linked to that of solvent refining.

Asphalt Blowing

- Applications: Asphalt blowing oxidizes asphalt hydrocarbons, Increasing their melting temperature, hardness, and weathering properties.

- Input materials: Vacuum fractionation residue and asphalt from deasphalting units.

- Process description: Asphalt is batch heated and a1r is blown through it. Exothermic oxidation reactlons proceed without additional heat input. Blowing is stopped when the desired product specifications have been attained. Reaction conditions foster the development of polycyclic aromatic hydrocarbons (PAHs), many of which are carcinogenic.

- Operating parameters: Temperature at $436^{\circ} \mathrm{F}\left(260^{\circ} \mathrm{C}\right)$ initiates oxidation reactions. 
- Products: Partially oxidized asphalt (bitumen).

- Wastes: Oxidizer overhead gases, rich in hydrocarbon vapors from blowing operations, are usually incinerated. Vented gases constitute one of the more objectionable forms of air pollution from a refinery. They have highly objectionable odors and contain a large proportion of polycyclic aromatic hydrocarbons.

Grease Manufacture

- Applications: Grease primarily consists of mixtures of soaps and lubrication oils. Sodium, calcium, aluminum, lithium, and barlum soap bases are produced by saponification of fatty acids and oils. The properties of a grease are largely determined by 1 ts soap component. Soaps are manufactured at the refinery or purchased as raw materials.

- Input materials: Alkali earth metal hydroxides and fatty acids for soap manufacture and lubricating o11s, waxes, and other materials for mixture with the soaps.

- Process description: Soaps are manufactured by saponification--through the heating and mixing of fatty acids and alkali earth hydroxides. Lubricating oils, waxes, and additives are mixed. wi.th the soap base in a heated ketrle and the resulting grease may be further processed to final specifications.

o Products: Lubricating greases.

- Operating parameters: Temperatures at $400^{\circ}$ to $600^{\circ} \mathrm{F}\left(204^{\circ}\right.$ to $316^{\circ} \mathrm{C}$ ) are reported for heating cycles.

- Wastes: Aqueous effluent results when process units are washed and soaps and ofl are discharged to a sewer or wastewater treatment system.

- Trends: Increased use of sealed grease fittings in newer automobiles may lead to a decrease in grease manufacture.

Wax Manufacture

- Applications: Paraffin and microcrystalline waxes with low oil content, high melting point, and other desired properties are manufactured. 
- Input materials: High oll content waxes from crude fractionation and/or waxes from dewaxing of lubricating oils are the feedstocks. Feedstock or product material may be hydrotreated.

- Process description: In the most common method of wax fintshing, the feedstock is dissolved in a solvent and chilled in double-pipe, scraped-surface chilling equipment to a temperature required to crystallize only the deolled wax components having the desired melting point.' Wax crystals are vacuum filtered and oils in the wax cake are washed out with cold solvent. The resulting wax cake 18 removed and refiltered; then filtrates are recycled.

- Products: Paraffin and micro-crystalline waxes with oil contents below 0.5 percent.

- Wastes: Wax manufacture is not a significant source of wastes. Solvents and oll may enter wastewater systems through leakage. Wax in sewer systems may interfere with settling operations in wastewater treatment plants and may clog sewers.

\section{Hydrogen Manufacture}

- Application: Several refinery processes, such as hydrotreatIng, hydrocracking, and associated petrochemical processes, require hydrogen feedstocks. Hydrogen by-products from catalytic reforming frequently do not satisfy a refinery's need for hydrogen.

- Input materials: Usually gases, such as natural gas, refinery gases, propane, and butane. In addition, heavy fuel oil cau be used in the partial oxidation process.

- Process description: Steam reforming, the most widely used process, involves the mixing of sweetened gases with superheated steam and the charging of the mixture to a hydrogen furnace consisting of a vertical combustion chamber with suspended alloy tubes containing a nickel-based catalyst. Hydrocarbons are catalyzed to hydrogen, carbon dioxide, and carbon monoxide. Gases are cooled by addition of steam and condensate and passed through a converter unit which reacts (oxidizes) carbon monoxide with water to produce additional carbon dioxide and hydrogen. Gases from the converter are cooled and passed to a carbon dioxide removing unit. Here, $\mathrm{CO}_{2}$ is absorbed in amine solutions. These solutions are 
reactivated by heating and the $\mathrm{CO}_{2}$ is vented to the atmosphere.

- Operating parameters: Superheated steam (steam at high temperature and pressure) is employed in the combustion chamber.

- Products: Hydrogen, typically 98 percent hydrogen with traces of $\mathrm{CO}_{2}$ and $\mathrm{CO}$.

- Wastes: Few wastes occur from hydrogen manufacture. Free carbon removed from a water wash associated with the partial oxidation process may be a minor waste.

- Trends: Hydrogen production at refineries may be expected to increase to satisfy hydrogen demands for hydrotreating, hydrocracking, and petrochemical processing.

Process Heaters and Steam Production

- Applications: Process heaters are used throughout the refinery to heat feedstocks to reaction temperatures and for distillation. Steam is produced in one or more units for direct use in various processes, for heating, and to drive equipment. Steam generation units may be used to recover waste heat and for cooling.

- Input materials: Refinery gases and residual and distillate fuel oils are used as fuels. Some fuels may be nonmarketable by-products. The quality of these fuels may vary greatly. Some Gulf Coast refineries purchase natural gas as a clean fuel source.

Approximately 5 to 10 percent of the heating value of crude oil processed at a refinery is consumed for refinery heat production. Heat requirements range from 218,000 to $435,000 \mathrm{Btu}$ 's per bbl $\left(460,000\right.$ to $920,000 \mathrm{Kcal}$ per $\left.\mathrm{m}^{3}\right)$ of crude. Steam production uses approximately $138,000 \mathrm{Btu}^{\prime} \mathrm{s}$ per bbl $\left(292,500 \mathrm{Kcal}\right.$ per $\left.\mathrm{m}^{3}\right)$ of crude. Water fed to steam production units is usually treated with anticorrosives, such as chromates or zinc compounds.

- Process description: Fuels are usually burned to heat process materials and steam is usually produced in fired boilers serving several points of use. The catalytic crackingassociated carbon monoxide boiler may be a major heat source for steam.

o Products: Heat and steam. 
- Operating parameters: Temperatures at 1,832 to $2,732^{\circ} \mathrm{F}$ $\left(1,000\right.$ to $\left.1,500^{\circ} \mathrm{C}\right)$, and pressure at 500 psig (35 $\mathrm{kg}$ per $\mathrm{cm}^{2}$ ) for steam production.

- Wastes: For residual ofl-fired boilers, industry-wide emissions have been reported to be:

(1) Particulates--0.72 1 bs per bbl (2.75 $\mathrm{kg}$ per $\mathrm{m}^{3}$ ) fuel;

(2) Sulfur dioxide--5 lbs per bbl (19 $\mathrm{s} \mathrm{kg}$ per $\left.\mathrm{m}^{3}\right)(\mathrm{S}=$ percent by weight of sulfur) fuel;

(3) Sulfur trioxide--0.06 lbs per bbl $\left(0.25 \mathrm{~s} \mathrm{~kg}\right.$ per $\left.\mathrm{m}^{3}\right)$ fuel;

(4) Carbon monoxide--0.12 1bs per bbl (0.5 kg per m $\left.{ }^{3}\right)$ fuel;

(5) Hydrocarbons- -0.09 lbs per bbl $\left(0.35 \mathrm{~kg}\right.$ per $\left.\mathrm{m}^{3}\right)$ fuel;

(6) Aldehydes--0.03 lbs per bbl $\left(0.12 \mathrm{~kg}\right.$ per $\left.\mathrm{m}^{3}\right)$ fuel; and

(7) N1trogen oxides -1.25 to 7.51 bs per bbl $(4.8$ to $9.6 \mathrm{~kg}$ per $\mathrm{m}^{3}$ ) fuel.'

For refinery gas-fired boilers, emissions have been reported to be:*

(1) Particulates--76 1bs per $10^{6} \mathrm{bbl}$ ( $290 \mathrm{~kg}$ per $10^{6}$ $\mathrm{m}^{3}$ ) fuel;

(2) Sulfur oxides--2.5 $1 \mathrm{bs}$ per $10^{6} \mathrm{bbl}\left(9.6 \mathrm{~kg}\right.$ per $10^{6}$ $\mathrm{m}^{3}$ ) fuel (based on $4,600 \mathrm{gr}$ sulfur per $10^{6} \mathrm{~m}$ fuel);

(3) Carbon monoxide--71 lbs per $10^{6}$ bbl (270 kg per $10^{6}$ $\mathrm{m}^{3}$ ) fuel;

(4) Hydrocarbons--13 1 bs per $10^{6} \mathrm{bbl}$ (48 $\mathrm{kg}$ per $10^{6}$ $\mathrm{m}^{3}$ ) fuel; and

(5) Nitrogen oxides--60 lbs per $10^{6}$ bbl (230 kg per $10^{6}$ $\mathrm{m}^{3}$ ) fuel.

* Note that emissions from gas-fired bollers are on the order of $10^{-4}$ times those from oll-fired burners. 
Aqueous wastes associated with steam production are primarily boller blowdown, which usually has low oll and phenols concentration and is often reused in other process units with minimal treatment. Solid wastes include ash from boilers and sludges from treatment of steam boiler feed water.

- Trends: Efforts are being made to reduce energy (fuel) consumption in refineries.

\section{Pressure Relief and Flare Systems}

- Applications: Pressure rellef and safety outlets are required to relieve potentially damaging pressures that may build up in equipment, especially during start-ups, shutdowns, and emergency situations. Environmental and safety concerns usually require the use of a closed blowdown or collecting system to catch released materials, although some pressure relief and safety valves may vent directly to the atmosphere. Flares are used to dispose of released gases through combustion.

- Input materials: Any refinery material (gases and/or 1iquids) may be released from pressure release and safety valves. Releases sometimes include waste process gases and gases separated from blowdown systems.

- Process description: Discharged materials are collected and gases and liquids are separated in a knockout drum. 'Fluids are collected and pumped to oll-water separation/recovery systems. Vapors are passed to a flare.supplied with a pilot flame to ensure hydrocarbon combustion. Steam may be injected into the flare to reduce visible smoking. Most flares employ verticle stacks 20 to 300 feet (600 to 9,000 cm) high.

- Products: recovered oil, water for reuse or processing, and vented and flared gases.

- Operating parameters: A pilot flame ensures combustion of flared hydrocarbon vapors. Smokeless flaring requires approximately 0.2 to 0.5 lbs of steam per $1 \mathrm{~b}$ of hydrocarbons flared.

- Wastes: Total flare emissions have been reported to average 120 to 200 lbs per 1,000 bbl crude oil.

- Trends: Flaring will continue to be a useful method for disposing of pressure released hydrocarbon emissions. More 
attention may be paid to the design and functioning of pressure rellef systems as they may be a major source of fugitive air emissions.

Blending and Packaging

- Application: Blending of refinery intermediates and products produces marketable products with desired qualities. Packaging places final products in contalners for marketing and consumption by industry, retallers, and consumers.

- Input materials: Various refinery products and additives.

- Process description: Blending may be performed in a single tank or by in-line mixing in a header. In-line blending is most commonly used for final products and tank blending is used for feedstocks and intermediates. Storage-blending tanks may be dedicated to a single operation or switched as needed.

- Wastes: Fugitive hydrocarbon and other emissions associated with product storage and transfer may occur during blending. Tetraethyl lead and other additives are highly toxic and require care in handling. Sludge from gasoline tanks may be high in lead content.

- Trends: Automation of blending and packaging is a continuing trend, along with contract packaging of lesser-volume products .

Crude 011 and Product Storage*

- Applications: Crude olls are stored to provide adequate feedstocks for economical use of refining facilities. Storage of intermediare products equalizes material flows within the refinery. Final products storage is used to store finis hed products prior to shipment, to $\mathrm{mlx}$ and blend products, and to lessen the effects of product demands on refinery operations.

Typical refinery crude ofl storage is 2 weeks to 2 months of supplies. Storage allows for the settling-out of water and suspended solids.

* Storage technology and emissions are discussed in the Transportation and Storage section of this report. 
- Input materials: Crude oils, intermediates, and final products.

- Products: Crude olls, intermediates, and final products. (Settled-out water and solids are usually removed.)

- Process description: Crude ofl and intermediate and final products are stored in steel tanks ranging in size from several thousand barrels to several hundred thousand barrels capacity. Settled water and suspended solids are drawn of $f$ periodically. Many tank storage systems employ methods to minimize releases of hydrocarbon vapors such as floating-roof tank covers, tank pressurization, and/or connections to vapor recovery systems.

- Operating parameters: Pressure is atmospheric or greater and the temperature is ambient.

- Wastes: Free and emulsified oil, as well water and suspended solids, are drawn off into the wastewater treatment system. Bottom sludge and sediments are removed less frequently and are generally disposed of in landfills or by landspreading. Leaks, spills, and tank cleaning produce additional wastes.

Intermediate storage may be a source of polysulfide-bearing wascewatērs and iron sulfide suspended solids. Final product storage wastewaters may contain tetraethyl lead and other additives.

- Trends: Many refinerles are instituting hydrocarbon vapor release minimization systems. Floating-roof covers will become more common due to recent regulations concerning volatile organic compounds (hydrocarbon emissions).

Bottom Sediment and Water (BS\&W) specifications are imposed on crude oils by many refineries. Increased use of drying processes during intermediate processing reduces wastewater from finished and intermediate products storage.

\section{Wastewater Treatment}

- Applications: Wastewater treatment is used to upgrade used process, runoff, and sewerage waters prior to their discharge into open waters, publically owned treatment works, or their reuse within the refinery. Refinery wastewaters typically contain oil, grease, dissolved and suspended solids, phenolic compounds, ammonia, chromium, sulfides, and other compounds for which effluent levels have been set by Federal, state, 
and local laws. Some refineries totally recycle their process water. This requires removal of oil and solids and the adjustment of water quality parameters such as $\mathrm{pH}$ to minimize fouling and corrosion.

- Input materials: Wastewater streams result from water used in various processes. Most wastewater results from condensed steam, sour water stripping, spent caustic solutions,. cooling tower and boller blowdown, acid/alkaline waste neutralization, and process-associated, in-plant water pretreatment processes. Water usage may vary from 5 gallons per day per barrel of crude in newer refineries to over 1,000 gallons per day per barrel of crude in older refinerles (Sittig 1978). Varlous streams, such as process water, cooling water, wash water, sewer runoff, and cooling tower blowdown, may be processed separately or combined for treatment.

- Process description: Pretreatment or primary wastewater treatment usually involves the separation of olls and settleable solids from the wastewater. API separator units, corrugated plate interceptors, and primary set.ting ponds are used for ofl, oily sludge, and grit removal. Gravity separation forms the physical basis for these units. Flocculation, involving the addition of organic particles to which ofl and particles adhere, is used in some refineries. Common flocculants are alum and polyelectrolytes, which are highmolecular-weight, polar, synthet ic, water-soluble, organic polymers. If process wastewaters are excessively acidic or alkaline, they must be neutralized. Acidic and basic waste streams may be mixed or ammonia, lime, limestone, or soda ash used to neutralize acidic streams. Sulfuric acid, hydrochloric acid, flue gases containing carbon dioxide, or sulfur may be used to neutralize alkaline streams.

After pretreatment, suspended solids are usually removed by sedimentation or air flotation. Sedimentation involves gravity separation (settling) of particulate matter. Dissolved air flotation involves saturation of wastewater with air under pressure (approximately 40 psig). The release of this pressure causes alr bubbles less than 100 microns in diameter to attach to particulace matter and float it to the surface. Dissolved air also aids subsequent blological oxidation of wastes. Screening and filtration may be used for was tewater with a low solids load.

Secondary treatment processes degrade soluble organic matter in the wastewater and reduce the biological and chemical oxygen demand (BOD and COD). Microorganisms catabolize or metabolically degrade most soluble organics, eventually to carbon dioxide, nitrogen, and 
water. Secondary treatment processes include activated sludge, trickling filter, aerated lagoon, unaerated lagoon, and anaerobic treatments. Unaerated lagoons are the simplest, but require large land areas and have lower capacities. Aerated lagoons involve mechanical aeration or oxygenation and mixing. Trickling filter processes involve wastewater flow and contact with microorganisms growing on solid media such as beds of rocks, polyvinyl chloride packings, or rotating partially submerged discs (Bio-Disk process). Anaerobic treatments such as stabilization ponds are not commonly used because sulfur dioxide odors result from the anaerobic bacterlal metabolism of sulfur-contalining compounds. Sludge is a by-product of secondary treatment processing.

Tertlary treatment processes may be applied to remove special pollutants or to comply with effluent or recycled water standards. Chlorination, ozonation, ion exchange, membrane separation (e.g. reverse osmosis), activated carbon and other types of filtration, coagulation, oxidation, and flotation processes may be employed. Chlorination is probably the most commonly used process for final chemical wastewater treatment. Calclum hypochlorite, sodium hypochlorite, and pure chlorine may be added to the effluent stream. Ion exchange resins can remove significant amounts of phosphates, nitrates, ammonia, and chromates. Actlvated carbon absorption preferentially removes large, non-polar organics. Granular media filters, using combinations of sand, coal (anthracfte), activated carbon, ballut, and resin beds, are currently in use. Membrane separation processes based on reverse osmosis, electrodialysis, ultrafiltration, and microfiltration provide a means for concentrating the wastewater $s$ tream.

Final effluent disposal is accomplished by direct discharge, controlled discharge from holding ponds, or eventual discharge from a series of aerated lagoons. Zero discharge may be achleved through use of evaporation ponds and extensive water recycling.

Wastewaters to be recycled for process water may require oxidation to remove remalning phenols, nitrates, and ammonia, and may require cooling to remove heat. Cooling-oxidation processes include spray ponds, air stripping, autoxidation, and cooling towers.

- Products: Water containing lesser amounts of pollutants for discharge or reuse, various waste streams, and settled or filtered sludges.

- Operating parameters: Most wastewater processing is done at ambient temperature and pressure. 
- Wastes: Atmospheric emissions consist primarily of hydrocarbons released from the collection system and primary treatment units. Typically, approximately 16 to 17 percent by volume of the ofl in an API separator vaporizes. Separators frequently are not sealed due to explosive hazards, but floating insulating materials on the oil can reduce fugitive emissions to approximately 2 percent by volume.

Primary treatment produces solid wastes in the form of dirt, grit, olly sludges, and clarifier sludges. Secondary treatment produces bacterlal sludges. These solid wastes are usually landfilled or landspread. Bacterial sludges may be incinerated and the resulting ash landfilled.

- Trends: All refineries perform primary treatment to remove olls and solids. Most utilize some form of secondary biological treatment, although some may use deep well disposal or chemical oxidation processes (oxidation with ozone, chlorine, or permanganate). 
THIS PAGE

\section{WAS INTENTIONALLY \\ LEFT BLANK}

212 
HAZARDS OF REFINERY OPERATIONS

Occupational Health

Trends in Petroleum Refining Affecting Safety and Health

Major technological changes in petroleum refining have had significant impacts on refinery employment (U.S. Bureau of Labor Statistics 1979). Computer control and advanced instrumentation, improved processes, and a trend toward larger refineries and consolidation of functions are among the factors that have contributed to an average annual productivity rise of 4.3 percent in petroleum refining from 1960 to 1977 , compared with 2.6 percent in all manufacturing. Th1s productivity rise is expected to continue through 1985 , but at a slower pace.

A number of process-related trends will affect health and safety in refineries. Increased fluid catalytic cracking, hydrotreating to process sour crudes, and reforming, alkylation, and isomerization to increase gasoline octane ratings add potential health and safety hazards. The decrease in the use of lead-based additives to increase octane ratings and the increase in use of petroleum-derived fractions as petrochemical feedstocks are leading to increases in the use of catalytic reforming and aromatic extraction units, which yleld process streams and products with higher concentrations of more toxic, h1gher-octane, aromatic hydrocarbons. Increased usage of higher sulfur crude oils results in accelerated corrosion and deterioration of refinery equipment, more hydrogen sulfide, and other safety hazards.

Some sources have charged the petroleum refining industry with misplaced priorities regarding health and safety (Engler 1975). Equipment run times have increased, turnarounds (periods when a unit is shut down for cleaning and repair) have been shorter and less frequent, and poor preventive maintenance and testing have beti noted in some refinerles. With increases in the prices obtained for refined products and the nation's needs for these products, it may be more economically attractive to run equipment until it falls, rather than to perform preventive maintenance. Government regulations, high interest rates, a long-run projected decline in the rate of growth of product demand, and other factors have been cited as disincentives for large capital investments and improvements by refineries.

On the other hand, better on-stream inspection techniques, newer and better materials, advanced instrumentation and control, corrosion-reducing additives, and experience and advances in refining allow longer run times and minimize potentially hazardous start-ups, shutdowns, and routine maintenance. 
Refinery employment is expected to decline to approximately 137,000 employees in 1985--for a drop of 1.9 percent annually from 1977 to 1985 (U.S. Bureau of Labor Stat1st1cs 1979). Newer and modernized refineries employ fewer workers than comparable older facilities. Cross-crafting, or the consolidation of various maintenance and operating job functions, also reduces manpower requirements. Contracting out many tasks is another trend contributing to lower refinery full-time payrolls. Many of these contract employees perform hazardous tasks and should not be forgotten when one considers health and safety hazards in refineries.

The reduction in the number of employees in processing areas may have several implications for plant safety. Fewer workers may be available for fire fighting and handling emergencies. Leaks, spills, and dangerous situations may tend to remain unidentifled. Essential work may be delayed as fewer men are available to perform essentlal tasks.

\section{Workers Employed in Refineries}

The number of workers employed in refining operations in 1978 was 81,168 , according to the American Petroleum Institute (1979b). Union sources estimate the refining industry total at about 135,000, of .which about 75,000 are considered production workers. The approximately 55,000 non-production workers include clerical, mana-

- gerial, and technical workers not directly working with refinery equipment: These non-production workers should not be included with refinery production workers when one considers most occupational hazards. However, they work within the confines of the refinery and may be exposed to alrborne toxic chemicals and catastrophic events. Other workers, such as contractor employees, construction workers, part-time employees, and truck drivers, may work within the processing area of the refinery and also may be exposed to its hazards.

A recent final Environmental Impact Statement (EIS) for a proposed 175,000 bb1-per-day refinery at Portsmouth, Virginia, contains the following information regarding employment (U.S. Army Corps of Engineer 1977):

- The refinery will employ 350 persons, with an additional 150 employees Involved in terminal, storage, and attendant operations.

- Employment is anticipated to be 90 percent male.

- The majority of workers are in skilled categories: pipefitters, welders, boiler makers, electricians, technicians, and laboratory workers. 
- In the typical refinery, 60 percent of the workforce would be classified as production workers and the remainder would be in support capacities.

- Approximately 10 percent of the employees have managerlal or highly technical (engineering) responsibilities.

These data are probably applicable to most larger, modern refineries.

\section{Recognttion of Refinery Occupational Hazards}

There is a general lack of published occupational health studies involving reflnery workers, despite the large number of known and suspected toxic chemical and physical hazards, including carcinogentc and neurotoxic agents, to which refinery workers are potentlally exposed. The reader is referred to a recent review for a discussion of epldemiological studies to date (Bingham et al. 1980). The Basic Effects Issues section of this report offers further information on potential chemical hazards and adverse effects that may be associated with refineries.

Avallable epidemiological studies do not present a consensus or support conclusions regarding excesses and causes of refinery workers' morbidity and mortality. These have focused mainly on the risks of developing cancer, espectally excessive cutaneous, pulmonary, and digestive tract cancers from benzo(a)pyrene and other PAHs which are constituents of crude o11, residuals, soots, and refinery alr emissions (Darby et al. 1978).

Data concerning refinery occupational injuries and ilinesses reported annually. to the Occupational Safety and Health Administration (OSHA) for 1978 are presented in Table 1 of the offshore section of this report. The data indicate that refining is one of the more hazardous aspects of the petroleum industry.

Ava1lable general population epidemiological studies do not specifically incriminate petroleum refineries as sources of generalized environmental hazards or carcinogens, but strongly suggest the need for further study and concern. A U.S. survey of lung cancer mortality by county from 1950 to 1969 found higher rates among males in 39 petroleum-industry-intensive counties (Blot et al. 1977). When compared to male residents of 117 demographically similar counties without intensive perroleum-related activity, male residents of petroleum-intensive counties had higher rates for cancers of the lung, nasal cavity and sinuses, and the skin, including malignant melanomas. Higher rates for lung cancer among female residents indicated a possibility of a pollution hazard beyond the workplace. Another study in the Los Angeles area revealed higher lung cancer 
mortality rates in areas that were heavily industrialized, including areas with petroleum refineries, and that had higher concentrations of benzo(a)pyrene and other PAHs in soll and atr (Menck 1974).

Published occupational health surveys of refinery workers generally have not been avallable. Several evaluations of 1solated health hazards within refineries have been performed by the National Institute for Occupational Safety and Health (NIOSH) and the Inst1tute is currently completing nine industrial hyglene surveys characterizing worker exposures to polycyclic aromatic hydrocarbons in petroleum refineries. Overall, except for studies on specific problems, little information ts avallable concerning the health of refinery workers.

\section{Hazardous Exposure Monitoring}

Little published worker exposure information is avallable. Industrial hyglene monitoring primarily involves measurement of concentrations of substances in air and sometimes extrapolated measurements of personal exposures obtained from toxic substance-adsorbing dosimeters carried by workers. Potentlal hazards that have been monttored include nolse, hydrogen sulfide, asbestos, benzene, hydrocarbons, and tetraethyl lead. Other hazards that constitute clear acute toxic hazards, which must be monitored in compliance with Federal or state laws, or which have been recognized as potential hazards on the part of refinery management, presumably also are monitored.

As discussed in other sections, many hazardous substances are known to be used within refineries. A 1977 survey of refineries by the U.S. Environmental Protection Agency (EPA) provides data regarding purchases and manufacture of EPA Prlority Pollutant Compounds. The number of U.S. refineries handling these is shown in Table 6. Exposures to these hazards may occur among workers as a result of Ignorance, negligence, unscheduled events and accidents, Improper design, or faulty equipment.

Chronic exposure to low levels of many toxic substances is a likely situation among refinery workers. Little is known of the synergist1c, antagonistic, carcinogenic, teratogenic, fetotoxic, neurological, and other toxic effects and interactions among the numerous substances to whlch refinery workers may be exposed.

Many exposures to toxic substances are difficult to assess and quantify, especially those recelved via contact and subsequent percutaneous absorption or ingestion. Measurement of toxic materials in respirable alr does not fully account for all toxic exposures. 
TABLE 6

EPA PRIORITY POLLUTANT CHEMICALS ${ }^{a}$

\begin{tabular}{|c|c|c|}
\hline $\begin{array}{l}\text { Priority } \\
\text { Pollutant }\end{array}$ & $\begin{array}{l}\text { Jumber of Refineries } \\
\text { That Purchase The } \\
\text { Chemicals as a Raw } \\
\text { or Intermediate } \\
\text { Material }\end{array}$ & $\begin{array}{c}\text { Number of Refineries } \\
\text { That Manufacture The } \\
\text { Chemicals as a Final } \\
\text { or Intermediate } \\
\text { Materlal }\end{array}$ \\
\hline Acenaphthene & 9 & 8 \\
\hline Acrolein & 1 & 0 \\
\hline Acrylonitrile & 2 & 0 \\
\hline Benzene & 42 & 62 \\
\hline Carbon tetrachloride & 30 & 2 \\
\hline Chlorobenzene & 0 & 0 \\
\hline 1,2-Dichloroethane & 6 & 0 \\
\hline $1,1,1$-Trichloroethane & 26 & 2 \\
\hline Hexachloroethane & 1 & 0 \\
\hline 1,1 -Dichloroethane & 2 & 0 \\
\hline $1,1,2$-Trichloroethane & 4 & 0 \\
\hline $1,1,2,2$-Tetrachloroethane & 1 & 0 \\
\hline Chloroethane & 1 & 0 . \\
\hline 2,4,6-Trichlorophenol & 1 & 0 \\
\hline Chloroform & 9 & 0 \\
\hline 2-Chlorophenol & 2 & 0 \\
\hline 1,2-Dichlorobenzene & 2 & 0 \\
\hline 1,3-Dichlorobenzene & 0 & 0 \\
\hline Dieldrin & 1 & 2 \\
\hline Benzidine & 0 & 4 \\
\hline P-chloro-m-cresol & 0 & 0 \\
\hline 1,4-Dichlorobenzene & 0 & 0 \\
\hline 1.,4-Dichloroethylene & 6 & 0 \\
\hline 1,2-Trans-dichlo roethylene & 2 & 0 \\
\hline 2,4-Dichlorophenol & 0 & 0 \\
\hline 1,2-Dichloropropane & 6 & 0 \\
\hline 1,3-Dichloropropylene & 3 & 0 \\
\hline 2,4-Dimethylphenol & 9 & 11 \\
\hline Asbestos & 18 & 0 \\
\hline Ethylbenzene. & 24 & 31 \\
\hline Fluoranthene & 13 & 11 \\
\hline Methylene chloride & 2 & 0 \\
\hline Methy1 bromide & 1 & 0 \\
\hline Trichlorofluoromethane & 12 & 0 \\
\hline Dichlorodifluoromethane & 9 & 0 \\
\hline Phenol & 32 & 32 \\
\hline Bis(2-ethylhexyl) phthalate & 1 & 1 \\
\hline
\end{tabular}


TABLE 6 (Continued)

\begin{tabular}{|c|c|c|}
\hline $\begin{array}{l}\text { Priority } \\
\text { Pollutant }\end{array}$ & $\begin{array}{l}\text { Number of Refineries } \\
\text { That Purchase The } \\
\text { Chemicals as a Raw } \\
\text { or Intermediate } \\
\text { Material }\end{array}$ & $\begin{array}{c}\text { Number of Refineries } \\
\text { That Manufacture The } \\
\text { Chemicals as a Final } \\
\text { or Intermediate } \\
\text { Material }\end{array}$ \\
\hline Buty1 benzy1 phthalate & 1 & 1 \\
\hline D1-n-butyl phthalate & $\overline{1}$ & 1 \\
\hline Diethy 1 phthalate & 1 & 1 . \\
\hline Dimethyl phthalate & 1 & 1 \\
\hline PCB-1242 & 1 & $\overline{0}$ \\
\hline PCB-1254 & 1 & 0 \\
\hline 1,2-Benzanthracene & 14 & 12 \\
\hline Benzo (a) pyrene & 14 & 12 \\
\hline 3,4-Benzofluoranthene & 10 & 12 \\
\hline $11 ; 12-$ Benzofluoranthene & 10 & 12 \\
\hline Chrysene & 16 & 14 \\
\hline Acenaphthylene & 11 & 12 \\
\hline Anthracene & 16 & 14 \\
\hline 1,12 -Benzoperylene & 14 & 12 \\
\hline Fluorene & 10 & 12 \\
\hline Phenanthrene & 16 & 14 \\
\hline Naphthaleine & 18 & 18 \\
\hline Nitrobenzene & 1 & 0 \\
\hline Pentachlorophenol & 10 & 1 \\
\hline 4-Nitrophenol & 1 & 0 \\
\hline Methyl chloride & $\overline{1}$ & 0 \\
\hline Isophorone & 0 & 1 \\
\hline $1,2: 5,6$-Dibenzanthracene & 11 & 12 \\
\hline Indeno $(1,2,3-C, D)$ pyrene & 11 & 12 \\
\hline Pyrene & 16 & 14 \\
\hline $3,2,7,8$-Tetrachlorodiben & 1zo- & \\
\hline p-dloxin & 0 & 1 \\
\hline Tetrachloroethylene & 2 & 1 \\
\hline Toluene & 53 & 53 \\
\hline Trichloroethylene & 12 & 0 \\
\hline Vinyl chloride & 0 & 0 \\
\hline Antimony and compounds & 8 & 1 \\
\hline Arsenic and compounds & 6 & 1 \\
\hline ZInc and compounds & 71 & $\overline{6}$ \\
\hline Beryllium & 0 & 0 \\
\hline Cadmium and compounds & 4 & 0 \\
\hline Chromium and compounds & 80 & 5 \\
\hline Copper and compounds & 26 & 1 \\
\hline Cyanides & 1 & 20 \\
\hline
\end{tabular}


TABLE 6 (Concluded)

\begin{tabular}{|c|c|c|}
\hline $\begin{array}{l}\text { Priority } \\
\text { Pollutant }\end{array}$ & $\begin{array}{c}\text { Number of Refineries } \\
\text { That Purchase The } \\
\text { Chemicals as a Raw } \\
\text { or Intermediate } \\
\text { Material }\end{array}$ & $\begin{array}{c}\text { Number of Refineries } \\
\text { That Manufacture The } \\
\text { Chemicals as a Final } \\
\text { or Intermediate } \\
\text { Material }\end{array}$ \\
\hline Lead and compounds & 121 & 9 \\
\hline Mercury and compounds & 5 & 0 \\
\hline Nickel and compounds & 21 & 6 \\
\hline Selentum and compounds & $\because$ & 1 \\
\hline Silver and compounds & $\therefore$ & 1 \\
\hline Thallium and compounds & 1 & 1 \\
\hline
\end{tabular}

ancludes chemicals reported as purchased or manufactured by 253 refineries surveyed.

Source: U.S. Enviromental Protection Agency $1979 \mathrm{~b}$. 
Several of the hazardous materials handled within the refinery are liquids or solids--and the frequency, amounts, and severity of worker exposure to the intake of liquids and solids are difficult to assess. Workers may be exposed to hazardous materials via contact with liquids on solld surfaces (ladders, valves, and rallings). Many exposures are likely to occur during maintenance, from leaks and spills, during start-up and shutdown operations, and from contact with materials condensed or splashed on surfaces.

Biologically-based methods for monitoring an individual worker's exposures through measurement of substances or their metabolites in body fluids, excretlons, and hair are avallable only for a limited number of toxic substances. The extent of biologically-based monitoring in the refining industry is unknown.

\section{Carcinogens in the Refinery}

The EPA's Carcinogen Assessment Group recently identified 150 chemicals as carcinogens (Inside Washington Publishers 1980). Many of these, shown in Table 7, are likely to be encountered in varying amounts in the refinery.

Condensed and settled solids and liquids on refinery surfaces and workers may contain appreciable amounts of PAHs. PAHs concentrations from an apron worn by a petroleum cokting unt worker aro shown in Table 8 .

\section{Other Refinery Hazards}

Hot Environments. Heat stress among refinery workers has been documented (Hervin et al. 1973) since considerable amounts of heat radiate from process equipment.

Confined Areas. Workers in confined areas, such as those performing periodic maintenance in bollers, tanks, exchangers, and reaction chambers, are potentially exposed to a number of hazardous vapors, Including asphyxiants such as hydrocarbons, carbon dioxide, and steam, and toxic substances such as volatilized lead additives, PAHs, and other hydrocarbons. Explosions may occur in confined areas. Moreover, solid and liquid wastes removed from equipment in confined areas may pose hazards for workers.

Catalysts. The exact nature of the catalysts employed in petroleum refining generally are proprletary or trade secrets. However, some catalyst types and their uses are identified in Table 9. Many of these catalysts are fixed on powdered or granular alumina, silica, or other substrates. Several pose hazards when they are inhaled or come in contact with the skin or eyes. The Doctor Sweetening process for converting thiols to disulfides (being replaced by other 
TABLE 7

EPA-DESIGNATED CARCINOGENS LIKELY TO

OCCUR IN REFINERIES

Polycyclic Aromatic Hydrocarbons

2-Ace ty laminof luorene

Benz(c)acridine

Benz(a)anthracane

Benzo(b)fluoranthene

$\operatorname{Benzo}(j)$ fluorant hene

Benzo(a)pyrene

Chrysene

Dibenz $(a, h)$ acridine

Dibenz $(a, j)$ acridine

Dibenz $(a, h)$ anthracene

Dibenzo $(a, h)$ anthracene

7H-Dibenzo(c,g)carbazole

Dibenzo(a,e)pyrene

Dibenzo $(a, h)$ pyrene

Dibenzo(a,i)pyrene

7,12-Dimethylbenz(a) anthracene

3-Methylcho lant hrene

Benzene

Coke oven emissions

Metals 
TABLE 7 (Cóncluded)

Cadmium and compounds

Chromium and compounds

Nickel and compounds.

Nickel carbonyl

Ethylene bis dithiocarbamate

Aldehydes

Formaldehyde

Glycidyl aldehyde

Nitrosamines

N-Nitrosodie thanolamine

N-Nitrosodiethylamine

N-Nitrosodimethylamine

Soots and Tars

$2,3,7,8-T e t r a c h l o r o d i b e n z o-p-d i o x i n$

2,4,6-Trichlorophenol 
TABLE 8.

POLYNUCLEAR AROMATICS ON A

REFINERY WORKER'S APRON

\begin{tabular}{|c|c|c|}
\hline PAH & $\begin{array}{c}\text { Quantity in } \\
1 / 2 \text { Apron } \\
\text { (Mmg) }\end{array}$ & $\begin{array}{l}\text { Quantity in } \\
\text { Swatches } \\
\text { (Mmg) }\end{array}$ \\
\hline Pyrene & 1,000 & \\
\hline Benz (a) anthracene & 790 & 950 \\
\hline Chrysene & 560 & \\
\hline Triphenylene & 370 & . \\
\hline Bethy1 benz (a) anthracene & 1,120 & \\
\hline CM/ET benz (a) anthracene & 530 & \\
\hline Benzo (a) pyrerie & 840 & 1,300 \\
\hline Benzo (e) pyrene & 1,130 & \\
\hline Benzo $(g, h, 1)$ perylene & 420 & \\
\hline Methyl benzo (a) pyrene & 400 & : \\
\hline Methyl benzo(e) pyrene & 1,330 & \\
\hline
\end{tabular}

Source: Venable 1975. 
TABLE 9

MISCELLANEOUS REFINERY CHEMICAL HAZARDS

\begin{tabular}{|c|c|c|}
\hline Substance & Uses & Hazards \\
\hline Acetic acid & $\begin{array}{l}\text { Emulsion breaking, polymer ex- } \\
\text { traction, dewaxing, sulfur } \\
\text { reduction }\end{array}$ & Irritant \\
\hline Acetone & $\begin{array}{l}\text { Benzene isolation fazeotropic } \\
\text { distillation), labe ofl } \\
\text { dewaxing }\end{array}$ & $\begin{array}{l}\text { Dermatitis; 1rritation, } \\
\text { narcosis }\end{array}$ \\
\hline Aluminum chloride & Isomerization catalyst & Irritant, corrosive \\
\hline Aluminum oxide (Bauxite) & Cracking catalyst constituent & Pulmonary disease (inhalation) \\
\hline Barium hydroxide & $\begin{array}{l}\text { Treat spent caustic solutions; } \\
\text { neutralize acid treated oils }\end{array}$ & Caustic, heart disorders \\
\hline Cadmium compounds & $\begin{array}{l}\text { Desulfurizing, lube ofl } \\
\text { additives }\end{array}$ & $\begin{array}{l}\text { Highly toxic; respiratory } \\
\text { irritant; pulmonary edema; } \\
\text { dypsnea; emphysema; kidney } \\
\text { damage }\end{array}$ \\
\hline Chlorine & $\begin{array}{l}\text { Disulfides oxidation; bentonite } \\
\text { clay regeneration }\end{array}$ & $\begin{array}{l}\text { Eye inflammation; pneumonitis; } \\
\text { pulmonary edema; fatal above } \\
\text { 1,000 ppm }\end{array}$ \\
\hline $\begin{array}{l}\text { Absorbents: alumina, } \\
\text { bauxite, silica gel, } \\
\text { bentonite, } \\
\text { diatomaceous earth, } \\
\text { activated carbon }\end{array}$ & $\begin{array}{l}\text { Improve color, odor, stability } \\
\text { of waxes and lube oils }\end{array}$ & Irritation; inhalation hazards \\
\hline
\end{tabular}


TABLE 9 (Continued)

\begin{tabular}{|c|c|c|}
\hline Substance & Uses & Hazards \\
\hline Copper chloride & $\begin{array}{l}\text { Convert mercaptans to insoluble } \\
\text { disulfides (sweetening) }\end{array}$ & $\begin{array}{l}\text { Skin irritation; liver } \\
\text { cirrhosis }\end{array}$ \\
\hline Dichloroethy1 ether & $\begin{array}{l}\text { Chlorex extraction--improve } \\
\text { yield and viscosity of highly } \\
\text { paraffinic oils }\end{array}$ & $\begin{array}{l}\text { Strong Irritant; nausea; } \\
\text { eye damage, liver dis- } \\
\text { order-death }\end{array}$ \\
\hline $\begin{array}{l}\text { Ethanolamines: } \\
\text { monoethanolamine (MEA), } \\
\text { diethanolamine (DEA), } \\
\text { triethanolamine (TEA) }\end{array}$ & $\begin{array}{l}\text { Extraction of water, } \mathrm{H}_{2} \mathrm{~S}, \mathrm{CO}_{2} \\
\text { from gaseous streams }\end{array}$ & $\begin{array}{l}\text { Skin and eye irritation; } \\
\text { nitrosamine precursors }\end{array}$ \\
\hline $\begin{array}{l}\text { Ethylene dichloride } \\
\quad(1,2 \text {-dichloroethane })\end{array}$ & $\begin{array}{l}\text { Solvent extraction--wax removal } \\
\text { from lube oils }\end{array}$ & $\begin{array}{l}\text { Dermatitis; serious eye } \\
\text { damage; liver and kidney } \\
\text { damage; carcinogenic }\end{array}$ \\
\hline Ethlene g1ycol & $\begin{array}{l}\text { Solvent extraction (Udex } \\
\text { Process) }\end{array}$ & $\begin{array}{l}\text { Irritation (skin, eyes, } \\
\text { mucous membranes) }\end{array}$ \\
\hline Furfural & $\begin{array}{l}\text { Solvent extraction of distillate } \\
\text { fuels (removes low octane } \\
\text { number and other substances) } \\
\text { and lube oils }\end{array}$ & $\begin{array}{l}\text { Irritation (skin, eyes, } \\
\text { mucous membranes); contact } \\
\text { dermatitis; photosensitivity }\end{array}$ \\
\hline $\begin{array}{l}\text { Hydrogen fluoride } \\
\begin{array}{c}\text {.. } \\
\quad\end{array}\end{array}$ & Alkylation catalyst & $\begin{array}{l}\text { Extremely corrosive and toxic; } \\
\text { burns wherever contact } \\
\text { occurs; may cause death over } \\
50 \mathrm{ppm} \text { (air) }\end{array}$ \\
\hline Hydrogen & Catalytic reforming & Explosive \\
\hline $\begin{array}{l}\text { Methy } 1 \text { ethyl ketone } \\
\text { (MEK) }\end{array}$ & Solvent dewaxing of lube oils & $\begin{array}{l}\text { Irritant (eyes, mucous mem- } \\
\text { branes); dermatitis; } \\
\text { narcosis }\end{array}$ \\
\hline
\end{tabular}


TABLE 9 (Continued)

\begin{tabular}{|c|c|c|}
\hline Substance. & Uses & Hazards \\
\hline Methyl isobutyl ketone & Deoiling of refinec waxes & $\begin{array}{l}\text { Irritant (eyes, mucous mem- } \\
\text { branes); dermatitis; } \\
\text { narcosis; similar compound } \\
\text { (n-butyl ketone) 1mplicated } \\
\text { in polyneuropathy }\end{array}$ \\
\hline Nitrobenzene & $\begin{array}{l}\text { Nitrobenzene extraction of lube } \\
\text { ofls; increase viscosity and } \\
\text { extract carbon and sludge- } \\
\text { forming compounds }\end{array}$ & $\begin{array}{l}\text { Eye irritant; methemoglo- } \\
\text { binemia and other blood dis- } \\
\text { orders; liver disorders } \\
\text { from chronic exposure; } \\
\text { nitrosating agent }\end{array}$ \\
\hline $\begin{array}{l}\text { Phosphoric acid, } \\
\text { copper pyrophosphate }\end{array}$ & Polymerization catalysts & Corrosive; irritant \\
\hline Propane & $\begin{array}{l}\text { Solvent extraction-deasphalting, } \\
\text { dewaxing, decarbonizing }\end{array}$ & $\begin{array}{l}\text { Flammable gas; asphyxiant; } \\
\text { narcotic effects }\end{array}$ \\
\hline $\begin{array}{l}\text { Sodium hydroxide } \\
\text { (caustic soda) }\end{array}$ & $\begin{array}{l}\text { Caustic washing-removal of acidic } \\
\text { substances, including naph- } \\
\text { thenic acids; phenolics, } \mathrm{H}_{2} \mathrm{~S} \\
\text { mercaptans }\end{array}$ & $\begin{array}{c}\text { Extremely corrosive; blindness } \\
\end{array}$ \\
\hline Sodium hypochlorite & Sweetening gasoline fractions & Irritant; corrosive \\
\hline Sodium plumbite & Doctor sweetening & Lead poisoning \\
\hline Sulfur dioxide & $\begin{array}{l}\text { Extraction of aromatic hydro- } \\
\text { carbons and sulfur compounds }\end{array}$ & $\begin{array}{l}\text { Irritant; corrosive, asphyxi- } \\
\text { ation of some hypersuscep- } \\
\text { tible individuals, co- } \\
\text { carcinogen }\end{array}$ \\
\hline
\end{tabular}


TABLE 9 (Concluded)

\begin{tabular}{|ccc|}
\hline Substance & Uses & Hazards \\
\hline Sulfuric acid & $\begin{array}{c}\text { Extraction of resinous materials, } \\
\text { asphaltic substances, } \\
\text { mercaptans }\end{array}$ & $\begin{array}{c}\text { Highly corrosive to any tissue } \\
\text { contacted }\end{array}$ \\
& $\begin{array}{l}\text { Lube oil dewaxing; extract } \\
\text { carbon- and sludge-forming } \\
\text { constituents of lube oils and } \\
\text { increase viscosity }\end{array}$ & $\begin{array}{c}\text { Carcinogenic; kidney disorders; } \\
\text { irritant and narcotic vapors }\end{array}$ \\
& &
\end{tabular}

Source: Adapted from DeNora and King 1967; Sittig 1979. 
processes) employs a solution of sodium plumbite, a water-soluble lead salt. Platinosis has been discussed as a potential health hazard. Platinum can promote mutagenicity and carcinogenicity.

Dyes. Numerous ofl-soluble dyes are added to gasoline and other refinery products in concentrations of up to flve ppm. Dyes impart characteristic colors to facilitate identification of different grades, products, and brands. Dyes added to avlation fuel include: 1,4-bis (alkylamino) anthraquinones (blue); methyl derivatives of 4-(phenylazo)-2-naphthols (red); (phenylazo)-2-naphthols (orange); and $\mathrm{N}, \mathrm{N}$-dimethyl-4-(phenylazo) benzeneamine (yellow) (Darby et al. 1978). These aromatic amine compounds may be carcinogenic, as are many other aromatic amine dyes with similar structures.

Asbestos. Considerable amounts of asbestos are used within refineries for insulation. Workers handling or working near this material may inhale asbestos fibers, certaln types and sizes of which are carcinogenic. Potential risks from asbestos inhalation might be lower for refineries than for many other establishments due to the outdoor nature of refineries.

Refinery-Associated Skin Disorders

Skin D1seases--General Incidence. Skin diseases of occupational origin outnumber all other work-incurred 11lnesoeo (Birmingham 1978). Between 1940 and 1970 , records complled by state health departments and compensation boards show that skin disorders accounted for 60 to 80 percent of all reported occupational diseases. Bureau of Labor statistics for 1972 show that skin disorders caused 41 percent of the total 210,500 occupational disease cases and 25 percent of all lost workdays.

Chemically-Induced Skin Disorders. Contact with oils may cause several types of severe skin disorders: contact dermatitis, follicu1itis, photosensitization, Irritation, and skin cancers. Additives in petroleum products and exposures to processing chemicals also may exacerbate or cause skin disorders.

Primary 1rritants cause direct injury to skin tissues. Most olls and petroleum products cause varying amounts of irritation on prolonged contact. Contact dermatitis disorders may be caused by irritation or contact sensitization. Contact sensitization (less frequent than irritant-mediated dermatitis) involves the development of acquired allergic reactions to substances. Once an individual has developed antibodies after initial exposure to an antigenic substance, subsequent contact induces allergic reactions, primarily contact dermatitis, which are apt to be more severe and prolonged than irritant-mediated dermatoses. Examples of cutaneous sensitizers Include polson ivy, poison oak, nickel salts, and formaldehyde. 
Photosensitization involves the interaction of photoreactive substances with light to produce conditions that induce dermatitis. Various constituents of crude oll and residual fractions (e.g., asphalts and residual fuel ofls)--phenanthrene, anthracene, and acridine--are known photosensitizers. Photosensitization among workers in an asphalt blowing unit has been documented (Vandervort and Lucas 1974). Hyperpigmentation may also be caused by contact with photosensitizers.

Acute contact dermatitis causes a number of signs and symptoms including redness, swelling, blistering, oozing, 1tching, burning, and general discomfort. Acute contact dermatitis can occur anywhere on the skin. Chronic dermaticls may involve marked dehydration leading to skin thickening, scaling, and cracking and fissuring of the digits and palm.

Folliculitis and acne may be caused by chronic contact with water-1nsoluble olls, especially crude olls, lubricating oils, asphalts, and greases. These disorders are caused by blockage of sweat ducts at the base of hair follicles.

Skin cancers may result from contact with crude olls or refinery products. Several PAHs in oll and petroleum products are known skin carcinogens. Refinery and storage facility workers are exposed to the major cause of skin cancer, sunlight, due to the outside nature of their work. The combined effect of exposure to sunlight, hydrocarbons, and other hazardous agents may present an added health risk to these workers.

\section{Occupational Safety}

\section{Safety in Design and Operation}

Petroleum refineries represent tremendous investments and have large, powerful components that continuously handle hazardous materials at high temperatures and pressures. Refinery design and process technologies are well developed, proprietary, and highly competitive. Safety, both for the physical plant and worker, is a major factor in refinery design and operation (Barber 1975).

Refinery safety factors presumably incorporated in the design phase include:

- Plans to isolate hazardous.

- Access to and egress from equipment during normal, maintenance, and emergency operating conditions. 
- Safe design of mechanical equipment. Workers require protection from moving parts and hot surfaces.

- Safe design of electrical equipment. Proper grounding, circuitry, Insulation, and isolation are required for electrical safety and to control potential ignition sources.

- Selection of corrosion-resistant materials.

- Preventive analysis of vibrations. Components and process units, both large and small, may be subject to destructive vibration.

o. Allowance for pressure fallures. Pressure-relleving valves and the discharge of excess materials to safe places are required. Both automatic and manual rellef valves and controls are also required.

- Nolse control. Acceptable noise levels and controls should be specified. Include:

Fire safety features incorporated into the refinery design

- Plans to minimize spread nf fires and damage to adjacuit units. Safe access to critical areas, equipment, values, and controls 18 also required.

- Design of control centers. Process control centers should be In safe areas, blast-resistant, sealable, and have an auxi1lary alr supply system.

- Safe electrical equipment. Where hazardous concentrations of flammable vapors may be present, equipment is enclosed in a housing capable of withstanding an internal explosion without Igniting outside vapors.

- Fireproofing of 1mportant structures.

- Surface drainage. Dralnage systems should carry spills, fire fighting water, and storm waters away from process units. Impounding basins should be away from storage tanks and process units.

- Thermal insulation.

- Water supply and distribution systems for fire fighting. An independent, continuously pressurized fire fighting water distribution system is maintained. 
- Fixed large volume water nozzles and sprayers. In case of fire, fixed water nozzels that are controlled automatically, manually, and/or remotely, are trained on equipment that is known to be unsafe.

- Vapor detection devices. Vapor detectors should monitor unattended, potentially hazardous equipment, such as gas compressor houses.

- Fire detection devices. These are linked to alarm systems and/or activate fixed fire extinguishing equipment.

- Special fire control systems. Certaln equipment and situations may require Installation of foam, dry chemicals, halogenated gases or liquids, or other fire fighting or suppressant systems.

In addition, some refineries require special fortification against earthquakes, hurricanes, and other natural disasters. Refineries and storage facilities in earthquake-prone areas of the U.S. such as California have survived damaging earthquakes without sustalning major losses.

Industry sources report that the majority (up to 80 to 90 percent) of infury-causing accidents are the result of personnel failures in operating or malntenance practices. Extensive training programs are conducted at many refineries to inform workers about their particular job and its place within the total refinery operation.

Petroleum refining is an area in which process control instrumentation and automation are becoming a highly advanced and utilized technology. Instrumentation and automation tend to increase safety by permitting remote and real-time supervision and increased control of refinery operations. Process control instrumentation and automation also permit the optimization of products and energy usage.

\section{F1res and Explosions}

Petroleum refineries handle vast quantities of combustible hydrocarbons and reactive substances that are frequently subjected to high temperatures, pressures, and are nearly always confined. Fires and explosions may $\mathrm{klll}$ or injure refinery workers and fire fighters, cause considerable property damage, disrupt vital refinery operations, endanger neighboring industrial and residential communities, and may release toxic materials to the atmosphere. 
Fires are usually classified by the financial losses they cause. American Petroleum Institute (API) data indicate that, during 1974 to 1975 for 83 refineries, 61 fires each caused a loss greater than $\$ 100,000$, and 19 each caused a loss greater than $\$ 500,000$ (Health and Safety Executive 1980). United Kingdom (U.K.) Fire Research Station statistics for the years 1972 to 1973 indicate that, of 22 refinerles, 10 had fires resulting in losses of more than $\$ 50,000$. Rat1os for fires causing losses on the order of $\$ 50,000$ to $\$ 100,000$ are about one in five per year in the U.S. and one out of four in the U.K.

API and U.K. data are not readily avallable on the incidence of deaths from fires and explosions, or on the incidence of explosions, e1ther as a cause or aftermath of fire (Health and Safety Executive 1978). A Canvey Is land risk assessment study concluded from ava11able data that about 50 percent of large refinery fires might be accompanied by some form of explosion, 1.e., the ignition of a cloud of flammable vapor, whether confined or unconfined. The study cited data indicating that $81 x$ unconfined vapor cloud explosions occured among the world's 600 refineries in a recent 10-year period (Health and Safety Executive 1978).

Some processes such as hydrotesting involve a feed of highly flammable hydrogen into large pressurized vessels. Explosion is possible if air enters the reaction chamber. In 1955 a hydroformer at Whiting, Indlana, exploded, scattering fragments over a wide radius. Fragment projectiles impacted on storage tanks causing leakage and widespread fires (Health and Safety Executive 1978). Leaks, espectally of gases, may cause explosions.

Hydrocracking and hydrotreating have the greatest potential for accidents, In terms of frequency and severity, of any current refinIng process units (Bliss et al. 1976). Catalytic reforming and cracking units are the next source of major accidents. Alkylation units have a better accident record. Because volatile, heavierthan-air hydrocarbons can be involved in alkylation unit accidents, larger areas may be affected by fires and explosions.

Explosions may result from overheating of trapped vapors in tanks, piping, valves, and process units. The violence of failure is apt to be greater, but less frequent, in thicker process containers and in piping that handles higher pressures. Violently escaping vapors and liquids may extinguish themselves temporarily, collect, and then reignite, often explosively, after an interval that typically lasts $1 / 2$ to 1 minute (Health and Safety Executive 1978). Shortages of cooling water, corrosion, wear, furnace collapse, environmental conditions, equipment failure, and human error are among the possible causes of fires and explosions. 
The refining industry exerts considerable effort in plant design and malntenance, process instrumentation, and employee training to minimize the number and extent of refinery fires and explosions. The frequency of refinery fires and explosions may be expected to rise, as most American refinerles age and few are decommissioned. The required large capital investment, industry's view that Federal regulations are inconsistent, taxation, uncertainty of crude oil supplles and product markets, and environmental permit constraints are among the factors cited as disincentives for domestic refiners to replace old factlities or build additional refining capacity.

Some statistics concerning fires at refineries are presented in Table 10. Note that the incidence of refinery fires spreading to other facilities is low.

Refinery and storage facility fires and explosions may cause a number of adverse secondary health, safety, and environmental effects. 011 fires are likely to produce significant atmospheric emissions of pollutants associated with incomplete hydrocarbon combustion: hydrocarbons, sulfur oxides, nitrogen oxides, carbon monox1de, PAHs, and particulate matter. Nearby areas may be exposed to hazardous concentrations, especially if an atmospheric inversion colncides with the fire. Nelghboring homes and industrial areas may require prompt evacuation. Abandonment by workers of endangered areas without following proper shutdown procedures and physical damage from blasts and fires may endanger other process untts or cause significant spills and emissions of oll and process chemicals.

Refinery and storage factlity explosions and fires may cause lengthy shutdowns. Economic dislocations for petroleum companies, insurers, workers, and the local economy may result. Coincident shutdowns at several refineries or storage facllities, whether due to accidents or sabotage, could result in shortages of refined petroleum products on a national scale. The economic and political significance of refining and storage facilities are bound to increase as world demand and prices for crude o1l and refined products increase.

\section{The Canvey Island Investigation}

The Health and Safety Commission of the British government has recently released the results of an investigation of potential hazards and rioke aecociated with industrial development in the Canvey Island area (Health and Safety Executive 1978). Canvey Island, an island in the Thames River, has a population of 33,000 and intense petrochemical activity. The island is $2.5 \mathrm{miles}$ wide by 9 miles in length. Within this small area are two large petroleum refineries, bullding sites for two more, several liquified natural gas (LNG) facilities, petroleum product and crude oil tank farms (besides those 
TABLE 10

PETROLEUM INDUSTRY FIRE LOSSES ${ }^{\mathrm{a}}$

\begin{tabular}{|lccc|}
\hline : & 1969 & 1974 & 1975 \\
\hline $\begin{array}{l}\text { Fire losses } \\
\text { (\$ million) } \\
\text { Total property damages } \\
\text { (\$ million) }\end{array}$ & 13.8 & 26.7 & $73.8^{\mathrm{b}}$ \\
Total number of fires & 541 & 390 & 490 \\
$\begin{array}{l}\text { Total refinery fires } \\
\text { Spread to other } \\
\text { property }\end{array}$ & 160 & 138 & 186 \\
$\begin{array}{l}\text { Origin outside but } \\
\text { spread to refinery } \\
\text { Tankers and barges }\end{array}$ & 1 & 0 & 1 \\
Tank farms & 2 & 2 & 1 \\
\hline
\end{tabular}

For $19 \%$ to 1973 , data is not available.

$\mathrm{b}_{\mathrm{Higher}}$ value of inventory is reflected in this loss compared to 1969 or 1974 .

${ }^{\mathrm{c}}$ All confined to company property.

Source: Health and Safety Executive 1978. (Data for 1969 from American Petroleum Institute 1971; 1974 and 1975. from American. Petroleum Institute 1974, 1975.) 
assoclated with the refineries), and an ammonium nitrate production facility. In addition, much ship traffic passes close by. Material transfer by ship and pipeline occurs at most of these facilities.

Quantitative risk assessment techniques were employed to assess the probability of numerous catastrophies occurring and to determine the risks to populations living near these facilities. Risks of fire, explosion, and release of toxic agents were quantified to assess the hazards associated with current facilities and with the addition of two more large refineries. The chance of a Canvey Island resident being $\mathrm{klll}$ ed as a consequence of a major accident at the existing facilities was calculated at 5 in 10,000 per year--about the same as the risk of dying from natural causes for persons 25 to 34 years old. (This risk is in addition to other risks the residents carry.) The socletal risk of numbers of casualties from several factlities is shown in Table 11. This table shows, for example, that for Refinery $A$, there are 7.8 chances in 10,000 for 10 or more casualties among non-employees. Thus, each year there is a 0.078 percent probability of 10 or more deaths among persons in adjacent neighborhoods or plants. These assessed risks depend on a number of factors and may not be relevant to American petrochemical factlities.

\section{Refinery Deterioration}

Refinery equipment is often subjected to high temperatures, pressures, corrosive substances, vibrations, and physical stress. Constant maintenance and inspections are required to ensure safe operation of the refinery. Aclds and other substances, such as hydrogen sulfide, inevitably corrode metal. Any of the above stresses may lead to leaks or more catastrophic events such as spills, fires, and explosions.

Internạ 1 hydrogen attack is a phenomenon causing embrittlement and subsequent cracking of steel, especially in steel pressure vessel walls and piping that handle hydrogen. Atomic hydrogen reacts with carbon in steel to form methane and other gases, or 1t may accumulate in voids and combine to form molecular diatomic hydrogen. Reaction with carbon causes depletion of the carbon in the metal and eventually large internal pressures and microfissures may develop. The steel's mechantcal properties (e.g., tensile strength, hardness, eductility) degrade, and it may eventually crack and blister. Equipment oubjected to high pressures may experience catastrophic fallure. Steel alloys incorporating metals, such as molybdenum, chromium, vanadium, titantium, and nioblum, are less vulnerable to internal hydrogen attack. Acoustical (ultrasonic) and high-frequency radiation absorption testing can be used to detect significant internal hydrogen attack at an early stage. However, some areas will always be inaccessible to such nondestructive testing. Moreover, the required equipment is expensive, and the testing labor-intensive. 
TABLE 11

SOCIETAL RISKS DUE TO FACILITIES

ON CANVEY ISLAND, UNITED KINGDOM

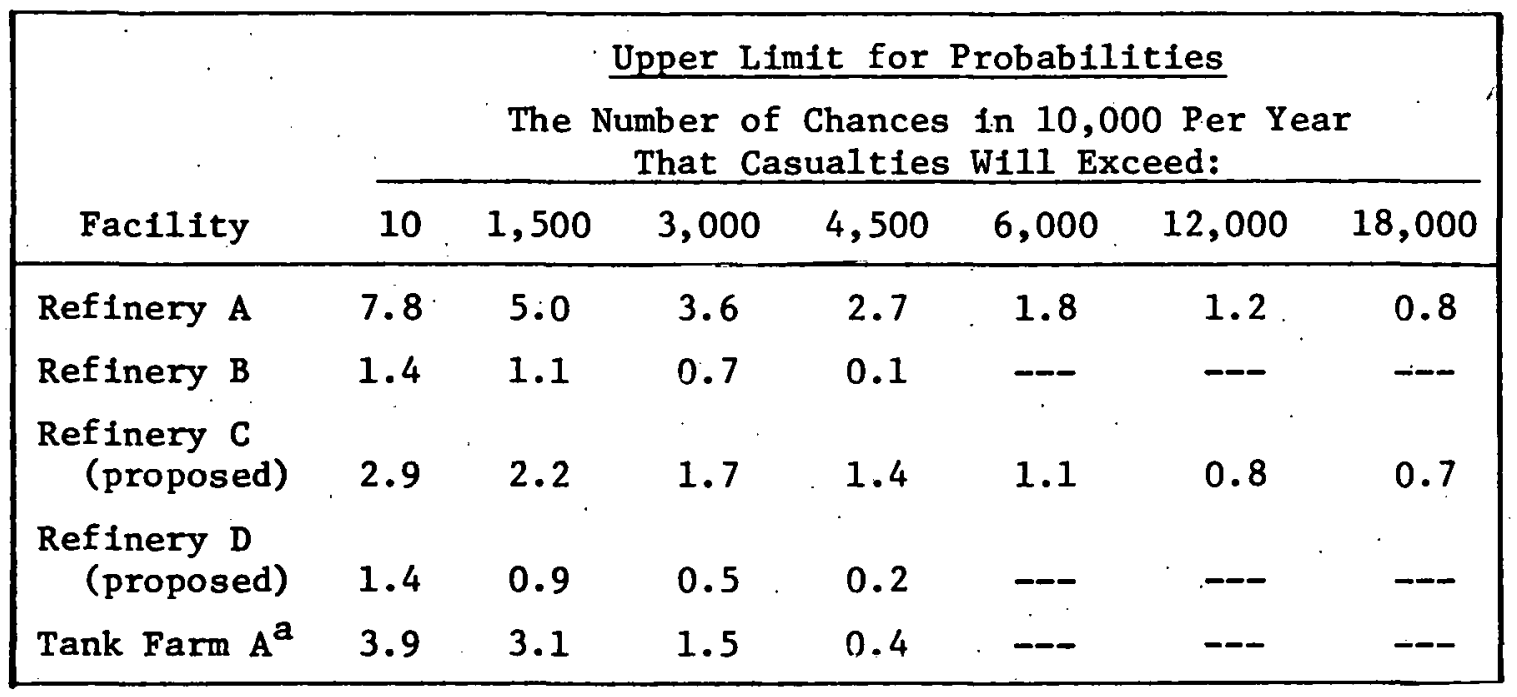

Note: --- Represents zero or rounds to zero.

Receives from ships, feeds; utilizes multiple distribution methods.

Source: Health and Safety Executive 1980. 


\section{Health Effects of Refinery Chemicals}

\section{Hydrocarbons}

A number of hydrocarbons can escape from refinery equipment to affect public and environmental health in addition to the health of workers within the plant boundary. Hydrocarbon emissions from refineries result primarily from fugitive emissions from storage tanks, leaks from processing units and transfer operations, and from combustion sources. Scarce data are avallable regarding hydrocarbon concentrations within and in the vicinity of petroleum refineries. Atmospheric dispersion modeling for large refineries indicates that Federal and state ambient air quality standards for hydrocarbons will be exceeded significantly under worst case conditions. These models indicate that under these conditions, refinerles will be in compliance with ambient air quality standards for $\mathrm{SO}_{2}$, particulates, $\mathrm{NO}_{\mathrm{x}}$, and $\mathrm{CO}$.

Several kinds of hydrocarbons can be emitted from refineries, and in the sections below they will be classifled according to the following scheme:

(1) Acyclic (aliphatic) hydrocarbons--hydrocarbons formed from chains of carbon atoms, with or without branching; may be saturated or unsaturated. Examples are propane, dodecane, and 2-methyl-2-butene.

(2) Alicyclic hydrocarbons--simllar to acyclic hydrocarbons, but containing non-resonant rings of carbon atoms; examples are cyclohexane, 1-methyl-3-cyclohexane, naphthanes, and naphthalenes.

(3) Aromatic hydrocarbons--benzene and its hydrocarbon derivatives; possess one or more non-fused, six-carbon, resonant ring (benzene) structures. Examples are benzene, toluene, and diphenyl.

(4) Phenolics--aromatic hydrocarbons with one or more hydroxyl $(-\mathrm{OH})$ groups substituted on an aromatic ring. Examples are phenol, 2,6-xylenol, and 4-chlorophenol.

(5) Polynuclear aromatic hydrocarbons--hydrocarbons with two or more fused aromatic rings; may be termed heterocyclic, if component rings contain one or more non-carbon atoms (usually nitrogen or sulfur). Examples are benzo(a)pyrene and phenanthrene. 


\section{Acyclic Hydrocarbons}

In general, members of the acyclic hydrocarbon series are relatively biologically and biochemically inert. Lower alkanes exert a slight anesthetic and depressant effect on the central nervous system at concentrations in the 5 to $10,000 \mathrm{ppm}$ range, with the exception of methane and ethane. For $\mathrm{C}_{5}$ to $\mathrm{C}_{7}$ alkanes (pentane, hexane, and heptane), narcosis, convulsions, and death may result if these are inhaled in high concentrations. Alkenes (olefins) and alkynes (acetylenics) are much more toxic. Methane and ethane produce no significant 111-effects, even at high concentrations in ambient air (except when approaching asphyxiant or explosive levels). At extremely high concentrations, acyclic hydrocarbons, frequently termed "simple asphyxiants," displace inhaled oxygen to cause anorexia and asphyxiation. Depressent effects are especlally pronounced during exposure to acetylene, ethylene, and propylene, which have been used as medical anesthetics. Acute toxicities for a number of hydrocarbons are compared in Table 12 .

Generally, alkanes from pentane $\left(C_{5}\right)$ through octane $\left(C_{8}\right)$ show increasingly narcotic properties. Acyclics, like most volatile hydrocarbons, Irritate the skin and mucous membranes. Contact with hydrocarbons defats and dries the skin, making it more susceptible to Irritation. Reported cases of alkane vapor exposure are simmartzed II Table 13. Since exposure to only one alkane is infrequent, the National Institute for Occupational Safety and Health (NIOSH) has recommended a time weighted average concentration of $350 \mathrm{mg}$ per $\mathrm{m}^{3}$ as the occupational $11 \mathrm{mit}$ for mixtures of pentane, hexane, heptane, and total alkanes. These concentration limits are equal to about 120 p pm pentane, $100 \mathrm{ppm}$ hexane, $85 \mathrm{ppm}$ heptane, or $75 \mathrm{ppm}$ octane. NIOSH also recommends a 15-minute maximum allowable concentration (ceiling $11 \mathrm{mit}$ ) of $1,800 \mathrm{mg}$ per $\mathrm{m}^{3}$ either for mixtures or single $\mathrm{C}_{5}$ through $\mathrm{C}_{8}$ alkanes (about $610 \mathrm{ppm}$ pentane, $500 \mathrm{ppm}$ hexane, $440 \mathrm{ppm}$ heptane, or $385 \mathrm{ppm}$ octane). These recommended standards are based on the conclusion that acute alkane intoxication involves transient central nervous system depression and that chronic intoxication may involve more persistent neurological disorders.

Acyclics above octane $\left(C_{8}\right)$ are not sufficiently volatile to pose serious vapor inhalation hazards at ambient temperature. In 1976, the American Conference of Governmental and Industrial Hygienists set a threshold limit value (TLV) of $200 \mathrm{ppm}$ for nonane $\left(\mathrm{C}_{9}\right)$, based on analogy with other alkanes, rather than on controlled tests or observations. 
TABLE 12

ACUTE TOXICITY OF ALIPHATIC HYDROCARBONS

\begin{tabular}{|c|c|c|c|c|c|c|}
\hline Hydrocarbon & Formula & Health Effects & $\begin{array}{c}\text { Concentration } \\
(\mathrm{ppm})\end{array}$ & $\begin{array}{l}\text { Percent of } \\
\text { Volume } \\
\text { of Air }\end{array}$ & Subject & $\begin{array}{c}\text { Ambient } \\
\text { Concentrations } \\
\text { (ppb) }\end{array}$ \\
\hline Methane & $\mathrm{CH}_{4}$ & No systemic effects & $<100,000$ & 10 & & $1,300-4,000$ \\
\hline Ethane & $\mathrm{C}_{2} \mathrm{H}_{6}$ & No systemic effects & $<50,000$ & 5 & Man & $0.05-95$ \\
\hline Propane & $\mathrm{C}_{3} \mathrm{H}_{8}$ & $\begin{array}{l}\text { No symptoms after brief } \\
\text { exposure } \\
\text { odor not detected } \\
\text { No irritation, but slight } \\
\text { dizziness in a few } \\
\text { minutes }\end{array}$ & $\begin{array}{r}<10,000 \\
<20,000 \\
<100,000\end{array}$ & $\begin{array}{r}1 \\
2 \\
10\end{array}$ & $\begin{array}{l}\text { Man } \\
\text { Man } \\
\text { Man }\end{array}$ & $12-94$ \\
\hline Butane & $\mathrm{C}_{4} \mathrm{H}_{10}$ & $\begin{array}{l}\text { Odor not detected } \\
\text { No syst mic effects } \\
\text { except drowsiness }\end{array}$ & $\begin{array}{r}<5,000 \\
10,000 \text { for } \\
10 \text { mins }\end{array}$ & $\begin{array}{l}0.5 \\
1.0\end{array}$ & $\begin{array}{l}\text { Man } \\
\text { Man }\end{array}$ & $0.01-182$ \\
\hline Pentane & $\mathrm{C}_{5} \mathrm{H}_{12}$ & $\begin{array}{l}\text { Threshold limit } \\
\text { Odor readily detectable } \\
\text { No mucous membrane ir- } \\
\text { ritation or other } \\
\text { symptoms } \\
\text { Narcosis in } 5 \text { to } 60 \text { mins }\end{array}$ & $\begin{array}{c}1,000 \\
5,000 \\
5,000 \text { for } \\
10 \text { mins } \\
9.0,000-120,000\end{array}$ & $\begin{array}{l}0.1 \\
0.5 \\
0.5 \\
9-12\end{array}$ & $\begin{array}{l}\text { Man } \\
\text { Man } \\
\text { Man } \\
\text { Mice }\end{array}$ & $0.023-64$ \\
\hline Hexane & $\mathrm{C}_{16} \mathrm{H}_{14}$ & $\begin{array}{l}\text { Threshold limit } \\
\text { No symptoms } \\
\text { Dizziness and sen- } \\
\text { sation of giddiness }\end{array}$ & $\begin{array}{r}500 \\
2,000 \text { for } \\
10 \text { mins } \\
5,000\end{array}$ & $\begin{array}{l}0.05 \\
0.2 \\
0.5\end{array}$ & $\begin{array}{l}\text { Man } \\
\text { Man } \\
\text { Man }\end{array}$ & $4-27$ \\
\hline
\end{tabular}


TABLE 12 (Continued)

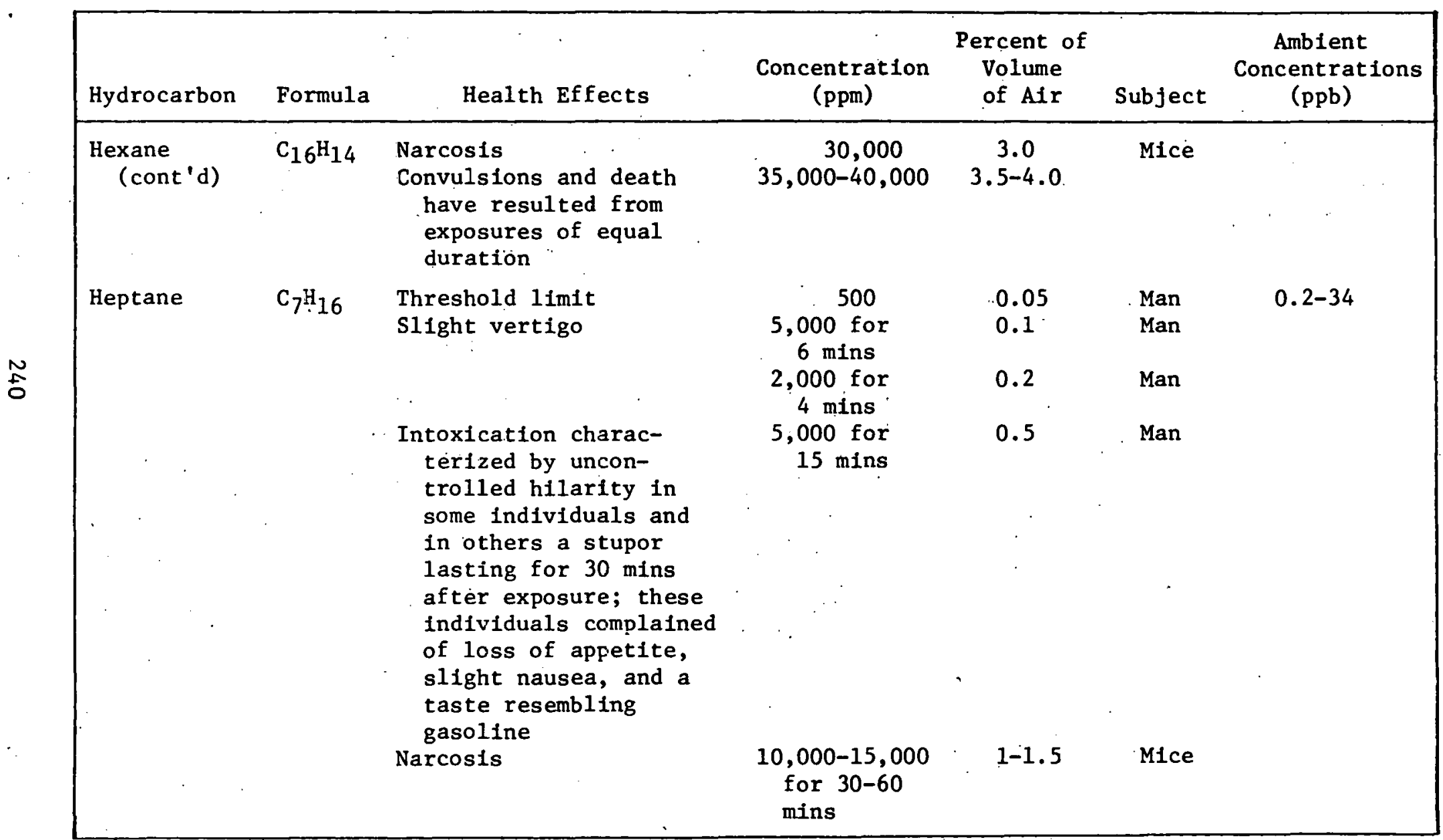


TABLE 12 (Continued)

\begin{tabular}{|c|c|c|c|c|c|c|}
\hline Hydrocarbon. & Formula & Health Effects & $\begin{array}{c}\text { Concentration } \\
\text { (ppm) }\end{array}$ & $\begin{array}{l}\text { Percent of } \\
\text { Volume } \\
\text { of Air }\end{array}$ & Subject & $\begin{array}{c}\text { Ambient } \\
\text { Concentrations } \\
\text { (ppb) }\end{array}$ \\
\hline $\begin{array}{l}\text { Heptane } \\
\quad(\text { Cont'd) }\end{array}$ & $\mathrm{C}_{7} \mathrm{Fi}_{16}$ & Convulsions/death & $\begin{array}{l}15,000-20,000 \\
\text { for } 20-60 \\
\text { mins }\end{array}$ & $1.5-2.0$ & Mice & \\
\hline Octane & $\mathrm{C}_{8} \mathrm{H}_{18}$ & $\begin{array}{l}\text { Threshold limit } \\
\text { Narcosis in } \\
\text { 30-90 mins } \\
\text { No deaths or con- } \\
\text { vulsians }\end{array}$ & $\begin{array}{c}500 \\
6,600-13,700 \\
<13,700 \text { for } \\
30-90 \text { mins }\end{array}$ & $\begin{array}{l}0.05 \\
0.66-1.37 \\
\quad . \\
1.37\end{array}$ & $\begin{array}{l}\text { Man } \\
\text { Mice } \\
\text { Mice }\end{array}$ & $0.04-3.4$ \\
\hline Ethylene & $\mathrm{C}_{2} \mathrm{H}_{2}$ & $\begin{array}{l}\text { TLVb } \\
\text { MPLC }\end{array}$ & $\begin{array}{l}1,000 \\
5,500\end{array}$ & $\begin{array}{l}0.1 \\
0.55\end{array}$ & $\begin{array}{l}\text { Man } \\
\text { Man }\end{array}$ & $0.7-700$ \\
\hline Propylene & $c_{3} \mathrm{n}_{6}$ & MPL $^{c}$ & 4,000 & 0.4 & Man & $1-52$ \\
\hline 1-Butene & $\mathrm{C}_{4} \mathrm{H}_{8}$ & MPL & 1,000 & 0.1 & Man & $0.7-700$ \\
\hline $\begin{array}{l}\text { 1, 3-Buta- } \\
\text { diene }\end{array}$ & $\mathrm{C}_{4} \mathrm{H}_{6}$ & $\begin{array}{l}\text { TLV } \\
\text { Only slight eye and } \\
\text { upper respiratory } \\
\text { tract irritation } \\
\text { in man } \\
\text { No deleterious effects } \\
\text { from these exposures; } \\
\text { however, the animals } \\
\text { were slightly anes- } \\
\text { thesthetized, showing } \\
\text { a lost of pupillary } \\
\text { reflex, Noisy } \\
\text { breathing and rales } \\
\text { were noted }\end{array}$ & $\begin{array}{l}1,000 \\
8,000 \text { for } \\
8 \mathrm{hrs} \\
200,000-250,000 \\
\text { once a day } \\
\text { for } 15-21 \\
\text { days }\end{array}$ & $\begin{array}{l}0.1 \\
0.8 \\
20-25 \\
\end{array}$ & $\begin{array}{l}\text { Man } \\
\text { Man } \\
\text { Rabbits }\end{array}$ & $1-9$ \\
\hline
\end{tabular}


TABLE 12 (Concluded)

\begin{tabular}{|c|c|c|c|c|c|c|}
\hline Hydrocarbon & Formula & Health Effects & $\begin{array}{c}\text { Concentration } \\
(\mathrm{ppm})\end{array}$ & $\begin{array}{l}\text { Percent of } \\
\text { Volume } \\
\text { of Air }\end{array}$ & Subject & $\begin{array}{c}\text { Ambient } \\
\text { Concentrations } \\
\text { (ppb) }\end{array}$ \\
\hline $\begin{array}{l}\text { 2-Methyl-1, } \\
\text { 3-butadiene } \\
\text { (isoprene) }\end{array}$ & $e^{\mathrm{C}_{5} \mathrm{H}_{8}}$ & No narcosis & $\begin{array}{l}20,000 \text { for } \\
2 \mathrm{hrs} \\
35,000-40,000\end{array}$ & $\begin{array}{l}2 \\
3.5-4.0\end{array}$ & Mice & $0.2-2.9$ \\
\hline Acetylene & $\mathrm{C}_{2} \mathrm{H}_{2}$ & $\begin{array}{l}\text { MPL }{ }^{C} \\
\text { S1ight Intoxicating } \\
\text { effect } \\
\text { Marked intoxication } \\
\text { Incoordination } \\
\text { Unconsciousness in } \\
\quad 5 \text { mins }\end{array}$ & $\begin{array}{c}5,000 \\
100,000 \\
200,000 \\
300,000 \\
350,000\end{array}$ & $\begin{array}{l}0.5 \\
10 \\
20 \\
30 \\
35\end{array}$ & $\begin{array}{l}\text { Man } \\
\text { Man } \\
\text { Man } \\
\text { Man } \\
\text { Man }\end{array}$ & $0.2-227$ \\
\hline
\end{tabular}

a Concentrations appearing in the literature up to 1978.

$b_{\text {TLV - Threshold limit value. }}$

MPL - Maximum permissible level.

Source: U.S. Environmental Protection Agency 1980. 
TABLE 13

EझFECTS OF ALKANE VAPOR EXPOSURE ON HUMANS

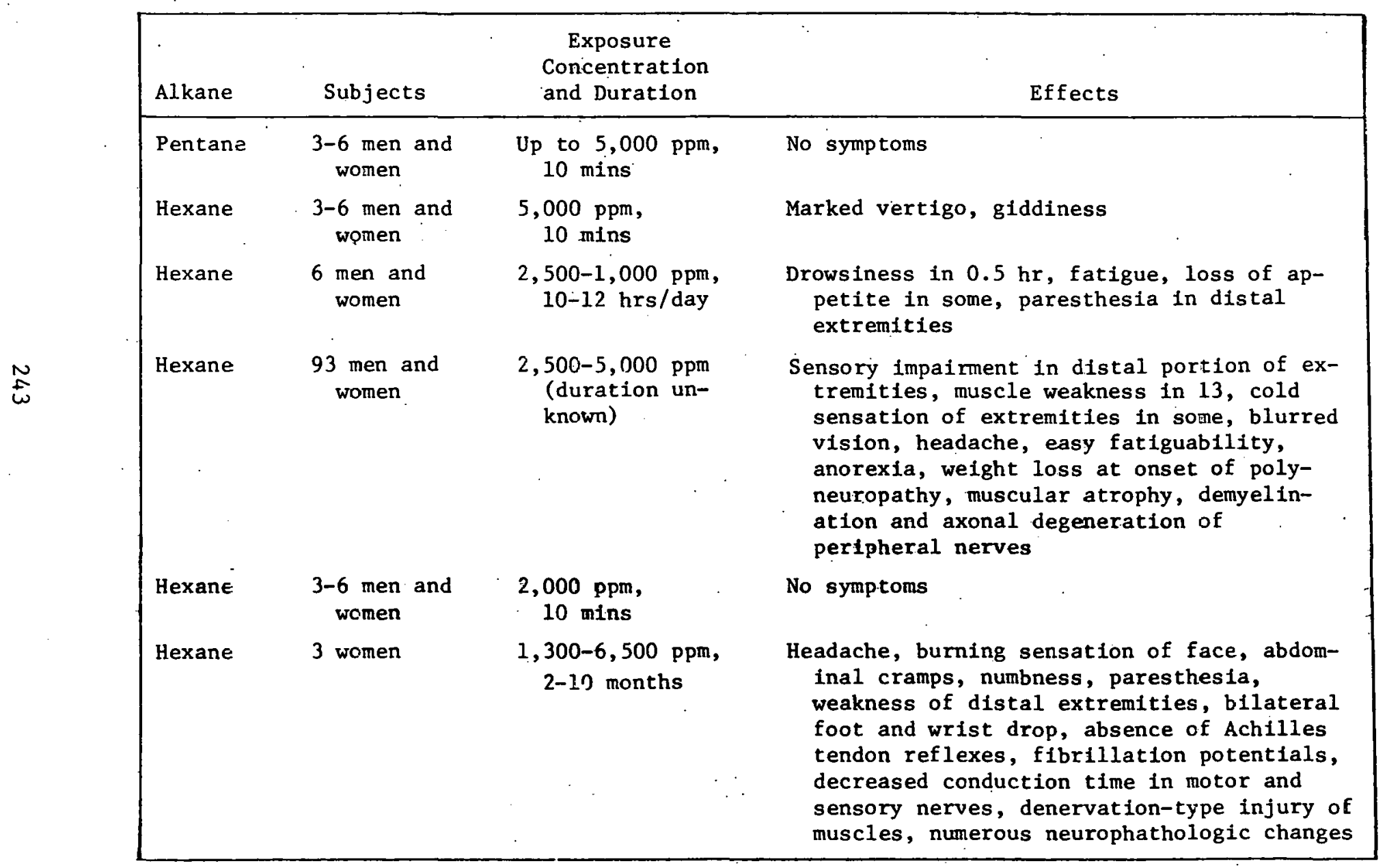


TABLE 13 (Concluded)

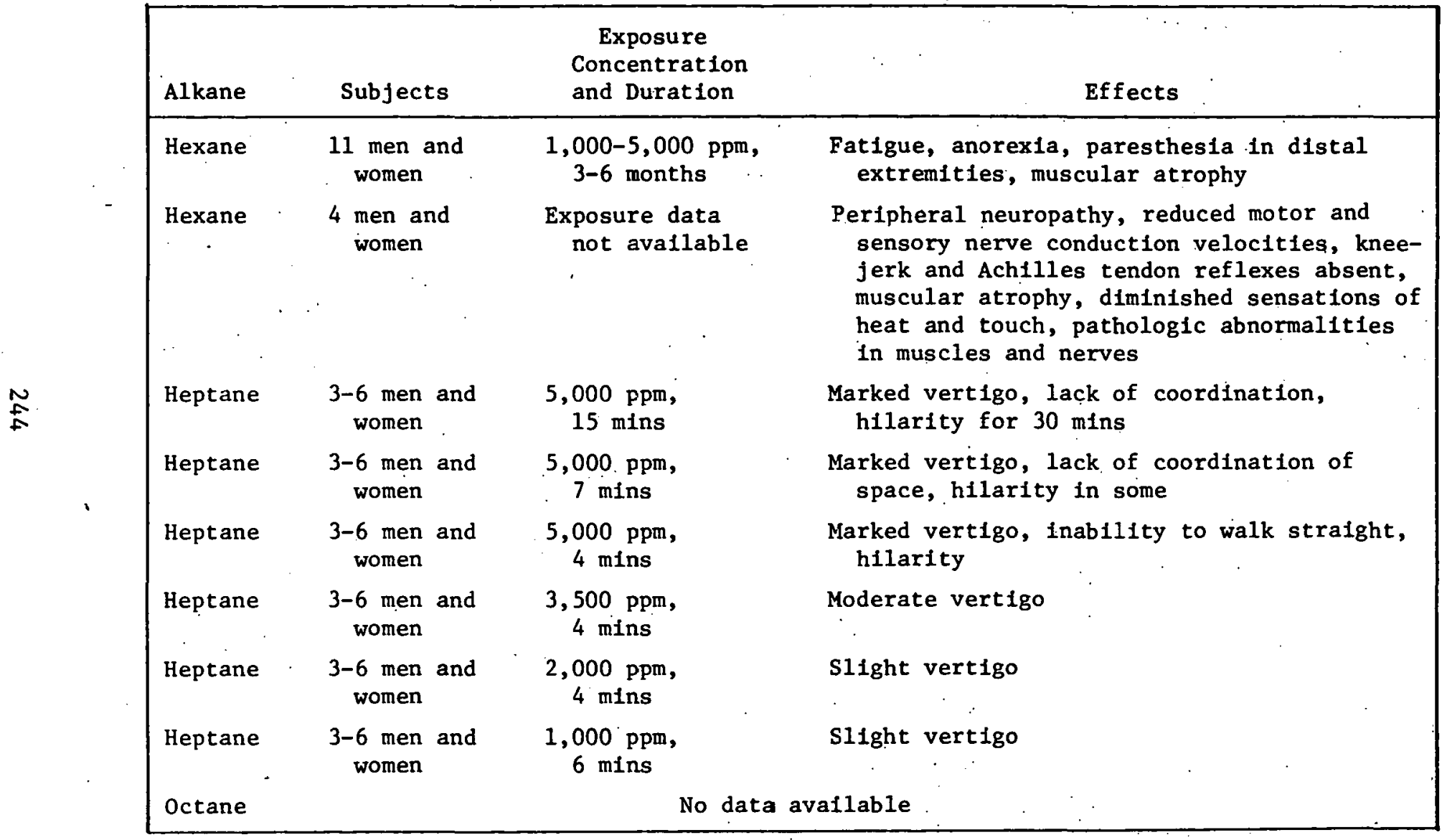

Source: National Institute of Occupational Safety and Health 1977a. 
The volatile acyclic and alicyclic hydrocarbons have not been demonstrated as carcinogenic, teratogenic, or mutagenic in humans or animals. However, some of the longer-chain $\left(c_{12}\right.$ or greater $)$ alkanes have been implicated as co-carcinogens, based on mouse skin experiments.

Acyclic hydrocarbons are generally metabolized to alcohols, which may be further metabolized to ketones, aldehydes, and acids. Alkenes (olefins) may be oxidized at saturated positions to yield alkenols.

Lower-molecular-weight hydrocarbons affect the surface tension and electrical conductivity of lipids, proteins, and lipoprotein membranes. These effects are related to their narcotic effects. In general, branched lower alkane lsomers are less actlve and less toxic than normal (straight chained) alkanes.

Animal experiments, usually with dogs, show definite inhibition of cardiac performance due to propane, butane, and isobutane (Aviado et al. 1977). Effects include a decrease in myocardial contract11ity, a decrease in mean aortic pressure and stroke work, a decrease in total cardlac output, and an increase in pulmonary vascular resistance. Mean threshold concentrations for these effects are in the 2 to 3 percent (volume/volume) range. Threshold levels vary, depending on other components in the respired air. The cause of these hemodynamic effects is unknown; they may be direct effects on the vascular system or may be induced via central nervous system depression.

\section{Hydrocarbon Neuropathy}

Scala (1976) wrote that, "Hydrocarbon Neuropathy is a clinical entity of relatively recent description." Perlpheral, chemicallyinduced neuropathies are believed to result from Impairment of metabolism in neuron (nerve) cell bodies. Distant portions of the body's longest axons become poorly nourlshed and degenerate--with the nerve fiber steadily "dying back" as the disease progresses. The longest sclatic nerves are affected first, with a decrease in sensation and motor abilities, first in the feet, then in the hands. Complete recovery has been claimed when the disease is treated early. Otherwise, permanent sensory and motor deficlts result. Reported symptoms include numbness, paresthesia (loss of tactile senses), tenderness, muscle weakness, fatiguability, lassitude, constriction of the visual field, muscle atrophy, hypo- and hyperactive reflexes, and pain (Scala 1976). Some patients experience a continuous increase in severity of the symptoms, even after several months of treatment and removal from sources of exposure. 
Most clinical reports of hydrocarbon neuropathy involve poorly characterized occupational exposures to $n$-hexane. A majority of cases involve exposure to technical or solvent grade hexane which may commonly contain significant amounts of other $C_{5}$ through $C_{9}$ alkanes, cycloalkanes, and aromatic compounds, including benzene and toluene. Technical grade hexane, defined by its physical properties, frequently contains less than 50 percent $n$-hexane. Hydrocarbon exposure levels on the order of over $500 \mathrm{ppm}$ have caused neuropathy outbreaks. Glue-sniffing cases, involving deliberate inhalation of hexane-containing toluene, have been reported to be clinically different from occupational n-hexane polyneuropathy. It is unknown whether toluene modifies the action of hexane, or if the different mode of exposure (short-term, high concentration) affects disease development.

Limited animal studies have assessed the peripheral neuropathy associated with hydrocarbon exposures (Scala 1976). In general, these studies confirm the occupationally observed polyneuropathies. Peripheral nerve degeneration and sensorimotor deficiencies are observed after chronic, 1- to 6-month exposures to technical grade hexane.)

The hydrocarbon 2-hexanone (methy1-n-butyl ketone) exhibits a polyneuropathy in animals similar to that caused by hexane. Both n-hexane and 2-hexanone have common metabolites, 2,5-hexanedione and 5-hydroxy-3-hcicanone. The 2,5-hexanedione has demonstrated neurotoxic effects in animals, but other alkane metabolites require thorough testing. A critical 2- or 2,5-relationship for oxygenbearing atoms may be assoclated with neurotoxicity. Similar oxidative metabolic reactions have been demonstrated with heptane. Metabolic reactions of hexane, heptane, and other hydrocarbons to neurotoxic metabolites require investigation. A structurally-based, generic, metabolic cause of hydrocarbon polyneuropathy may be possible and bears examination. As exposure to pure hydrocarbons is rare, studies are needed involving synergistic and other interactive neurotoxic effects among hydrocarbons and other agents commonly fcund in the workplace.

\section{Alicyclic Hydrocarbons}

The toxicological effects of alicyclic hydrocarbons closely resemble those of the acyclic hydrocarbons, however their toxicities do not correlate as well as the acyclics with respect to structure (e.g., number of carbon atoms, degree of unsaturation). There are few reported cases of human exposure to alicyclic hydrocarbons because they are infrequently used or encountered in pure form. Animal toxicity for these compounds is summarized in Table 14. 
TABLE 14

TOXICITY OF ALICYCLIC HYDROCARBONS

\begin{tabular}{|c|c|c|c|c|c|c|c|c|c|c|}
\hline \multirow[b]{2}{*}{ Hydrocarbon } & \multirow[b]{2}{*}{ Formula } & \multirow[b]{2}{*}{ Health Effects } & \multicolumn{3}{|c|}{ Concentration } & \multicolumn{2}{|c|}{ Exposure } & \multirow[b]{2}{*}{ Subject } & \multirow{2}{*}{$\begin{array}{l}\text { Type of } \\
\text { Study }\end{array}$} & \multirow{2}{*}{$\begin{array}{c}\text { Ambient } \\
\text { Concentrations } \\
\text { (ppb) }\end{array}$} \\
\hline & & & (ppm). & $\left(\mathrm{mg} / \mathrm{m}^{3}\right)$ & (\% by Air) & Hrs & Days & & & \\
\hline \multirow[t]{7}{*}{ Cyclohexane } & $\mathrm{C}_{6} \mathrm{H}_{12}$ & No effect & 434 & 1,491 & 0.043 & 8 & 130 & Rabbits & Chronic & $3-6$ \\
\hline & & $\begin{array}{l}\text { Minor microscjpic } \\
\text { changes in kidneys } \\
\text { and liver }\end{array}$ & .786 & 2,710 & 0.078 & 5 & 50 & Rabbits & Chronic & \\
\hline & & No effect & 1,243 & 4,270 & 0.12 & 6 & .50 & Monkey & Chronic & \\
\hline & & $\begin{array}{l}\text { Ne fatalities or } \\
\text { signs of injury }\end{array}$ & 3,300 & 11,439 & 0.33 & 6 & 50 & Rabbits & Chronic & \\
\hline & & Some fatalfties & 7,400 & 25,419 & $0.74-1.85$ & 6 & 10 & Rabbits & Chronic & \\
\hline & & No deaths & 18,500 & 63,548 & 1.85 & 8 & 1 & Rabbits & Acute & \\
\hline & & Deaths & 26,600 & & 2.66 & 1 & 0 & Rabbits & Acute & \\
\hline \multirow{5}{*}{$\begin{array}{l}\text { Methylcyclo- } \\
\text { hexane }\end{array}$} & $\mathrm{C}_{6} \mathrm{H}_{11} \mathrm{CH}_{3}$ & No effect & 241 & 996 & 0.024 & 24 & 70 & Rabb1ts & Chronic & $3-7$ \\
\hline & & No effect & 1,162 & 4,659 & 0.116 & 24 & 70 & Rabb1ts & Chrontc & \\
\hline & & No effect & 2,800 & 11,228 & 0.28 & 24 & 70 & Rabbits & Chronic & \\
\hline & & $\begin{array}{l}\text { Minor evidence of } \\
\text { kidney and liver } \\
\text { injury }\end{array}$ & 3,300 & $1: 3,233$ & 0.33 & 5 & 70 & Rabb1ts & Chrontc & . \\
\hline & & $\begin{array}{l}\text { No fatalities } \\
\text { lethargy in } 50 \%\end{array}$ & 5,600 & 22,456 & 0.56 & 6 & 28 & Rabb1ts & Chronic & \\
\hline
\end{tabular}


TABLE 14 (Concluded)

\begin{tabular}{|c|c|c|c|c|c|c|c|c|c|c|}
\hline \multirow[b]{2}{*}{ Hydrocarbon } & \multirow[b]{2}{*}{ Formula } & \multirow[b]{2}{*}{ Health Effects } & \multicolumn{3}{|c|}{ Concentration } & \multicolumn{2}{|c|}{ Exposure } & \multirow[b]{2}{*}{ Subject } & \multirow{2}{*}{$\begin{array}{l}\text { Type of } \\
\text { Study }\end{array}$} & \multirow{2}{*}{$\begin{array}{c}\text { Amblent } \\
\text { Concentrations } \\
\text { (ppb) }\end{array}$} \\
\hline & & & (ppm) & $\left(\mathrm{mg} / \mathrm{m}^{3}\right)$ & ( $\%$ by Air) & Hrs & Days & & & \\
\hline \multirow{3}{*}{$\begin{array}{l}\text { Methylcyclo- } \\
\text { hexane } \\
\text { (Cont'd) }\end{array}$} & & $25 \%$ fatalities & 7,300 & 29,273 & 0.73 & 6 & 14 & Rabb1ts & Chronic & \\
\hline & & 100\% fatailties & 10,000 & 40.100 & 1.0 & 6 & 14 & Rabbits & Chrontc & - \\
\hline & & $100 \%$ fatalltes & 15,000 & 60.150 & 1.5 & $\begin{array}{l}70 \\
\text { mins }\end{array}$ & 0 & Rabbits & Chronic & \\
\hline
\end{tabular}

${ }^{a}$ The threshold 11mit value for cyclohexane $1 \mathrm{~s} 400 \mathrm{ppm}$.

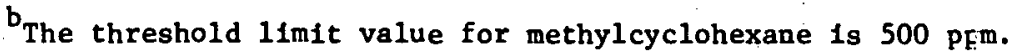

Source: U.S. Environmental Protection Agency 1980. 
Alicyclics act as general anesthetics and central nervous system depressants with a relatively low order of acute toxicity. Massive acute exposure may cause asphyxiation and narcotic effects-exhilaration, vertigo, headache, anorexia, incoordination, and nausea. Most cycloalkenes such as cyclopentene, cyclohexene, and cycloheptene are known to be metabolized to their corresponding, more toxic trans-diols in in vitro microsomal preparations.

Chronic animal exposure studies are deficient with respect to alicyclic dose-response relationships (U.S. Environmental Protection Agency 1980a). Available occupational and epidemiological studies do not demonstrate systemlc effects due to naphthenes. Naphthenes (hydrocarbons with fused $s 1 x$-member nonaromatic rings) are abundant in gasoline and gasoline vapors and behave much like other alicyclics.

Alicyclics tend not to accumulate within the body. Most cycloalkanes are rapidly exhaled, metabolized, and eliminated in the urine as glucouronide and sulfate derivatives.

\section{Aromatic Hydrocarbons}

Benzene. Concentrations of benzene vapors over $100 \mathrm{ppm}$, in either acute or chronic exposures, may cause multiple central nervous system (CNS) and other effects--euphoria, dizziness, confusion, narcosis, CNS stimulation followed by depression with respiratory paralysis, mucous membrane irritation with pulmonary edema, gastrointestinal irritation, skin blistering, and paresthesia (10ss of tactile senses). Benzene toxicity is summarized in Table 15. Most acute effects are reversible. Benzene is quite soluble in body fluids and tissues. Due to its high vapor pressure, it is rapidly eliminated via lungs and concentrated in urine by the kidneys within minutes after exposure terminates. It is primarily metabolized to phenol, with minor metabolites including trans-1,2-dihydrobenzene, catechol, hydroquinone, phenylmercaptic acid, and trans-muconic acid. Hydroxylated species are further metabolized and excreted as conjugated glucouronides and sulfates.

Chronic exposure to benzene may eliclt a number of responses, including leukemia, pancytopenia, and chromosomal aberrations. Hematopoletic (blood forming) anomalies can affect a number of blood parameters, 1icluding erythrocyte count, hemoglobin, mean corpuscular volume of red blood cells, platelet counts, and leukocyte counts. These abnurmalities heve developed as a result of repeated occupational exposure to benzene concentrations from 60 to $105 \mathrm{ppm}$. Benzene chronic exposures as low as 20 to $25 \mathrm{ppm}$ have been associated with hematologic alterations (U.S. Environmental Protection Agency 1980). 
TA3LE 15

TOXICITY OF BENZENE

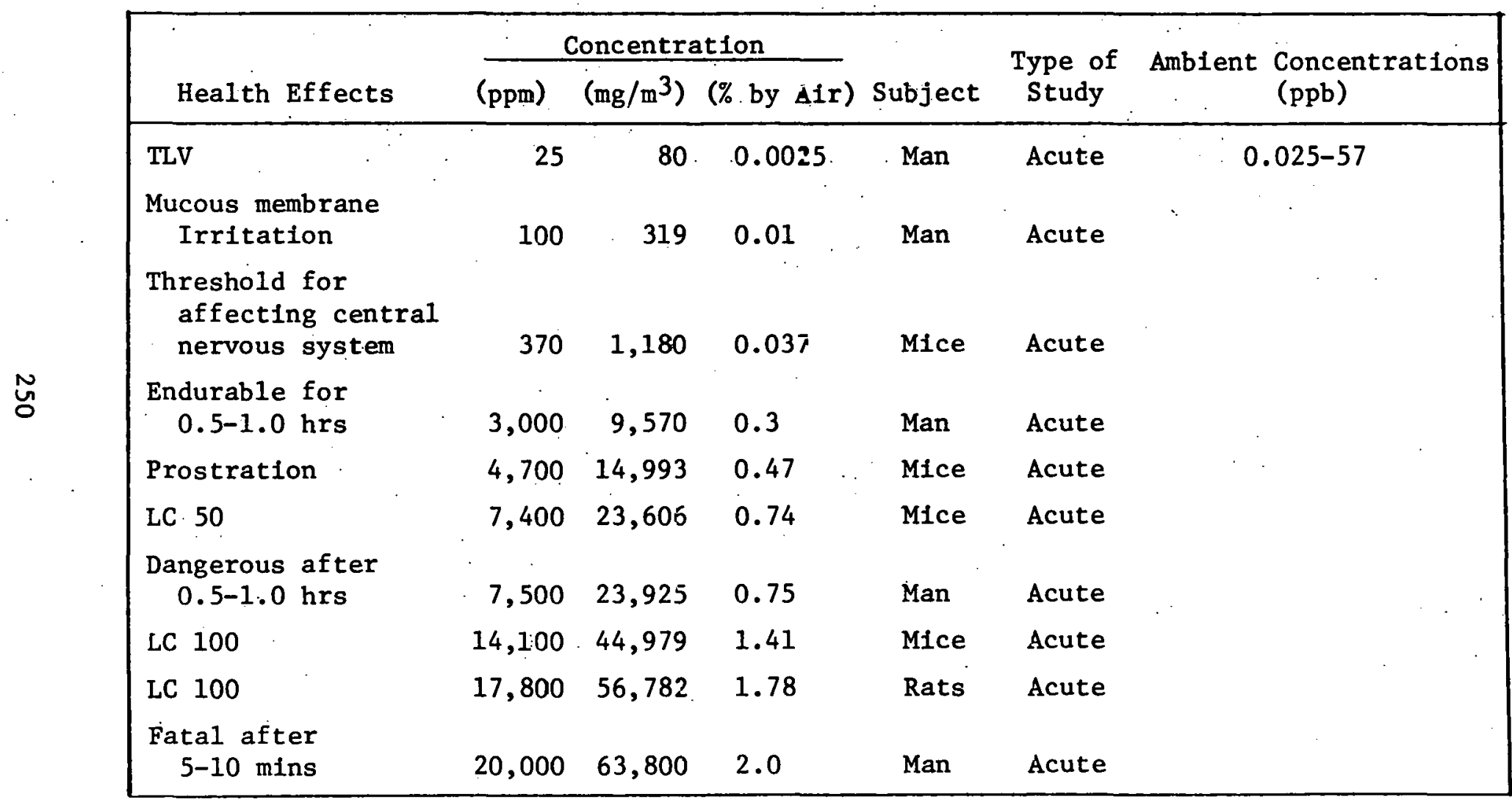

Note: $\operatorname{TLV}=$ threshold $11 \mathrm{mit}$ value.

LC $50=$ lethal concentration 50 .

LC $100=$ lethal concentration 100 .

Source: U.S. Environmental Protection Agency 1980. 
Benzene is recognized as a toxic agent. Exposure has caused leukemia in some animal studies. Human occupational exposure experience and epidemiological studies confirm benzene's leukemia-causing potential, but do not support accurate derivation of dose-response curves. Most of these studies report exposure levels of 100 to 500 $\mathrm{ppm}$. Benzene was recently judged to be fetotoxic to rats at exposures of 50 and $500 \mathrm{ppm}$ and to cause teratogentc effects at $500 \mathrm{ppm}$ (Kuna and Kapp 1981). NIOSH recently revised its recommendations for the threshold limft value for occupational exposure to benzene from $10 \mathrm{ppm}$ to $1 \mathrm{ppm}$; however, the U.S. Supreme Court blocked enforcement of the lower exposure limit.

Toluene and Xylenes. Toluene and xylene lsomers are methyl derivatives of benzene (toluene is 1 -methylbenzene and xylene is dimethylbenzene). Xylene exists in three isomeric forms determined by the relative position of two methyl groups on the six-member benzene ring: 1,2 (ortho); 1,3 (meta); and 1,4 (para). These two aromatics act as irritants on skin and mucous membranes, including the respiratory tract and conjunctiva (eyes). These compounds were thought to affect the blood, blood-forming organs, and nervous system, much the same as benzene (National Institute for Occupational Safety and Health 1975a). However; recent testing suggests that benzene and other contaminants were primarily responsible for these effects. Acute toxicity tests for these compounds are suspect, unless the agents tested are fully characterized and the amount of benzene is $10 \mathrm{w}$, on the order of less than 0.1 percent ( $100 \mathrm{ppm}$ ) (National Institute for Occupational Safety and Health 1975a).

The major toxic effects of these compounds (summarized in Table 16) are due to their narcotic properties. Habituation to toluene has occurred in painters and "glue sniffers." These persons may purposefully absorb toluene up to the point of unconsciousness, but in most cases no. permanent pathological changes occur. Xylene toxicity is similar, although it may be slightly more irritating. These compounds detrimentally affect human judgment, attention, performance, and perception, but these effects have not been quantified relative to other hydrocarbons.

Toluene is readily metabolized to benzoic acid, which is eliminated as hippuric acid in the urine. Small amounts of benzyl alcohol intermediate may be isolated and lesser amounts of systemic toluene are hydroxylated to $o-$ and $\mathrm{p}$-cresol. Xylene metabolism involves oxidation of a methyl group, conjugation with glycine or glucouronic acid, and excretion as methylhippuric acid. While some xylene may be hydroxylated to phenolic metabolites, the amount is small and apparently does not significantly affect acute toxicity. 
TABLE 16

TOXICITY OF TOLUENE AND XYLENES

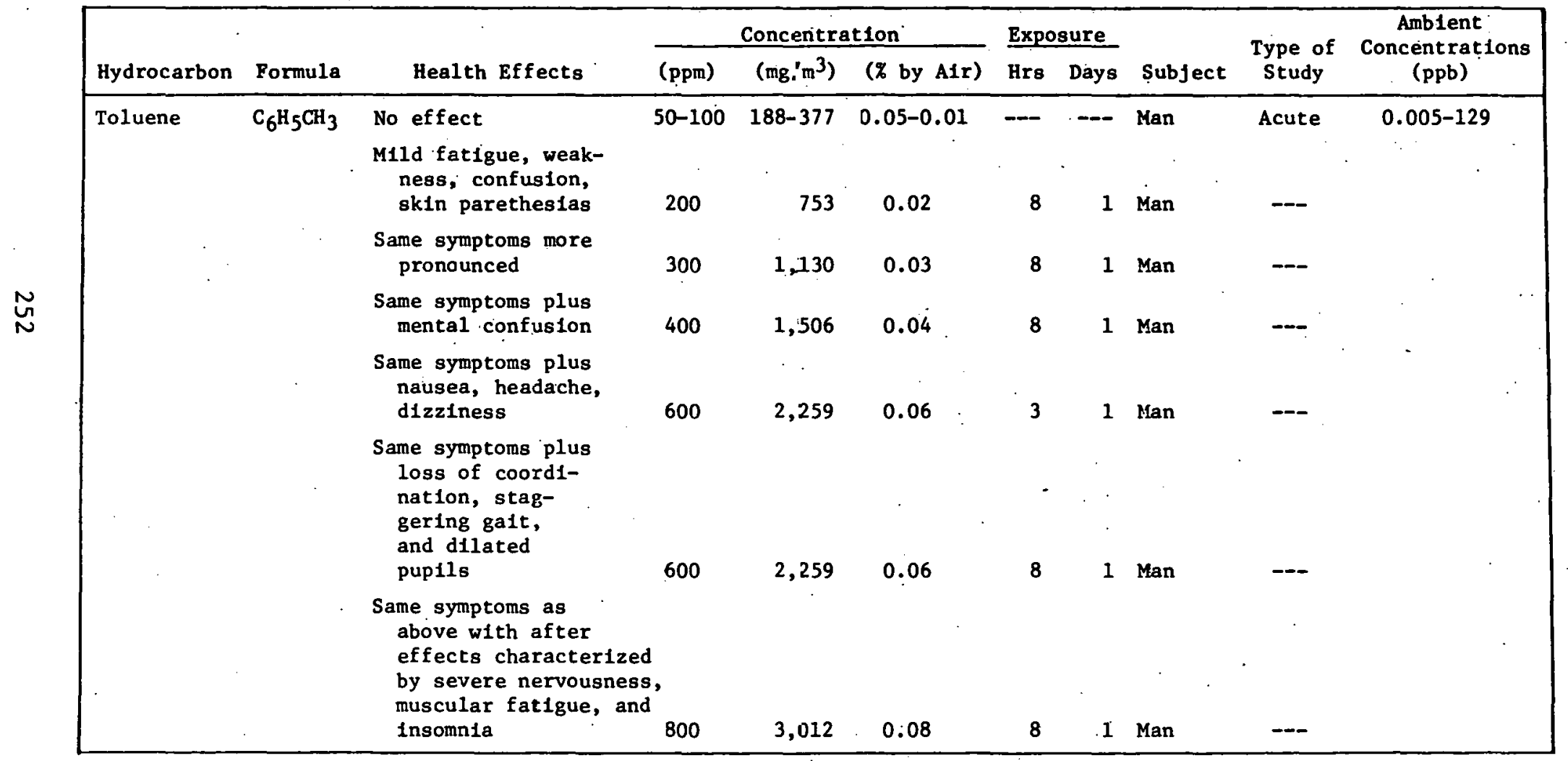


TABLE 16 (Concluded)

\begin{tabular}{|c|c|c|c|c|c|c|c|c|c|c|}
\hline \multirow[b]{2}{*}{ Hydrocarbon } & \multirow[b]{2}{*}{ Formula } & \multirow[b]{2}{*}{ Heal th Effects } & \multicolumn{3}{|c|}{ Concentration } & \multicolumn{2}{|c|}{ Exposure } & \multirow[b]{2}{*}{ Subject } & \multirow{2}{*}{$\begin{array}{l}\text { Type of } \\
\text { Study }\end{array}$} & \multirow{2}{*}{$\begin{array}{c}\text { Amblent } \\
\text { Concentrations } \\
\text { (ppb) }\end{array}$} \\
\hline & & & (ppm) & $\left(\mathrm{mg} / \mathrm{m}^{3}\right)$ & (\% by a1r) & Hrs & Days & & & \\
\hline \multirow[t]{8}{*}{$\begin{array}{l}\text { Xylenes } \\
(0, M, P)\end{array}$} & $\left.\mathrm{C}_{6} \mathrm{H}_{4} \cdot \mathrm{CH}_{3}\right)_{2}$ & $\begin{array}{l}\text { Threshold for af- } \\
\text { fecting central } \\
\text { nervous system }\end{array}$ & 174 & 755 & 0.017 & - & -- & Mice & Acute & $2.5-119$ \\
\hline & & $\begin{array}{l}\text { Threshold 11nit } \\
\text { value (TLV) }\end{array}$ & 200 & 868 & 0.02 & - & -- & Man & Acute & \\
\hline & & $\begin{array}{l}\text { No hematologic } \\
\text { effects }\end{array}$ & 690 & 2,995 & 0.069 & 8 & 130 & $\begin{array}{c}\text { Rat and } \\
\text { Rabb1t }\end{array}$ & -- & \\
\hline & . & $\begin{array}{l}\text { Decreased leukocytes } \\
\text { and red blcod } \\
\text { cells; increased } \\
\text { platelets }\end{array}$ & 1,150 & 4,991 & 0.115 & 8 & 55 & Rabbit & - & \\
\hline & & Prostration & 4,699 & 20,394 & 0.469 & -- & -- & Mice & Acute & \\
\hline & & LC50 & 9,200 & 39,928 & 0.920 & - & -- & Micè & Acute & \\
\hline & & LC100 & 12,650 & 54,901 & 1.26 & -- & -- & Mice & Acute & \\
\hline & & LC100 & 17,250 & 74,865 & 1.72 & -- & -- & Rat & Acute & \\
\hline
\end{tabular}

Note: -- Represents data not avallable or applicable.

Source: U.S. Environmental Protection Agency 1980. 
NIOSH has recommended a time weighted average concentration of $100 \mathrm{ppm}$ and a ceiling $11 \mathrm{mit}$ of $200 \mathrm{ppm}$ for toluene and xylene. These recommendations are primarily based on a lack of dat a to alter existIng standards, rather than on recent, adequate studies of humans or antmals.

No epidemiological studies characterizing exposures to these compounds are available, but they are underway at NIOSH. Data concerning the mutagenic; teratogenic, fetotoxic, and carcinogenic properties of these compounds (In pure form) are not available either. older studies or observations of these and other effects should be evaluated in light of probable contamination by benzene and other compounds. Impurities in these commercial products, when derived from petroleum, may Include benzene, toluene (In.xylenes), xylenes (in toluene), ethylbenzene, trimethylbenzene, phenol, thiophene, pyridine, and nonaromatic compounds (National Institute for Occupatlonal. Safety and Health 1975a). Complex mixtures of benzene and other aromatics are likely to be encountered in refinery process streams. Benzene commonly occurs in gasoline and other fuels (see the End Use section of this report).

Phenolic Compounds. Phenolic compounds--those with an aromatic (benzene) ring to which a hydroxyl (OH-) group is attached--occur in crude oll and its fractions, and in high concentration in acidic petroleum extracts. Phenolic compounds include phenol, cresols, thiophenols, alkyl phenols, and alkyl cresols. They generally are water soluble and exist in refinery solid, liquid, and atmospheric emissions and wastes. Phenolic compounds are acidic and on contact are corrosive to skin, eyes, and membranes. Most are readily absorbed into the body when contact or exposure occurs. Phenolics have been found to act as carcinogens and co-carcinogens in animal testing and to induce a host of cytologic and genetic changes during in vitro testing.

Phenol readily enters the body through a number of routes-Including percutaneous absorption, inhalation, and ingestion (National. Institute for Occupational Safety and Health 1976). Because of its relatively low volatility and characteristic odor, it does not frequently pose a respiratory hazard at ambient temperatures. Skin and other membranes burn on concentrated contact. Symptoms following exposure may include nausea, vomiting, difficult breathing, pulmonary edema, headache, dizziness, visual disturbances, convulsions, and partial paralysis.

Phenol is readily metabolized and excreted as conjugated glucouronides and sulfates, with some small amounts oxidized to quinone and catechol-related compounds. The average human fatal dose is in 
the range of 15 grams, but as little as 1 gram has been reported to cause death, even by skin absorption (Windholz 1976). Chronic exposure may lead to pulmonary and hepatic disorders.

The Occupational Safety and Health Administration has set a time welghted average (TWA) limit of five ppm for continuous occupational skin exposure to phenol. NIOSH has recommended air concentration limits of $20 \mathrm{mg}$ per $\mathrm{m}^{3}$ as a TWA and $60 \mathrm{mg}$ per $\mathrm{m}^{3}$ for any 15-minute exposure.

Phenol has been reported to be carcinogenic and co-carcinogenic in some animal experiments, but is not presumed to be a human carcinogen.

Cresols exist in crude ofl and various refinery process and waste streams. Cresols, also known as hydroxy-methylbenzene, methylphenol, and hydroxytoluene, possess a methyl and hydroxyl group attached to a $\mathbf{s i x}$-member aromatic (benzene) ring. There are three isomeric forms--1,2 (ortho); 1,3 (meta); and 1,4 (para). Cresol isomers are difficult to separate and cresylic acid refers to $\mathrm{m} 1 \mathrm{x}-$ tures of cresols and other phenolic compounds with similar boiling ranges. Cresols are highly reactive--oxidizing to form more toxic quinones and hydroxybenzenes in the atmosphere and in water (Gordon 1976). Their estimated detectable lifetime is 1 day in air and less than 10 days in water. The chemical behavior of cresols is similar to that of phenol-mildly acidic and soluble in water.

Cresols, like phenol, may be absorbed through the skin and mucous membranes, causing severe irritation and corrosive tissue burns when in concentrated form. No data are avallable concerning the toxicity of cresol vapors to humans, but acute inhalation hazards at ambient temperatures should be low due to their low vapor pressure and characteristic odor, noticeable well below hazardous levels. Cresols especially affect the central nervous system, liver, and kidneys (Gordon 1976). Cresols have long been used commercially for their microbicidal effects.

Cresols are cominercially produced within some refineries from acid extracted phenolic fractions after thermal or catalytic cracking (Gordon 1976). These solutions may contain 25 percent phenols, cresols, and xylenols. Cresols may also be present in phenolic 11quid wastes and air emissions.

A U.S. time welghted average of $5 \mathrm{ppm}\left(22 \mathrm{mg}\right.$ per $\left.\mathrm{m}^{3}\right)$ in the air based on a 40-hour work week exposure has been set. However, the Federal Republic of Germany (West Germany) has established a more stringent standard of $0.05 \mathrm{ppm}$ for a 30-minute averaging period and a permissible standard ( $1 . e .$, not to exceed more than once in any 4-hour period) of $0.15 \mathrm{ppm}$. 
P-cresol exists in a number of natural products and is permitted as a food and cosmetic additive in the U.S. However, the Council of Europe has classed p-cresol as an "artificial flavoring substance not admissible at present" (Gordon 1976).

Cresols, like phenol, have been ascribed with tumor-promoting, co-carcinogentc properties. Several animal studies with cresolcontaining extracts of natural products have reported significant co-carcinogenicity. Teratogentc effects of the central nervous system have been reported for rats orally administered $0.0001 \mathrm{mg}$ per $\mathrm{kg}$ of p-cresol per day for 8 months.

\section{Sulfur Compounds}

Hydrogen Sulfide. Hydrogen sulfide $\left(\mathrm{H}_{2} \mathrm{~S}\right)$ is a leading cause of death in the workplace (National Institute for Occupational Safety and Health 1976). Substantlal quantities are extracted and produced in petroleum refineries, which usually convert it to sulfur or burn it in flares. Most reports of human $\mathrm{H}_{2} \mathrm{~S}$ toxicity involve acute occupational exposures.

Acute exposure to high concentrations, usually over $1,000 \mathrm{ppm}$, produces unconsciousness immediately and death in several minutes due to respiratory paralysis. At lower concentrations (200 ppm or less), hydrogen sulfide may cause eye irritation; confunctivitis; blurred vision; aud corneal blistering, opacity, and pitting. The presence of carbon disulfide accelerates development of these symptoms. The symptoms usually subside within several days, but secondary bacterial infection may cause permanent injury.

olfactory thresholds for hydrogen sulfide exibit both dose- . response and duration-response relationships. The lower limit for $\mathrm{H}_{2} \mathrm{~S}$ odor detection is 0.02 to $0.03 \mathrm{ppm}$. At concentrations up to 30 $\mathrm{ppm}$ it has an odor of rotten eggs, while above $30 \mathrm{ppm}$ it may seem sweet or sickeningly sweet. Above about $100 \mathrm{ppm}$, hydrogen sulfide may not be detectable due to olfactory fatigue, which may result from prolonged exposure to lower concentrations. Thus, odor cannot be relied upon as a warning of dangerous $\mathrm{H}_{2} \mathrm{~S}$ concentrations. Headaches are a common result of exposure to low concentrations of $\mathrm{H}_{2} \mathrm{~S}$.

There are few reports of humans suffering permanent adverse effects from long-term exposure to $\mathrm{H}_{2} \mathrm{~S}$ below $50 \mathrm{ppm}$. Few chronic low-level animal studies have been performed. NIOSH has recommended a ceiling limit of $10 \mathrm{ppm}$ ( $15 \mathrm{mg}$ per $\mathrm{m}^{3}$ ) for continuous occupational exposure, and a 1 imtt of $50 \mathrm{ppm}$ ( $70 \mathrm{mg}$ per $\mathrm{m}^{3}$ ) for shortterm exposures (National Institute for Occupational Safety and 
Health $1977 b)$. No literature reports 1 ink $\mathrm{H}_{2} \mathrm{~S}$ human airborne exposures with carcinogenic, mutagenic, or teratogenic effects. Chronic exposure to $\mathrm{H}_{2} \mathrm{~S}$ and carbon disulfide combinations have caused weak teratogenic effects in rats. No information is available concerning the extent of low-level chronic and acute exposures among refinery workers and persons in the nelghborhood of refineries.

Hydrogen sulfide is heavier than air and may accumulate to toxic levels in confined spaces, pits, sewers, and low areas. $\mathrm{H}_{2} \mathrm{~S}$ has upper and lower explosive limits of 4.3 percent and 45.5 percent, respectively. Federal regulations require precautions to ensure levels below 0.43 percent $(4,300 \mathrm{ppm})$, or 10 percent of the lower explosive limit. Because $\mathrm{H}_{2} \mathrm{~S}$ readily causes corrosion and brittleness in metal piping and fittings, these require frequent inspection, monitoring, and maintenance. Extensive monitoring and alarm devices, employee training, and respiratory equipment are required wherever $\mathrm{H}_{2} \mathrm{~S}$ may be encountered in the workplace.

Available epidemiological studies suggest that certain individuals may be particularly susceptible to $\mathrm{H}_{2} \mathrm{~S}$ at low levels. Eye and pulmonary irritation, nausea, abdominal cramps, headaches, acute asthma attacks, and sleep disturbances were observed in the general population exposed to less than $0.125 \mathrm{ppm}$ in a 1964 air pollution incident in Terra Haute, Indiana. A particular hazard may exist for susceptible individuals such as the aged, infants, infirm, and those with lung or heart allments. Such sensitive persons are not likely to remain employed in $\mathrm{H}_{2} \mathrm{~S}$ exposure-prone refinery operations.

Thiol Compounds. The terms thiol, mercapto, and sulfhydryl may be used interchangeably, with thiol being the preferred term for the -SH group, the sulfur-containing analog of the hydroxyl group that characterizes alcohols. Thiols may constitute several percent by welght of crude olls, especially sour and heavy crude oils. Thiol compounds present in crude oil include the alkyl thiols with a thiol group attached to the primary carbon, such as 1-butanethiol, and cyclic thiols, primarily cyclopentanethiol and cyclohexanethiol.

Thiols are highly objectionable in refined petroleum products. Their acidity corrodes most metal alloys, they contribute to the total sulfur content of fuels, and they cause significant odor problems. Sweetening processes using oxidants, such as sodium plumbite or cupric chloride, convert thiols into non-corrosive, less malodoroue disulfides. Thinls are removed by extraction with amine and other caustic solutions, and by hydrotreating.

Naturally occurring thiols exist in nearly all living systems. Examples are cysteine, an amino acid, and glutathione. Thiols and disulfides are involved in many of the body's natural metabolic processes. 
The $\mathrm{C}_{1}$ through $\mathrm{C}_{5}$ alkane thiols have relatively high vapor pressures and obnoxious odors at low concentrations. Higher alkane thiols, cyclohexanethiol, and benzenethiol have relatively lower vapor pressures, and thus are less volatile. Methanethiol is a gas at room temperature, and the others are liquids. Thiols are relatively insoluble in water, act as weak acids, and form insoluble mercaptides with a variety of metal cations found in petroleum, including lead, copper, cadmium, silver, and mercury.

Odor Intensity thresholds for several thiols are presented in the End Use section of this report. Because of their low thresholds-as low as 0.02 ppb--alkane $\left(C_{1}\right.$ through $C_{3}$ ) thiols are commonly used as natural gas odorants to warn of gas leakage. Methanethiol is a major contributor to abnormal mouth odor. The odor of onions is primarily due to 1-propanethiol, and butanethiol is a major odorant in skunk secretions. Nausea is the most common response to strong thiol odors.

Thiols exert their primary toxic effect on the central nervous system (National Institute for Occupational Safety and Health 1978). Acute exposure to high concentrations (over $50 \mathrm{ppm}$ ) in humans and animals may cause narcosis, cyanosis, paralysis, fatigue, coma, and death from respiratory fallure. The alkane $C_{1}$ through $C_{6}$ thiols are relatively equitoxic when inhaled, and less toxic than heavier thiols. Definttive studies to determine thiols' dose-response and structure-activity relationships are lacking. Most available human toxicity data are derived from odor threshold studies. Thiols' toxic effects may be additive upon simultaneous exposure.

Animal experiments and human observations suggest that the compounds exert ocular and cutaneous effects (National Institute for Occupational Safety and Health 1978). Animal experiments show that the higher (1onger chain) alkane thiols may cause contact sensitization. Octadecanethiol, applied undiluted to mouse skin, produces hyperplasia of the follicles, sebaceous gland degeneration, hyperkeratinization, a decrease in skin delta-7-cholesterol, and an increase in skin cholesterol. These changes are similar to those resulting from dermal application of methylcholanthrene, a known skin carcinogen. Studies are not available which determine whether similar effects occur in humans. Because of their acidic nature, thiols cause eye irritation. Human ocular effects are not well documented or studied and nelther are human acute or subchronic dermal effects.

No data on reproductive or teratogenic effects of thiols are available. Several studies suggest a potential humanomutagenic effect, but these studies involved simultaneous expoşure to chloroprene, a known mutagen. Carcinogenic effects have not been investigated. 
NIOSH has recommended a threshold limtt value (TLV) of $0.5 \mathrm{ppm}$ in air for exposure to any combination of thiols for any 15-minute period. As permanent effects from low-level exposures have not been documented, no time welghted average or ambient workplace concentrations have been recommended. Because benzenethiol 18 more toxic and irritating, a TLV of $0.1 \mathrm{ppm}\left(0.45 \mathrm{mg}\right.$ per $\left.\mathrm{m}^{2}\right)$ has been recommended.

No epidemfological studies concerning thiols are avallable, nor is there any information concerning thiol exposures within petroleum refineries and their environs.

\section{Nitrogen Compounds--Health Effects}

Ammonia. Ammonia $\left(\mathrm{NH}^{3}\right)$ is a colorless gas that acts as a base in water or blological fluids, forming ammonium hydroxide $\left(\mathrm{NH}_{4} \mathrm{OH}\right)$. It has a characteristic odor. which 18 detectable and recognizable above approximately $1 \mathrm{ppm}$. Caustic ammonia solutions are used in refineries for scrubbing crude fractions to remove acidic compounds, primarily thiols and phenolics. Ammonia is also still in limited use as a refrigerant, although it is being phased out.

Avallable human studies and clinical reports do not fully elaborate on dose-responses for ammonia exposures (National Institute for Occupational Safety and Health 1974). In low concentrations (less than several hundred ppm), ammonla atmospherlc exposure causes upper respiratory irritation and eye irritation. Low concentrations generally do not reach the lower lungs. Solutions of 1 to 3 percent ammonia cause skin irritation and may cause blistering on prolonged contact. At high concentrations, ammonia vapors may cause pulmonary edema, suffocation, and permanent damage (burns) to the skin, mucous membranes, and cornea.

Systematic epidemiological studies of ammonia exposures are not available. Several studies indicate a possible excess of cancer deaths in workers exposed to moderate ammonia levels (National Institute for Occupational Safety and Health 1974). Animal studies indicate that inhalation of ammonia in concentrations as low as 100 ppm decreases cillary activity. Available animal and human studies indicate no permanent health hazards from intermittent, low-level ammonia exposures. Plant surveys indicate that concentrations in the range of 5 to $50 \mathrm{ppm}$ may cause eye and respiratory irritation in some individuals. Animal studies indicate that alrborne particulates may potentiate ammonia's toxic effects, apparently by facilitating ammonia transport deeper into the respiratory tract. In animal studies, tracheal damage was found to increase with ammonia adsorbed on Inhaled carbon particles. 
NIOSH has proposed a celling limit of $50 \mathrm{ppm}$ for any occupational exposure to ammonia vapors. Some persons may find this level disagreeable, but no permanent injuries can be expected from this or other brief exposures to less than several hundred ppm. These values are well below the annoyance odor threshold for ammonia.

Theoretical modeling and accident reports indicate that extremely hazardous ammonia concentrations can exist at considerable distances downwind from liquid anhydrous ammonia spills. In one test, one ton of 11quid (compressed) anhydrous ammonia was spilled into a pool and 50- to 1,000-ppm concentrations were measured downwind. Modeling Indicates that the sudden release of 1,000 tons of anhydrous ammonia from a pressurized storage tank could result in fatal exposures 3.2 or more miles ( 5 kllometers) away (Fryer et al. 1979). Ammonia is ignited with difficulty, although its ignition temperature is lowered in a mixture with oil and in the presence of 1ron.

No studies of ammonia's teratogenic or carcinogenic effects are avallable.

Nitrosamines in Refineries. Nitrosamines are substances having an $\mathrm{N}$-nitroso group (nitrosyl radical or nitric oxide attached to the nitrogen atom of an amine molecule). Frequently, the amine is a simple alkyl or aromatic hydrocarhon derivative. They are most commonly prepared in the laboratory by the reaction of amines with nitrous acid $\left(\mathrm{HNO}_{3}\right)$. Nitrosamines are photosensitive--the nitrosyl group tending to split off on exposure to UV 11ght, and to a lesser extent, on exposure to visible light. The $\mathrm{N}$-nitroso group and its characteristics offer the only common features among nitrosamines and their chemical and physical properties such as volatility and solubility.

The chemistry of nitrosamine formation is not fully understood. However, petroleum refining processes, their air emissions, and ambient polluted atmospheres may individually and together be expected to foster nitrosamine formation. Large quantities of amines--including dimethylamine, ethanolamine, methanolamine, diethanolamine, and diethylamine--are used in petroleum refining for alkaline scrubbing, sweetening, and solvent extraction.

Secondary and atmospheric formation of nitrosamines is a well documented phenomenon. Amines, usually secondary amines, may form nitrosamines through reaction with nitrites, nitrates, or $\mathrm{NO}_{\mathrm{x}}$ gases. Nitrogen dioxide $\left(\mathrm{NO}_{2}\right)$ and nitric oxide (NO) are refinery emissions, both from combustion and from refinery processing. Crude 
oil may contain up to 0.5 percent organic nitrogen compounds. From 20 to 100 percent of this nitrogen may be oxidized during combustion to form nitric oxide and nitrogen dioxide. NO emissions may be oxidized to $\mathrm{NO}_{2}$ in hot stack gases or through reaction with ozone.

Although data concerning nitrosamine levels within process streams and in the atmosphere around petroleum refineries are largely lacking, conditions there should favor nitrosamine formation. Reactive amines and nitrogen oxides are present in relatively large quantities. A number of other precursors and nitrosating agents may be present:

- Nitric acid. Nitric acid may be used or formed during processing. Some refineries manufacture nitric acid as a by-product.

- Bacterial decomposition products. Ammonia, nitrates, and . amines may be formed during secondary wastewater treatment or in solid wastes.

- Incineration by-products. Incomplete incineration of solid wastes may release amines, ammonla, nitrogen oxides, and nitrates.

o Nitrilotriacetic acid (NTA). NTA may be formed by the reaction of formaldehyde, ammonia, and hydrogen cyanide--all present in refinery process and waste streams and emissions. NTA 18 a potent chelating agent that has been used as a scale preventative in cooling water systems. The extent of NTA use in refinerles for this purpose or as a chelating agent for crude desalting or wastewater treatment 18 not known. NTA has been found to be carcinogenic in experimental animals.

- Nitrosamine additives. Nttrosamines have been patented for use as gasoline and lubricant additives. The extent of their use 18 not known.

N1trosamine formation is known to be catalyzed by a number of agents that are present in the refinery. Formaldehyde catalysis of alkaline nitrosation appears to be a general reaction of unhindered secondary amines (Roller and Keefer 1975). Carbonyl compounds, especially aldehydes, can catalyze nitrosation in alkaline or neutral media. Acidic conditiono foster some nitrosation reactions.

Nucleophilic anions, such as chloride, acetate, and thlocyanate, are catalysts below $\mathrm{pH} 3$ (Schweinsberg 1975). Some metals may also catalyze nitrosation reactions. These compounds are present in refining process and waste streams. 
It is possible that nitrosamines are cycled within the atmosphere. Nitrosamines generally degrade to their precursors on exposure to ultraviolet and visible 1ight. Daylight half-lives on the order of an hour have been observed experimentally. Nitrosamines in the atmosphere may cyclically form at night and degrade during the day. General atmospheric transport and buildup of nitrosamines are not expected due to their photolability. However, diethylnitrosamine formation has been shown experimentally to be accelerated upon exposure of diethylamine to amblent nitrogen oxides levels and sunlight (Grosjean et al. 1977). Such nitrosamines are formed in a photooxidative reaction similar to that of smog formation.

Most Investigated nitrosation reaction mechanisms involve the presence of water. Atmospheric nitrosamine production may utilize water vapor adsorbed on particulates. Nitrosamine levels in refinery wastewaters have not been thoroughly documented. Nitrosamines may form there from the reaction of amines with nitric acid and other nitrosating agents. Simllarly, nitrosamine levels in process streams have not been documented. Some o11- and water-borne nitrosamines may volatilize to the atmosphere. Concentrations of nitrosamines condensed on surfaces in refineries remain unknown.

Many factors that contribute to secondary nitrosamine formation are present in the polluted atmospheres associated with large cities aid Industrial areas. The presence of petroleum refinerles in these areas with their emissions of potentlal precursors and catalyzing agents may signicantly impact local nitrosamine formation.

Nitrosamines are known to be hepatotoxic and carcinogentc. The potency of various nitrosamines in causing acute injury, and even death, has been shown to vary considerably (Walker 1976). Most of the approximately 200 nitroso compounds that have been tested in animal studies have been shown to be carcinogenic. They are versat1le carcinogens--inducing many types of organ tumors in nearly all species tested, including primates. Most animal testing has Involved oral administration, with small dally doses over an extended period proving more effective than single large doses. Nitrosamines have been reported to exhibit synergistic or additive effects in combination with other carcinogens, including PAHs. N1trosamines are not mutagenic in most in vitro test systems. Metabolic activation is evidently required for expression of their mutagenic and carcinogenic effects.

Epidemiological studies among workers exposed to nitrosamines suggest these compounds pose a hazard to man. Additional evidence of the carcinogencity of ingested nitrites, nitrates, nitrosaminecontaining foods, and of clgarette smoking (which involves inhalation 
of $\mathrm{NO}_{\mathrm{x}}$ and amines) implies their carcinogenic potential in man. The limited animal inhalation studies that have been performed suggest that nitrosamines are effective carcinogens when inhaled. The risk to refinery workers, other occupational groups, and the general population from refinery nitrosamines has not been assessed.

\section{Metals}

Metals in 01ls. Crude o1l, refinery intermedlates, products, and wastes contain varying amounts of numerous metals. The metals content. of crude o1ls and approximate throughput per year are shown in Table 17. Many metals are essentlal nutrients, but several (sometimes these same metals) pose carcinogenic, mutagenic, teratogenic, or other toxic hazards. The toxic potential of metals is determined by a number of factors, including oxldation state, route of exposure, concentration, other substances consistent with exposure, frequency of exposure, and physical state.

Metal concentrations in crude olls can range from 1 to 10,000 ppm: Vanadium and nickel are usually the most predominant, and their concentrations generally increase with the asphaltic content or welght of the crude oll-with lighter ofls contalning less metal (Smith et al. 1975). Most metal atoms are chelated within large hydrocarbon complexes. Refineries treat crude oils by acid extraction and fractionation to reduce metal content prior to catalyst treatments. Little is known about the chemical structure of metallic compounds in crude olls, other than vanadium and nickel. Besides these two metals, cobalt, Iron, chromium, arsenic, mercury, zinc, copper, and antimony compounds are likely to be present.

Many metals are undesirable in refining crude to intermediates and final products. Metals act as catalyst polsons (deactivators), causing bulldups in internal combustion engines, bollers, and furnaces, and causing miscellaneous undesirablc. quallties in final products. Refining tends to concentrate about 90 percent of the crude oll's metals content in the heavy distillate residuals, such as residual fuel oils and asphalts, and the liquid and solid waste streams.

Besides metals occurring naturally in crude o11, a variety of metallic substances are employed in refinery operations, notably catalysts and final product additives (e.g., lead compounds in gasoline). Corrosion of steel and other alluys used in refinery piping and equipment adds to the metal content of o1l fractions and wastes. Re-refining of used petroleum products, especially lubricants, compounds the metal-associated health and environmental problems from refineries, as discussed in the End Use section of this report. 
TA3LE 17

METAL CONTENT IN CRUDE OILS

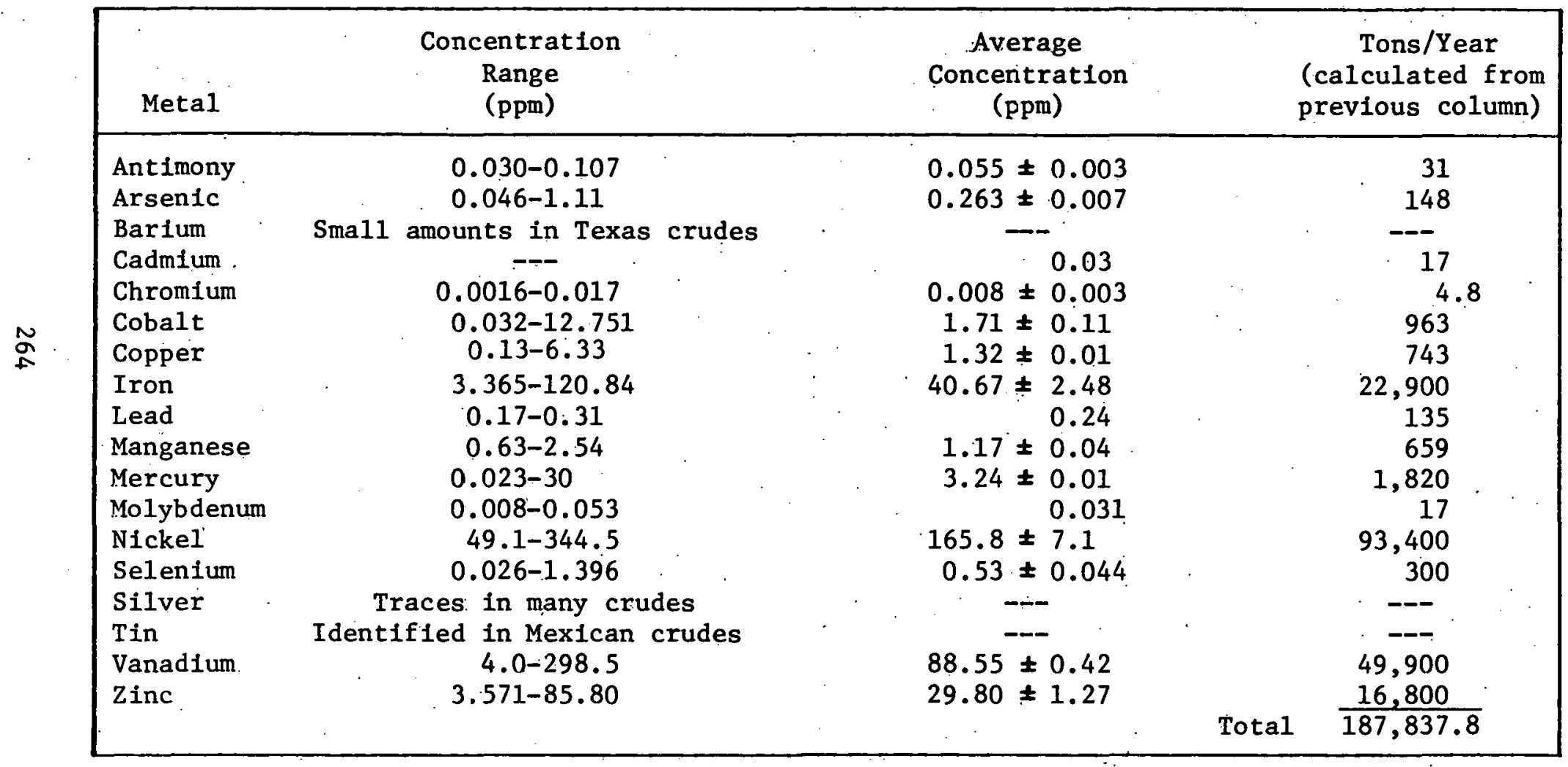

Note: ---Represents data not available or applicable.

Source: Smith et al. 1975; Yen 1975. 
Lubricants constitute a major source for entry of metals into the environment and metal compounds exposures within the refinery. Metal salts and compounds are added to refined lubricating oils to perform a varlety of functions--prolonging a lubricant's usable life, reducing wear, and acting as detergents, bactericides, antistatic agents, and rust inhibitors. Table 18 presents some representative lubricant metallic additives and their uses. The acute and chronic hazards these additives pose to refinery and other workers who come into contact with them are largely unknown. Many are highly toxic and some, such as the dithiocarbamates and chromfum salts, may have carcinogenic properties. The constitution and amounts of additives used in various lubricants and petroleum products are unknown; this Information is usually proprietary and additive product mixtures are likely to be custom-blended.

Effects of Metals. The concentrations of metals found in refinery intermediates and wastes are unlikely to cause acute toxic effects in humans, but may present chronic health and environmental hazards. Understanding of metals toxicity and adverse effects is confounded by potential synergistic and antagonistic effects among and between varlous other metals, other substances, and environmental factors such as temperature and $\mathrm{pH}$. Metal compounds may potentiate the toxicity of other compounds. Interreactions between metals and environmental factors are especially evident in aquatic systems, but are also observed in vivo, in the soll, and in the atmosphere.

Metals considered by many to be essential nutrients to higher animals include: chromium, cobalt, copper, iron, manganese, molybdenum, selentum, vanadium, and zinc (Beliles 1975). More limited documentation indicates that several additional metals may be essential: arsenic, barium, cadmium, nickel, and strontium (Smith et al. 1975). However, chronic exposure to compounds containing some of these same metals, such as cadmium, arsentr, lead, selentum, antimony, and nickel compounds, has been strongly associated with carcinogenic effects in humans and experimental animals. Physiological, toxic, and environmental effects of metals found in petroleum are shown in Table 19 (Smith et al. 1975).

In order to understand environmental hazards associated with trace metals, it is necessary Lu cunsider whcre they onter the environment, their transport and transformation, and the means by and forms in which they move llirough the food cha1n. However, these factors are poorly understood.

Metals In Refining Wastes. Elemental metals applied to 1and (e.g., landfarming) are relatively 1mmobile. Metal salts and compounds may be relatively water-soluble and mobile. Many physicalchemical prucesses affect the mobility of metal compounds, but the 
TA3LE 18

SOME METALLIC LUBRICANT ADDITIVES AND THEIR USES

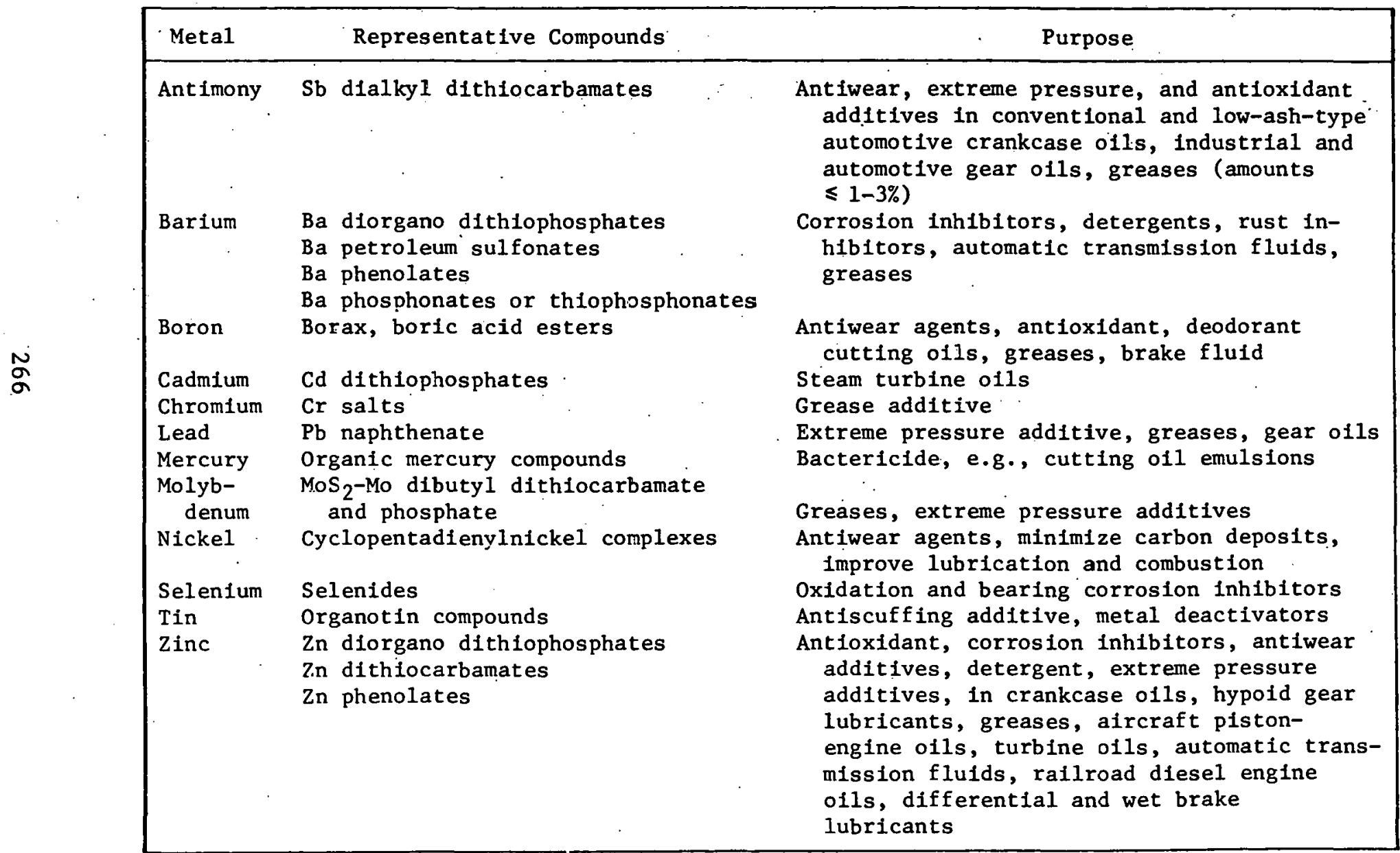

Source: Smith et al. 1975 . 
TABLE 19

PHYSIOLOGICAL EFFECTS OF METALS FOUND IN PETROLEUM PRODUCTS

\begin{tabular}{|c|c|c|c|c|}
\hline Metal & Human Effects & Animal Effects & Plant Effects & Toxicity Data \\
\hline Antimony & $\begin{array}{l}\text { Dermatitis, keratitis, } \\
\text { conjunctivitis, and } \\
\text { nasal septum ulcera- } \\
\text { tion by contact fumes } \\
\text { or dust. }\end{array}$ & $\begin{array}{l}\text { Shortens Iifespan when } \\
\text { fed to rats and mice. } \\
\text { Sb oxtde caused pneu- } \\
\text { monitis and heart and } \\
\text { liver damage. }\end{array}$ & $-\infty$ & $\begin{array}{l}\geqslant 0.1 \mathrm{~g} \text { lethal oral } \\
\text { dose in humans. }\end{array}$ \\
\hline Arsenic & $\begin{array}{l}\text { Dermat1t1s, bronchi- } \\
\text { tls, skin cancer. } \\
\text { Damages the heart, } \\
\text { kidney, nerves, and } \\
\text { possibly the liver. } \\
\text { GI symptoms in acute } \\
\text { systemic poisoning. }\end{array}$ & $\begin{array}{l}\text { Counteracts the toxic } \\
\text { effects of Se in rats } \\
\text { and chickens. As }(\mathrm{V}) \\
\text { is nontoxic. Morphol. } \\
\text { changes in blood; } \\
\text { kidney damage. }\end{array}$ & $\begin{array}{c}0.1 \mathrm{ppm} \mathrm{AsO}_{2} \text { reduces } \\
\text { heterotrophic ac- } \\
\text { tivity of fresh- } \\
\text { water micro-flora. }\end{array}$ & $\begin{array}{l}\text { Normal Ingestion } 0.1 \\
\text { mg/day. Toxic } \\
\text { level 5-50 mg/day. } \\
\text { Smallest fatal } \\
\text { dose recorded } \\
130 \mathrm{mg} .\end{array}$ \\
\hline Barlum & $\begin{array}{l}\text { Baritosis, a benign } \\
\text { pneumoconiosis. } \\
\text { Soluble salts highly } \\
\text { toxic orally. Sol- } \\
\text { uble salts are skia } \\
\text { and mucous membrane } \\
\text { irritants. }\end{array}$ & $\begin{array}{l}\text { Full strength } \mathrm{Ba} \text { lubri- } \\
\text { cant dispersant } 1 \mathrm{~s} \text { a } \\
\text { m1ld eye irritant. } \\
\text { BaO and } \mathrm{BaCO}_{3} \text { caused } \\
\text { paralysis. }\end{array}$ & $\begin{array}{l}\text { Polsonous to most } \\
\text { plants. } 0.1 \text { ppm } \\
\text { Ba2t reduces hetero- } \\
\text { trophic activity of } \\
\text { freshwater micro- } \\
\text { flora. }\end{array}$ & $\begin{array}{l}\text { LD50 diesel exhaust } \\
\text { solids }>10 \mathrm{~g} / \mathrm{kg} \\
\text { (anImals). LD50 } \\
\text { (oral) Ba sulfo- } \\
\text { nates, } 3-10 \mathrm{~g} / \mathrm{kg} \text {. } \\
\text { Fatal dose in } \\
\text { humans } \geqslant 0.55 \\
\mathrm{~g} \mathrm{BaCl} 1_{2} .\end{array}$ \\
\hline
\end{tabular}


TABLE 19 (Continued)

\begin{tabular}{|c|c|c|c|c|}
\hline Metal & Human Effects & Animal Effects & Plant Effects & Toxic1ty Data \\
\hline Boron & $\begin{array}{l}\text { Therapeutic use of } \\
\mathrm{H}_{3} \mathrm{BO}_{3} \text { and borax has } \\
\text { caused fatalities. } \\
\text { CNS depressant and } \\
\text { GI 1rritant. Boranes } \\
\text { h1ghly toxic. Cumu- } \\
\text { lative poison. }\end{array}$ & $\begin{array}{l}\text { 2,500 mg/liter in } \\
\text { drink1ng wat } 2 x \text { in- } \\
\text { h1b1ted an1mal } \\
\text { growth. }\end{array}$ & $\begin{array}{l}0.5-1.0 \mathrm{ppm} \text { in soll } \\
\text { required for growth } \\
\text { of fruit trees. } \\
2.0 \mathrm{ppm} \text { possibly } \\
\text { toxic. Prevents } \\
\text { pitting of apples. } \\
\text { Most B fertilizer } \\
\text { used on alfalfa. }\end{array}$ & $\begin{array}{l}\mathrm{H}_{3} \mathrm{BO}_{3} \text { fatal dose in } \\
\text { adults } 15-20 \mathrm{~g} \text { and } \\
\text { In infants } 5-6 \mathrm{~g} \text {. }\end{array}$ \\
\hline Cadnium & $\begin{array}{l}\text { Cumulative polson. Pul- } \\
\text { monary emphysema, hy- } \\
\text { pertension, kidney } \\
\text { damage. Cardiovas- } \\
\text { cular disease. In- } \\
\text { terferes with } \mathrm{Zn} \text { and } \\
\text { Cu metabolism. In- } \\
\text { halation of } 0.03- \\
35 \mathrm{mg} / \mathrm{m}^{3} \text { signifi- } \\
\text { cantly reduced } \\
\text { children's welght. } \\
\text { GI symptoms. }\end{array}$ & $\begin{array}{l}1 \text { ppm present in many } \\
\text { plant and an:mal tis- } \\
\text { sues. Caries, anemia, } \\
\text { and retarded growth in } \\
\text { rat. Maximun concen- } \\
\text { tration in earthworms } \\
\text { near a highway, } 115 \\
\text { ppm. }\end{array}$ & $\begin{array}{l}\text { Stunts growth of let- } \\
\text { tuce, radish, bean } \\
\text { and turnip plants. } \\
\text { Tomatoes, barley } \\
\text { and cabbage more } \\
\text { tolerant. Leaves } \\
\text { accumulate exces- } \\
\text { sive amounts when } \\
\text { solutions contain } \\
\text { a few tenths } \mu \mathrm{g} / \mathrm{m} \text {. }\end{array}$ & $\begin{array}{l}\text { LD (oral) for rab- } \\
\text { b1ts } 200-600 \mathrm{mg} \text {. } \\
\text { LD50 Cdo fume } \\
500 \mathrm{mg} / \mathrm{m}^{3} \text { for rats } \\
\text { to } 1,500 \mathrm{mg} / \mathrm{m}^{3} \text { for } \\
\text { monkeys. }\end{array}$ \\
\hline Chromium & $\begin{array}{l}\text { Dermatitis, ulceration } \\
\text { of skin, perforation } \\
\text { of nasal septum, } \\
\text { chronic catarrh, em- } \\
\text { physema, carcino- } \\
\text { genesis when In- } \\
\text { haled. Cr(VI) ex- } \\
\text { tremely toxic. Not } \\
\text { cumulative. Appar- } \\
\text { ently essential in } \\
\text { glucose metabolism. }\end{array}$ & $\begin{array}{l}100 \mathrm{ppm} \text { recommended } \\
\text { limit for fisheries. }\end{array}$ & $\begin{array}{l}5 \mathrm{ppm} \text { recommended } \\
\text { limit for irrigation } \\
\text { water. Soils contg. } \\
0.2-0.4 \% \mathrm{Cr} \text { are in- } \\
\text { fert1le. Toxic to } \\
\text { some aerobic microbes } \\
\text { at ppb level. A } \\
\text { micronutrient. }\end{array}$ & $\begin{array}{l}\text { Normal ingestion } \\
0.05 \mathrm{mg} / \mathrm{day} \text {. Toxic } \\
\text { level } 200 \mathrm{mg} / \mathrm{day} . \\
\text { No } 111 \text { effects } \\
\text { from well water } \\
\text { with } 1.0-25.0 \\
\text { mg/11ter. LD } \\
\text { (ora1) } \mathrm{K} \text { chromate } \\
\text { in rabbits } 1.9 \mathrm{~g} \\
\text { within } 2 \mathrm{hrs.}\end{array}$ \\
\hline
\end{tabular}


TABLE 19 (Continued)

\begin{tabular}{|c|c|c|c|c|}
\hline Metal & Human Effects & Animal Effects & Plant Effects & Toxicity Data \\
\hline Cobalt & $\begin{array}{l}\text { Goltrogenic, lung ef- } \\
\text { fects disputed. Der- } \\
\text { matitis. No injury } \\
\text { from } \mathrm{Co}_{2}(\mathrm{CO}) 8 \text {. Af- } \\
\text { fects heart and GI } \\
\text { tract. n } 7 \text { mg/day } \\
\text { beneficial. Liver } \\
\text { and kidney damage. }\end{array}$ & $\begin{array}{l}\text { Essential nutrient. } \\
\text { Polycythemia. Bone } \\
\text { hyperplasia. Meta- } \\
\text { plasia in spleen, } \\
\text { liver and kidneys. } \\
\text { Hyperglycemla due to } \\
\text { reversible pancreatic } \\
\text { damage. }\end{array}$ & $\begin{array}{c}\text { Essentiality not } \\
\text { established. }\end{array}$ & $\begin{array}{l}\text { Normal Ingestion } \\
0.002 \mathrm{mg} / \text { day; } \\
\text { toxic level } 500 \\
\text { mg/day. Co metal } \\
\text { dust more toxic } \\
\text { tan salts in lung } \\
\text { irritation; le- } \\
\text { thal dose of } \\
\text { either relatively } \\
\text { high. LD Co2(C0)8 } \\
\text { in animals by in- } \\
\text { halation } 100 \mathrm{ppm} \text {. }\end{array}$ \\
\hline Copper & $\begin{array}{l}\text { Antagonist1c to } \mathrm{Zn} \\
\text { toxicity. Not cumu- } \\
\text { lative. Require 1-2 } \\
\text { mg/lay. Inhalation } \\
\text { of Ju-contg. dust } \\
\text { causes lung and GI } \\
\text { disturbar.ces. Af- } \\
\text { fects erythrocytes } \\
\text { and 11ver. Skin and } \\
\text { mucous membrane } \\
\text { lrritants. }\end{array}$ & $\begin{array}{l}\text { Ingestion or inhalation } \\
\text { caused hemochromatosis } \\
\text { and lung and liver 1n- } \\
\text { jury. Limits: irri- } \\
\text { gation water, salt- } \\
\text { water organisms, and } \\
\text { freshwater organisms, } \\
0.1,0.05 \text { and } 0.02 \text { ppm } \\
\text { respectively. }\end{array}$ & $\begin{array}{l}\text { A micronutrient. } \\
\text { Toxic to some } \\
\text { aerobic microbes at } \\
\text { ppb level. } 0.05 \mathrm{M} \\
\mathrm{Cu} 2 \text { inhibits root } \\
\text { growth and } 0.1 \mathrm{M} \\
\text { stops germination } \\
\text { of lettuce. }\end{array}$ & $\begin{array}{l}\text { Normal ingestion } 2-5 \\
\text { mg/day; } 65-130 \text { mg } \\
\text { CuSO }_{4} \text { dangerous and } \\
648-972 \text { mg highly } \\
\text { toxic. } 27 \mathrm{~g} \mathrm{CuSO} 4 \\
\text { fatal. }\end{array}$ \\
\hline
\end{tabular}


TABLE 19 (Continued)

\begin{tabular}{|c|c|c|c|c|}
\hline Metal & Human Effects & Animal Effects & Plant Effects & Toxicfty Data \\
\hline Iron & $\begin{array}{l}\text { Siderosis (a pneumocon- } \\
\text { losis due to } \mathrm{Fe} \mathrm{1n-} \\
\text { halation. }\end{array}$ & -- & A micronutrient. & $\cdots$ \\
\hline Lead & $\begin{array}{l}\text { Brain damage, convul- } \\
\text { sions, behavioral dis- } \\
\text { orders, death. }\end{array}$ & $\begin{array}{l}\mathrm{Pb} \text { naphthenate kills } \\
\text { rabbits by skin ab- } \\
\text { sorption (death due } \\
\text { to pneumonia). Cu- } \\
\text { mulative poison in } \\
\text { vertebrates. Renal } \\
\text { and vascular poison. }\end{array}$ & $\begin{array}{l}0.1 \mathrm{ppm} \mathrm{Pb}^{2+} \text { reduces } \\
\text { heterotrophic ac- } \\
\text { tivity in micro- } \\
\text { flora. }\end{array}$ & $\begin{array}{l}\text { Oral toxicity of } \mathrm{Pb} \\
\text { naphthenate } 3.5- \\
5.1 \mathrm{~g} / \mathrm{kg} \text {. Normal } \\
\mathrm{Pb} \text { ingestion } 0.4 \\
\text { mg/day. }\end{array}$ \\
\hline Manganese & $\begin{array}{l}\text { Chronic Mn poisoning } \\
\text { and/or Mn pneumoni- } \\
\text { t1s. Reduces Fe ab- } \\
\text { sorption. Require- } \\
\text { ment } 3-9 \mathrm{mg} / \text { day. } \\
\text { Primar1ily a nerve } \\
\text { toxin. CNS symptoms } \\
\text { often result In per- } \\
\text { manent disability. }\end{array}$ & $\begin{array}{l}\text { Pathological effects on } \\
\text { nerve cells and the } \\
\text { liver. 1.9- } 5.9 \mathrm{mg} \\
\text { 1s thyroid irhibitor } \\
\text { In rats. }\end{array}$ & $\begin{array}{l}\text { A key role in photo- } \\
\text { synthesis. }\end{array}$ & . \\
\hline Mercury & Nerve damage and death. & $\begin{array}{l}\text { Detrimental to aquatic } \\
\text { ecosystems at } 0.005 \\
\text { ppm. }\end{array}$ & $\begin{array}{l}0.1 \mathrm{ppm} \mathrm{Hg}{ }^{2+} \text { reduces } \\
\text { heterotrophic ac- } \\
\text { tivity of micro- } \\
\text { flora. }\end{array}$ & $\begin{array}{l}\text { Normal Ingestion } \\
0.005-0.2 \mathrm{mg} / \text { day; } \\
\text { toxic leve1 } 10 \\
\text { mg/day. }\end{array}$ \\
\hline
\end{tabular}


TABLE 19 (Continued)

\begin{tabular}{|c|c|c|c|c|}
\hline Metal & Human Effects & Animal Effects & Plant Effects & Toxic1ty Data \\
\hline $\begin{array}{l}\text { Molyb- } \\
\text { denum }\end{array}$ & $\begin{array}{l}\text { Nc Indication of even } \\
\text { an industrial hazard. } \\
\text { Not cumulative. }\end{array}$ & $\begin{array}{l}\text { Appears to have a recip- } \\
\text { rocal antagonism with } \\
\text { Cu. Requirement in rats } \\
<0.5 \mathrm{mg} / \text { day. Low order } \\
\text { of toxicity. No fatal- } \\
\text { itfes from molybdic } \\
\text { oxide fumes for } 25 \text { one- } \\
\text { hour exposures at } 1.5 \\
\text { mg/ft } 3 \text { alr. Toxic to } \\
\text { ruminants when fed in } \\
\text { excess. }\end{array}$ & $\begin{array}{l}\text { Essential to higher } \\
\text { plants. Possible } \\
\text { role in photo- } \\
\text { synthesis. }\end{array}$ & 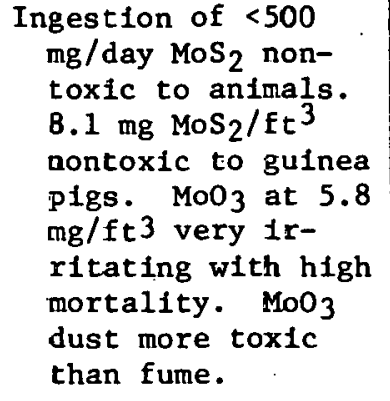 \\
\hline Nickel & $\begin{array}{l}\text { Rarely gives systemic } \\
\text { toxic effects even } \\
\text { from therapeutic doses } \\
\left(65-195 \mathrm{mg} \mathrm{N} \mathrm{NSO}_{4} \text { and }\right. \\
324-454 \mathrm{mg} \mathrm{N} \mathrm{NBr}_{2} \text { ). } \\
\text { Dermatitis, respira- } \\
\text { tory disorder, car- } \\
\text { cinogenesis (nose and } \\
\text { lung). }\end{array}$ & $\begin{array}{l}\text { Moderately toxic to } \\
\text { aquatic organisms. } \\
\text { Maximum } \mathrm{N} 1 \text { concentra- } \\
\text { tIon In earthworms } \\
\text { near a h1ghway } 38 \mathrm{ppm} \text {. } \\
\text { Inhibits enzyme systems. } \\
\text { Kidney damage (calf) } \\
1-3 \mathrm{mg} / \mathrm{kg} \mathrm{Ni} \text { compound } \\
\text { causes Intestinal dis- } \\
\text { orders, convulsions, } \\
\text { and asphyxia in dogs. }\end{array}$ & $\begin{array}{l}\text { Can be very toxic de- } \\
\text { pending on } 1 \text { ts chemi- } \\
\text { cal form. A micro- } \\
\text { nutrient. } 0.01 \text { ppm } \\
\text { reduces the hetero- } \\
\text { trophic activity of } \\
\text { freshwater micro- } \\
\text { flora. }\end{array}$ & $\begin{array}{l}\text { Normal ingestion } 0.3- \\
0.5 \mathrm{mg} / \text { day. } 30-73 \\
\mathrm{mg} \mathrm{NiSO}_{4} 6 \mathrm{H}_{2} \mathrm{O} \text { toxic } \\
\text { in humans. }\end{array}$ \\
\hline
\end{tabular}


TABLE 1S (Continued)

\begin{tabular}{|c|c|c|c|c|}
\hline Metal & Human Effects & Animal Effects & Plant Effects & Toxicity Data \\
\hline $\begin{array}{l}\text { Sele- } \\
\text { nium }\end{array}$ & $\begin{array}{l}\text { May cause caries. Pre- } \\
\text { vents teratogenic } \\
\text { effects of Cd and As. } \\
\text { Affects kidneys, } \\
\text { liver, marrow, and } \\
\text { CNS. Se compounds } \\
\text { are potent skin and } \\
\text { mucous membrane } \\
\text { Irritants. }\end{array}$ & $\begin{array}{l}\text { Carcinogenic in large } \\
\text { doses in rats. Essen- } \\
\text { tial to mammals and } \\
\text { ch1cks in low doses. } \\
\text { Teratogenic in ch1cks. } \\
\text { "B1ind staggers" and } \\
\text { "alkali disease" in } \\
\text { cattle and "white } \\
\text { muscle disease" in } \\
\text { sheep. }\end{array}$ & $\begin{array}{l}2.5 \mathrm{mg} / 11 \mathrm{ter} \text { Se In- } \\
\text { hibits the BOD and } \\
\text { growth of aquatic } \\
\text { saprophytic micro- } \\
\text { flora. }\end{array}$ & $\begin{array}{l}\text { Industrial selenosis } \\
\text { symptoms when Se } \\
\text { 1n air }<0.2 \mathrm{ppm} \text {. } \\
\text { Liver damage In } \\
\text { humans from } 5-7 \\
\text { mg/11ter In food. } \\
\text { L1ver cancer in } \\
\text { animals from food } \\
\text { containing } 10 \mathrm{ppm} \\
\mathrm{Se} \mathrm{H}_{2} \mathrm{Se} \text { and } \\
\mathrm{SeO}_{2} \text { more toxic } \\
\text { than } \mathrm{S} \text { analogs. } \\
\text { LD by inhalation } \\
\text { of SeO } 10 \text { ppm } \\
\text { for } 2 \mathrm{hrs} \text {. Normal } \\
\text { Ingestion } 0.2 \mathrm{mg} / \\
\text { day; toxic level } \\
5 \mathrm{mg} / \text { day. Extreme } \\
\text { tolerance limit in } \\
\text { food (dry weight) } \\
20 \mathrm{ppm} \text {. }\end{array}$ \\
\hline Silver & $\begin{array}{l}\text { Argyria (1mpregnation } \\
\text { of the tissues with } \\
\text { Ag) following ab- } \\
\text { sorption from the } \\
\text { GI tract or lung. } \\
\text { IV injections of } \\
\text { colloidal Ag fatal. }\end{array}$ & $\begin{array}{l}\text { Affects Immunolcgical } \\
\text { capacity. Histopatho- } \\
\text { logical changes in tis- } \\
\text { sues of encephalon and } \\
\text { medulla of rabbits. }\end{array}$ & $\begin{array}{l}0.0001 \mathrm{ppm} \mathrm{Ag}^{+} \text {re- } \\
\text { duces the hetero- } \\
\text { trophic activity } \\
\text { of m1croflora. }\end{array}$ & $\because$ \\
\hline
\end{tabular}


TABLE 19 (Continued)

\begin{tabular}{|c|c|c|c|c|}
\hline Metal & Hunan Effects & Anfmal Effects & Plant Effects & Toxicity Data \\
\hline Tin & $\begin{array}{l}\text { Little absorbed when In- } \\
\text { gested. Affects GI } \\
\text { tract and CNS. Sn } \\
\text { oxide dust produces } \\
\text { benign pneumoconiosiz. } \\
\text { Ingestion of organ- } \\
\text { ot1n compounds causes } \\
\text { acute cerebral edema } \\
\text { and of ten death. }\end{array}$ & $\begin{array}{l}\text { Decreases longevity } \\
\text { slightly when fed to } \\
\text { rats and mice for } \\
\text { life. }\end{array}$ & $\begin{array}{l}\text { Toxic to some aero- } \\
\text { bic microbes at ppb } \\
\text { levels. }\end{array}$ & $\begin{array}{l}500 \mathrm{mg} / \mathrm{kg} / \mathrm{day} \text { of } \\
\mathrm{SnCl}_{2} \text { for } 14 \\
\text { months paralyzed } \\
\text { a dog. LD50 } \\
\text { (IV) } \mathrm{R}_{2} \mathrm{SnCl}_{2} \\
\text { (where } \mathrm{R}=\leqslant \mathrm{C}_{8} \\
\text { alky1) } 5-40 \mathrm{mg} / \mathrm{kg} \\
\text { rats. Trialkyltin } \\
\text { salts are more } \\
\text { toxic. }\end{array}$ \\
\hline Vanadium & $\begin{array}{l}\text { Cardiovascular disease, } \\
\text { carcinogenesis. Main } \\
\text { toxtc effects on res- } \\
\text { pitory system. } \mathrm{V}_{2} \mathrm{O}_{5} \\
\text { residues from fuels } \\
\text { 1rritating to those } \\
\text { who clean oil-fired } \\
\text { burners, renew fire- } \\
\text { brtek linings, and } \\
\text { clean heat-exchanger } \\
\text { tubs (dugts contain } \\
6-2 \mathrm{~J} \% \mathrm{~V}) \text {. }\end{array}$ & $\begin{array}{l}\text { Feeding } 5 \mathrm{mg} / \text { liter } \mathrm{v}^{4+} \\
\text { for Iffe to rats gave } \\
\text { no significant re- } \\
\text { ductlon in growth or } \\
\text { longevity. Not car- } \\
\text { cinogenic in rats or } \\
\text { mice. }\end{array}$ & $\begin{array}{l}\text { Essential for green } \\
\text { algae. Stimulates } \\
\text { higher green plants } \\
\text { In small amounts. }\end{array}$ & $\begin{array}{l}10 \mathrm{mg} / \mathrm{kg} \text { fatal to } \\
\text { rat. Sublethal } \\
\text { doses } 92-368 \mathrm{ppm} \text {. } \\
49 \mathrm{\mu g} / \mathrm{ml} \text { dr1nking } \\
\text { water highly toxic. } \\
0.205 \mathrm{mg} / 11 \text { ter } \\
\text { causes lung changes } \\
\text { in an1mals. LD } \\
\text { (IV) in humans } 30 \\
\mathrm{mg} \mathrm{V}_{20} \mathrm{O} \text { as tetra- } \\
\text { vanadate. }\end{array}$ \\
\hline
\end{tabular}


TABLE 19 (Concluded)

\begin{tabular}{|c|c|c|c|c|}
\hline Metal & Human Effects & Animal Effects & Plant Effects & Toxicity Data \\
\hline Zinc. & $\begin{array}{l}\text { Dermatitis, hyperten- } \\
\text { sion, arteriosclerotic } \\
\text { and heart diseases. } \\
675-2,280 \mathrm{mg} / 11 \text { ter } \\
\text { is emet1c. Causes } \\
\text { mineral loss from } \\
\text { bones. Most Zn } \\
\text { compounds not par- } \\
\text { ticularly toxic at } \\
\text { moderate concentrations } \\
\text { orally. 2n inhibits } \\
\text { the teratogenic, } \\
\text { embryocidal, and } \\
\text { neo-plastic effects } \\
\text { of cd. Essential. }\end{array}$ & $\begin{array}{l}\text { Zn dithiophosphates } \\
\text { are severe eye irri- } \\
\text { tants, } 0.1-1.0 \mathrm{ppm} \\
\text { lethai to fish and } \\
\text { other aquatic } \\
\text { animals. }\end{array}$ & $\begin{array}{l}\text { Essent1al. } 0.1 \mathrm{ppm} \\
\mathrm{Zn}^{2+} \text { reduces hetero- } \\
\text { troph1c-activity of } \\
\text { microflora. }\end{array}$ & $\begin{array}{l}\text { LD50 (oral) Zn di- } \\
\text { thiophosphates } \\
2.13-3.7 \mathrm{~g} / \mathrm{kg} . \\
\text { LD50 (skin) } 11.3 \\
\text { g/kg. for rabbits } \\
\text { (24-hr contact). } \\
\text { Mixed } \mathrm{Mg}-\mathrm{Zn} \\
\text { phenolate LD50 } \\
\text { (oral) } 9.5 \mathrm{mg} / \mathrm{kg} \text {. } \\
\text { LD50 (ora1) 2nCl } 2 \\
\text { in guinea p1gs; } \\
\text { rats, and mice } \\
200-350 \mathrm{mg} / \mathrm{kg} . \\
\text { Normal ingestion } \\
\text { Zn } 10-15 \mathrm{mg} / \text { day. }\end{array}$ \\
\hline
\end{tabular}

Notes: $L D 50=$ The dose at wh1ch 50 percent of the subject animals die.

CNS = Central nervous system.

--- Represents data not avallable or applicable.

Source: Yen 1975. 
most important factor is the strength of the complexes and chelates they form with soil components. Accumulation of metals by plants grown in contaminated solls depends on soll conditions and plant varlety. Some metals may be concentrated by plants, posing serious animal and human health hazards. An example 18 selentum.

Metals in surface and groundwaters pose largely unknown hazards. Water quality criteria and standards for the metals content of drinking water have been set, but many of these standards are based on inadequate scientific knowledge. Most metals in surface water eventually become physically assoclated with particles or form organic complexes. They may settle out and become 1mmobilized in sediment. However, some compounds, depending primarily. on solubility, particle size, and chemical equilibrla, will always be available to enter the aqueous phase, and waters may be contaminated, especially when sediments are disturbed. Aquatic plants, especlally algae, are excellent scavengers and concentrators of many metals in surface waters. These plants form the base of higher organisms' food chains and may ultimately be a source for human exposures.

The final fate of the metals content in crude petroleum has never been fully determined (Smith et al. 1975). Avallable information Indicates that about 90 percent of the metals content is retalned in heavier residue fractions during fractionation (Smith et al. 1975). Much residual fuel ofl ts consumed in various industrial facilities and within the refinery itself, but the largest portion is consumed by electric power plants. After combustion, a substantial portion of the ofl's metal content remains in the bottom ash or is emitted in fly ash. The more volatile metals, metal oxides, and finer particulates may be released into the atmosphere. Few data are available to account for the environmental transport and ultimate fate of these metals. Bottom ash may be used as an aggregate material for road construction, concrete, and other similar purposes. Collected fly ash has less commerclal value, and, 1tke unused bottom ash, may be discarded as solid waste. Metals in fly ash occur primarily as metal oxides, which are generally susceptible to solubilization and leaching and may contaminate ground and surface waters.

There are not enough rellable data concerning the disposition and behavior of petroleum-assoclated metal compounds to predict their environmental fate and effects. The fate and significance of metals entering the environment from refinery-associated operations, especially solid and liquid waste streams, require further study. Basic knowledge concerning metals toxicity, physlological roles, environmental. transport, environmental effects, occupational health hazards, and pathways through the food chain is required to assess the relative hazards. 


\section{Metal Carbonyls}

Metal carbonyls--substances in which carbonyl (CO-) radicals are covalently bonded to a metal atom--may pose significant hazards to exposed refinery workers and those in the Immediate area. Metal carbonyls form by reaction of carbon monoxide with transition series metals under certain conditions of temperature and pressure. Hydrogen and nitrogen gases, which are used extensively in refinery operations, often contain trace amounts of carbon monoxide ( $\mathrm{CO}$ ). Nitrogen gas is frequently used as an inert gas in processes involving hydrogen, such as hydrotreating, to prevent reactive oxygen (air) from entering the reaction chambers. The nitrogen may contain up to 0.6 percent $C O$ and the hydrogen gases may contain up to 3 percent $C O$ (Brief et al. 1971). Under conditions of high temperature and pressure encountered in refinery operations, $C 0$ may react with nickel, cobalt, and iron from catalysts and piping. The resulting carbonyls are unstable in the air at ambient temperatures--nickel carbonyl [ $\mathrm{Ni}(\mathrm{CO})_{4}$ ] has an estimated half-1ife of about 11 minutes and cobalt carbonyl [ $\mathrm{Co}(\mathrm{CO})_{4}$ ] has a half-life of 10 to 15 seconds (Brief et a1. 1971). In more recent work, parts per million concentrations of nickel carbonyl in the absence of $C O$ have been found to have a lifetime of less than 1 minute (Stedman et al. 1980). The presence of CO increases the lifetime by about $1 / 2$ minute for every part per million of additional $\mathrm{CO}$. These volatile carbonyls have high vapor pressures.

Nickel carbonyl is the most readily formed and the most toxic metal carbonyl. It 18 acutely toxic by both dermal and inhalation routes. No clear estimate 18 available of the dose producing acute effects in man, but a 30-ppm-exposure in alr for 30 minutes is reported to have been lethal. Chronfc exposure to lower levels of nickel carbonyl has been shown to cause sinus and lung cancer in ep1demlological studies and in laboratory experiments with several specles. Chronic exposure may also lead to severe dermatitis.

Refinery workers may be exposed to carbonyls during the termination and intiation of operations, and during maintenance, since metal carbonyls may be present in process streams. The odor threshold for nickel carbonyl is 1 to $3 \mathrm{ppm}-$-well above safe exposure levels. Rellable and quick methods to detect personal exposure to carbonyls in the workplace are not avallable, nor are data avallable concerning concentrations encountered by workers in refinery operations.

The Occupational Safety and Health Administration has established a TWA of seven micrograms per cubic meter for nickel carbonyl. 


\section{Platinosis}

Platinum and other precious metal catalysts are used extensively in catalytic reforming and hydrotreating. Information concerning catalysts is largely proprietary, but most probably involve platinum, chloroplatinic acids, or other precious metal complexes fixed on alumina or silica. Catalysts must be perlodically removed for regeneration or recycling, during which workers may be exposed to these compounds. Platinosis is a disease involving allerglc respiratory and cutaneous reactions from contact with or inhalation of chloroplatinic acid and other platinum salts, but not metallic platinum (Parrot et al. 1969). Exposure of susceptible individuals results in recurrent, persistent asthma and eczema.

Most reported cases of platinosis are assoclated with platinum and precious metals refining. The. incidence of this disease and other catalyst adverse reactions among refinery workers is unknown.

\section{$\underline{\text { Dioxins }}$}

A recent Dow Chemlcal Corporation report asserts that chlorinated dioxins may be formed in trace amounts during the combustion of organtc matter and fossil fuels, including refined petroleum products (Chlorinated Dioxin Task Force 1978). These chlorinated dibenzo-p-dioxins include many highly toxic lsomers, such as the more extensively studied $2,3,7,8$-tetrachloro-dibenzo-p-dioxin (TCDD), one of the most toxic substances known to man. Chlorinated dioxins have been postulated to form during combustion from the condensation of chlorophenols and by thermal synthesis from inorganic chloride and hydrocarbons.

Petroleum refining juxtaposes many materials, factors, and processes that may contribute to the formation of chlorinated dioxins: steam; heat; a wide varlety of hydrocarbons; phenolics; catalytic and thermal cracking; catalytic reformation; pressure; combustion for catalyst regeneration; and inorganic chloride from water, crude o11 salt content, and $\mathrm{HCl}$ and chlorides used in varlous processes. There have been no reports of chlorinated dioxin and halogenated dibenzo furan concentrations associated with various refinery process and effluent streams.

\section{Summary of Research Needs}

The area of health effects research related to refineries is just beginning to receive substantial attention with respect to Federally-funded, energy-related research. This is primarily due to the fact that the development of a responsive Federal program of health research related to energy technologies has focused on 
emerging energy technologies such as synthetic fuels and solar energy technologies. Research concerning conventional technologies (coal, ofl, and gas) has focused on the fossil based extraction and end use facets of the industries. Perhaps another reason that refineries have not recelved significant at tention in terms of energy-related health and environmental research is that refineries, like most industrial facilities, have been subjected to stringent air and water pollution control regulations for many years.

Federally-funded, energy-related research began during the 1978 fiscal year with the initiation of two projects, coordinated by the U.S. Department of Energy and the National Institute for Occupational Safety and Health. The Department of Energy project recognizes that there are poorly defined reports of elevated cancer mortality rates in many areas, including Contra Costa County, California, a major refining center. The study, accompanied by modest funding, is intended to focus on a number of disorders, concentrating at first on cancer, cardiovascular, and respiratory disorders among refinery workers. The second study involves the development of a program to identify and quantify worker exposures to potentially hazardous agents in refineries and to provide baseline data for the development of control measures. This effort also has received limited funding.

\section{Integrated Health Assessment}

As seen from the numerous pages in the preceding discussion of potential health effects associated with petroleum refining, there is a voluminous amount of relevant data available in the public domain. Still more data exists as proprietary information concerning catalysts, process chemicals, and in-plant, company-sponsored emissions and ambient monitoring studies. A great deal of information, generally in the baslc effects research category, still needs to be amassed.

All of these data--whether missing, existent but not avallable, or published--present a fragmented and incomplete picture of the health and safety risks in the refinery industry as a whole. An intensive, major effort is needed to bring all of this information together in an attempt to conduct a rigorous risk assessment. Such an activity would be large in scope and diverse in its approach.

In addition to information collected from published articles on the toxicity and exposure levels of various refinery emissions, a data base should be developed containing the results of epidemiological studies already conducted that are relevant to refineries. Retrospective mortality studies of refinery workers should be initiated. The resultant data and registry of workers would provide the basis for risk assessment studies. 
This comprehensive assessment of risks associated with the refinery industry should include individuals working and living around refinery sites. It is important in such a study to use and assoclate data on emissions of pollutants from a refinery with varlous vectors of transport to estimate population exposure and possible resultant health impacts.

Emisstons estimates for pollutants from refinery operations and their uptake and transport by water, food, wind, and rain should be compiled to facilitate an adequate estimate of exposure and health impacts of refinery operations on nearby communities and ecosystems. This work should be site-specific, perhaps using a grid system to model emission measurements and resultant exposures. The quality and availability of epidemiological data through state registers should be considered in selecting sites for assessment studies. The monitoring data should be correlated with the epldemlological data of persons living and working in the modeled region. Abnormal increases in 1llnesses, miscarriages, birth defects, or deaths should be noted and Investigated.

The comprehensive health assessment activity needs to recelve input and coordination from the many organizational entities having jurisdiction over or an interest in the health of persons who work or live in or near refinery complexes. These entities include, but are not limited to, the Department of Energy; the Environmental Protection Agency; the National Institute for Occupational Safety and Health; the Occupational Safety and Health Administration; the National Petroleum Refiners Association; the American Petroleum Institute; the 011, Chemical and Atomic Workers International Union (AFL-CIO); and refining companies.

\section{Specific Basic Research Needs}

The textual discussion has identified numerous gaps in our understanding of the health effects of various hydrocarbon species. Much of the information that is available is of a generic nature, i.e., it is also useful to the understanding of the effects of hydrocarbons emanating from other technologies such as synthetic fuels and chemical coal cleaning. The reader should revlew the Lextual discussion in depth to decide whether extensive additional research in these areas is needed to resolve the particular health problems associated with refineries. A partial listing of basic information needs follows:

- The extent of biologically-based monitoring in the refining industry is unknown. Blologically-based monitoring of Individual worker exposures through measurement of substances 
or their metabolites in body fluids, excretions, and hair are avallable only for a limited number of toxic substances. A survey is needed to identify the extent of current monitoring, to amass a data base of monitoring findings, and to recommend expanded monitoring programs. The inftial focus should be on the presence of representative mixtures.

- The cause of the hemodynamic effects of propane, butane, and lsobutane is unknown. These chemicals may act directly on the vascular system or via the central nervous system depression. This problem area needs to be explored.

- The complex mixtures of substances encountered in the refinery require toxicological testing.

- It is unknown whether toluene modifies the neurotoxic actions of hexane or whether short-term, high concentrations of hexane-toluene mixtures are responsible for neuropathy. Information in this area would be useful, not only for understanding health effects problems related to refinery workers, but also for mitigating the degradation of the health of glue-sniffers.

- As exposure to pure hydrocarbons 18 rare, studies are needed which Investigate synergistic and other Interactive neurotoxic effects among constituents of mixtures of hydrocarbons and other agents (e.g., gases, metals) commonly present in the workplace environment.

o. Hydrocarbon-induced neuropathies require further study to determine underlying causes and mechanisms of neurotoxicity.

- Epidemiological studies designed to characterize exposures to toluene and xylene do not exist. These would be important and should be conducted to provide input to risk assessment studies.

- Data on the reproductive and teratogenic effects of thiols are not available. Several studies suggest a potential human mutagenlc effect, but these studies involved simultaneous exposure to chloroprene, a known mutagen. Carcinogenic effects have not been investigated. No epidemiological studies concerning thiols are avallable, nor are data concerning exposures to thiols within petroleum refineries. These data gaps should be filled.

- Nitrilotriacetic acid (NTA) is a chelating agent used as a scale preventative in cooling water. This is a potential 
nitrosating chemical and the level of its use in refinerles for scale prevention and chelation during crude desalting or wastewater treatment should be determined.

- Metals and metal oxides present major fugitive emissions, solid waste, and effluent problems for refineries, yet few data are avallable to account for the environmental transport and fate of these metals from a health hazard point of view. This area needs to be expiored.

- Reliable and quick methods to detect personal exposure to toxic metal carbonyls in the workplace are not generally avallable, nor are data concerning carbonyl concentrations encountered by workers in refinery operations. This area needs substantial research.

- Platinosis is a disease involving allergic respiratory and cutaneous reactions from contact with or inhalation of chloroplatinic acid and other platinum salts. Most reported cases of platinosis are associated with platinum and preclous metal refining. The incidence of this disease and other adverse reactions to platinum and other catalysts among refinery workers should be investigated.

- Petroleum refining utilizes many materials under conditions that may contribute to the formation of toxic chlorinated dioxins. The presence of and concentrations of chlorinated dioxins and halogenated dibenzofurans should be determined with respect to the refinery workplace environment, process streams, and wastewater effluents.

- Workers' exposures to refinery process and waste streams and chemicals shnuld he examined to devise appropriate and accurate means of assessing exposures to toxic agents.

\section{Occupational Health}

Brain Cancer and Refinery Workers. Reports have recently appeared in the popular press concerning large numbers of brain tumor deatlis occurring among workers at several fulf Coast petroleum refinerles and petrochemical complexes. So far, at one facility 18 brain cancer deaths between 1956 and 1980 have been identifled among male workers. Th1s is roughly twice the number expected among workers at the plant and investigators belleve this to be the largest single series of presumably occupationally-related brain tumors to date (Chemlcal and Engineering News 1980a). Another study reported a similar high incidence and risk of brain cancer (approximately double the normal) at several other sites, including three refineries. These studies are st1ll in progress or have not been published. 
Available epidemiological studies appear to indicate a high proportionate mortality ratio or high incidence of brain tumor deaths among workers at a number of Gulf Coast refineries and petrochemical complexes, but the significance of these findings is not clear. Several case control studies comparing tumor victims to employees with similar job histories have found no significant increased risk. No specific areas, processes, work classes, or agents have been implicated to date. One conflicting study has found no significant increased incidence of brain tumors at one of the refineries reported to have a high incidence. This retrospective cohort study was conducted at a Texas refinery with 44 years of employment experience and it claims to be the largest study of its kind in North America in terms of years of operation and person-years observed. Similarly, other preliminary studies and analyses, most performed by affected industrial concerns, refute findings of high incidence and risk of brain tumor mortality.

A recent mortality study of workers at elght refineries in the United Kingdom found no significant increased risk for brain cancer, but above normal incidences of malignant melanoma (skin cancer) and esophagal, stomach, intestinal, and rectal cancers (Rushton and Alderson 1980).

The relative increased risk and the linkage of brain tumors with employment in the petroleum refining and petrochemical industries requires further examination. However, it may not be possible to resolve the issue, and it may not be relevant to these industries under current industrial hygiene practices (Chemical and Engineering News 1980b). Most observed mortality cases involve workers who began employment more than 30 years ago, prior to significant changes in petroleum refining and work practices. Varlations in methodology, data validity and availability, and investigators' professional commitments will result in the questioning of results and conclusions from these and most epidemiological studies. An increased understanding of brain tumor initiation and reliable animal models and testing systems relevant to human risk assessment should be developed. Coordinated research, espectally epidemlological study, is required to determine the extent and cause of petrochemical-related occupational concerns. It is possible that a new workplace hazard, akin to the now-recognized threat posed by vinyl chloride exposure, may be recognized and defined.

Data Reporting for Non-refinery Employees. Many workers such as contractor employees, construction workers, part-time employees, railroad workers, and truck drivers may work within the boundary of a refinery site and may be exposed to its hazards. Normally, data concerning industrial refinery accidents, diseases, chemical rashes, neurological disorders, and incidences of exposure do not extend to these workers, even when they may work on site on a full time basis. 
A reporting mechanism should be initiated for the refining industry that w111 include these individuals. The collected data should be aggregated with similar data for refinery employees. This information would serve as a data base for future health assessment activities.

Industrial Hygiene. There is a need to develop criteria for refinery workers' medical examinations that. will identify persons with special sensitivities to stresses present in refinery facilities. The criteria should be implemented industry-wide and they should focus on physlological and psychological changes that are precursors of occupational diseases. Since human behavior can be affected by exposure to a wide varlety of metals, organic solvents, and noxious gases, the 1dentification of behavioral and-neurotoxic effects should be a high priority.

Detection of Dermal Exposure. The current method for detecting the presence of polynuclear aromatic hydrocarbons (possible carcinogens) on the skin of workers involves detection with ultraviolet 1ight. This method may introduce the potential for photoactivation (see text discussion) of the compounds present on the skin surface. Although the resultant health risk is far lower than that from exposure to sunlight for a few minutes, an additional margin of safety could be introduced if alternative detection methods were avallable.

Of upmost Importance is the development of a safe and effective decontamination procedure for removing organic compounds from the skin and clothing on a dafly basis. The development of such a procedure is important, not only to worker health, but also to ensure that the contamination is not carried home to workers' families.

\section{Public Health--Community Surveillance}

The survelllance and monitoring of communities that may be Impacted adversely by refinery operations should be maintained and expanded. The incidences of disease in these communities should be monitored and significant differences should prompt in-depth investigations.

Existing registries of the prevalence of cancer, heart disease, birth defects, and neurological disorders should be examined to determine whether disease trends can be detected for communities near refineries. If not avallable, such minimal statistics as births, deaths, year, cause, and age should be amassed to provide a data base 
for continuing assessment. In this light, a review of the adequacy of existing registeries should be conducted. The registries should be expanded, if necessary, to assure the adequacy of data-base coverage and comparability with occupational and other related registries. 
ECOLOGICAL EFFECTS OF REFINERY OPERATIONS

Aquatic Biota

Refined oils may be much more toxic than crude oils when released into marine or surface waters. Crude olls are rapidly altered by weathering phenomena involving evaporation, dissolution, microbial decomposition, and chemical oxidation. Low-boiling, highly toxic fractions in crude oils are rapidly depleted, frequently in 2 to 4 days. Refined petroleum products such as gasoline and fuel o1ls contain greater percentages of these toxic, low-bolling fractions. The toxic effects of spilled crude and refined petroleum products are discussed at length in the Transportation and Storage section of this report.

Long-term, continuous-flow bloassays of blologically treated oil refinery effluents indicate that refineries produce effluents which contaln substances causing cumulative toxlc effects in fish (National Academy of Sclences 1972). Passage of treated effluents through activated carbon columns does not significantly remove the fish toxicants. Compounds implicated are $C_{11}$ through $C_{18}$ alkanes and phenolic compounds, and 1somers of cresol and xylenol.

Sedimented ofl has been found downstream from refineries. Sed1ment in the Ottawa River in Ohio downstream from a refinery consisted of up to 17.8 percent oll. (National Academy of Sclences 1972). Sed1mented ofl may slowly release its hydrocarbon, metallic, and other constituents to the aquatic environment and may act as a concentrator for hydrocarbon-soluble substances such as chlorinated hydrocarbon pestlcides. Metal compounds from refinery effluents may become sedimented. They also may remain suspended in water in particulate form. Sedimented metals and hydrocarbons can be redissolved or resuspended, especially if sediment is physically disturbed.

Soluble aromatic hydrocarbons, which may enter surface waters through wastewater discharges, runoff, or deposition of atmospheric emissions from refineries, can affect many forms of aquatic biota.

Table 20 provides comparisons of the toxic levels of these hydrocarbons as they affect various blota.

Phenolics may be major pollutants in surface and drinking water. They adversely affect the organoleptic (odor and taste) characteristics of drinking water, usually at concentrations of less than 1 ppm ( $1 \mathrm{mg}$ per liter), and may taint the flesh of fish. Cresol has a threshold concentration of $0.055 \mathrm{mg}$ per 11ter in water (National Academy of Sclences 1972). Phenolic-bearing water, when chlorinated for drinking water disinfection or wastewater treatment, yields chlorinated phenols that have much lower odor/taste threshold 
TABLE 20

TOXICITY OF SOLUBLE AROMATIC HYDROCARBONS

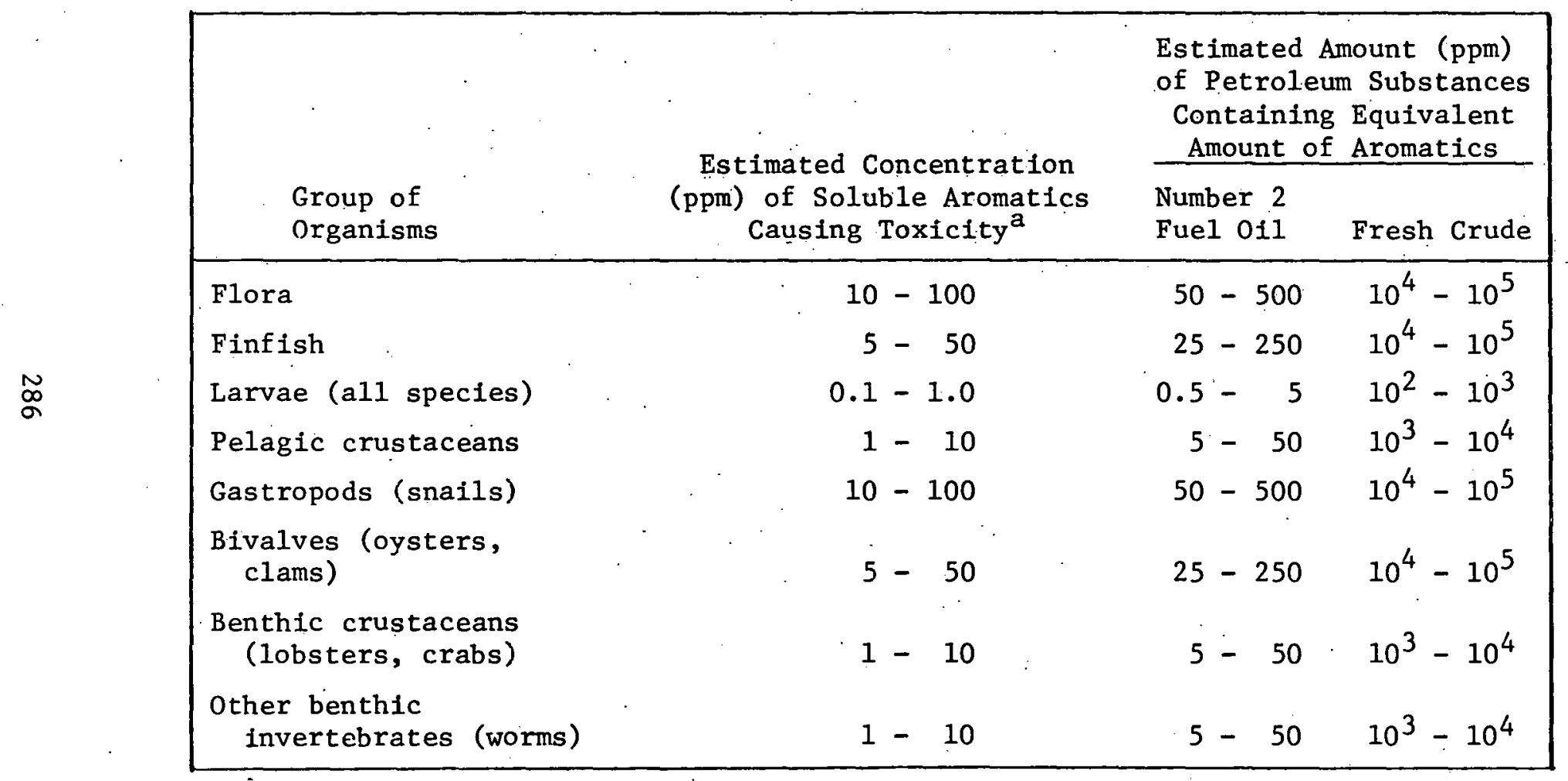

a Not inclusive of all members of each group due to limited data base.

Source: Britt and Hushon 1976. 
concentrations: 2-chlorophenol (2 ug per 1iter), and 4-chlorophenol (250 ug per liter). Because treatment processes such as chlorination may increase the odor and toxicity of phenolic compounds, it is recommended that public water supply sources contain no more than 1 ug per liter of these compounds (National Academy of Sciences 1972).

Effluents from the refinery may include complex phenolic mixtures whose adverse aquatic effects may vary over a wide range, depending on the substances, concentrations of their components, and environmental conditions. Many phenolics, especially chlorinated derivatives, are more toxic than phenol itself. Phenol toxicity varies greatly with fish specles $(0.079 \mathrm{mg}$ per liter in 30 minutes for minnows, and $56 \mathrm{mg}$ per liter in 96 hours in mosquito fish, or Gambusia affinis) (National Academy of Sciences 1972). The phenollc and other compounds that taint or adversely affect the taste of fish at low concentrations are shown in Table 21 .

Terrestrial Biota

Solid Wastes

Refinerles typically produce a number of process-related solid wastes, including (Rosenberg 1976):

(1) Crude o1l tank bottoms,

(2) Leaded gasoline tank bottoms,

(3) API and other o1l-water separator sludge,

(4) Neutralized hydrofluoric acid alkylation sludge,

(5) Kerosene filter clays,

(6) Cooling water sludge,

(7) Dissolved air floatation skimmings,

(8) Spent lime from boller feedwater treatment (acld neutralization),

(9) Spent amine solids,

(10) Exchanger cleaning sludge,

(11) Waste biological processing sludge,

(12) Silt from stormwater runoff, 
TABLE 21

REFINERY EFFLUENT COMPONENTS THAT CAN CAUSE TAINTING OF THE FLESH OF AQUATIC ORGANISMS

\begin{tabular}{|c|c|}
\hline Chemical & $\begin{array}{c}\text { Estimated Threshold } \\
\text { Level in Water } \\
(\mathrm{mg} / 1)\end{array}$ \\
\hline Acetophenone & 0.5 \\
\hline Cresol & 0.07 \\
\hline M-cresol & 0.2 \\
\hline O-cresol & 0.4 \\
\hline P-cresol & 0.12 \\
\hline Cresylic acid (meta para) & 0.2 \\
\hline N-butymercaptan & 0.06 \\
\hline 0-sec. butylphenol & 0.3 \\
\hline P-tert. butylphenol & 0.03 \\
\hline o-chlorophenol & 0.0001 to 0.015 \\
\hline P-chlorophenol & 0.01 to 0.05 \\
\hline 2,3-Dichlorophenol & 0.084 \\
\hline 2,4-Dichlorophenol & 0.001 to 0.014 \\
\hline 2,5-Dicholorophenol & 0.023 \\
\hline 2,6-Dicholorophenol & 0.035 \\
\hline 2-Methy1, 4-chlorophenol & 0.075 \\
\hline 2-Methyl, 6-chlorophenol & 0.003 \\
\hline o-phenylphenol & 1 \\
\hline $\begin{array}{l}2,4 ; 6-T r i c h l o r o p h e n o l \\
\text { Phenol }\end{array}$ & $\begin{array}{l}0.003 \text { to } 0.05 \\
1 \text { to } 10\end{array}$ \\
\hline Phenols in polluted water & 0.02 to 0.15 \\
\hline Diphenyl oxide & 0.05 \\
\hline O-dichlorobenzene & 0.25 \\
\hline Ethylbenzene & $<0.25$ \\
\hline Ethanethiol & 0.24 \\
\hline Formaldehyde & 95 \\
\hline Kerosene & 0.1 \\
\hline Kerosene plus kaolin & 1 \\
\hline Isopropylbenzene & $<0.25$ \\
\hline Naphtha & 0.1 \\
\hline Naphthalene & 1 \\
\hline Naphthol & 0.5 \\
\hline 2-Napthol & 0.3 \\
\hline Dimethlamine & 7 \\
\hline Oil, emulstfiable & $<15$ \\
\hline Pyridene & 5 to 28 \\
\hline Pyrocatechol & 0.8 to 5 \\
\hline Quinolene & 0.5 to 1 \\
\hline P-quinone & 0.5 \\
\hline Styrene & 0.25 \\
\hline Toluene & 0.25 \\
\hline
\end{tabular}

$a_{\text {The threshold is the concentration in water at }}$ which the effluent component can cause tainting of the flesh of $f$ ish and other aquatic organisms.

Source: National Academy of Sciences 1972. 
(13) Fluid catalytic cracker catalyst fines,

(14) Coke fines,

(15) Lube ofl filter clays,

(16) Spent catalysts,

(17) Chemical precipitation sludges,

(18) Vacuum or centrifuge filtration sludge, and

(19) Silica gel and other filtration media.

Recent estimates of the amounts of each solid waste stream are shown in Table 22. Note the degree of uncertainty associated with these values.

The first 13 wastes 1 is ted above are typically produced by topping and all other types of refineries. Cracking, petrochemical, and integrated refineries also generate fluid catalytic cracking (FCC) fines and coke fines. Lube refineries generate lubricating oil filter clay wastes. Spent metallic catalysts may not be refinery wastes, for many undergo off-site reprocessing to recover their precious metals content. Chemical precipitation sludges, silica gel, and other filtration media will usually be waste products from refineries with tertiary was tewater treatment systems.

A number of variables affect the compositions and quantities of wastes produced by a refinery. One of the major variables is the crude oil feedstock. Crude oil heavy metals content will significantly affect the metals content of crude oll storage tank bottoms and a number of other wastes. Another set of variables Involves the mix of processes performed at the refinery. For example, hydrofluoric acid and sulfuric acid alkylation units generate distinctly different wastes. As noted above, the processes used at refineries vary greatly. This contributes to a wide variation in the quantity and constituents of wastes among refineries.

Air and water pollution control processes are a major solid waste determinant (Rosenberg et al. 1976). For example; the use of electrostatic precipitation units in conjunction with fluid catalytic cracking catalyst regene ration removes particulate matter that would otherwise be an air emission. Hydrotreating, rather than using clay filters to remove sulfur, decreases the amount of solid waste produced. Operational practices and the condition of individual process units may significantly affect the amounts of wastes produced. 
TABLE 22

ANNUAL SOLID WASTE GENERATION

OF THE U.S. PETROLEUM REFINING INDUSTRY

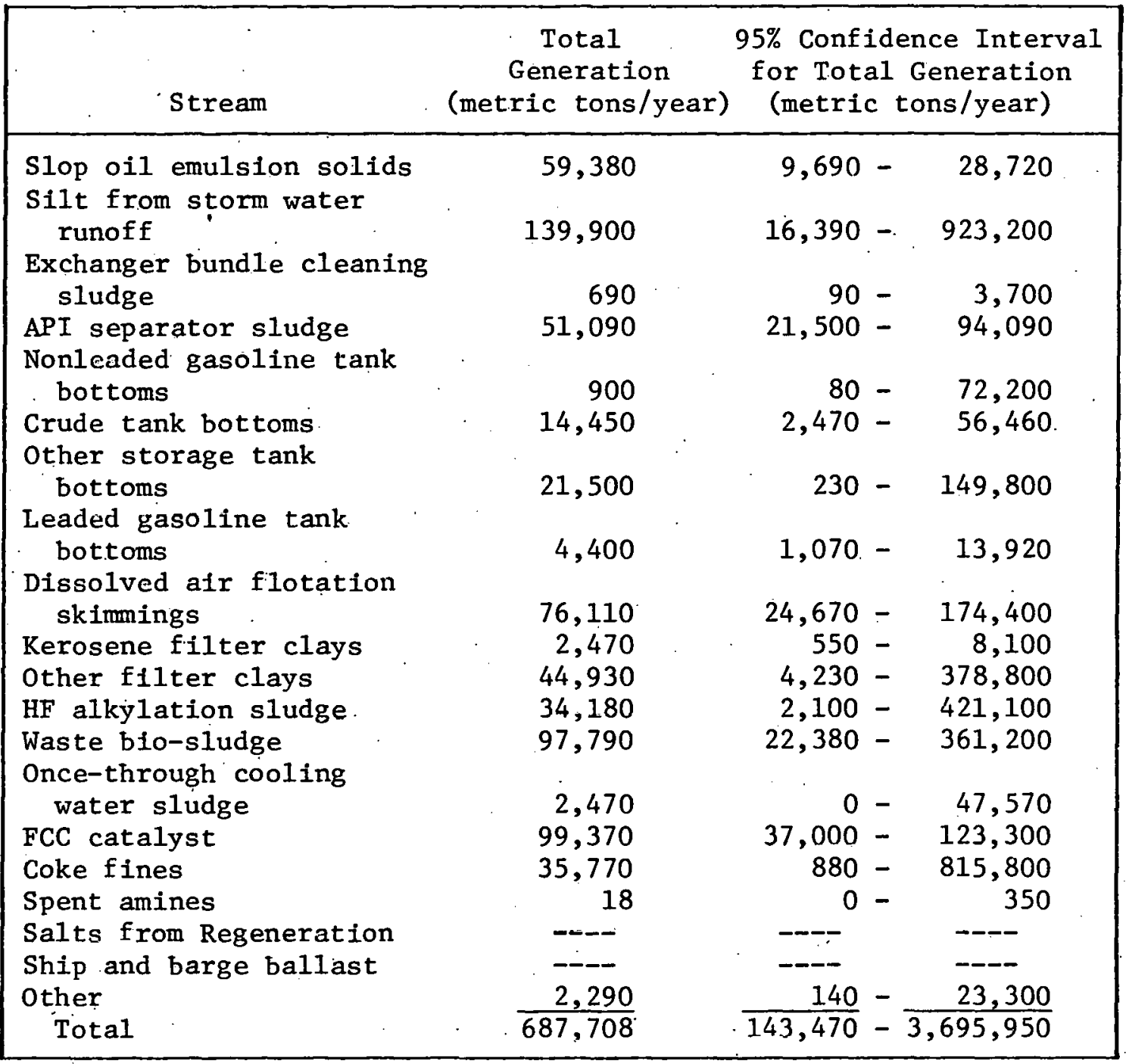

Note: ----Represents data not available

Source: Galloway 1979. 
Industry-wide, annual estimates of constituents of refinery solid wastes have been developed (Rosenberg et a1. 1976). Tables 23 and 24 present 1974 and 1983 estimates of constituents of all refinery solid wastes. Individual waste streams contain higher concentrations of particular waste constituents. 011 is the principal component of refinery wastes, representing approximately 110,000 metrlc tons per year. About 250 metric tons of metallic compounds are annually contalned in refinery wastes: .87 metric tons (35 percent) chromium; 78 metric tons ( 31 percent) zinc; 23 metric tons ( 9 percent) nicke1; 22 metric tons ( 9 percent) copper; and 20 metric tons ( 8 percent) vanadium. The remaining 9 percent consists primarily of lead, arsentc, molybdenum, cobalt, selentum, mercury, Bilver, and cadintum. Additional waste estimates are 812 metric tons of fluorides, 5 metric tons of phenols, 1 metric ton of cyanide, and 0.1 metric ton of benzo(a)pyrene. Recovery of strateglc metals such as chromium from refinery wastes 18 apparently not yet an economical proposition for it is not a common practice.

Solld Waste Disposal. An estimated $687,7.08$ metric tons per year of solid waste (dry weight) is generated by U.S. petroleum refineries (Galloway 1979). Current final disposal technologles include on-site or off-site landfilling, landfarming, and to a lesser extent, incineration, deep well and salt mine disposal, ocean dumping, and lagooning. Results of a survey of waste disposal methods at 19 refinerles In 1973 and projections for 1983 are shown 1n Table 25. Treatments currently used (prior to ultimate disposal) include: vacuim filtration, pressure filtration, centrifugation, dewatering lagoons, aerobic digestion, anaerobic digestion, and chemical fixation. Predisposal solld waste treatments are primarily used to dewater (concentrate) solid wastes, and perform some blodegradation.

As shown in Table 25, in 1973, 44.3 percent of all solld wastes were disposed of on site, versus 55.7 percent disposed of off site. Projections for 1983 Indicate a signiflcant increase in the amount of solid waste disposed of on site versus off site, a decrease in lagooning, and a major increase in the amount of on-site landspreading (landfarming). Increased on-site landspreading 18 the mafor factor responstble for the decrease in off-site disposal, from 55.7 percent in 1973 to 27 percent in 1983. Little 18 known about current refinery waste disposal practices.

A number of factors are influencing the trend toward on-site disposal:

- The closing of many off-site dumps, lagoons, landfills, and other disposal sites;

- Increasingly stringent regulatory actions, public scrutiny, and adverse opinion concerning waste disposal practices; 
TABLE 23

WASTE CONSTITUENTS GENERATED BY REFINERIES (1974)

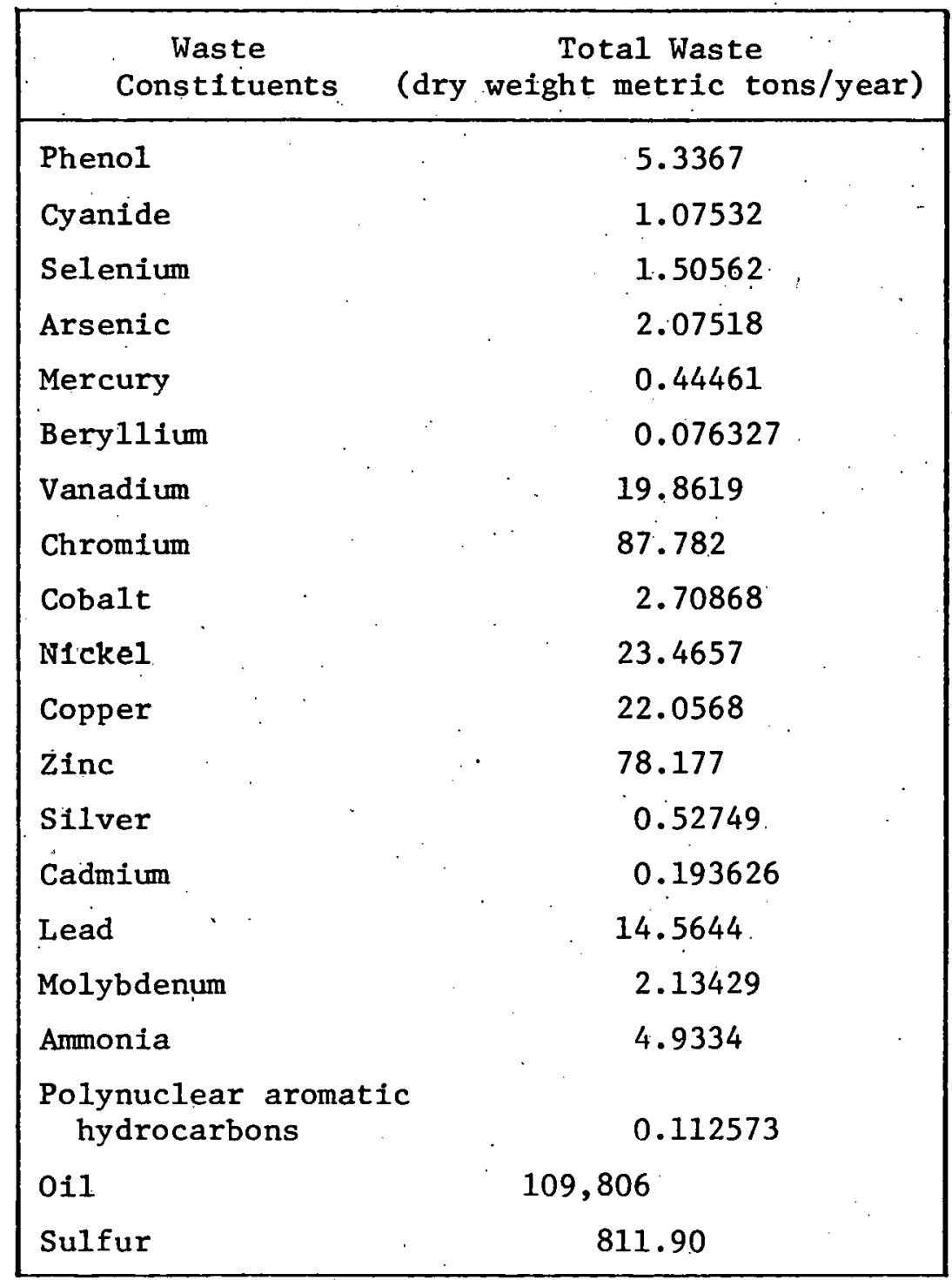

Source: Rosenberg et al. 1978. 
TABLE 24

ESTTMATES OF REFINERY WASTE GENERATION

(1983)

\begin{tabular}{|c|c|c|}
\hline $\begin{array}{c}\text { Waste } \\
\text { Constituent }\end{array}$ & (dry & $\begin{array}{l}\text { Total Waste } \\
\text { weight metric tons/day) }\end{array}$ \\
\hline Phenol & & 7.28 \\
\hline Cyanide & · & 1.40684 \\
\hline Selenium & & 2.0912 \\
\hline Arsentc & & 2.48803 \\
\hline Mercury & & 0.58041 \\
\hline Beryllium & & 0.102325 \\
\hline Vanadium & & 30.7632 \\
\hline Chromium. & & 75.144 \\
\hline Cobalt & & 2.87359 \\
\hline Nickel & & 33.736 \\
\hline Copper & & 21.7729 \\
\hline Zinc & & 69.980 \\
\hline Silver & & 0.69295 \\
\hline Cadmium & & 0.203681 \\
\hline Lead & & 16.4492 \\
\hline Molybdenum & & 2.27229 \\
\hline Ammonia & & 4.1432 \\
\hline $\begin{array}{l}\text { Polynuclear aromatic } \\
\text { hydrocarbons }\end{array}$ & & 0.152803 \\
\hline Oil & & 112,238 \\
\hline Sulfur & & $1,044.99$ \\
\hline
\end{tabular}

Source: Rosenberg et al. 1978. 
TABLE 25

ESTIMATES OF REFINERY WASTE DISPOSAL METHODOLOGIES

\begin{tabular}{|c|c|c|c|c|}
\hline \multirow{2}{*}{$\begin{array}{r}\text { Disposal } \\
\text { Procedure }\end{array}$} & \multicolumn{2}{|c|}{1973} & \multicolumn{2}{|c|}{1983} \\
\hline & $\begin{array}{c}\text { Onsite } \\
(\%)\end{array}$ & $\begin{array}{c}\text { Offsite } \\
(\%)\end{array}$ & $\begin{array}{c}\text { Onsite } \\
(\%)\end{array}$ & $\begin{array}{c}\text { Offsite } \\
(\%)\end{array}$ \\
\hline Landfilling & 16.8 & 34.3 & 24 & $20^{\circ}$ \\
\hline Lagooning & 18.3 & 21.4 & 12 & 7 \\
\hline Incineration & 0.8 & 0 & 3 & 0 \\
\hline Landspreading & 8.4 & $\underline{0}$ & 34 & 0 \\
\hline Total & 44.3 & 55.7 & 73 & $27^{\circ}$ \\
\hline
\end{tabular}

Source: Rosenberg et al. 1976. 
- Increased transportation costs and distances to certified dumping sites;

- Increasingly stringent alr and water emission regulations, which make less-regulated land disposal more attractive; and

- A trend toward corporate and plant self-sufficlency, especlally in waste disposal practices.

Some of the trends tending to increase the amount and change the constituents of refinery solid wastes include

- Increased crude ofl processing capactity;

- Increased use of fluld catalyt1c cracking, hydrotreating, alkylation, and other solld waste producing processes;

- Changes in crude ofl feeds, espectally an increased use of heavy and sour (high sulfur) crudes;

- Increased use of biological treatment, air flotation, and tertiary wastewater treatment systems in response to government regulations; and

- Increased enhanced ofl recovery methods for crude o1l extraction.

Some of the minor trends tending to decrease the amount and change the constituents of refinery solid wastes include:

- A reduction In separated oll emulsion sol1d wastes due to. increased refinery ofl recovery and recycling;

- Regulations reducing the use of lead compounds in gasoline; and

- Reduced levels of chromium and zinc concentrations as corrosion inhibitors in cooling tower water due to environmental concerns.

While treated wastewater effluents from modern refineries tend to be relarively. unlfurm and chemical analygis program results are available, the nature and quantity of solid wastes are highly variable and not well documented. Many refinery solid wastes are only intermittently generated--their volume and accumulation periods largely governed by process unit designs and individual refinery housekeeping and waste management practices. Continuously generated 
wastes (those requiring disposal at less than 2-week intervals) generally result from major refinery processes and include (Sittig 1978):

- Coking unit wastes--coke fines, spilled coke from unloading operations;

- Spent catalyst and catalyst fines from fluid catalytic cracking catalyst regenerators;

- Spent and spilled grease and wax wastes, especlally in lubè ofl processing units;

- Dissolved a1r flotation float;

- Waste blological sludges; and

- Slop ofl (considered as a solid waste due to treatment and disposal practices).

Wastewater treatment ylelds a high volume and varlety of solids and emulsions requiring disposal. These wastes are generated largely as a function of refinery throughput and wastewater processing. 01ly solids and slop olls usually undergo emulsion breaking and filtration or centrifugation steps to remove water and recoverable oil. Sludges may be dewatered to facilitate transport.

Most off-site disposal is handled by private contractors. Recent changes in record-keeping and other requirements issued under the Resource Conservation and Recovery Act (RCRA) for handling hazardous solid wastes should make more information avallable concerning refinery solid waste disposal practices.

Environmental Effects of Solld Waste Disposal. The environmental adequacy of the treatment and disposal methods employed by the petroleum refining industry varies greatly, much the same as it does with the rest of the nation's industries (Rosenberg et al. 1976). Major environmental hazards from refinery solid waste disposal are ground and surface water contamination and volatile emlssions. Mandatory minimum requirements for off-site management are generally monitored by state or local regulatory agencies. Disposal sites typlcally operate under renewable permits. Off-site landfilling operations are increasingly being required to monitor groundwater quality. Some on-site landfills use bentontte clays or other linings with presumed high ion exchange capabilities and low permeability under their landfill sites, but some do not. 
Landfarming or landspreading involves the spreading and mixing of the wastes into surface soll for biodegradation of organic material by soll bacteria. Land requirements for landspreading depend on the soll's ofl-loading potential and the amount of ofl in the wastes. In many cases, landfarming may improve soll texture and fertility, however the sultability of growling food crops on land-farmed solls requires scrutiny. Fleld test plots have shown that climate has little long-term effect on oll degradation--the cold and arid climate of Montana and the warm and humid climate of the Gulf Coast states support landfarming (Kincannon 1976; Huddleston and Cresswe11 1976). Safeguards observed in 1974 were limited to the construction of ralnwater runoff-preventing dikes and low-level berms surrounding spreading areas (Rosenberg et al. 1976). During that year, only one surveyed facility utllized monitoring wells, a program for leachate detection, and an analysis program to Identify intermediate degradation by-products.

Landf 111 and landspreading monitoring programs may not prevent contamination of local groundwaters. Monitoring networks must be carefully designed. Chemlcal identities and solubilities may change with time in the complex chemical and bacterlal environment of solls. Little information is avallable concerning the transformations refinery wastes undergo in various solls. It is nearly impossible to remove contamination once 1 t has reached an aquifer.

The majority of lagoons observed in 1974 were constructed from native earth materials and the only safeguards observed were the occastonal use of concrete, plastic, and clay liners to reduce or impede exfiltration of hazardous liquids.

Incineration is one method for disposing of organic solid wastes. It has advantages of being free from most objectionable odors and Independent of weather conditions, and it facilitates a high reduction in the volume of solid wastes requiring disposal. However, incinerators require considerable capital and operating expenditures, and may require supplemental fuel if the solids have a heat content of less than 10,000 Btu's per pound. Multiple hearth and fluidizedbed Incinerators are the most commonly used. Alr pollution scrubbing systems are frequently required and ash must still be disposed of as solid waste.

Refinerles with a high level of water intake and wastewater effluent treatment may generate solid wastes high in inorganic salts. High salt-containing wastes result from:

- Treatment of brine (mostly sodium chloride) from crude desalting operations; 
- Rinsing and regeneration of lon exchange resins used to pretreat water for steam generation; and

- Cooling tower and boller blowdown concentrates (salts in raw water supply plus any additives used).

Resulting inorganic salts, mostly sodium, calclum, magnesium, and other salts present in the raw water supply, are not amenable to disposal by most landfill or landfarming methods. Most of these salts are deliquescent, absorbing atmospheric molsture and ultimately dissolving and leaching into groundwater or running off into nearby bodies of water. Potential 1mpacts include the kiling of terrestrial vegetation, Impalrment of water quality for public and industrial uses, and adverse effects on aquatic ecosystems. These wastes may not be disposed of in impervious clay containment basins, as they tend to destroy the clay's impervious characteristics. Inorganic salts are not amenable to disposal by incineration. The only acceptable methods for disposing of these inorganic salts are by ocean dumping ( 1 they do not contain high concentrations of other toxic wastes), disposal in plastic-lined or sealed basins, and disposal in salt mines.

Certain precautions are exercised in the disposal of leaded gasoline sludges and residues. Special breathing and ventilation systems are required to protect workers within tanks and when handling these materials. The sludge reportedly is placed on elevated outdoor concrete slabs with a peripheral curbing. The entire slab is sloped and it drains to the refinery wastewater collection system. Presumably, lead and other compounds in the sludge are permitted to partially wash into the wastewater treatment system while they are dried prior to final disposal, probably in landf111s.

Only landfarming can truly be consldered an ultimate land-based disposal technique because the wastes are degraded and become Incorporated Into the so11 (Galloway 1979). Although anaerobic degradation theoretically occurs in landfills, some recently reopened landfills show no significant anaerobic digestion of olly wastes. Lagooning, disposal wells, salt mine disposal, and ocean dumping do not foster biodegradation. All of these, except ocean dumping, are long-term storage techniques.' Incineration is energy and capital intensive, and generates air pollutants and ash residues requiring solid waste disposal. Optimum methods for disposing of refinery solid wastes require further study and discussion.

The total hydrocarbon content of refinery solid wastes has recently been estimated at 190,000 tons per year (dry weight) (Galloway 1979). Four waste streams contain about 75 percent of these 
hydrocarbons: dissolved air flotation skimmings, slop. oil emulsion solids, API separator sludge, and waste biological processing sludge. Dat a concerning hydrocarbon volatility and volatile organic compound emissions from disposed solid wastes are not avallable.

Safeguards, such as encapsulation in plastic or concrete, burial in steel drums, and leachate analysis and treatment, were not observed in 1974 according to the study of refinery wastes disposal. "The industry simply believes that this type of treatment and/or handling is not warranted or economically justified" (Rosenberg et al. 1976). The recent implementation of the Resource Conservation and Recovery Act (RCRA) and increased corporate and public awareness of the hazards associated with solid waste disposal will probably result in the availability of more information on this subject, fostering the development of better disposal practices and treatment facilities.

Effect of Air Emissions on Blota. Of the primary acyclic and alicyclic hydrocarbons, only ethylene has been found to significantly affect vegetation. The hydrocarbons most nearly approaching the activity of ethylene are acetylene and propylene. These gases require levels 60 to 500 times that of ethylene to produce similar adverse effects. At concentrations of $1 . \mathrm{ppm}$ or less, ethylene may be the only hydrocarbon harmful to vegetation (Britt and Hushon 1976).

Besides its phytotoxic effects, ethylene is also produced naturally by plants and functions as a hormone in regulating growth, development, and other processes such as the ripening of fruit.

Symptoms of ethylene toxiclty include: growth reduction, decreased optical dominance, bud abscission (leaf fall), and flower deformities. Leaf damage includes growth abnormalities, yellowing, death of tissue (necrosis), and premature abscission (Britt and Hushon 1976).

Some mononuclear aromatic hydrocarbons Inhibit or reduce photosynthesis in plants. The effects of benzene on different species of trees have led Russia to establish a permissible air pollution concentration of $0.031 \mathrm{ppm}\left(0.1 \mathrm{mg}\right.$ per $\left.\mathrm{m}^{3}\right)$. An increase in the number of methyl groups on the benzene ring has been reported to enhance the phytotoxicity significantly. Therefore, benzene is less toxic than toluene, which in turn may be less toxic than other substituted alkyl benzenes (Walker 1976).

No substantial information has been reported to indicate that airborne polycyclic hydrocarbons affect vegetation, except by contaminating soil. However, they can be incorporated into vegetation by absorption from the soil through roots and may settle on exposed 
surfaces. Although relatively non-toxic to plants at low concentrations, aromatic hydrocarbons may be alr-oxidized to quinones which may be phytotoxic at a few parts per billion.

With regard to phenols, cresols are used as agents for breaking dormancy and as herbicides to destroy various plant tumors. The effects of airborne refinery emissions of, phenols on plants is unknown.

The reader is referred to the Transporation and Storage section of this report for information concerning the effects of spilled crude oll. and its refined products on terrestrial vegetation.

Summary of Research Needs

Aquatic Effects. The discharge of refinery liquid effluents into surface waters from point sources is regulated through the National Pollutant Discharge Elimination System (NPDES). Some of these discharges enter municipal sewage treatment systems. Uncontrolled runoff, leaching from disposal and storage areas, and atmospheric deposition deserve research as routes by which significant amounts of refinery hydrocarbons enter the aquatic environment.

The biological effects of aromatic hydrocarbons and phenols are well understood. Research emphasis should focus on the areas of their control and transport, transformation, and fate.

Terrestrial Effects. As one can see from the discussion above, airborne ethylene and phenols can have a detrimental effect on plant growth. Research is needed on the significance of this problem to fruit and vegetable growers. Fruit, vegetable, and other types of farms are located near many refinery sites. Research emphasis should be placed on the effects of these hydrocarbons on the retardation of plant growth, premature abscission, and dormancy breaking, as well as the impacts on farm animals and animal products.

Solid Wastes. The refining industry has made significant strides in recent years in the area of utilizing refinery wastes by landfarming. These innovations focus on using the soil environment for planned, orderly was te treatment. Research should be Intensified in this area, with emphasis placed on: the precise nitrogen and phosphate requirements needed to landfarm oily wastes (this has economic implications); the types of vegetation that can be grown on oily waste land farms; the effects that factors such as plant growth have on the rate and extent of oil degradation; the demonstration that no hazardous substances are present or produced when oily wastes are landfarmed; and the degree to which toxic materials may enter plants and thus may pass through several food chains, affecting wildlife and posstbly man. 
TRANSPORT AND TRANSFORMATION

Air Medium

Air emissions vary greatly among refineries. Factors such as crude feedstocks, processes, equipment, air pollution control measures, housekeeping and malntenance practices, and the age and type of refinery strongly influence the amount and kinds of refineryreleased air pollutants. Major air pollution sources within the refinery are:

- Combustion sources-process heaters and boilers;

- Process units-mainly fluid catalytic cracking catalyst. regenerators, coking units, and asphalt blowing;

- Storage and transfer activities; and

- Wastewater and air pollution control and treatment systems.

Most available information and data regarding air pollutants concern regulated refinery pollutants, primarily sulfur oxides, particulate matter, nitrogen-dioxide, carbon monoxide, and volatile organic compounds (hydrocarbons). In addition, aldehydes and ammonia have recelved attention. Table 26 presents air emissions estimates for several model refineries.

Unlike wastewater and liquid effluents, which are collected and usually combined for treatment, air emissions occur from a multitude of specific sources and are usually handled separately. Atr pollution control systems, when used, are associated with specific process units and are usually designed to remove or modify specific pollutants. Wastewater effluent treatment processes tend to remove or reduce concentrations of many different types of compounds at once. The chemical content and disposition of refinery air emissions are less well-documented due to the multiplicity of sources within the refinery, the three-dimensional atmospheric dispersion of these pollutants, and regulations requiring comprehensive monitioring of select pollut ants.

Environmental Transpurt.

Air pollutants from petroleum refineries disperse in much the same way as other industrial airborne emissions. Concentrations of pollutants in the plant's immediate vicintty depend on the spatial distribution and physical characteristics of the emission sources. Combustion source stack emission height and emission temperature affect local ground concentrations of emissions--higher stacks and 
TABLE 26

REFINERY AIR EMISSIONS

\begin{tabular}{|c|c|c|c|}
\hline Pollutant & $\begin{array}{c}200,000 \text { BPCD } \\
\text { Fuel Oil } \\
\text { Refinery Modela }\end{array}$ & $\begin{array}{c}200,000 \text { BPCD } \\
\text { Gasoline } \\
\text { Refinery Model }\end{array}$ & $\begin{array}{c}200,000 \mathrm{BPCD} \\
\text { Gasoline Refinery } \\
\quad(\text { Reference) }\end{array}$ \\
\hline Particulates, $1 \mathrm{bs} / \mathrm{hr}$ & 263 & $432^{b}$ & 353 \\
\hline $\begin{array}{l}\text { Sulfur dioxide }\left(\mathrm{SO}_{2}\right) \text {, } \\
\text { lbs/hr }\end{array}$ & 667 & 948 & $1,918^{c}$ \\
\hline $\begin{array}{l}\text { Hydrocarbons (HC), } \\
\text { lbs/hr }\end{array}$ & 3,082 & 3,200 & $6,418^{d}$ \\
\hline $\begin{array}{l}\text { Carbon monoxide }(\mathrm{CO}) \text {, } \\
\text { lbs/hr }\end{array}$ & 50 & 95 & $138^{e}$ \\
\hline $\begin{array}{l}\text { Nitrogen oxides }\left(\mathrm{NO}_{\mathrm{x}}\right) \text {, } \\
\text { lbs } / \mathrm{hr}\end{array}$ & 493 & 1,250 & $1,846^{e}$ \\
\hline
\end{tabular}

$\mathrm{a}_{\mathrm{Bb} 1}$ per calendar day average daily production.

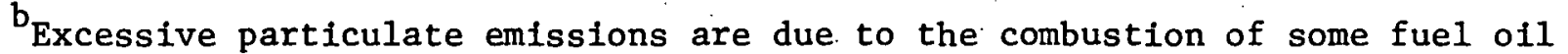
in the gasoline refinery module, whereas only fuel gas is combusted in the reference refinery.

The larger $\mathrm{SO}_{2}$ emission rate is due to a larger volume of tail gas being emitted from the reference refinery, which is a result of a higher percentage of sulfur in the crude.

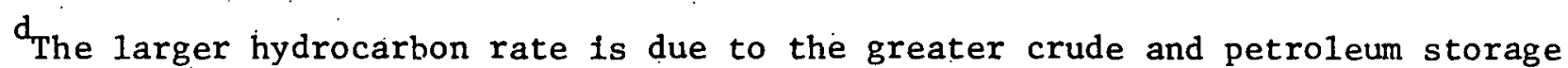
capacity in the reference refinery.

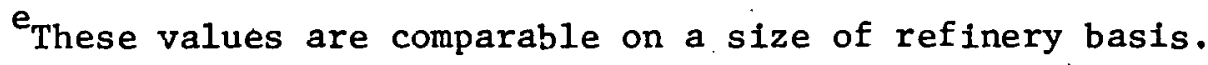

Source: Sittig 1978. 
hotter emissions generally lead to lower ground concentrations. The trend toward maximum heat recovery may be lowering the temperatures of stack emissions and exacerbating combustion-related ground levels of pollutants. Fugitive emissions generally occur near ground level and, thus, may pose hazards to employees and those in the immediate area.

Meteorological factors are the primary determinants influencing dispersion of alr pollutants. Concentrations of air pollutants are functions of dilution and diffusion processes. These depend largely on interrelated meteorological factors, such as atmospheric stabil1ty, wind speed and direction, mixing depth, temperature, humidity, precipitation, and inversions. Other local conditions such as terrain barrlers may affect dispersion, possibly causing a bulldup of pollutants in the vicinity of or downwind from the refinery. Insufficlent information is avallable to make conclusions regarding a generalized distribution pattern for concentrations of pollutants in the vicinity of petroleum refineries.

\section{Source Characterization}

Emissions may occur from a number of sources within the refinery. Table 27 lists some of these emissions and their sources. Estimates for the volume of process untt emlssions in a mode refinery are presented in Table 28.

Hydrogen Sulfide. Hydrogen sulfide 18 an odorous, toxic gas assoclated with several sources within the refinery (American Petroleum Institute 1977). It is potentially dangerous to workers because of 1ts greater-than-alr density and 1 ts tendency to paralyze the olfactory nerves, thus becoming undetectable by odor. Quantitles of hydrogen sulfide may form from a number of sources within the refinery:

- Vaporization from crude ofl and raw distillates. Many sour crude oils contain quantitles of hydrogen sulfide in solution that may be released.

- Decomposition of sulfur compounds and interaction of free sulfur with hydrocarbons.- Hydrogen sulfide is released from crude ofl when heated, as during fractionation. Gas evolution increases with temperature and is further increased by chemlcal reactions among crude constituents. Sulfur compounds decompose and free sulfur reacts with hydrocarbons, ylelding hydrogen sulfide. Gases driven off during distillation may contain up to 80 percent hydrogen sulfide. 
POTENTIAL SOURCES OF ATMOSPHERIC

EMISSIONS WITHIN REFINERIES

\begin{tabular}{|c|c|}
\hline Type of Emission & Source \\
\hline Particulates & $\begin{array}{l}\text { Catalytic cracker, fluid coking, } \\
\text { catalyst regeneration, } \\
\text { process heaters, boilers, de- } \\
\text { coking operations, in- } \\
\text { cinerators }\end{array}$ \\
\hline Sulfur oxides & $\begin{array}{l}\text { Sulfur recovery unit, catalytic } \\
\text { cracking, process heaters, } \\
\text { boilers, decoking operations, } \\
\text { unit regenerations, treating } \\
\text { units, flares }\end{array}$ \\
\hline Nitrogen oxides & $\begin{array}{l}\text { Process heaters, boilers, } \\
\text { catalyst regeneration, flares }\end{array}$ \\
\hline Hydrocarbons & $\begin{array}{l}\text { Storage tanks, loading op- } \\
\text { erations, water treating, } \\
\text { catalyst regeneration, baro- } \\
\text { metric condensers, process } \\
\text { heaters, boilers, pumps, } \\
\text { valves, blind changing, } \\
\text { cooling towers, vacuum jets }\end{array}$ \\
\hline Carbon monoxide & $\begin{array}{l}\text { Catalyst regeneration, decoking, } \\
\text { compressor engines, in- } \\
\text { cinerators }\end{array}$ \\
\hline Odors & $\begin{array}{l}\text { Treating units, drains, tank } \\
\text { vents, barometric condensers, } \\
\text { sumps, oil-water separators }\end{array}$ \\
\hline
\end{tabular}

Source: Barrett and Goldfarb 1979. 
TABLE 28

MODULE ATMOSPHERIC EMISSIONS

FROM A GASOLINE REFINERY

(lbs/day)

\begin{tabular}{|c|c|c|c|c|c|}
\hline Process & Particulates & $\mathrm{SO}_{\mathrm{x}}$ & Co & Hydrocarbons & ${ }^{\mathrm{NO}_{x}}$ \\
\hline Crude distillation & $3,080.0$ & $6,400.0$ & 533.0 & 533.0 & $5,330.0$ \\
\hline Mid-dist1llate & & & & & \\
\hline hydrotreating & 45.0 & 64.0 & 38.0 & 65.4 & 518.0 \\
\hline Straight run naphtha & & & & & \\
\hline hydrotreating & 18.0 & 26.0 & 15.0 & 25.7 & 207.0 \\
\hline Heavy naphtha reformer & $1,660.0$ & $3,560.0$ & 287.0 & 288.0 & $2,870.0$ \\
\hline Gas ofl hydrotreater & 326.0 & 703.0 & 57.0 & 56.0 & 567.0 \\
\hline \multicolumn{6}{|l|}{ Fluid catalytic } \\
\hline $\begin{array}{l}\text { cracking } \\
\text { co boller }\end{array}$ & $\begin{array}{l}124.0 \\
491.0\end{array}$ & $\begin{array}{r}176.0 \\
3,020.0\end{array}$ & $\begin{array}{l}106.0 \\
256.0\end{array}$ & $\begin{array}{l}181.0 \\
160.0\end{array}$ & $\begin{array}{l}1,425.0 \\
6,370.0\end{array}$ \\
\hline Hydrocracker & 131.0 & 185.0 & 110.0 & $1,077.0$ & $1,110.0$ \\
\hline \multicolumn{6}{|l|}{ Heavy Hydrocrackate } \\
\hline reformer & $1,650.0$ & $3,540.0$ & 285.0 & 286.0 & $2,854.0$ \\
\hline Propane deasphalting & 622.0 & 884.0 & 48.0 & 81.0 & .656 .0 \\
\hline \multicolumn{6}{|l|}{ Deaspha1ted ofl } \\
\hline hydrotreating & 29.0 & 42.0 & 25.0 & 42.0 & 336.0 \\
\hline HF alkylation & 0.4 & 0.6 & 0.4 & 0.7 & 5.0 \\
\hline Light ends recovery & 11.0 & 15.0 & 9.2 & 15.7 & 125.0 \\
\hline $\mathrm{C}_{5} / \mathrm{C}_{6}$ isomerization & 105.0 & 225.0 & 18.5 & 18.2 & 181.0 \\
\hline Hydrogen plant & $1,720.0$ & 345.0 & 344.0 & 338.0 & $6,890.0$ \\
\hline \multicolumn{6}{|l|}{ Storage } \\
\hline Crude & -- & -- & -- & $7,550.0$ & -- \\
\hline Motor gasoline & -- & -- & -- & $5,050.0$ & -- \\
\hline Mid-distillates & -- & -- & --- & 97.0 & --- \\
\hline Heavy fuel o1l & $= \pm$ & $-\infty$ & -- & Negligiblc & $=-$ \\
\hline Sludge Incineration. & 361.0 & 600.0 & 133.0 & 42.0 & 510.0 \\
\hline Tail gas treating & 3.1 & $\begin{array}{l}3,560.0 \\
\text { Ta11 gas }\end{array}$ & 2.6 & 4.6 & 36.0 \\
\hline Miscellaneous & --- & --- & $=--$ & $60,900.0$ & --- \\
\hline Total & $10,380.0$ & $22,750.0$ & $2,270.0$ & $76,800.0$ & $29,990.0$ \\
\hline
\end{tabular}

Notes: Assumes a crude feed of 200,000 bbl per day.

Source: Cavanaugh 1975. 
- Evaporation from aqueous solutions, such as settled water in crude and sour distillate storage tanks. When drawn off, hydrogen sulfide gas evolves in proportion to its concentration in the solution.

- Acidification or neutralization of caustic and amine solutlons used to absorb or remove hydrogen sulfide leads to its release as a gas. Hydrogen sulfide also is released when inorganic sulfides, such as iron sulfide tank scale, are acidified.

- Anaerobic bacterial decomposition of sulfur-containing . organic materials in refinery sewer systems and stationary bodles of water release hydrogen sulfide.

Carbon Monoxide. Carbon monoxide ( $\mathrm{CO}$ ) results from the Incomplete combustion of fuels. Large quantities are released during the regeneration of fluld catalytic cracking catalysts. Dry flue gases. from a regenerator unit may contain 6 to 10 percent carbon monoxide, compared to 0.1 to 0.2 percent that may result from fuel combustion. Most CO 18 discharged hot from high stacks and, because of 1ts lessthan-alr density, constitutes little hazard. Co.1s highly toxic and is espectally hazardous when allowed to accumulate in enclosed areas.

Hydrogen Cyantde. Hydrogen cyanide (HCN), a highly toxic gas, is produced during catalytic cracking catalyst regeneration and 18 usually exhausted with other hot flue gases.

Sulfur Dioxide and Sulfur Oxides. Sulfur oxides, mostly sulfur dioxide $\left(\mathrm{SO}_{2}\right)$ and some sulfur trioxide $\left(\mathrm{SO}_{3}\right)$, are emitted from refineries in a quantity that is largely a function of the sulfur content of the crude o1ls being processed. Hazardous concentrations of $\mathrm{SO}_{2}$ may result from the following sources:

- Release from sulfuric acld used in processing.

- Combustion of fuels containing sulfur compounds and the burning of coke in catalytic cracking units.

- Disposal of sulfuric acid'sludges, whether by processing in a recovery units or by direct burning in spectal furnaces.

- Sulfuric acid reduction when hydrocarbons or other organic matter is oxidized, especially during the alr-blowing of lubrication oils after acid treatment. Sulfur dioxide remalning in the treated ofl and acid sludge may vaporize continously under some conditions. 
Thiols. Thiol or mercaptan compounds are probably the most prevalent malodorous gases released from refineries. Present in crude oll (espectally sour crudes), thlois may be released from:

- Fractionation unfts. Lower bolling point thiols may be released through leaks or from the jet ejectors and barometric condenser waters of vacuum distillation units.

o Cracking units.

o. Caustic regeneration untts, or steam stripping units that remove thiols to regenerate caustic solutions. Air blowing converts extracted mercaptans into less odorous organic sulfides.

- Asphalt blowing. Thiols and other malodorous organic sulfides not removed during the alr-blowing oxidation process may be a major source of refinery malodor.

- Reactions among process stream constituents. Olefins in crude oll or formed by hydrocracking may react with sulfides to form thiols.

Phenolic Compounds. Phenolic compounds are present in large quantities in cracked distillates and some crude ofls. These are usually extracted using alkaline solutions and may be released from spent caustic solutions, especially when neutralized. The presence of thiol odors, even in small concentrations, severely aggravates the obnoxious odors of phenolic compounds. Phenolic compounds may escape from process equipment in which phenols are used as extraction solvents or absorptive distillation agents, and from phenolic aqueous waste streams.

Aldehydes. Aldehydes, 1ncluding formaldchyde, result from the incomplete or partial oxidation of hydrocarbons and may be found in discharged gases from asphalt alr-blowing units, fluid catalytic cracking catalyst regenerating units, and from furnaces or boflers with incomplete fuel combustion.

Ammonla. Some of the ammonla used in alkaline washing solutions, for neutralizing acids, and as a refrigerant may be released. In addition, catalytic cracking may produce small amounts of ammonia.

Hydrogen Chloride. Hydrogen chloride (HC1) is an 1rritant gas used as an 1somerization catalyst. It forms hydrochloric acid in aqueous solution. As a vapor, it may be liberated by leakage, other equipment fallure, or by decomposition of catalyst sludge. The 
volume of $\mathrm{HCl}$ used as a catalyst is relatively small and is 1ikely to cause hazardous situations only within the refinery.

Hydrogen Fluoride. Hydrogen fluoride (HF) is an especlally toxic and irritant acidic gas forming hydrofluoric acid in aqueous solution. Sources of hydrogen fluoride emissions include:

- Leakage from HF alkylation equipment;

o Leakage and evaporation during shutdowns;

- Combustion of HF-containing oils from acid regeneration units;

- Acidification or neutralization of spent. HF-neutralizing agents, especially dry limestone or treated anhydrous sludge; and

- Wastewater discharge and solid wastes containing spent caustic solutions if they are not completely neutralized.

Particulate Matter. Particulate matter is primarily emitted from process heaters and catalyst regeneration units, especially those associated with fluid catalytic cracking and reforming. These emissions are the result of combustion, except for the emissinn of some catalytic fines during regeneration.

Data regarding the amounts, constitutions, and sizes of refinery-generated particles are unavailable. Particulate matter may be presumed to be formed from organic compounds undergoing incomplete combustion. Various amounts and forms of PAHs, metal oxides, aldehydes, and other products of incomplete combustion or combustion of dirty fuels may be associated with particulate matter.

Organic Sulfides and Nitrogen Bases. These malodorous compounds are usually extracted with sulfuric acid when present in crude oil fractions. They may be released from actd sludges, elther during acid recovery or when acid sludge is neutralized. If acid sludge and spent caustic solutions are used to neutralize each other, the resulting combined odors may be particularly nauseating and persistent even in low concentrations. Other sources of malodors are:

- Fatty acids, soaps, and tallows used in grease manufacture;

- Hydrogen sulfide and other organic sulfur gases used to sulfurize cutting oil;

- Clays, earth, sorbents, filter media, and solid wastes that may release a number of obnoxious odors; and 
- Wastewater collection and processing facilities, such as separators and ponds, that may be sources of various offensive odors, espectally. during wet weather.

Hydrocarbon Emissions. Refineries may release considerable quantities of airborne organic compounds, mostly light-weight, volatile hydrocarbons. Federal regulations refer to these emissions as volatile organic compound (VOC) emissions. These hydrocarbons range in size and complexity from the simple alkanes to the polynuclear aromatic hydrocarbons (PAHs) and may contain elements other than carbon and hydrogen. Hydrocarbon emissions from transfer and storage facilities are discussed in the Transportation and Storage section of this report.

Considerable at tention has been directed toward characterizing sources of inadvertent or fugitive hydrocarbon releases. These hydrocarbon emissions often represent constituents of marketable products, have been associated with health hazards and photochemical smog, and in high concentrations may constitute a fire or explosive hazard. Refinery hydrocarbon emissions may range from 0.1 to 0.6 percent by weight of total crude oil processed, with the lower percentage generally applicable to new facilities. Thus, a refinery processing 100,000 barrels of crude per day may release 0.5 percent, or about 500 barrels of hydrocarbons, as unintentional fugitive emissions. The composition of hydrocarbon emissions from a refinery may be expected to be a composite of all the volatile substances in the crude oil, refinery intermediates, and final products. In general, more hydrocarbons are released from refineries concentrating on producing light fractions, such as gasoline, and process units handling lighter fractions.

Fluid catalytic cracking (FCC) catalyst regeneration units may be major sources of hydrocarbon emissions. Table 29 presents concentraliuns of some hasardous hydroc.arhons that have been identified in regenerator flue gas streams, but hydrocarbon emissions are negligible when a Co boller, high temperature (in situ) regeneration, or other control measures are used (Barrett and Goldfarb 1979). At present, FCC-associated hydrocarbon emissions are unregulated. The high concentrations and amounts of emitted polynuclear aromatic hydrocarbons (PNAs) are of concern because many of these have been implicated as carcinogens. The concentration of benzo(a)pyrene (BAP) can be reduced to $1.41 \times 10^{-5} \mathrm{~kg}$ per $1,000 \mathrm{bbls}$ of feed through use of a co boller. PAHs and benzo(a)pyrene concentrations are unknown for flue gases from catalyst regenerators employing Co-oxidation catalysts and high-temperature regeneration (Barrett and Goldfarb 1979). 
TABLE 29

HAZARDOUS HYDROCARBONS EMITTED FROM FCC UNIT REGENERATORS

\begin{tabular}{|c|c|}
\hline Hydrocarbons & Concentration \\
\hline $\begin{array}{l}\text { Aldehydes } \\
\text { (as formaldehyde) }\end{array}$ & $3-130 \mathrm{ppm}$ \\
\hline Cyanides (as $\mathrm{HCN}$ ) & $0.19-0.94 \mathrm{ppm}$ \\
\hline Phenanthrenes & $400,000 \mathrm{ppm}$ \\
\hline Anthracene & $\begin{array}{l}2,070 \text { ugr/barrel of oil } \\
\text { charge }\end{array}$ \\
\hline Pyrenes & $\begin{array}{l}40-28,000 \text { ugr/barrel of } \\
\text { oil charge }\end{array}$ \\
\hline $\begin{array}{l}\text { Benzo (ghi)- } \\
\text { perylenes }\end{array}$ & $\begin{array}{l}\text { 15-424 ugr/barrel of } \\
\text { oil charge }\end{array}$ \\
\hline $\begin{array}{l}\text { Benzo(a)- } \\
\text { pyrene }\end{array}$ & $\begin{array}{l}\text { 4-460 ugr/barrol of } \\
\text { oil charge }\end{array}$ \\
\hline $\begin{array}{l}\text { Benzo(e) - } \\
\text { pyrene }\end{array}$ & $\begin{array}{l}11-3,600 \text { ugr/barrel of } \\
\text { oil charge }\end{array}$ \\
\hline
\end{tabular}

Source: Barrett and Goldfarb 1979. 
Equipment in a refinery operates at pressures ranging from less than atmospheric pressure to greater than 1,000 psig. Automatic and manual safety and pressure relief valves are necessary to permit safe discharge of excess gases, to minimize the effects of operational irregularities, and to prevent emergency situations such as fires and explosions. In the past, waste gases and liquids were routed to open p1ts and burned. Currently, most refineries have manifolded pressure-rellef or blowdown recovery and disposal systems, usually incorporating 11quid-gas separators and flares. A wide range of hydrocarbon emission types and levels may be assoclated with pressure-rellef systems. Estimates of these emissions are not widely avallable.

Fug1tive Hydrocarbon Emissions. Considerable attention has been pald to the release of hydrocarbons from inadvertent equipment leaks (Fernandes 1978). Pressure, heat, vibration, wear, temperature changes, and corrosion may cause leaks in valves, joints, and seals In piping and machinery. Gases, 11quids, or both may leak in varying quantities, depending on the pressure, viscosity, and other factors. Testing of petroleum refinery equipment has shown that, while leaks for most equipment are not significant and are largely unavoldable, a small percentage can have high leak rates (Hustvedt and Weber 1978).

It 18 estimated that a typical 133,000-bb1-per-day $(15,900$ $\mathrm{m}^{3}$-per-day) refinery would have 27,000 potential leak sources-25,000 valves, 1,400 process drains, 250 pump seals, 14 compressor seals, and 130 rellef valves (Hustvedt and Weber 1978). Nationwide, volatile organic compound emissions from equipment leaks in petroleum refineries are estimated at 170,000 metric tons per year--equal to about 1 percent of the total volatile organic compound emissions from stationary sources (Hustvedt and Weber 1978). A single leak of 1 to $10 \mathrm{~kg}$ per day leads to 0.4 to 3.7 metric tons of emissions per year. For comparison, a typlcal modern chemical plant manufacturing over 48 million pounds per year ( $22 \mathrm{~kg}$ per year) of maleic anhydride would have only about 500 potential leak sources. Most potential sources do not leak, some leak a minor amount, and a few account for a high percentage of volatile hydrocarbon release.

The distribution of leaking components in a "typical" facllity 1s shown in Table 30 (Harrison 1978). Although the refinery-wide median leak rate is approximately 0.00035 ounces per hour $(0.01$ grams per hour), a small-number of leaks account for a large amount of emissions ( $i . e$. , one component leaking at 3.5 ounces per livur, or 100 grams per hour, equals 10,000 leaks at 0.00035 ounces per hour.) Many other sources of fugitive emissions are transltory or area sources, such as spills and sewers. These are more difficult to quantify. 
TABLE 30

DISTRIBUTIONS OF APPROXIMATE LEAK RATES

FOR TWO REFINERIES OF SIMILAR THROUGHPUT

\begin{tabular}{|lcc|}
\hline \multicolumn{1}{|c}{ Leak Rate } & $\begin{array}{c}\text { Older Refinery } \\
(\%)\end{array}$ & $\begin{array}{c}\text { Newer Refinery } \\
(\%)\end{array}$ \\
\hline Less than $0.10 \mathrm{gr} / \mathrm{hr}$ & 96.0 & 98.0 \\
$0.10-6 \mathrm{gr} / \mathrm{hr}$ & 2.0 & 0.9 \\
$6-600 \mathrm{gr} / \mathrm{hr}$ & 2.0 & 0.7 \\
Over $600 \mathrm{gr} / \mathrm{hr}$ & 2.0 & 0.3 \\
Total number of & & $50,000.0$ \\
\hline
\end{tabular}

Source: Harison 1978. 
Maintenance practices and methods of testing for leaks vary among refineries. Leak detection is complicated by the number of potential sources, their inaccessibility, and manpower and equipment requirements. Total fugitive emissions are difficult to quantify due to diffusion and dispersion above and downwind from the refinery. One method of assessing overall refinery fugitive emissions involves quantifying the distribution of hydrocarbons within a vertical transection downwind from the refinery. There is no consensus regarding the interpretation, accuracy, and reproducibility of these current methods.

Polycyclic Aromatic Hydrocarbons (PAHs). PAHs include numerous compounds that are responsible for a number of adverse effects, including: cancer of the skin, lungs, bladder, and scrotum; contact dermatitis; skin photosensitization; hyperpigmentation; acne; and folliculitis. These health effects and environmental effects of PAHs are discussed in the End Use section of this report. Refinery process streams typically contain over 5 percent four- to six-member ring PAHs, which include most PAHs associated with carcinogenic activity. These are shown in Table 31 (U.S. Environmental Protection Agency 1978).

PAHs may form from petroleum constituents by two basic reaction mechanisms: pyrosynthesis and pyrolysis. Pyrosynthesis involves the formation of PAHs from saturated hydrocarbons at high temperatures under oxygen-deficient conditions (Manahan 1975). Even lowmolecular-weight hydrocarbons, including methane, may be precursors for the synthesis of PAHs. At temperatures exceeding about $930^{\circ} \mathrm{F}$ $\left(500^{\circ} \mathrm{C}\right)$, carbon-hydrogen and carbon-carbon bonds are broken to form free radicals which undergo dehydrogenation and combine to form stable PAHs.

Pyrolysis involves the breaking down of large paraffinic molecules under high heat in a low-oxygen atmosphere to form less stable molecules and radicals that combine to form PAHs. PAHs readily adsorb and condense onto particulate and other surfaces and may enter the body via inhalation or percutaneous absorption.

Petroleum refineries emit considerable amounts of PAHs. Major sources are catalyt1c cracking catalyst regeneration units and asphalt blowing. Additional sources of refinery PAHs exposure include crude oils and the considerable amount of process furnace and boiler combustion emissions in the refinery.

PAHs are relatively large and heavy molecules, tending to remain in the residual oil and asphalt fractions during fractionation. Residual fractions may be used as a fuel within the refinery, as 
TABLE 31

PETROLEUM REFTNERY PROCESS STREAMS

LIKELY TO CONTAIN SIGNIFICANT

POTENTIALLY HAZARDOUS PAHs ${ }^{a}$

\begin{tabular}{|c|c|}
\hline Process Stream & Process Source \\
\hline $\begin{array}{l}\text { Atmospheric tower } \\
\text { residuum (petroleum) }\end{array}$ & $\begin{array}{l}\text { Fractionation } \\
\text { (atmospheric) }\end{array}$ \\
\hline $\begin{array}{l}\text { Heavy vacuum gas oil } \\
\text { (petroleum) }\end{array}$ & $\begin{array}{l}\text { Fractionation } \\
\quad \text { (vacuum) }\end{array}$ \\
\hline $\begin{array}{l}\text { Heavy thermal cracked } \\
\text { distillate (petroleum) }\end{array}$ & Thermal cracking \\
\hline $\begin{array}{l}\text { Thermal cracked residuum } \\
\text { (petroleum) }\end{array}$ & Thermal cracking \\
\hline $\begin{array}{l}\text { Light paraffinic } \\
\text { distillate solvent } \\
\text { extract (petroleum) }\end{array}$ & Solvent extraction \\
\hline $\begin{array}{l}\text { Heavy paraffinic } \\
\text { distillate solvent } \\
\text { extract (petroleum) }\end{array}$ & Solvent extraction \\
\hline $\begin{array}{l}\text { Light naphthenic } \\
\text { distillate solvent } \\
\text { extract (petroleum) }\end{array}$ & Solvent extraction \\
\hline $\begin{array}{l}\text { Heavy naphthenic } \\
\text { solvent extract } \\
\text { (petroleum) }\end{array}$ & Solvent extraction \\
\hline $\begin{array}{l}\text { Hydrotreated vacuum } \\
\text { gas oil (petroleum) }\end{array}$ & Hydrotreating \\
\hline $\begin{array}{l}\text { Hydrodesulfurized } \\
\text { atmospheric tower } \\
\text { residuum (petroleum) }\end{array}$ & Hydrotreating \\
\hline $\begin{array}{l}\text { Hydrodesulfurized } \\
\text { heavy vacuum gas } \\
\text { oil (petroleum) }\end{array}$ & Hydrotreating \\
\hline $\begin{array}{l}\text { Steam cracked } \\
\text { residuum } \\
\text { (petroleum) }\end{array}$ & $\begin{array}{l}\text { Steam cracking (steam } \\
\text { hydrocracking/ } \\
\text { distillation) }\end{array}$ \\
\hline
\end{tabular}

Four- to six-membered condensed ring aromatics.

Source: U.S. Environmental Protection Agency 1978. 
commercial fuel, as feedstock for catalytic cracking units, as asphalt for road paving, and as feedstock for manufacturing lubricating olls. Lubricating oils, food grade waxes and oils, and other more extensively refined oils generally contain few or negligible PAHs .

Fluidized Catalytic Cracking (FCC). As discussed in the processes section, FCC involves using a catalyst in the form of fine particles, fluidized or suspended in rising hot gases. Heavier crude oll fractions are broken down catalytically when passed through the catalyst bed to produce lighter aromatic fractions, highly prized for use in gasoline and as petrochemical feedstocks. In the process, a layer of coke (polymerized hydrocarbon) forms on the catalygt particles. Catalyst is regenerated by burning this off. Considerable amounts of PAHs, carbon monoxide, and other pollutants are emitted, much of these in the form of particulate emissions. Emissions estimates of hydrocarbons for FCC regenerators are 1isted in Table 32 .

Cracking catalyst regeneration emits an estimated 6 percent of annual U.S. industrial PAHs emissions (National Academy of Sciences 197.2). There were 122 refineries with fluidized-bed catalytic cracking (FCC) units with a total capacity for processing 4.7 million barrels of oll daily in 1978 (Barrett and Goldfarb 1979). F1xed-bed catalytic cracking is considered obsolete, and only three refineries employ this process. The moving-bed process 18 used by only 16 refineries as it is beling phased out in favor of FCC. Additional FCC units are under construction, largely as replacements for older crackers or as add-ons to refineries.

New Source Performance Standards for FCC alr emissions have been promulgated (Barrett and Goldfarb 1979). These rules primarily af fect FCC units constructed or modified after June 1973 and call for emissions controls on particulate matter and carbon monoxide from FCC catalyst regenerators. Control measures, including electrostatic and cyclone precipitators and filters for particulate collection, and CObollers, which combust the $C O$ and other organics in regenerator emissions, are implicitly required. These control measures should significantly reduce PAHs emisstons and increase PAHs-laden solid waste, but data concerning this are not available.

Other Sources of PAHs. A source of some PAHs, asphalt blowing accounts for less than 1 percent of total benzo(a)pyrene Industrial emissions in the U.S. (National Academy of Sciences 1972). However, it is a major source of non-combustion related PAHs emissions. Other refinery sources of PAHs may include flare systems, sludge incinerators, and process heaters. 
TABLE 32

HYDROCARBONS EMITTED FROM FCC UNIT REGENERATORS

\begin{tabular}{|lc|}
\hline \multicolumn{1}{|c}{ Hydrocarbons } & $\begin{array}{c}\text { Concentration } \\
\text { (ppm) }\end{array}$ \\
\hline Aldehydes (as $\mathrm{H}_{2} \mathrm{CO}$ ) & $3-130$ \\
Cyanides (as HCN) & $0.19-0.94$ \\
Anthracene & $2,070^{\mathrm{a}}$ \\
Pyrenes & $40-28,000^{\mathrm{a}}$ \\
Benzo(ghi) perylenes & $15-424^{\mathrm{a}}$ \\
Benzo(a) pyrene & $4-460^{\mathrm{a}}$ \\
Benzo(e) pyrene & $11-3,600^{\mathrm{a}}$ \\
Phenanthrenes & 400,000 \\
\hline
\end{tabular}

Micrograms per barrel of oil charged.

Source: Barrett and Goldfarb 1979. 
Refinery solid and liquid waste streams contain PAHs. Solid wastes for 1983 are projected to contain over 54 metric tons per year, based on 3001 bs ( 0.15 metric tons) per day of PAHs (Rosenberg et a1. 1976). The environmental fate of refinery PAHs in soldd and liquid wastes is largely unknown. Little is known about the environmental transport and effects of PAHs from solid waste, although much can be presumed to be broken down by bacterla or 1mmobilized. Industry-wide data concerning PAHs in refinery wastewater streams are unavallable.

PAHs may pose significant health hazards to refinery workers via Inhalation and skin contact. Atmospheric concentrations of various PAHB within refineries are unknown. PAHs probably condense on our- . faces and pose cutaneous hazards. Simultaneous exposure to probable co-carclnogens, such as phenol and dodecanol, and irritants is 11kely to occur among refinery workers, perhaps exacerbating risks of cancer Induction by PAHs. Photosensitization due to presumed phenanthrene exposure has been observed among asphalt blowing workers (Vandervort and Lucas 1974).

Persons residing in the vicinity of and downwind from refinertes may be exposed to hazards from PAHs. Within the LOs Angeles area, high average concentrations of potentially carcinogenlc PAHs have been measured in the viclnity of several Long Beach petroleum refineries and chemical plants (Gordon and Bryan 1973).

Odors from Refineries. Processing units which may emit odors Include catalytic cracking, asphalt production, lubricating ofl treatment, and sulfur recovery units (Habib. 1975). Typ1cal sources may be vapor leakages, and crude 011 and distillate vapors. The types of odors vary from sulfurous, ammoniacal, amino, phenolic, and aldehydic to those of thiols (mercaptans). Compounds emitted by refinerles, their odor threshold, and odor characteristics are presented in Table 33. Hydrogen sulfide is probably the major malodorous emission from refinery operations. Other major odor emissions include aldehydes from catalyst regenerators and compressor engines, fumes from asphalt blowing, ammonla from catalyst regenerators, thlols from deodorization of gases, and sulfur oxides from incinerators, flares, bollers, and heaters. Gas freeing of storage tanks and ship compartments may provide major sources of odors. Any open stirring, venting, or flaring is ilable to create odor emissions.

In the petroleum Industry, absorption and combustion are the most used odor control methods and include: aldehyde absorption in bisulfite solutions; thiols absorption in sodium hydroxide solutions; hydrogen sulfide absorption in amine solutions, activated carbon, active manganese dloxide, and on sawdust; and hydrogen sulfide absorption followed by incineration or oxidation. Flares may be 
TABLE 33

ODORS OF COMPOUNDS FOUND IN REFINERY EMISSIONS

\begin{tabular}{|c|c|c|}
\hline Chemica1 & $\begin{array}{l}\text { Odor } \\
\text { Threshold }(p p b)^{*}\end{array}$ & Odor Description \\
\hline Acetic acid & 1,000 & Sour \\
\hline $\begin{array}{l}\text { Acetone } \\
\text { Amine, monomethy } 1\end{array}$ & 21 & $\begin{array}{l}\text { Chemical, sweet } \\
\text { Fishy, pungent }\end{array}$ \\
\hline Amine, dimethy 1 & 47 & Fishy \\
\hline Amine, trimethy 1 & 0.2 & Fishy, pungent \\
\hline Ammonia & 46,800 & Pungent \\
\hline Benzene & 4,700 & Soivent \\
\hline Benzyl sulfide & 2 & Sulfidy \\
\hline Carbon disulfide & 210 & Vegetable-like, sulfidy \\
\hline Chlorine & 314 & Bleach, pungent \\
\hline Chlorophenol & 0.03 & Medicinal \\
\hline Dimethyl sulfide & $1-2$ & Vegetable-1ike, sulfidy \\
\hline Diethyl sulfide. & 6 & Garlic-1ike, foul \\
\hline Dipheny 1 sulfide & 5 & Burnt, rubbery \\
\hline Hydrogen sulfide & 5 & Rotten egg \\
\hline Methyl ethyl ketone & 10,000 & Sweet \\
\hline Merraptan, methyl. & $1-?$ & Snlfidy, decayed cahbage \\
\hline Mercaptan, ethyl & $0.4-1$ & Sulfidy, decayed cabbage \\
\hline Mercaptan, n-propy 1 & 0.7 & Sulfidy \\
\hline Mercaptan, n-buty 1 & 0.7 & Strong, sulfidy \\
\hline Paracreso1 & 1 & Tarry, pungent \\
\hline Paraxylene & 470 & Sweet. \\
\hline Phenol & 47 & Medicinal \\
\hline Phosphine & 21 & Oniony, mustard \\
\hline Sulfur Dioxide & 470 & Sharp, pungent \\
\hline Toluene & $2,000-4,700$ & Solvent, moth balls \\
\hline Butane & 6,000 & \\
\hline Heptane & 18,000 & \\
\hline Amylenes and pentenes & $170-2,100$ & \\
\hline
\end{tabular}

*Units in parts per billion by volume.

Source: Habib 1975. 
associated with regeneration of caustic washing solutions to combustthiols and hydrogen sulfide. Oxygen may even be added to flares to assure complete combustion. Masking agents and odor counteractants may be used to cover up odors.

Odor emissions eptsodes outside the refinery tend to be sporadic, but may cause annoyance and adverse health effects in adjacent neighborhoods (Deane and Sanders 1978). Residents near several Los Angeles refineries have reported repeated annoyance with odors and some have complained of frequent or occasional dizziness, nausea, vomiting, eye irritation, burning and irritation of the nose, and other symptoms.

Refinery Contributions to Smog. Reaction mechanlsms, transport, and effects of hydrocarbon-associated oxldizing smog are presented in the End Use section of this report. Approximately 85 percent of global hydrocarbon emissions originate from natural sources, mostly terpenes emitted by forests and vegetation, and methane from the bacterfal decomposition of organic matter. Combustion of organic hydrocarbons, especially wood, coal, and petroleum products, contributes the major anthropogenic source of atmospheric hydrocarbon emissions. Although refinery hydrocarbon emissions account for a small percentage of global emissions, they may make significant contributions to hydrocarbon concentrations on the local and regional level.

Little Information is avallable regarding the refinery's relative contribution to smog production. This is primarily due to: a lack of Information regarding the amounts and relative proportions of constituents of refinery hydrocarbon emissions; a lack of information concerning these hydrocarbons' relative reactivities, effects, and interactions; and a lack of data concerning the environmental distribution, transformations, and fates of refinery emissions. "Most available estimates of hydrocarbon emissions consider aggregate, rather than Individual, hydrocarbon specles emissions. Laboratory studies demonstrate a wide range in individual hydrocarbon photoreactivities. Field atmospheric studies of smog phenomena from refinery emissions are lacking.

Many refinerles are located in the vicinity of large cities that have high pollution levels and experlence recurring eplsodes of photochemical and other atmospheric pollution. Combustion sources, usually from automobile exhaust, power generation, and Industry emissions, are generally cited as the major sources of. reactive hydrocarbon emissions. The relative importance of refinery hydrocarbon emissions in these localities remains largely unassessed. Refinery fugitive emissions, though largely uncharacterized, are different from those emitted by petroleum product combustion sources. The interactions among refinery fugitive emissions and other atmospheric 
hydrocarbons (both natural emissions and from combustion), including the significant emissions from refinery and other combustion sources, are unknown. Refinery atmospheric emissions also contain a number of other substances that may be involved in the atmospheric chemistry of pollution: metals, nitrogen oxides, particulate matter, aldehydes, acids, amines, ammonia, and sulfur oxide compounds.

Because of difficulties involved in the real-time measurement of various concentrations of hydrocarbon emission constituents, most Federal and state regulations and activities emphasize monitoring secondary. oxidants such as ozone and nitrogen oxides.

Emissions from Petrochemical Operations. Petrochemical refineries may use various process streams to produce petrochemical feedstocks and products. Although these activities are not within the scope of this report, it should be noted that in many instances such complexes are adjacent to or an integral part of refinery operations. This additional processing produces wastes and emissions besides those associated with non-petrochemical manufacturing refineries. Table 34 lists some of these processes and the wastes they produce. Distinctions between normal refinery processes and products and petrochemical-based manufacturing and processing are becoming more difficult to make as petrochemical operations become integrated with refining operations.

Air Emissions

As discussed above, petroleum refineries generate a variety of air pollutants that disperse as much as other industrial plant emissions. Information needs with respect to this subject are generic in nature, as they are also related to other facets of the oil and gas industry. These transport and transformation research needs are discussed in the Basic Effects Issues section of this report.

Water Medium

A refinery generates a variety of liquid wastes, mostly wastewaters, as a result of various processes. Major waste streams include sour water or condensates, cooling tower blowdown, boiler blowdown, storm water, ballast water, tank water bottoms, caustic scrubs, and crude desalter water (Engineering Science 1975). Most refineries apply primary and secondary wastewater treatment processes to their wastewater streams. Since it is a typical practice in refineries to collect all or several contaminated wastewater streams and combine them for treatment and disposal, it is difficult to deal with the volumes and contents of individual process-related wastewater effluent streams. Table 35 presents major process wastewater streams with qualitative indications of the contributions they make to various pollution parameters. 
TABLE 34

PETROCHEMICAL PROCESSES AS WASTE SOURCES

\begin{tabular}{|c|c|c|}
\hline Process & Source & Pollutants \\
\hline Alkylation: ethylbenzene & & $\begin{array}{l}\text { Tar, hydrochloric acid, caustic } \\
\text { soda, fuel oil }\end{array}$ \\
\hline Ammonia production & $\begin{array}{l}\text { Demineralization } \\
\text { Regeneration, process } \\
\text { condensates } \\
\text { Furnace effluents }\end{array}$ & $\begin{array}{l}\text { Acids, bases } \\
\text { Ammonia } \\
\text { Carbon dioxide, carbon monoxide }\end{array}$ \\
\hline Aromatics recovery & $\begin{array}{l}\text { Extract water } \\
\text { Solvent purification }\end{array}$ & $\begin{array}{l}\text { Aromatic hydrocarbons } \\
\text { Solvents--sulfur dioxide, } \\
\text { diethylene glycol }\end{array}$ \\
\hline Cyanide production & Water slops & $\begin{array}{l}\text { Hydrogen, cyanide, unreacted } \\
\text { soluble hydrocarbons }\end{array}$ \\
\hline Dehydrogenation & & \\
\hline $\begin{array}{l}\text { Butadiene production } \\
\text { from n-butane and } \\
\text { butylene }\end{array}$ & Quench vaters & $\begin{array}{l}\text { Residue gas, tars, oils, } \\
\text { soluble hydrocarbons }\end{array}$ \\
\hline Ketone production & Distillation slops & $\begin{array}{l}\text { Hydrocarbon polymers, chlori- } \\
\text { nated hydrocarbons, glycerol, } \\
\text { sodium chloride }\end{array}$ \\
\hline $\begin{array}{l}\text { Styrene from } \\
\text { ethylbenzene. }\end{array}$ & $\begin{array}{l}\text { Catalyst: } \\
\text { Condensates from.spray }\end{array}$ & $\begin{array}{l}\text { Spent catalyst }(\mathrm{Fe}, \mathrm{Mg}, \mathrm{K}, \mathrm{Cu}, \mathrm{Cr}, \mathrm{Zn}) \\
\text { Aromatic hydrocarbons, including } \\
\text { styrene, ethylbenzene and } \\
\text { toluene, tars }\end{array}$ \\
\hline Desulfurization & & Hydrogen sulfide, mercaptans \\
\hline
\end{tabular}


TABLE 34 (Continued)

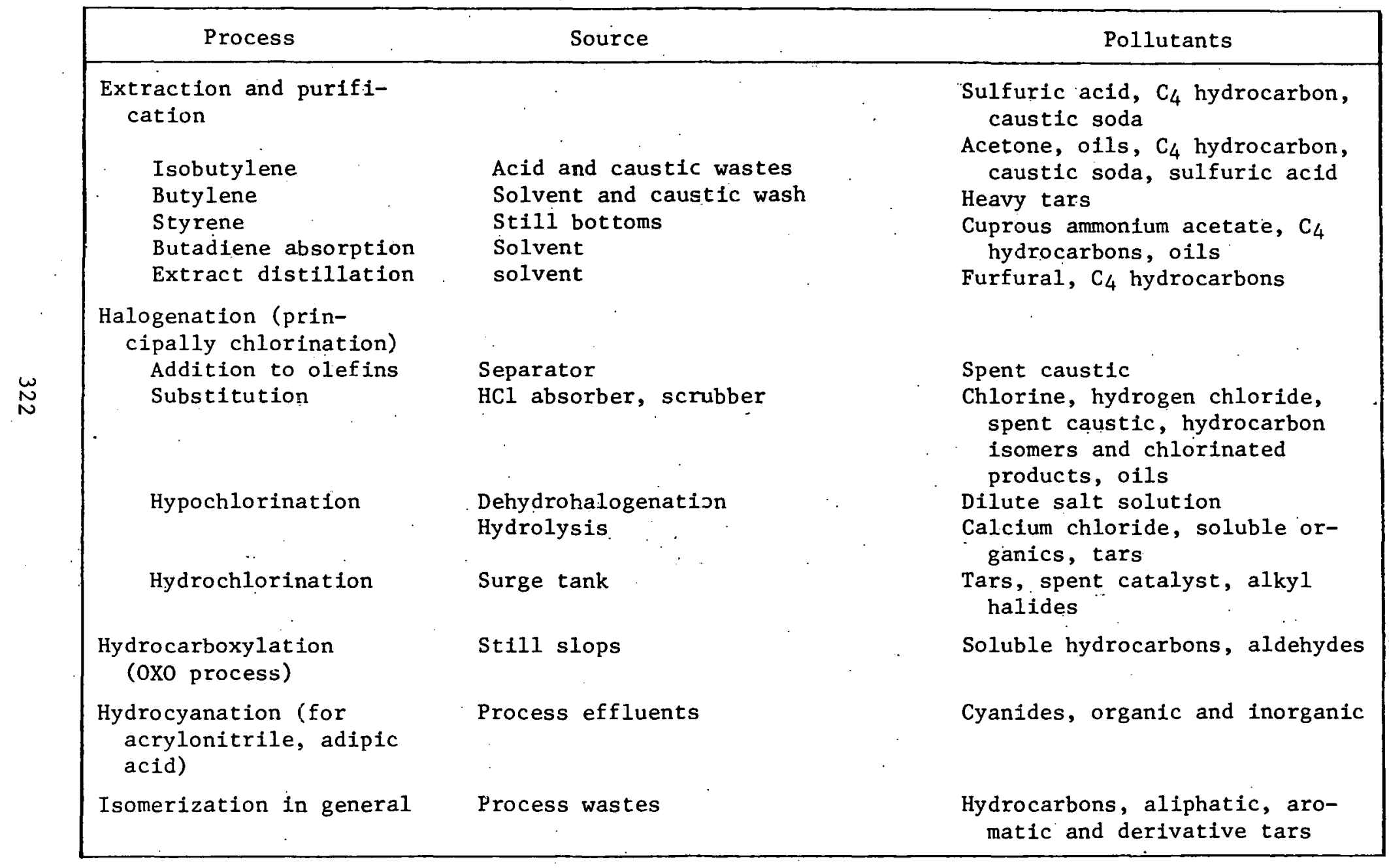


TABLE 34 (Continued)

\begin{tabular}{|c|c|c|c|}
\hline Process & Source & & Pollutants \\
\hline $\begin{array}{l}\text { Nitration } \\
\text { Paraffins } \\
\text { Aromatics }\end{array}$ & . & . & $\begin{array}{l}\text { By-product aldehydes, ketones, } \\
\text { acids, alcohols, olefins, } \\
\text { carbon dioxide } \\
\text { Sulfuric acid, nitric acid, } \\
\text { aromatics }\end{array}$ \\
\hline $\begin{array}{l}\text { Oxidation } \\
\text { Ethylene oxide and } \\
\text { glycol manufacture. }\end{array}$ & Process slops & . & $\begin{array}{l}\text { Calcium chloride, spent lime, } \\
\text { hydrocarbon polymers, ethylene } \\
\text { oxide, glycols, dichloride }\end{array}$ \\
\hline $\begin{array}{l}\text { Aldehydes, alcohols and } \\
\text { acids from hydrocarbons }\end{array}$ & Process slops & & $\begin{array}{l}\text { Acetone, formaldehyde, acetalde- } \\
\text { hyde, methanol, higher } \\
\text { alcohols, organic acids }\end{array}$ \\
\hline $\begin{array}{l}\text { Acids and anhydrides } \\
\text { from aromatic oxidation }\end{array}$ & $\begin{array}{l}\text { Condensates } \\
\text { Still slops }\end{array}$ & & $\begin{array}{l}\text { Anhydrides, aromatics, acids } \\
\text { Pitch }\end{array}$ \\
\hline $\begin{array}{l}\text { Phenol and acetone } \\
\text { from currene oxidation }\end{array}$ & Decanter & & Formic acid, hydrocarbons \\
\hline Carbon black manufacture & Cooling, quenching & & $\begin{array}{l}\text { Carbon black, particulates, dis- } \\
\text { solved solids }\end{array}$ \\
\hline $\begin{array}{l}\text { Polymerizatiori, } \\
\text { alkylation }\end{array}$ & Catalysts & & $\begin{array}{l}\text { Spent acid catalysts (phosphoric } \\
\text { acid), aluminum chloride }\end{array}$ \\
\hline $\begin{array}{l}\text { Polymerization, } \\
\text { Polyethylene }\end{array}$ & Catalysts & . & $\begin{array}{l}\text { Chromium, nickel, cobalt, } \\
\text { molybdenum }\end{array}$ \\
\hline
\end{tabular}


TABLE 34 (Concluded)

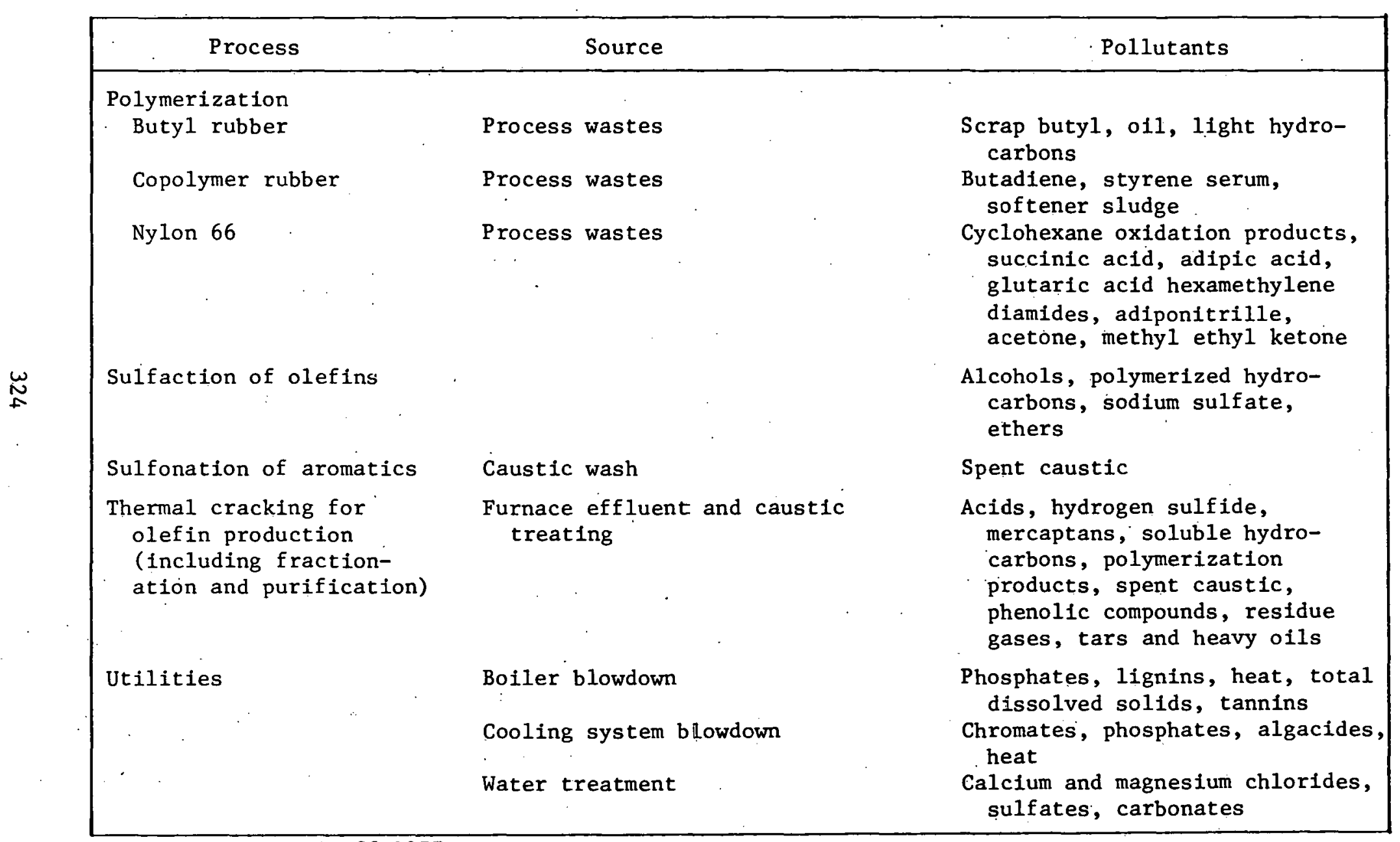

Source: Cherimisinoff 1977. 
TABLE 35

EVALUATION OF WASTEWATER FLOW AND CHARACTERISTICS

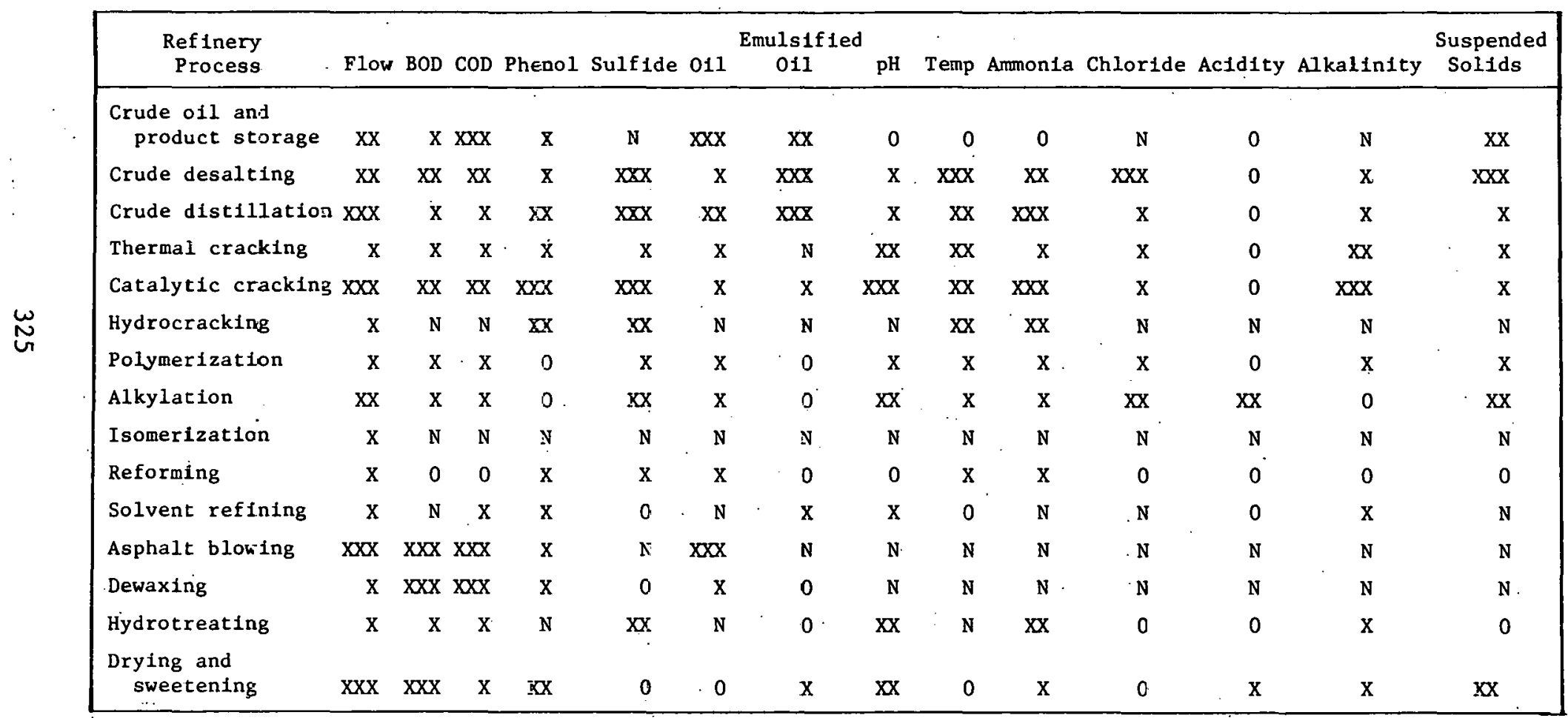

XXX - Major Contribution; XXX - Moderate Contribution; X - Minor Contribution; 0 - No Problem; $N$ - No Data

Source: Lebowitz et al. 1975. 
It is estimated on a worldwide scale that as much oil reaches the seas from refinery and petrochemical plant effluents as from tanker and other accidents--approximately 200,000 to 300,000 tons per year (Baker 1973). For comparison, the estimated worldwide total is 1.9 million tons per year. Coastal refineries by themselves have been estimated to account for about 3.3 percent of all o1l entering the ocean (National Academy of Sciences 1975).

The effects of continuous, low-level discharges of refinery effluents containing trace metals and process related chemicals not found in more common crude oll or products have recelved little study. Non-blodegradable effluents such as trace metals may eventually cause significant ecological damage.

Thermal pollution does not appear to be a major problem for most refineries. Cooling water is reused as much as posstble for energy recovery, and when discharge is required, it 1ikely will be passed through or added to wastewater treatment streams.

A recent review of the literature has resulted in a compilation of 370 organic substances identified in refinery effluents (Thoman and Hushon 1979). Many of these compounds are considered to be carcinogens based on animal and.human tests. Others are highly toxic or pose unknown toxic hazards.

Analyses of refinery effluents have concentrated on compounds for which regulations have been implemented or proposed. These include the 129 substances on EPA's Priority Pollutant List and the parameters EPA has proposed to regulate under the Clean Water Act of 1977--parameters that include:

of Biochemical oxygen demand (BOD);

- Chemical oxygen demand (COD);

- Total organic carbon, in lieu of COD;

- Total suspended solids (TSS);

- 011 and grease;

- Phenolic materials;

o. Sulfides;

- Ammonia-nitrogen; 
- Total chromium;

- Hexavalent chromium;

- Cadmium; and

- Cyanides.

The presence and concentration of 129 priority pollutants and trace elements in refinery effluents have been assessed in parallel studies by EPA and the American Petroleum Institute (American Petroleum Institute 1978). The EPA study sampled intake waters, wastewater. feed to blological (secondary) treatment units, and final effluent streams from 17 refineries. Concurrent1y, the API study sampled 9 of these 17 refineries. Samples were composites taken over a 24-hour or longer pertod.

Test results may be viewed as approximate rather than absolute values, 28 many fleld and laboratory factors are involved in these multiple site and laboratory sampling programs. Summaries of EPA data are presented in Tables 36 through 40. API and EPA analyses show many simflarities and dissimflarities. However, several conclusions may be reached:

o Thirty-elght of the 129 organic Priority Pollutants and 13 trace elements were Identified in refineries' final effluents from combined API and EPA data.

- Organic compounds concentrations ranged up to 2,000 ppb. Thirteen trace elements were found ranging in concentrations up to $1,000 \mathrm{ppb}$.

- In no case were all the identified pollutants detected in any of the samples from any one refinery.

- Blological treatment significantly reduced or removed pollutants.

The rellability and reproduclbility of wastewater effluentrelated analytical programs are considered inadequate by API. Disparitles and anomalies in data have been identified through studies involving interlaboratory comparisons of samples, analyses of spiked samples, and duplicate analyses. EPA sampling and analysis protocols have been criticlzed (American Petroleum Institute 1978).

Assoclated with the direct discharge effluent analysis program described above, EPA sponsored a sampling program at two Los Angeles area municipal water treatment plants and refineries that contribute 
TABLE 36

ORGANIC PRIORITY POLLUTANTS IN REFINERY INTAKE WATERS ${ }^{a}$.

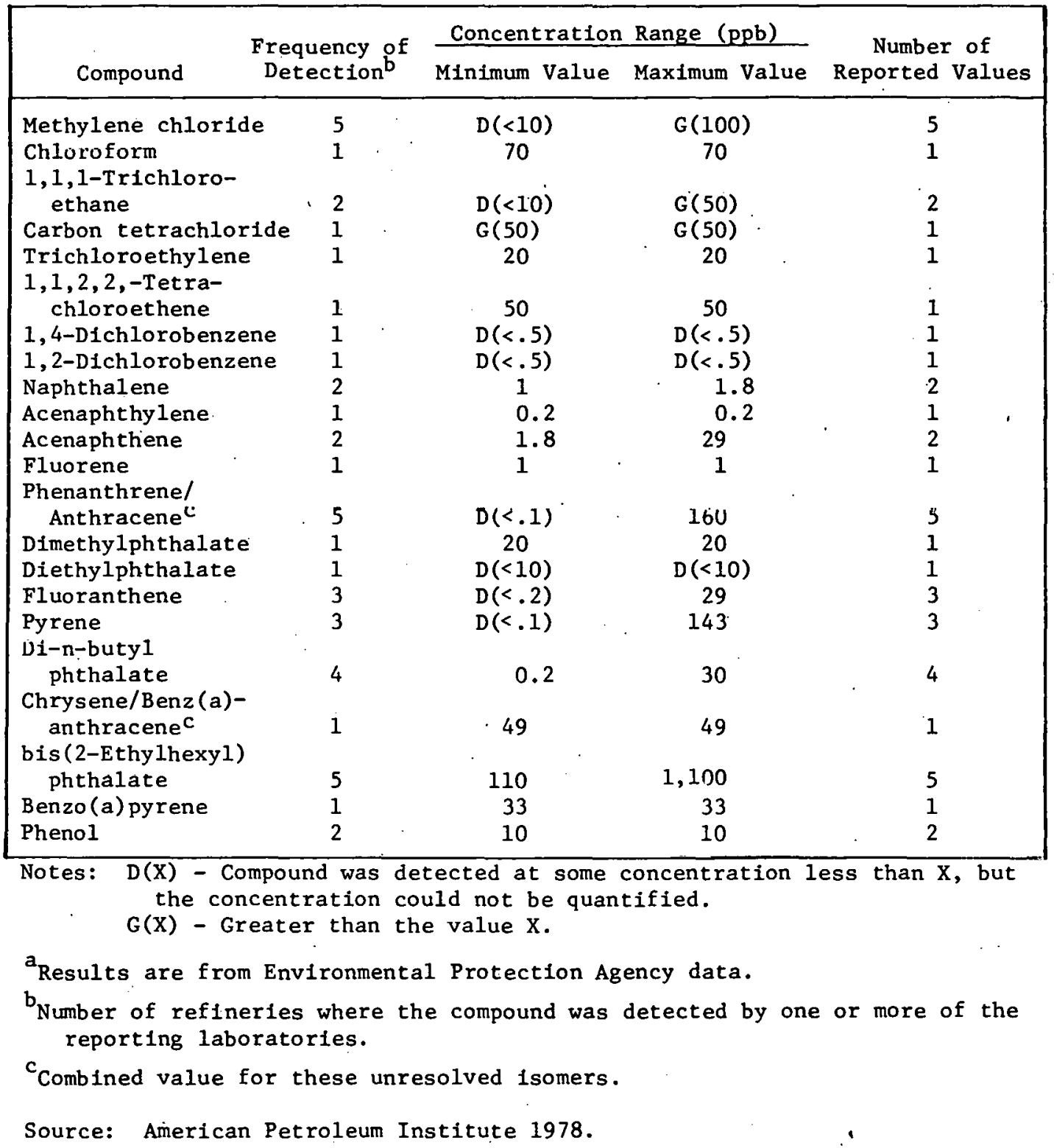


TABLE 37

ORGANIC PRIORITY POLLUTANTS IN REFINERY WASTEWATER FEEDS TO BIOTREATMENT ${ }^{a}$

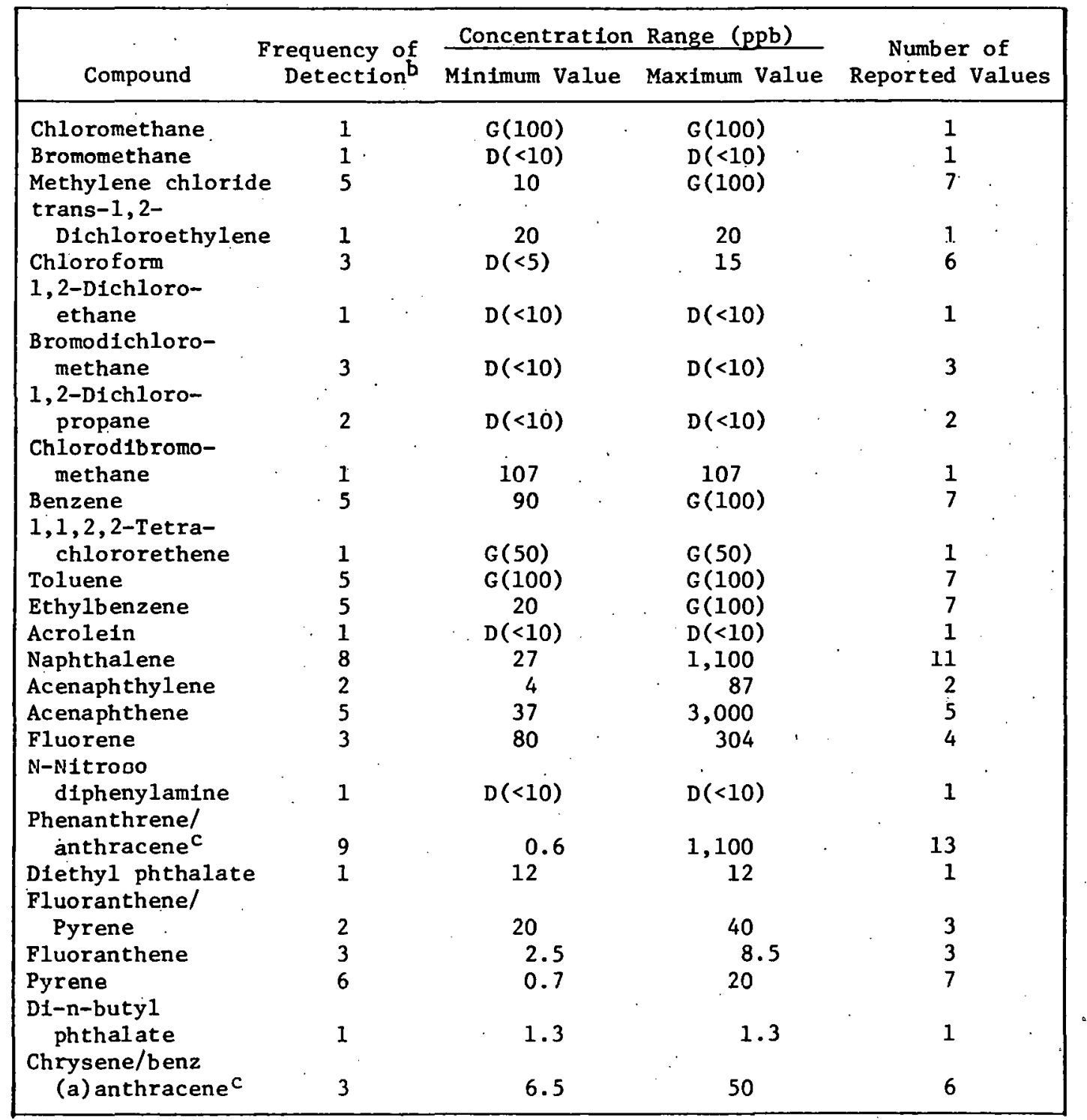


TABLE 37 (Concluded)

\begin{tabular}{|c|c|c|c|c|}
\hline \multirow[b]{2}{*}{ Compound } & \multirow{2}{*}{$\begin{array}{l}\text { Frequency of } \\
\text { Detection }\end{array}$} & \multicolumn{2}{|c|}{ Concentration Range (ppb) } & \multirow{2}{*}{$\begin{array}{l}\text { Number of } \\
\text { Reported Values }\end{array}$} \\
\hline & & Minimum Value & Maximum Value & \\
\hline Chrysene & 4 & 0.1 & 20 & 6 \\
\hline Bis (2-ethylhexyl) & & & & \\
\hline phthalate & 5 & 50 & 1,100 & 11 \\
\hline Benzo (a) pyrene & 1 & 9.5 & 9.5 & 1 \\
\hline Phenol & 9 . & 13 & 16,000 & 15 \\
\hline 2,4-Dimethylphenol & 4 & 71 & 750 & 7 \\
\hline p-Chloro-m-cresol & 1 & 10 & 10 & 1 \\
\hline Pentachlorophenol & 1. & 850 & 850 & 1 \\
\hline
\end{tabular}

Notes: $\mathrm{D}(\mathrm{X})$ - Compound was detected at some concentration less than $\mathrm{X}$,' but the concentration could not be quantified.

$G(X)$ - Greater than the value $X$.

Results are from Environmental Protection Agency data.

${ }^{b}$ Number of refineries where the compound was detected by one or more of the reporting laboratorfes.

${ }^{c}$ Combined value for these unresolved isomers.

Source: American Petroleum Institute 1978. 
TABLE 38

ORGANIC PRIORITY POLLUTANTS IN

REFINERY FINAL EFFLUENTS ${ }^{a}$

\begin{tabular}{|c|c|c|c|c|}
\hline \multirow{2}{*}{ Compound } & \multirow{2}{*}{$\begin{array}{l}\text { Frequency of } \\
\text { Detectton }\end{array}$} & \multicolumn{2}{|c|}{ Concentration Range (ppb) } & \multirow{2}{*}{$\begin{array}{c}\text { Number of } \\
\text { Reported Values }\end{array}$} \\
\hline & & Minịum Value & Maximum Value & \\
\hline Methylene chloride & 4 & $D(<10)$ & 60 & 4 \\
\hline Chloroform & 1 & $D(<5)$ & $D(<5)$ & 1 \\
\hline Benzene & 1. & 6 & 6 & 1 \\
\hline $1,1,2,2$-Tetra- & & & & \\
\hline $\begin{array}{l}\text { chloroethene } \\
\text { Toluene }\end{array}$ & 1 & $\mathrm{D}(<10)$ & $\begin{array}{c}\mathrm{D}(<10) \\
35\end{array}$ & 1 \\
\hline Naphthalene & 1 & $\begin{array}{c}35 \\
0.1 .\end{array}$ & $\begin{array}{l}35 \\
0.1\end{array}$ & 1 \\
\hline Acenaphthene & 1 & 6 & 6 & 1 \\
\hline Phenanthrene/ & $\because$ & 08 & $5(<10)$ & 2 \\
\hline Dimethylphthalate & 1 & 3 & 3 & 1 \\
\hline Diethylphthalate & 2 & $\dot{D}(<I 0)$ & 30 & 2 \\
\hline Fluoranthene & 1 & $\mathrm{D}(<.1)$ & $D(<.1)$ & 1 \\
\hline Pyrene & 3 & $D(<.1)$ & 7 & 3 \\
\hline $\begin{array}{l}\text { Chrysene/benz } \\
\text { anthracene }\end{array}$ & 1 & 0.8 & 0.8 & 1 \\
\hline Chrysene & 3 & $\mathrm{D}(<.1)$ & 1.4 & 3 \\
\hline Bis (2-ethylhexyl) & & & & \\
\hline phthalate & 5 & 190. & 2,000 & 5 \\
\hline Benzo (a) pyrene & 2 & 1.3 & 2.9 & 2 \\
\hline
\end{tabular}

Notes: $\mathrm{D}(\mathrm{X})$ - Compound was detected at some concentration less than $\mathrm{X}$, but the concentration could not be quantified. $G(X)$ - Greater than the value $X$.

aresults are from Environmental Protection Agency data.

- ${ }^{\mathrm{N} \text { umber }}$ of refineries where the compound was detected by one or more of the reporting laboratories.

${ }^{c}$ Combined value for these unresolved isomers.

Source: American Petroleum Institute 1978. 
TABLE 39

FREQUENCY AND CONCENTRATION RANGE OF TRACE ELEMENTS IN REFINERY INTAKE WATERS ${ }^{a}$

\begin{tabular}{|c|c|c|c|c|}
\hline \multirow[b]{2}{*}{ Element } & \multirow{2}{*}{$\begin{array}{l}\text { Frequency } \\
\text { of } \\
\text { Detection }\end{array}$} & \multicolumn{2}{|c|}{ Concentration Range ( $\mathrm{ppb}$ ) } & \multirow{2}{*}{$\begin{array}{c}\text { Number of } \\
\text { Reported } \\
\text { Values }\end{array}$} \\
\hline & & Minimum Value & Maximum Value & \\
\hline Zine & 15 & 15.0 & 120 & 15 \\
\hline Chromium & 13 & 1.0 & 60 & 13 \\
\hline Copper & 10 & 1.0 & 210 & 10 \\
\hline Lead & 8 & 1.0 & 40 & 8 \\
\hline Antimony & 1 & .1 .0 & 1 & 1 \\
\hline Thallium. & 1 & 3.0 & 3 & 1 \\
\hline Nickel & 5 & 1.0 & 58 & 5 \\
\hline Arsenic & 5 & 3.0 & 27 & 5 \\
\hline Selenium & h & 2.0 & 13 & 1.1 \\
\hline Cadmium & 1 & 2.0 & 2 & 1 \\
\hline Mercury & 5 & 0.1 & 6 & 13 \\
\hline
\end{tabular}

a Results àre from Environmental Protection Agency data.

${ }^{b}$ Number of refineries where the element was detected by one or more of the reporting laboratories.

Source: American Petroleum Institute 1978. 
TABLE 40

FREQUENCY AND CONCENTRATION RANGE OF TRACE ELEMENTS IN REFINERY FINAL EFFLUENTS ${ }^{a}$

\begin{tabular}{|c|c|c|c|c|}
\hline \multirow[b]{2}{*}{ Element } & \multirow{2}{*}{$\begin{array}{l}\text { Frequency } \\
\text { of } \\
\text { Detection }^{b}\end{array}$} & \multicolumn{2}{|c|}{ Concentration Kange (ppb) } & \multirow{2}{*}{$\begin{array}{l}\text { Number of } \\
\text { Reported } \\
\text { Values }\end{array}$} \\
\hline & & Minimum Value & Maximum Value & \\
\hline Zinc & 16 & 25.0 & 700 & 22 \\
\hline Chromium & 15 & 1.0 & 1,000 & 18 \\
\hline Copper & 10 & 3.0 & 180 & 10 \\
\hline Lead & 5 & 2.0 & 58 & 8 \\
\hline Antimony & 3 & 1.0 & 370 & 3 \\
\hline Thallium & 2 & 3.0 & 12 & 5 \\
\hline Nickel & 5 & 3.0 & 58 & 8 \\
\hline Arsenir. & 4 & 5.0 & 900 & 7 \\
\hline Selenium & $?$ & 3.0 & 32 & 21 \\
\hline Silver & 1 & 15.0 & 15 & 1 \\
\hline Cadmium & 2 & 1.0 & 5 & 2 \\
\hline Mercury & 5 & 0.5 & 6 & 10 \\
\hline
\end{tabular}

Results are from Environmental Protection Agency data.

$b_{\text {Number of }}$ refineries where the element was detected by one or more of the reporting laboratorica.

Source: American Petroleum Institute 1978. 
their wastewaters to these plants. The results show that secondary biological treatment by publicly owned treatment works (POTWs), involving the treatment of refinery wastes by municipal wastewater treatment facilities, reduced concentrations of pollutants to levels simflar to those achleved by on-site refinery secondary treatment.

In 1977, EPA conducted the 1977 EPA Petroleum Refining Industry Survey. Three mallings were made to obtain and verlfy data from each refinery in the U.S. Included in the survey were questions regarding wastewater flows, priority pollutant chemicals purchased and manufactured, and analyses of wastewaters. Seventy-one toxic (priority) pollutants were 11 sted as being purchased as raw or intermediate materials, as indicated in Table 6. At least 10 percent of U.S. refineries purchased the following compounds: benzene, carbon tetrachloride, 1,1,1-trichloroethane, phenol, toluene, and zinc, chromium, copper, and lead compounds. Zinc and chromtum compounds were purchased by 28 percent, and lead compounds (probably gasoline additives) were purchased by nearly 48 percent of the refineries. Forty-five toxic pollutants were manufactured as intermediate or final products, while at least 10 percent of the refineries manufactured benzene, ethylbenzene, phenol, and toluene. The purchase, manufacture, and use of these chemicals may be more relevant to workers' health than to wastewater effluent hazards.

Based on the Information gathering activitles summarized above and other information, EPA has proposed 1imltations on refinery effluent discharges into U.S. waters and into publicly owned treatment works (U.S. Environmental Protection Agency 1980b). Levels of treatment technologies and timetables for proposed refinery effluent treatment requirements are shown in Table 41. EPA has proposed controlling effluent levels of chromfum (both total and hexavalent), phenolic compounds, oil and grease, total suspended solids, blochemical oxygen demand (BOD), ammonla (nitrogen), sulfides, and effluent $\mathrm{pH}$ from several classes of refineries. The current and future implementation and effects of effluent limitations are difficult to assess. Ultimately, the goal is to eliminate wastewater discharges (Level VI of abatement technology in 1985; Table 41). This would be accomplished by treating wastewaters for reuse, which would have a strong Impact on the amount and types of solid wastes that refineries generate.

\section{Summary of Research Needs}

Basic research needs related to refinery alr and water effluent emissions, but also relevant to other facets of the oll and gas industry, are discussed in the Basic Effects Issues section of this report. The following are selected research issues relating primarily to refineries. 
TABLE 41

SUMMARY OF ABATEMEIVT LEVEL TECHNOLOGY

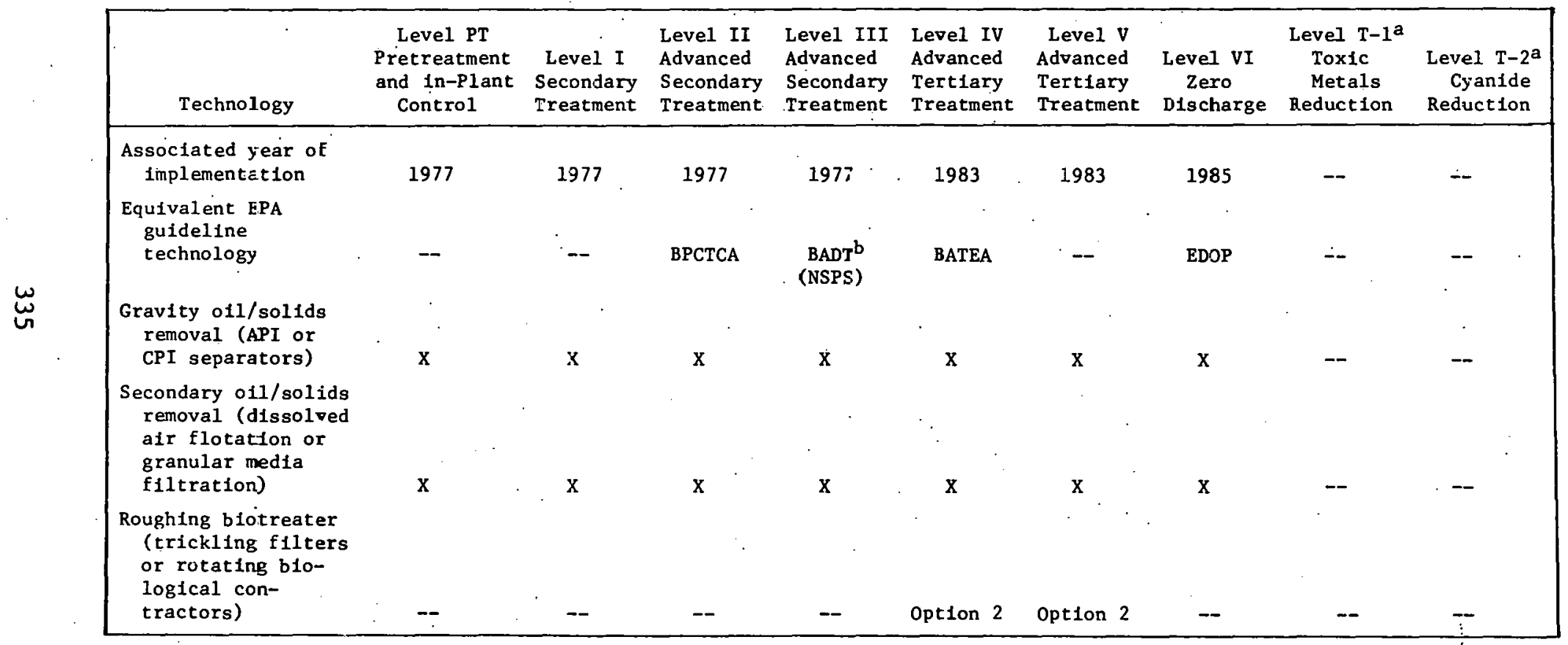


TABLE 4:- (Continued)

\begin{tabular}{|c|c|c|c|c|c|c|c|c|c|}
\hline Technology & $\begin{array}{l}\text { Leve1 PT } \\
\text { Pretreatment } \\
\text { and in-Plant } \\
\text { Control }\end{array}$ & $\begin{array}{l}\text { Leve1 I } \\
\text { Secondary } \\
\text { Treatment }\end{array}$ & $\begin{array}{l}\text { Level II } \\
\text { Advanced } \\
\text { Secondary } \\
\text { Treatment }\end{array}$ & $\begin{array}{l}\text { Leve1 III } \\
\text { Advanced } \\
\text { Secondary } \\
\text { Treatment }\end{array}$ & $\begin{array}{l}\text { Level IV } \\
\text { Advanced } \\
\text { Tertiary } \\
\text { Treatment }\end{array}$ & $\begin{array}{l}\text { Leve1 v } \\
\text { Advanced } \\
\text { Tert1ary } \\
\text { Treatment }\end{array}$ & $\begin{array}{l}\text { Level VI } \\
\text { Zero } \\
\text { Discharge }\end{array}$ & $\begin{array}{l}\text { Leve1 } T-1^{a} \\
\text { Toxic } \\
\text { Metals } \\
\text { Reduction }\end{array}$ & $\begin{array}{c}\text { Level } \mathrm{T}^{\mathrm{a}} \mathrm{a}^{\mathrm{a}} \\
\text { Cyanide } \\
\text { Reduction }\end{array}$ \\
\hline $\begin{array}{l}\text { High efficiency } \\
\text { biotreater } \\
\text { (aerated lagoons } \\
\text { or activated } \\
\text { sludge w1th } \\
\text { clariffers) }\end{array}$ & -- & $\mathrm{x}$ & $x$ & $\mathrm{x}$ & Option 1 & Option 1 & $\mathrm{x}$ & -- & - \\
\hline $\begin{array}{l}\text { Tertiary oil/solids } \\
\text { removal (mixed- } \\
\text { media fil- } \\
\text { tration) }\end{array}$ & -- & -- & $\mathrm{x}$ & $\mathrm{x}$ & $\mathrm{x}$ & $\mathrm{x}$ & $\mathrm{x}$ & - & -- \\
\hline $\begin{array}{l}\text { Treated wastewater } \\
\text { reuse (reuse of } \\
\text { treated process } \\
\text { wastewater to } \\
\text { reduce total } \\
\text { effluent dis- } \\
\text { charge). }\end{array}$ & -- & -- & -- & $\mathrm{x}$ & $\mathrm{x}$ & $\mathrm{x}$ & $\mathrm{x}$ & - & - \\
\hline $\begin{array}{l}\text { Áctivated carbon } \\
\text { adsorption }\end{array}$ & -- & -- & $\therefore$ & -- & $\mathrm{x}$ & $\mathrm{x}$ & $\mathrm{x}$ & -- & - \\
\hline
\end{tabular}


TABLE 41 (Concluded)

\begin{tabular}{|c|c|c|c|c|c|c|c|c|c|}
\hline Technolagy & $\begin{array}{l}\text { Level PT } \\
\text { Pretreatment } \\
\text { and In-Plant } \\
\text { Control }\end{array}$ & $\begin{array}{l}\text { Level I } \\
\text { Secondary } \\
\text { Treatment }\end{array}$ & $\begin{array}{l}\text { Level II } \\
\text { Advanced } \\
\text { Secondary } \\
\text { Treatment }\end{array}$ & $\begin{array}{l}\text { Level III } \\
\text { Advanced } \\
\text { Secondary } \\
\text { Treatment }\end{array}$ & $\begin{array}{l}\text { Level IV } \\
\text { Advanced } \\
\text { Tert1ary } \\
\text { Treatment }\end{array}$ & $\begin{array}{l}\text { Level v } \\
\text { Advanced } \\
\text { Tertiary } \\
\text { Treatment }\end{array}$ & $\begin{array}{l}\text { Leve1 VI } \\
\text { Zero } \\
\text { Discharge }\end{array}$ & $\begin{array}{l}\text { Level T-1 } \\
\text { Toxic } \\
\text { Meta1s } \\
\text { Reduction }\end{array}$ & $\begin{array}{l}\text { Level } \mathrm{T}-2^{\mathrm{a}} \\
\text { Cyan1de } \\
\text { Reduct Ion }\end{array}$ \\
\hline $\begin{array}{l}\text { Dissolved salts } \\
\text { removal (reverse } \\
\text { osmos1s, 10n ex- } \\
\text { change, freeze } \\
\text { crystallization, } \\
\text { evaporation) }\end{array}$ & -- & -- & -- & -- & -- & $x^{c}$ & $\mathbf{x}$ & - & -- \\
\hline $\begin{array}{l}\text { Chemical pre- } \\
\text { cipitation and } \\
\text { sedimentation }\end{array}$ & -- & -- & -- & -- & -- & - & -- & $x$ & -- \\
\hline $\begin{array}{l}\text { Alkaline chlorin- } \\
\text { ation or } \\
\text { electrolysis }\end{array}$ & - & - & -- & - & - & - & -- & - & $\mathbf{x}$ \\
\hline
\end{tabular}

Notes: $X$ ReTreserts an applicable regulation.

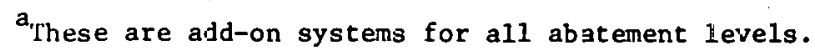

$b_{B A D T}$ (NSPS) is equivalent to Level aI end-of-pipe treatment with Level III in-plant control.

${ }^{\mathrm{c}}$ Fifty percent of wastewater flow.

Source: Sit:1g 1978. 
Acid Rain. Considerable research is directed toward defining and resolving issues associated with acid rain. This problem has primarily been attributed to the product of a series of complex chemical reactions in which sulfur and nitrogen oxides, resulting from the combustion of coal and oil, combine in the atmosphere to form acids, which can return to earth as components of rain or snow.

Currently, collected data are beginning to show that agents other than sulfur and nitrogen (e.g., halogens and metals), present in the precipitation may contribute to biological effects on terrestrial and aquatic biota. Certain gases released from refinerles may play a role in the formation or effects of acid rain, at least on a local scale.

Hydrogen chloride, released as a gas from refineries, forms hydrochloric acid in an aqueous solution. Hydrogen fluoride, also released as a gas, forms hydrofluoric acid in an aqueous solution. Releases of formaldehyde, metals, ammonla, and sulfates from refineries can contribute to the formation of precipitation that can be detrimental to blota. This problem should be explored with respect to 1 ts pervasive characteristics, especially. on a local scale.

Toxic Hydrocarbon Emlssions. A comprehensive and detailed source characterization study is needed to determine, both qualitatively and quantitatively, the nature and extent of constituents of airborne refinery emissions that are potential carcinogens, mutagens, teratogens, or reproductive hazards. This study should focus on unit processes and include fugitive emissions from leaks; spills, and liquid and solid waste disposal. The study also should include emissions in the form of gases, vapors, particles, and condensates on refinery equipment.

Toxic Hydrocarbon Effluents. A comprehensive and detalled source characterization study (similar to the one described above) is needed with respect to liquid refinery effluents. Low-level hydrocarbon discharges of potential carcinogens should be quantifled. This study should be a follow-up to a recent study which identified 370 organic substances in refinery effluents (Thoman and Hushon 19792 .

Precision and Reproductbility of Analyses. Analyses should be standardized and made rellable, especially.with regard to the detection and measurement of organic compounds, notably potential carcinogens existent in low concentrations in refinery waters. The disparities and anomalies, as cited by the American Petroleum Institute, with respect to interlaboratory comparisons of samples, analyses of spiked samples, and duplicate analyses, should be 
resolved through the development and implementation of quality assurance procedures. New data should be collected utlifing these procedures.

Characterization of Refinery Wastes and Emissions. Refinery emissions and wastes are complex mixtures. These require more Industry-wide analysis and characterization. Toxic effects from these mixtures require study. 
THIS PAGE

\section{WAS INTENTIONALLY \\ LEFT BLANK}




\section{Part 5}

\section{Liquefied Energy Gases}


A great deal of controversy has surrovoded the liquefied energy gas industry, particularly the liquefied natural gas (LNG) industry, for several decades. Many relevant studies have been conducted. although a total, integrated study of the entire industry has not been performed. A well structured and rigorous risk assessment is needed which would deal comprehensively with current and projected LNG imports, domestic production, LNG transportation and handiing operations and movement patterns, and the probability of sabotage.

Cooling water discharges from liquefaction facilities are an envirormental problem. Research should be directed toward the following areas: finding beneficial uses for the waste heat, determining the capacity of aquatic biota to assimilate biocides and other cooling water additives, and evaluating the use of air as a heat sink. 
THIS PAGE

\section{WAS INTENTIONALLY \\ LEFT BLANK}

342 


\section{LIQUEFIED ENERGY GASES}

TABLE OF CONTENTS

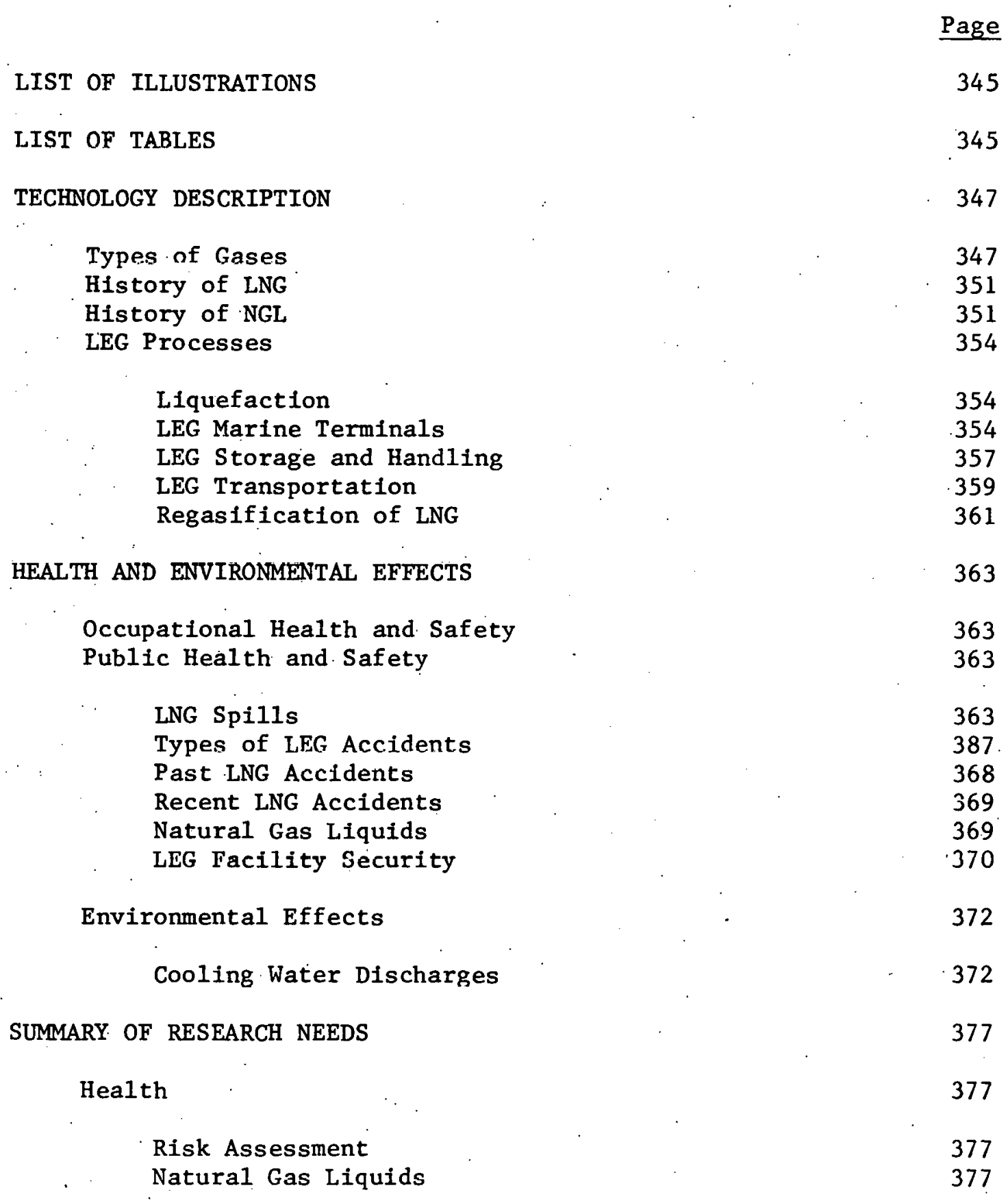


TABLE OF CONTENTS (Concluded)

Page

Environment

378

Cooling Water Discharges

378

Baseline Aquatic Studies

378

Use of Air as a Heat Sink

379 


\section{LIST OF ILLUSTRATIONS}

\section{F1gure Number}

Page

1 Typlcal Flow Plan for L1quefled Energy Gases

2 Schemat1c Flow Chart of Crude 011, Natural Gas, and Natural Gas Liquids

3 Cascade Cycle for the Liquefaction of Natural Gas

4 Expander Cycle for the Liquefaction of Natural Gas

\section{LIST OF TABLES}

\section{Table Number}




\section{THIS PAGE \\ WAS INTENTIONALLY \\ LEFT BLANK}




\section{LIQUEFIED ENERGY GASES}

\section{TECHNOLOGY DESCRIPTION}

This section primarily addresses the processing and handling of liquefied natural gas (LNG) and liquefled petroleum gas (LPG). These substances are commonly stored and handled with the use of cryogenic temperatures. Propane (a major LPG) can also be stored as a liquid under pressure without refrigeration or with only moderate refrigeration, but this is not the case with LNG. Naphtha, another liquefied gas, can be stored as a liquid at near atmospheric temperature and pressure.

Another group of hydrocarbons, the natural gas 11quids, (NGL), are also discussed in this section. These include liquid propane and other compounds and mixtures. These hydrocarbons are usually transported and stored as liquids. (Except for LNG, all other hydrocarbons discussed in this section can exist in the liquid state through the application of pressure or moderate refrigeration.)

\section{Types of Gases}

Liquefied energy gases (LEG) are hydrocarbon gases converted to a liquid state by pressure and cooling. The liquefled state may reduce their gaseous volume by hundreds of times and allows for efficlency in storage and handling (Figure 1). One cubic meter of LNG w111 form about 12,000 cublc meters of a flammable natural gas-air mixture and 1 cublc meter of LPG will form a slightly larger volume of a flammable gas-alr mixture. Naphtha, a less hazardous group of heavler hydrocarbons, is transported and stored as a liquid at near atmospheric temperature and pressure. Currently, liquefied energy gases (1mported LNG, LPG, and naphtha derived from crude oil) comprise about 3 percent of the energy used in the U.S. and are used to supplement domestic supplies of natural gas. About 2 percent of the nation's energy is supplied by LPG, primarily propane (General Accounting office 1978).

When cooled to $-260^{\circ} \mathrm{F}$, natural gas becomes a liquid about $1 / 600$ th of its volume at normal atmospheric temperature and pressure. Thus, a storage tank of LNG contains 600 times more energy than an identical tank containing natural gas. LPG 11 quefies at $-44^{\circ} \mathrm{F}$ as propane and $-310^{\circ} \mathrm{F}$ as butane. LYG also liquefies under pressure at atmospheric temperature (see the History of Natural Gas Liquids, below in this section of the report). 


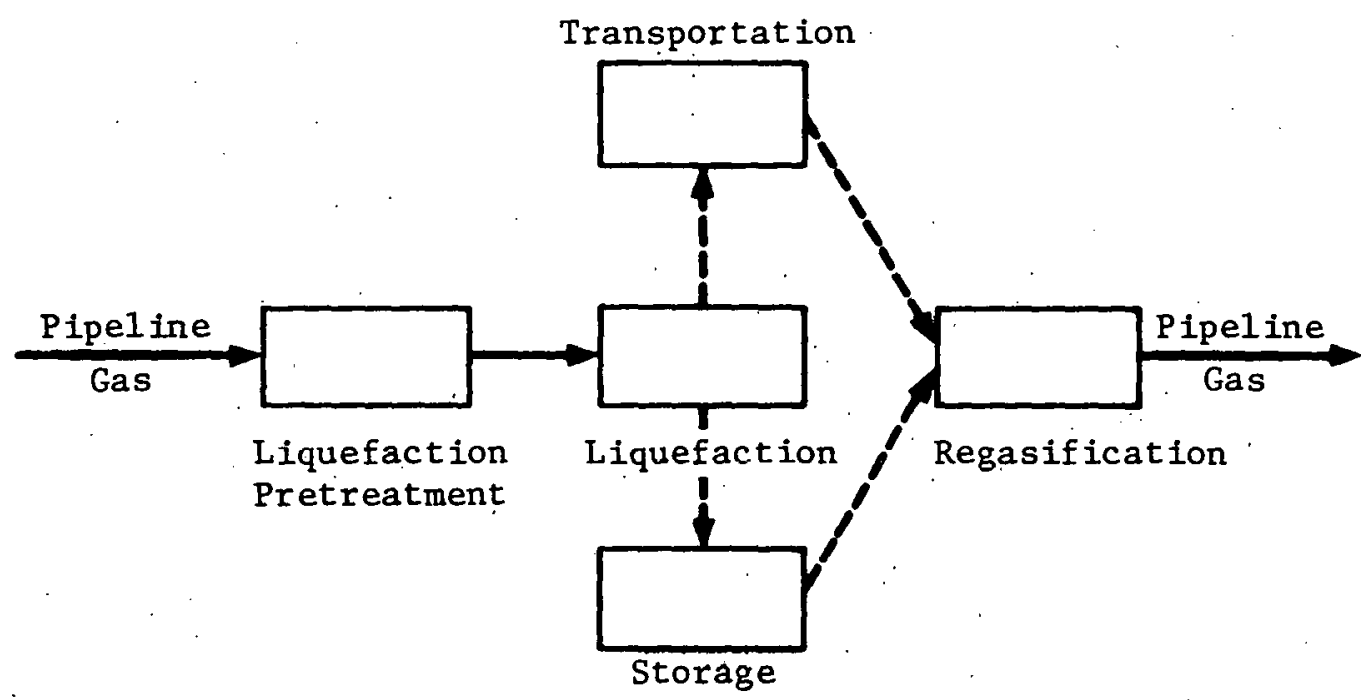

FIGURE 1

TYPICAL FLOW PLAN FOR LIQUEFIED ENERGY GASES 
Although accounting for the majority of LEG usage, LPG has received much less public attention than the relatively new LNG industry. LPG and naphtha have been used for many years as feedstocks for petrochemicals. In 1976, $13 \mathrm{million}$ customers, mostly in rural areas, used LPG as an energy source. Naphtha has been a major source of jet fuel and it is used in the production of synthetic natural gas (SNG). The SNG is pipeline quality gas, of almost pure methane, and is synthesized from naptha by the sequential processes of sulfur removal, catalytic gasification, methanation, and carbon dioxide and water removal.

Although LNG has been used as a form for the storage of domestic natural gas since the early 1940s, recently it has been imported in ships. These imports, which supplied less than $1 / 10$ th of 1 percent of U.S. natural gas demand in 1978, could supply up to 15 percent by 1985 (Office of Technology Assessment 1977), posing additional problems with respect to national dependence upon foreign sources of fossil fuel.

NGL are heavier hydrocarbon mixtures recovered in conjunction with oil and gas production and at natural gas processing plants (Figure 2). These liquids are gaseous in underground reservoirs, but they are also recoverable in liquid form by condensation, absorption, and adsorption within surface equipment and at natural gas processing plants. In addition, they accumulate as liquid products of petroleum refining. Natural gas liquids are considered a supplemental rather than an alternative hydrocarbon resource (U.S. Department of the Interior 1970).

The mixtures of gaseous compounds within the paraffin hydrocarbon series, from which liquid products are recovered, are divided into four broad categories: LPG, liquefied refinery gas (LRG), natural gasoline, and condensate. * As a natural gas 1iquid, LPG is mostly propane or butane or mixtures of both compounds which are maintained in a liquid state under pressure. LRG is liquefied propane or butane produced by a crude oil refinery. It differs from LPG in that propylene and butylene may be present due to various chemical reactions within the refinery. Natural gasoline refers to liquid hydrocarbon mixtures containing quantities of pentanes and heavier hydrocarbons which have been extracted in a natural gas

* Condensate is the liquid formed by the condensation of a vapor or gas; especially the hydrocarbon liquid separated from natural gas, which because of changes in temperature and pressure, condenses when the gas from the field reservoir is delivered to the surface separators and which remains liquid at atmospheric temperature and pressure. 


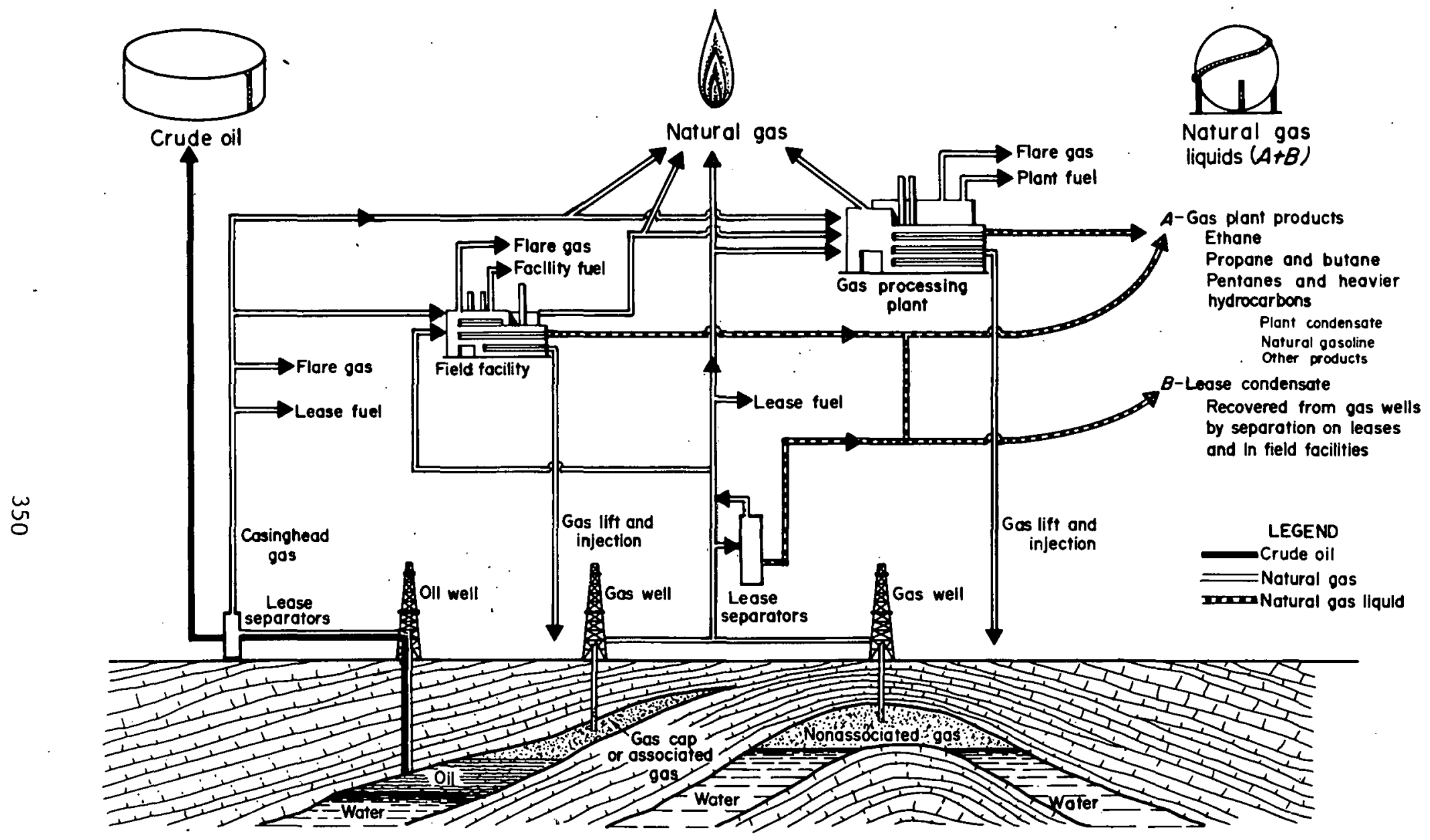

Source: U.S. Department of the Interior 1970.

FIGURE 2

SCHEMATIC FLOW CHART OF CRUDE OIL, NATURAL GAS, AND NATURAL GAS LIQUIDS 
processing plant from gases and liquids that remain after previous separation of liquid containing condensate or crude oll.

\section{H1story of LNG}

Since 1960 the LNG industry has undergone rapid growth, primar1ly because of an Increase in 1 ts use in peak-shaving, 1.e., supplying fuel gas for distribution from an auxiliary storage source during periods of maximum demand when the primary source is not adequate. Peak-shaving has played an Important role in meeting peak demands for natural gas in New England and the South Atlantic states. There are now about $64 \mathrm{U} . \mathrm{S}$. peak-shaving plants in operation and 2 more are expected to begin operation by the end of 1982 (Scorecard 1980).

Recently, LNG has also been 1mported to meet baseload needs. Currently baseload LNG is imported from Algerla and is recelved and gasified at three East Coast marine terminals: Everett, Massachusetts; Cove Polnt, Maryland; and Elba Island, Georgia. One new LNG terminal is under construction in Lake Charles, Loulsiana, and three are planned for Little Cojo, California; Ingleside, Texas; and Port o'Connor, Texas (Hale 1980; Scorecard 1980).

Currently, one domestic baseload LNG liquefaction facllity with ancillary marine terminal facilities is in operation. Located at Kenal, Alaska, it began operations in 1969 with the first commercial shipment of LNG ever exported from North America and also with the first LNG ever imported into Japan. Another baseload LNG 11quefaction facility is expected to begin operation in Cook Inlet, Alaska, In 1982 (Scorecard 1980).

Many scenarios exist for the projected dependence of the U.S. on LNG 1mports. These vary from a modest increase of 1.5 times the present level that would take place with an extension of the past 20-year trend, to almost a fivefold increase by the year 2000. The future of LNG imports will be Influenced markedly by the size of recoverable gas reserves within the exporting countries, the political pressures exerted by exporting countries in the form of production curtallments and price increases, and national concern over the U.S. balance of payments. Methane and similar gases produced from domestic fossil based synthetic fuels and blomass may shift in the LEG Industry from Imports to domestic baseload and peak-shaving scorage facilities.

History of NGL*

In 1903, years before the first commercial extraction of natural gasoline, hydrocarbon liquid accumulations were accidentally observed

" Taken largely from U.S. Department of the Interior 1970. 
in field gathering lines of natural gas pipelines. In such instances, the natural gas in the line had been collected from casingheads (space between the tubing and casing in oll wells), and the recovered liquids were called casinghead gasoline. Later, as other gas sources were developed, the term casinghead gasoline became a misnomer and the term natural gasoline evolved.

Between 1908 and 1910, billions of cubic feet of gas became avallable for extraction. When gas processors began to compress natural gas to higher pressures, they discovered that higher NGL ylelds were obtained than at lower pressures. This was the first compression method developed for collecting NGL.

Throughout the first half of the 20th century, gas processors blended natural gasoline with purchased naphthas to ralse gasoline quality, making the product competitive with refinery gasoline. Soon the refiners began using a greater portion of their naphthas in gasoline refining, making blending stocks scarce to gas processors. At the same time, oll refineries required a gasoline product with high API gravity to add volatility to their products; therefore, natural gasoline became a vital ingredient of standard gasoline to meet quality specifications. This trade-off reduced the competitive relationships between naphtha and natural gasoline.

Despite the rapld growth of the early compression plants, and their ability to process richer gas streams, they were inefficient and not amenable to processing the leaner natural gas.

The early natural gas compression plants were called gasoline plants because most of thelr output was natural gasoline. They were built in the absence of marketing surveys or economic analyses, and relied upon days' payout (time required for net income to equal initial investment). Processors selected plant locations primarily on the basis of adequacy of gas supply and open marketing.

Following World War II, available steel and advances in electrical welding technology permitted the use of high-carbon steel in pipe making and manufacturing and allowed the construction of largerdiameter pipelines. This development, coupled with increased demand for natural gas, shifted the fuel supply in the Southwest from oil to gas. Long-distance gas pipelines were extended from the Southwest to the West Coast, the Midwest, and the East Coast. As an outgrowth of this expansion, natural gas processing plants were constructed to meet the rapidly increasing demand for both natural gas and natural. gas liquids. 
In the early 1940s a trend toward joint ownership of processing plants had begun. Joint operations made it feasible for a group of operators to finance larger plants to meet changing demand. Gas cycling recovery from select unitized petroleum reservoirs was found to be Ideally suited for this purpose. Cycling permits royalty owners and leaseholders to obtain a present return on their mineral rights through production of NGL rather than to defer returns until the future when markets exist for residual gas. During the 1940s, propane and butane were consumed in ever-increasing quantities as a raw material for petrochemical plants and to meet the demand for domestic bottled gas.

In the late 1950s significant technological advances permitted the storage of natural gas liquids in salt domes along the Gulf Coast, which helped overcome price instability and offered a means for supplying the wide seasonal variations in markets. More recently, economical methods for storing liquids have been extended to apply to depleted oil and gas reservoirs, salt water sands, shale deposits, mined caverns, frozen earth, and aboveground refrigerated storage.

Within the last two decades marked refinements in technology have accompanied a high rate of growth in production. Higher recoveries of plant concentrations of ethane and propane have coincided with increased automation and the construction of refrigeration processing plants located adjacent to markets. New liquid hydrocarbon supplies have emerged as the petroleum industry has expanded to offshore operations in Louisiana and Alaska.

Domestic production of natural gas liquids from gas processing plants in 1976 was about 587 million barrels, or 1.5 percent less than in $1975 .^{*}$ The year 1976 represented the fourth consecutive annual decline in production, which was attributed to a decline in the availability of supplies of natural gas and to a decrease in the liquid content of the gas being processed. Production at gas processing plants has been variable since 1976. In 1979, production was about 615 million barrels (U.S. Department of the Interior 1978; U.S. Department of Energy 1979).

\footnotetext{
* Because of the complexity of the petroleum and natural gas industry and the absence of accepted definitions pinpointing the phase of extraction or separation, numerous reporting sources have used different systems of classifying and measuring production data over the years. This has created inconsistencies in the reported data. Data in this section should be used in this light and is presented only as an indicator of general industry trends.
} 
Domestic demand for production at refineries in 1976 , exclud1ng that blended into other products at refineries or terminals, increased 5.1 percent over 1975. Increases since 1976 have averaged 3 percent or less.

Total natural gas liquids have increased at a falrly constant rate since 1950. In millions of barrels per year, the approximate growth has been: 1950,$182 ; 1960,340 ; 1970,600$; and 1979, 752. From 1950 to 1970, natural gas liquids increased from 6 percent. to over 11 percent of the total U.S. liquid hydrocarbon supply.

\section{LEG Processes}

\section{Liquefaction}

The two principal methods used for 11quefaction are the cascade cycle and the expander cycle. The cascade cycle uses a serles of. refrigerants to sequentially lower the temperature. The refrigerants are usually liquid propane or ammonia, ethane or ethylene, and methane. Usually propane 18 used first to decrease the temperature to about $-31^{\circ} \mathrm{F}$ to $-44^{\circ} \mathrm{F}$. The second stage uses ethane or ethylene to decrease the temperature further to about $-142^{\circ} \mathrm{F}$ to $-148^{\circ} \mathrm{F}$. The final stage reduces the temperature to at least $-258^{\circ} \mathrm{F}$ by means of methane-cooled heat exchangers (F1gure 3 ).

The expander cycle is based on the concept. of self-refrigeration as gas expands during a large pressure drop. When compressed gas passes through an engine it expands, resulting in a lowering of the temperature of the gas. Multiple refrigerants are not used. Th1s method of liquefaction is ideal for use in peak-shaving plants at the end of high pressure transmission lines where a large volume of gas needs to be depressurized before entering distribution mains (F1gure 4). It 18 not as useful for baseload export-import systems.

Prior to liquefaction, gas cleaning is needed to remove water, carbon dioxide, hydrogen sulfide, lubricating olls, odorants, and dust. These contaminants solidify at low temperatures and must be removed to avoid clogging of ilquefaction, regasification, and transmission equipment (American Gas Association 1973).

\section{LEG Marine Terminals}

A refrigerated LEG marine terminal can serve as a dispensing or recelving depot serving oceanic tankers or barges that transship LEG cargo via inland waterways. Due to high unloading rates from tankers (off-loaded in 20 hours or less), it may not be economically practical for marine terminals to store substantial amounts of LEG at any temperature and pressure different from the storage conditions aboard sh1p. 


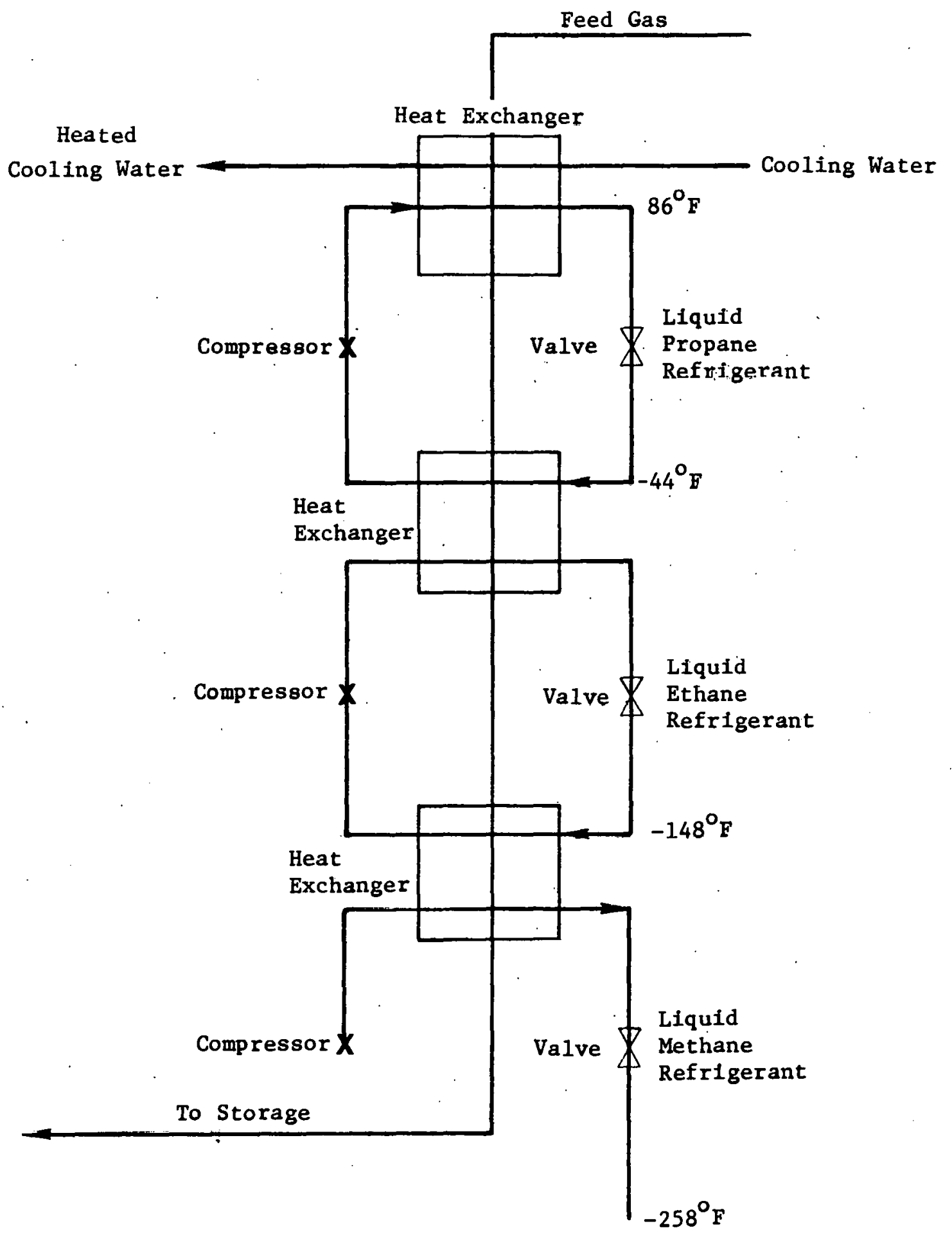

Source: Adapted from American Gas Association 1973.

FIGURE 3

CASCADE CYCLE FOR THE LIQUEFACTION OF NATURAL GAS 


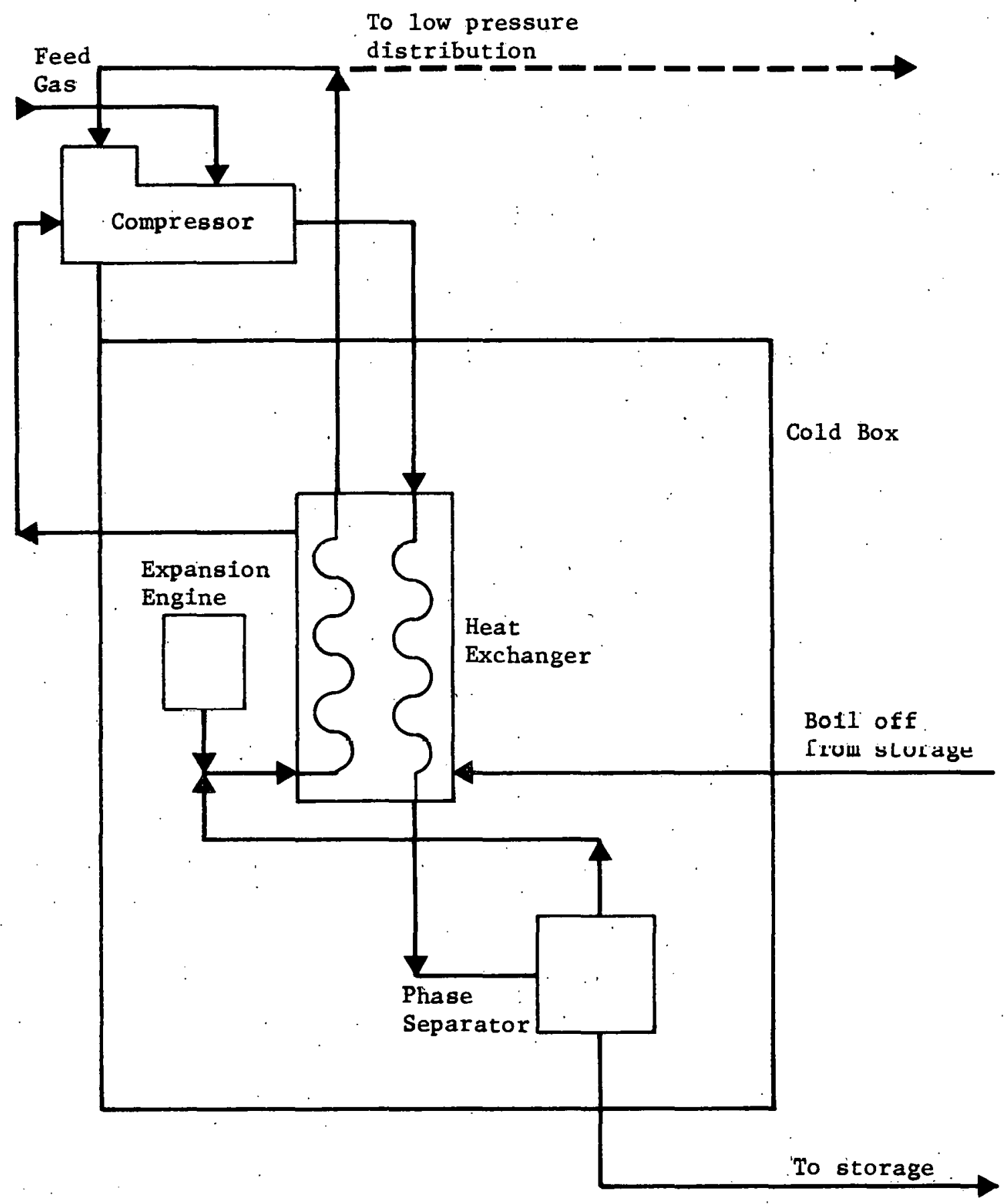

Source: Adapted from American Gas Association 1973.

FIGURE 4

EXPANDER CYCLE FOR THE LIQUEFACTION OF NATURAL GAS 
The relative costs of storage under pressure and refrigeration for natural gas and propane are shown in Table 1. The data are for land storage, but also are representative for storage on ships. LPG can be stored under pressure with a relatively low level of refrigeration, but this is not true for LNG.

\section{LEG Storage and Handling}

LNG usually is stored in aboveground, double-walled metal tanks prior to transfer to tankers or to regasification facilities. One type of storage tank can contain up to 65,000 gallons, and can operate at pressures between 50 and 250 psig (pounds per square inch as observed on a gauge). The inner wall is composed of a material capable of withstanding cryogenic temperatures and the outer wall is usually constructed of carbon steel. The space between the inner and outer wall contains a partial vacuum and may be filled with perlite or urethane.

In another type of storage tank, capable of contalning up to 1.2 million gallons, LNG is stored at atmospheric pressure. The space between the inner and outer walls may be filled with insulation in a dry, inert atmosphere. In a variation of this type of tank, a suspended and insulated ceiling eliminates the need for a roof composed of cryogenic materials. The capacity of these modified tanks is up to 24 million gallons (U.S. Environmental Protection Agency 1977).

Several pre-stressed concrete storage tanks are in service. A 13.2-million-gallon tank surrounded by an earthen berm is in service on Staten Island, New York. There, a heating cable is located below the concrete floor to prevent the upthrust of ground caused by moist soll freezing (frost heaves). Others in operation are located at Yarmouth, Massachusetts, on Cape Cod (2.2 million gallons), Massachusetts, and in Cumberland, Rhode Island ( 1.1 million gallons).

Other storage techniques, such as frozen holes or pits in the earth and mined caverns, have been tested or investigated in the U.S. . and have been found not to be feasible because excessive heat leaks lead to a high rate of boil-off, frost heaves, or other problems. However, an 1l.3-million-gallon inground storage unit is located in Arzew, Algeria, and four 13.2-million-gallon units are on Cagney Island, England. These units are being phased out of service.

In transfer operations between ship and onshore storage, sufficient interlocks must be provided to prevent overpressuring or overfilling storage tanks. Emergency shutdown measures must be available to terminate filling if abnormal conditions develop. Fill rates may 
TABLE 1

CONDITIONS OF CONTAINMENT

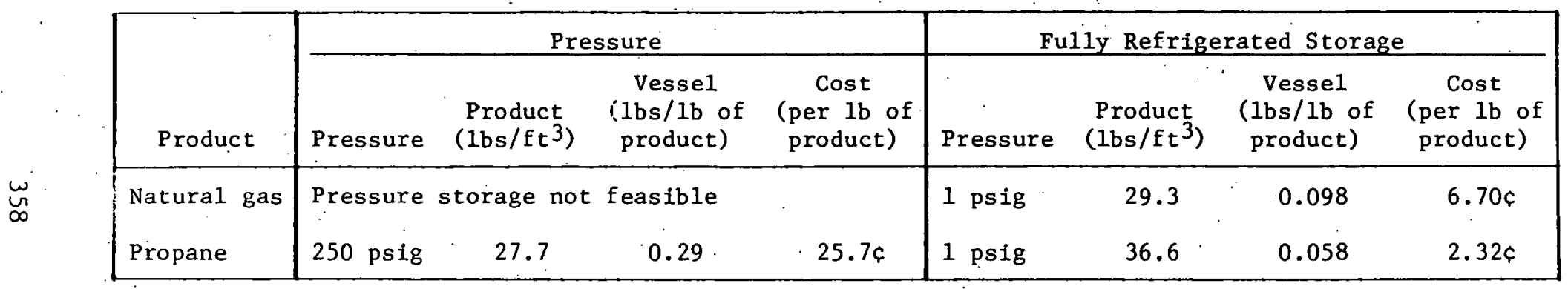

Notes: Costs in 1972 dollars.

Comparisons are for 20,000 tons of product.

psig = pounds per square inch ábove atmospheric pressure (as read by a gauge).

Source: Adapted from Clapp and Litzinger 1972. 
vary from a few hundred to tens of thousands of gallons per minute. High volume fill rates can result in large quantities of vapor being displaced from an onshore storage tank. Ship pump energy also may create a large volume of vapor. Vaporization can occur from the heat of the ship and fill lines. Such heat loss generally is controlled through the use of insulation. Vapors formed during handling may be refrigerated, vented, flared, or returned from a storage tank to the off-loading tanker to replace the evacuated space within on-board tanks.

For .LPG, it usually is economical to use only a minimal amount of insulation in the construction of storage tanks and to provide a refrigeration system capable of reliquefying the boll-off gas. An LPG boll-off vapor reliquefaction cycle may consist of several stages of compression and the rejection of latent heat to the atmosphere and may utilize an alr-cooled condenser. The resultant high-pressure liquid is flashed into the relatively low pressure and temperature environment of the storage tank. Pressurized storage is another alternative for storing LPG. Under these conditions, LPG stored at $-10^{\circ} \mathrm{F}$ and warmer is more of ten placed in single-walled tanks. For temperatures colder than $-10^{\circ} \mathrm{F}$, LPG tanks are either double-walled or single-walled, depending on construction costs, operating and extra refrigeration costs, maintenance and longevity of insulation, and safety (Clapp and Litzinger 1972).

The reliquefaction of LNG boil-off vapors is more expensive and also undesirable because of the need to maintain a positive pressure of an atmosphere saturated with boil-off vapors within a storage tank to avoid the formation of an atmosphere susceptible to combustion. For these reasons, LNG tanks are heavily insulated and only small amounts of boil-off gas are compressed and sent to a distribution system. A portion of the boil-off gas may be reliquefied.

About 85 percent of LPG is stored under pressure in underground salt domes or mined caverns. Some is stored in relatively small aboveground tanks. As of 1978, only 23,000 cubic meters of LPG was stored aboveground and distributed among 20 storage facilities (General Accounting office 1978).

\section{LEG Transportation}

Domestic transportation of LPG is mostly by high-pressure pipeline $(70,000$ miles). The remainder is transported by rail cars ( 16,000 , mostly uninsulated with a capacity of 700 barrels per car) and highway vehicles $(25,000)$. A large LPG tank truck, usually a tractor-trailer combination, can hold about 250 barrels. Refrigerated barges with capacities of up to 16,000 barrels are used for transporting LPG and anhydrous ammonia in cylindrical tanks 
approximately 16 feet in diameter and 240 feet long (General Accounting office 1978; Tiratsoo 1979).

For over two decades, LPG has been successfully transported by sea from the Middle East to North America, Japan, and Western Europe. The early, low-tonnage vessels carried LPG under pressure in heavy cylindrical tanks in their holds and were limited to a carrying capacity of 3,800 barrels by the difficulty of manufacturing and installing sultable tanks (T1ratsoo 1979).

W1th time $1 \mathrm{t}$ was determined that refrigerated LPG could be handled more economically at atmospheric pressure than if liquefaction had to be maintained under pressure. Thus, in 1959 the first semi-refrigerated LPG carrier was constructed and 2 years later it was put into service. It was used to carry butane and had a capacity of 64,500 barrels, maintalned at atmospheric pressure. (TIratsoo 1979).

The largest of today's LPG tank ships holds about 629,000 barrels (about 60 percent of the capacity of the largest LNG carriers). Currently, 10 major LPG 1mport terminals are operating.

Due to the high costs of insulation and refrigeration, LNG is usually stored and regasifled before it is transported by pipeline. On.1y about 75 LNG tanker-trallers, each about 40 feet long and with a capacity of about 250 barrels, are avallable for transporting LNG to small or remote gas companies where it 18 regasifled. A "thermos bottle" design is used which includes an aluminlum inner sheli vacuum insulated from a steel outer she11. The evacuated space between the walls is filled with perlite. Unloading is carrled out by pressurizIng the gas space in the top of the tanker to about two atmospheres using revaporized gas (General Accounting office 1978; Tiratsoo 1979).

The first barge built especially to transport LNG in shallow waterways was the 297-foot-long Massachusetts, commissioned in 1973 for the Distrigas Corporation. It has been used to carry LNG between U.S. Gulf Coast terminals in 320,000-barrel loads contalned in four insulated aluminum tanks (T1ratsoo 1979).

The transportation of LNG is esentially, by volume, restricted to the marine environment. Since 1964 when the first tankers were put into service, tanker capacities have risen from 27,400 cubic meters to over 165,000 cubic meters. LNG tankers are double-hulled and have insulated cargo tanks constructed with cryogenic materials. The LNG tanks are freestanding and anchored in the hull or to the deck of the ship. They are comprised of a membrane that is supported by insulation lining the hul1, or forms a structural part of the 
sh1p's hull. Tanker engines can use elther boll-off from the cargo or conventional fuel. Boll-off gas 18 always avallable because $a$ portion of the LNG load 18 kept on board to keep the tanks cold (General Accounting office 1978; Univers1ty of Oklahoma 1975).

\section{Regasification of LNG}

LNG regasification facilities vaporize the liquid by passing it through heat exchangers. These are heated by alr or water at amblent temperature, which may be raised in the winter by the heat of fuel combustion or by the gas itself. Regasification occurs at pressures of up to $1,200 \mathrm{psig}$, which are sufficlent for Input of the gas into a conventional natural gas pipeline. 
THIS PAGE

\section{WAS INTENTIONALLY \\ LEFT BLANK}


HEALTH AND ENVIRONMENTAL EFFECTS

The salient health and environmental issues associated with liquefied energy gases are discussed in this section. The information is categorized by problem area.

Occupational Health and Safety

In cryogenic LEG facilities, several types of health and safety hazards can exist. Insulation fallures and escaping LNG, vapor, or refrigerants present the possibility of cryogenic burns from contact with cold liquid, vapor, or surfaces. The severity of the burn would depend upon length of exposure, temperature of the source, and the rate of heat transfer. If the skin has surface moisture, it may freeze onto the cold object. Skin may adhere to the cold surface when the affected area is removed.

Prolonged exposure to cryogenic temperatures also results in hypothermia--a decrease in body temperature. At a lower body temperature, physical and mental capabilities are greatly reduced and death usually occurs at a body temperature below $80.5^{\circ} \mathrm{F}$.

Vapors are not toxic, but they hug the ground and exclude oxygen to the point that asphyxiation occurs. This may occur so slowly that the victim realizes the danger too late to save himself. These hazards, under normal conditions, are limited to the boundaries of an LNG facility.

LNG workers are protected, to an extent, by safety glasses or goggles, non-conductive fire-resistant hard hats, and protective clothing, gloves, and shoes. These items are fallible, however. Temperature cycling and sudden drops in temperature can create thermal stresses and lead to material weakening and possible failure unless vaporization takes place at a constant rate.

\section{Public Health and Safety}

\section{LNG Spil1s*}

Major LNG spills (i.e., those considered to have the greatest potential for harm) may result from groundings, failures of the integrity of storage tanks, and collisions at sea involving an LNG tanker. Minor spills can occur when released refrigerants and solids block a pipeline during or after liquefaction. They can also result from malfunctions on board tankers, leaks in the transportation system linking an LNG tanker to onshore storage areas, and accidents

* Taken largely from U.S. Environmental Protection Agency 1977. 
during maintenance. Thus, an LNG spill may occur on land or water, and even underwater in the case of a submerged tanker. The consequences of these events are substantially different.

If LNG is spilled on the ground, it begins to boil violently and vaporize. If the spill continues, a pool forms; it freezes the ground underneath, and the boiling rate becomes constant. If LNG spills on water, it is usually unconfined, which allows it to spread rapldiy and continue to boll at a high rate. An ice layer will form under an unconfined spill. As this layer thickens, the rate of heat transfer is reduced and the bolling rate 18 reduced.

Spilled LNG will either ignite immediately or form a lowlying vapor cloud. Such a cloud will be denser than air (up to a temperature of $-40^{\circ} \mathrm{F}$ ) and will hover above the ground or water. The vapor generation rate 18 proportional to the pool area and the vapor cloud can be clgar or pancake shaped. It will begin to rise when $1 t$ is warmed sufficlently and its density approaches that of alr. The cloud will elther eventually dissipate or be driven by the wind as a plume. The distance a plume can travel before it falls below the lower flammable limit (LFL) depends on meteorological conditions. Estimates range from 1 to $50 \mathrm{miles}$. Unt 11 the LFL 1 s reached, Ignition may occur at any time and involve flashbacks to the original pool. For LNG to 1gnite, it must form a 5 to 15 percent mixture with air and an energy source (e.g., frictional heating, electrical sparking, static electricity) must be present. The resulting fire can radiate more intense heat than an equal amount of gasoline, but 1t w11l be shorter-lived than a gasoline fire. Experiments in the U.S., France, and Japan have shown that, once the vapor has been lgnited, a flame front burns back through the vapor cloud toward its source (Drake and Re1d 1977).

If LNG is released underwater in a tanker accident, it is belleved that the vapor will rapidly dissipate due to the heating of the water. The resulting flammable portion of the cloud rising from the water will be much smaller than that from a surface spill of equal size.

There has been much speculation on the likelihood of an LNG spill Igniting immediately instead of forming a vapor cloud that drifts some distance from the site of the spill. A 90 percent probability of Immediate ignition is assumed in most of the 11terature reviewed on risk analysis modeling. However, this value is arbitrary, and other values have been used. A vapor cloud explosion intense enough to create a damaging blast wave has not been confirmed, even when a high-exposure charge served as the Initiator (Drake and Re1d 1977). 
Another consequence of an LNG spill is that the superheating of LNG In contact with water can result in low energy, non-chemical explosions. Th1s phenomenon occurred during many Federal government. and industry experiments and during the transport of LNG (second voyage of the Ploneer Methane In 1959 when 4,900 gallons of LNG were pumped overboard in a period of 7 minutes, and at a Wisconsin natural gas facllity when LNG was dralned from storage into a pond). These explostons resulted from sudden vaporization accompanied by a rapid increase in volume. A study conducted by the National Academy of Sclences in 1972 concludes, "The nature of the explosion can be shown to have a relatively low potential for causing physical damage since It is flameless and not supported by the energy of a chemical reaction, only the energy of the superheat" (National Academy of Sclences 1972).

Th1s phenomenon, termed, "flameless vapor explosion," can occur when LNG contacts water and apparently is related to the presence of small amounts of ethane, propane, and nitrogen. No fire or 1gnition of the vapor occurs, but there is a rapid upward movement of gas accompanted by a loud bang.

After extensive experiments designed to determine the cause of these explosions, Shell pipeline Research Company concluded that they resulted from a homogeneous nucleation of vapor in a thin layer next to the water surface. The flameless vapor explosion can happen only when concentrations of ethane and propane in the LNG are relatively high:

Delayed vapor explosions can occur as the LNG weathers after a sp111. If the initial spill were large, the amount of LNG remaining after weathering could be substantial; however, during the period of weathering, the LNG probably will disperse on the water surface, lowering the probability of a single large explosion.

When a flameless vapor explosion occurs, damage is slight. If such an explosion took place on water adjacent to a tanker, it would have little effect on the hull. Since no chemical reaction is Involved, the available energy is $11 \mathrm{mited}$ to the amount of superheat achleved while the LNG 18 in contact with water (Drake and Reid 1977; Pederal Power Commission 1973).

\section{Types of LEG Accidents *}

Potential onshore LEG accidents can fall within the following broad categorles:

\footnotetext{
*Unless otherwise noted, taken from U.S. Environmental. Protection Agency 1977.
} 
- Malfunction of Transfer System. The transfer arms, the LEG piping to the storage tanks, and the trestle carrying the piping are sites of possible accidents. The risks associated with these operations have been reduced to low levels by the installation of safety devices. The potential risk to the public has been judged to be small relative to that associated with tanker or land storage tanks.

- Damage to Storage Tanks. Storage tanks may rupture because of internal causes (e.g., inadequate design, "roll-over" turbulence), or external causes. Roll-over is a phenomenon resulting from improper mixing of LNG from different sources and of different compositions.

- Malfunction of Vaporization Plant. It is estimated that only small leaks of LNG or gas can occur in the piping from LNG tanks and in the vaporization process. Valve corrosion may occur, leading to leaks and icing, and possible pressure buildups in piping sections. Insulation failures will cause frost, icing, and possible leaks. Safety practices of leak detection, spill prevention and containment, and fire warning devices greatly reduce risks.

When LNG is stored for a period of several months, its constituents (e.g., methane, ethane, propane) evaporate at different rates, resulting in a change in their initial relative proportions, and thus, in an overall change in LNG density. When a new batch of LNG is added to a tank, the old and new LNG volumes may stratify due to density differentials. After a period of time, as convective currents store energy in each layer, the layers can mix or roll over very. suddenly, resulting in the boll-off of large amounts of gas. Such a roll-over occurred in 1971 in a storage tank in Italy and it. resulted in the venting of 150,000 kilograms of natural gas within 1 hour. Fortunately, the huge amount of vented gas did.not ignite and the pressure within the tank did not cause serious damage (Drake and Reid 1977).

Modern facilities utilize standard procedures for preventing roll-over. Stratification is prevented by loading liquids with a greater density into the top of storage tanks. If fresh LNG is always loaded on top, the time required for roll-over is much longer than the typical. residence time of LNG in a storage tank. There is general agreement that stratification and subsequent release of excess vapor should not develop spontaneously in an initially well mixed and monitored tank (Chatterjee and Geist 1972; Drake and Reid 1977; Federal Power Commission 1973; Maher and Van Gelder 1972; and Sarsten 1972). 
If a spill does occur, damage will be minimized if the tank is diked and located far within the facility boundaries as is required by the strict building codes regulating LNG terminal construction. Dike design is critical to minimizing potential damage. The dike should be capable of contalning more than 100 percent of the tank's contents and 1 ts location and dimensions selected to assure that damage will not extend beyond a facility's boundarles. The surface area of the dike should be small compared to the volume of any spill. It should also have an insulated floor to minimize heating of the spilled liquid and maintain a low rate of vaporization. Some dikes are broad and shallow, while others extend only a few feet from the edge of the tank, which effectively make them an outer wall. The former promote higher evaporation rates, but are less likely to rupture from the same cause as the tank.

Storage tanks should have double walls to provide good insulation. The inner wall must be of a cryogenic material and an additional safety factor is gained if the outer wall is also cryogenic. In this way, the LNG would be contained to allow draining if a rupture to the inner lining occurred.

Accidents associated with the marine phase of LNG operations may be classifled as malfunctions aboard the tanker or impact with another object:

- On board. On-board malfunctions may Involve spills and fires. LNG tanks are designed so that a fire in one tank w11l not ignite another and care is taken to place tanks as far as possible from potential ignition sources. Onboard spills may cause embrittlement and fracture of metal surfaces. Insulated catchments are standard equipment and should contain spills so that the ship and crew are not serlously threatened. Since there are spaces within which LNG vapor may accumulate by accident, the threat of fire cannot be ruled out.

- Impact with another object. Th1s group of accidents includes collisions, rammings, and groundings. In rammings (ship-toobject impact) and groundings (ship-to-harbor floor impact), the impact point frequently is in the bow. Since the LNG tanks are located aft of the bow, many authorlties belleve they will not be affected In these types of accidents. A collision (ship-to-ship impact) In which the LNG vessel is struck in 1 ts side by another ship is considered to be more serious. 
In a collision, only one tank will probably rupture. Rupture of two tanks will occur only if impact takes place at a bulkhead intersection between two tanks. Consequently, the largest possible amount of LNG to be released w11l be $75,000 \mathrm{~m}^{3}$ or the contents of two tanks, assuming each contains $37,500 \mathrm{~m}^{3}$.

Several measures may be taken to reduce the possibllity of collisions, rammings, and groundings. These include crew training, Installation of on-board safety devices, and close Coast Guard survelllance, which would include providing escorts, and excluding other ships in a zone around LNG vessels, or halting all other traffic while an LNG vessel enters and docks.

\section{Past LNG Accidents*}

In spite of the potential for severe accidents, there have been only four major incidents involving LNG facilities. The most catastrophic was a 1944 accident in Cleveland, Ohio. A large storage tank contalning 38,000 barrels of LNG collapsed, which was later attributed to brittle fracture of the tank wall caused by exposure to cryogentc temperatures. The tank was constructed with an alloy that contained only 2 percent nickel and was not resistant to brittle fractures at temperatures below $-76^{\circ} \mathrm{F}$. In addition; no dike existed to contaln the spill. In the resulting catastrophe, a spreading pool of fire flowed into the surrounding residential and industrial area. Vapor accumulated in closed bulldings and sewers and later exploded, demolishing many structures. Fire also spread by thermal radiation from flames near the collapsed tank. Distant combustible materials were 1gnited and flames reached a helght of 2,800 feet. In all, 130 people were killed and 300 injured. Property damage totaled $\$ 10 \mathrm{mil}-$ $110 \mathrm{n}$, with the destruction of 80 houses and 10 industrial plants. The likelihood of a similar accident occurring has been greatly reduced by the development of materials better able to withstand cryogenic temperatures (alloys now contain 9 percent nickel which can withstand temperatures as low as $-328^{\circ} \mathrm{F}$ ), and the containment of spills through diking.

Other accidents have been associated with LNG facilities. In February 1973, Texas Eastern's LNG storage tank on Staten Is land exploded and burned. Forty workers were trapped and died in the incident, which occurred during maintenance of the tank 1ining. Invest1gators concluded that, although the tank had been emptied of LNG for 1 year, gas vapors had been trapped inside. The flame from a welder's torch ignited them, and the insulation caught fire.

\footnotetext{
* Taken largely from U.S. Environmental Protection Agency 1977;

office of Technology Assessment 1977.
} 
At a Northwest natural gas facility in Oregon, four workers died when a tank exploded during construction before LNG was introduced. Investigators attributed the accident to careless work practices and not to LNG.

In 1972, natural gas leaked through an alr line to the control room of an LNG plant in Montreal, Canada. A large fire followed, creating more damage than would have occurred in an area of less importance.

In 1979 , one worker was killed as a result of an explosion at the Cove Point, Maryland, LNG terminal. The cause of this explosion Is under investigation.

\section{Recent LNG Acc1dents}

The LNG vessel E1 Paso Paul Kalser ran aground near Gibraltar on June 29, 1979. The loaded tanker was stranded because it maneuvered to avold colliding with a flshing boat. After the ship was refloated and towed to a sheltered anchorage, the $90,000 \mathrm{~m}^{3}$ of LNG was transferred to a sister ship, the El Paso Sonatrach, which delivered the cargo to the Cove Point, Maryland, LNG terminal. The El Paso Paul Kaiser did not release any LNG into the environment even though it received extensive damage. About $\$ 10$ million in repairs were expected to be completed In May 1980 (Hale 1980).

On October 6, 1980, an explosion in the motor control center of an electrical substation at the Cove Point terminal resulted from the Ignition of natural gas that leaked into the building through an electrical conduit connecting 1 of 10 second-stage LNG pumps. Equipment containing LNG was not damaged and LNG was not released. By the beginning of December, the plant was able to vaporize at its capacity of 500 million $\mathrm{ft}^{3}$ of gas per day (Hale 1980).

\section{Natural Gas Liquids}

Natural gas processing plants are assumed to have a lesser effect on air quality than petroleum refineries. This is because the plants are essentially miniature ofl refineries with simpler process streams and lower temperatures. Alr emissions from natural gas liqufds (and sulfur removal plants) emanate mostly from steam generation bollers. In natural gas ilquids plants, air emissions total about three tons per $10^{12}$ Btu's processed (based on using 3.1 percent of the gas processed as plant fuel and flaring 0.1 percent). By weight, these emissions are comprised of nitrogen oxides (64 percent), hydrocarbons (21 percent), particulate matter ( 10 percent), aldehydes (50 percent), and sulfur oxides and carbon monoxide (less than 1 percent). About $1 / 2$ of all air emissions released in gas extraction 
processing come from natural gas 11quids plants. Most of the remainder-about 45 percent--is attributed to nitrogen oxides emissions from gas engines that drive compressors on gathering pipelines (University of Oklahoma 1975).

No significant amounts of water contaminants are released by natural gas processing plants. Some discharges of lubricants and caustic wastes may occur, but they are treatable by state-of-the-art industrial waste treatment systems. However, the thermal discharge from a natural gas 11quids plant 18 estimated at 25 percent of the energy content of gas used for plant fuel ( $7.7 \times 10^{9} \mathrm{Btu}$ 's discharged for each $10^{12}$ Btu's of natural gas processed). The use of cooling towers can minimize the heat content of the discharge water (University of Oklahoma 1975).

No appreclable solid wastes are assoclated with natural gas liquids plants. Land use impacts are insignificant, equaling about five acres for a 100-mil11on-ft ${ }^{3}$-per-day plant.

\section{LEG Facility Security}

In a summary of the findings of 1ts Liquefied Energy Gases Safety study, the General Accounting office (1978) determined that U.S. public utilities and petroleum companies have of ten been targets of sabotage and that many domestic as well as foreign organtzations have the weapons, explosives, knowledge, and capability tn sabotage LEG facllities. In urban areas, such sabotage could have catastrophic results, especially if equipment is manipulated to allow the discharge of a spill outside diked areas. The study noted that urban LEG storage facilities are often adjacent to sites that store large quantities of hazardous substances, including volatile liquids. Thus, the Ignition of vapor from a spill could lead to the destruction of many LEG storage tanks as well as tanks containing other chemicals at nearby industrial complexes.

Other adverse natural and man-caused incidents have been cited as threats to such industrial installations, including hurricanes, tornadoes, floods, tsunamis, snow and ice storms, earthquakes, land subsidence, avalanches and landslides, volcanoes, meteorites, a1rplane and missile crashes, and war, as well as worker carelessness (U.S. Environmental Protection Agency 1977).

As the LNG industry continues to expand, especially in the development of peak-shaving plants, and unmanned satellite and storage facilities in urban areas, the public concern focused on safety and security will intensify. Today, the LNG Industry is faced with safety and security concerns that are parallel, in the view of a 
large segment of the public, to those assoclated with nuclear power. This concern may spread to include the LPG Industry in the future (Tutko 1979).

Responding to the concern, LEG Industry officlals say that in 30 years of worldwide experience.with transoceanic LEG shipping and 18 years with LNG shipping, the industry has had an outstanding safety record. The American Gas Association (1977) points to the i following accomplishments:

- Betwéen 1959 and 1977, 25 LNG tankers completed more than 2,700 voyages without incident.

- Since 1t began operating in 1969, the Phillips-Marathon baseload LNG 11quefaction facllity has operated without incident.

- The storage of LNG for peak-shaving in the U.S. has expanded from 2 sites in 1965 to well over 100, including satellite storage areas.

- In a rating of the relative hazards of materials which regularly pass through U.S. ports, LNG has been ranked 19 th out of 22 (18 other commodities were considered more hazardous).

- A varlety of risk assessments agree that the risk of fatality from LNG operations 18 of the same order as, or 1ess than that assoclated with many common activities such as commercial airline travel, driving, or living in a dwelling.

The facts clted by the trade assoclation reflect the safety of past LNG (as'well as LPG) operations. Future predictions based on risk assessment tend to ignore sabotage as a potentlaily important factor (Van Horn and Wilson 1976). Predictions also Ignore threats related to sabotage, which can be acts through stealth, decelt, or in extreme cases, force. The range of such threats are 118 ted and categorlzed below (Tutko 1979).

\begin{tabular}{lccc} 
Adversary Threat & System Vulnerabilities & & Adversary Modes \\
\cline { 2 - 3 } Terrorists & Sabotage & Decelt \\
Outside dissidents & Theft & Stealth \\
Criminal elements & Diversion & Force
\end{tabular}

Guerrilla activities

Disgruntled employees 
Environmental Effects

Cooling Water Discharges

A major environmental problem related to the removal of heat by LNG liquefaction facilities is the potential aquatic effect associated with cooling water discharges. The problem is most severe for large liquefaction plants such as one that was proposed (now terminated) by El Paso Gas Company to be located on Gravina Point

- in Prince William Sound, Alaska. The facility was suggested as part of an alternative proposal for the transportation of Alaskan gas. Planning for the facility was terminated in 1977 when the President and a joint Congressional resolution favored another alternative.

Designs for the proposed plant called for a once-through seawater cooling system with a flow of 658,000 gallons per minute (about 1 billion gallons or 3,000 acre-feet per day). The chlorinated discharge would have had a temperature of $20.7^{\circ} \mathrm{F}$ above the average ambient temperature of the recelving water of the Sound. Largely as a result of thermal shock, a 100 percent mortality was expected for organisms (e.g., plankton, eggs, larvae, young fish) that entered the system.

For such large liquefaction facilities, cooling towers, or some form of a staged heat reduction process may be required. This would add a substantial cost to construction. Alternatives to the use of a once-through water cooling system include the use of dry couling towers (mechanical or natural draft), wet cooling towers (mechanical or natural draft), a combination of wet and dry cooling towers, a cooling pond or cooling lake, and a combination of these options. The relative cost ratios for these options as estimated for the proposed El Paso facility are as follows (U.S. Department of the Interior 1977): 


\section{Type of System}

Once-through seawater

Cooling pond or lake

Wet cooling tower

Mechanical draft

Natural draft

Dry cooling tower

Comparative*

\section{Capital Costs Operating Costs}

$1.0 \quad 1.0$

$1.3-1.4 \quad 1.06-1.08$

$1.3-1.4$

$1.08-1.11$

$1.8-2.0$
Mechanical draft

Natural draft
$3.2-3.4$

$6.4-7.0$
$1.68-1.88$

$1.98-2.42$

A significant environmental issue related to the use of cooling water within an LNG 11quefaction facility is the entrainment (organisms drawn Involuntarily into the plant with the cooling water) of all pelagic/planktonic organisms and other smaller organisms not capable of avolding or swimming against the intake current. For large facllities, entralnment may result in the deaths of 100 percent of all living organisms entering the plant.

Three factors leading to the 100 percent mortallty rate for all entrained organtsms are:

(1) A high and rapld heat gain above ambient temperature;

(2) Contact with a chemical blocide; and

(3) Pressure changes and turbulence induced by pumping.

A 100 percent mortality rate, coupled with the tremendous volumes of water used, can result in heavy losses of phytoplankton and zooplankton, along with the egg, larvae, and Juventle stages of larger organisms in the surface water used as a water supply, especlally if a large portion of the body of water passes through the plant within a short period of time.

\footnotetext{
*As a point of reference, capital costs for a large natural draft wet cooling tower for a large utility plant in the contiguous 48 states amounted to about $\$ 90$ million in 1976 (Power Engineering 1976).
} 
There are also several environmental problems related to the once-through cooling system outside of the LNG faclilty. These Include (Brown and Helfand 1977; Kalberer 1980):

(1) Impingement of larvae and juvenile organisms on traveling screens at intake. This is a serious problem at power plants and a potentially serious problem at large water cooled liquefaction plants, especially during the spring and summer months.

(2) Chlorine. An unknown, but large amount (owing to the huge volume of water treated) of the free chlorine used as a biocide within the cooling system will be released into surface waters. Chlorine in a free or complexed form. is extremely toxic in low concentrations.

(3) Heated effluent. The adverse environmental effects of heated water include the following:

(a) Thermal shock (both standard high temperature shock and the shock that can be experienced by organisms accustomed. to a high temperature when a plant is shut down and the temperature drops).

(b) Behavioral changes (e.g., changes in migration routes, thermal barrler, feeding behavior).

(c) Physlological changes (changes in the temperaturespectflc life history stages of organisms, i.e., premature spawning or delayed migration, accelerated development of larval and juventle stages).

(d) Increased metabolic rate (which leads to increased susceptibility to pathogens and pollutants).

(e) Increase in pathogens. (H1gh temperatures increase diseases of low temperature organisms.)

(f) Supersaturation of atmospheric gases (leads to lethal gas bubble diseases in $\mathrm{fish}$ ).

(g) Establishment of exotic species.

(4) Heavy metals. These may be toxic to marine organisms through their action in the cooling system discharge stream. The heavy metals that can be present in the seawater cooling system discharge stream of a liquefaction plant include aluminum, copper, and zinc (these also may be a problem in 
some freshwater systems). The sources of these metals are the seawater exchangers which ut1lize aluntinum brass for exchange tubes. Given an errosion-corrosion rate of two to five mils per year and the surface area that 18 exposed to metal 1088 , the heavy metal concentration in the discharge stream contributed by a large LNG plant can be 31 to 77 parts per billion (ppb) by welght. of the three metals, only copper is highly toxic to marine life, and an LNG plant's contribution to the total concentration can be in the range of 24 to $59 \mathrm{ppb}$. For comparison, the concentrations of the three metals normally found in seawater are: aluminum, 10ppb; zinc, $10 \mathrm{ppb}$; and copper, 3 ppb.

Other Impacts on aquatic resources include brine emissions from desalination facllities (various forms of marlne organisms may be affected by varfations in salinity); water pollution caused by tanker operation and other wastes assoclated with facilities supporting the LNG plant; removal of flsh habitat through the construction of pier facilities; and some interference with and disruption of commercial flshing operations and sites. 
THIS PAGE

\section{WAS INTENTIONALLY \\ LEFT BLANK}




\title{
SUMMARY OF RESEARCH NEEDS
}

Research needs related to liquefied energy gases fall into two major areas: those concerning health and the environment. These areas are discussed below.

Health

Risk Assessment said :

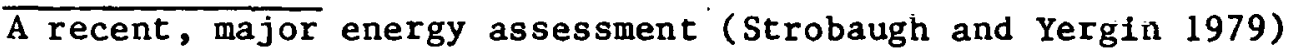

\begin{abstract}
"Some scientific experts have claimed that the handling and transportation of LNG poses great hazards to the public. Accidents to LNG tankers entering port or while unloading, accidents at LNG storage facilities, and motor vehicle accidents involving trucks that transport LNG--all threaten the public with the risk of potentially catastrophic explosions and fires. Equally reputable scientists support the gas industry's view that such risks are under control. They cite the special design features and operating requirements of LNG ships and storage facilities as protection against catastrophe, and argue that highway transport of LNG 1s no more hezardous than the transportation of gasoline.
\end{abstract}

"As with the nuclear safety controversy, there seem to be serious gaps in government-sponsored research and development programs to answer the issues that are in dispute. There is, for example, no good experimental basis for predicting the consequences of a collision between an LNG ship and another vessel. Gaps in scientific knowledge such as these create so much uncertainty that a wide range of risk asgegements is possible."

This statement would indicate that a well structured and rigorous risk assessment is needed. It could deal comprehensively with current and projected LNG imports, domestic production, LNG transportation and movement patterns, and with the probability of sabotage.

\section{Natural Gas Liquids}

Since no appreciable solid waste or liquid emissions occur from natural gas liquids plants, no technology-specific aquatic or terrestrial effects research appears warranted. Air quality may be affected by emissions of nitrogen oxides, hydrocarbons, particulate matter, and aldehydes. Much research has focused on the effects of nitrogen oxides and particulate matter on air quality. Thus: 
- No new NGL technology-specific research appears to be warranted with respect to nitrogen oxide.

- The nature, reactivity, and metals content of the particulate matter emitted from natural gas liquids plants may need to be determined.

- The toxic properties as well as the constituents of the hydrocarbon component of the emissions from natural gas liquids plants may need to be examined with state-of-the-art methods and equipment. The nature and air quality effects of aldehydes associated with natural gas liquids plants may need to be examined, especially with respect to their interaction with other air quality parameters.

\section{Environment}

\section{Cooling Water Discharges}

Research may find beneficial uses for waste heat. The large quantity of water required by a liquefaction facility for cooling provides a significant potential for energy recovery. Research is needed to explore this option for. future U.S. liquefaction plants. Information already developed in this area for coal and nuclear power plant effluent waters should be applied to liquefaction plants. Feasibility studies should focus on using waste heat for wastewater treatment (e.g., enhancement of flocculation, desalination, drying of sludges, evaporation of wastewater), for residential and commercial heating, and for freshwater aquaculture or mariculture. (For potential options see University of Maine 1979; Hari et al. 1974.)

The cold temperatures associated with regasification may provide a benefit through energy conservation and cost reduction. The cold waters can be used to cool heated power plant and industrial effluent waters, thereby eliminating thermal impacts from both sources.

\section{Baseline Aquatic Studies}

Baseline aquatic studies should be performed to gather information on the assimilative capacity of the aquatic environment potentially impacted by discharges from future liquefaction plants. Such studies should include collecting information related to flushing and turnover rates of the receiving water, the effects of water temperature on the timing of invertebrate and fish spawning and on the rate of development of aquatic organisms, and the composition and diversity of plant and animal aquatic populations with respect to temperature tolerances (species that are tolerant of warm temperatures will thrive and cold water species will be eliminated). 


\section{Use of Alr as a Heat Sink}

Basically, liquefaction is achleved by using a refrigerant to remove heat from a gas at a low temperature and to transfer $1 t$ to another medium, 1.e., cooling water. The heat also can be transferred to atmospheric alr. The feastbility of using alr as a medium for waste heat disposal in large liquefaction facllities should be explored and the potential resultant atmospheric effects should be assessed. 


\section{Part 6 \\ Transportation and Storage}


This section identifies several research needs associated with land transportation. A health misk assessment is needed, for example, to define the level of exposure of pipeline construction workers to coal tar pipe coatings, coal tar saturated wrapping materials, and asphalt coatings and wrapping materials. The toxic properties of ethanolamine should be studied more closely, especially with respect to dermal exposure. The potential for nitrosamine formation should be examined when ethanolamine is exposed to ambient air. safety procedures need to be developed to protect the public from unguarded deep trenches during pipeline construction through urban areas.

Research nosds related to marine transportation are also identified here. A port health and safety study should be initiated which would address best case conditions. with respect to proming, inerting, venting, and purging to minimize impact upon air quality. Such a study should. include guidelines for assumptions used to evaluate emission rates associated with proposed new marine terminals.

Finally, this section notes that environmental research should focus on the following areas: plant mycorrhizal associations as they are affected by crude and products; degradation of petroleum by soil biota under differing soil conditions lespecially those of the semi-arid West and the Appalachian Basin subject to new oil and gas development); effect of spilled crude and products on soil bacteria, fingi, and other biota and their capacity to recover to normal levels; and the effect of vapor phase and gaseous hydrocarbon organics (including natural gas) on soil biota as a result of underground pipe ruptures. 
THIS PAGE

\section{WAS INTENTIONALLY \\ LEFT BLANK}


OIL AND GAS TRANSPORTATION AND STORAGE

TABLE OF CONTENTS

$\underline{\text { Page }}$

LIST OF ILLUSTRATIONS 386

LIST OF TABLES : $\quad 386$

$\begin{array}{ll}\text { TECHNOLOGY DESCRIPTION } & 387\end{array}$

History of ofl Transportation $\quad 387$

History of Gas Transportation 389

Generic Description of 011 and Gas Transportation 392

011 Transportation $\quad 392$

Gas Transportation $\quad 392$

Pipeline Construction $\quad 394$

Preliminary Steps $\quad 394$

Pipe Storage and Handling 394

Ditching 395

Pipe Bending $\quad 395$

Welding $\quad 395$

Coating and Wrapping 395

Pipe Laying $\quad 395$

Backfilling and Cleanup 395

Pipeline Testing. 396

P1peline Maintenance . 396

Plpeline Gas Processing 396

Separation, Compresolon, Drying 396

Desulfurization $\quad 397$

Pipeline Regulation 399

Alternatives to Normal Transportation 400

$\begin{array}{ll}\text { Natural Gas Storage } & 401\end{array}$

Underground Gas Storage $\quad 402$

Abovegruund Gas Storage 403

The Gas Storage Industry . 403

Gas Storage Emissions $\quad 404$ 
TABLE OF CONTENTS (Continued)

Page

Crude 011 and Product Storage $\quad 404$

Fixed-Roof Tanks $\quad 405$

Floating-Roof Tanks $\quad 405$

Other Tank Types 407

Special Purpose Tanks $\quad 407$

Underground Storage $\quad 407$

HEALTH AND ENVIRONMENTAL EFFECTS $\quad 409$

Marine Terminal Operations ․ $\quad \therefore \quad 409$

Loading Emissions $\quad 410$

Ballasting $\quad 4.13$

Inerting Systems $\quad 414$

Gasfreelng . $\quad 414$

Compartment Washing . $\quad 415$

Emission Control $\quad 415$

Storage Tank Operations $\quad 415$

Tanle Safety $\quad 417$

Design Trends $\quad 417$

Pipeline Gas Processing . . . . . $\quad 417$

Gas Pipelines . . 418

Pipeline Spills . . 419

$\begin{array}{ll}\text { Microorganisms } & 421\end{array}$

Crude 0il $\quad 421$

Diesel $011 \quad 422$

Micorrhizal Fungi $\quad 422$

Methanol. $\quad 423$

Vapor Phase Organics . 423

Upland Vegetation $\quad 424$

Crude oil $\quad 424$

Products $\quad$.' 425

Wetlands $\quad 425$

Evaporative and Gaseous Emissions 426 
TABLE OF CONTENTS (Concluded)

Page

SUMMARY OF RESEARCH NEEDS

429

Health

429

Environment

430 
LIST OF ILLUSTRATIONS

Figure Number

$\underline{\text { Page }}$

1

Growth of Crude 011 Pipeline in the United States

388

2

Alaska Production Areas

390

3

Typical Natural Gas Processing Sequence

398

\section{LIST OF TABLES}

Table Number

Page

1 Various Estimates of 011 Transportation Efficiencies

Atmospheric Emissions for a Fuel Oil Refinery Module

3 Yearly Emissions from Alaskan Crude Tankers at Port of Long Beach

Summary of Gas Pipeline Accidents and Casualties 
OIL AND GAS TRANSPORTATION AND STORAGE

\section{TECHNOLOGY DESCRIPTION}

Crude oil, petroleum products, and natural gas are transported on land and fresh water* to refineries, storage areas, and markets, utilizing tank trucks, railroad tank cars, barges, and pipelines. The choice of the mode of transportation depends on the distance traveled, the nature of the material being transported, the avallability of the transport system, and other factors.

\section{History of 011 Transportation}

In the early 1800s, ofl was collected from surface deposits and sold as medicine and for lubrication or lighting. Following the "Drake" ofl well completion in 1859, crude was carried in wooden barrels to western Pennsylvania refineries by riverboats, horse-drawn wagons, and railroad flatcars. Charging only $1 / 20$ th of the price for the same service, pipelines quickly replaced other forms of oil transportation by 1900 (Brown and Helfand 1977a).

After 1900, crude production shifted from the east-central states of Pennsylvania, Ohio, Indlana, West Virginia, and Kentucky to newly discovered fields in Texas, Oklahoma, Louisiana, and California (Figure 1). By 1940 more than 85 percent of crude supplies to eastern refineries were derived from production areas west of the Mississippi River (Brown and Helfand 1977b).

To aid acceleration of oil pipeline construction during World War II, Congress passed the Cole Act in 1942 which allowed the President to grant a petroleum pipeline company the right of eminent domaln when acquiring land and rights-of-way during wartime. Within 2 years accelerated construction provided a total of more than 11,000 miles of new pipeline, 3,000 miles of relocation and modernization of older lines, and 3,000 miles of reversed flow in existent lines. Pipeline flow Increased from pre-war levels of less than 50,000 barrels a day to 754,000 (Brown and Helfand 1977b). In 1980 over 11,000 miles of oil and gas liquid pipelines were under construction in the U.S. and Canada (Hale 1980).

\footnotetext{
* See the offshore Development section of this report for information related to marine transportation of oil. Marine transport of gas is addressed in the Liquefied Energy Gases section.
} 

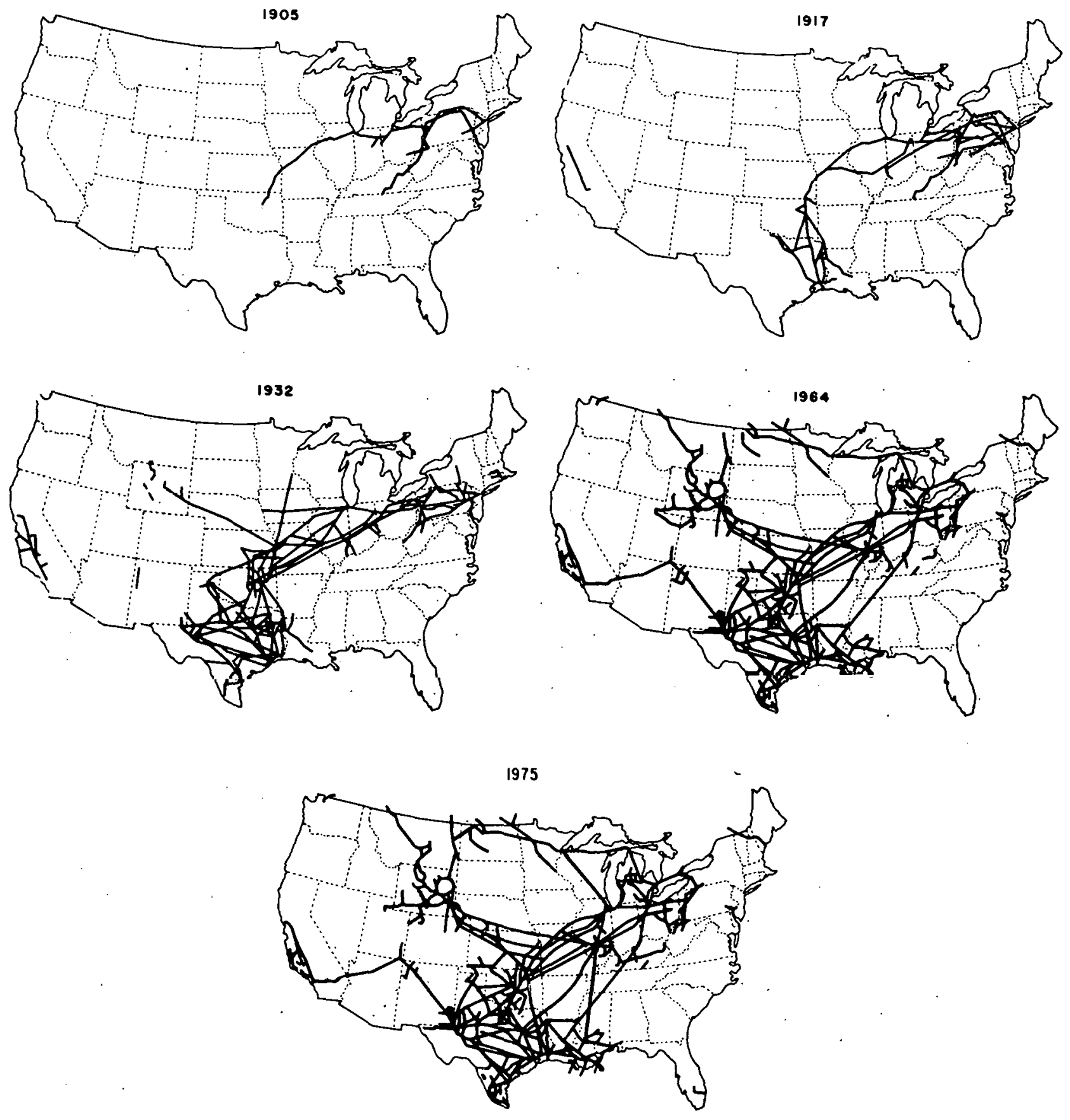

Source: Brown and Helfand 1977a.

FIGURE 1

GROWTH OF CRUDE OIL PIPELINES IN THE UNITED STATES 
After the war many oil pipelines were taken out of service, reversed, or converted to gas pipelines as military demands declined. Tankers soon became available for inter-coastal shipments. During the war, large diameter trunk lines (20 to 24 inches) proved capable of transporting considerable amounts of oil at a lower cost than the pre-war small diameter lines (less than 16 inches). This marked the beginning of a new era in U.S. pipeline construction, characterized by the building of large, long-distance pipelines. The trend began in the 1950s and continues today. Many of the older lines have been removed, used for the transport of products (gasoline, kerosene, turbine fuel, diesel fuel, and heating oil), or converted for the transmission of natural gas.

In the early 1900s, many oil seeps were discovered in Alaska, but further exploration determined that these were not economically recoverable. However, discoveries of oil along the south-central Alaskan coast in the 1950 s and 1960 s led to a modest production peak in 1970 of about 80 million barrels. Following the North Slope discovery in 1958, oil consultants have estimated that the new field contains 5 to 20 billion barrels, or even as much as 50 billion barrels (Figure 2).

After a series of court injunctions and trials, the Trans-Alaska Pipeline Act of 1973 authorized construction of the Alaskan oil pipeline. Work began in 1974 under the direction of Alyeska Pipeline Service Company and involved the construction of almost 800 miles of 48-inch pipe, twelve pump stations, three crude topping plants (which provide turbine fuel for pump stations), an oil storage and shipping complex at the southern terminus in Valdez, and other support facilities. Completed in 1978, the pipeline has a normal flow of 1.2 million barrels a day.

At present, proven economically recoverable reserves in the Prudhoe Bay field amount to about 9.6 billion barrels (Figure 2). Other North Slope reserves and those under the Beaufort Sea are expected to bring the total proven reserves in Norll Alaska to 15.1 billion barrels by 1989. As these reserves are brought on line, production should peak in 1985 at about 3 million barrels a day, which would equal 21 percent of total U.S. crude production. Maintaining the flow after this time will depend upon new finds in existing fields or in new fields such as the National Petroleum Reserve in northwest Alaska. New pipelines (both oil and gas) will be needed to tap these sources.

\section{History of Gas Transportation}

Early records refer to gas being piped through bamboo in 10 th century China, to wells drilled for natural gas in 7 th century Japan, 


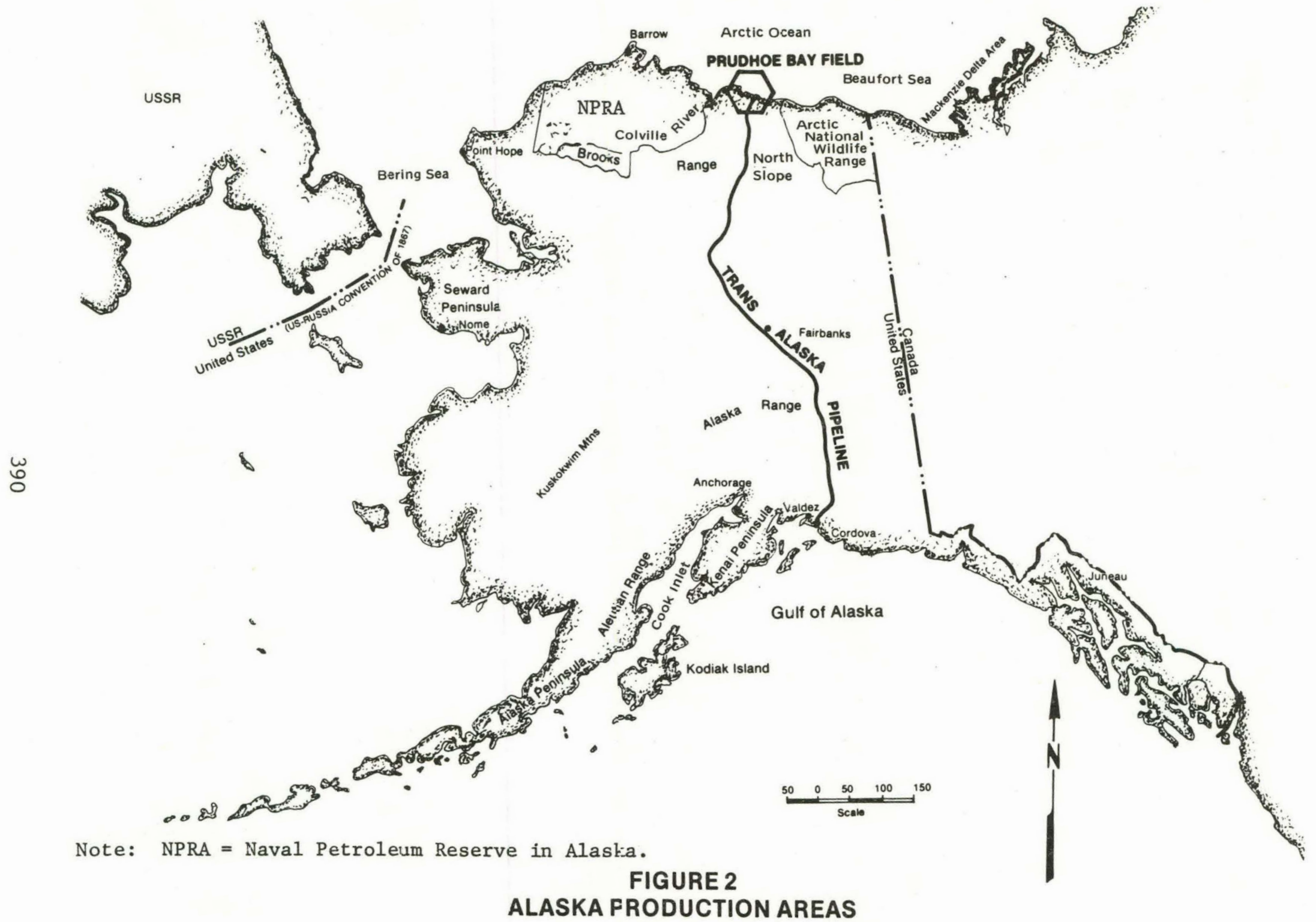


and to the famed Greek oracle at Delphi, where men breathed gas and became lightheaded. In 1577 the Belgian chemist Van Helmont observed a "wild spirit or breath" burst forth from a material being heated in his crucible. He named the substance "gas" after its similarity to a "geist" (a German word for ghost or spirit). Manufactured gas, produced in 18th century Europe by heating coal in the absence of air, soon replaced the candle and oil lamp as a principal source of illumination. Gas manufactured from coal or ofl is still being burned in many countries, but has largely been replaced by less expensive and more convenient natural gas.

Gas companies were established in 1812 in Europe and in 1816 in the U.S. By 1859 more than 300 U.S. cities were 1lluminated with gas. Today natural gas meets over 20 percent of the world's energy requil rements and about 30 percent of U.S. energy needs. It supplies more than 50 percent of the gross energy input to household, commercial, and industrial facilities in the U.S. In addition to its use as a fuel to produce heat and 1ight, natural gas is used as a raw material in the production of chemicals including antifreeze, fertilizers, pesticides, solvents, and synthetic fibers.

As reserves were discovered, long distance pipelines were constructed. Early U.S. pipelines consisted of bored logs joined together and tarred to form wooden pipes which lasted up to 75 years. The first major iron pipeline served the city of. Titusville, Pennsylvania, in 1872. Steel pipes and electric welding came on line in 1887 and 1931, respectively. In 1947, a major change in the gas industry occurred when natural gas from the Southwest was transported to the East Coast through large crude oil pipelines abandoned after World War II (Brown 1978).

Since 1950, the gas utility industry has experienced significant growth, expanding from 400,000 miles to approximately 1 million miles of gas pipelines. The industry also has experienced recent growth in the storage and marine transport of liquefied natural gas (LNG). When refrigerated to $-258^{\circ} \mathrm{F}\left(-161^{\circ} \mathrm{C}\right)$, natural gas can be condensed from 600 cubic feet of gas to 1 cubic foot of liquid, which greatly reduces the volumetric capacity needed for storage or containerized transport. Past use of LNG has largely been dedicated to reserves for peak load service. Recent development of an LNG tanker industry has provided supplemental natural gas for baseload service supplied by gas pipelines. Since 1971 natural gas imports, primarily by pipeline from Canada and Mexico, have accounted for abour 5 percent of the annual domestic consumption of natural gas. In 1978 only about 1 percent of these imports were in the form of LNG.

An ongoing project to move Alaskan gas across Canada to markets in the contiguous states will result in the largest privately 
financed energy project in history--a 4,782-mile system at a cost of $\$ 11$ to $\$ 14$ billion. This project, which has recelved final Federal approval, was selected after exhaustive debates before Federal and state agencies and Congressional committees, as well as numerous assessments of environmental, social, and economic impacts. Federal regulation of this pipeline is to be provided through a Federal. inspector (a new concept in regulation) who will provide a "onewindow" approach intended to simplify the regulatory process, reduce costs and delays, and avoid unnecessary duplication of efforts in builder interactions with various Federal agencies (Brown 1978).

\section{Generic Description of $0 i 1$ and Gas Transportation}

\section{O11 Transportation}

Tank trucks, railroad tank cars (tankers are covered in the offshore Development section of this report), and pipelines are used for domestic transportation. Tank trucks carry relatively small quantities for distances of less than $500 \mathrm{miles}$. Railroad tank cars generally are most cost effective for distances greater than several hundred miles and for tank car quantities. Utilized in coastal waters, tankers carry Alaskan crude to coastal ports. Barges are utilized in major inland waterways, usually in the transport of petroleum products. Both tankers and barges are used for longdistance and large volume transportation, but are limited by available port facilities.

Oill pipelines are competitive with waterborne and railroad transportation. Pipelines are. constructed of welded steel and are as large as four feet in diameter. Pumping stations, which utilize centrifugal pumps and reciprocating engines powered by electric or diesel engines, are located every 50 to 100 kilometers to compensate for pressure drops. The primary efficiency of the various oil transportation methods is nearly 100 percent. Land losses are limited to leaks or spills. Although a threat to the environment, these spills constitute much less than 1 percent of the total amount of oil transported, as indicated in Table 1. That table also shows ancillary energy requirements for different transport methods. These are not comparable because each method is depicted by data for oil transported over different distances.

\section{Gas Transportation}

Most domestic gas is transported by buried steel pipelines with diameters also as large as four feet. The gas usually is compressed to 600 to 1,000 pounds of pressure per square inch and this pressure drives the gas through the pipe. Valves installed every 10 to 30 miles allow for isolation of a pipeline section if a large pressure 
TABLE 1

VARIOUS ESTIMATES OF OIL TRANSPORTATION EFFICIENCIES

\begin{tabular}{|c|c|c|c|c|}
\hline Method & $\begin{array}{l}\text { Primary } \\
\text { Efficiency } \\
\text { (percent) }\end{array}$ & $\begin{array}{l}\text { Ancillary } \\
\text { Energy } \\
\left(10^{9} \text { per }\right. \\
\left.10^{12} \text { Btu's }\right)^{-}\end{array}$ & $\begin{array}{l}\text { Overall } \\
\text { Efficiency } \\
\text { (percent) }\end{array}$ & $\begin{array}{c}\text { Distance for } \\
\text { Ancillary } \\
\text { Energy } \\
\text { (miles) }\end{array}$ \\
\hline Pipeline & 100.0 & 3.69 & 99.3 & 300 \\
\hline Pipeline & $\mathrm{U}$ & $U$ & 99.1 & NA \\
\hline Pipeline ${ }^{c}$ & 99.6 & $\mathrm{U}$ & $\mathbf{U}$ & NA \\
\hline $\begin{array}{l}\text { Tankers and } \\
\text { supertankers }\end{array}$ & 99.6 & 40.7 & 95.8 & 10,000 \\
\hline $\begin{array}{l}\text { Tankers and } \\
\text { supertankers }\end{array}$ & $\mathrm{U}$ & $\mathrm{U}$ & 99.5 & NA \\
\hline Barges $^{a}$ & 100.0 & 25.7 & 97.4 & 1,500 \\
\hline Barges $^{b}$ & $\mathrm{U}$ & $\mathbf{U}$ & 99.6 & NA \\
\hline Tank trucks ${ }^{a}$ & $\mathrm{U}$ & 14.1 & $U$ & 500 \\
\hline Tank cars ${ }^{a}$ & U & 14.6 & $\mathrm{U}$ & 500 \\
\hline
\end{tabular}

Notes: $U=$ Efficiency unknown.

$\mathrm{NA}=$ Data not available.

$a, b$, and $c=$ Different estimators.

Estimates are, subject to a possible error of 25 percent or less.

Source: University of Oklahoma 1975. 
drop occurs. Gas pipelines are coated to protect them from physical (abrasive), chemical, and electrolytic activity. In urban areas, corrosion as a result of electrical currents may be enhanced. Stray electrical charges may cause loss of metallic ions, resulting in a weakening of the pipeline. One mechanism to offset this problem is the use of cathodic protection in which a direct current is applied to the pipe.

\section{Pipeline Construction}

Preliminary Steps. The construction of a typical pipeline begins with preparatory procedures that may involve construction of roads, storage factlities, pumping stations, control and ancillary facilities, and temporary housing. Rights-of-way widths must be surveyed and staked.

Next the land must be cleared and graded. Clearing involves the removal of trees, brush, crops, boulders, and bulldings in the ditch line that would interfere with ditching machine operations. Grading requires leveling the ground surface as necessary for vehicles and equipment so the pipeline may be placed at the desired elevation. Construction of bridges, diverting streams, enbankments and stormwater diversion trenches, and the stabilization of soil to support heavy equipment is required.

During this activity, fences may need to be crossed. This requires the construction of temporary gates, usually of wire. Gatekeepers may be needed to keep livestock from straying or to prevent improper use of the passageways. Following construction, these fence openings need to be repalred.

Pipe Storage and Handling. Sometimes the line pipe is strung before the ditch is dug and sometimes afterward, depending on local conditions and contractor preference. This of ten leads to safety hazards because, in many instances, the ditching activities and the pipeline supply operation are handled by separate contractors who operate on different time schedules driven by variations in economic incentives, efficiency of operation, and convenience. Often the deep trench is left open and unguarded for several months before the pipeline is delivered.

The line pipe and casing pipe is hauled over public roads, which requires licenses and permits from Federal, state, and local agencies. With double-jointed pipe, special routes must be carefully selected to avold sharp turns and weak bridges. Should storage be required before the string is laid, care must be taken to keep the pipe from sinking into the ground, to distribute pipe weight to prevent flattening or other deformation, and to prevent or control 
corrosion, especially at the beveled edges of the pipe (Petroleum Extension Service 1973).

Coating materials, gate valves, fittings, and plpe must be hauled to the rlght-of-way and strung (1.e., distributed in the places where they will be needed for construction). The pipe is usually loaded onto trucks and unloaded by tractors or trucks fitted with sidebooms. Care must be taken to avold damaging pipes and coatings.

Ditching. Ditching includes all excavation work required to provide a ditch of the specified dimensions and depth of pipe cover. Depending on topography and location, the depth of the ditch may vary from a few feet to dozens of feet. The trenches usually are dug to provide at least a foot clearance on each side of the pipe. TrenchIng is by mechanical, wheel-mounted, self-propelled, or tractor-drawn ditching machines; single-toothed rippers; or sometimes by backhoes. Explosives may be used where rock or permafrost is encountered. Burial is the preferred method of crossing stream beds, except where high scouring rates exist.

Pipe Bending. The pipeline must conform to the terrain and contour of the ditch, both vertically and horizontally. The pipe is bent using heavy, hydraulically operated machines mounted on tracks. or skids.

Welding. Welding in the field is performed both manually and with automatic equipment. The welds are subjected to inspection with visual, mechanical, electronic, and $x$-ray techniques to ensure integrity.

Coating and Wrapping. This procedure is for pipe protection. The wrapping material is chosen for its resistance to soll corrosiveness and chemical content of the groundwater. Coating and wrapping materials include asphalt, asphalt-saturated paper, somastic (asphalt and sand), coal tar with coal tar-saturated paper, butyl tape, or thin film epoxy. Concrete coatings and collars are also used, especlally for stability when pipes cross waterways and wetlands.

P1pe Laying. The lowering-in operation normally is integrated with the welding, bending, coating, and wrapping sequence in major pipeline projects and requires specially designed equipment. Commonly, sideboom, crawling tractors are used to lower the pipe into the liench. Swabbing 18 performed to reduce the amount of foreign matter rematning after welding.

Backfilling and Cleanup. After the pipe is placed, the excavated material is backfilled. It may be necessary to pad the pipe 
with processed soil or sand. Special techniques are required to prevent frost heave, maintain aquifer movement and surface and tile drainage, and to prevent crushing under highway and railroad traffic corridors. Site cleanup, revegetation, and restoration are required. This involves disposing of unused excavated materials, construction wastes and debris, and the removal and obliteration of temporary camps, roads, and storage areas. If pipeline work is conducted in winter, revegetation and restoration will carry over into summer. More than 1 year may be required to restore the land (or to retain its natural surface configuration with proper backfilling) and reestablish the vegetative cover.

\section{Pipeline Testing}

After construction and before operation, a pipeline is tested hydrostatically (usually with air) for leaks in the pipe or welds, and to verify structural integrity at expected operating pressure. In cold areas such as Alaska, a methanol solution or air may be used to test gas pipelines (see U.S. Department of the Interior 1977 for a discussion of the pros and cons associated with each testing method). With hydrostatic testing, care must be taken to avold discharging contaminated water into natural draining courses. Usually, test water, which accumulates metals and products of corrosion and welding, is stored and used again without discharge. When construction progress is in the direction of oil flow, ofl can be used to displace water from successive sections of the pipeline as construction is complet ed.

\section{Pipeline Maintenance}

Usually compressor stations are designed to operate automat 1cally by remote control. Mainline block valves, located at about 20-kilometer intervals, serve to close portions of the pipeline for repair. Pipeline scrapers or pigs are used for internal cleaning and are released and captured in specially designed traps. Right-of-way inspections are a continuous activity involving aerial survelllance, mechanized patrol, or sometimes foot patrol. Usually this activity also includes the maintenance of a right-of-way permanently cleared to a width of 50 feet.

\section{Pipeline Gas Processing}

Separation, Compression, Drying. Fluids from both oll and gas wells are usually first processed through a free water knock-out separator to remove water and sand. They then pass through a separation sequence. Both water and water vapor must be removed from natural gas to prevent the formation of methane hydrates (solid snowlike compounds of water and methane). The hydrates are formed when 
the gas cools as it expands. Hydrates can plug wellhead valves, metering equipment, and pipelines. If hydrate formation is a problem at the wellhead, the produced fluids can be heated prior to flowing into any gas processing equipment.

After water and sand have been removed, the hydrocarbons are passed through a low-pressure separator and split into ofl and gas streams. The separation of assoclated gas (gas occurring with the oil elther free or in solution) and condensates may: be performed in several stages to increase the recovery. of liquid hydrocarbons (Figure 3). The gas also may be dried using a glycol process in which a combination of heat and a glycol vapor are used to dry the gas (University of Oklahoma 1975, 1979).

The type of gas produced and the extent of separation needed determines, in large part, the amount of gas marketed from a particular hydrocarbon reservolr. "Normally, a fluid stream rich in natural gas is processed using a single-stage, low-pressure separator. However, the gas recovered from a single oll-gas separator frequently cannot be economically compressed and transmitted to shore or to an existing gas transmission 11ne. Such gas, in past years, was vented to the atmosphere or flared. It may be returned to the reservoir in order to enhance the recovery of liquids from gas condensate reservoirs or crude oll from crude oll reservolrs contalning gas caps.

As pressures are normally high in the early production life of a gas reservoir, compression may not be needed to trangmit the gas through the gathering system until the later years of the tapped reservoir's life. In an oil-gas reservolr, however, compression is needed throughout the life: of the reservoir because all fluids are passed through low-pressure separators. Depending on the type and stage of the reservoir, no compression may be needed, a single wellhead compressor may be used, or an extensive central compressor complex may be required (Unilversity of Oklahoma 1975).

Desulfurization. The process of removing sultur from natural gas 18 adjunct to other natural gas processing steps (e.g., field separation, natural gas liquids removal, compression) and in many situations may be used in conjunction with them. The process involves removing hydrogen sulfide $\left(\mathrm{H}_{2} \mathrm{~S}\right)$ from natural gas in which its relative concentration may range from 0 to 76 percent. As with crude oil, natural gases containing relatively high concentrations of hydrogen sulfide are termed "sour;" whereas, those" that are essentially free of hydragen sulfide are termed "sweet."

Sour gases present several problems in the processing and handling of natural gas. They are extremely toxic and corrosive. When burned, they may produce substantial amounts of sulfur dioxide 


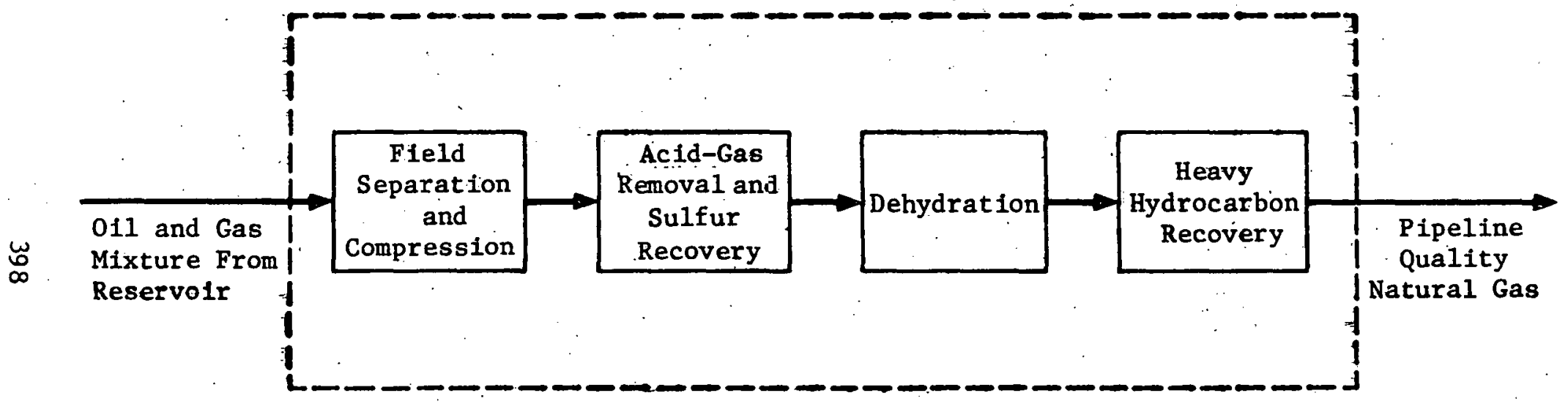

FIGURE 3

TYPICAL NATURAL GAS PROCESSING SEQUENCE 
$\left(\mathrm{SO}_{2}\right)$ or sulfur trioxide $\left(\mathrm{SO}_{3}\right)$. Thus, when sour gas is extracted and processed, special grades of steel must be used in the construction of wells, well equipment, gathering field pipelines, and treatment facilities.

Because of 1 ts toxic and corrosive properties, $\mathrm{H}_{2} \mathrm{~S}$ is removed in desulfurization plants before the gas is transported by pipeline and marketed. The process which is most commonly used involves the extraction of hydrogen sulfide through the use of a solution of ethanolamine. This process removes carbon dioxide and almost all of the hydrogen sulfide (F1gure 3). After removal from the gas and regeneration of the ethanolamine solution, the hydrogen sulfide often has been flared in past years, resulting in a discharge of sulfur dioxide directly into the atmosphere. Today, up to 95 percent of the hydrogen sulfide is converted to elemental sulfur. New--but expensive-techniques allow for the recovery of 99.9 percent of the sulfur in sour natural gas (University of Oklahoma 1975).

\section{Pipeline Regulation}

Both the gas and ofl pipeline industries are heavily regulated with respect to health, safety, and the environment. Regulations relate to pressure testing, weld integrity, safety, and air emissions. Regulating agencies include the Federal Energy Regulatory Commission, the National Transportation Safety Board, the Department of Transportation (DOT), and the U.S. Environmental Protection Agency. Pending legislation (PL 196-29) is designed to give DOT the authority to promulgate safety regulations for liquid as well as gas pipelines.

DOT is sued amendments to CFR 49 Part 195 that, for the most part, became effective July 15, 1980. These rules include highly volatile liquids. (HVL) for the first time and impose more stringent requirements. For example, pipeline operating manuals must contain more detafled information than was formerly required. The monitoring of pressure, temperature, and flow from unattended stations is required unless the facility is equipped with fall-safe devices; and, the requirements for training and public education are more extensive.

The Environmental Protection Agency is also stepping up its activities. For example, it is becoming increasingly difficult to obtain permits to construct and operate new storage tanks. Tanks handling liquid petroleum products between approximately 1.5 and 11.5 psia vapor pressure must submit to Prevention of Significant Deterioration (PSD) review, which may require site monitoring and offset activities. As a result, liquid pipeline projects may easily be delayed for several years while permit requirements are being resolved (Polasek 1980). 


\section{Alternatives to Normal Transportation}

Over the years several exotic ideas have been proposed for the transportation of oil and gas. Some may be utilized in the future, and they include:

- Submarine Tankers. The General Dynamics Corporation of New York has proposed a 900-foot-1ong submarine tanker that can carry a 170,000-ton cargo. 0il or LNG would be carried almost everywhere in the sub, except for a portion in the center pressure cylinder reserved for living and machinery space.

The sub-tanker could travel long distances, even under polar ice, and could easily travel through tropical storms. The tanker could be fully loaded from undersea terminals or offshore platforms and surface to discharge at coastal or inland ports.

Also proposed is that the submarine or a tug boat pull submerged oil tank trains, cement barges, or large rubber containers of crude oil. These units could be transported inland by rivers and canals.

- Hovercraft. Another proposal involves using hovercraft (surface effect ships and vehicles, air cushion vehicles, and captured air-bubble ships). These heavy transport vehicles could provide an ideal air-water-land interface for coastal wetland or rugged terrain transport of relatively small volumes of oil to remote areas. The method offers flexibility of destination at a speed faster than ships and slower than aircraft. It also provides the shipping economy of large tankers and rail tank trains, and the possibility of year-round transport (Dyas 1972).

- Aerotankers. An unusual proposal is to employ airplanes or cargo planes. The Boeing aircraft company has developed plans for a mammoth plane with a wingspan of 478 feet (compared to 195 feet for the 747), requiring the thrust of a dozen jet engines to lift its 3.5 million pounds gross net weight. This "resource carrier" could carry 8,100 barrels of oil or LNG in two wing-mounted detachable cargo pods.

- Ice Breakers. Ice-breaking tankers have been proposed for both LNG and crude oil. There is at least one known design for an ice-breaking supertanker to carry oil from the arctic area, but none has actually been built. The largest icebreaking vessel which has operated in the arctic thus far is 
the 114,668-dead-weight-ton MANHATTAN, which made two voyages in 1969 and 1970. Those voyages should provide sufficient dat a to permit the design of a hull configuration that would withstand the forces and accelerations of 1ce breaking. The characteristics of an adequate hull configuration would be an ice-breaking bow of the standard type (experiments with "novel" ice-breaking bows have given poor results), addition of a high-tensile steel ice-belt to protect areas of shell plating exposed to ice damage, and additional hull framing and stiffening members (Dyas 1972; U.S. Department of the Interior 1976).

- Dirigibiles. Interest in dirigibles for cargo transportation has been rising since the first international conference on dirigibles was held in 1973. Thus, the possibillty of using this method for LNG transport warrants mention.

Sonstegaard has studied the possible transport of LNG by dirigible on the principle that the cheapest way to transport a commercial gas could be to put it in a streamlined bag and float it in the atmosphere. According to his findings, reported in 1970, natural gas could be transported by large dirigible alrships from as far as the Alaskan North Slope to the New York-Philadelphia area at a price. (based on 1970 figures) competitive with gas pipelined from the Gulf coast region.

Most persons at the international conference on airships belleved a possible use date was at least 10 years away. Shell 011 Company has experimented with the use of smaller blimps to transport natural gas from the Middle East in lieu of building foreign LNG plants (U.S. Department of the Interior 1976).

\section{Natural Gas Storage}

Natural gas storage and transfer technologles are old and well established. Facilities were established to meet a demand that varies over a 24-hour period and is seasonal. Thus, storage facilities primarily function to equalize pressures and meet peak supply demands placed on plpelines and gas delivery systems. Pipelines are generally deslgned for a delivery rate roughly equal to the average demand rate. Excess gas delivered during periods of low demand is stored for use during peak demand periods. Operation of pipelines near their capacity with high loads minimizes unit transportation costs. 
The first recorded experiment in storing gas underground was successfully accomplished in Welland County, Ontario, in 1915. Several old wells were reconditioned. Then gas was injected into the partially depleted field, and withdrawn the following winter to meet peak requirements. The next year, the first storage operation in the U.S. was begun in the depleted Zoar Field near Buffalo, New York. This storage reservolr is still in operation. Subsequently, techniques were developed to store gas in depleted water sands (aquifers), salt caverns, coal mines, and tanks. In 1978, over 68 billion cubic feet of gas was in storage, of which 54 billion cubic feet was in underground storage.

\section{Underground Gas Storage}

Normally, natural gas is stored underground in depleted gas reservoirs, but depleted oil reservoirs are also used. Water-bearing formations or aquifers, dug caverns, and sealed mines have been used in areas where depleted gas or oil fields are unavailable.

In most underground, depleted gas or ofl fleld reservolrs, water present in porous media is the confining mechanism; the stored gas tends to form a bubble (Katz 1980). Caprocks normally are low permeability rocks filled with water. The pores are so small that gas pressure cannot displace the water at prevalling pressure differentials due to surface effects. Underneath the gas-saturated reservoir, water-filled zones prevent the gas from moving downward or laterally. It is taken for granted that the caprock can withstand pressure from the buoyed gas reservoir, for the same caprock previously held a gas or ofl deposit through a substantial geological time span. However, extensive testing is conducted and structural safety factors are built in. Leakage may occur due to such anomalies as caprock fractures, faults, solution cavities, "pinching-out" around the caprock, and leaks around well casings.

It is reportedly common to hear the hissing sound of gas leaking at storage fields (Katz 1980). Gases are stored under pressure, from several hundred to several thousand pounds per square inch, and fugitive leaks from valves, flanges, compressors, well heads, and joints are Inevitable. Gas in the atmosphere of audibly leaking equipment at one location has been measured at 5 to $10 \mathrm{ppm}-$-well within the safe range for occupational exposures. Like the distribution of leak sources within a refinery, a few sources account for a large proportion of the loss. The orifice tap and other equipment under the highest pressure are likely to emit detectable leakage. Losses from such leakage, if unrepaired, may run into millions of cublc feet per year (a small percentage of the gas stored). 
Techniques developed to measure gas losses have shown that an audible leak could cause the loss of 1 billion cubic feet per year. Within well bores, temperature and noise logs are used to detect leakage areas where gas expansion creates a temperature drop and detectable pressure waves. Storage operators closely monitor their reservoirs and underground gas movements, and repair leaking equipment.

Gas storage reservolis normally have operational lifetimes of 30 to 50 years or more. Over this period, some gas can leak through casings or caprock to enter zones above the intended storage zone. The gases may eventually reach local water supplies, permeate surface soil, and enter buildings or their water supplies, creating explosive mixtures. This rarely occurs and storage operators may place monitors on water supplies and in basements in the 1 mmediate area.

Pressures in oil or gas reservoirs are described in pounds per square inch per foot of depth. Internal pressures alone would fracture reservolr caprock and cement structures if it were not for the counterbalancing, depth-dependent external pressures which relieve much of the strain.

Prior to storage and transmission, natural gas is cleaned of hydrogen sulfide, carbon dioxide, water, and other contaminants. When gas is transferred up from underground storage, it may contain some $\mathrm{H}_{2} \mathrm{~S}$ due to contamination from caprock or oil within the reservoir. Exiting gases may be periodically or continuously monitored for $\mathrm{H}_{2} \mathrm{~S}$ concentrations. Natural gases may naturally contain traces of oxygen and occasionally compressed air is added to dilute overly rich (high in ethane and propane) gases to normal heating values. Propane-air mixtures may be stored or transported for injection into the storage or distribution stream as a method of meeting peak demands.

\section{Aboveground Gas Storage}

Aboveground tanks or gasholders are used to meet dally peak demands in local distribution systems. The use of these tanks is declining since they are being replaced by liquified gases peakshaving plants. Gasholders are frequently of the lifter-roof type that is also used for petroleum products storage.

\section{The Gas Storage Industry}

As of November 1978, there were 396 underground storage fields belonging to 91 companies, of which 10 fields were under development. Nearly all storage facilities are operated for natural gas pipeline and regional consumption peak-shaving operations. For 1978 to 1979, 
the gas industry had the potential of feeding 80 to 84 billion cubic feet or more total peak day sendouts into distribution (pipeline) systems. Underground gas storage provides most of the nation's storage capacity (over 54 billion cubic feet). Reservoirs may hold varying proportions of injected and native gas, 1.e., gas remaining in the reservoir from its previous use as a gas or oil well (Hale 1980).

Gas storage facilities are primarily located near major gas consumption areas and natural gas fields. Most factlities are clustered in the northern Appalachian and Indiana-Illinols-Kentucky regions.

\section{Gas Storage Emissions}

Negligible alr pollution results from underground and aboveground gas storage. However, products of combustion are emitted by compressors required for injection and withdrawal. Methane, the major constituent of stored natural gas, is not photochemically active and does not result in ozone production.

A leaking reservoir may permit gases to enter local aquifers, but this is usually remedied quickly; the gas dissipates rapidly and constitutes little toxic hazard, although occasionally it may pose a safety hazard by creating an explosive mixture that accumulates in an aboveground confined space. Natural gas that leaks to the surface may also accumulate in depressions, disrupting sensitive vegetation.

Natural gas storage poses few occupational health hazards under normal operating conditions, although major leaks may pose the hazards of explosions and asphyxiation.

Crude 011 and Product Storage

Large tanks are used to store crude oil and refinery products prior to transport or use. Tanks may be located with production sites, pipelines, terminals, refineries, tank farms, or usage locations. The filling and emptying of storage tanks may result in the release of hydrocarbon emissions. A 1976 survey identified 25,000 storage tank locations (Petroleum Extension Service 1978). There are approximately 40,000 tanks with capacitles greater than 40,000 gallons $(151,000$ liters). Annual volatile organic compounds (hydrocarbon) emissions from these tanks are estimated at $8.3 \times 10$ kilograms per year, or approximately 1.8 billion pounds per year. About 83 percent of these emissions are from tanks with fixed roofs and 17 percent from tanks with floating roofs which minimize emissions, as will be described below. 
In 1976, the estimated ratio of fixed-roof to floating-roof tanks was about two to one, but the total capacities of both types we re approximately equal. Recent regulatory actions will change this ratio, increasing floating-roof tank storage. For both tank types, the majority of hydrocarbon emissions were from tanks.storing gasoline and crude oil. Hydrocarbon emissions from these tanks are shown in Table 2.

\section{F1xed-Roof Tanks}

Fixed-roof tanks provide the simplest and least expensive kind of aboveground bulk storage. They basically consist of a cylindrical steel shell topped by a hemispherical roof. They are generally equipped with a pressure/vacuum vent designed to minimize minor, pressure-induced outflows of hydrocarbon-laden. vapors and inflows of air.

Vapor pressure changes that result in hydrocarbon vapor em1ssions are caused by a number of factors. Tank loading can cause vapors above the liquid surface to be displaced into the atmosphere. Evaporation, a constant process from the surface of any liquid, results in pressure buildup and eventual emissions. Solar heating of tank contents and the resulting expansion of vapors causes emissions. Heating may result from hourly, daily, or seasonal temperature changes. Tank "breathing" is a diurnal phenomenon that results in considerable emissions; heat from sunlight impacts on tanks, resulting in expansion and emission of vapors. Then cooling at night draws in fresh alr, which increases vapor pressures, causing emissions as it becomes saturated with hydrocarbon vapors. Emission controls for storage tanks involve minimizing vapor spaces, tight sealing, reflective paints, and vapor recovery.

\section{Floating-Roof Tanks}

Floating-roof tanks mintmize vapor losses by constantly minimizing vapor spaces. As the name implies, the roofs of these tanks actually float on the surface of the stored liquid. (They are not used for gas storage.). The roof rides up and down inside the tank shell as the oil level changes. Emissions from.floating-roof tanks can be 95 percent lower than those from fixed-roof tanks. A fixedroof storage tank may be made into a floating-roof tank with the incernal installation of a floating ronf.

Fluating-roof tanks may be open (uncovered) or covered--essentially a floating roof within a fixed-roof tank. They may vary in their complexity, cost, and degree of emissions control. Major types of roofs include: simple floating decks consisting of a flat metal plate with a vertical rim and bracing for rigidity, decks with 
TABLE 2

ATMOSPHERIC EMISSIONS FOR A FUEL OIL REFINERY MODULE ${ }^{a}$ (lbs/day)

\begin{tabular}{|c|c|c|c|c|c|}
\hline & Particu:ates & $\mathrm{SO}_{\mathrm{x}}$ & $\mathrm{CO}$ & Hydrocarbons & $\mathrm{NO}_{\mathbf{x}}$ \\
\hline Crude distillation & 3,080 & 6,400 & 533 & 533 & 5,300 \\
\hline Gas oil hydrotreater & 280 & 539 & 90 & 128 & 1,084 \\
\hline Naphtha hydrotreater & 19 & 27 & 16.2 & 27.7 & 219 \\
\hline Heavy naphtha reformer & 1,960 & $4,0.73$ & 340 & 340 & 3,390 \\
\hline Propane deasphalting unit & 474 & 673 & 49.6 & 84.8 & 680 \\
\hline Deasphalted oil hydrotreater & 30 & 42 & 25.2 & 42.9 & 340 \\
\hline Tail gas treating & 3.4 & $3,410^{*}$ & 3.0 & 4.9 & 39 \\
\hline Light ends recovery & 2.6 & 3.7 & 2.2 & 3.8 & 30.4 \\
\hline $\begin{array}{l}\mathrm{C}_{5} / \mathrm{C}_{6} \text { isomerization } \\
\text { Storage }\end{array}$ & 120 & 250 & 21 & 20.8 & 208 \\
\hline Crude & -- & $-\infty$ & -- & 7,550 & -- \\
\hline Motor gasoline & -- & -- & --- & 3,730 & -- \\
\hline Light fuel ofl & -- & -- & -- & 564 & -- \\
\hline Heavy fuel oil & -- & -- & --- & Negligible & -- \\
\hline Sludge incineration & 354 & 597 & 125 & 41 & 510 \\
\hline Miscellaneous emissions & --- & --- & --- & 60,900 & -- \\
\hline Total & $\overline{6,320}$ & $\overline{16,000}$ & $\overline{1,200}$ & $\overline{73,970}$ & $\overline{11,830}$ \\
\hline
\end{tabular}

Based on $200,000 \mathrm{bbl} /$ day crude feed.

* Mainly due to the tail gas itself. 
pontoons around the rim to provide additional floating stability under heavy loads of water and snow, and double-deck roofs that employ two interspaced decks above the 1iquild surface. Double-deck roofs provide insulation between the top surface exposed to the sun and atmosphere, and the bottom surface covering the oil, thus providing thermal insulation and minimizing evaporation. Various types of seals are employed around the edge of the floating-roof deck to maintain vapor sealing and to permit raising and lowering of the roof.

Besides lowering vapor emlssions, floating roofs perform a number of other functions. Fire hazards are reduced since vapors are minimized and the ofl surface is almost entirely covered. Corrosion due to vapors rising from sour crudes, such as hydrogen sulfide, are kept to a minimum as their area of alr contact is minimized.

Floating roofs still require pressure and vacuum release vents and produce evaporative and breathing emissions, but these are minimized due to the decreased vapor space.

Floating-roof tanks may be covered. In fact, covers may be required in some climates due to heavy rain or snow. Space between the fixed and internal floating roofs must be vented to prevent formation of explosive vapor concentrations.

- Other Tank Types

Variable vapor space tanks are equipped with expandable vapor reservolrs to limt vapor volume fluctuations due to temperature, barometric, and pumping-induced changes. A variable vapor space tank normally is connected to the vapor spaces of more than one tank, usually fixed-roof tanks. The two most common variable space tanks are lifter-roof tanks and flexible-dlaphragm tanks. Lifter-roof tanks have a telescoping, sealed roof that fits around the outside of and over the maln tank wall. Local natural gas supplies are frequently held in simple tanks called gasholders.

Special Purpose Tanks

Pressure tanks, designed to withstand relatively large pressure variations without vapor loss, are generally used to store highly volatile refinery products. These tanks are typically spherical or cylindrical in shape and may withstand pressures up to 265 psia.

Underground Storage

The storage of oil underground is a recent activity. One of the goals of the Strategic Petroleum Reserve System as established by the 
Energy Policy and Conservation Act (PL 94-163) is to have 150 and 500 million barrels of petroleum in underground storage (salt domes and salt or limestone mines) by December 1980 and 1982 , respectively. Ultimately, the Department of Energy plans to store up to 1 billion barrels of crude oil in caverns created under Louisiana and Texas. The amount entering storage has fallen short of anticipated goals as a result of price and supply complications. A recent testing of withdrawal capability exceeded design rates at three storage sites.

The proposed caverns are expected to be produced by dissolving subterranean salt deposits with water. The dissolved rock salt forms a saline solution of about 265 parts of salt per 1,000 parts of water with a temperature range of $81^{\circ}$ to $99^{\circ} \mathrm{F}\left(27^{\circ}\right.$ to $\left.37^{\circ} \mathrm{C}\right)$. The process appears feasible wherever adequate water supplies and brine disposal conditions exist. (Brine disposal at inland sites may result in severe damage to terrestrial biota and upland solls.) The National Oceanic and Atmospheric Administration (NOAA) is evaluating the environmental impact of pumping saturated brine into the Gulf of Mexico's coastal waters. The study includes site-specific assessments and the development of a monitoring plan for brine discharges (Flagg 1980).

To date, the focus of attention on underground storage has been on safety problems as a result of an explosion and subsequent fire during filling operations at a Gulf Coast salt dome. Environmental concern has focused on impacts of the construction phase on wetlands as a result of the truck transport of materials, ditching, dredging, spoil stowage, and road and stream crossings causing noise, dust, mud, exhaust emissions, stream turbidity, and stream bottom disruption in pristine areas. Concerns over operations have focused on the permanent change in groundwater movement and the encroachment on and injury to local animal and plant species.

Underground ofl storage is an area that should recelve research attention since it is related to many national policy issues as well as to several facets of the oil and gas industry. For example, the proposed Northern Tier Pipeline, the survivor in the competition to move Alaskan North Slope crude oil from the West Coast to midwestern U.S. markets, is currently arranging financing for and acquiring the remainder of its permits to build the 1,557-mile pipeline from Port Angeles, Washington, to Clearbrook, Minnesota. One of the selling points of the project is that the route crosses the Williston Basin, an area with deep lying salt deposits along the Montana-North Dakota border. For several years the Northern Tier Pipeline Company has Indicated that these deposits could be utilized for an inland strategic oil storage area served by the pipeline. 
HEALTH AND ENVIRONMENTAL EFFECTS

Health and environmental effects associated with oil and gas transportation and storage are discussed in this section. The issues are categorized by the major facets of technology that have received attention as sources of potentially damaging emissions. The health ef fects of one group of pollutants--hydrocarbons--are not discussed in detail here. Humans are exposed to hydrocarbons at various points in the movement of oil, but much of the information on this subject is presented in the Refinery Operations section.

Marine Terminal Operations

Nearly all foreign and Alaskan crude oll is transported by marine tankers and barges, as is much of the oil produced in the lower 48 states. Crude oll is typically held in bulk storage facilities and pipelines at terminals or port facilities both before and after shipping. Refinery products frequently are also shipped by sea. Ship transfer--both the loading and unloading of crude oil and refinery products--may pose serious health, safety, and environmental hazards.

Marine terminal emissions generally have been unregulated. This lack of regulation is, in part, due to an unclear legal authority over the operations of ships while they are in port and underway. The tanker captain, Coast Guard, Environmental Protection Agency, and local or state authorities have varying interpretations as to their respective authority over different ship operations.

Tankers transporting oil between ports in the U.S. are subject to the Merchant Marine Act of 1920, commonly known as the Jones Act. This act.requires that movement between domestic ports be carried out by U.S. built and owned tankers operating under the U.S. flag with American crews and masters. Coast Guard regulations implementing the Ports and Waterways Act of 1972 require vessels larger than 70,000 dead weight tons (dwt) to have segregated ballast tanks, two slop tanks (for retention of tank washings and oil residues), and an oil residue tank for the containment of oil leakages and sludge. 0il spills, ship collisions, discharge of water used for hydrostatic testing and cleaning, flushing of ballast tanks, discharge of bilge water and sewage, and other ship operations may result in intentional and accidental air and water pollution.

Most hydrocarbon emissions in or near port are associated with tankers that do not contain inerting and segregated ballast systems. A majority of these vessels are small (less than 75,000 dwt in size). Owing to their shallow draft, many U.S. crude oil importing ports are 
served only by these unregulated small tankers which supply 60 percent of imported crude to U.S. coastal ports, mostly to the major crude importation areas of the East and Gulf coasts.

Many factors affect the magnitude of crude oll and refinery product transfer emissions. Adequate emission factors or correlations for estimating these hydrocarbon transfer emissions are difficult to develop due to the many ship, cargo, and operating variables involved (Burklin et al. 1976). Considerable work has been performed toward assessing emissions and other environmental concerns involved with the tanker transport of Alaskan crude ofl to West Coast ports, primarily in the already hydrocarbon-polluted Los Angeles area.

Estimates based on the SOHIO project, a proposed (now terminated) major terminal for handling Alaskan crude (involving approximately 270 tanker visits per year), indicate that yearly $\mathrm{SO}_{\mathrm{x}}$ emissions could range from 220 tons per year to 880 tons per year. These ranges are based on differences in fuels, particularly the, sulfur content ( 0.5 to 2 percent). If transit time in the port vicinity is included, this range could be from 500 to 2,000 tons per year. $\mathrm{NO}_{x}$ emissions were estimated to range from 120 tons per year to 210 tons per year, depending on whether transit time 18 included. Carbon monoxide and particulate emissions were minimal and have not been an 1ssue (alrborne particles were estimated to be 40 tons per year; Co emissions generally were not calculated). One scenario of estimated emissions, compared with emission levels that define "major" air pollution sources, ${ }^{*}$ is shown in Table 3 .

Marine terminal emissions are primarily associated with loading and unloading operations. Loading emissions may be separated into an arrival and a generated component. The arrival component of loading emissions consists of displacement venting of hydrocarbon vapors left in empty cargo compartments from previous cargoes. The generated component consists of hydrocarbon vapors formed in the cargo tanks as liquids are loaded. The quantity of hydrocarbon vapors generated during loading depends on the vapor pressure of the hydrocarbons and loading practices, especially loading rates.

Loading Emissions

When a vessel arrives in port, prior to loading or unloading operations, hydrocarbon vapor concentrations typically are uniform throughout the compartment's vapor space. Upon arrival, a compartment in a gasoline loading vessel characteristically contains from 0

\footnotetext{
*Facilities categorized as "major" air pollution sources would be subject to offsetting requirements.
} 
TABLE 3

YEARLY EMISSIONS FROM ALASKAN CRUDE TANKERS AT PORT OF LONG BEACH

\begin{tabular}{|c|c|c|c|}
\hline \multirow[b]{2}{*}{ Pollutant } & \multirow{2}{*}{$\begin{array}{l}\text { EPA } \\
\text { Guidelines } \\
\text { (tons/year) }\end{array}$} & \multicolumn{2}{|c|}{$\begin{array}{c}\text { Estimates from soHIo Project } \\
(270 \text { visits/year) }\end{array}$} \\
\hline & & Port Only & Port $\&$ Transit \\
\hline Particulates & 50 & 40 & 60 \\
\hline${ }^{\text {so }} x$ & 50 & $220^{c}-880^{d}$ & $500^{c}-2,000^{d}$ \\
\hline $\mathrm{NO}_{\mathbf{x}}$ & 50 & 120 & 210 \\
\hline $\mathrm{HC}$ & 50 & $0^{\mathrm{e}}-7,000^{\mathrm{f}}$ & $0^{e}-10,000^{f}$, \\
\hline $\mathrm{CO}$ & 500. & \multicolumn{2}{|c|}{ Negligible } \\
\hline
\end{tabular}

auidelines for defining a "major" source in effect at the time of SOHIO (Alaskan crude) environmental impact statement review.

b Only large tankers considered (100 visits, $80,000 \mathrm{dwt} ; 73$ visits, 120,000 dwt; 97 visits, 165,000 dwt).

${ }^{c}$ Assumes a fuel sulfur content of 0.5 percent.

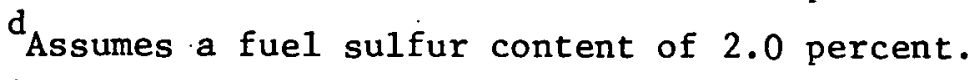

No ballasting or tank cleaning (purging) assumed.

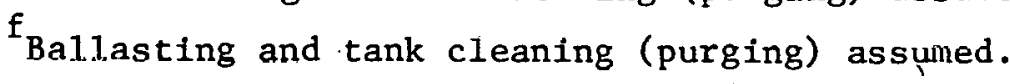


to 20 percent hydrocarbons by volume, but the proportion can exceed 50 percent hydrocarbons by volume (Burklin 1976). During loading, a vapor blanket two to eight feet thick, contalning a high concentration of hydrocarbons, forms above the liquid surface. The generated component of loading emissions, this vapor blanket is primarily attributable to evaporation and turbulence of the input liquid. For vessels such as barges, which have shallow compartments (on the order of $12 \mathrm{feet}$ ), loading will cause the venting of the dense vapor blanket, producing proportionately more hydrocarbon emissions than the loading of tankers that have deeper drafts (on the order of 55 feet), unless the last few feet of compartment depth is filled. Loading-generated, turbulence-induced, vapor blanket depth may be significantly reduced--up to 50 to 60 percent--by slow initial loading. Cleaned and vented tanks (lacking an arrival vapor component), which are intially loaded slowly and not filled to the top, will produce minimal emissions. Slow final loading can lower hydrocarbon emissions due to less disturbance and venting of the vapor blanket.

The true vapor pressure (TVP) of a hydrocarbon liquid has a marked impact on the hydrocarbon content of its loading and unloading emissions (Burk1in 1976). TVP is an indicator of volatility and is a function of the liquid's Reid Vapor Pressure and temperature. High TVP liquids have high evaporation rates (high volatility) and produce high hydrocarbon concentrations in loading and unloading vapor emissions. The TVP of crude oils can range from 0 to over 15 psia and the TVP of gasolines may range from 6 to 10 psia.

Many different estimates for port hydrocarbon emissions have been developed, based on different assumptions of what tanker operations are performed in port or at sea. Limited barge emissions data Indicate that hydrocarbon emissions are in the range of 27 percent by volume. Hydrocarbon concentrations in emptied crude oil tanks may reach 10 percent by volume, but are more typically in the 5 percent range. Actual concentrations depend on a number of factors, includIng the TVP and volatility of the crude oil, mixing time, and turbulence. For emptied gasoline tanks, vented vapors may be within the explosive concentration range, typically 1.4 to 8.4 percent by volume, during most of the loading operation. Vented vapors may pose explosive hazards, besides adding to the ambient hydrocarbon concentrations in the vicinity of the port and at sea.

Tankers in port produce considerable emissions besides hydrocarbons. A ship.'s boilers are rarely shut down while it is in port, so there are combustion-related emissions that result from hotelling or idling at the pier, pumping and ballasting operations, maneuvering to dock, and the maintenance of many of a ship's systems. It is belleved that tankers in berth burn more fuel than other ships of similar size, as on-board pumps are used to unload crude and refinery 
products. Offloading involves using the tanker's on-board engines at 80 percent of full power for 10 to 12 hours for tankers in the 80,000 to 165,000 dead welght tonnage class. The sulfur content of the fuels that tankers use may vary and, even ignoring these variations, sulfur oxides and other avallable emissions estimates vary greatly. Tanker hydrocarbon emissions.fron fueling and boiler combustion are negligible compared to those from transfer operations.

Tanker purging, ballasting, venting, and storage tank emissions are the major sources of hydrocarbon emissions from crude and refinery product marine transfer operations. The present operating practices, frequency of occurrence, and levels of emissions and emission controls associated with these and other transfer operations are unknown.

Emission controls for marine tanker and barge operations involve basic design features and operating practices. Significant hydrocarbon emlssions from oil tankers and barges result malnly from the displacement of hydrocarbon-laden alr from empty storage compartments and from the operation of a ship's internal combustion engines. Various sources of marine transfer emissions and their control measures are discussed below.

\section{Ballasting}

Ballasting involves filling empty cargo space or segregated, dedicated ballast tanks with seawater after discharging cargo. Ballast is required to ensure proper ship seaworthiness, stability and balance, trim, and propeller immersion. The amount of ballast taken on depends on a number of factors, including the vessel's route, displacement characteristics and proportions, and expected weather conditions. Normally, from 15 to 20 percent of the vessel's total cargo carrying capacity may be taken on as ballast in port. Once at sea, cargo-empty vessels take on additional ballast to approximately 40 percent of their total cargo capacity.

Conventional tankers take on ballast In three alternative ways:

- All necessary ballast is taken on in cargo tanks (with the minor exception of fore and aft peak tanks).

- A portion of the necessary ballast is taken on in segregated ballast tanks, and the remainder is taken into cargo tanks.

- All necessary ballast is taken on in segregated ballast tanks. 
The majority of tankers in world trade do not have 15 to 20 percent of their capacity devoted to segregated ballast tanks; thus, initial ballasting is largely accomplished in cargo compartments in port. U.S. Coast Guard regulations and the Inter-Governmental Maritime Consultive Organization recommend that new tankers of 70,000 dead weight tons or more be required to have fully segregated ballast tanks equal to about 35 percent of capacity.

Taking on ballast displaces hydrocarbon vapors present in previously unloaded cargo tanks, much the.same as does the loading of crude oll or refinery products.

\section{Inert1ng Systems}

Vapor spaces in cargo compartments carrying crude oil or refinery products contain potentially explosive concentrations of hydrocarbon vapors and air containing oxygen. Inerting systems pressurize the vapor space of cargo compartments with oxygen-poor flue gas from the ship's bollers. Exhausted flue gases are passed through a scrubber where they are cleaned and cooled before they are vented into the cargo tanks. During this process, approximately 17 percent of the flue gas is diverted from entering the atmosphere, which reduces total stack emissions proportionately for tankers in the 120,000 to 165,000 dead-weight-tonnage class. During loaded passage, the inert atmosphere above the cargo liquids is maintained by periodic repressurizing. When oil is offloaded, inert flue gases are pumped into the tanks as oil is pumped out to ensure that the tank's atmosphere remains inert. Besides eliminating explosive hazards, such inerting sys tems reduce corrosion in cargo compartments.

When cargo-empty inerted compartments are loaded, the flue gases are displaced and exhausted, along with some hydrocarbon vapors from evaporating fluids that remain on the sides and bottom of the compartments.

\section{Gasfreeing}

Empty and ballasted cargo compartments may be purged of their hydrocarbon-laden atmospheres by replacement with air. Atr may be blown in (purging) or cargo compartment covers removed (venting). If empty tanks have previously been washed thoroughly at sea, the gasified tanker may take on cargo without venting hydrocarbons in port, or workers may enter the compartments for maintenance. Significant hydrocarbon emissions may occur in port if gasfreeing operations are performed there. 


\section{Compartment Washing}

Emptied cargo compartments contain hydrocarbon liquids that lie in residual puddles and wet the side walls. Tank walls and floors are usually washed down with water before a new cargo 1s loaded. A recent practice is to wash with crude oll, thus eliminating a potential water pollution problem. Residual hydrocarbon liquids in the cargo compartment, with or without washing, volatilize to form the empty cargo compartment's vapor component. Compartment washing may significantly reduce the concentration of hydrocarbon vapors in the tanks upon arrival, subsequently decreasing hydrocarbon emissions upon loading. Liquids from washing usually are stored in slop tanks for disposal onshore, often in a refinery wastewater treatment system.

\section{Emission Contro1}

Emission control technology for marine loading is a young technology with a unique set of problems (Burklin et al. 1976). A ship's hydrocarbon vapors are exhausted at high rates and frequently contain. air, presenting an explosive hazard when handled by any type of machinery. The cumulative loading rate for a gasoline tanker can be as high as 50,000 barrels $(210,000$ gallons) per hour--equivalent to . $4,700 \mathrm{scfm}$ of displaced vapors.

Vapor control technology used for truck loading is not directly applicable to marine terminals, because hydrocarbon vapor concentrations in tank truck loading are above the explosive range and the rates of vapor displacement are much lower. Some control technologies currently available include vapor collection and condensation at cryogenic temperatures $\left(-80^{\circ} \mathrm{F}\right.$ to $\left.-100^{\circ} \mathrm{F}\right)$, absorption in a refinery oll stream, and incineration or flaring of vapors. All of these methods pose additional hazards and considerable expense. The first two methods do not remove methane vapors. Vapor dilution or saturation, required in most systems to avold handling vapors $1 \mathrm{n}$ Llieli explosive concentration range, is energy-intensive.

\section{Storage Tank Operations}

Vapor emissions from storage tanks result from the following:

- Fixed-roof breathing losses--due to thermal expansion of vapors, vapor expansion caused by lowered atmospheric barometric pressures, and Increases in vapor due to 11quid evaporation.

o Fixed-roof working losses--due to vapor expelled from tanks as a result of filling and emptying operations. (Emptying 
loss is attributable to subsequent vapor pressure increases as newly inhaled air becomes saturated with hydrocarbons.)

- Floating-roof standing storage losses--due to improper fit of roof seals.

- Floating-roof working losses--same causes as fixed-roof working losses, but amounts emitted are significantly less.

- Floating-roof withdrawal losses--due to evaporation from wet ted tank walls as tanks are emptied. The loss is small in comparison to other loss types.

- Variable space filling losses--due to loss of vapors upon filling when expandable storage capacity is exceeded.

- Pressure tank losses-due to rellef venting when operating pressures are exceeded. This is not a significant source of emissions under normal operating conditions.

The amount of evaporation and other losses from storage tanks depends on a number of factors, including:

- True vapor pressure of the stored liquid;

o Temperature changes in the tank;

- Helght of the vapor space;

o. Tank diameter;

- Schedules of filling and emptying;

- Mechanical condition of tanks and seals;

- Type of tank and paint applied to outer surface; and

- Fugitive emissions due to vapor and/or liquid leaks.

Equations to estimate tank vapor losses have been developed, but have not been extensively field tested or universally accepted.

Vapor recovery systems are the major emissions control technology appropriate for the recovery of vapors exhausted from storage tanks. These are not as widely used in refineries as floating-roof tanks, probably due to their high cost and energy requirements. 
Tank Safety.

Fire walls are required around storage tanks holding flammable liquids. These dikes, at least equal in capacity to the storage tank they surround, are designed to hold a tank's contents in case major leaks or spills occur. Besides holding oil for recovery, fire walls prevent the spread of burning ofl to adjacent tanks and buildings. Sometimes, but rarely, safeguards may break down, allowing spilled oil to enter stormwater runoff drains. When this occurs, a catastrophe could result.

When ignited, light refined oll products usually burn quietly until extinguished or burned dry. Crude oil, heavier refined ofls, and fuel ofls are liable to boll over after burning for some time in the tank. Bolling over results when heat from the burning surface works its way down to the bottom layer of water present in nearly every tank. The water layer flashes into steam, expelling burning ofl out of the tank.

Numerous mechanical safeguards and operating procedures are employed within the oll industry to maximize safety in case of human error, fires, explosions, ground settling, earthquakes, and other mishaps that inevitably may affect storage tanks.

\section{Design Trends}

Recently, new standards concerning storage tank technology and emissions control have been promulgated (Federal Register 4 April 1980). These standards, designed to limit volatile organic compounds (hydrocarbons) emissions, apply to new, modifled, or reconstructed petroleum liquid storage vessels with a capacity for more than 40,000 gallons (151,000 11ters) of liquids with a true vapor pressure greater than 1.5 psia $(10.3 \mathrm{kPa})$. These regulations require et ther the use of double seals on external floating roofs, a seal on internal floating roofs, a vapor recovery and disposal or recurn system that reduces emissions by more than 95 percent (by weight), or any equivalent, demonstrated emissions control method. Most crude oils and refinery intermediates and products are covered by these regulations. Storage vessels used in crude ofl extraction operations and those with a capacity of less than about 420,000 gallons ( 1.6 million liters) are exempt. Petroleum product tanks are covered by the regulations, wherever their location, including those in chemical plants.

\section{Pipeline Gas Processing}

Accidents occur more frequently in natural gas operations than in corresponding crude oil operations. However, natural gas 
operational accidents generally cause far less environmental damage. Accidents include gas well blowouts, gas gathering line leaks, and malfunctions of gas processing equipment.

No substantial amounts of water or solid waste contaminants are released during gas gathering or separation. The major environmental impact relates to air quality. The estimated emission level of nitrogen oxides during gas gathering is 2.6 tons per $10^{12}$ Btu's gathered. This is derived from the use of 3.7 percent of the produced fuel in gas engines used to drive compressors. The level represents over 55 percent of all nitrogen oxides emisstons associated with the extraction, gathering, and processing of natural gas.

Nitrogen oxides emissions pose problems for health and the environment (e.g., acid rain). For discussion of effects and research needs associated with nitrogen oxides emissions related to natural gas (mostly emanating from compressors), see the End Use section of this report and the Report of the Interagency Task Force on Environmental Issues (U.S. Department of the Interior 1977).

Alr emissions associated with sulfur removal are smal1-amounting to about 0.4 tons per $10^{12} \mathrm{Btu}$ 's of gas processed (based on processing 60 million cubic feet per day). About 70 percent by weight are nitrogen oxides. The emissions are a result of using natural gas as a fuel to produce process steam. Elemental sulfur, produced in this process, can be marketed and is not considered to be a waste material.

Based on a plant processing 60 million cubic feet per day of a gas containing one grain of hydrogen sulfide per standard cublc foot of gas, about $0.8 \times 10^{9} \mathrm{Btu}$ 's per $10^{12} \mathrm{Btu}$ 's of natural gas processed is released in the water effluent. This thermal enrichment is about $1 / 10$ th of the amount released from a natural gas liquids processing plant (University of Oklahoma 1975).

Because of the danger to operating personne1, field procedures for sour gases must include precautions not required in the production of sweet gas. Safety measures have been developed to cope with this long-recognized problem.

Gas Pipelines

Almost all pipeline accidents can be attributed to corrosion damage by outside forces, construction defects, or material failure. Corrosion may be internal or external. External corrosion may result from the chemical and electrolytic salt action of water, groundwater, soils, and sediments. Internal corrosion is caused by hydrogen sulfide, water, or acidic conditions. External corrosion is lessened 
with coatings, cathodic protection, and the use of corrosion resistant materials such as plastic, aluminum, and stainless steel. Internal corrosion is lessened by interior coatings, injecting corrosion inhibitors, and chemicals. Chemicals include oxygen scavengers to reduce dissolved oxygen concentrations, dehydrants, and bases.

Gas pipeline accidents tend to affect non-employees rather than employees of pipeline companies (Table 4). Examples can illustrate the accidents which may occur. In Bainbridge, Georgla, on August 26, 1976, a two-1nch steel pipeline was damaged. It had an open end and inadvertent opening of a valve permitted gas to escape. The gas migrated under pavement and into a post office. An explosion and fire resulted, k1liling one person in the post office and injuring two others. In Hugo, North Carolina, on September 29, 1975, three fata1ities occurred from a fire and explosion resulting from the escape of natural gas into an air-conditioning control room. The accident was traced to the weight of a sewer line causing a split in polyethylene service line carrying 45 psig 12 feet from the bullding (BIiss 1977).

\section{Pipeline Spills}

This section considers the potential effects of terrestrial ofl spills resulting from the pipeline transport of crude and refined petroleum products. Some emphasis will be placed on northern and arctic areas. There, the construction and operation of the TransAlaska Pipeline has resulted in much preliminary information being made avallable. The discussion will include a consideration of the potential effects from both 11quid and gaseous components. Where possible, the impacts of combusted petroleum on plants and animals also will be considered. Because petroleum fires may accompany large spills, this area would also seem to merlt some consideration. The approach taken here will be to consider how an ecosystem's microorganisms, plants and animals may be impacted by petroleum. It should be emphasized that potential ecological effects of any petroleum spill will be subject to many varlables, and that the extrapolation of results from one terrestrial system (e.g., the arctic) to another requires caution. Among such varlables are the:

o Type and quantity of oil spilled,

- Location of the spil1,

- Topography of the area,

- Single or repetitive spills,

- Season of the year, 
TABLE 4

SUMARY OF GAS PIPELINE ACCIDENTS AND CASUALTIES

\begin{tabular}{|c|c|c|c|c|c|c|c|c|c|c|}
\hline \multirow[b]{3}{*}{$\begin{array}{c}\text { Calendar } \\
\text { Year }\end{array}$} & \multicolumn{5}{|c|}{ Distribution } & \multicolumn{5}{|c|}{ Transmission and Gathering } \\
\hline & \multirow{2}{*}{$\begin{array}{c}\text { Number } \\
\text { of } \\
\text { Faflures }\end{array}$} & \multicolumn{2}{|c|}{ Fatalities } & \multicolumn{2}{|c|}{ Injuries } & \multirow{2}{*}{$\begin{array}{c}\text { Number } \\
\text { of } \\
\text { Fatlures }\end{array}$} & \multicolumn{2}{|c|}{ Fatalitieg } & \multicolumn{2}{|c|}{ Injuries } \\
\hline & & Employees: & $\begin{array}{c}\text { Non- } \\
\text { Employees }\end{array}$ & Employees & $\begin{array}{c}\text { Non- } \\
\text { Employees }\end{array}$ & & Emploỳees & $\begin{array}{c}\text { Non- } \\
\text { Employees }\end{array}$ & Employees & $\begin{array}{c}\text { Non- } \\
\text { Employees }\end{array}$ \\
\hline $1970^{\circ}$ & 676 & 1 & 20 & 32 & 170 & 343 & 1 & 0 & 8 & - 8 \\
\hline 1971 & 875 & 6 & 36 & 36 & .329 & 410 & 2 & 1 & 14 & 10 \\
\hline 1972 & 884 & 2 & 26 & 32 & 262 & 409 & 3 & 3 & 23 & . 13 \\
\hline 1973 & 893 & 1 & 32 & 48 & 285 & 471 & 1 & 1 & 3 & 16 \\
\hline 1974 & 1,017 & 1 & 19 & 31 & 283 & 460 & 1 & 3 & 7 & 13 \\
\hline 1975 & 979 & 0 & 8 & 29 & 191 & 394 & 5 & 1 & 8 & 9 \\
\hline
\end{tabular}

Source: Bliss 1977. 
- Type of soil,

- Life stages of impacted organisms,

- Metabolic rates of organisms, and the

- Mobility of organisms.

This list is not meant to be inclusive, but only representative of factors that can change from one area to another.

\section{Microorganisms}

Crude 011. Bacteria and fungi are responsible for both the degradation of organic matter and the concomitant recycling of nutrients. As such, they play a vital role in all terrestrial ecosystems. Various investigations have been carried out to discover how petroleum may affect both the population dynamics and physiological functions of these organisms. In this context, Sparrow et al. (1978) studied the response of microorganisms to crude oll spills on subarctic soll. These were short-term experiments carried out over summer and winter. The research was designed to determine how crude oll spllled during different seasons would affect soll microorganisms. Hot crude of1 (7,570 1iters) was applied to each of two ( 10 by 50-meter) plots. One application was made during winter, the other during summer; and no oll was applied to a control plot. Following the winter application there was a marked difference in the way the fung $i$ and bacterla responded to the oll. The number of fung $i$ declined while the bacteria increased in number on the ofled plot compared to the control. After the summer application even greater numbers of bacterla were present on the ofled plot compared to the control. The number of fung1 st111 showed either lower or approximately equal numbers of organisms. This remained the case unt1l September when the fungal count rose to flve times that of the control plot.

In another project designed to study the response of soil fungl to oil, similar inhibitory responses were noted (Miller et al. 1978). In this 3-year study, ofl was applied to experimental plots at 5 and 12 liters per $\mathrm{m}^{2}$. The treated plots were compared to unolled control plots. Fungal biomass was significantly less in both oiled plots over all 3 years. Furthermore, no difference was detected between the two levels of oil in this response. In addition to fung1, other groups of microorganisms have been found to respond to applied o11. It also has been reported that denitrifying, proteolytic, and cellulose-utflizing organisms may actually be stimulated by the presence of oil (Sparrow et a1. 1978). 
Longer-term studies have been carried out on mfcrobial response to crude oil. Sexstone et al. (1978) examined the effects of crude oil at Barrow, Alaska, on microbial populations 2 and 7 years after oil was applied to experimental plots. They also attempted to correlate the relationship of various soll parameters to interactions between petroleum and microorganisms. The experimental plots were designed so that a gradient of soil moisture existed within them. In those plots that were studled 2 years after the application of crude ofl, a general increase in microbial numbers was observed in all plots except for those with wetter, less well-drained soil. Residual oil was found in soll from both the 2- and 7-year-old plots, with the greatest concentration found at the surface (zero- to two-cm) level. In the wel1-drained soll plots, some ofl was detected throughout the entire zero- to eight-cm cores of soil. In the wetter, less-we11drained soil, oil remalned much closer to the surface. In general, 1t was found that oil remained at or relatively near the soll surface, and that oil reached its maximum soil penetration within 1 year of application. Evidence that microbial degradation of the applied oll was slowly taking place was inferred from column chromatographic studies. However, no evidence was gathered in this particular study which demonstrated that specific classes of oil hydrocarbons were being preferentially degraded by microorganisms.

Diesel 0i1. . In another geographic area with different soil topography, another study (Sexstone et a1. 1978) analyzed the results of both controlled crude and refined (diesel) oil spills. The numbers of hydrocarbon-utilizing mlcroorganioms wero found to increase in the wetter solls in plots treated with both crude and refined oils. These results differed from those obtained in the former study, where wetter soll had relatively fewer organisms then did drier, better-drained soll.

Micorrhizal Fungi. The impact of oil on soll microorganisms extends beyond its effect on relatively simple, free-living organisms. What must also be considered are the effects that petroleum may have on symblotic microorganisms. Mycorrhiza are a widespread and important group of such organisms. The word mycorrhiza literally translates as "root fungus." These fung1 are extremely important to the plants with which they are assoclated. It is through such fungi that nutrients which nourish plants must first pass. The potential impact of a petroleum spill on such microbial-plant associations could be large and potentially as severe as a marine oil spill.

Preliminary studies on the effects of crude oil on such symbiotic fungi have been carrled out. Antibus and Linkins (1978) examined the effects of crude oil on such a fungal deciduous shrub association over a 3-year period. Changes in both anatomical structure and the number of viable mycorrhizae were found. There was an espectally 
large reduction in the number of viable mycorrhizae after the first week the oll (12 1iters per $\mathrm{m}^{2}$ ) was applied. It was reported that after this high initial response, destruction continued, but at a slower rate throughout the remainder of the growing season. Three seasons later, the effects were s.t111 apparent.

The effects of ofl on mycorrhizal-root respiration have also been investigated. Antibus and Linkins (1978) studied the effects of 5- and 12-1iter per $\mathrm{m}^{2}$ applications of crude ofl on the shrub Salix rotundifolla. Within 48 hours after the application of o1l, respiration for the 5- and 12-1iter per $\mathrm{m}^{2}$ plots was depressed by 22 percent and 56 percent, respectively. Respiration values remained depressed (below controls) for the remainder of that summer. The following summer, respiration rates for the 5-11ter per $\mathrm{m}^{2}$ plots were above controls, while the 12-11ter per $\mathrm{m}^{2}$ plots were sti11 20 percent below controls. The third and final summer found little difference in respiration between the treated and control areas.

Methanol. In addition to terrestrial effects that may result from accidents in petroleum pipeline transport, there are potential effects involving the chemicals used to initially test pipelines. Methanol is one chemical that has been strongly proposed for use.in hydrostatic pipeline pressure testing. The conversion of natural gas (methane) into methanol for ease of transport has also been proposed. There have been few in-depth studies conducted on the potential effects of such a spill on soll microorganisms and the concomitant persistence of methanol in soll. Bryant (1975) reported the results of laboratory studies in which varying amounts of methanol were applied to soll cores. Both absolute and 20 percent methanol solutions were used for these experiments (distilled water served as a control). It was reported that 20 percent methanol had an immediate effect on soil bacterla, causing an overall decrease in bacterial numbers; however, 1 week later the population had recovered and no dramatic population shifts were observed. When absolute (100 percent) methanol was applled to soll cores, a more sustained effect on bacterial numbers was noted, as well as some population shifts. In another study (Parkinson 1974) in which 20 percent methanol was applied directly to field plots at varying rates, greater bacterial numbers were found in the methanol plots than in the control plots. Fungal response to methanol was also noted; however, no significant difference was found in the total number of species. Field samples from treated plots were examined for the possible persistence of methanol, but none was detected.

Vapor Phase Organics. In addition to the effects from liquid petroleum or microorganisms, are those that may result from petroleum associated vapor emissions. For example, vapor phase organics may affect soil fertility by inhibiting the germination of spore forming 
bacilli-that are common to fertile soll. Such a spore inhibiting effect has been demonstrated for many vapor phase organics, includIng: propane, $n$-butane, propylene, 1-butene, trans-2-butene, 1,3 butene, 3-methy 1-1-butene and 1sobutane (Rode and Foster 1965). In experiments with spore suspensions of various specles of Bacillus, it was found that spores remained dormant under a butane atmosphere, but germinated after the gas was removed (U.S. Environmental Protection Agency 1975). Not all vapor phase organics have such an effect. For example, some of the more important petroleum associated organics (e.g., methane and ethane) have not been shown to cause this inhibiting effect. In addition to spore inhibition, other effects on soll microorganisms also have been shown to result from exposure to various hydrocarbons. For example, Kolke (1961) examined the effects of various hydrocarbons on the soll microflora and found that some compounds significantly retard soll nitrification. Other investigators have shown that some halogenated hydrocarbons had more effects on bacteria than fung1 (Wensley 1953). Such interactions between hydrocarbons and microbes could disrupt a sensitive balance within so11 ecosystems.

\section{Upland Vegetation}

Crude 011. In addition to impacts on soll microorganisms, petroleum and 1ts constituent or derivative components (both liquid and gaseous) may also strongly affect terrestrlal vegetation. Some potential disasters for soli and vegetation along the proposed (now terminated) crude oll pipeline from Long Beach, Callfuiula, to Midland, Texas, have been 1dentified. Not only could a major pipeline rupture result in serious soll and groundwater contamination in general, but this pipeline in particular would have crossed agricultural valleys and grazing lands such as San Bernardino, Palo Verde, and Casa Grande, as well as natural desert and prairle land. In agricultural areas, it was speculated that, if not removed or leached out after a major spi11, o11 might remain in the top two to three feet of soll, causing soll contamination and crop loss (U.S. Department of the Interfor 1976). It was further noted that it might take a "few years" before aeroblc soll microbes degraded the ofl in such agricultural areas; and that soll and native vegetation in nonagricultural areas over which the pipeline crossed might take even longer periods to recover.

Direct experimental studies on the effects of ofl and related compounds on vegetation also have been undertaken. Generally conducted in northern (e.g., Alaskan and Canadian arctic) regions, they have dealt primarily with the effects of such compounds on natural upland vegetation. A few studies have also considered effects on transitional ecosystems such as marsh lands. Hutchinson and Freedman (1975) studied the effects of crude ofl on tundra vegetation in the 
Canadian arctic. Both short- and long-term effects were recorded over a 3-year period and the crude oil was applied by two methods. In one, ofl was evenly applied at a relatively low level ( 9.2 liters per $\left.\mathrm{m}^{2}\right)$. In the other, a point source spill of 50 barrels was employed. Both spills were reported to have had a devastating effect on vegetation with very little recovery even after the third summer. Lichens and mosses were almost completely eliminated. 0il was said to have acted as a "contact herbicide." Both chlorophyll and water metabolism appeared to be affected. Winter spills were reported to be less severe than summer spills, due to little follage growth during the winter. Plant reproduction was severely affected whether the oil was applied in summer or winter. It was noted that few species had flowered or borne fruit 3 years after the spills.

Jenkins et al. (1978) analyzed the effects of crude oll spills on a specific vegetation type (black spruce) in Alaska. As in the former study, both summer and winter spills were employed. In both seasons, 2,000 gallons (7,570 11ters) of crude o11 were used. 011 was found to have flowed much farther in summer and covered a greater total area than in winter. Vegetation mortality was complete within those areas covered by surface flows of oll. It was reported that deciduous species had the most rap1d injury, with evergreen species having a more delayed response. Where ofl covered the surface, vegetation did not recover.

Linkins et al. (1978) also examined the effects of surfaceapplied crude ofl on vegetation. They found that the rate of root respiration in higher plants was depressed more than a year after an Initial application of crude oil with concomitant decreases in viable biomass noted over a 3-year period. It was suggested that the continued decline in blomass may indicate that, when roots are subjected to fresh or weathered oil, their ability to tolerate environmental extremes such as drought or cold is impaired.

Products. Other research has examincd the effecls of refined petroleum spills on northern vegetation and possible restorative measures. Hunt et al. (1973) found that vegetation affected by spills of various refined products such as gasoline responded well to revegetation when nitrogen and phosphorous fertilizers were applied. Their experimental plots showed both an increase in density of vegetation and in microbial activity. It was not determined if the increase in vegetation resulted from the fertilizer alone, or from an increased rate of microbial petroleum degradation.

Wetlands. In addition to studies on the impact of ofl on upland vegetation, research has also been carried out on transitional emergent vegetation such as is found in marshes. Marshes, besides being 
near coastal and inland waterways that are highly susceptible to navigational petroleum spills, may also be at risk from coastal and major inland pipelines.

The effect of ofl on marsh vegetation 1s apparently severe. For example, crude oil that had surface contact with plants, such as sedges, horsetails, and mosses, has been observed to cause extensive chlorophyl1 loss and death to young plant shoots. On the other hand, it has been reported that plant parts which are below water level survive and emerge the next season (Hellebust et al. 1975). Another study, however, reported that there actually was greater net productivity in stands of Spartina alterniflora (a major marsh species) exposed to an ofl spill than in control plots. In another study on a spill involving a lighter oll (no. 2 fuel oil), it-was postulated that marshes were acting as a "sponge." The spilled oil was retained by the marsh and subsequently released over long periods of time (U.S. Environmental Protection Agency 1979). This persistence of a relatively light fuel oil for long periods of time disproves the frequently-stated assumption that light fuel olls are quickly dissipated in wetlands.

\section{Evaporative and Gaseous Emissions}

Petroleum-related gases and vapors, including those generated by combustion processes, may have varying effects on a plant community. Probably the most important of the petroleum-derived gas products transported through pipelines is methane, the major component of natural gas. When breaks occur in underground pipelines carrying this compound, local vegetation may be severely Impalred. Various physical and chemical changes leading to plant deaths have been observed (Adams and E1lis 1960).

Probably of more direct concern are the reactions that hydrocarbon vapors and/or petroleum combustion products may undergo, and any adverse effect that may result. It is important to recognize that such gaseous pollutants may undergo reactions with each other, and. with normal atmospheric constituents, to produce compounds that may have pronounced effects greater than those of the Individual components.

Vapor phase compounds that may be classed as organic pollutants include a large number of organic compounds that are the result of incomplete combustion (partial oxidation), varying from almost a pure carbon to peroxyacetylnitrates (U.S. Environmental Protection Agency 1975). Such vapor phase organics, if arising from a large-scale spill, with or without an ensuing fire, may react with atmospheric components such as ozone, $\mathrm{SO}_{\mathrm{x}}$, and various nitrogen oxides $\left(\mathrm{NO}_{\mathrm{x}}\right.$ ) to produce highly phytotoxic compounds. Such reactions are of ten of 
a photochemical nature (1.e., catalyzed by sunlight), and have been extensively studied in urban areas such as Los Angeles where the pollutants are collectively termed "smog." It is not unreasonable to assume, in the event of a massive or multiple spill, that relatively large volumes of potentially reactive vapors may undergo simflar photochemical transformations. This could especlally be true of petroleum fuel fires.

The effects of urban smog on vegetation are well known and have been implicated in the injury of vascular plants. Three important, specific phytotoxic compounds have been identified: ozone, nitrogen dioxide, and peroxyacylnitrate (PAN) (U.S. Environmental Protection Agency 1978). Peroxacylnitrates are the most phytotoxic of these known oxidants. Many studies have attributed plant symptoms resulting from smog to be directly due to PAN or its derivatives (Middleton 1961; Taylor 1969; Hershaft 1976).

The general effects of smog-induced injury have been reported as irregularly distributed bronzing or glazing on the bottom side of the leaf (Middleton et al. 1958; Middleton 1961). Plants exposed to PAN also develop distinctive characteristics including visible and internal metabolic changes such as chlorosis, necrotic streaking and stippling (U.S. Environmental Protection Agency 1975). Stephens and Scott (1962) have reported the development of lesions on sensitive petunia and tobacco varleties exposed to PAN. Simllarly, noticeable effects have been reported for Ilma beans and corn.

Depending on such variables as the concentration of pollutants and the duration of exposure, increases in cell permeability and decreases in photosynthetic rates following exposure to PAN and ozone have also been documented (TIngey 1977). It has been speculated that other effects may include abberant enzyme activity and changes in translocation of materials within plants.

The effects of urban smog on vegetation are well known and have been implicated in the injury of vascular plants. Three important, specific phytotoxic compounds have been identified: ozone, nitrogen dioxide, and peroxyacylnitrate (PAN) (U.S. Environmental Protection Agency 1978). Peroxacylnitrates are the most phytotoxic of these known oxidants. Many studies have attributed plant symptoms resulting from smog to be directly due to PAN or its derivatives (Middleton 1961; Taylor 1969; Hershaft 1976).

The general effects of smog-induced injury liave been reported as irregularly distributed bronzing or glazing on the bottom side of the leaf (Middleton et al. 1958; Middleton 1961). Plants exposed to PAN also develop distinctive characteristics including visible and inter- 
nal metabolic changes such as chlorosis, necrotic streaking and stippling (U.S. Environmental Protection Agency 1975). Stephens and Scott (1962) have reported the development of lesions on sensitive petunia and tobacco varieties exposed to PAN. Similarly, noticeable effects have been reported for lima beans and corn.

Depending on such variables as the concentration of pollutants and the duration of exposure, increases in cell permeability and decreases in photosynthetic rates following exposure to PAN and ozone have also been documented (TIngey 1977). It has been speculated that other effects may include abberant enzyme activity and changes in translocation of materials within plants. 
SUMMARY OF RESEARCH NEEDS

The following are research needs related to o1l and gas transportation and storage.

Health

- Because of the potential for dermal exposure to ethanolamine, toxic properties of the chemical should be studied more closely. It is considered a corrosive material, but its toxicity has not been established (Lewis 1979).

- The potential for nitrosamine formation should be examined for areas where considerable amounts of ethanolamine are exposed to ambient air.

- Safety procedures should be developed regarding public exposure to unguarded deep trenches during pipeline construction through urban areas.

- A health risk assessment is needed with respect to the exposure of pipeline construction workers to coal tar pipe coatings, coal tar-saturated wrapping materials, and asphalt coatings and wrapping materials.

- A set of guidelines should be developed to provide conformity in the as sumptions used in determining emission factors for air. quality analyses of proposed marine terminals. The guidelines would recommend approaches for scenarios involving the number of tankers in port simultaneously, the duration of such a condition, and the length of travel into port associated with air quality implications. The guidelines would provide common ground for the development of worst case, business-as-usual, and best case scenarios, as well as consequent emission factors for the evaluation of new port facilities.

- There is a need for epidemiological studies of individuals involved in oll transfer operations. Loading and offloading operations can result in occupational exposure via inhalation and dermal contact.

o. Relating to the hazard of explosions and fires at terminal facilities, several measures can be taken during the construction or operation of tankers and their support facilities to eliminate or significantly reduce adverse impacts upon air quality in or near port locations. These Include: 
- Ship or facility design--a minimum 35 percent segregated ballast capacity; controlled offshore mooring sites; and required inerting systems for cargo holds.

- Control technology--the use of recycling flue gas scrubbers for all flue gas emissions(in place of once-through systems); requiring vapor recovery systems for terminal operations (in addition to storage tanks); continuous on-board monitoring of tanker emissions; and combustion modification processes.

- Operations--requiring the use of low sulfur fuel $(0.5$ percent sulfur content or less); use of natural gas as an inerting medium; and curtailment of in-port purging or gas freeing.

The feasibility of implementing these options should be explored in depth. It is conceivable that ships, while non-mobile and tied up at a pler facility, may be considered stationary sources of emissions and may come under the jurisdiction of EPA under the Clean Air Act. The ramfications of this possibility should also be explored.

\section{Environment}

The following are research areas where additional information is needed, especlally with reepect to microorganisms:

- More research on how oil may affect plant-microorganism symbiotic relationships (e.g., mycorrhizal-plant associations). This is an important research area which may provide useful data for the development of reclamation strategies.

- Increased research on the effect of oil in different soil types; specifically, how do physical and chemical characterlstics of a particular soil interact with petroleum to affect microorganisms? Can predictive indices on the effects of oil on microorganisms be developed using regional soil classifications?

- More research on how crude and refined petroleum affects such basic microbiological processes as nitrification, denitrification, and soil nutrient cycling.

- More study of the effects of oil on different populations of soil organisms. To what degree does oil affect bacterial versus fungal populations? What is the regeneration limit of major soil groups after exposure to oil? 
- Additiunal research on how vapor phase and gaseous hydrocarbons affect microbial dynamics and interactions. Such studies could be especially useful in understanding the terrestrial effects and subsequent reclamation procedures associated with underground pipe ruptures involving natural gas or other related petrochemicals. 
THIS PAGE

\section{WAS INTENTIONALLY \\ LEFT BLANK}

432 
END USE SUMMARY

This section. Iists numerous research needs related to human health. Of particular importance is the newly recognized problem of indoor air pollution. Recent research has found that combustion of oil and gas products in the home has led to potentially harmful indoor levels of nitrogen dioxide, carbon monoxide, and radon.

In addition to being pollutants themselves, nitrogen dioxide and other emissions from indoor oil and gas combustion also may compound the problems and reactions of indoor air pollutants. Nitrogen dioxide levels have been found to be significantly higher (in some cases seven times higher) in homes with gas stoves than in homes with electric stoves. Gas appliances have been cited as significant sources. of carbon monoxide. 'However, air emission research has focused largely on air pollutants associated with the infiltration of automotive exhausts and on volatile solvents.

Research on indoor radioactive emissions has focused on radon emanating from construction materials and on water supplies derived from aquifers located in sedimentary deposits rich in radioactive nuclides. Evidence suggests the possibility of an equal amount of radon released from the combustion of natural gas in gas ranges and space heaters.

Various aspects of indoor air pollution are discussed at length here in the Techology Description section under Indoor Emissions, the Health Effects section under Indoor Air Pollution, and in the Summary of Research Needs relating to health effects and transport and transformation.

The nature, magnitude, and role of radioactive and chemical emissions from the indoor, energy-related use of oil and natural gas should be determined. Research in this area should be integrated with a comprehensive research program that addresses all fucels of indoor air pollution.

A large number of research needs involve dermal and inhalation effects associated with human exposure to petroleum products and combustion gases. These highlight an overall need for an expanded research effort dealing with exposures from oil and gas retailing. This effort should focus on workers (e.g., gas station attendants), as well. as the public using self service gasoline stations. The nature and magnitude of acid and alkaline metal emissions from catalytic converters needs to be fully explored with respect to both health and environmental impacts. 
With respect to environmental effects research, additional research is seen as needed in the following areas: the biological transport of lead, canadium, and nickel in soil and food chain accumulation; the landfarming of waste oils; and the effect of evaporative hydrocarbons from road surfaces on roadside flora and crops.

Several transport and transformation research needs are cited in this section. Some of the more important relate to photocatalytic processes that can convert innocuous hydrocarbons into polynuclear aromatic species; the role of organometallic emissions which may serve as catalysts, solvation agents, or forces responsible for sorption; interaction of coal fly-ash and condensed hydrocarbons; and the development of standardized and reliable techniques to characterize diesel engine exhausts that eliminate the formation of artificial compounds during testing. 
END USE

TABLE OF CONTENTS

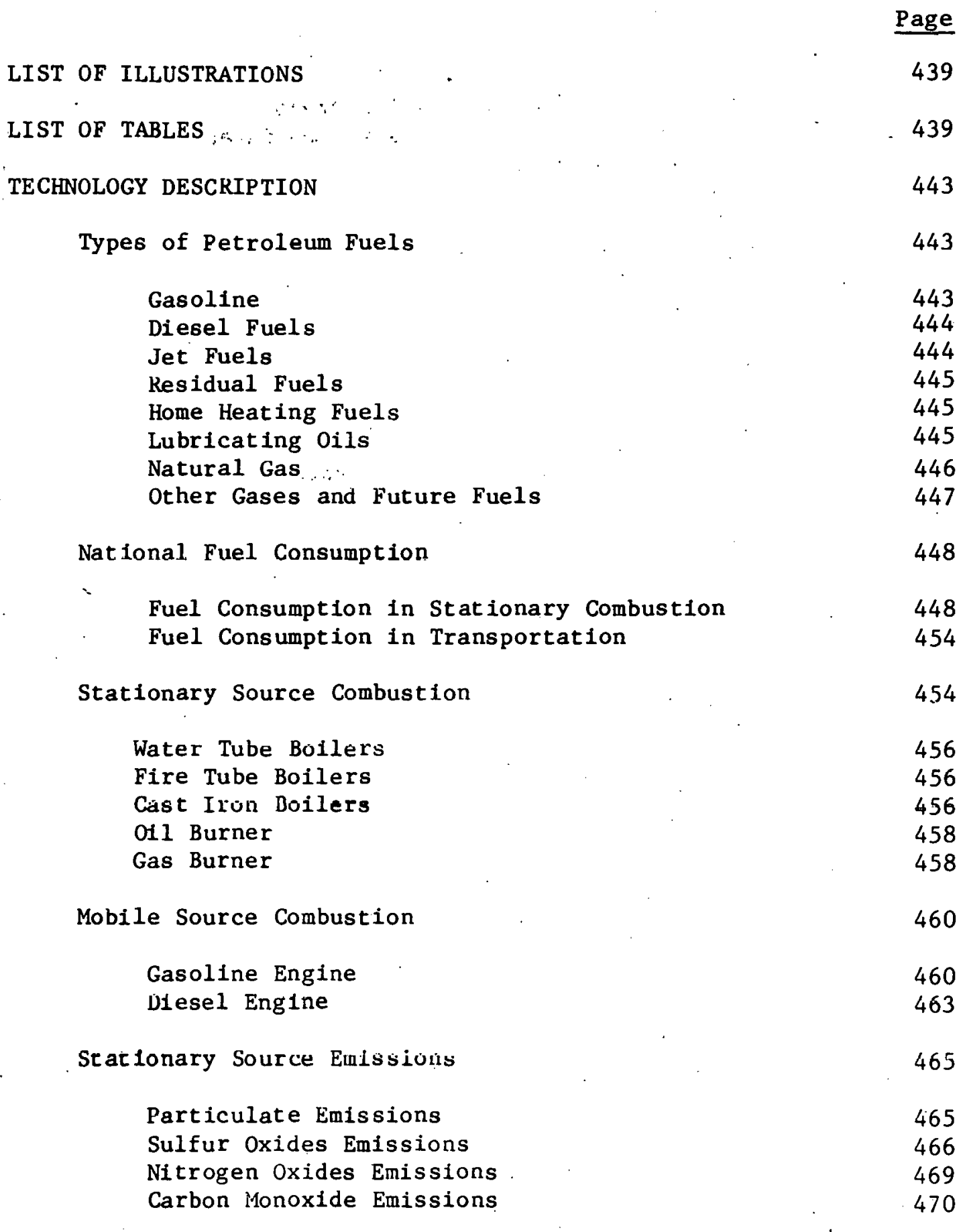


TABLE OF CONTENTS (Continued)

Page

Hydrocarbon Emissions $\quad 470$

Trace Metals $\quad \ldots \quad 473$

Indoor Emissions $\quad 474$

Emissions from Gas Stoves and Ovens $\quad 476$

Emissions of Sulfur Dioxide and Sulfates . 476

Nitrogen Oxides and Nitrates. 477

Carbon Monoxide $\quad 481$

Radloactive Materials . 482

Emissions from Space Heaters $\cdot \cdot \cdot 483$

Mob1le Source Emissions $\quad .483$

Particulate Emissions . $\quad 485$

Sulfur Emissions $\quad \cdot \quad 487$

Hydrocarbon Emlssions $\quad$. . . . 494

Polycyclic Aromatic Compounds . . 495

Chlorinated Dioxins. 499

Volat1le Phase Compounds $\quad 503$

Cyanides and Sulfides ... . 50.3

Trace Metals Emissions $\quad 503$

Lead in Gasoline 507

Nitrogen Oxides Emișsions . 508

Carbon Monoxide Emlssions 509

Smoke and Odor. 509

Smoke 509

Odor 511

Aircraft Emissions $\quad 511$

Locomotive Engines 515

Sumary of Mobile Emissions $\quad 518$

Waste Lubricating Oils $\quad 524$

Control of Einfsions . . 527

Stationary Source $\quad 527$

Mobile Source $\quad \cdot \quad \cdot \quad 528$

Oxidants $\quad 533$

Lead $\quad 535$

HEALTH EFFECTS OF OIL AND GAS USE

Outdoor Air Pollution $\quad 537$ 
TABLE OF CONTENTS (Continued)

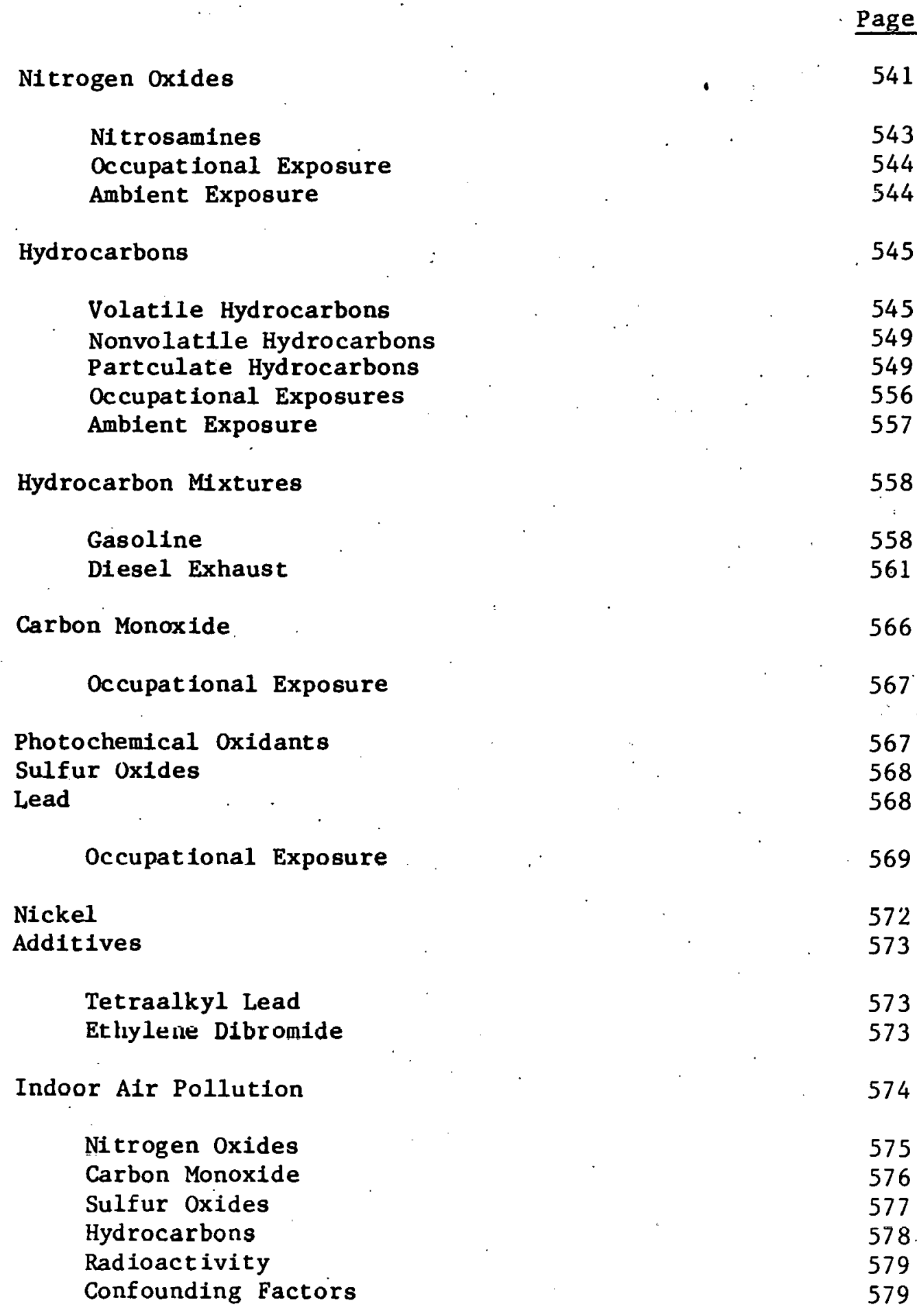


TABLE OF CONTENTS (Concluded)

Page

Summary of Research Needs $\quad 580$

Stationary Source Combustion $\quad 580$

Mobile Source Combustion . 581

Indoor Alr Pollution 583

ECOLOGICAL EFFECTS OF OIL AND GAS USE $\quad 585$

Effects on Vegetation : $\quad 585$

Effects on Biota $\quad \because \cdots, \quad 587$

Impacts of Waste 011 Disposal $\quad 587$

Summary of Re search Needs $\quad 589$

TRANSPORT AND TRANSFORMATION EFFECTS $\cdot 591$

Photochemical Air Pollution 591

Single Source Pollution

Indoor Pollution 596

Summary of Research Needs 599

Effectés 600

Atmospheric Pollution $\quad 600$

Indoor Pollution 600

Characterization, Measurement, and Monftoring '. 601

Stationary Source Combusition 601

Mobile Emissions 602

Indoor Air Pollutants 603 


\section{LIST OF ILLUSTRATIONS}

Figure Number

Page

1 United States 011 and Gas Consumption Forecasts

449

2 Relative Distribution of Total Boller Firing Capacity

452

3

Simplified Diagrams of Boilers

457

4

A High-Efficiency Oil Burner

459

5

Forced A1r System for Residential 0il and Gas Furnaces

461

6

The Automobile's Four-Stroke Cycle and Fuel Sys tem

462

7

The Carburetor

464

8

Typical Aircraft Turbine Engine Exhaust Emissions Characteristics

\section{LIST OF TABLES}

Table Number

$\underline{\text { Page }}$

$1 \quad 1974$ U.S. Energy Consumption 450

2 Number of Boilers by Fuel Type

Consumption of Natural Gas in Residential

End Uses

4 Energy Consumption in the Transportation Sector

Boiler Types and Capacities

455

Emission Factors for Fuel oil Combustion

Emission Factors for Natural Gas Combustion 


\section{LIST OF TABLES (Continued)}

Table Number

Page

8 Relative Benzo(a)pyrene Emission Rates

from Stationary Fuel Combustion Sources · 472

9 Estimated Emissions of Five Criteria

Pollutants from Boilers . . 473

10 Average Residual 0il Composite Analys is 475

11 Pollutant Emissions from Gas Appliances 478

12 Summary of Emissions from Residential

Gas and 011 Combustion _. . . 484

13 : Exhaust Emission Rates. for Mobile Combustion.

Sources : : 486

14 Particulate Enissions from Diese1- and

Gasoline-Powered Passenger Cars

488

15 Effect of the Catalytic Converter on

Particulate Emission Rates

16 Effect of Variables on Particulate Emission

from Gasoline- and Diesel-Powered Cars

$17 \quad$ Sulfate Emisision Rates 492

18 Polycyclic Aromatic Hydrocarbons Detected in Various Atmospheric Pollutant Samples

19 Comparison of Polycyclic Aromatic Hydrocarbon Emissions from Heavy Duty Diesel- and GasolinePowered Vehicles:

Benzo(a)pyrene Emission Rates

21 Effect of Gasoline Engine Mileage on Polycyclic Aromatic Hydrocarbon Emissions

22 Chlorinated Dioxin Content of Particulate Matter in Mufflers 


\section{LIST OF TABLES (Continued)}

Table Number

23 Oxygenates in Exhaust from Sample

Hydrocarbon Fuels

504

24

Phenol Range in Gasoline Exhaust Gas

505

25

Emission Rates of Selected Metals from a

Varlety of Cars Under Different Operating

506

Conditions

26 Gaseous Emission Data for Diese1-Powered

and Gasoline-Powered Cars

510

27

Diesel Exhaust Odorants

512

28

Aircraft Turbine Emissions

513.

Typicai Time for a Landing and Takeoff

Cycle at a Metropolitan Airport

Emission Factors per Aircraft Landing and Takeoff Cycle

Emission Factors by Locomotive Engine Category

Estimated Emissions from Mobile Equipment

33 Nationwide Estimates of Volatile Organic Compounds Emitted from Highway vehicles

Summary of Typical Emission Modifications

Proposed Automobile Emissions Standards

36 Composition of Some Lubricating 0il

\section{Additives}

Emission Control Techniques

Hydrocarbon and/or Nitrogen Oxide Control 
LIST OF TABLES (Concluded)

Table Number

Page

39

Nationwide Air Pollution Emissions by

Pollutant and Source

538

40 Major Air Pollutants and their Principal Ef fects

41 Volatile Hydrocarbons Identified in

Various Combustion Soruces

42 Polynuclear Aromat1c Hydrocarbons from

Various Sources

43 Specific Activity and Relative Potency

of Various Combustion Organics

$44 \quad$ Human Exposure to Gasoline Vapors 560

45. Effects of Lead Poisoning 570

46 Proposed Limits for Lead and 1ts Biochemical

Indices

571

47 Comparison of Reactivities of Different

Types of Organics

593

48 Classification of Organics with Respect to Oxidant-Related Reactivity in Urban

Atmos pheres

594

49

Summary of Indoor and Outdoor CO Data

598 
END USE

\section{TECHNOLOGY DESCRIPTION}

In the multifaceted oil and gas technology sequence, the final step (after onshore and offshore exploration and extraction, transportation and storage, and refinery operations) is end use. This section deals with oil and natural gas as an energy source used in the stationary and mobile combustion processes. It also touches on the use of petroleum oils'as lubricants in gasoline engines, diesel engines, machines, and industrial applications, after first discussing the different types of fuels in use.

\section{'Iypes of Petroleum Fuels}

Petroleum fuels are essentially mixtures of various hydrocarbons and different additives intended to improve quality or to counteract and reduce hazards associated with some of the hydrocarbons and their impurities. Because petroleum fuels are refined--or distilled from a broad range of feedstocks--they may be categorized by their end uses.

\section{Gasoline}

In the early days of the automobile, gasoline was a simple mixture of petroleum fractions derived from straight-run and thermally cracked stocks. The major chemical components were total saturates, 56.38 to 68.38 percent; total alkanes, 5.0 to 7.69 percent; and total aromatics, 24.32 to 32.91 percent. The percentages vary because of the different constituents in low-, medium-, and high-octane gasolines. The maximum sulfur content set by the American Petroleum Institute was $1,000 \mathrm{ppm}$.

In contrast, modern fuels are a complex mixture of blends derived from catalytic cracking, alkylation, catalytic reforming, polymerization, isomerization, and hydrocracking, plus small amounts of additives designed to improve the efficiency and reliability of the internal combustion engine. From 1925 to 1950 , there was a gradual but steady inçease in the compression ratio of the automotive engine intended to improve gasoline efficiency. This increase was more rapid during the 1950 s, until it finally leveled off in the late 1960s.

The higher compression ratio made it necessary to increase the fuel octane rating by adding lead alkyls during petroleum refining. During the 1950s and 1960s, other changes also were made in automotive gasoline to aid performance. Additives were developed to minimize such problems as carburetor icing and fouling, valve and engine 
deposits, spark plug fouling, fuel system corrosion, and poor fuel distribution. All of these factors have contributed to today's complex gasoline formulations.

In 1972 , the compression ratio in U.S. passenger car engines was sharply lowered. This trend reversal created a car population with widely different octane requirements. To satisfy varied requirements while complying with regulations limiting lead antiknock additives; gasoline distributors marketed several grades of gasoline. This diversity in gasoline is diminishing, however, with the onset of lowlead gasoline cars.

\section{Diesel Fuels}

Diesel fuels are categorized as: diesel fuel oils for automobiles, city-buses and similar vehicles; fuels for diesel engines in trucks and tractors; fuels for railroad diesel engines; and heavydistillate and residual fuels for large stationary and marine diesel engines.

They are characterized by their physical properties such as gravity, flash point, color, viscosity at $100^{\circ} \mathrm{F}\left(37.8^{\circ} \mathrm{C}\right)$, cloud point, pour point, sulfur content; aniline point, carbon residue based on 10 percent by weight, ash percentage by weight, octane index, octane number, and distillation temperature.

Fuel standards are based on physical parameters rather than chemical composition. Diesel fuel generally has a distillation range between $374^{\circ} \mathrm{F}\left(190^{\circ} \mathrm{C}\right)$ and $716^{\circ} \mathrm{F}\left(380^{\circ} \mathrm{C}\right)$ and a specific gravity $\left(15^{\circ} \mathrm{C} / 15^{\circ} \mathrm{C}\right)$ range between 0.76 and 0.935 . The properties of diesel fuel overlap with those of kerosene, jet fuels, and burner fuel oils. Thus, all of these products are generally referred to as intermediate distillates.

\section{Jet Fuels}

Jet fuels closely resemble diesel fuels, although they have a lower flash point, indicating that they contain more low-molecularweight compounds. Commercial kerosene was used as a fuel in early development work on jet aircraft in the U.S. It was chosen over gasoline because of its low volatility--a characteristic that would prevent vapor lock under certain flight conditions--and its availability as a commercial product with uniform characteristics. JP-1 was a military jet fuel developed during war time and it was followed by JP-2, JP-3, and JP-4. The latter is a blend of 25 to 35 percent kerosene and 65 to 75 percent gasoline components. JP-5 is a newly developed fuel for aircraft carriers. Commercial airline jet fuels are of different blends that fulfill a dual purpose in the aircraft: 
providing energy and serving as a coolant for lubricating oils and other aircraft components. Jet fuel quality has improved over the years because of stringent end point specifications, and the addition of antioxidants, copper deactivators, corrosion inhibitors, antiicing additives, and antistatic additives, as well as the Inhibition of contaminants.

\section{Residual Fuels}

Grades 4, 5, and 6 are the designations given to the fuels most commonly used for space heating and/or process steam in commercial, industrial, and other large facilities. Typically; these fuels are used to provide steam and heat for industry. The largest single user of residual fuels is the electrical power generating industry, which consumes about 45 percent of available residual fuel.

Most advances in residual fuel technology since World War II have led to improvements in its use rather than in oil quality. The oil industry and boiler manufacturers have increased their efforts to desulfurize fuel oil and flue gas, and reduce fuel oil metal content. A number of additives have been developed that reduce residual fuel oil sludge, tube deposit formation, and corrosion, and that increase combustion efficiency.

\section{Home Heating Fuels}

Residential heating oil must be a clean product that does not form sediment in storage or leave much ash or other carbonaceous deposits upon burning. Because it may be stored outdoors during winter months, it must be fluid at low temperatures. The chemical composition of the product must be controlled to reduce smoke emissions.

The fuel oil most commonly used in homes is grade no. 2, which has a sulfur content of $2,500 \mathrm{ppm}$, far lower than the specified standard of $5,000 \mathrm{ppm}$. Nonexplosive at ordinary storage temperatures, it is an intermediate distillate, normally fractionated to a boiling range of $350^{\circ} \mathrm{F}$ to $650^{\circ} \mathrm{F}\left(177^{\circ} \mathrm{C}\right.$ to $\left.343^{\circ} \mathrm{C}\right)$. Grade no. 2 fuei oil contains paraffins ( 30.4 percent by weight), naphthenes ( 31.5 percent by weight), and aromatics ( 38.2 percent by weight), with benzene accounting for about $1 / 3$ rd of the aromatics.

\section{Lubricating Oils}

Lubricants are used to decrease friction and wear between two surfaces that move against each other. Such substances may be gaseous, liquid, semisolid or solid. Lubricants are also used to control temperatures, prevent corrosion and oxidation, provide electrical 
insulation, avoid power losses through friction, and transmit power. Liquid lubricants, mineral oils, synthetic liquids, semisolid lubricants, and solid lubricants are generally oil based substances, and are known as lubricating oils.

A variety of compounds are added to lubricating oils to improve their physical or chemical properties. These additives are oxidation inhibitors that prevent the formation of acids and sludge, detergent and dispersants to control fuel soots and oil oxidation products, viscosity index additives to improve the viscosity properties of motor oils, corrosion inhibitors and antirust additives to coat metal surfaces, and pour point depressants to increase the fluidity of the oil at low temperatures.

Natural Gas

Natural gas is a combustible gaseous mixture of low-molecularweight paraffin hydrocarbons generated or found in porous geologic formations below the surface of the earth. Its major constituent is methane and it contains some ethane along with small amounts of propane, butane, higher hydrocarbons, and sometimes nitrogen, carbon dioxide, hydrogen sulfide, and helium. Natural gas is mainly used by three types of customers: residential users with and without space heating or air conditioning, commercial establishments, and industrial complexes. Natural gas is a collective term used here for associated natural gas, dissolved natural gas, liquified natural gas, gas liquids, nonassociated gas, sour gas, sweet gas, and wet gas-products that are defined as:

- Associated natural gas--free natural gas in immediate contact with but not in solution with crude oil in the reservoir.

- Dissolved natural gas--natural gas in solution with crude oil

. in the reservoir.

- Liquified natural gas (LNG)--natural gas cooled to $-259^{\circ} \mathrm{F}$ $\left(-162^{\circ} \mathrm{C}\right)$ so it forms a liquid at approximately atmospheric pressure. Natural gas in its liquid state must be regasified and introduced to the consumer at the same pressure as other natural gas. The cooling process does not alter the gas chemically and the regasified LNG is indistinguishable from other natural gases of the same composition. LNG is discussed in detail in the section of this report on liquified energy gases.

- Natural gas liquids--liquid hydrocarbons that are gaseous at reservoir temperatures and pressures, but are recoverable by condensation or absorption. 
- Nonassociated natural gas--free natural gas in contact with, not dissolved in, crude oil in the reservoir.

- Sour--gas found in its natural state, containing enough compounds of sulfur to make it impractical to use without purifying because of its corrosive effect on piping and equipment.

- Sweet--gas found in its natural state, containing such a small amount of sulfur that it can be used without purifying with no deleterious effect on piping and equipment.

- Wet natural gas--unprocessed or partially processed natural gas produced from strata containing condensable hydrocarbons.

Other Gases and Future Fuels

Currently, liquefied energy gases (imported LNG, LPG, and naphtha derived from crude oil) comprise about 3 percent of the energy consumed in the U.S. and are used to supplement domestic natural gas supplies. About 2 percent of the nation's energy is supplied by LPG, primarily propane. In 1976, 13 million customers, mostly in rural areas, used LPG as an energy source.

Traditional sources of methane will be supplemented in the future by new technologies. These will include pipeline quality gas from the gasification of coal and oil shale and methane derived from biomass.

With $1 / 2$ the Btu content of gasoline, methanol, a fuel currently being combined with gasoline, releases 20 percent more energy through more efficient burning. It makes an automobile engine burn five times cleaner than with gasoline. Engine life is extended because alcohol burns cooler, and there is the added benefit of lower maintenance costs because of decreased hydrocarbon buildup, but aldehyde emissions may be increased. Compared with gasoline, methanol and ethanol offer a less expensive alternative for automobiles and small airplanes. Many different methanol combustion processes are currently being evaluated.

Converting engines to utilize alcohol fuels involves increasing the compression ratio to about 12 to 1 , redesigning the fuel delivery system, changing the timing, installing a larger fuel tank that is not treated with turnplate, and changing gasket materials which may be adversely affected by alcohol (Fisher 1980). 
National Fuel Consumption

Total U.S. fuel consumption over the last 30 years has more than doubled, rising from $32.96 \times 10^{15} \mathrm{Btu}$ 's in 1948 to $78.01 \times 10^{15}$ Btu's in 1978 (Council on Environmental Quality 1979). By the same token, petroleum use has increased from $11.81 \times 10^{15}$ to $37.79 \times$ $10^{15}$ Btu's, and natural gas consumption has risen from $4.90 \mathrm{x}$ $10^{15}$ to $19.82 \times 10^{15} \mathrm{Btu}$ 's. Use of has coal remained at the level of $14 \times 10^{15}$ Btu's over the same period. Figure 1 illustrates projected trends in oil and gas consumption through the year 2000 .

U.S. oil and gas consumption in 1974 by various sectors is listed in Table 1. Households utilize oil and gas primarily for home heating and cooling, cooking, water heating, and clothes drying. Commercial uses include space heating and steam generation. Electric utilities use oil and gas in power plants to generate electricity which is, in turn, transmitted and distributed to the consumer. In the transportation sector, petroleum fuels are used in automobiles, aircraft, locomotives, ships, and tankers. Analysis of the table reveals that the ratio of natural gas to petroleum consumption is. about 41 to 59. Analysis by sector suggests that transportation accounts for 32 percent; industrial, 27 percent; household and commercial, 25 percent; electric utilities, 12 percent; and the remaining 4 percent is consumed by raw materials and miscellaneous sectors (Loftness 1978). Per capita energy consumption in the U.S. for 1974 was $73.1 \times 10^{15}$ Btu's, of which natural gas and petroleum accounted for $22.2 \times 10^{15} \mathrm{Btu}$ 's and $30.9 \times 10^{15} \mathrm{Btu}$ 's, respectively.

\section{Fuel Consumption in Stationary Combustion}

Utility boilers that produce steam to generate electricity consume 59 percent of the fossil fuel used in the U.S. Industrial boilers generating steam or hot water for process heat, electricity generation, or space heat use 24 percent; and boilers for space heating in commercial and institutional facilities consume 17 percent (U.S. Environmental Protection Agency 1979b). Some residential space heating takes place in boilers that are not represented in the percentages above. The fuels consumed in boilers in large quantities are natural gas, distillate oil, residual oil, and coal. In Table 2, the numbers of boilers are identified by the types of fuels used (U.S. Environmental Protection Agency 1979b). 


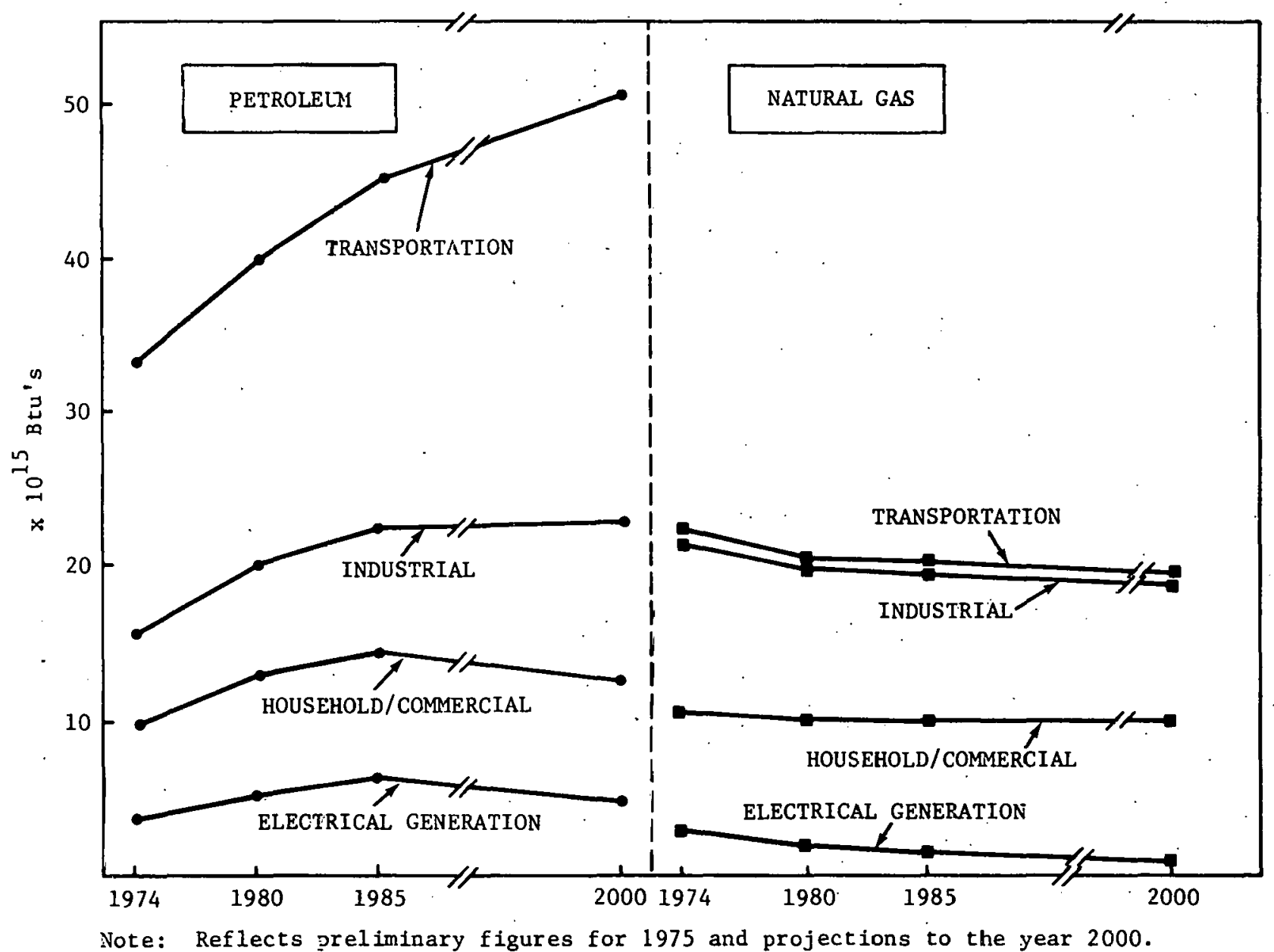

Source: Loftness 1978 .

\section{FIGURE 1}

UNITED STATES OIL AND GAS CONSUMPTION FORECASTS 
TABLE 1

1974 U.S. ENERGY CONSUMPTION (1012 $\left.\mathrm{Btu}^{\prime} \mathrm{s}\right)$

\begin{tabular}{|c|c|c|c|c|c|c|}
\hline Fuel & $\begin{array}{l}\text { Household/ } \\
\text { Commercial }\end{array}$ & Industrial & $\begin{array}{l}\text { Electric } \\
\text { Dtilities }\end{array}$ & Transportation & other ${ }^{a}$ & Total \\
\hline Natural gas & 7,116 & 10,394 & 3,328 & 644 & 689 & 22,191 \\
\hline Petroleum & & & $\cdot$ & & & \\
\hline Gasoline & -- & -- & - & 12,596 & -- & 12,596 \\
\hline Jet fuel & --- & -- & -- & 3,006 & --- & 3,006 \\
\hline Distillate & 3,000 & 769 & 396 & 2,027 & 50 & 6,242 \\
\hline Residual & 1,125 & 1,182 & 3,018 & 685 & 62 & 6,072 \\
\hline Kerosene & 289 & 83 & -- & -- & -- & 372 \\
\hline Liquid gases & 734 & 1,964 & -- & 113 & $237^{\circ}$ & 3,068 \\
\hline other ${ }^{b}$ & 1,241 & 391 & -- & 160 & 1,307 & 3,099 \\
\hline Total & 13,505 & 14,783 & 6,742 & 19,231 & 2,345 & 56,646 \\
\hline
\end{tabular}

Note: ---Represents zero or rounds to zero.

${ }^{a}$ Constitutes raw materials and miscellaneous sectors.

b Includes naphthas, lubes and waxes, asphalt, petroleum coke, and miscellaneous.

Source: Adapted from Loftness 1978. 
TABLE 2

NUMBER OF BOILERS BY FUEL TYPE

\begin{tabular}{cccc}
$\begin{array}{c}\text { Type of } \\
\text { Fuel }\end{array}$ & $\begin{array}{c}\text { Number of } \\
\text { Utility } \\
\text { Boilers }\end{array}$ & $\begin{array}{c}\text { Industrial/ } \\
\text { Commercial } \\
\text { Boilers }\end{array}$ & $\begin{array}{c}\text { Total } \\
\text { Number of } \\
\text { Bo1lers }\end{array}$ \\
\hline Natural Gas & 948 & 954,350 & 955,334 \\
Distillate 011 & 196 & 244,206 & 244,402 \\
Residual 0i1 & 1,038 & 389,104 & 390,142 \\
Coal & $\underline{1,533}$ & $\underline{214,400}$ & 215,933 \\
Total & 3,751 & $1,802,060$ & $1,805,811$ \\
\hline
\end{tabular}

Natural gas is the primary fuel used in the industrial and commercial sectors. Industrial and commercial boilers consume more than half of the distillate and residual oil burned in bollers. This represents about $1 / 4 \mathrm{th}$ of the oil burned in the U.S. Most industrial and commercial facilities use cleaner-burning natural gas-fired boilers, which generate less pollution than coal- and oil-fired units.

Figure 2 illustrates the distribution of relative firing capacity by fuel type for each kind of boiler used by utilities, industry, and commercial facilities. Natural gas-fired boilers represent 45 percent of the total firing capacity in commerce and industry. oil-filed bullers account for $3 /$ percent, while coal units account for the remaining 18 percent of the firing capacity for industrial and commercial boilers. Of the utility boilers, natural-gas-fired boilers account for 26 percent; oil-fired, 31 percent; and coal-fired, 41 percent.

In residences, oil and natural gas are used for cooking, home heating, water heating, clothes drying, and space heating, as shown in Table 3. Residential gas utility customers in 1970 totaled $40,670,600$, while commercial and industrial users totaled 3,392,000 and 193,800, respectively (American Gas Association 1974). The utility gas companies are the largest distributors of natural gas, followed by liquid fuel and bottled gas suppliers. 


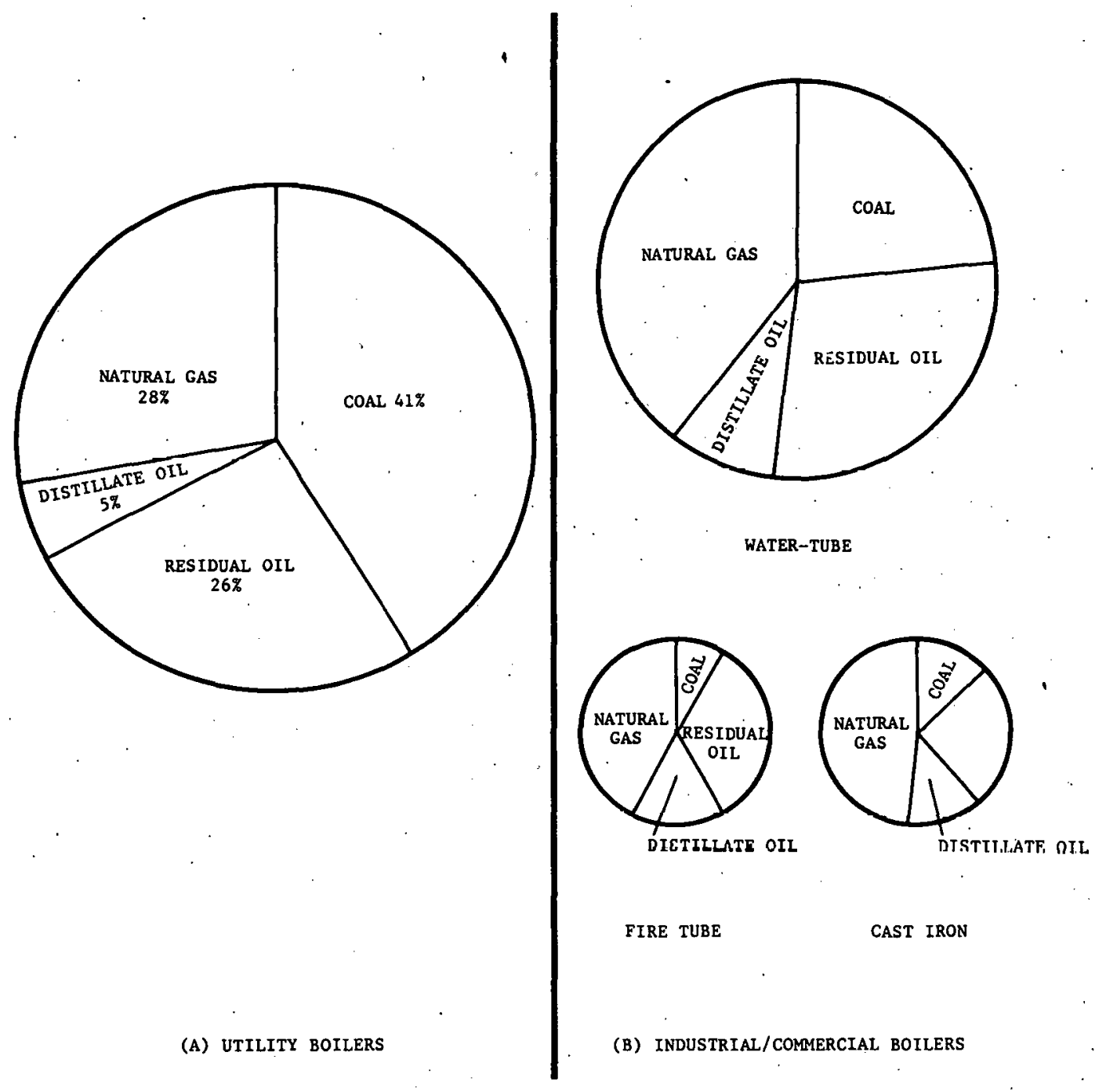

Source: (B) adapted from U.S. Environmental Protection Agency 1979 a.

FIGURE 2

RELATIVE DISTRIBUTION OF TOTAL BOILER FIRING CAPACITY 
TABLE 3

CONSUMPTION OF NATURAL GAS IN RESIDENTIAL END USES (1970)

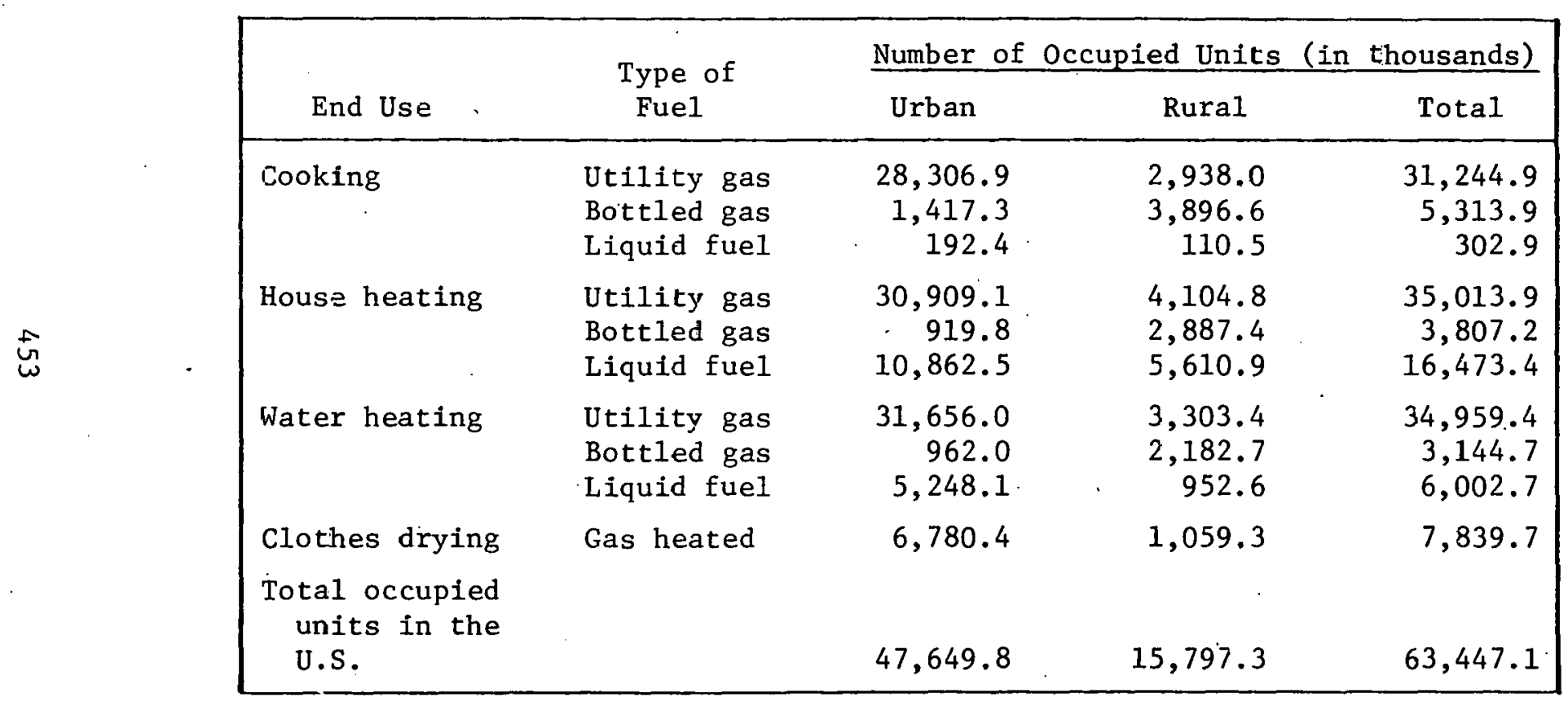

Source: American Gas Association 1975. 
Fuel Consumption in Transportation

, U.S. energy consumption in the transportation sector for 1973 was 18,763 trillion Btu's; the breakdown is shown in Table 4 below (Loftness 1978):

TABLE 4

ENERGY CONSUMPTION IN THE TRANSPORTATION SECTOR

\begin{tabular}{lrr}
\hline $\begin{array}{c}\text { Petroleum Products } \\
\text { and }\end{array}$ & & \\
Natural Gas Liquids & Trillion Btu's & $\begin{array}{r}\text { Percent of } \\
\text { Total }\end{array}$ \\
\hline Gasoline & 12,872 & 71.5 \\
Jet fuel & 2,131 & 11.3 \\
Liquified gas & 135 & 0.8 \\
Distillate fuel oil & 2,132 & 11.8 \\
Residual fuel oil & 731 & 4.1 \\
\multicolumn{1}{c}{ Total } & 18,001 & 99.5 \\
\hline
\end{tabular}

Note: Percentages may not add to 100 due to rounding. Source: Loftness 1978.

Stationary Source Combustion

The rapid chemical combination of oxygen with the combustible element of a fuel is called "combustion." Three significant combustible elements are found in oil and natural gas: carbon, hydrogen, and sulfur. As a source of heat, sulfur is of minor importance, but it is of concern because of the corrosion and pollution problems associated with its presence.

The objective of good combustion is to release all exothermic heat while minimizing losses from combustion imperfections and superfluous air, as in the following generic equations:

$$
\begin{aligned}
\mathrm{C}+\mathrm{O}_{2}=\mathrm{CO}_{2}+\text { heat (heat }=\begin{array}{l}
14,000 \mathrm{Btu} \\
\text { carbon). }
\end{array} & \begin{aligned}
2 \mathrm{H}_{2}+\mathrm{O}_{2}=2 \mathrm{H}_{2} \mathrm{O}+\text { heat } \text { (heat }= & 61,000 \mathrm{Btu} \text { 's per pound of } \\
& \text { hydrogen). }
\end{aligned}
\end{aligned}
$$


These simple equations describe combustion in the variety of boilers and burners used to generate steam, heat, and electricity.

Boilers or boiler surfaces may be defined as those parts of tubes, drums, and shells that are part of the boller circulatory system and are in contact with hot gases on one side and water or a mixture of water and steam on the other side. Botlers may be classified by heat transfer configuration, which is an important consideration in evaluating environmental impacts, partly because the configuration has a direct effect on combustion conditions (and resulting emissions). Boilers are classified as water-tube, firetube, and cast iron or shell type. Water-tube boilers are used in a variety of applications, ranging from supplying large amounts of process steam, to providing space heat for industrial and commercial facilities. Fire-tube bollers are not available with capacities as large as those of water-tube boilers, but they are used to supply process steam and space heating. Cast iron boilers are limited in size and are used only to supply space heat. The type of heat configuration by total boller capacity is shown in Table 5 below (U.S. Environmental Protection Agency 1979b).

TABLE 5

BOILER TYPES AND . CAPACITIES

\begin{tabular}{|c|c|c|c|c|}
\hline $\begin{array}{l}\text { Heat Transfer } \\
\text { Configuration }\end{array}$ & $\begin{array}{l}\text { Number of } \\
\text { Boilers }\end{array}$ & $\begin{array}{c}\text { Total Capacity } \\
\left(10^{6} \text { Btu's/ }\right. \\
\text { Hour })\end{array}$ & $\begin{array}{l}\text { Percent } \\
\text { of Total } \\
\text { Capacity }\end{array}$ & Use \\
\hline $\begin{array}{l}\text { Water-tube } \\
\text { (utility) }\end{array}$ & 3,751 & $3,647,500$ & 45 & $\begin{array}{l}\text { Electricity } \\
\text { generation }\end{array}$ \\
\hline $\begin{array}{l}\text { Water-tube } \\
\text { (nonutility) }\end{array}$ & 50,495 & $2,552,500$ & 31 & $\begin{array}{l}\text { Process steam, } \\
\text { electricity } \\
\text { and space } \\
\text { heat genera- } \\
\text { tion }\end{array}$ \\
\hline Fire-tube & 275,075 & $1,033,300$ & 13 & $\begin{array}{c}\text { Process steam, } \\
\text { space heat }\end{array}$ \\
\hline Cast Iron & $1,476,490$ & 896,200 & 11 & Space heat \\
\hline Total & $1,805,811$ & $8,129,500$ & 100 & \\
\hline
\end{tabular}




\section{Water-Tube Boilers}

In a water-tube boller, hot combustion gases are in contact with the insides of tubes that are interconnected with common water channels and a steam outlet(s). Water-tube boilers generate high pressure and high-temperature steam. Used in a variety of utility, industrial, and commercial applications, they are available as packaged or field-erected units. Capacities of the packaged units range from 10,000 to 250,000 pounds of steam per hour. Higher capacity boiler units are field erected.

Water-tube boilers can efficiently burn any economically available fuel. They are sold in a variety of designs to fit any plant. capacity and space requirement. Major types of water-tube boilers are vertical, vertically inclined, and horizontal. They are classified as units with: (1) natural circulation resulting from the difference between water and steam densities; or (2) forced circulation achieved with pumps that circulate water and steam through the boiler. Forced circulation boilers can operate in a supercritical range at capacities exceeding 10 million pounds of steam per hour. (Figure 3 compares a water-tube boiler with a fire-tube boiler, discussed below.)

\section{Fire-Tube Boilers}

Tn fire-tube boilers, combustion products flow through a tube that is surrounded by a water basin (Figure 3). 'These units are used primarily for heating, generating industrial process steam, and as portable power boilers where loads are relatively constant because they are susceptible to structural fallure when subjected to large variations in steam demand. These units produce steam more efficiently than a simple shell or cast iron boiler because the water basin absorbs heat through the shell and also through the tubes.

Most fire-tube boilers have internal furnaces, $1 . e$. , the combustion chamber is enclosed in the boiler shell, unlike an external arrangement in which the boiler shell and combustion chamber are separate. Internal furnaces are preferred because of better water circulation and easier ash removal. There are six types of fire-tube boilers: horizontal return tubular, scotch marine, vertical, locomotive, short fire-box, and compact boilers.

\section{Cast Iron Boilers}

Cast iron or shell boilers are used in homes and small commercial operations to produce low-pressure steam or hot water. A residential cast iron boiler is a small, round unit in which the furnace is surrounded by a water basin. Flues allow combustion products to 


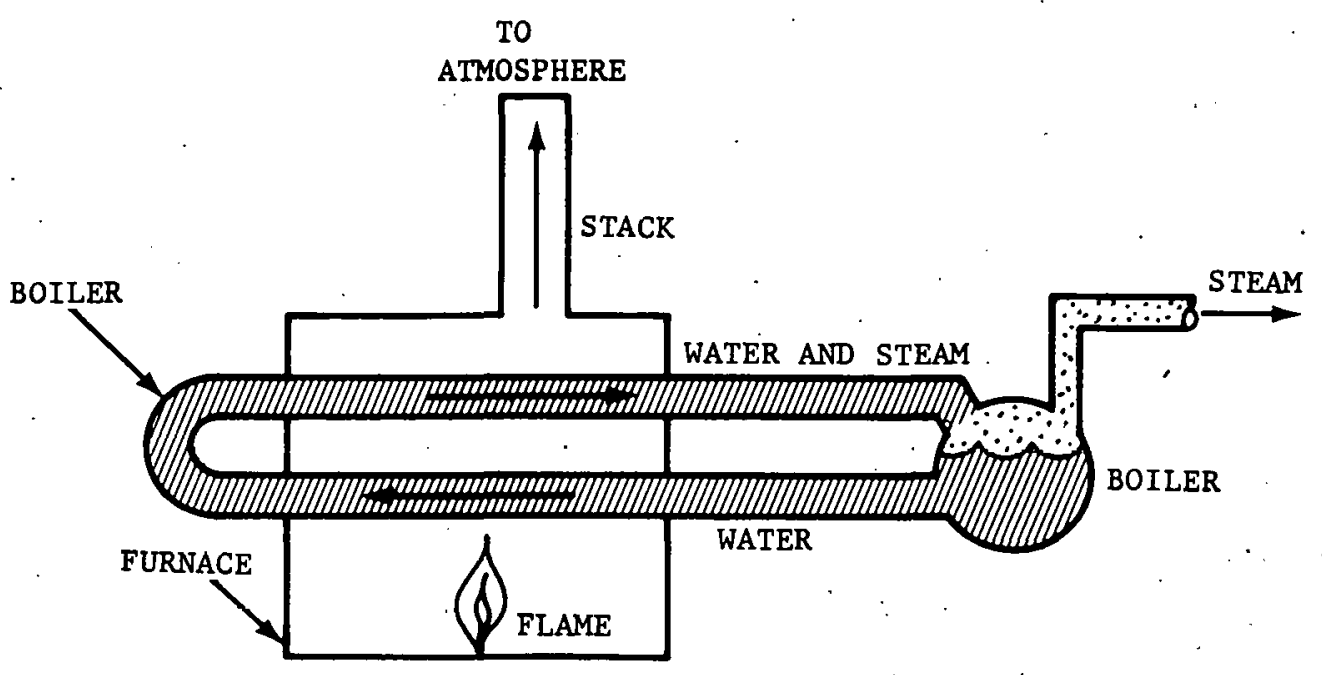

A WATER-TUBE BOILER

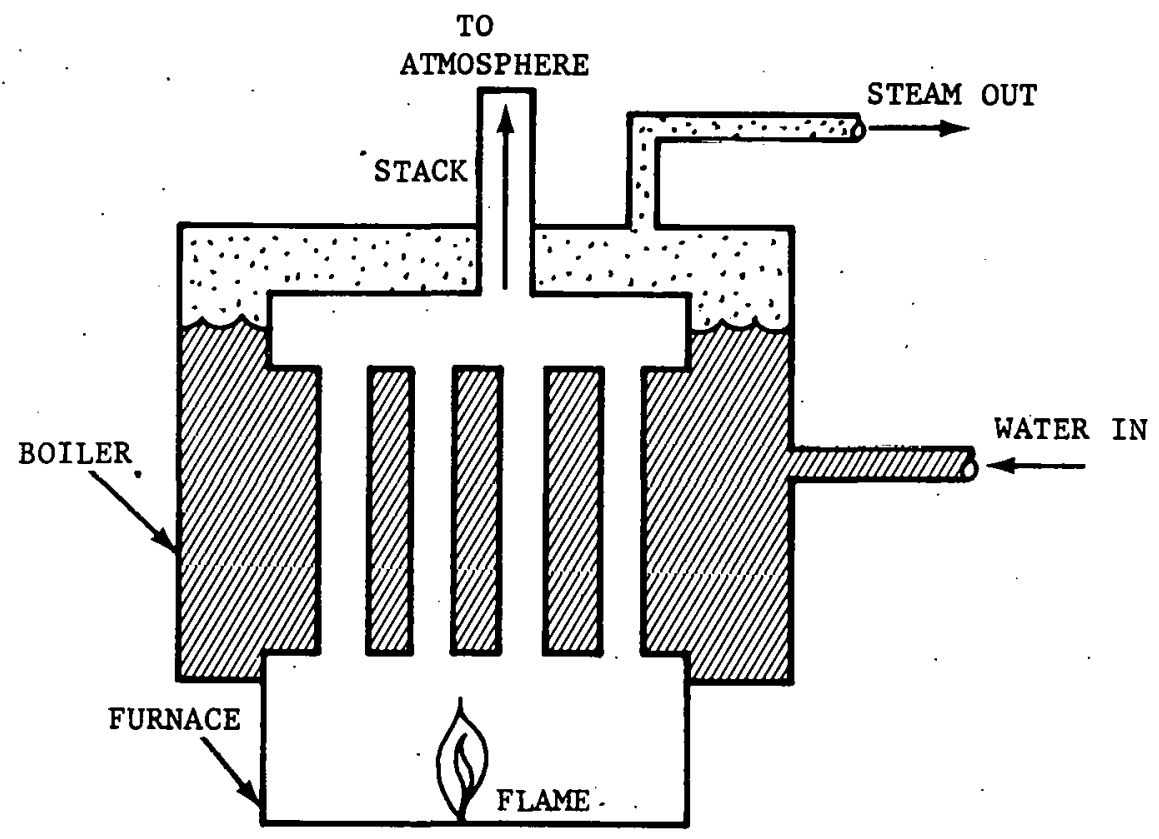

A FIRE-TUBE BOILER

Source: Adapted from U.S. Environmental Protection Agency 1979a.

\section{FIGURE 3}

SIMPLIFIED DIAGRAMS OF BOILERS 
escape from the combustion chamber and transfer heat from the gases to the water. Cast iron boilers are reliable, with an average life of about 50 years. They require little maintenance and can handle overloading or demand surges. The major problem associated with cast iron boilers is that the sections tend to deform, which may cause flue gases to leak from the joints.

\section{Oil Burner}

The oil burner converts fuel oil from a liquid phase into a combustible mixture. A number of different kinds of oil burners are in residential use, including sleeve burners, natural-draft pot burners, and air-atomizing and pressure-atomizing gun burners: The most common and modern type is the pressure-atomizing burner, shown in Figure 4, which accounts for 80 percent of the oil burners used to heat homes in the U.S.

The important feature of a high-pressure atomizing gun burner is $i$ ts method of air delivery. It completely burns oil with the smallest quantity of air by properly proportioning and mixing the atomized oil and air required for combustion. The essential working parts of the burner are the electric motor, squirrel-cage-type blower, housing, fuel pump, electric ignition, and a primary control. Fuel oil is pumped from the tank through the pump gears, and oil pressure is regulated by an internal valve at a pressure of 100 to $300 \mathrm{psi}$ at the burner nozzle. The oil is then ignited, atomized, and burned.

Safety is an important consideration with oil burners and one of the most important safety features on an automatic oil burner is the primary control. This will shut off the burner when it is not functioning properly, protecting against such occurrences as incorrect primary air adjustments, dirt in the atomizing nozzle, inadequate oil supply, and improper combustion.

\section{Gas Burner}

The gas burner converts natural gas into a heat source that is used in residential heating and cooling systems. Most residential units are warm, forced-air furnaces with capacities of up to about $300,000 \mathrm{Btu}$ 's per hour. In residential gas heaters, air discharge and return is accomplished in one of two ways: by gravity or by a pressure blower. The furnace is enclosed in a rectangular steel casing and gas is burned in a primary combustion space within a metal-walled heat exchanger.

Natural gas, which is supplied by utility companies through pipelines, is the most widely used home heating fuel in the U.S. In the home, low-pressure gas is burned in approved gas burners that 


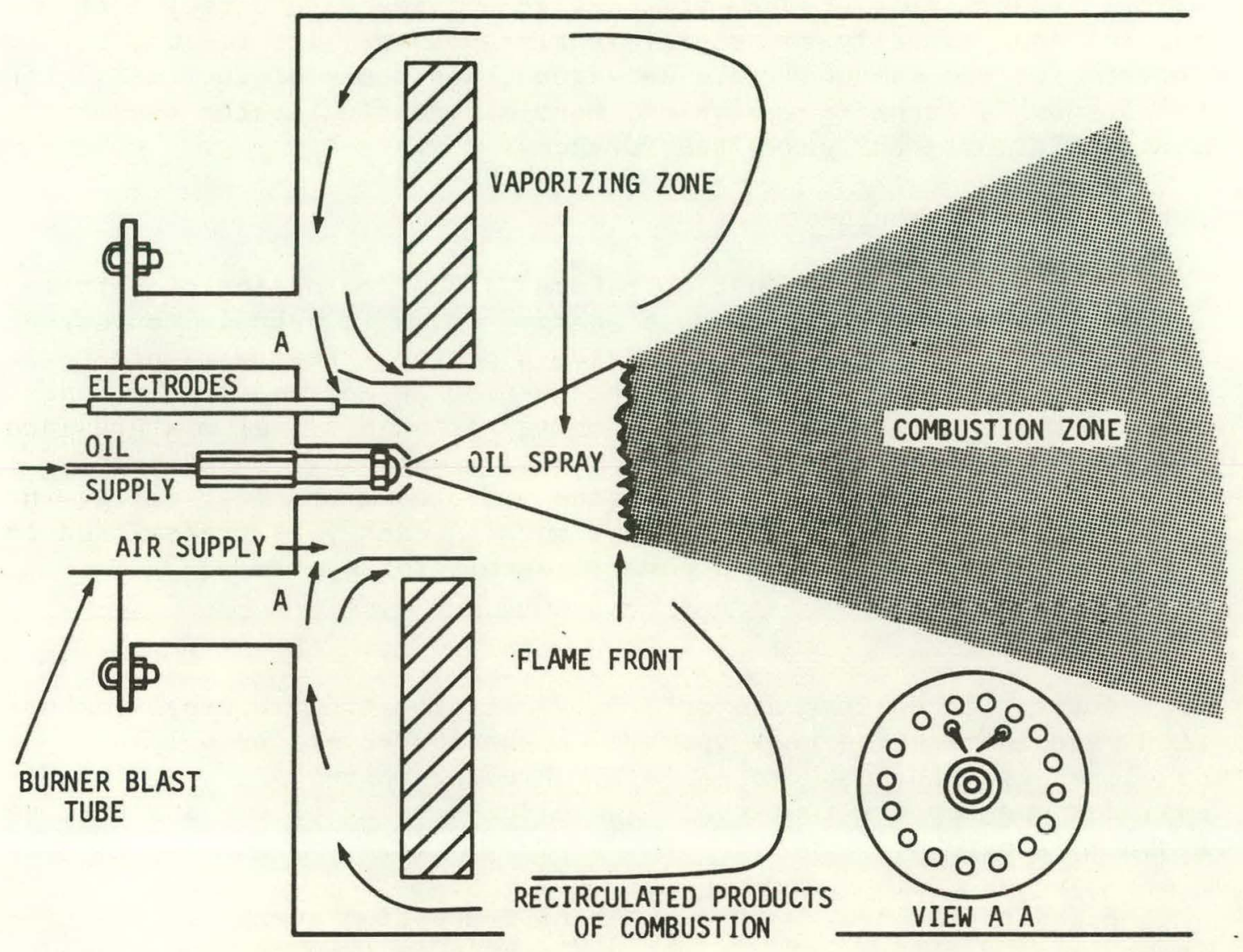

Source: The MITRE Corporation 1977.

FIGURE 4

A HIGH-EFFICIENCY OIL BURNER 
have an essentially trouble-free design and adequate safety controls. Natural gas generally burns efficiently; however, its flammable characteristics are somewhat more dangerous than those of fuel oil. Figure 5 shows a forced-circulation, warm-air heating system used for residential oil- and gas-fired furnaces.

Mobile Source Combustion

The term mobile combustion refers to the combustion of petroleum-derived fuels to produce heat energy, which in turn is converted into mechanical energy that can drive a piston, rotor, or turbine in an internal combustion engine. The automobile engine's basic function is to transform the chemical energy of an air-fuel mixture into the mechanical energy required to propel a vehicle. Quite simply, the burning of fuel inside the engine produces mechanical energy in the form of a rotating shaft. This working energy is transmitted to the wheels of a vehicle by a power-transmission system.

Gasoline Engine

Automobile engines are driven by reciprocating internal combustion gasoline engines that operate on the four-cycle principle developed by Nikolaus ot to in 1876. Present four-, six-, and eightcylinder engines are four-cycle, gasoline-burning piston engines, as shown in Figure 6 .

A basic component of the internal combustion engine is the cy1inder, closed at one end, in which a piston is free to move up and down. When a mixture of air and gasoline is burned above a piston, the resulting expansion drives the piston down into the cylinder. This vertical thrust is transmitted by a connecting rod and bearings to an offset crankshaft, where it is converted into rotary motion. In a gasoline engine, fuel and air are mixed before they enter the combustion chamber and then are spark-ignited. In the four-cycle engine illustrated in Figure 6 , each piston travels alternately from the top to the bottom of the cylinder four times as it completes the following cycle:

- Intake stroke. Piston moves down, pulling a mixture of air and gasoline into the cylinder through the open intake valve.

- Compression stroke. Intake valve closes, piston moves up and compresses the mixture.

- Power (expansion) stroke. Near the top of the compression stroke, the highly compressed mixture of air and gasoline is ignited by the spark plug. Expanding rapidly, it forces the piston back down to the bottom of the cylinder. 


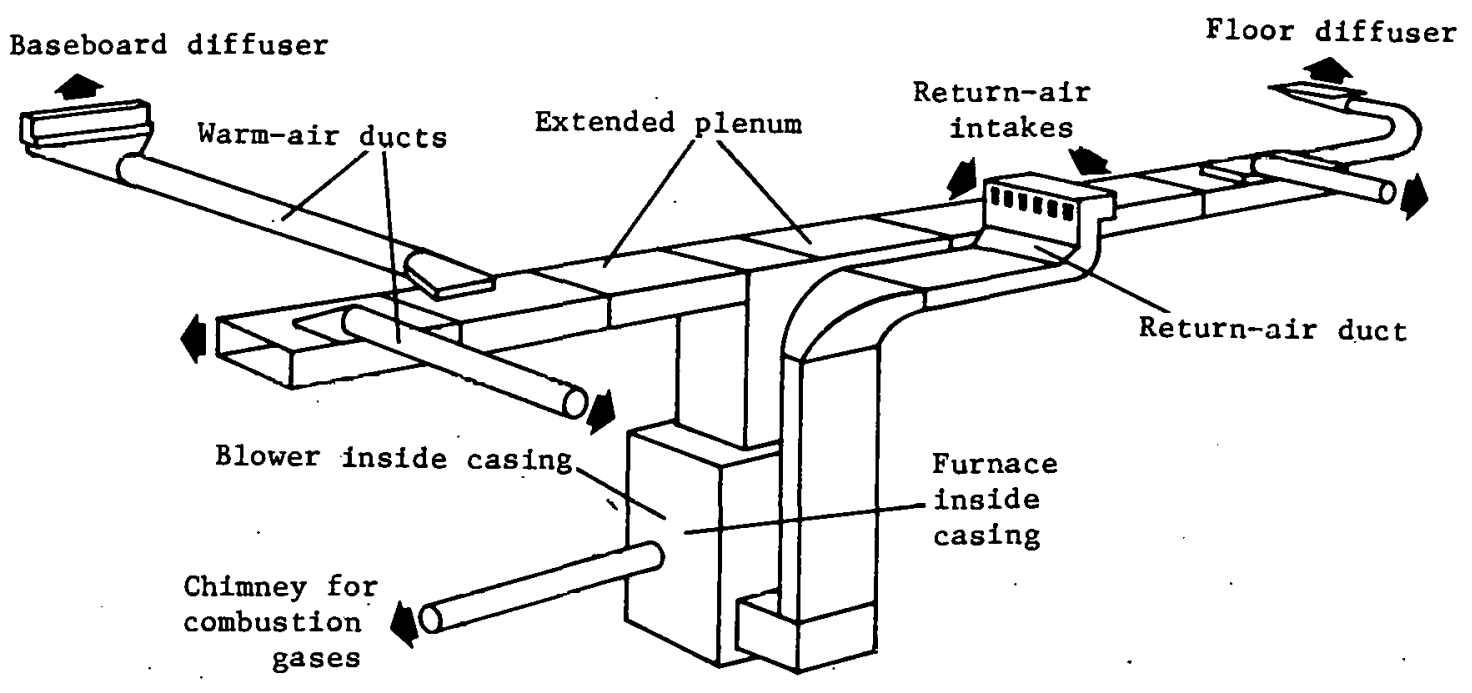

Source: Adapted from McGraw Hill 1977.

FIGURE 5

FORCED AIR SYSTEM FOR RESIDENTIAL OIL AND GAS FURNACES

461 

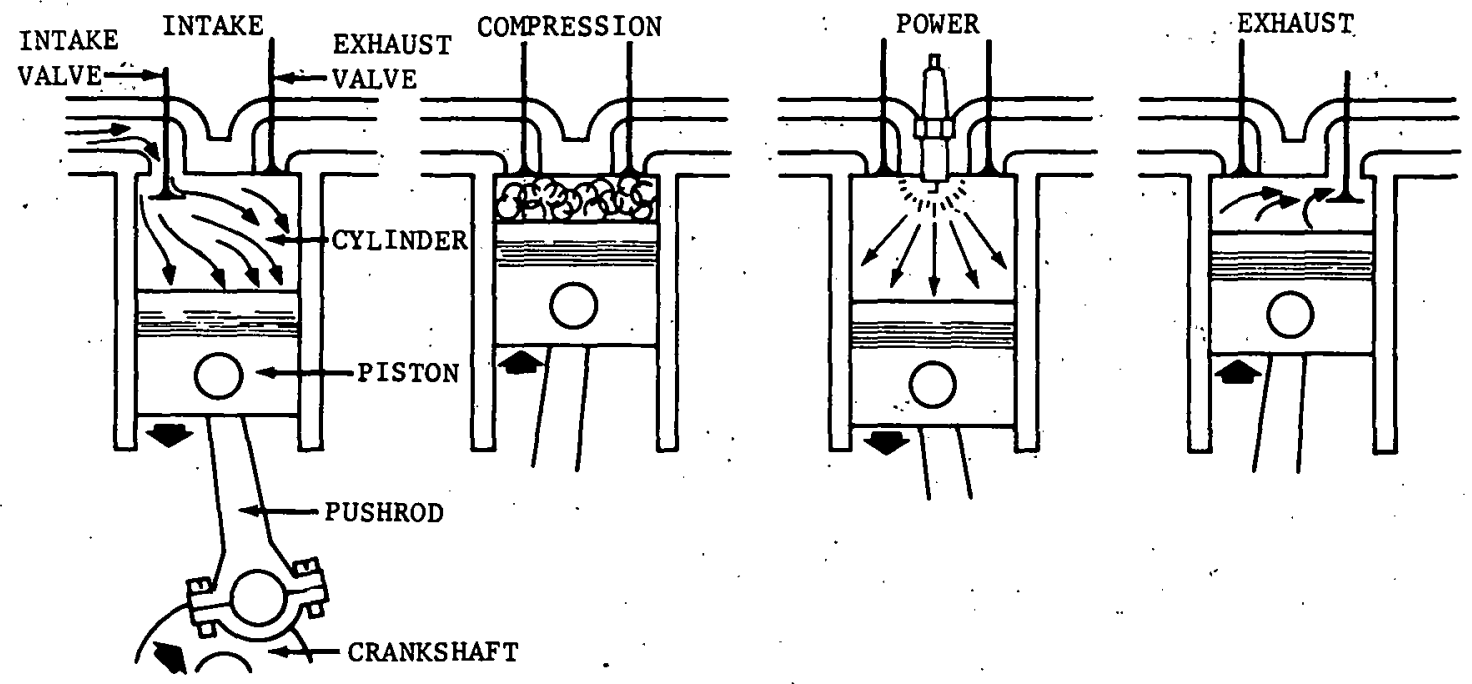

A. The 4-stroke cycle. Fuel is drawn into the cyclinder from the carburetor (Intake stroke), compressed by the rising piston (compression stroke), and ignited by the spark plug; piston 1s forced downward (power stroke) by burning gasoline; burned gases are expelled (exhaust stroke).

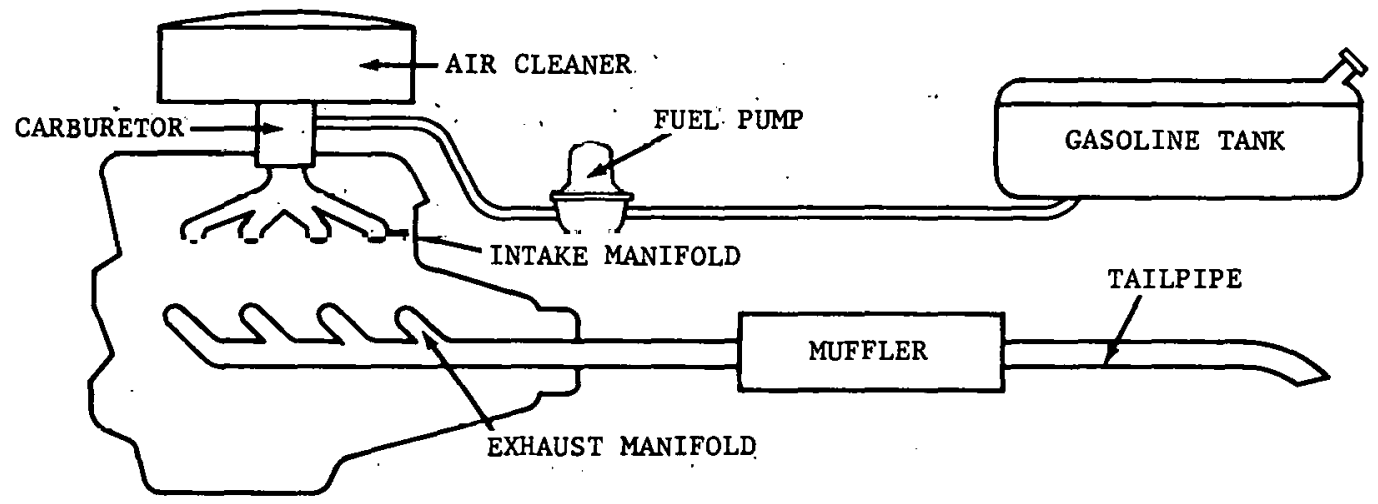

B. The Automobile Fuel System. The fuel pump moves gasoline from the tank to the carburetor, discussed below.

Source: Adapted from McGraw Hill 1977.

FIGURE 6

THE AUTOMOBILE'S FOUR-STROKE CYCLE AND FUEL SYSTEM 
- Exhaust stroke. Exhaust valve opens; the piston moves up and sweeps the cylinder clear of burned gases. At the end of the exhaust stroke, the piston is at the top of the cylinder with the exhaust valve closing, ready to begin the cycle again.

The valve mechanism plays an important role from the standpoint of pollution. One intake and one exhaust valve are provided for each cylinder. Valves have three distinct functions: (1) the intake valve admits an afr-gasoline mixture in the carburetor and intake manifold, (2) the intake and exhaust valves seal off the cylinder space during compression, and (3) the exhaust valve opens to discharge exhaust gases from the engine. Combustion-chamber temperatures range from $50^{\circ}$ to $5,000^{\circ} \mathrm{F}\left(65.5^{\circ}\right.$ to $\left.2,760^{\circ} \mathrm{C}\right)$ and heat generated durlng combustion is not fully transformed into useful energy. The unused heat is generally dissipated by circulating water through jacketed spaces in the cylinder head and cylinder block.

The fuel system of an automobile engine, also fllustrated in Figure 6, consists of a fuel tank, remote reading fuel gauge, filter, fuel pump, and carburetor. The fuel pump usually is of the diaphragm type. The carburetor, shown in Figure 7, meters and atomizes the fuel so alr and gasoline are mixed in a ratio of about 14.7 to 1 . Modern engines continuously vary this ratio for maximum operating effictency. The gasoline and air mixture formed by the carburetor is carried to each cylinder by a ducting system called the intake manifold. Exhaust gases travel from the exhaust ports of the engine through a manifold connected to the exhaust plpe and the muffler. Mufflers are cylindrical or oval chambers of sheet steel installed between the exhaust pipe and tallpipe. The environment of the muffler is highly corrosive and coatings of zinc, aluminum, or ceramic are often used to extend muffler $11 \mathrm{fe}$.

The compression ratio expresses the relationship of the cylinder volume when the piston is at the bottom of its stroke to the volume when the piston is at the top of its stroke. Fuel burns more efficlently at higher compression ratios. For example, with a compression ratio of 6 to 1 , only 25 percent of potential fuel energy is converted into mechanical power by the engine; however, with a com pression ratio of 12 to 1 , the efficlency 1 s close to 32 percent. Compression ratios in American automobiles generally vary from 8 to 1 to more than 11 to 1 .

\section{Dlesel Engine}

The diesel engine differs from other internal combustion engines mainly in the way fuel is introduced and ignited. The diesel engine is more heavily built than a gasoline engine, and has fewer moving parts. Fuel is sprayed directly into the combustion chamber and 


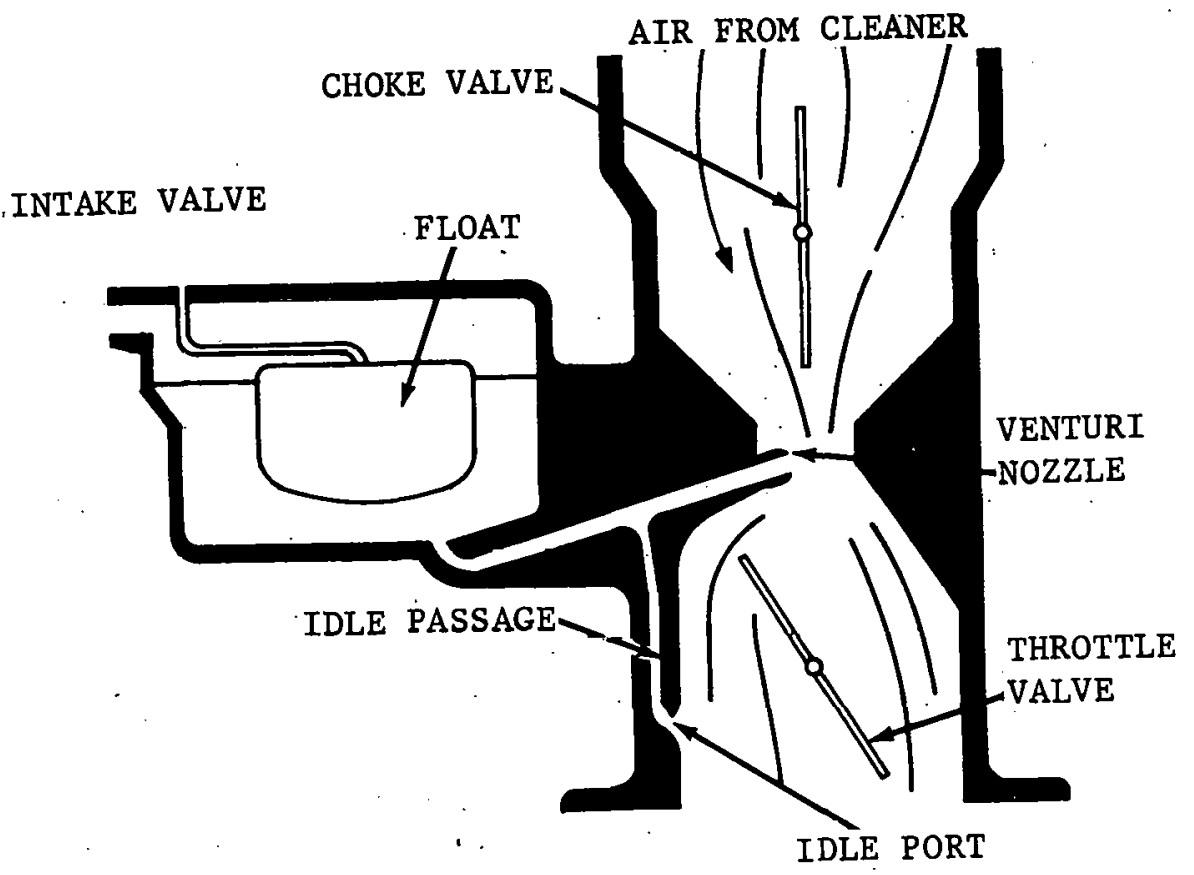

In the automobile carburetor, measured amounts of fuel are mixed with air and sprayed through the intake manifold to the cylinders. After ignition, burnt gases are forced out by the pistons through the exhaust manifold, exhaust pipe, muffler, and tailpipe, and then into the atmosphere.

Source: Adapted from McGraw Hill 1977.

FIGURE 7

THE CARBURETOR 
ignited by the high temperature to which air in the combustion chamber has been heated during the compression process. The engine operates on a thermodynamic cycle in which the air pressure is high enough to ignite the fuel subsequently injected into the combustion chamber. The diesel engine utilizes a wide variety of fuels with higher thermal efficiency than its gasoline counterpart, and it has consequent economic advantages under many service applications.

The diesel engine cycle consists of air compression in the combustion chamber, fuel injection into the combustion chamber, combustion and expansion of the hot gases, and exhaust. The cycle then begins again and the process continues. Combustion is considered to take place at a constant pressure. The method of fuel introduction is the key element in the efficient operation of a diesel engine. A high pressure pump is used to inject fuel at precisely the proper moment in the stroke, which is accurately metered.

Because of its use of heavy fuels and its combustion system, the diesel engine has certain limitations. Smoking occurs in the exhaust if an attempt is made to use more than 60 to 70 percent of the air in the cylinder during combustion. This smoking determines the maximum power produced by the engine. The air in diesel engines is compressed until its pressure is over $500 \mathrm{ps} 1$ and its temperature around $800^{\circ} \mathrm{F} .\left(427^{\circ} \mathrm{C}\right)$.

Modern diesel engines used in trucks, buses, and tractors range from a single-cylinder model with a bore and stroke of little more than three inches, and a weight of 200 pounds, that produces 7 horsepower at 2,400 revolutions per minute; to a version with 16 cylinders, a bore of nine inches, a stroke of 10.5 inches, and a weight of $4 \mathrm{i}, 000$ pounds, that produces 3,600 horsepower at 1,100 revolutions per minute.

Stationary Source Emissions

Burning oil and natural gas causes emissions of nitrogen oxides $\left(\mathrm{NO}_{\mathrm{x}}\right.$ ) and relatively minor amounts of particulate matter, sulfur dioxide $\left(\mathrm{SO}_{2}\right)$, carbon monoxide ( $\left.\mathrm{CO}\right)$, and hydrocarbons ( $\mathrm{HC}$ ), with the quantity of pollutants dependent on the extent of combustion. The following paragraphs discuss atmospheric emissions from oll- and gas-fired hoilers that produce electricity, steam, and heat.

\section{Particulate Emissions}

Fuel oil properties such as API gravity, carbon residue, as content, viscosity, and volatility are important in determining particulate emissions from oil-fired units. These properties influence atomization and vaporization, which contribute to proper combustion. 
Proper atomization is necessary to achleve complete, smoke-free ofl combustion. The quantity of emitted particulates is directly dependent on the size of the oll droplets, which is a function of burner type or atomization method. Incomplete vaporization of larger oil droplets contributes to particulate emissions.

Fly ash particles emitted from ofl-fired power plants are crystaliltes--principaliy magnesium, sulfur, and vanadium. The metals present in fuel oils are concentrated. in the ash products that remain after combustion. For example, a fuel oll containing 50 to $400 \mathrm{ppm}$ of vanadium could result in a fly. ash content of 5 . to 40 percent vanadium. 011- and coal-fired bollers produce $f l y$ ash containing several water soluble chemicals, including carbon, $\mathrm{H}_{2} \mathrm{SO}_{4}, \mathrm{NH}_{4}$ $\mathrm{HSO}_{4}, \mathrm{MgO}, \mathrm{MgSO}_{4} \cdot \mathrm{H}_{2} \mathrm{O}, \mathrm{V}_{2} \mathrm{O}_{5}, \mathrm{VOSO}_{4} \cdot 3 \mathrm{H}_{2} \mathrm{O}, . \mathrm{Fe}_{2} \mathrm{O}_{3}$, $\mathrm{FeSO}_{4} \cdot 7 \mathrm{H}_{2} \mathrm{O}, \mathrm{N1O}, \mathrm{NiSO}_{4}, \mathrm{Al}_{2} \mathrm{O}, \mathrm{Al}_{2}\left(\mathrm{SO}_{4}\right)_{3}, \mathrm{SiO}_{2}$, $\mathrm{Na}_{2} \mathrm{SO}_{4}, \mathrm{~K}_{2} \mathrm{SO}_{4}, \mathrm{CaO}$, and $\mathrm{CaSO}_{4}$ (Henry and Knapp 1980).

Uncontrolled particulate emissions from firing no. 6 residual oll depend on the o1l's sulfur content. The sulfur level affects. $\mathrm{SO}_{3}$ adsorption, thus, greater particulate formation occurs with oils of higher sulfur content. Particulate emissions from residual oll firing decrease as the boller size increases, probably because of better combustion control and increased maintenance. With distillate o11, particulate emissions depend on the design of the boller barrier rather than the size of the boiler (Offen et al. 1976).

Operating parameters affecting particulate emissions are boller load, cycling, and maintenance. At low boiler load conditions, particulate matter may be lowered by 30 to 40 percent with utility and by as much as 60 percent with small industrial and commercial units firing grade 6 o11. No significant particulate reduction has been noted at low loads from bollers firing any of the 11ghter grades. If loading is too low, proper combustion conditions cannot be maintalned and particulate emissions may increase drastically. Any condition that prevents proper boller operation can result in excessive particulate formation.

Gas-fired bollers do not generate large particulate emissions of coke or soot which result from incomplete combustion (Cato et al. 1974). Emission factors for uncontrolled particulates from o11- and gas-fired bollers are listed in Tables 6 and 7.

\section{Sulfur Oxides Emisstons}

The predominant sulfur oxide $\left(\mathrm{SO}_{\mathrm{x}}\right)$ is sulfur dioxide $\left(\mathrm{SO}_{2}\right)$, although sulfur trioxide $\left(\mathrm{SO}_{3}\right)$ can also be emitted. These emissions are often reported collectively as $\mathrm{SO}_{x}$, even though $\mathrm{SO}_{3}$ may constitute only 1 to 3 percent of the total (U.S. Environmental 
TABLE 6

ERISSION FACTORS FOR FUEL OIL COMBUSTION

\begin{tabular}{|c|c|c|c|c|c|c|c|c|}
\hline \multirow[b]{2}{*}{ Pollutant } & \multicolumn{2}{|c|}{$\begin{array}{c}\text { Utility } \\
\text { Residual 0il Boilers }\end{array}$} & \multicolumn{4}{|c|}{ Industrial and Commerc1al Boflers } & \multicolumn{2}{|c|}{$\begin{array}{c}\text { Residential } \\
\text { Distillate 01l Bollers }\end{array}$} \\
\hline & $1 \mathrm{~b} / 10^{3} \mathrm{ga} 1$ & $\mathrm{~kg} / 10^{3}$ liter & $1 \mathrm{~b} / 10^{3} \mathrm{gal}$ & $\mathrm{kg} / 10^{3}$ liter & $1 \mathrm{~b} / 10^{3} \mathrm{gal}$ & $\mathrm{kg} / 10^{3} 11$ ter & $16 / 10^{3} \mathrm{gal}$ & $\mathrm{kg} / 10^{3}$ 11ter \\
\hline Particulates & $\begin{array}{l}10(S)+3^{a} \\
10^{b} \\
7 b\end{array}$ & $\begin{array}{l}1.25(\mathrm{~S})+1) .38^{\mathrm{a}} \\
1.25^{\mathrm{b}} \\
0.88^{\mathrm{c}}\end{array}$ & $\begin{array}{l}10(S)+3^{a} \\
10^{\mathrm{h}} \\
7^{\mathrm{c}}\end{array}$ & $\begin{array}{l}1.25(\mathrm{~S})+0.38 \\
1.25^{\mathrm{b}} \\
0.88^{\mathrm{c}}\end{array}$ & 2 & 0.25 & 2.5 & 0.31 \\
\hline $\begin{array}{l}\text { Sulfur } \\
\text { dioxide }\end{array}$ & $157 \mathrm{~s}$ & 19Ṣ & $157 \mathrm{~s}$ & $19 \mathrm{~S}$ & $142 \mathrm{~S}$ & $17 \mathrm{~s}$ & $142 \mathrm{~s}$ & 178 \\
\hline $\begin{array}{l}\text { Sulfur } \\
\text { triokide }\end{array}$ & $2 \mathrm{~S}$ & $0.25 \mathrm{~S}$ & $2 \mathrm{~S}$ & $0.25 \mathrm{~S}$ & $2 \mathrm{~S}$ & $0.25 \mathrm{~s}$ & $2 \mathrm{~s}$ & $0.25 \mathrm{~s}$ \\
\hline $\begin{array}{r}\text { Nitrogen } \\
\text { oxides }\end{array}$ & $15 C^{e}(50)^{f}$ & $12.6(6.25)$ & 60 & 7.5 & 22 & 2.8 & 18 & 2.3 \\
\hline $\begin{array}{l}\text { Carbon } \\
\text { monoxide }\end{array}$ & $\leq$ & 0.63 & 5 & 0.63 & 5 & 0.63 & 5 & 0.63 \\
\hline Hydrocarbons & $\mathbf{I}$ & 0.12 & 1 & 0.12 & 1 & 0.12 & 1 & 0.12 \\
\hline
\end{tabular}

aparticulate values for grade 6 ofl where $s$ is the percentage by welght of sulfur in the ofl.

barticulate values for grade 5 oil.

Carticulate values for grade 4 oil.

${ }^{d} S$ is the percentage by weight of silfur in the oil.

e $A l 1$ boilers except tangentially fired hoilers.

fFor tangentially fired bollers.

Source: U.S. Environmental Protection Agency 1977d. 
TABLE 7

EMISSION FACTORS FOR NATURAL GAS COMBUSTION

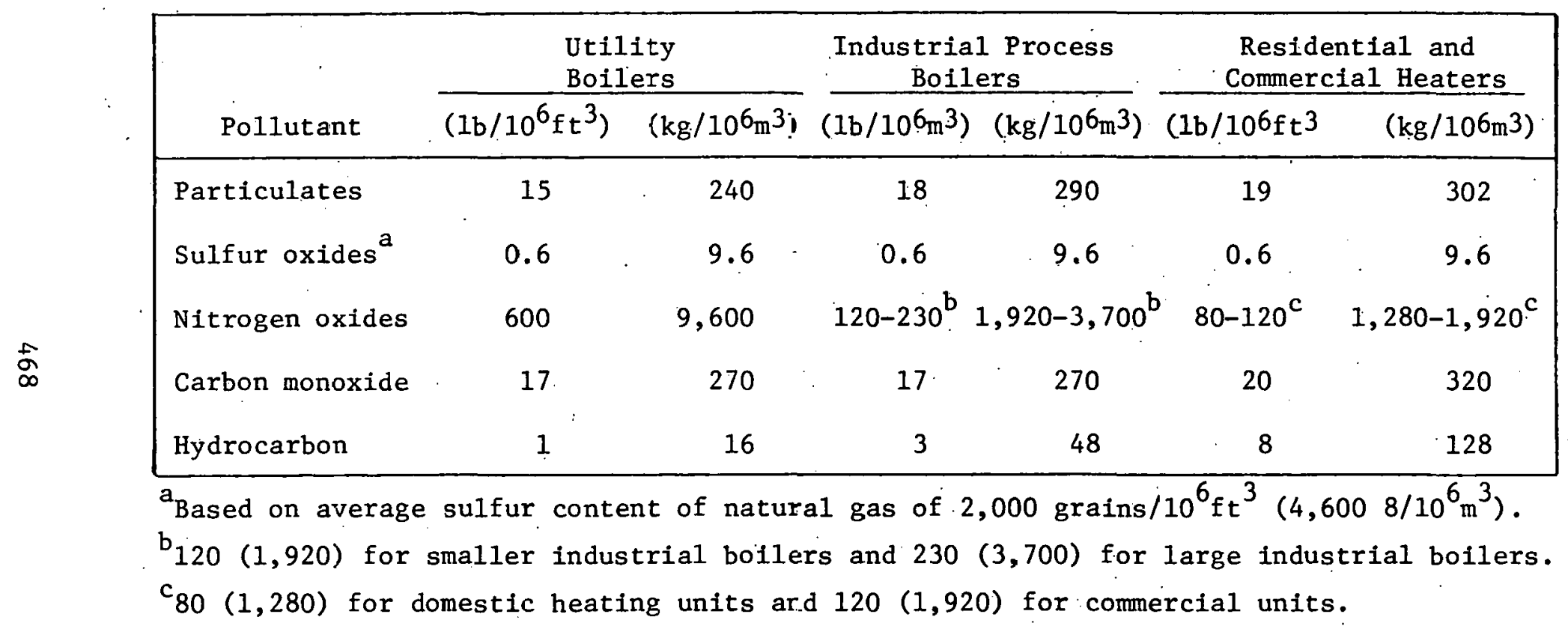

Source: U.S. Environmental Protection Agency 1977d. 
Protection Agency 1977d). SO $x$ emissions depend on the sulfur content of the fuel oll and are not affected by boller size, burner design, or grade of fuel. Table 6 presents uncontrolled $\mathrm{SO}_{\mathrm{x}}$ emission factors for firing residual and distillate oil in various boiler types.

The natural gas used in boilers has chemical additives that detect sulfur leaks. Small amounts of $\mathrm{SO}_{\mathrm{x}}$ are emitted from natural gas-fired units, as indicated by the $\mathrm{SO}_{\mathrm{x}}$ emission factors listed in Table 7.

Sulfate emissions also are of concern in boller operations. Sulfur-bearing residual oil produces sulfates directly in combustion (primary) or when sulfur dioxide emisstons are converted to sulfates in the atmosphere (secondary). Not much is known about formation mechanisms or the relative contributions of various sources of sulfates, but it is believed that sulfates represent a significant environmental problem. Epidemlological studies have implicated suspended water soluble sulfates as respiratory iritants. Primary sulfates represent 3 to 12 percent of the sulfur oxides discharged from ofl combustion in boilers. Primary sulfates can have a direct impact on people, particularly. when they are emitted from low-level stacks in urban areas. Secondary sulfates are the dominant source of "remote pollution," which manffests itself as acid rain or by impairing visibility. The potential impact of sulfates from bollers can vary significantly with the type of boiler, mode of operation, and fuel composition.

Sulfate emissions from oll-burning sources are 3 to 10 times greater than from sources burning coal with an equivalent sulfur content. It is believed that the higher flame temperatures, the vanadium and nickel content, and the lack of particulate control devices for ofl-fired units contribute to observed sulfate emissions (Homolya and Cheney 1978).

Much of the combustion in industrial and commercial boilers is likely to be poorly controlled for conditions such as excess air. If the industrial and commercial sectors continue to burn large amounts of oil, more effective control of both large and small oil-fired boilers would be necessary to effectively reduce exposure of the U.S. population to sulfates.

\section{Nitrogen Oxides Emissions}

Nitrogen oxides are produced during fuel oil combustion by two mechanisms, namely, oxidation of fuel-bound nitrogen and thermal fixation of nitrogen present in combustion air. The quantity of fuel $\mathrm{NO}_{x}$ emitted depends on the nitrogen content of the fuel and the 
amount of oxygen available. The quantity of thermal $\mathrm{NO}_{\mathrm{x}}$, on the other hand, is largely a function of peak flame temperature and the amount of oxygen. It also depends on boiler size, firing configuration, and operating practices. Nitrogen oxides are mainly nitric oxides (NO) and nitrogen dioxide $\left(\mathrm{NO}_{2}\right)$. NO usually makes up more than 90 percent of $\mathrm{NO}_{\mathrm{x}}$ when the pollutant is initially emitted from a boiler. In the atmosphere, most NO eventually becomes $\mathrm{NO}_{2}$ -

Residual oil-fired boilers contribute a major portion of total airborne $\mathrm{NO}_{\mathrm{x}}$ emissions, while distillate oil-fired and natural gasfired boilers contribute a minor amount. These emissions depend upon parameters such as combustion air temperature, flue gas recirculation heat release rate, excess air, and the air-to-fuel ratio. The effects of these parameters are fairly consistent with all types of boilers and fuels. Heating combustion air increases flame temperature and enhances formation of thermal $\mathrm{NO}_{\mathrm{x}}$. Excess air seems to encourage thermal $\mathrm{NO}_{\mathbf{x}}$ generation.

The quantity of nitrogen oxides emitted from natural gas-fired boilers is a function of the temperature. In the combustion chamber and the cooling rate of the combustion products. These values vary considerably with the type and size of unit. (Factors for uncontrolled $\mathrm{NO}_{\mathbf{x}}$ emissions from oil- and gas-fired boilers are provided above in Tables 6 and 7 , respectively.)

\section{Carbon Monoxide Emissions}

The rate of carbon monoxide ( $\mathrm{CO}$ ) emissions from boilers is heavily dependent upon the efficiency of fuel combustion. (Again, factors for uncontrolled, carbon monoxide emissions from oil-and gas-fired boilers are provided above in Tables 6 and 7 , respectively.) Efficiency of combustion and, consequently, boiler maintenance have a major influence on $\mathrm{CO}$ emissions. Because proper combustion lowers emissions, the units should be operated while carefully controlling excess air, using high combustion temperatures, and providing for intimate air-fuel contact. Improper operation and on/off cycling of smaller boilers can increase Co emissions by several orders of magnitude. This is most likely to be the case with small, frequently unattended units, and not with larger units that are continuously operated and routinely maintained.

\section{Hydrocarbon Emissions}

The rate of hydrocarbon (HC) emissions from boilers is also dependent upon fuel combustion efficiency. Hydrocarbon emissions are minimal when proper combustion practices are used. (Again, factors for uncontrolled hydrocarbon emissions from oil- and gas-fired boilers are listed in Tables 6 and 7, respectively.) Combustion 
efficlency is related to the condition of the boller. As with Co, careful control of excess air, use of high combustion temperatures, and provision of intimate fuel-air contact w111 minimize HC emissions. Hydrocarbon emissions from ofl- and gas-fired units generally are negligible unless the units are improperly operated or malntalned. Then emissions may increase by several orders of magnitude.

Hydrocarbons include volatile organic compounds (VOC), such as methane, formaldehyde, ethane, ethylene, acetylene, ace tone; propane, propylene, n-butane, isobutane, n-pentane, hexane, heptane, octane, cyclohexane, benzene, and toluene. Stationary combustion sources using residual, distillate, or natural ofl emit an estimated 5 percent of evaporative VOC emissions whtch total $28.3 \times 10^{6}$ million tons per year (U.S. Environmental Protection Agency 1978b).

Another group of hydrocarbons, polycyclic organic matter (POM) has been defined most simply as all organic matter with two or more benzene rings. Th1s class of compounds has been considered hazardous, but little is known about the relative amounts of POM discharged by varlous sources.

Two interrelated boller characteristics affect the amount of POM : generated: the type of fuel used and combustion efficiency. In general, more POM would be expected from burning o11 than from gas. Larger bollers operated continuously under we11-controlled, we11maintalned conditions would produce less POM. More common small bollers, which generally are loosely controlled and poorly maintalned, can emit much larger quantities of POM per unit of fuel burned.

The POM class includes polynuclear aromatic hydrocarbons commonly 1dentified as PAHs, and nitrogen-containing heterocyclic compounds. Although the physical states of POM and soot are different, they probably have common origins and similar chemical reactivity. The materfals labeled POM are emitted in small or trace quantities during the combustion of residual oil. Studies of the mode of formation and destruction of POM in the combustion process are difficult to carry out because of the low concentrations, the lack of simple analytical procedures for identifying them, and the large number of Individual compounds making up this class of material. Typical POMs that have been observed are anthracene, pyrene, methyl anthracene, fluoranthene, methyl fluroranthene/pyrene, ehryscne, perylene, benzo(gh1)perylene, and coronene (U.S. Environmental Protection Agency 1978a).

The relationship between fuel type, boller efficlency and efficlency of one POM, benzo(a)pyrene (BaP), is illustrated in Table 8 (Hangebrauck et al, 1967). 
TABLE 8

RELATIVE BENZO(A)PYRENE EMISSION RATES FROM STATIONARY FUEL COMBUSTION SOURCES

\begin{tabular}{cc}
\hline Fuel & $\begin{array}{c}\text { Estimated } \\
\text { Emission Rate } \\
(\text { ug/106 Btu's })\end{array}$ \\
\hline Coal & $1,451,790$ \\
Gas & 200 \\
\hline
\end{tabular}

These data are average values for gas and oil furnaces and suggest that oil- and gas-fired furnaces produce less BaP than coal-fired furnaces. A recent study by the U.S. Environmental Protection Agency (EPA), which assessed pollution from fossil fuel combustion boilers, suggests that the fuel burned in utility bollers would produce less POM then simflar fuels burned in industrial and commercial boilers (U.S. Envirónmental Protection Agency 1979b). Small, oil-burning industrial and commercial boilers are located mostly in urban areas and emit POM at low elevations from many sources. These sources could have a greater impact on human health than larger, more remote sources.

Estimated controlled emissions of criteria pollutants from utility, industrial, and commercial boilers for 1975 are shown in Table 9, along with EPA estimates for total annual emissions for the U.S. (U.S. Environmental Protection Agency 1979b). 


\section{TABLE 9}

ESTIMATED EMISSIONS OF FIVE

CRITERIA POLLUTANTS FROM BOILERS

$\left(10^{6}\right.$ tons/year)

\begin{tabular}{|c|c|c|c|c|c|}
\hline Sector/Fuel & Particulate & $\mathrm{SO}_{\mathbf{x}}$ & $\mathrm{NO}_{\mathbf{x}}$ & $\mathrm{CO}$ & $\mathrm{HC}$ \\
\hline \multicolumn{6}{|l|}{ Utility } \\
\hline $\begin{array}{l}\text { Oil } \\
\text { Gas }\end{array}$ & $\begin{array}{l}0.08 \\
0.00 \\
\end{array}$ & $\begin{array}{l}1.49 \\
0.00 \\
\end{array}$ & $\begin{array}{l}1.11 \\
1.0 \\
\end{array}$ & $\begin{array}{l}\text { Unknown } \\
\text { Unknown }\end{array}$ & $\begin{array}{l}\text { Unknown } \\
\text { Unknown }\end{array}$ \\
\hline Total & 0.08 & 1.49 & 2.11 & 0.27 & 0.09 \\
\hline \multicolumn{6}{|l|}{ Industrial/Commercial } \\
\hline $\begin{array}{l}\text { Oil } \\
\text { Gas }\end{array}$ & $\begin{array}{l}0.11 \\
0.05 \\
\end{array}$ & $\begin{array}{l}1.55 \\
0.00 \\
\end{array}$ & $\begin{array}{l}0.44 \\
0.43 \\
\end{array}$ & $\begin{array}{l}\text { Unknown } \\
\text { Unknown }\end{array}$ & $\begin{array}{l}\text { Unknown } \\
\text { Unknown }\end{array}$ \\
\hline Total & 0.16 & 1.55 & 0.87 & 0.21 & 0.07 \\
\hline Total U.S. Emissions ${ }^{a}$ & $16.0^{\mathrm{a}}$ & $28.5^{a}$ & $24.4^{a}$ & $95.0^{b}$ & $28.9^{b}$ \\
\hline
\end{tabular}

asource: U.S. Environmental Protection Agency 1976, based on NEDS data.

bource: U.S. Environmental Protection Agency 1979b.

The particulate emission values reflect an assumed 95 percent average efficlency for 1975. The data indicate that oil- and gasfired boilers contribute 1.5 percent of the particulates emitted during combustion in the U.S., 10.7 percent of the $\mathrm{SO}_{\mathrm{x}}, 12.2$ percent of the $\mathrm{NO}_{x}, 0.22$ percent of the $\mathrm{CO}$, and 0.24 percent of the hydrocarbons.

\section{Trace Metals}

Many of the trace metal ions present in oil (e.g., arsenic, cadmium, and mercury) have the potential for being emitted as toxic substances, while vanadium and nickel have the potential for 
catalyzing undesirable atmospheric transformations such as the conversion of sulfur dioxide to sulfates. The sparse data available on trace elements suggest that their presence and concentrations in crude oils vary. Refinling concentrates trace metals in oil by a factor of 5 to 10 or more. Hence, potentlally hazardous trace metal compounds may be discharged in the combustion of refined ofl in small boilers.

An EPA study shows that actual residual o1l composition may vary (U.S. Environmental Protection Agency 1978b). Of the 60 or so detectable trace species in residual ofl, vanadium concentrations were found as $10 \mathrm{w}$ as $10 \mathrm{ppm}$ by welght and as high as $300 \mathrm{ppm}$ by welght. This wide variation is due to the varlation in imported crude ofls and the common refinery practice of blending the bottoms from several different crudes into one final residual o1l. Table 10 illustrates an average residual oll composite analysis (U.S. Environmental Protection Agency 1978b).

Of the most abundant trace metal compounds formed, only s11icon dioxide $\left(\mathrm{S}_{2}\right)$ and vanadium pentoxide $\left(\mathrm{V}_{2} \mathrm{O}_{5}\right)$ remain constant over the temperature range between $440^{\circ} \mathrm{F}$ and $2,780^{\circ} \mathrm{F}$. Aluminum, iron, and magnesium tend to form oxides at $980^{\circ} \mathrm{F}$ and above and sulfates at $710^{\circ} \mathrm{F}$ and below. Nickel and calclum predominantly form oxides at $2,780^{\circ} \mathrm{F}$, but form mostly sulfates at lower temperatures. The predominant sodium compound at $2,780^{\circ} \mathrm{F}$ is sodium silicate $\left(\mathrm{Na}_{2} \mathrm{~S}_{3}\right)$, but, below that temperature; sodium tends to favnr sulfates. 'The metal sulfate distribution agrees well with the $\mathrm{SO}_{2}$ distribution, which is highest at higher temperatures where there are fewer metal sulfates, and lowest at lower temperatures where there are more metal sulfates. The sulfur from residual oll reacts to form predominant $1 \mathrm{y} \mathrm{SO}_{2}$ at $2,780^{\circ} \mathrm{F}$, but as the combustion temperature decreases, more of the sulfur is taken up in metal sulfates. Lead emissions from all ofl combustion sources were estimated to be 110 tons in 1975 (U.S. Environmental Protection Agency 1977c). These lead emissions are comparatively small and of little concern.

\section{Indoor Emissions}

The combustion of ofl and natural gas for cooking, space heating, etc., In the residential sector causes the indoor generation of air pollutants, namely nitrogen dioxide $\left(\mathrm{NO}_{2}\right)$, nitric oxide (NO), carbon dioxide, sulfur dioxide, carbon monoxide, and hydrocarbons. Indoor air quality is a complex function of outdoor pollutant concentrations, bullding permeability, meteorological conditions, ventilation system design, and indoor generation of pollutants. 
TABLE 10

AVERAGE RESIDUAL OIL COMPOSITE ANALYSIS

\begin{tabular}{|c|c|c|c|c|c|}
\hline \multirow{3}{*}{$\begin{array}{l}\text { Element } \\
\begin{array}{l}\text { Carbon } \\
\text { Hydrogen }\end{array}\end{array}$} & \multicolumn{2}{|c|}{ Concentration ${ }^{a}$} & \multirow{2}{*}{$\frac{\text { Element }}{\text { Uranium }}$} & \multicolumn{2}{|c|}{ Concentration $^{a}$} \\
\hline & $85.1 \%$ & & & 0.7 & $\mathrm{ppm}$ \\
\hline & $11.2 \%$ & & Antimony & 0.4 & $\mathrm{ppm}$ \\
\hline Sulfur & $2.5 \%$ & & Doron & 0.41 & ppm \\
\hline Nitrogen & $4,400.0$ & ppm & Gallium & 0.4 & ppm \\
\hline Vanadium & 160.0 & $\mathrm{ppm}$ & Indium & 0.3 & $\mathrm{ppm}$ \\
\hline Nickel & 42.2 & $\mathrm{ppm}$ & Silver & 0.3 & ppm \\
\hline Potassium & 34.0 & $\mathrm{ppm}$ & Germanium & 0.2 & ppm \\
\hline Sodium & 31.0 & $\mathrm{ppm}$ & Tahllium & 0.2 & $\mathrm{ppm}$ \\
\hline Iron & 18.0 & $\mathrm{ppm}$ & Zirconium & 0.2 . & $\mathrm{ppm}$ \\
\hline Silicon & 17.5 & ppm & Strontium & 0.15 & $\mathrm{ppm}$ \\
\hline Calcium & 14.0 & $\mathrm{ppm}$ & Bromine & 0.13 & ppm \\
\hline Magnesium & 13.0 & ppm & Fluorine & 0.12 & $\mathrm{ppm}$ \\
\hline Chlorine & 12.0 & ppm & Ruthenium & 0.1 & ppm \\
\hline Tin & 6.2 & ppm & Tellurium & 0.1 & ppm \\
\hline Aluminum & 3.8 & $\mathrm{ppm}$ & Cesium & 0.09 & ppm \\
\hline Lead & 3.5 & ppm & Beryllium & 0.08 & ppm \\
\hline Copper & 2.8 & $\mathrm{ppm}$ & İodine & 0.06 & ppm \\
\hline Cadmium & 2.27 & $\mathrm{ppm}$ & Lithium & 0.06 & ppm \\
\hline Cobalt & 2.21 & ppm & Mercury & 0.04 & ppm \\
\hline Rubidium & 2.0 & ppm & Tantalum & 0.04 & ppm \\
\hline Titanium & 1.8 & ppm & Thodium & 0.03 & ppm \\
\hline Manganese & 1.33 & ppm & Gold & 0.02 & ppm \\
\hline Chromium & 1.3 & ppm & Platinum & 0.02 & ppm \\
\hline Barium & 1.26 & ppm & Scandium & 0.02 & ppm \\
\hline Zinc & 1.26 & ppm & Bismuth & 0.01 & $\mathrm{ppm}$ \\
\hline Phosphorus & 1.1 & ppm & Cerium & 0.006 & ppm \\
\hline Molybdenum & 0.9 & ppm & Tungsten & 0.004 & ppm \\
\hline Arsenic & 0.8 & ppm & Hafnium & 0.003 & ppm \\
\hline Selenium & 0.7 & ppm & Yttrium & 0.002 & ppm \\
\hline & & & Niobium & 0.001 & ppm \\
\hline
\end{tabular}

Source: U.S. Environmental Protection Agency 1978. 
Many indoor-generated pollutants are emitted in a fugitive manner, i.e., they enter the indoor atmosphere through uncontrolled stove and oven emissions and from leaks from faulty combustion systems such as space heaters, gas-fired hot water heaters, and gas dryers. Energy conservation measures in single family homes and apartment buildings tend to aggravate this problem by concentrating indoor pollutants.

\section{Emissions from Gas Stoves and Ovens}

Unvented gas stoves can contribute measurable quantities of carbon monoxide to the indoor atmosphere (Yocum et al. 1971). Indoor air quality is degraded by combustion products from gas stoves, especially $\mathrm{NO}_{2}$, $\mathrm{NO}$, and $\mathrm{CO}$ emissions. Pilot lights on gas stoves generate measurable amounts of $\mathrm{NO}, \mathrm{NO}_{2}$, and $\mathrm{CO}$ when a stove is not in use. Highest indoor concentrations of stove-generated pollutants. occur in the winter when houses are tightly closed. The amounts of pollutants generated are directly.related to the number of burners in operation and the amount of gas consumed. Vented stove hoods are moderately effective in removing gaseous pollutants, but recirculating hoods are not. Stove use and outdoor air quality influence indoor air quality. This joint influence is a function of house permeability. Concentrations of pollutants in the kitchen are always higher than in other parts of the house (Cote et al. 1974).

Emissions of Sulfur Dioxide and Sulfates. The literature indicates that indoor $\mathrm{SO}_{2}$ concentrations are primarily the result of the introduction of outdoor-generated $\mathrm{SO}_{2}$ into buildings. Few studies demonstrate indoor $\mathrm{SO}_{2}$ generation from oil-burning heating systems (Yocum et al. 1974) or gas stoves (Hollowell et al. 1976). It is suggested that $\mathrm{SO}_{2}$ is reactive and may be differentially absorbed by interior walls, ceilings, floors, and their interior surfaces and finishes. Differences in room sizes, building materials, fixtures, furniture, ventilation rates, and occupancy are probable variables that account for differences in indoor-tooutdoor ratios (Anderson 1972).

A study conducted in Boston and Cambridge homes (Arthur D. Little 1975) lends support to the results cited above. In a study conducted on 60 homes heated with oil, coal, or gas in Rotterdam, the Netherlands, investigators concluded that indoor $\mathrm{SO}_{2}$ concentrations are not significantly affected by the heating system used if it is in good condition, but they reported that indoor concentrations of $\mathrm{SO}_{2}$ were 3.8 times the outdoor levels for a 30-year-old home where a heater was believed to be faulty (Biersteker et al. 1965). They noted that newer homes tend to have lower $\mathrm{SO}_{2}$ emissions than older homes. 
Recently, p1lot measurements of $\mathrm{SO}_{2}$ and pollutants were taken at varfous indoor and outdoor locations by a team of investigators from the Lawrence Berkeley Laboratory of the University of California (Hollowell et al. 1976). SO 2 levels observed by this group with a gas oven operating at $550^{\circ} \mathrm{F}\left(287^{\circ} \mathrm{C}\right)$ for approximately 20 minutes ranged from $<15$ to $110 \mathrm{ug} / \mathrm{m}^{3}$, with average values varying:

Stove Condition

Kitchen background

One burner on, no grate

One burner on with grate

One burner on with grate and all stainless steel pans
$\mathrm{SO}_{2}\left(\mathrm{ug} / \mathrm{m}^{3}\right)$

$<15-40$

$25-65$

$<1.5-90$

$<15-80$

A study conducted in Germany on air pollution due to home heatIng systems suggests that the systems are responsible for 58.5 percent of indoor $\mathrm{SO}_{2}$ emissions that total 5,092 tons per year (Gred1schnik 1972).

Nitrogen Oxides and Nitrates. Nitrogen oxides concentrations are reported to be lower outdoors than at all locations indoors because of the gas stove, an Indoor nitrogen oxide source (Cote et al. 1974). An investigation of indoor and outdoor nitrogen oxides concentrations suggests that Indoor peaks seem to be related to rush hour traffic. The impact of gas stoves on indoor $\mathrm{NO}_{x}$ concentrations was studied extensively (Cote et a1. 1974). Table 11 illustrates the results of the laboratory study, which concluded the following:

- The gas stoves tested emit significant quantitles of nitrogen oxides in the following ranges depending upon stove operation: No, 90 to $130 \mathrm{ug}$ per Kcal, 200 to $1,000 \mathrm{mg}$ per hour; $\mathrm{NO}_{2}, 50$ to $80 \mathrm{ug}$ per Kcal, 100 to $500 \mathrm{mg}$ per hour.

- Pollutant emissions from the newer stove were not consistently higher or lower than those from the older stove for the range of operations evaluated.

- The different designs of the burners of the two stoves did not appear to have consistent and reproducible effects upon pollutant emissions. Tests designed to evaluate the effect of alr-fuel mixture upon burner operation indlcated that the 
TABLE 11

POLLUTANT EMISSIONS FROM GAS APPLIANCES ${ }^{a}$

\begin{tabular}{|c|c|c|c|c|c|c|c|c|c|}
\hline & \multirow{2}{*}{ Appliance } & \multirow[b]{2}{*}{ Operation } & \multirow{2}{*}{$\begin{array}{c}\text { Heat Input } \\
\text { Rate } \\
\text { (Kcal/hr) }\end{array}$} & \multicolumn{3}{|c|}{$\begin{array}{l}\text { Pollutant Emission } \\
\text { Factors }(\mu \mathrm{g} / \mathrm{Kcal})\end{array}$} & \multicolumn{3}{|c|}{$\begin{array}{l}\text { Pollutant Emission Rates } \\
(\mathrm{mg} / \mathrm{hr})\end{array}$} \\
\hline & & & & No & $\mathrm{NO}_{2}$ & $\mathrm{CO}$ & No & $\mathrm{NO}_{2}$ & $\mathrm{CO}$ \\
\hline & $\begin{array}{l}\text { older gas } \\
\text { stove with } \\
\text { cast iron } \\
\text { burners }\end{array}$ & $\begin{array}{l}\text { Pilot lights } \\
1 \text { burner, high flame } \\
3 \text { burners, high flame }\end{array}$ & $\begin{array}{r}150 \\
2,700 \\
6,780\end{array}$ & $\begin{array}{r}45.3 \\
92.6 \\
117.0\end{array}$ & $\begin{array}{l}54.6 \\
51.8 \\
72.8\end{array}$ & $\begin{array}{l}419 \\
382 \\
475\end{array}$ & $\begin{array}{r}6.8 \\
250.0 \\
793.0\end{array}$ & $\begin{array}{r}8.2 \\
140.0 \\
494.0\end{array}$ & $\begin{array}{r}62.9 \\
1,031.0 \\
3,220.0\end{array}$ \\
\hline & & $\begin{array}{l}\text { Transient } \\
\text { Steady-state }\end{array}$ & $\begin{array}{l}2,300 \\
2,200\end{array}$ & $\begin{array}{r}157.0 \\
91.4\end{array}$ & $\begin{array}{r}159.0 \\
73.1\end{array}$ & $\begin{array}{r}1,790 \\
530\end{array}$ & $\begin{array}{l}361.0 \\
201: 0\end{array}$ & $\begin{array}{l}366.0 \\
161.0\end{array}$ & $\begin{array}{l}4,117.0 \\
1,166.0\end{array}$ \\
\hline \multirow{6}{*}{$\stackrel{ \pm}{\infty}$} & & $\begin{array}{l}\text { Broiler } \\
\text { Transient } \\
\text { Steady-state }\end{array}$ & $\begin{array}{l}3,000 \\
3,800\end{array}$ & $\begin{array}{r}137.0 \\
88.8\end{array}$ & $\begin{array}{r}123.0 \\
48.5\end{array}$ & $\begin{array}{r}1,350 \\
818\end{array}$ & $\begin{array}{l}411.0 \\
337.0\end{array}$ & $\begin{array}{l}369.0 \\
184.0\end{array}$ & $\begin{array}{l}4,050.0 \\
3,108.0\end{array}$ \\
\hline & $\begin{array}{l}\text { New gas } \\
\text { stove with } \\
\text { pressed } \\
\text { steel }\end{array}$ & $\begin{array}{l}\text { Pilot lights } \\
1 \text { burner, high flame } \\
3 \text { burners, high flame }\end{array}$ & $\begin{array}{r}100 \\
3,500 \\
10,200\end{array}$ & $\begin{array}{r}4.7 \\
130.0 \\
138.0\end{array}$ & $\begin{array}{l}18.6 \\
79.0 \\
65.6\end{array}$ & $\begin{array}{l}842 \\
510 \\
315\end{array}$ & $\begin{array}{r}0.5 \\
455.0 \\
1,408.0\end{array}$ & $\begin{array}{r}1.9 \\
277.0 \\
669.0\end{array}$ & $\begin{array}{r}84.2 \\
1,785.0 \\
3,213.0\end{array}$ \\
\hline & burners & $\begin{array}{l}\text { Oven } \\
\text { Transient } \\
\text { Steady-state }\end{array}$ & $\begin{array}{l}4,00 G \\
2,20 G\end{array}$ & $\begin{array}{r}331.0 \\
77.9\end{array}$ & $\begin{array}{l}79.0 \\
50.4\end{array}$ & $\begin{array}{l}1,010 \\
1,620\end{array}$ & $\begin{array}{r}1,324.0 \\
171.0\end{array}$ & $\begin{array}{l}316.0 \\
111.0\end{array}$ & $\begin{array}{l}4,040.0 \\
3,564.0\end{array}$ \\
\hline & & $\begin{array}{l}\text { Broiler } \\
\text { Transient } \\
\text { Steady-state }\end{array}$ & $\begin{array}{l}4,90 \mathrm{C} \\
3,70 \mathrm{C}\end{array}$ & $\begin{array}{l}126.0 \\
136.0\end{array}$ & $\begin{array}{l}80.6 \\
57.1\end{array}$ & $\begin{array}{l}846 \\
757\end{array}$ & $\begin{array}{l}617.0 \\
503.0\end{array}$ & $\begin{array}{l}395.0 \\
211.0\end{array}$ & $\begin{array}{l}4,145.0 \\
2,800.0\end{array}$ \\
\hline & $\begin{array}{l}\text { Unvented } \\
\text { space } \\
\text { heater }\end{array}$ & $\begin{array}{l}\text { Low flame, steady-state } \\
\text { High flame, steady-state }\end{array}$ & $\begin{array}{l}2,80 \mathrm{C} \\
6,20 \mathrm{C}\end{array}$ & $\begin{array}{r}76.4 \\
135.0\end{array}$ & $\begin{array}{l}46.4 \\
43.8\end{array}$ & $\begin{array}{l}632 \\
319\end{array}$ & $\begin{array}{l}214.0 \\
837.0\end{array}$ & $\begin{array}{l}130.0 \\
272.0\end{array}$ & $\begin{array}{l}1,770.0 \\
1,978.0\end{array}$ \\
\hline & $\begin{array}{l}\text { Domestic } \\
\text { gas } \\
\text { furnace }\end{array}$ & --- & $\begin{array}{l}\text { Approx } \\
30,00 \mathrm{C}\end{array}$ & & 90.0 & 36 & &, 700.0 & $1,080.0$ \\
\hline
\end{tabular}

${ }^{a}$ Summary for several typical operating dwellings in Hartford, Connecticut.

Source: Cote et al. 1974 
best blue luminous flame was produced at an intermediate air shutter opening for each stove. Varlation in the shutter opening had little effect on the pollutant emissions for the older stove, but had a greater effect on the newer stove. The intermediate air shutter opening (best flame) also had the highest nitrogen oxides levels for the newer stove.

- Pilot lights, although using gas at a slow rate, do contribute quantities of pollutants comparable to those generated during cooking operations over a typical 24-hour period because of their continuous operation. P1lot light NO and $\mathrm{NO}_{2}$ emissions from the newer stove were less than those from the older stove. The newer stove also has a pilot $11 \mathrm{ght}$ designed to use less gas than the older stove.

- Evaluation of the number of burners in use and the Ir flame intensity showed that the emissions are similar for all conditions when adjusted to an equivalent heat input basis. Oven and broller emissions are somewhat less than those for the burners on the same heat input basis.

- Total pollutant emissions per unit of time from a gas stove are roughly proportional to the number and type of burners used and the period of use (Cote et al. 1974).

Based on the findings of the fleld study the investigators concluded the following:

- Indoor $\mathrm{NO}_{2}$ concentrations in the kitchens of most houses would exceed the National Ambient Air Quality Standard for $\mathrm{NO}_{2}$ of $100 \mathrm{ug}$ per $\mathrm{m}^{3}$ annual average (1f the concentrations were projected over 1 year). Average kitchen $\mathrm{NO}_{2}$ concentrations for most sampling periods were two to four times the outdoor $\mathrm{NO}_{2}$ concentrations.

- The half-11fe. for NO was 1.8 hours, Indicating lts high stabillty indoors. On the other hand, $\mathrm{NO}_{2}$ had a half-life of 0.6 hours indicating that it is lost not only to dispersion and dilution, but also through reaction, absorption, or adsorption.

- Stove pilot lights were found to be a significant source of $\mathrm{NO}_{2}$ (Cote et al. 1974).

Another study of air pollution in a house with a gas stove found significantly higher indoor kitchen concentrations of $\mathrm{NO}_{2}$ (Eaton et a1. 1972). It found peak $\mathrm{NO}_{2}$ values of $1 \mathrm{ppm}\left(1,880 \mathrm{ug}\right.$ per $\left.\mathrm{m}^{3}\right)$ 
with 1-hour averages ranging from 0.25 to $0.5 \mathrm{ppm}$ ( 470 to 940 ug per $\mathrm{m}^{3}$ ) when the kitchen was closed with no ventilation. The gas flow was $0.204 \mathrm{ft}^{3}$ per minute, and the sampling intake was 6 feet from the stove.

The study conducted at the Lawrence Berkeley Laboratory, mentioned above, measured not only sulfur dioxide, but also NO and $\mathrm{NO}_{2}$ emissions with the gas oven operating at $550^{\circ} \mathrm{F}\left(287^{\circ} \mathrm{C}\right)$ for approximately 20 minutes (Hollowel 1 et al. 1976). The results were:

Pollutant

\begin{tabular}{lll}
\hline No Duct, & No Duct, & Duct, \\
Fan Off & Fan On & No Fan \\
\hline
\end{tabular}

NO $\left(\mathrm{ug} / \mathrm{m}^{3}\right)$ $2,000 \quad 1,000 \quad 150-500$

$\mathrm{NO}_{2}\left(\mathrm{ug} / \mathrm{m}^{3}\right)$

850

320

$95-150$

The study also illustrated the effects of gas surface burner. condtions on gaseous emissions of $\mathrm{NO}$ and $\mathrm{NO}_{2}$, observing the following levels:

Stove Condition

$\frac{\text { Pollutant }}{\frac{\mathrm{NO}}{\left(\mathrm{ug} / \mathrm{m}^{3}\right)}} \cdot \underline{\left(\mathrm{Ng} / \mathrm{m}^{3}\right)}$

Kitchen background 25-85 $30-85$

One burner on, no grate $165-1,260 \quad 115-450$

One burner on with grate $125-1,100$. $65-380$

One burner on with grate and all stainless steel pans $160-740$ $125-380$

Such variations in $\mathrm{NO}_{\mathrm{x}}$ emissions are due to differences in sampling point locations, gas fired appliances, air-fuel ratios, and dwellings.

The relationship between indoor nitrogen dioxide pollution and heating was studied in Japan (Kogai 1976). In winter, the indoor $\mathrm{NO}_{2}$ level was higher than the outdoor level. The kitchen level was the highest of indoor levels. The average $\mathrm{NO}_{2}$ level found in $126 \mathrm{kitchens}$ was $238 \mathrm{ug}$ per $100 \mathrm{~cm}^{2}$ per day, which was 10 times more than the outdoor $\mathrm{NO}_{2}$ level of 22 ug per $100 \mathrm{~cm}^{2}$ per day in Japan. The $\mathrm{NO}_{2}$ level in rooms decreased as the distance between the room and the kitchen increased. 
Carbon Monoxide. A literature review by Benson and associates (1972) concluded that indoor carbon monoxide (CO) concentrations appear to follow a pattern similar to those of sulfur dioxide. Indoor concentrations of CO ranged from 80 to 100 percent of outdoor concentrations when outdoor concentrations were below $10 \mathrm{ppm}$. They ranged from 60 to 80 percent when outdoor concentrations were above $10 \mathrm{ppm}$. Carbon monoxide is a reactive, odorless gas with a half-life of 2.1 hours. A General Electric Company study (1972) found that the variation in the ratios of indoor to outdoor CO concentrations can be explained by variables such as traffic conditions, nontraffic-related sources, meteorological conditions, and site configurations. This finding is strengthened by another study in which the relationship between $\mathrm{CO}$ emissions from gas stoves and from several variables was measured and measurements were made of indoor and outdoor CO concentrations (Yocum et al. 1974).

Still another study was conducted in Hartford, Connecticut (Cote et al. 1974). It suggested that the ovens of new stoves emit about three times as much $\mathrm{CO}$ as older stove ovens, but pilot lights on older stoves emit more CO than those on newer stoves. The gas stoves tested emitted 400 to $1,000 \mathrm{ug}$ per $\mathrm{Kcal}$ of $\mathrm{CO}(1,000$ to 4,000 mg per. hour).

The Hollowell study (1976), mentioned above, shows carbon monoxide concentrations ranging from 2,000 to 2,300 ug per $\mathrm{m}^{3}$ under varying venting duct and fan conditions. It provides data on co concentrations in the breathing zone under various operating conditions of the top burners of a gas stove as indicated below:

$\begin{array}{lc}\text { Stove Condition } & \frac{\mathrm{Co}\left(\mathrm{ug} / \mathrm{m}^{3}\right)}{1,000-9,000} \\ \text { Kitchen background } & 2,000-10,000 \\ \text { One burner on, no grate } & 3,000-9,000 \\ \text { One burner on, with grate } & \\ \text { One burner on with grate and } & 3,000-27,000 \\ \text { all stainless steel pans }\end{array}$

Such a large spectrum of Co concentrations is due to the different variables suggested for $\mathrm{NO}_{\mathrm{x}}$ levels.

An early German study suggested that 011 and gas-fired furuaces generate negligible amounts of CO (Baum 1972). 
Radioactlve Materials. Recently, the Federal Radiation Policy Council warned that indoor exposure to radon is a nationwide problem that threatens to grow worse and requires Immediate steps to assess the magnitude of the problem and control options (General Electric Company 1972). Although this has been recognized as a problem only recently, Indoor radon is thought to come from alrborne radon and radon daughter products found in groundwater supplies used in the home and in masonry construction materials such as concrete and gypsum blocks. About half the radon present in household water supplies becomes alrborne. In fact, after radon-rich groundwater is sprayed through a showerhead, concentrations in bathroom alr can approach occupational 1imits (National Academy of Sciences 1980).

However, o1l and gas can make a significant contribution to indoor radon levels. The average annual dose equivalent rate for persons who cook with gas ranges is six to nine. For persons exposed to unvented heaters, the average dose equivalent is 22 mrems per year. The bronchial lining is the most affected part of the body. The dose equivalents are the highest (next to smoking) of these for any other consumer product (including outdoor combustion of fossil fuels, luminous compounds, television sets, and construction materials) (National Academy of Sclences 1980).

Natural gas contains about 10 to $20 \mathrm{pCI}$ per 11 ter of radon. This contributes less than $10^{4} \mathrm{C} 1$ per year to the worldwide Inventory of $40 \mathrm{MCl}$. The dose equivalent to the lungs of persons using natural gas ranges in the home has been calculated to be about 2 percent of the normal, natural background dose equivalent from radon and its daughters. On this basis, the resulting dose equivalent rates to persons in homes using natural gas for cooking would be about two mrem per year to the alveolar region and nine mrem per year to the segmented bronchlal region of the lung (National Council on Radiation Protection and Measurements 1977).

Assuming that about 41 million households use natural gas and there are 3.1 persons per household, the total number of persons exposed to radon from natural gas ranges within U.S. homes is est1mated at about 125 million. This means the average annual bronchial lining dose equivalent is about 5 mrem (National Council on Radiation Protection and Measurements 1977).

High ventilation rates would reduce the indoor concentration of radon. For example, four air changes per hour with outside alr at 70 $\mathrm{pC} 1 / \mathrm{m}^{3}$. would drop a room concentration from over $4,000 \mathrm{pCl} / \mathrm{m}^{3}$ to less than $80 \mathrm{pCl} / \mathrm{m}^{3}$. This drop is possible because normal emanation does not supply radon fast enough to replace the amount removed. Thus, for normal bullding matertals without extensive unvented indoor ofl and gas combustion, Indoor concentrations of radon are probably 
high only in closed or poorly ventilated areas (National Council on Radiation Protection and Measurements 1975).

This presents a serious conflict with a national goal of energy conservation and energy efficient homes. With a well insulated, tightly closed house, radon released from the burning of natural gas may at tain levels high enough to warrant concern for human health.

\section{Emissions from Space Heaters}

Residential emissions from oil and gas combustion are listed in Table 12. The data include emissions from residentlal cooking, space heating, and water heating. It is assumed that approximately 75 percent of residential natural gas consumption is for water heating and cooling and that 95 percent of distillate oil consumption is for space heating (Helfand 1977). The data indicate that, except for emissions of nitrogen oxides $\left(\mathrm{NO}_{\mathrm{x}}\right.$ ) and carbon monoxide $(\mathrm{CO})$, natural gas is a "cleaner" fuel than oil. For $\mathrm{NO}_{\mathrm{x}}$, and to a $11 \mathrm{~m}$ ited extent $\mathrm{CO}$, the ratio of gas to oil emissions is proportionate to the number of units (two to one). Relative to national emissions, the pollution contribution of space heating systems appears small. However, by nature, residential heating emissions are concentrated during winter, and occur in populated areas. The ratio of No to $\mathrm{NO}_{2}$ has been found to be about nine to one in residential heating systems. From an indoor air pollution standpoint these $\mathrm{NO}_{\mathbf{x}}$ emissions, if escaping from faulty emission control systems, could have a severe impact on human health during the winter season. (See the above discussion of gas stoves and ovens for additional information on emissions from space heaters.)

Research needs related to the behavior of these indoor pollutants are discussed below in the section on the transport and transformation effects of indoor air pollutants generated as a result of the combustion of oil and gas for home heating and cooking.

\section{Mobile Source Emisisions}

Automobile emissions result from burning gasoline or diesel fuel in internal combustion engines, as well as evaporation from crankcase leakage, engine head, storage tank, and carburetor. Significant exhaust emissions include particulate matter, $\mathrm{CO}, \mathrm{NO}_{\mathrm{x}}, \mathrm{SO}_{2}, \mathrm{HC}$, and aldehydes. These are considered to pose the greatest health hazard and to warrant detailed identification and characterization. Because of their widespread use in light duty, automobiles are responsible for a large share of air pollutant emissions in many areas of the U.S. EPA's Emission Factor Program (EFP) estimates emission levels of in-use vehicles. The program showed that, during 1970, internal combustion engines were responsible for approximately 
TABLE 12

SUMMARY OF EMISSIONS FROM FESIDENTIAL GAS AND OIL COMBUSTION (1973)

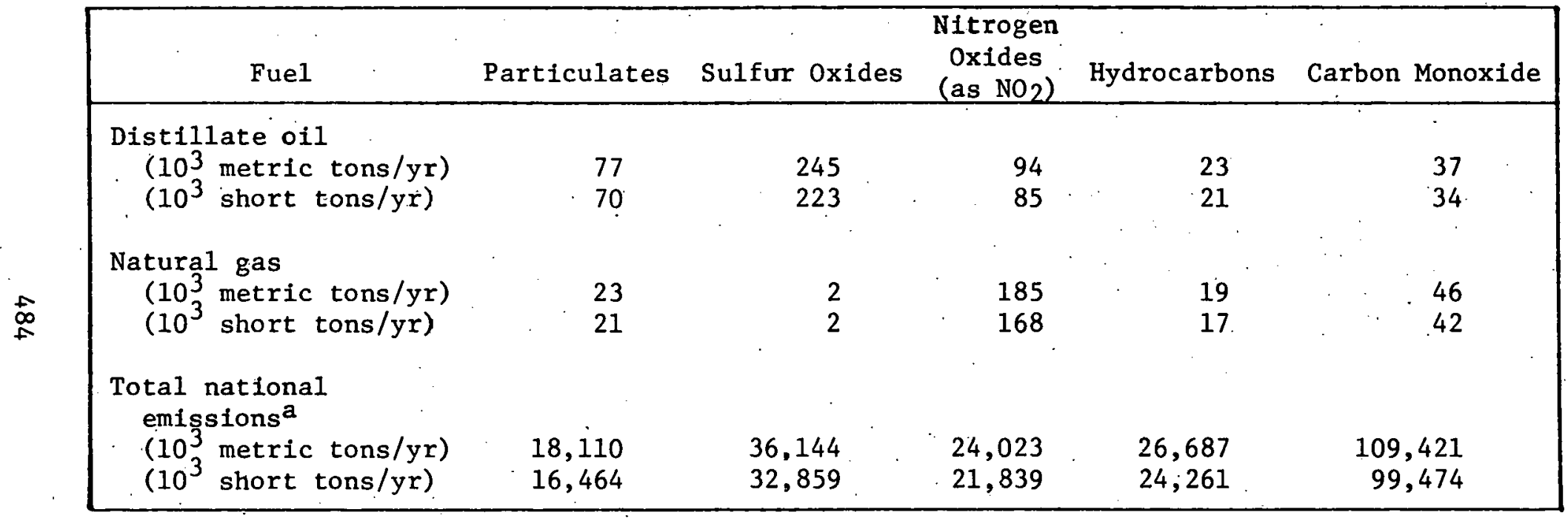

a Total includes emissions from all sources.

Source: Hefland 1977. 
73 percent of carbon monoxide, 56 percent of hydrocarbons, and 50 percent of nitrogen oxides emitted in the U.S. (U.S. Environmental Protection Agency 1977a). Automoblles also contributed 2.5 percent of the total particulates and 3,4 percent of the sulfur dioxides. These percentages have been significantly reduced as a result of emission control devices, eng Ine modifications, and changes in fuel composition, although there are more vehicles on the road. Table 13 summarlzes exhaust emission rates.

\section{Particulate Emissions}

Several parameters, such as fuel composition, engine design and malntenance, operating conditions, and emission control devices, may influence the physical characteristics of particulates emltted from diesel engines. The particle size, number, surface area, and settling velocity determine the potential for adsorptive capacity and airborne characteristics. The physical characteristics of particles from diesel exhaust are presented below (U.S. Environmental Protection Agency 1978c).

\section{Parameter}

Mass medium diameter

Particulate count

Surface area

Settling velocity
Value

$0.1-0.3$ um

107 count $/ \mathrm{cm}^{3}$

$2 \mathrm{~m}^{2} / \mathrm{m}^{3}$

$0.25-40 \mathrm{mins} / \mathrm{hr}$

The particulate size distribution and mass output in diesel englne exhausts were measured in a study which showed that particulate concentrations ranged from 14.2 to $250.9 \mathrm{mg}$ per $\mathrm{m}^{3}$ and mass outputs from 52 to $3,443 \mathrm{mg}$ per minute (Breslin et al. 1976). Statistically significant differences were found to occur with different engine types, fuels, and operating modes.

According to sclentists in the General Motors Research Laboratories, engine o11 contributes 1.5 to 25 percent by mass of diese 1 particulate emissions, depending upon engine speed and load. An increase in load or engine speed increases the engine oil's contribution to the total particulate concentration.

With the exhaust from gasoline engines, particulate size depends on fuel composition. Unleaded fuel results in the emission of larger particles. For leaded fuels, approximately 90 percent by weight of the emitted particles are less than $0.35 \mathrm{um}$ in diameter and 88 percent by weight have diameters shorter than $10 \mathrm{um}$. The particle size 
TABLE 13

EXHAUST EMISSION RATES FOR MOBILE COMBUSTION SOURCES

\begin{tabular}{|c|c|c|c|c|c|c|c|c|c|c|}
\hline \multirow[b]{2}{*}{. } & \multicolumn{2}{|c|}{$\begin{array}{l}\text { New Light-Duty } \\
\text { Gas Automobiles }\end{array}$} & \multicolumn{2}{|c|}{$\begin{array}{l}\text { New L1ght-Duty } \\
\text { Diese1 Vehicle }\end{array}$} & \multicolumn{2}{|c|}{$\begin{array}{l}\text { New Light-Duty } \\
\text { Gas Truck. }\end{array}$} & \multicolumn{2}{|c|}{$\begin{array}{c}\text { New Heavy-Duty } \\
\text { Gas Truck }\end{array}$} & \multicolumn{2}{|c|}{$\begin{array}{l}\text { New Heavy-Duty } \\
\text { Diese1 Vehicle }\end{array}$} \\
\hline & $\begin{array}{l}\text { Model } \\
\text { Year }\end{array}$ & $\begin{array}{l}\text { Emission } \\
\text { Rate } \\
\text { (gm/mile) }\end{array}$ & $\begin{array}{l}\text { Model } \\
\text { Year }\end{array}$ & $\begin{array}{l}\text { Emfission } \\
\text { Rate } \\
\text { (gm/mfle) }\end{array}$ & $\begin{array}{l}\text { Mode1 } \\
\text { Year. }\end{array}$ & $\begin{array}{c}\text { Emission } \\
\text { Rate } \\
\text { (gm/mile) }\end{array}$ & $\begin{array}{l}\text { Model } \\
\text { Year }\end{array}$ & $\begin{array}{l}\text { Emission } \\
\text { Rate } \\
\text { (gm/mile) }\end{array}$ & $\begin{array}{l}\text { Model } \\
\text { Year }\end{array}$ & $\begin{array}{c}\text { Emission } \\
\text { Rate } \\
\text { (gm/mile) }\end{array}$ \\
\hline Hydrocarbonsa & $\begin{array}{c}\text { Pre-1968 } \\
1968-1974 \\
1975-1979 \\
1980+\end{array}$ & $\begin{array}{l}4.45 \\
2.43 \\
1.13 \\
0.13\end{array}$ & Pre-1973 & 0.46 & $\begin{array}{r}\text { Pre-1968 } \\
1968-1969 \\
1970-1974 \\
1974-1978 \\
1979-1982 \\
1983+\end{array}$ & $\begin{array}{l}4.76 \\
3.25 \\
2.56 \\
1.92 \\
0.94 \\
0.31\end{array}$ & $\begin{array}{c}\text { Pre-1970 } \\
1970-1973 \\
1974-1978 \\
1979-1982 \\
1983+\end{array}$ & $\begin{array}{r}23.90 \\
18.54 \\
22.02 \\
5.22 \\
1.46\end{array}$ & $\begin{array}{c}\text { Pre-1974 } \\
1974-1978 \\
1979-1982 \\
1983+\end{array}$ & $\begin{array}{l}4.30 \\
4.50 \\
4.50 \\
2.85\end{array}$ \\
\hline $\begin{array}{l}\text { Carbon } \\
\text { monoxide }\end{array}$ & $\begin{array}{c}\text { Pre-1968 } \\
1968-1974 \\
1975-1979 \\
1980 \\
1981+\end{array}$ & $\begin{array}{r}68.30 \\
31.14 \\
18.60 \\
3.00 \\
1.40\end{array}$ & Pre-1973 & 1.7 & $\begin{array}{c}\text { Pre-1968 } \\
1968-1969 \\
1970-1974 \\
1975-1978 \\
1979-1982 \\
1983+\end{array}$ & $\begin{array}{r}70.38 \\
42.08 \\
31.48 \\
23.44 \\
14.50 \\
3.87\end{array}$ & $\begin{array}{c}\text { Pre-1970 } \\
1970-1973 \\
1974-1978 \\
1979-1982 \\
1983+\end{array}$ & $\begin{array}{r}272.90 \\
212.70 \\
218.80 \\
191.90 \\
15.38\end{array}$ & $\begin{array}{r}\text { Pre-1974 } \\
1974-1978 \\
1979-1982 \\
1983+.\end{array}$ & $\begin{array}{l}35.10 \\
27.00 \\
27.00 \\
27.00\end{array}$ \\
\hline $\begin{array}{l}\text { Nitrogen } \\
\text { oxides }\end{array}$ & $\begin{array}{c}\text { Pre-1968 } \\
1968-1972 \\
1973-1974 \\
1975-1976 \\
1977-1980 \\
1981+\end{array}$ & $\begin{array}{l}3.58 \\
4.43 \\
2.98 \\
2.42 \\
1.50 \\
0.29\end{array}$ & Pre-1973 & 1.6 & $\begin{array}{c}\text { Pre-1968 } \\
1968-1969 \\
1970-1972 \\
1973-1974 \\
1975-1978 \\
1979-1984 \\
1985+\end{array}$ & $\begin{array}{l}4.16 \\
4.90 \\
4.59 \\
3.56 \\
3.62 \\
1.73 \\
0.41\end{array}$ & $\begin{array}{c}\text { Pre-1970 } \\
1970-1973 \\
1974-1978 \\
1979-1982 \\
1983+\end{array}$ & $\begin{array}{r}8.80 \\
12.80 \\
10.50 \\
9.10 \\
3.99\end{array}$ & $\begin{array}{c}\text { Pre-1974 } \\
1974-1978 \\
1979-1982 \\
1983+\end{array}$ & $\begin{array}{r}21.40 \\
20.10 \\
15.90 \\
5.35\end{array}$ \\
\hline Particulates ${ }^{b}$ & Pre-1973 & 0.34 & Pre-1973 & 0.73 & Pre-1973 & 0.34 & Pre-1973 & 0.91 & Pre-1973 & 1.3 \\
\hline $\begin{array}{l}\text { Sulfur } \\
\quad \text { oxides }\end{array}$ & Pre-1973 & 0.13 & Pre-1973 & 0.54 & Pre-1973 & 0.18 & Pre-1973 & 0.36 & Pre-1973 & 2.8 \\
\hline
\end{tabular}

a Source: U.S. Environmental Protection Agency 1978.

bource: U.S. Environmental Protection Agency 1977a (AP-42). 
distribution with leaded and unleaded fuels suggests that the weight of the small particles ( $<0.35$ um diameter) is much higher with leaded than with unleaded fuel (Sampson and Springer 1973). About 71 to 91 percent of the lead particles emitted in exhaust from an automobile using leaded gasoline fall in the respirable size range, compared to 34 to 59 percent with unleaded gas (Mueller 1970). The size of exhaust particles is similarly dependent. on the fuel's sulfur content. Mueller (1970) demonstrated that respirable particles in the range of 0.1 to 1.0 um can $s$ tay dispersed in the atmosphere.

The diameter of emitted particles depends not only on fuel composition, but also on engine operating conditions. Habibi et al. (1970) demonstrated that, with leaded fuel, cyclic operations yield larger particles than steady-state operations. They also noted that the average size of the emitted lead particles. increases significantly with mileage accumulation, rising from 1.1 um at 6,530 average mileage to $4.7 \mathrm{um}$ at 21,350 average mileage. The corresponding effects on particle'size for unleaded fuels have not been studied.

Table 14 provides data on particulate emissions from diesel- and gasoline-powered passenger cars, illustrating the effect of catalytic converters on particulate emission rates (U.S. Environmental Protection Agency 1978c). Table 15 shows the effects catalytic converters can have on emissions and Table 16 lists qualitatively summarized data on the effect of different variables on particulate emissions from diesel- and gasoline-powered cars (U.S. Environmental Protection Agency 1978c).

It should be noted that both diesel- and gasoline-powered engines release suspensions of microsize solid particles and liquid droplets in either a gas or vapor phase.

Sulfur Emissions

Sulfur dioxide and sulfate emissions are directly related to the sulfur content of diesel and gasoline fuels. The sulfate emission rates for diesel- and gasoline-powered passenger cars are shown in Table 17. The comparison of the average values shows that diesel cars have higher sulfur emission rates than noncatalyst gasoline cars. However, diesel cars and gasoline cars equipped with a catalyat have comparable sulfate emission rates. These emission rates are substantially lower for advanced noncatalyst and three-way catalyst gasolifne-fueled vehicles. The sulfate emission rates for both diesel- and gasoline-powered cars depend on four variables: vehicle design and engine displacement, sulfur content of the fuel, vehicle operation mode, and engine mileage. Emission rates tend to increase in proportion to vehicle size, since larger vehicles consume more fuel. 
TABLE 14

PARTICULATE EMISSIONS FROM

DIESEL- AND GASOLINE-POWERED PASSENGER CARS

\begin{tabular}{|c|c|}
\hline Vehicle Type & $\begin{array}{c}\text { Total Particulates In FTP Mode } \\
\text { (mg/mile) }\end{array}$ \\
\hline Diesel vehicles & 294.0 \\
VW Rabbit & 397.0 \\
Peugeot 504 & 477.0 \\
Mercedes 240D & 490.0 \\
Mercedes 300D & 924.0 \\
Oldsmobile 350 & \\
Gasoline vehicles & \\
With emission control & 6.8 \\
VW Rabbit. & 9.1 \\
Oldsmobile 350 & 246.0 \\
Without emission control & 181.0 \\
Leaded gasoline car & 2.0 \\
Unleaded gasoline car & \\
Advanced unleaded gasoline car & \\
\hline
\end{tabular}

Source: Adapted from U.S. Environmental Protection Agency $1978 \mathrm{c}$. 
TABLE 15

EFFECT OF CATALYTIC CONVERTER ON

PARTICULATE EMISSION RATES

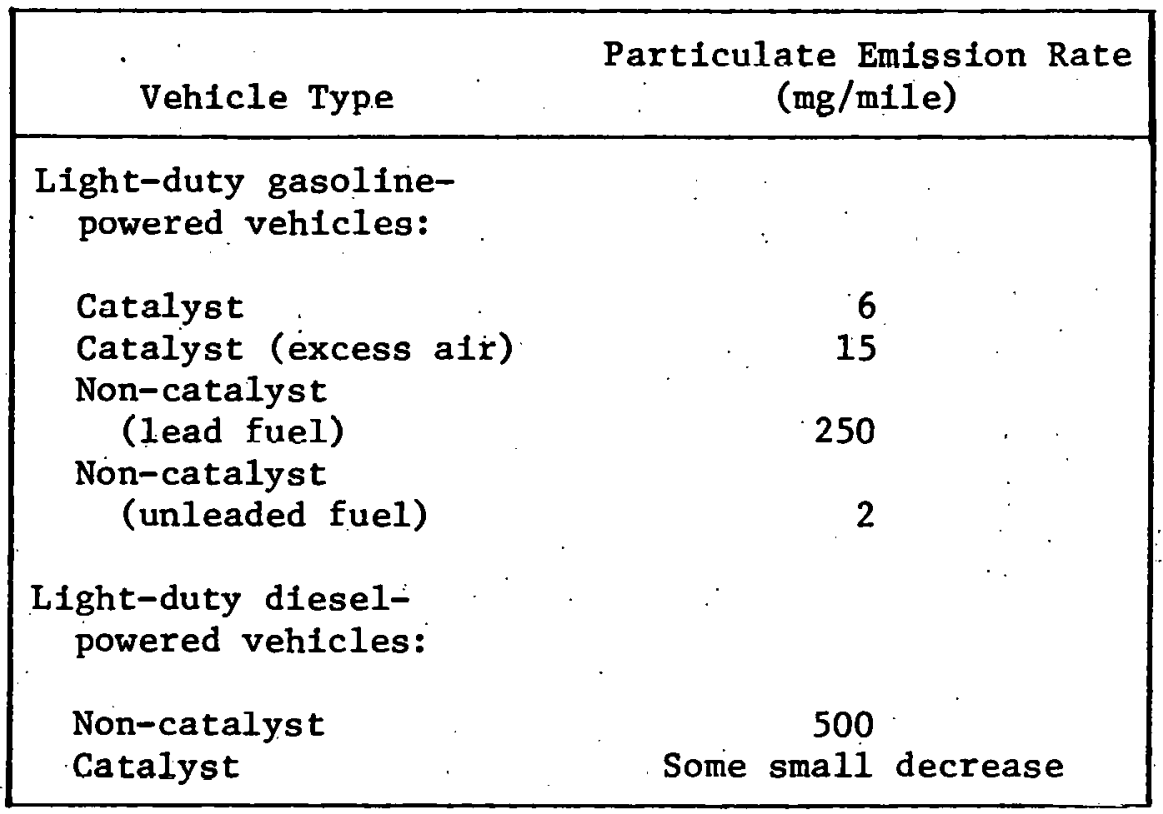

Source: Adapted from U.S. Environmental Protection Agency 1978c. 
FABLE 16

EFFECT OF VARIABLES ON PARTICULATE EMISSION FROM

GASOLINE- AND DIESEL-POWERED CARS

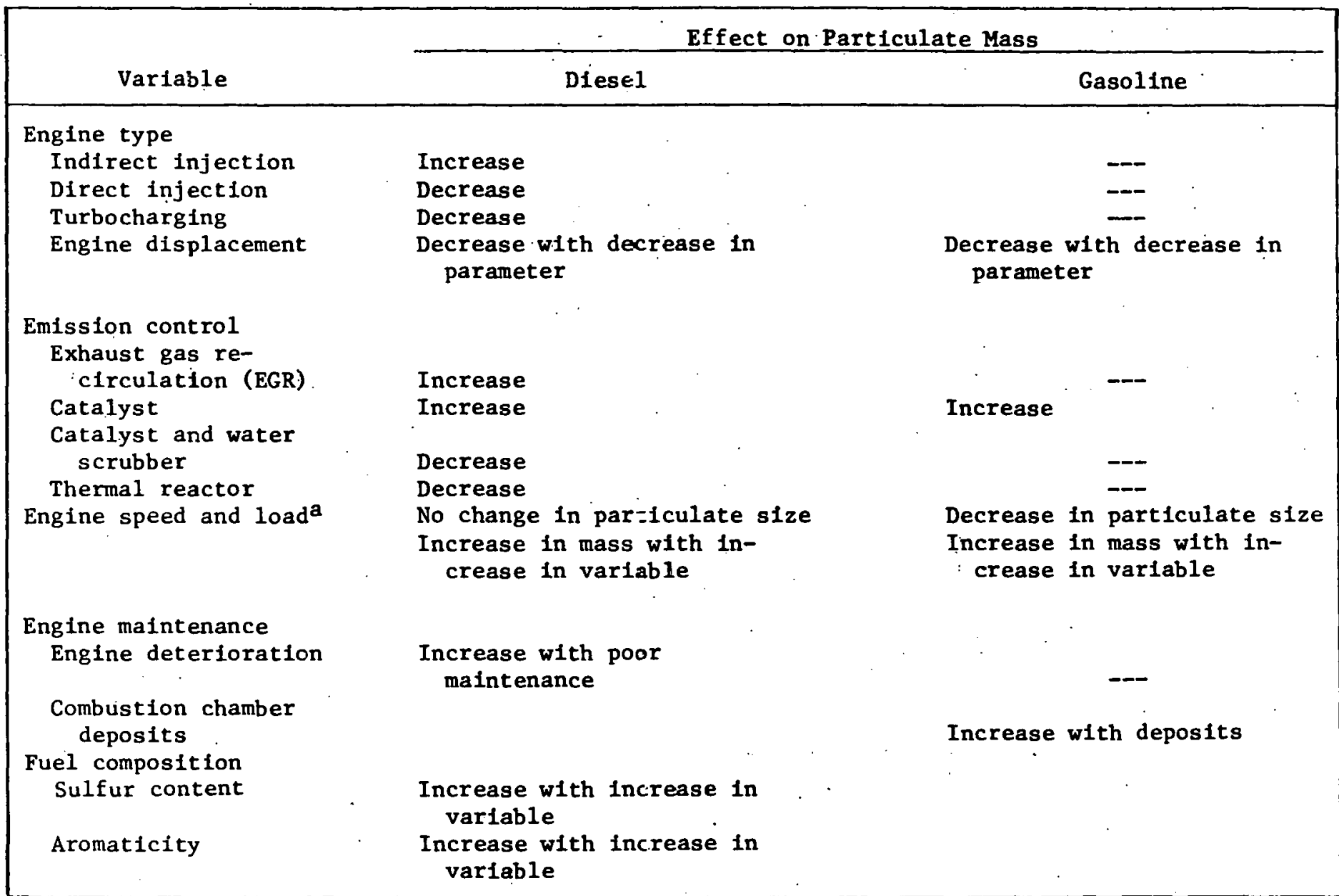


TABLE 16 (Concluded)

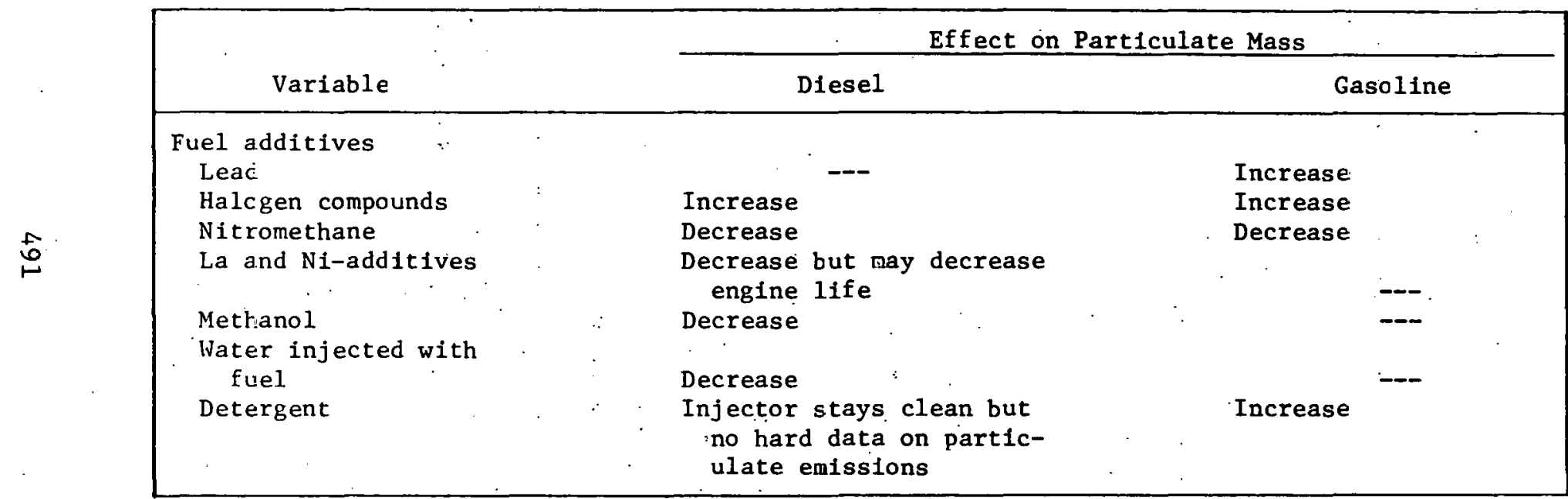

Note: --- Represents trend not analyzed.

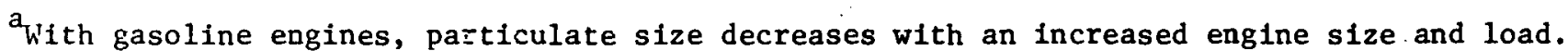

Source: U.S. Environmental Protection Agency 1978c. 
TABLE 17

SULFATE EMISSION RATES

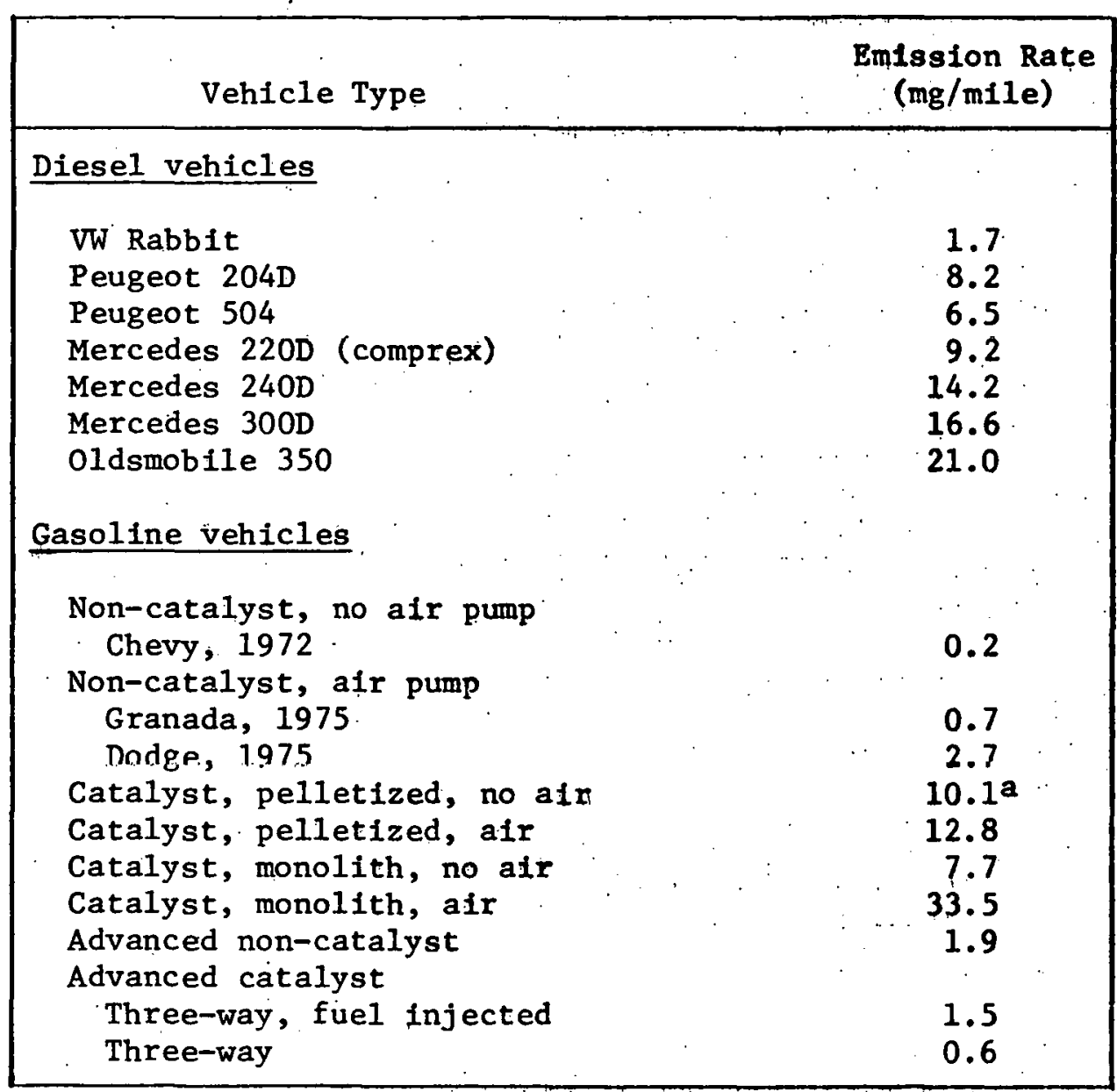

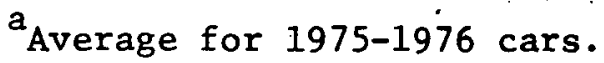

Source: U.S. Environmental Protection Agency 1978c. 
Braddock and Gabele (1977) found that $\mathrm{SO}_{2}$ and sulfate emissions from the Peugeot are simflar to those from the Nissan diesel. Using the average no. 2 diesel test fuel containing approximately 0.23 percent sulfur, they found a sulfate emission rate of $8.9 \pm 1.7$ mg per mile for the Peugeot and $7.8 \mathrm{mg}$ per mile for the Nissan diesel.

Carbonyl sulfide, a sulfur-containing compound, is also emitted in diesel exhaust, and emission rates for test vehicles are given below (Braddock and Gabele 1977):

CARBONYL SULFIDE EMISSIONS (mg/mile)

Type of Vehicle

$\begin{array}{lcccc}\begin{array}{l}\text { Test } \\ \text { Engine }\end{array} & \begin{array}{c}\text { Peugeot } \\ \text { Diese1 }\end{array} & \begin{array}{c}\text { Honda } \\ \text { CVCC }\end{array} & \begin{array}{c}\text { Lean-Burn } \\ \text { Chrysler }\end{array} \\ \text { FTP } & \text { 0.55+0.15 }(\mathrm{N}=4) & 0.06+0.06(\mathrm{~N}=3) & 0.40+0.35(\mathrm{~N}=4) \\ \text { FET } & 0.19+0.22(\mathrm{~N}=6) & 0.51 \pm 0.67(\mathrm{~N}=3) & 0.26 \pm 0.16(\mathrm{~N}=3) \\ \text { SET } & 0.24 \pm 0.14(\mathrm{~N}=11) & & \end{array}$

This is part of a limited data base currently avallable and detalled work is needed to develop conclusive data. These data are important to. the study of health effects of diesel exhausts.

With gasoline-powered passenger cars, sulfate is emitted as sulfuric acid. A striking increase in the acidity of emitted particles has been observed when gasoline englne exhausts are treated with a catalytic converter (Stara et al. 1974). It has been shown that the acidity of emissions from catalyst-fitted engines is 65 to 260 times greater than that of emissions from engines with no catalytic converters. The sulfate emission composition from diesel-powered automobiles is not known. The sulfuric acid emitted from vehicles is partly neucrallzed by ammonia to form $\left(\mathrm{NH}_{4}\right)_{2} \mathrm{SO}_{4}$ and $\mathrm{NH}_{4} \mathrm{HSO}_{4}$. Part of the acid reacts with other metallic elements in the atmosphere to form metal sulfates. However, it has been estimated that more than 70 percent of the sulfate emitted by vehicles remains in the form of $\mathrm{H}_{2} \mathrm{SO}_{4}$ at 20 meters downwind from the point of emission (W1lson et a1. 1977). This phenomenon is of major Importance to the acid rain problem in the U.S.

*These terms are used in the following discussions on mobile emission rates: Federal Test Procedure (FTP), Highway Fuel Economy Test (FET), Sulfate Emissions Test (SET). 


\section{Hydrocarbon Emissions}

The burning of hydrocarbon fuels under "nonideal." mobile conditions involves complex processes and results in hydrocarbon emissions. In addition, uncombusted fuel and lubricating ofl are partially responsible for these emissions. Both absolute and relative concentrations of combustion products are influenced by the fuel-to-oil ratio, ignition timing, inlet mixtcure density, combustion chamber geometry, and variable parameters such as speed, load, and engine temperature.

Exhaust hydrocarbons can be separated into a particulate phase and a volatile/vaporous phase. The nature of organic emissions adsorbed on particulate phase hydrocarbons emitted from dieselpowered automoblles was determined to range from $\mathrm{C}_{1}$ to about $\mathrm{C}_{40}$ (Black and High 1978). Hydrocarbons in the $\mathrm{C}_{1}$ to $\mathrm{C}_{10}$ range result from combustion while the $C_{10}$ and $C_{40}$ organics generally or Iginate from uncombusted fuel and lubricant and from partial combustion and rearrangement of compounds. Some of the organics in the range of $\mathrm{C}_{10}$ to $\mathrm{C}_{40}$ are particle bound and some are in the gaseous or volatile phase. Generally, the particle-bound organics range from $\mathrm{C}_{14}$ to about $\mathrm{C}_{40}$, and gas phase organics from $\mathrm{C}_{1}$ to about $\mathrm{C}_{25}$. The principal sources of these organic particles are uncombusted fuel, partial combustion products, and lubricating oils (Black and High 1979). Black and High (1979) conclude that for organic emissions above $\mathrm{C}_{25}$, lubricating ofl must be the princtpal source since there are no significant fuel components in that range. Both fuel and lubricants contribute those between $\mathrm{C}_{14}$ and $\mathrm{C}_{25}$.

The mix of hydrocarbons in exhaust emlssions from gasolinepowered automobiles is generally 50 percent saturated aliphatics, 5 percent PNAs, and 30 percent oxygenated hydrocarbons. The compounds have a molecular weight range of 300 to 500 by GC-MS (Boyer and Laitenen 1975). The aliphatic hydrocarbons include straight chained, branched chain, unsaturated, and small ring compounds; while oxygenated hydrocarbons include the following: diethyl phthalate, di-isobutyl phthalate, di-n-butyl phthalate, triphenyl phosphate, di-n-octyl phthalate, methyl triphenyl phosphate, trimethyl triphenyl phosphate, dimethyl triphenyl phosphate, benzanthrone, suspected B-capryophyllene, benzo[c]-cinnoline, benzolc acid, 2,6-di-tert-butyl hydroquinone or nonylphenol, and a number of unidentifled compounds including oxygenated PNAs.

Recently, scientists from General Motors Research Laboratorles have suggested that low-molecular-weight aliphatic amines in exhaust are emitted from catalyst-equipped cars. It has been demonstrated (using a 1975 FTP test) that total aliphatic amine emissions amount to less than $2.2 \mathrm{mg}$ per mile and that the average emission rates of 
monomethylamine and dimethylamine are no more than 0.3 and $0.1 \mathrm{mg}$ per mile, respectively. The scientists concluded that automotive amine emissions are not high enough to account for nitrosamine concentrations which have been reported at roadway sites (Cadle and Mulawa 1980).

Organic compounds in the range of $c_{1}$ to $C_{40}$ adsorbed on diesel exhaust particulate matter have been detected by Metser and Sharkey' (1977) with diesel fuel oil no. 1 and no. 2. These organic compounds are: crotonaldehyde; B-propriolactone; unresolved 2-but anone; tetrahydrofuran; pentane; unresolved ethylformate; 2,3epoxy-1-propanol; methyl acetate; carbon disulfide; benzene; pyridine; cyclohexane; cyclohexene; methylacrylate; 2-pentanone; hexane; unresolved dioxane; ethyl acetate; toluene; aniline; phenol; furfural; furfuryl alcohol; unresolved mesityl oxide; cyclohexanone; methyl cyclohexane; unresolved. cyclohexanol; 2-hexanone; unresolved ethyl acrylate; methyl methacrylate; heptane; styrene; unresolved ethyl benzene; xylene; unresolved monomethylaniline; o-toluidine; cresol; hydroquinone; methylcyclohexanone; allylglycidyl ether; octane; unresolved vinyl toluene; a-methyl styrene; cumene; isophorone; p-ter-butyl toluene; phenylglycidyl ether; camphor; phenyl ether; and dinitro-o-cresol. The lower-molecular-weight compounds in the list have not been reported by other workers. Besides these compounds, sulfur containing compounds, namely benzothiophenes and dibenzothiophenes, have been detected in diesel exhaust (National Institute for Occupational Saftey and Health 1978).

Polycyclic Aromatic Compounds. This class of compounds is found in the automotive exhaust, mostly in the particulate adsorbed phase. One group of polycyclic aromatic compounds, the polynuclear aromatic hydrocarbons, has been detected in both diesel and gasoline exhaust. The compounds are believed to result from three sources: (i) incomplete combustion of materials in the fuel, (2) synthesis of aromatic hydrocarbons of lower molecular weight during fuel ignition, and (3) pyrolysis of lubricating oil. Laity et al. (1973) demonstrated the mechanism of their formation in automobile engines. They observed that polynuclear emissions are enhanced by increased heat input in the combustion chamber. The emissions of these compounds from a gasoline-powered car and a diesel-powered omnibus are listed in Table 18. A comparison of emissions from heavy-duty diesel vehicles and typical gasoline automoblles run under urban American driving conditions is provided in Table 19 (U.S. Environmental Protection Agency 1978c). The data on American cars is for older models since current data are not available. 
TABLE 18

POLYCYCLIC AROMATIC HYDROCARBONS

DETECTED IN VARIOUS ATMOSPHERIC POLLUTANT SAMPLES

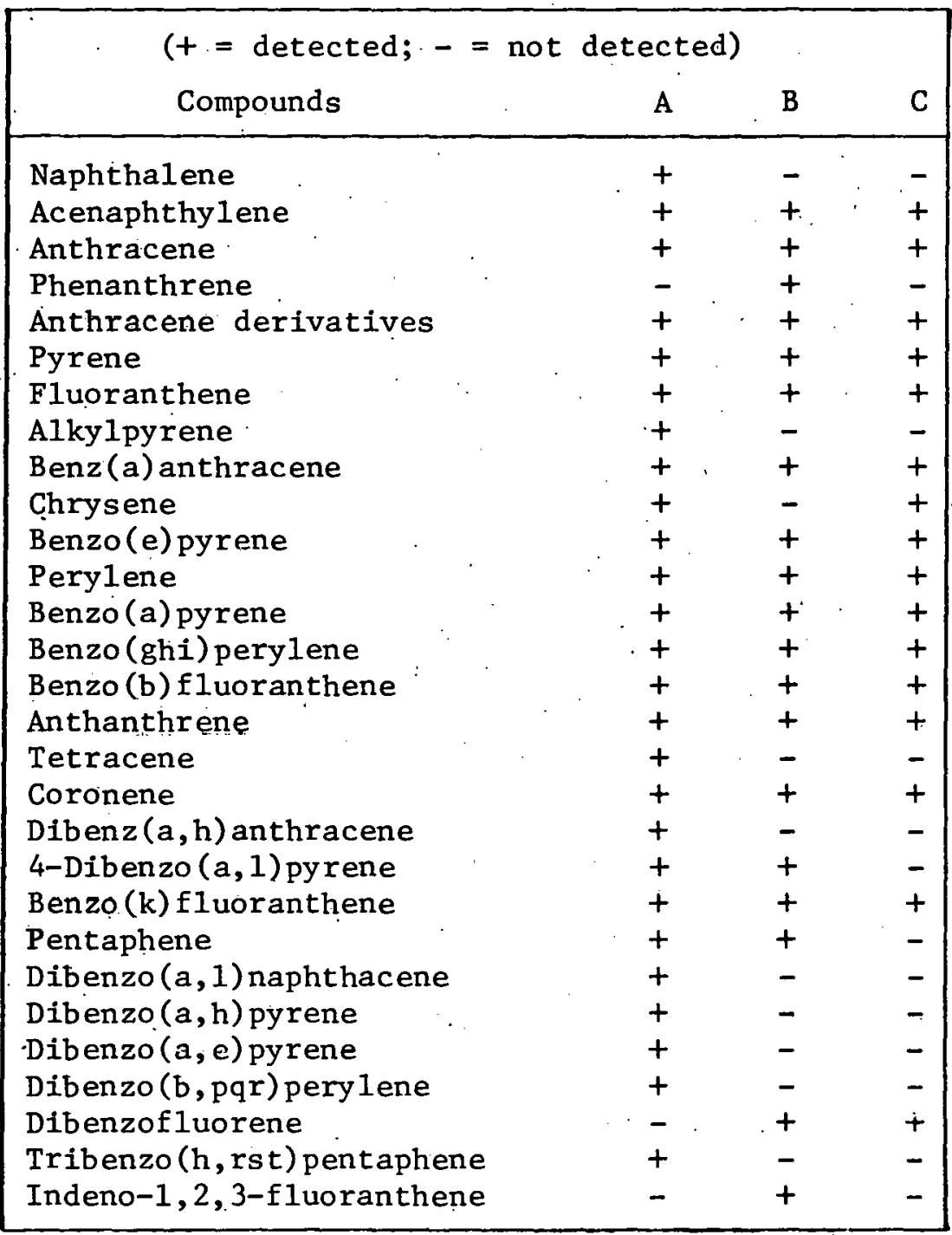

Notes: $A=$ Gasoline soot.

$B=$ Diesel soot.

C. $=$ Atmospheric soot.

Source: U.S. Environmental Protection Agency 1978c. 
TABLE 19

COMPARISON OF POLYCYCLIC AROMATIC HYDROCARBON EMISSIONS FROM HEAVY-DUTY DIESEL- AND GASOLINE-POWERED VEHICLES ${ }^{a}$

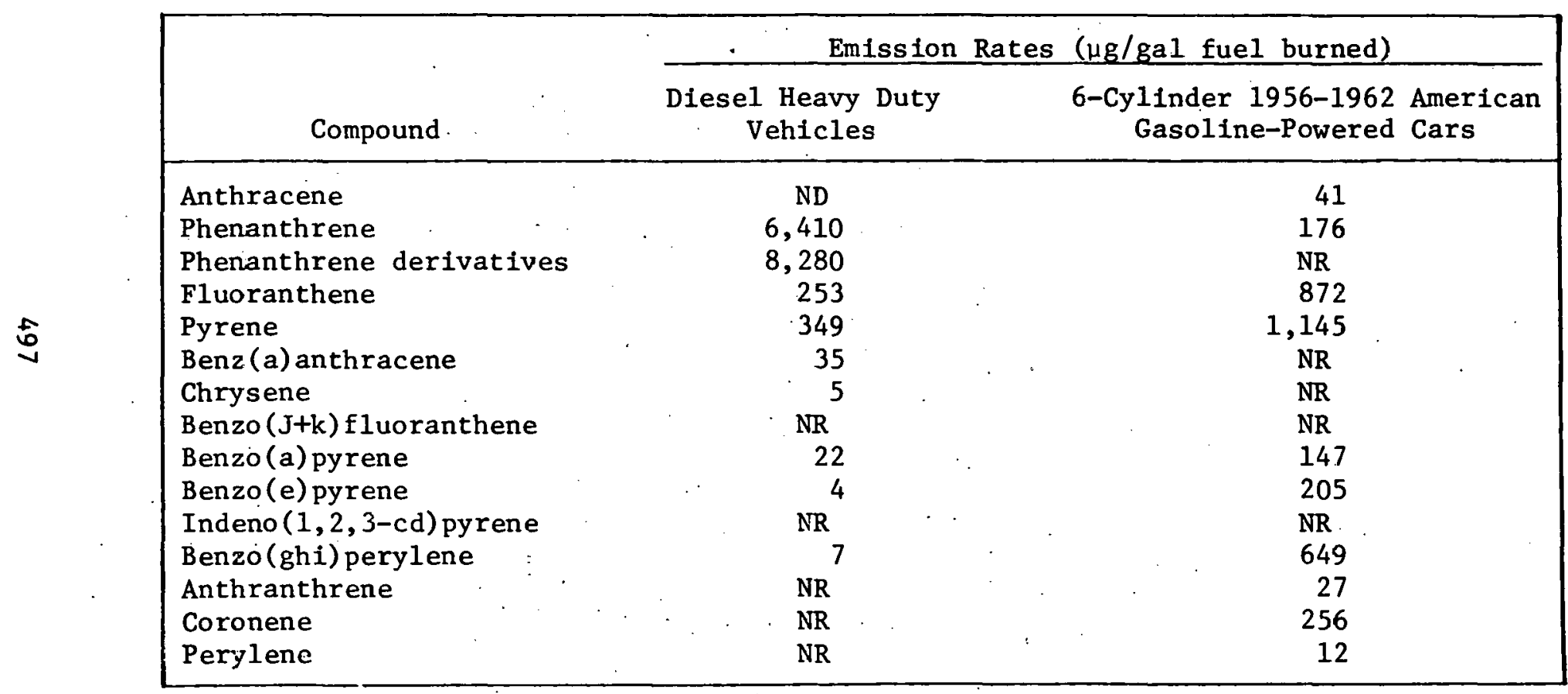

Notes: $\quad$ ND $=$ not detected.

$\mathrm{NR}=$ not reported.

a Diesel fuel with 26 fercent aromatics and gasoline fuels with 25 percent aromatics.

Source: Adapted from U.S. Environmental Protection Agency 1978c. 
Polynuclear aza heterocyclics make up another class of compounds in automobile exhausts which include the following arenes (Sawicki et a1. 1965):

\section{Arenes}

Benz (h) quinoline

$\operatorname{Benz}(c)$ acridine

Indenoquinolines

$\operatorname{Dibenz}(9, j)$ acridine

Dibenz $(a, h)$ acridine

Alkylbenz(c)acridine
Particulate Matter ug/g Exhaust*

0.2

0.4

0.9

$<0.2$

$<0.2$

$<0.2$

Benzo(a)pyrene (BaP) has typically been measured and used in vehicular emission research and air pollution monitoring as an indicator of total concentration of polycyclic aromatic hydrocarbons (PAHs). Consequently, the bulk of available data is in terms of BaP. The use of $\mathrm{BaP}$ as an indicator or index of total PNA emissions is questionable.

Aralysis of diesel tuels has shown that these tend to contain lower concentrations (up to $422 \mathrm{ppb}$ ) of BaP than gasoline (up to 300 ppb) (Lyons 1962). Although one might expect higher concentrations of PAHs in less volatile diesel fuel, gasoline actually contains much higher concentrations of catalytically processed aromatic hydrocarbons. BaP emission levels from diesel and gasoline cars without catalysts are 1.57 ug per mile and 1.95 ug per mile, respectively (Pedco 1978). Use of oxidative catalysts and other pollution control devices has reportedly reduced all emissions from gasoline-fueled engines by about 99 percent. These results have not been confirmed or validated conclusively; thus, they should be interpreted with caution.

The PAHs emissions, like all other exhaust emissions, are dependent on a number of parameters, including: vehicle characteristics and engine design, engine operation mode, engine maintenance, fuel composition, and exhaust emission control systems. BaP emission rates with respect to increasing load with constant speed and

* These data were generated with cars not equipped with a catalyst and may be subject to change. 
increasing speed with no load are listed in Table 20. From the data, one can conclude that increasing engine load results in a rapid decrease in BaP emissions in gasoline-powered cars, but results in an increase in BaP emisstons in diesel-powered cars.

Deposits in the combustion chamber and fouling of the fuel injection system can dramatically increase PAHs emissions. As much as 6.5 times more BaP can be emitted from gasoline engines with combustion chamber deposit than from cleaner engines (Gross 1972). Diesel engines with chamber deposits due to poor maintenance have a Bap emission rate of 1,706 ug per minute under full load conditions, compared to negligible BaP emissions from a well maintained diesel engines.

An increase in fuel aromaticity results in increased PAHs emissions. Gross (1972) demonstrated that increasing a fuel's aromatic content from 11 percent to 46 percent results in a 124 percent increase in uncontrolled PAHs emissions from gasoline-powered cars. This result has not been conclusively proven.

The effect of lead in gasoline on PAHs emlssions is being studied in several laboratories. The effect of gasoline engine mileage on PAHs emissions is shown in Table 21 (Hangebrauck et al. 1967). PAHs emissions are highest from older cars that have traveled more than 50,000 miles.

Emission control devices and engine modifications substantially reduce BaP emissions in gasoline- and diesel-powered automobiles. The reduction has been shown. to be 70 to 98 percent for gasolinepowered and 80 to 90 percent for diesel-powered cars (Gross 1972; National Institute for Occupational Safety and Health 1978).

Chlorinated Dioxins. The chlorine content of leaded gasoline is $300 \mathrm{ppm}$, while that of unleaded gasoline is 1 to $6 \mathrm{ppm}$ (National Academy of Sciences 1976a). The combustion of these fuels cuuld release chlorinated dloxins. To study chlorinated dioxin emissions, Dow Chemical Company tested mufflers from gasoline-powered automobiles and diesel-powered trucks. Muffler particulate solids were analyzed by both GC-MS and GC-EC following liquid chromatography separation. The results of the study are shown in Table 22 (Dow Chemical Company 1978). The dioxins that were present included TCDD (the total of all 22 tetra isomers), HCDD (the total of all 10 hexa isomers), H7CDD (the total of the 2 hepta isomers), and OCDD (octachloro-dibenzo-p-dioxin). More work is needed to study and identify chlorinated dioxins in automobile exhausts. 
ZABLE 20

BENZO (A) PYRENE EMISSION RATES

(img/min)

\begin{tabular}{|c|c|c|c|c|c|}
\hline $\begin{array}{l}\text { Engine } \\
\text { Load with }\end{array}$ & \multicolumn{2}{|c|}{ Emissions } & \multirow{2}{*}{$\begin{array}{l}\text { Rpm } \\
\text { with no Load }\end{array}$} & \multicolumn{2}{|c|}{ Emissions } \\
\hline Speed at $1,000 \mathrm{Rpm}$ & Gasoline & Diesel & & Gasoline & Diesel \\
\hline 0 & 61 & 1.46 & 500 & 120 & Not reported \\
\hline $1 / 4$ & 0 & 465. & 1,000 & 61 & 146 \\
\hline $1 / 2$ & 1 & $\pi 72$ & 1,500 & 33 & Not reported \\
\hline $3 / 4$ & 0 & 1,320 & 2,000 & 40 & Not reported \\
\hline Fu11 & 0 & 876 & 2,500 & 25 & Not reported \\
\hline & & & 3,000 & 13 & Not reported \\
\hline
\end{tabular}

Source: Adapted from U.S. Environmental Protection Agency 1978c. 


\section{TABLE 21}

EFFECT OF GASOLINE ENGINE MILEAGE ON POLYCYCLIC AROMATIC HYDROCARBON EMISSIONS

\begin{tabular}{|cccccccc|}
\hline & \multicolumn{7}{c|}{ PNA Emissions ( $\mathrm{gg} / \mathrm{mile})$} \\
\cline { 2 - 7 } Car Mileage & B(a)P & Pyrene & B (c)P & Perylene & B (ghi)P & Anthranthrene & Coronene \\
\hline 19,000 & 5.6 & 81 & 9.5 & 0.28 & 26.0 & 2.3 & 9.6 \\
26,000 & 4.2 & 70 & 8.1 & 0.7 .8 & 35.0 & 0.64 & 10.7 \\
49,000 & 3.9 & 27 & 8.6 & 0.57 & 14.3 & 0.3 & 4.1 \\
58,000 & 21.5 & 119 & 23.5 & 1.38 & 77.0 & 3.17 & 32.2 \\
\hline
\end{tabular}


TABLE 22

CHLORINATED DIOXIN CONTENT OF PARTICULATE MATTER IN MUFFLERS

\begin{tabular}{|c|c|c|c|c|c|c|c|c|}
\hline \multirow[b]{3}{*}{ Sample Source } & \multicolumn{8}{|c|}{ Apparent Dioxins (ppt) } \\
\hline & \multicolumn{2}{|c|}{ TCDD } & \multicolumn{2}{|c|}{ HCDD } & \multicolumn{2}{|c|}{$\mathrm{H}_{7} \mathrm{CDD}$} & \multicolumn{2}{|c|}{ OCDD } \\
\hline & $\begin{array}{l}\text { Other } \\
\text { Isomers }\end{array}$ & $2,3,7,8$ & GC-MS & GC-EC & GC-MS & GC-EC & GC-MS & GC-EC \\
\hline \multicolumn{9}{|l|}{ Auto mufflers } \\
\hline 非 non-catalytic & $4.0(2.0)$ & $\mathrm{ND}(2.0)$ & ND (14) & NA & $\mathrm{ND}(6)$ & $3(0.4)$ & $16(8)$ & $10(0.6)$ \\
\hline \#1 non-catalytic & $4.0(2.0)$ & ND $(2.0)$ & ND (14) & NA & $\mathrm{ND}(6)$ & $3(0.4)$ & $16(8)$ & $10(0.6)$ \\
\hline \#5 catalytic carbon - & $\mathrm{ND}(1.0)$ & ND $(3.0)$ & $\mathrm{ND}(10)$ & $2.0(0.4)$ & $1.4(8)$ & $10(0.4)$ & 68 & $72(1.0)$ \\
\hline \#5 catalytic rust & $4: 0$ & $0.4(0.1)$ & - & $0.7(0.1)$ & + & $3(0.1)$ & + & $28(0.4)$ \\
\hline \#2 catalytic & $0.1(0.1)$ & ND $(0.2)$ & - & $0.5(0.1)$ & + & $2(0.2)$ & + & $8(0.5)$ \\
\hline \multicolumn{9}{|l|}{ Diesel mufflers } \\
\hline \# 7 & $\mathrm{ND}(7.0)$ & ND $(3.0)$ & ND (25) & $4.0(2.0)$ & $110(30)$ & $35(2.0)$ & 280 & $205(3.0)$ \\
\hline$\# 6$ & 20 & $3.0(1.0)$ & $20(15)$ & $37(1.0)$ & $100(15)$ & $49(1.0)$ & 260 & $190(3.0)$ \\
\hline
\end{tabular}

Notes: $+=$ The positive result was confirmed by GC-MS.

- = That BC-MS was unable to confirm the positive result.

$\mathrm{NA}=$ Not analyzed.

ND $=$ Not detectable at 2.5 times noise.

Data less than 10 times noise will have a detection limit reported in parentheses.

Source: Dow Chemical Company 1978. 
Volatile Phase Compounds. The volatile phase hydrocarbon emissions include low-molecular-weight hydrocarbons, phenols, and aldehydes. (The gaseous hydrocarbons emitted from gasoline- and diesel-powered passenger cars have been discussed.) With the exception of methane and toluene, individual hydrocarbons are emitted at higher levels for diesel. than for gasoline cars (U.S. Environmental Protection Agency 1978c). The oxygenated hydrocarbons, including alcohols, ethers, phenols, aldehydes, ketones, esters, peroxides, and organic acids, are emitted from automobiles as vapors during fuel combustion. Table 23 lists some typical oxygenates found in automobile exhaust emissions (Urone 1976). The aldehydes discussed earlier are the major oxygenates in the vapor phase of hydrocarbons. With the exception of crotonaldehyde, diesel cars emit more aldehydes than catalyst-equipped gasoline cars. Many oxygenated compounds are secondary products from photochemical reactions. The aldehydes are carbonyl-containing organic compounds emitted from gasoline- and diese1-powered cars. The emission rates for aromatic aldehydes have been shown to increase from 5.8 to $13.6 \mathrm{ppm}$, with an increase in the aromatic content of gasoline fuel from 27.3 to 46.6 (molar percent) (Hinkamp et al. 1971). The aromatic content of leaded regular gasoline is 27.3 molar percent. For leaded premium it is 30.8 molar percent; and for unleaded premium gasoline it is 46.6 molar percent. Phenols have also been detected in exhaust gases from gasoline cars. Like aromatic aldehydes, phenols 1ncrease with an increase in fuel aromaticity (Gross 1972). Phenol emission ranges are listed in Table 24.

Cyanides and Sulfides. Hydrogen cyanide ( $\mathrm{HCN}$ ) and carbony 1 sulfide (COS) are combustion products emitted from diesel- and gasoline-powered cars (Braddock and Gabele 1977). These compounds are emitted at low levels, but more research is needed to define emission rates.

\section{Trace Metals Ëmiscions}

Metals in automobile emissions originate from two distinct sources: (1) fuel and lubricating oil, and (2) engine and exhaust system wear. When catalytic converters are used, a third possible source could be products from the catalyst.

When leaded gasoline is used, the predominant metal content in the exhaust is lead, which will be discussed separately. Typical emission factors for metals cannot be derived from baseline characterization of auto exhaust as performed by EPA, but euphasis on the ef fect of emissions as a function of variation in operating condition is valid. The data in Table 25 reflect this approach because the different test cycles differ significantly in the average speed and variability of the operating mode (U.S. Environmental Protection 
TABLE 23

OXYGENATES IN EXHAUST FROM SAMPLE HYDROCARBON FUELS

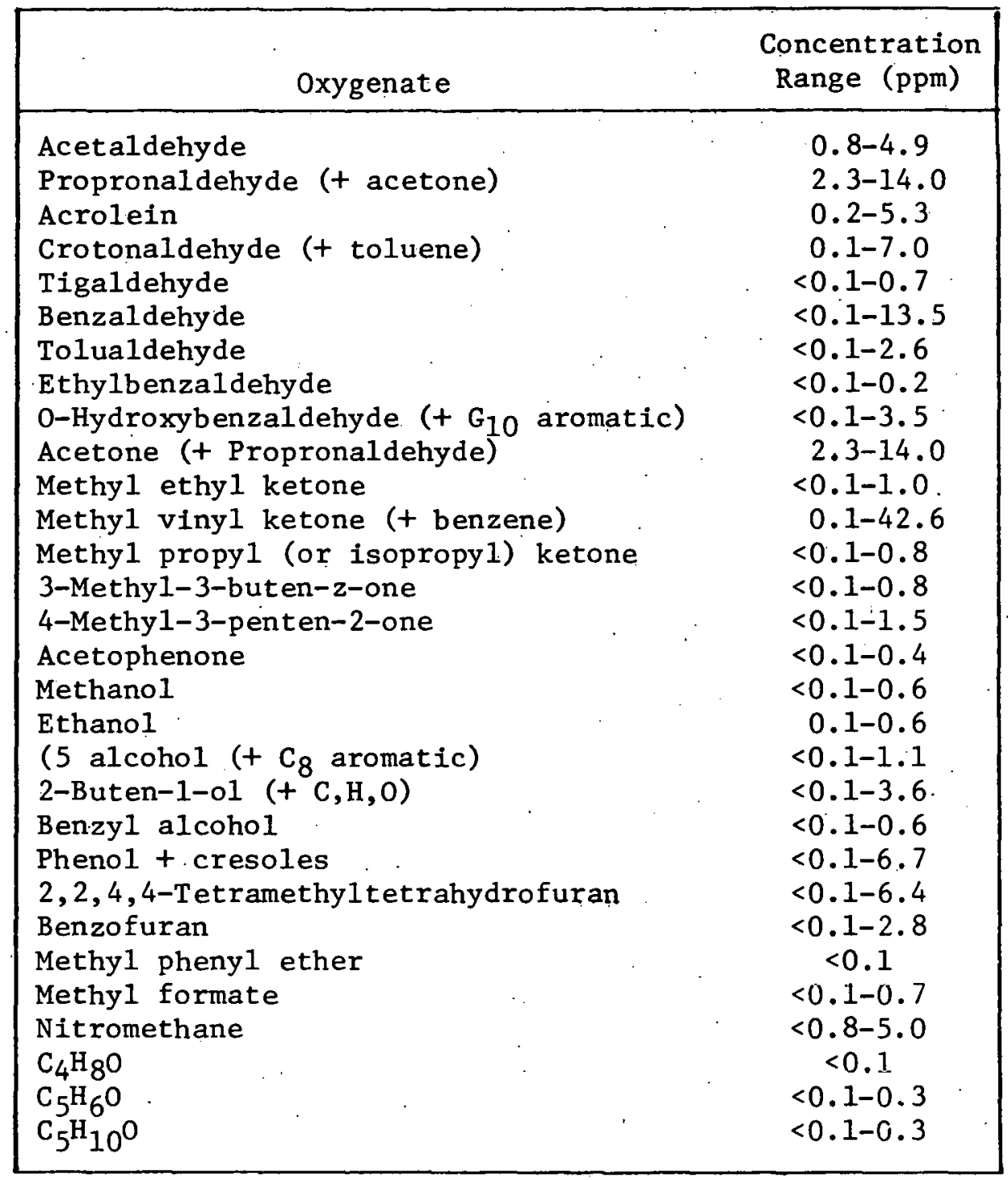

Source: Urone 1976. 
TABLE 24

PHENOL RANGE IN GASOLINE EXHAUST GAS

(mg/gal)

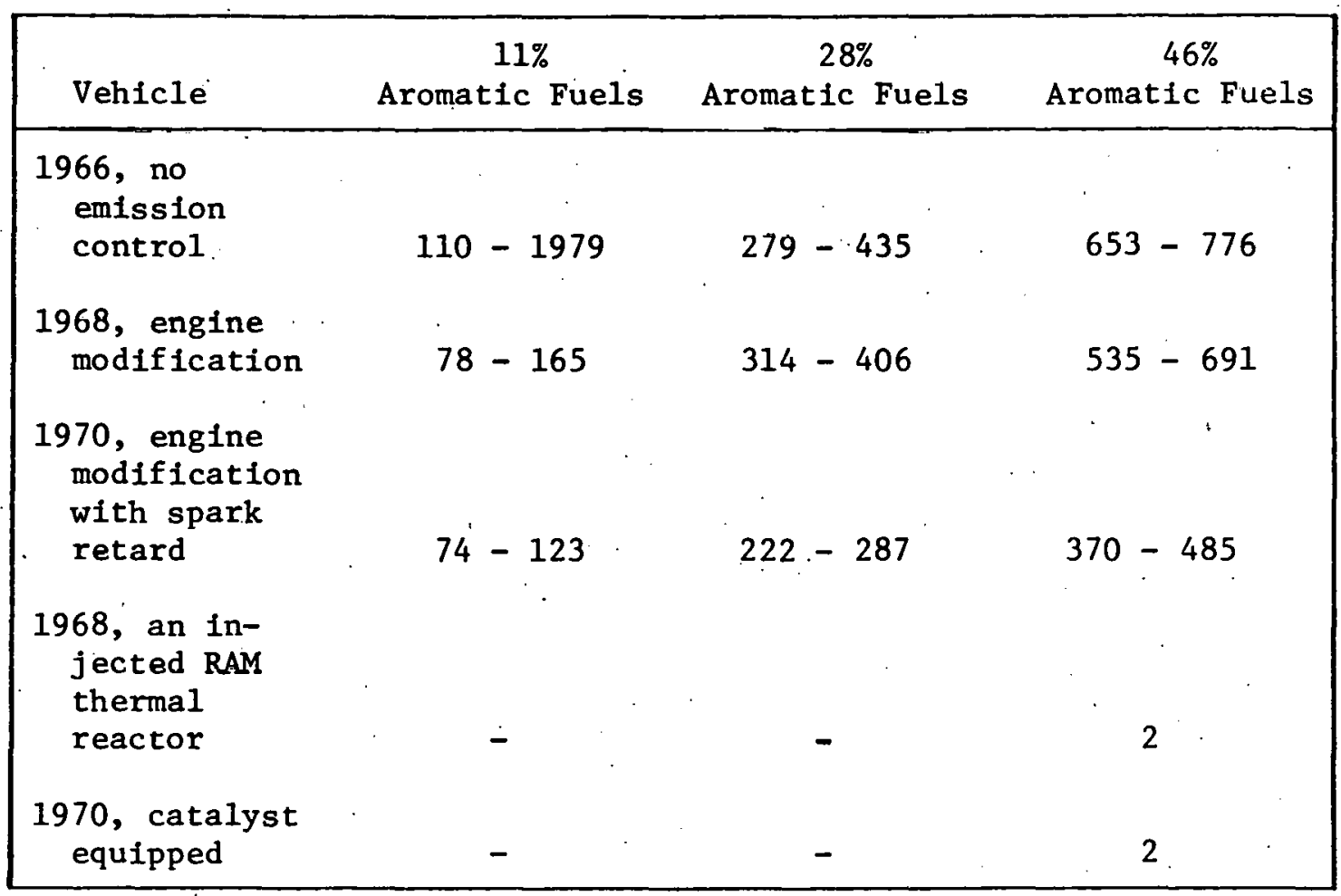

Source: Gross 1972. 
TABLE 25

EMISSION RATES OF SELECTED METALS FROM A VARIETY OF CARS UNDER DIFFERENT OPERATING CONDITIONS

\begin{tabular}{|c|c|c|c|c|c|}
\hline Cars & $\begin{array}{c}\mathrm{Pb} \\
(\mathrm{mg} / \mathrm{mi})\end{array}$ & $\underset{(m g / m i)}{M n}$ & $\begin{array}{c}\mathrm{Cu} \\
(\mathrm{mg} / \mathrm{mi})\end{array}$ & $\begin{array}{c}\mathrm{Fe} \\
(\mathrm{mg} / \mathrm{mi})\end{array}$ & $\begin{array}{c}\mathrm{Ni} \\
(\mathrm{mg} / \mathrm{mi})\end{array}$ \\
\hline \multicolumn{6}{|l|}{$\begin{array}{l}\text { Pre-catalyst }(60 \\
\text { mph cruise) }\end{array}$} \\
\hline FTP & 40.5 & NA & NA & NA & ND \\
\hline FET & 19.8 & NA & NA & NA & ND \\
\hline SET & 20.0 & NA & NA & NA & NA \\
\hline $\begin{array}{l}\text { Catalyst (49-state } \\
\text { standard) ( } 50 \mathrm{mph} \\
\text { cruise) }\end{array}$ & . & & & & \\
\hline Mean & 0.028 & NA & 0.016 & 0.029 & NA \\
\hline Median & 0.015 & NA & 0 & 0.007 & NA \\
\hline Range & $0-0.325$ & NA & $0-0.293$ & $0-0.341$ & NA \\
\hline \multicolumn{6}{|l|}{$\begin{array}{l}\text { Catalyst (Calif. } \\
\text { standard) }\end{array}$} \\
\hline FTP & 0.03 & ND. & 0.18 & 2.28 & 0.01 \\
\hline \multicolumn{6}{|l|}{ Dual catalyst } \\
\hline FTP & 0.18 & NA: & 0.12 & 0.50 & $4: 12$ \\
\hline FET & 0.03 & NA & 0.01 & 0.03 & 0.27 \\
\hline SET & 0.07 & NA & 0.02 & 0.07 & 0.50 \\
\hline \multicolumn{6}{|l|}{ Lean burn engine } \\
\hline FTP & 6.69 & 0.05 & 0.06 & 1.17 & ND \\
\hline FET & 3.76 & 0.12 & 0.08 & 0.07 & ND \\
\hline SET & 7.00 & 0.07 & 0.08 & 0.15 & ND \\
\hline \multicolumn{6}{|l|}{ Stratified charge } \\
\hline ETP & ND & ND & ND & 0.13 & 0.01 \\
\hline FET & ND & ND & ND & 0.23 & 0.01 \\
\hline SET & 0.12 & 0.01 & ND & 0.05 & ND \\
\hline \multicolumn{6}{|l|}{ Rotary } \\
\hline FTP & 0.40 & 0.09 & 0.04. & 0.70 & 0.06 \\
\hline \multicolumn{6}{|l|}{$\begin{array}{l}\text { Diesel. (\#2 national } \\
\text { average fuel) }\end{array}$} \\
\hline FTP & 2.55 & 1.46 & 1.56 & 1.56 & NA \\
\hline FET & 2.50 & 1.45 & 2.03 & 0.12 & NA \\
\hline SET & 2.00 & 1.19 & 1.54 & 0.08 & $\mathrm{NA}$ \\
\hline
\end{tabular}

Notes: NA $=$ Not available.

ND $=$ Not detectable.

Source: U.S. Environmental Protection Agency 1978c. 
Agency 1978c). More research is needed to establish the possible trace metal emission rates with both diesel- and gasoline-powered passenger cars. Sulfur, lead, manganese, and copper are elements of particular prominence from diesel-powered passenger cars in amounts related to fuel composition and combustion. Calcium, phosphorous, and Iron emissions appear to be related to lubricating oil consumption, and engine and exhaust system wear. Nickel is present only in trace quantitles (U.S. Environmental Protection Agency 1978c;

Braddock and Gabele 1977).

\section{Lead in Gasoline}

In 1975; atmospheric emissions of lead in the U.S. totaled 155,900 tons, and 90.4 percent of that amount was from gasoline combustion (U.S. Environmental Protection Agency 1977a). Although gasoline sales have increased since then, lead emissions from gasoline combustion have probably declined as Federal law forced the lead content of gasoline to be reduced from 0.45 ug per 11 ter to $0.13 \mathrm{ug}$ per 11ter by 1979. In fact, the 1975 level of lead emissions is expected to be reduced by 58 percent in 1985. Lead compounds such as . lead halides and lead oxyhalldes are emitted only with leaded gasoline.

The antiknock compounds tetraethyl and tetramethyl lead are added to gasoline to increase its octane rating. There is a nonlinear relationshlp between gasoline lead content and octane number. The antiknock quality of gasoline is primarily controlled by the chemical composition of hydrocarbons in the gasoline. The lead alkyls suppress knocking by varying the chemical composition. Not all lead contained in fuel is emitted in the exhaust system from a gasoline engine; some is retained in the engine, exhaust system, and the crankcase oil.

The following arp nnnclusions derived from EPA investigations:

(1) A large portion of the lead (approximately 40 to 75 percent) generated by engines burning leaded fuel is in particles of submicron size, with mass median equivalent diameters in the order of 0.1 to $0.3 \mathrm{um}$.

(2) Lead compounds accumulate in crankcase o11 and on components of the engine and exhaust system. Over the life of an automoblle about 75 percent of the lead in fuel is emitted as particulate matter in the exhaust. 
(3) In general, 40 to 75 percent of the lead emitted from production vehicles in typical operation modes is in fine particles, i.e., in particles with diameters of less than 1 um. This suggests that, on the average, 35 to 40 percent of lead in fuel is emitted as fine particulates. About an equal amount ( 35 to 40 percent) must then be emitted as coarse particles. The emission rate of coarse particles is greatly influenced by reentrainment of lead compounds that have been deposited in the exhaust and is highly variable; fine particles are 1ikely to be those emitted directly from the engine at a rate more uniform than that of large-particle emissions (U.S. Environmental Protection Agency 1977a).

The Inorganic lead compounds identified from lead trap deposits in the exhaust from engines burning leaded fuel include $\mathrm{PbSO}_{4}$, $\mathrm{PbBr}_{2}, \mathrm{~Pb}_{3}\left(\mathrm{PO}_{4}\right)_{2}$, and $\mathrm{PbO}$. These Inorganic lead compounds account for about 84 percent of potential particulate lead exhaust emissions from vehicles (Kunz et al. 1975). Along with these inorganic lead compounds, exhausts also contain $\mathrm{Fe}_{2} \mathrm{O}_{3}$, soot, and carbonaceous material. The amount of inorganic lead compounds in exhaust emissions is a function of exhaust gas temperature and the amount of lead in the gasoline.

\section{Nitrogen Oxides Emissions}

Nitrogen oxides $\left(\mathrm{NO}_{x}\right)$ are formed during mobile combustion : of automotive fuels. Nitric oxide (NO) is produced in the high temperature of the combustion zone. The amount of No emitted is a function of temperature as well as the rate at which the combustion mixture cools. The proper reducing catalyst can expedite decomposition to nitrogen and oxygen and can control $\mathrm{NO}_{\mathrm{x}}$ emissions (Hurn 1968). In exhaust gases where higher concentrations and temperatures prevall, some $\mathrm{NO}$ is oxidized to nitrogen oxide. The amount of $\mathrm{NO}_{\mathrm{x}}$ produced is a function of the ratio of the air-to-fuel mixture used for the engine. At low air-to-fuel ratios, nitrogen oxide emissions are low. At higher air-to-fuel ratios, the temperature of the combustion flame becomes hotter and the nitrogen oxides increase until the air-fuel ratio is greater than the stoichlometric point, and then decrease rapidly as excess air cools the flame (Urone 1976).

The concentration of nitrogen oxides in exhaust is most heavily influenced by'peak combustion temperatures and by oxygen availability at the fixation temperature. Reduction in either reduces $\mathrm{NO}$ levels and the effects are additive. Diesel exhausts contain significant amounts of nitric oxide. The concentration levels are deceptively low if compared with similar data from gasoline auto exhausts. This is because diesel engines are operated with an unthrottled air intake 
and induct large quantities of excess air that dilute the combustion products. Comparable dilution does not occur with spark-ignited engines that operate with the intake throttled and with fuel metered in proportion to air flow to maintain the air-fuel ratio within a narrow range of values. Table 26 summarizes gaseous emissions data relating to diesel-powered and gasoline-powered cars for $\mathrm{NO}_{x}$ and $\mathrm{CO}$. The $\mathrm{NO}_{\mathrm{x}}$ emission rates for the gasoline cars are higher than for diesel cars in all modes of cyclic operation (U.S. Environmental Protection Agency 1978c).

\section{Carbon Monoxide Emissions}

The emission of carbon monoxide also is a function of alr-fuel ratio. At the air-fuel ratio of approximately 14.5 pounds of air per pound of a typical gasoline, carbon monoxide emission is near zero. Advances in engine design beyond 1968 models have achieved low CO emission without sacrificing drivability and performance. Typically, concentrations of $\mathrm{CO}$ in exhaust emissions are high during the engine idle mode and decrease as the engine speed is increased beyond idle range. At a speed of $5 \mathrm{mph}$, the carbon monoxide level is 7 percent; at $20 \mathrm{mph}$, it is 3.1 percent; and at $60 \mathrm{mph}$ it is 1.8 percent (Hurn 1968). Thus, a car's total Co emissions will be influenced by the amount of time spent idling and driving at low speeds. Table 26 summarizes emissions data for carbon monoxide. The $\mathrm{CO}$ emissions rates for both diesel- and gasoline-powered cars are about equal, with gaso1ine cars emitting more $C O$ in the FTP and less in the FET and SET modes than diesel cars.

Smoke and Odor

Smoke and odor pollution is a phenomenon assoclated with dieselpowered engines.

Smoke. Diesel smoke is classified in three categories: b.lack, blue, and white. Black smoke results from incomplete combustion of the diesel fuel due to fuel injection irregularity or overfueling the engine. Blue smoke results from excessive ofl consumption and indicates an engine problem. White smoke represents unburned fuel and is generally assuciated with cold engine malfunction. Black smoke indicates a significant problem with diesel engines. Good maintenance practice and rapid correction of engine problems are obvious tactics to control such pollution.

Unfortunately, well-maintained diesel engines also discharge black smoke. Fuel additives (catalysts) such as barium-based materials are highly effective in suppressing diesel smoke. The smoke suppressant additives are typically oil-soluble, fully miscible, metallic, or organic liquids. The effect of these additives on 
TABLE 26

GASEOUS - EMISSION DATA - FOR DIESEL-POWERED

AND GASOLINE-POWERED CARS

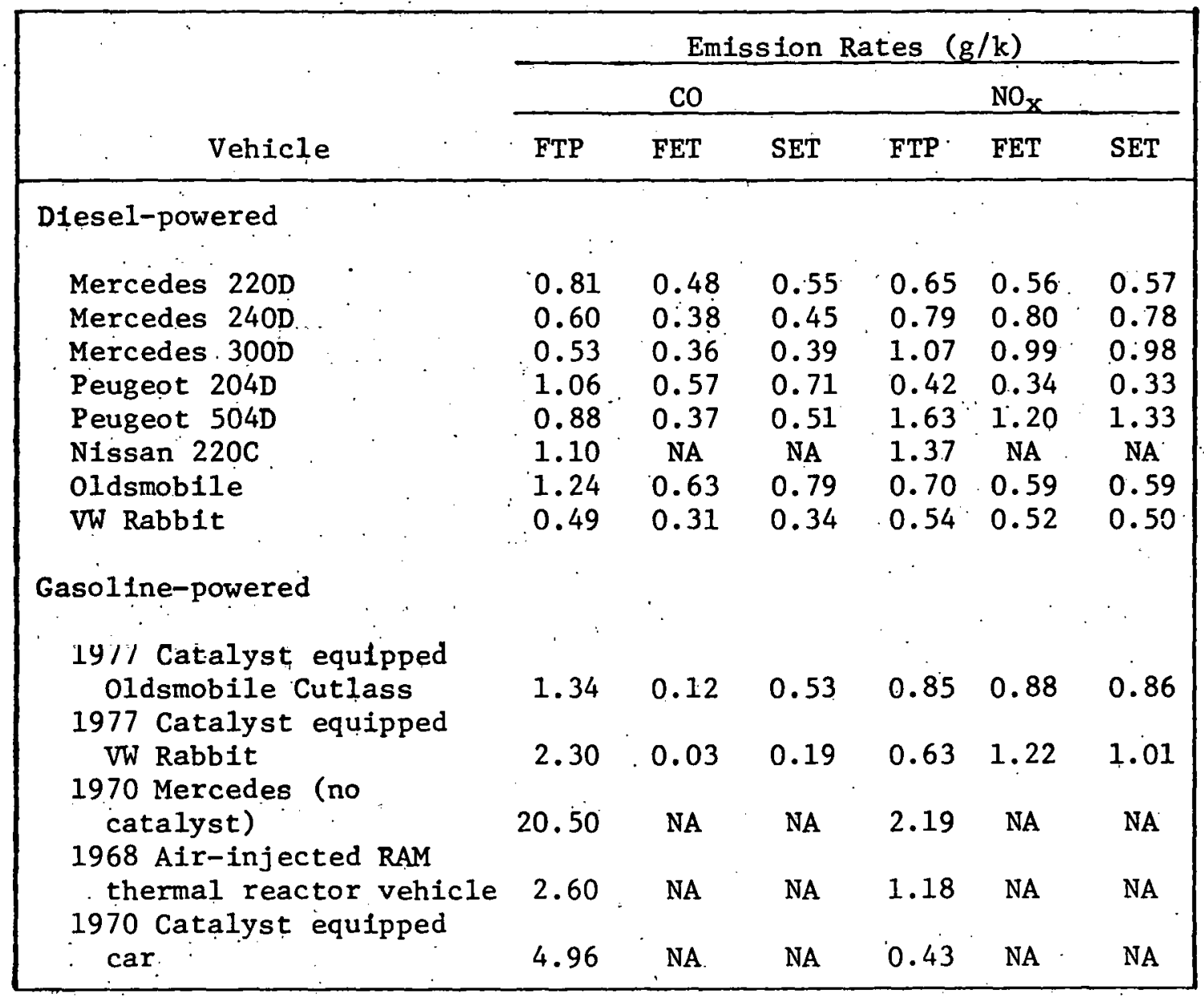

Note: $\quad$ NA $=$ Not applicable.

Source: U.S. Environmental Protection Agency 1978c. 
engine emissions is negligible, and the toxicity of emitted barium (especially of barium sulfate) is not fully understood.

Odor. Specific odorants in diesel exhaust are commonly associated with the broad family of oxygenates. Various additives have been used experimentally to inhibit diesel odor, but the results have been Inconclusive. Some diesel exhaust components that are responsible for odor formation have been ( $0^{\prime}$ Donnell and Dravnieks 1970) determined with high resolution chromatography. These odorants are acetaldehyde, n-butanol, decane, methyl benzene, C5 substituted benzene, allyl toluene, methylinden, benzaldehyde, naphthalene, and methyl naphthalene. Other diesel exhaust odorants, identified as a large number of aromatic compounds by Arthur D. Little Company researchers, are listed in Table. 27 (Spicer and Levy 1975).

\section{Alrcraft Emissions}

Gas turbines of aircraft jet engines emit hydrocarbons, carbon monoxide, and nitrogen oxides. Estimates of these emissions are presented in Table 28 (Hurn 1968).

Overall, aircraft cannot be considered a significant source of ground-level pollution, but they may present local nuisances or aggravate alr pollution in the vicinity of airport operations. There 18 some question as to the effect of emisstons of high flying aircraft on the quality of the stratosphere and on ozone.

In addition to the gaseous emissions mentioned above, aircraft turbines present a smoke problem that became serlous in the late $1960 \mathrm{~s}$ at major airports in the United States and Europe. Dense jet engine smoke was first associated with water injection used for power boost on takeoff, but dry engines, subsequently developed, have retained the smoke problem. Fuel characteristics, including the presence of aromatic hydrocarbons, markedly influence the amount of smoke generated by an aircraft. The fuel's aromatic content is generally $11 m i t e d$ to 25 percent to control carbon deposition and smoke generation.

The exhaust emission characteristics of today's aircraft turbine engines are illustrated in Figure 8 (Bahr 1971). The peak $C O$ and $H C$ emission levels occur when the engine is idling or operating at low power. In some engines, particulate emissions are detected in vist= ble concentrations of smoke, particularly at takeoff. Although not generally regarded as a significant health hazard, these visible smoke particulate emissions are undesirable and can result in dirt and visibility problems in and around busy airports. 
TABLE 27

DIESEL EXHAUST ODORANTS ${ }^{a}$

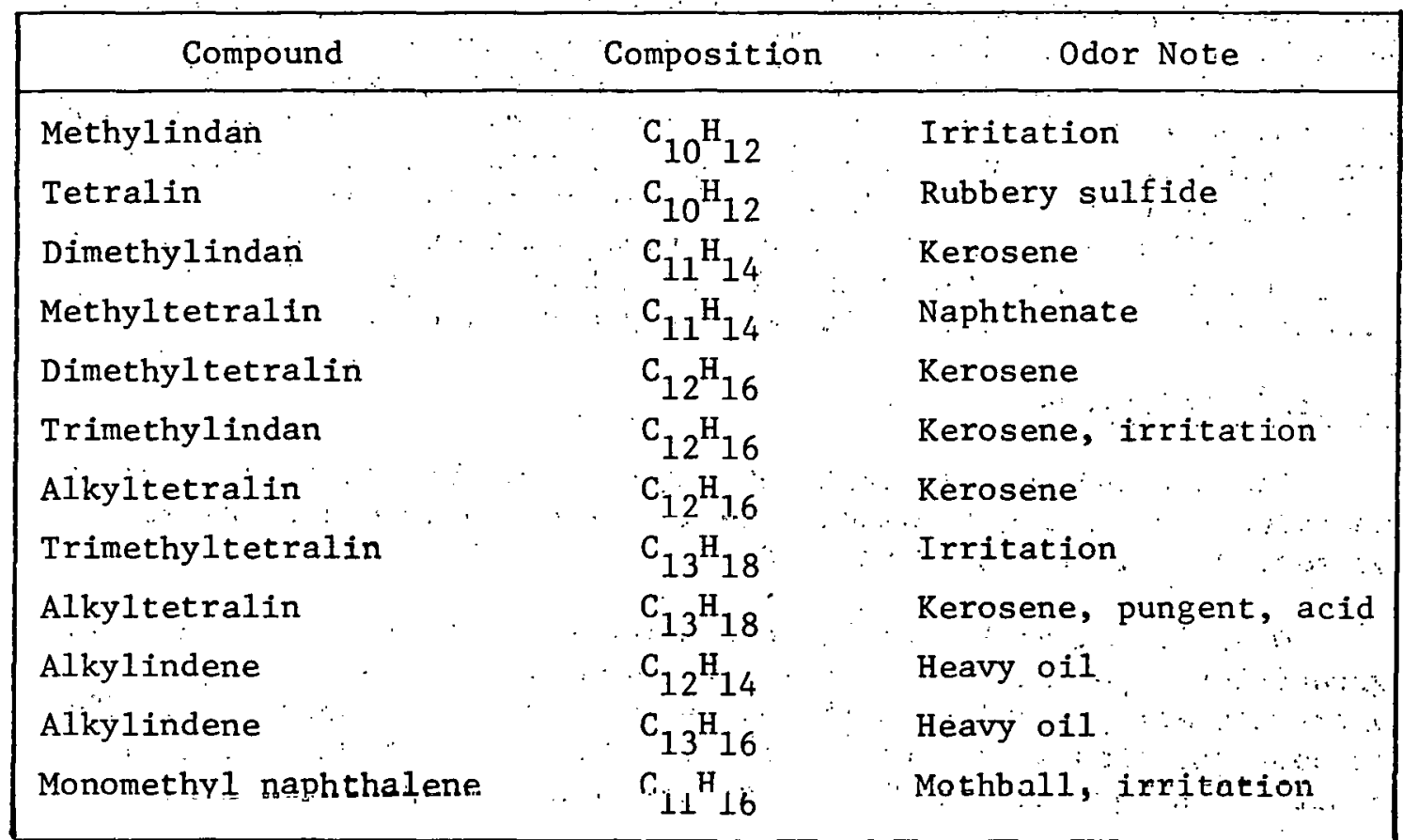

adorants noted by the Arthur D. Little Company.

Soùce: Spicer and Levy 1975. 
TABLE 28.

AIRCRAFT TURBINE EMISSIONS ${ }^{\mathrm{a}}$

\begin{tabular}{|c|c|c|c|c|c|c|}
\hline \multirow[b]{3}{*}{$\begin{array}{l}\text { Engine } \\
\text { Mode }\end{array}$} & \multicolumn{6}{|c|}{ Emissions } \\
\hline & \multicolumn{2}{|c|}{ Hydrocarbons } & \multicolumn{2}{|c|}{$\mathrm{NO}_{x}$} & \multicolumn{2}{|c|}{ Aldehydes } \\
\hline & $\begin{array}{c}\text { Concentration } \\
(\mathrm{ppm})\end{array}$ & $\begin{array}{c}\text { Mass } \\
\text { (1bs/hour) }\end{array}$ & $\begin{array}{c}\text { Concentration } \\
\text { (ppm) }\end{array}$ & $\begin{array}{c}\text { Mass } \\
\text { (1bs/hour) }\end{array}$ & $\begin{array}{c}\text { Concentration } \\
(\mathrm{ppm})\end{array}$ & $\begin{array}{c}\text { Mass } \\
\text { (lbs/hour) }\end{array}$ \\
\hline Idle & 150 & 20 & 5 & 2 & 5 & 2 \\
\hline Cruise & 5 & 2 & 50 & 45 & 1 & 1.5 \\
\hline Takeoff & 2 & 1 & 5 & 5 & Trace & $\mathrm{Nil}$ \\
\hline
\end{tabular}

${ }^{a}$ Includes emissions from engines in the 15,000-pound thrust category.

Source: Hurn 1968. 


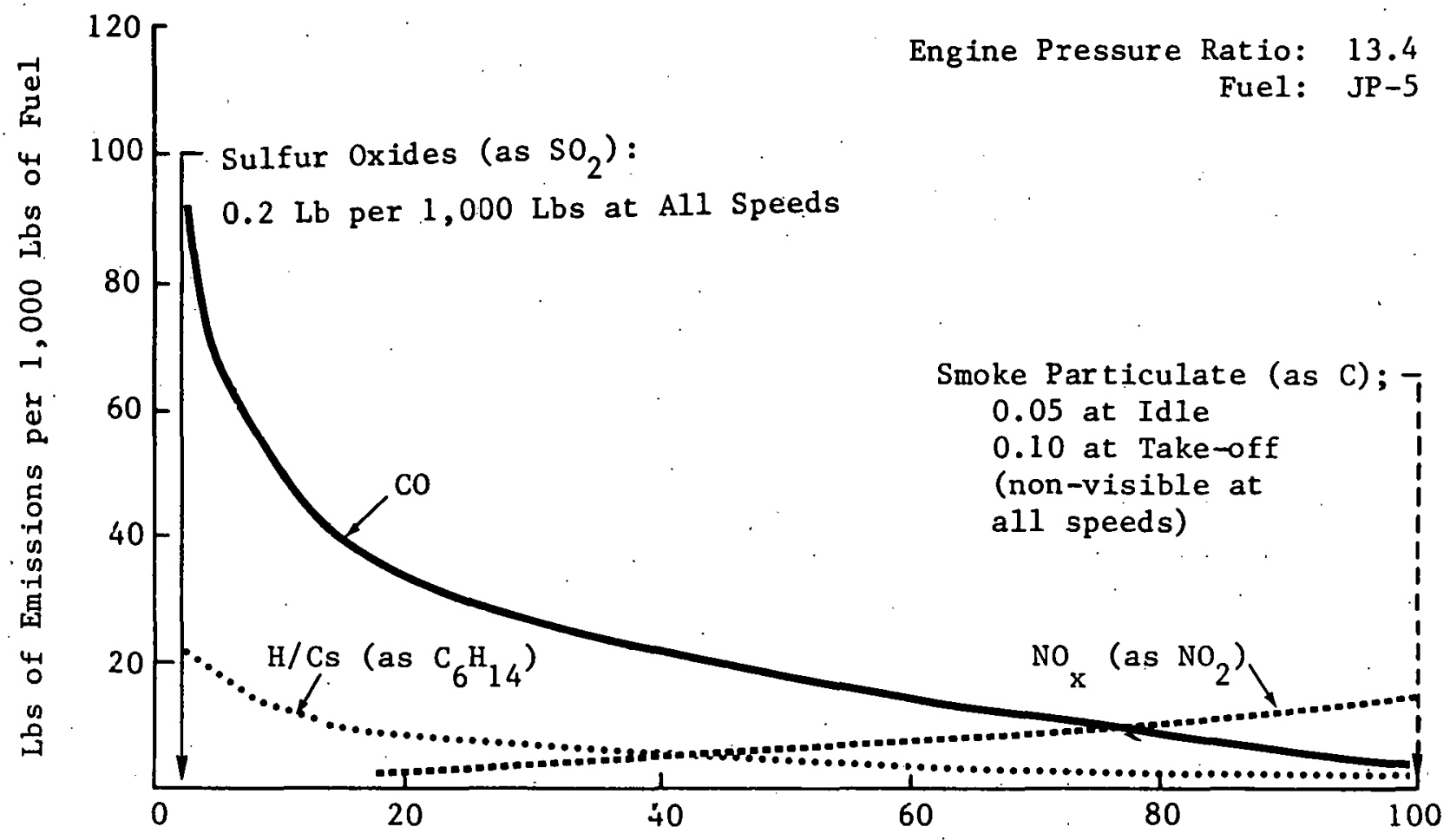

Percent of Full Power at Sea Level Static Operating Conditions

Source: Bahr 1971 .

FIGURE 8

TYPICAL AIRCRAFT TURBINE ENGINE EXHAUST

EMISSIONS CHARACTERISTICS 
In addition, any emissions that are generated during cruise operations are generally dispersed over wide geographic areas. In view of these considerations, aircraft turbine engine exhaust emissions during cruise operations may not be a significant health concern. However, this view is not held by many scientists, some of whom believe that these emissions may have a negative impact on the upper atmosphere.

Table 29 shows the length of time spent by varlous kinds of planes in each phase of the landing and takeoff cycle at a metropolitan airport. The average level of any given exhaust emission may be defined as the average value resulting from all aircraft within the metropolitan area that taxi, Idle, takeoff, climb-out to 3,500 feet, approach from 3,500 feet, land, and taxi back. For any particular exhaust constituent, the average emission level determined in this manner is a more suitable value for assessing the impact of aircraft operations on the airport environment than the peak emission level, which reflects only very specific engine operating conditions. Emission factors for aircraft operation are listed in Table 30. Taxi, idle, and approach times are worst in the most congested, and generally most polluted metropolitan areas.

Locomotive Engines

The primary emissions produced by locomotive diesel engines are smoke, $\mathrm{NO}_{\mathrm{X}}, \mathrm{HC}$, and $\mathrm{CO}$. Smoke is recognized as a nuisance that is not a potential health hazard (toxic particulate matter is treated separately). Nitrogen oxides are the only gaseous pollutants emitted from diesel engines at levels approaching those from gasoline engines. Diesel engines emit $\mathrm{HC}$ and $\mathrm{CO}$ at low levels (compared to gasoline engines) and these levels have been further reduced by various control techniques.

$\mathrm{NO}_{x}$ formation is a function of combustion temperature, oxygen availability, and of the rime that conditions favorable to $\mathrm{NO}_{x}$ formation exist in the cylinder. Thus, $\mathrm{NO}_{\mathbf{x}}$ formation is intimately related to the combustion efficiency of diesel engines. In other words, the greatest quantity of $\mathrm{NO}_{x}$ is usually formed when the engine at tains maximum efficiency and minimum fuel consumption.

The concentration of unburned hydrocarbons in diesel exhaust is determined more by design and performance of the injection system, and by combustion chamber geometry, than by operating variables such as engine speed and load. Co concentration is a function of malfunctions or changes in the operating mode that increase the fuel-to-air ratio. An increase in black smoke is due to an increased fuel-to-air ratio, while increased white smoke is due to bad maintenance, low speed, and low temperature operations. Improved engine components 
TABLE 29

TYPICAL TIME FOR A LANDING

AND TAKEOFF CYCLE AT A METROPOLITAN AIRPORT

\begin{tabular}{|c|c|c|c|c|c|}
\hline \multirow[b]{2}{*}{ Aircraft ${ }^{a}$} & \multicolumn{5}{|c|}{ Time in Mode (minutes) } \\
\hline & Taxi-Idle & Takeoff & Climbout & Approach & Taxi-Idle \\
\hline Jumbo jet $(3-4)$ & 19.00 & 0.70 & 2.20 & 4.00 & 7.00 \\
\hline Long range jet (4) & 19.00 & 0.70 & 2.20 & 4.00 & 7.00 \\
\hline $\begin{array}{c}\text { Medium range } \\
\text { jet }(2-3)\end{array}$ & 19.00 & 0.70 & 2.20 & 4.00 & .7 .00 \\
\hline $\begin{array}{l}\text { Air carrier } \\
\text { turboprop }(2-4)\end{array}$ & 19.00 & 0.50 & 2.50 & 4.50 & 7.00 \\
\hline Business jet $(2-4)$ & 6.50 & 0.40 & 0.50 & 1.60 & 6.50 \\
\hline $\begin{array}{l}\text { General aviation } \\
\text { turboprop }\end{array}$ & 19.00 & 0.50 & 2.50 & 4.50 & 7.00 \\
\hline $\begin{array}{l}\text { General aviation } \\
\text { piston (1) }\end{array}$ & 12.00 & 0.30 & 4.98 & 6.00 & 4.00 \\
\hline Piston transport (4) & 6.50 & 0.60 & 5.00 & 4.60 & 6.50 \\
\hline Helicopter (2) & 3.50 & 0 & 6.50 & 6.50 & 3.50 \\
\hline Military transport & 19.00 & 0.50 & 2.50 & 4.50 & 7.00 \\
\hline Military jet & 6.50 & 0.40 & 0.50 & 1.60 & 6.50 \\
\hline Military piston & 6.50 & 0.60 & 5.00 & 4.60 & 6.50 \\
\hline
\end{tabular}

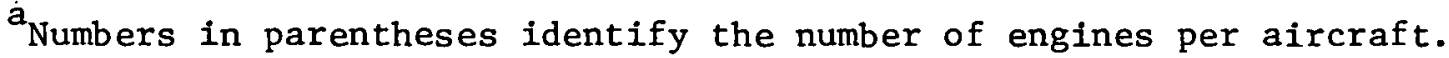

Source: U.S. Environmental Protection Agency 1977b. 
TABLE 30

EMISSION FACTORS PER AIRCRAFT LANDING AND TAKEOFF CYCI.E

\begin{tabular}{|c|c|c|c|c|c|}
\hline$\cdot$ & $\begin{array}{c}\text { Solid } \\
\text { Particulates } \\
\end{array}$ & $\begin{array}{l}\text { Sulfur } \\
\text { Oxides }\end{array}$ & $\begin{array}{c}\text { Carbon } \\
\text { Monoxide }\end{array}$ & Hydrocarbons & $\begin{array}{l}\text { N1trogen Oxides } \\
\left(\mathrm{NO}_{x} \text { as } \mathrm{NO}_{2}\right) \\
\end{array}$ \\
\hline Afrcraft & (1bs) & (1bs) & (1bo) & (1bs) & (1hs) \\
\hline Jumbo jet & 1.3 & 1.82 & 46.8 & 12.2 & 31.4 \\
\hline Long range jet & 1.21 & 1.56 & 47.4 & 41.2 & 7.9 \\
\hline Medium range fet & 0.41 & 1.01 & 17 & 4.9 & 10.2 \\
\hline Afr carrier turboprop & 1.1 & 0.4 & 6.6 & 2.9 & 2.5 \\
\hline Business fet & 0.11 & 0.37 & 15.8 & 3.6 & 1.6 \\
\hline $\begin{array}{l}\text { General aviation } \\
\text { turboprop }\end{array}$ & 0.2 & 0.18 & 3.1 & 1.1 & 1.2 \\
\hline $\begin{array}{l}\text { General aviation } \\
\text { piston }\end{array}$ & 0.02 & 0.014 & 12.2 & 0.4 & 0.047 \\
\hline Piston transport & 0.56 & 0.28 & 304 & 40.7 & 0.4 \\
\hline Helicopter & 0.25 & 0.18 & 5.7 & 0.52 & 0.57 \\
\hline Military transport & 1.1 & 0.41 & 5.7 & 2.7 & 2.2 \\
\hline Military jet & 0.31 & 0.76 & 15.1 & 9.93 & 3.29 \\
\hline Military piston & 0.28 & 0.14 & 152 & 20.4 & 0.2 \\
\hline
\end{tabular}

Source: U.S. Environmental Protection Agency 1977c. 
such as a change in fuel injection; use of governors, turbochargers, piston and cylinder liners; alteration of injection timing; changes in engine operation and other engine modifications reduce emissions from diesel engines (Storment et al. 1975). Emission factors associated with locomotive engines are listed in Table 31.

Summary of Mobile Emissions

The important gaseous emissions from mobile source combustion are hydrocarbons (including aldehydes), carbon monoxide, and nitrogen oxides. Emission estimates for a 30-year period from 1955 to 1985 were projected prior to the enactment of the Clean Air Act Amendments of 1970 (National Petroleum Council 1971). These estimates are listed. in Table 32. A downward emissions trend was projected, and by 1985 the peak reached between 1965 and 1970 was expected to be reduced by approximately 80 percent for hydrocarbons, 60 percent for carbon monoxide, 45 percent for nitrogen oxides, and 40 percent for particulate matter. The lower hydrocarbon and nitrogen oxides emissions were expected to reduce the incidence of photochemical smog. Table 33 provides 1970 to 1977 estimates of hydrocarbon emissions from highway vehicles.

Historically, various automobile modifications have been proposed to reduce automobile emissions in the U.S. Listed in Table 34, they include recirculation of crankcase and exhaust gases, leaner fuel mixtures, changes in timing and spark ignition, decreased rompression ratios, and catalytic exhaust recombiners (Loftness 1978).

Table 35 details proposed automobile emisstons standards by the years in which they would take effect (Council on Environmental Quality 1976, 1977). These proposed standards would help reduce air pollution caused by automobile emissions.

Data in a National Petroleum Council report (1971) indicate that hydrocarbon and carbon monoxide emissions from trucks and buses will deviate only slightly from peaks reached in 1970, while nitrogen oxides and particulate emissions will remain constant. The authors of the report suggest that emissions estimates could prove to be high if the use of diesel engines is greater than that assumed in their. study. Recent trends, unknown to the authors in 1971, indicate that this may be the case.

Alrcraft emissions produced below 35,000 feet from air carriers and general aviation operations are expected to increase. Redesigning and retrofitting jet engine combustors would significantly reduce the smoke problem. 
TABLE 31

EMISSION FACTORS BY LOCOMOTIVE ENGINE CATEGORY

\begin{tabular}{|c|c|c|c|c|c|c|}
\hline Pollutant & $\begin{array}{l}\text { 2-Stroke } \\
\text { Supercharged } \\
\text { (switch } \\
\text { locomotive) }\end{array}$ & $\begin{array}{l}\text { 4-Stroke } \\
\text { (switch } \\
\text { locomotive) }\end{array}$ & $\begin{array}{l}\text { 2-Stroke } \\
\text { Supercharged (long } \\
\text { distance locomotive) }\end{array}$ & $\begin{array}{l}\text { 2-Stroke } \\
\text { Turbocharged (long } \\
\text { distance locomotive) }\end{array}$ & $\begin{array}{c}\text { 4-Stroke } \\
\text { (lang distance } \\
\text { locomotive) }\end{array}$ & $\begin{array}{l}\text { Average } \\
\text { Emissions } \\
\text { Based on } \\
\text { Nationwide } \\
\text { Statistics }\end{array}$ \\
\hline \multicolumn{7}{|l|}{ Carbon monoxide } \\
\hline $\begin{array}{ll}\text { lbs } / 10^{3} & \text { gal } \\
\mathrm{kgs} / 10^{3} & \text { liter }\end{array}$ & $\begin{array}{l}84 \\
10\end{array}$ & $\begin{array}{r}380 \\
46\end{array}$ & $\begin{array}{r}66.0 \\
7.9\end{array}$ & $\begin{array}{r}160.0 \\
19.0\end{array}$ & $\begin{array}{r}180 \\
22\end{array}$ & $\begin{array}{r}130 \\
16\end{array}$ \\
\hline Hydrocarbor.s & & & & & & \\
\hline $1 \mathrm{bs} / 10^{3} \mathrm{gal}$ & 190 & 146 & 148.0 & 28.0 & 99 & 94 \\
\hline $\mathrm{kgs} / 10^{3} \mathrm{gal}$ & 23 & 17 & 18.0 & 3.4 & 12 & 11 \\
\hline $\begin{array}{l}\text { Nitrogen oxides } \\
\left(\mathrm{NO}_{\mathrm{x}} \text { as } \mathrm{NO}_{2}\right)\end{array}$ & & & & . & & \\
\hline $\begin{array}{ll}\text { lbs } / 10^{3} & \text { gal } \\
\mathrm{kgs} / 10^{3} & \text { liter }\end{array}$ & $\begin{array}{r}250 \\
30\end{array}$ & $\begin{array}{r}490 \\
59\end{array}$ & $\begin{array}{r}350.0 \\
42.0\end{array}$ & $\begin{array}{r}330.0 \\
40.0\end{array}$ & $\begin{array}{r}470 \\
56\end{array}$ & $\begin{array}{r}370 \\
44\end{array}$ \\
\hline
\end{tabular}

Source: U.S. Environmental Protection Agency $1977 \mathrm{~b}$. 
TABLE 32

ESTIMATED EMISSIONS FROM MOBILE EQUIPMENT

(millions of tons per year)

\begin{tabular}{|c|c|c|c|c|c|c|c|}
\hline & 1955 & 1960 & 1965 & 1970 & 1975 & 1980 & 1985 \\
\hline \multicolumn{8}{|l|}{ Hydrocarbons } \\
\hline Autos & 9.9 & 12.0 & 13.0 & 11.0 & 5.9 & 2.4 & 0.9 \\
\hline Trucks and buses. & 1.2 & 1.4 & 1.7 & 1.9 & 1.7 & 1.4 & 1.4 \\
\hline Aircraft & 0.3 & 0.3 & 0.2 & 0.3 & 0.2 & 0.1 & 0.1 \\
\hline off-highway & 0.7 & 0.7 & 0.7 & 0.6 & 0.6 & 0.6 & 0.5 \\
\hline Total & 12.1 & 14.4 & 15.6 & 13.8 & 8.4 & 4.5 & 2.9 \\
\hline \multicolumn{8}{|l|}{ Carbon monoxide } \\
\hline Autos & 37.3 & 45.7 & 55.2 & 54.3 & 40.6 & 24.3 & 12.7 \\
\hline Trucks and buses & 11.1 & 12.7 & 15.6 & 17.4 & 16.2 & 14.0 & 14.2 \\
\hline Aircraft & 2.2 & 1.4 & 0.9 & 0.4 & 0.5 & 0.7 & 0.8 \\
\hline off-highway & 6.7 & 6.8 & 5.7 & 5.3 & 5.5 & 4.4 & 3.4 \\
\hline Total & 57.3 & 66.6 & 77.4 & 77.4 & 62.8 & . $\quad 43.4$ & 31.1 \\
\hline \multicolumn{8}{|l|}{ Nitrogen oxides } \\
\hline Autos & 3.3 & 4.0 & 4.8 & 5.7 & 5.0 & 2.8 & 1.3 \\
\hline Trucks and buses & 0.8 & 0.9 & 1.1 & 1,4 & 1.6 & 1.5 & 1.7 \\
\hline Aircraft & 0.01 & 0.01 & 0.03 & 0.05 & 0.06 & 0.08 & 0.09 \\
\hline off-highway & 0.8 & 0.9 & 0.9 & 0.9 & 0.9 & 1.1 & 1.1 \\
\hline Total & 4.9 & 5.8 & 6.8 & 8.1 & 7.6 & 5.5 & 4.2 \\
\hline \multicolumn{8}{|l|}{ Particulates } \\
\hline Autos & 0.2 & 0.2 & 0.2 & 0.3 & 0.3 & 0.2 & 0.1 \\
\hline Trucks and buses & 0.1 & 0.1 & 0.1 & 0.2 & 0.2 & 0.2 & 0.2 \\
\hline Aircraft & 0.01 & 0.01 & 0.02 & 0.04 & 0.04 & 0.04 & 0.05 \\
\hline off-highway & 0.2 & 0.2 & 0.2 & 0.2 & 0.2 & 0.2 & 0.1 \\
\hline Total & 0.5 & 0.5 & 0.5 & 0.7 & 0.7 & 0.6 & 0.5 \\
\hline
\end{tabular}

Source: National. Petroleum Council 1971. 
TABLE 33 NATIONWIDE ESTIMATES OF VOLATILE
ORGANIC COMPOUNDS EMITTED FROM HIGHWAY VEHICLES

\begin{tabular}{|llllllllll|}
\hline & 1970 & 1971 & 1972 & 1973 & 1974 & 1975 & 1976 & 1977 \\
\hline $\begin{array}{l}\text { Highway } \\
\text { emissions }\end{array}$ & 10.6 & 10.6 & 10.9 & 10.7 & 10.0 & 9.8 & 10.0 & 9.9 \\
\hline $\begin{array}{c}\text { Total of al1 } \\
\text { transportation } \\
\text { emissions }\end{array}$ & 12.2 & 12.2 & 12.5 & 12.3 & 11.5 & 11.3 & 11.6 & 11.5 \\
\hline
\end{tabular}

$\star$

*Data in millions of tons per year.

Source: U.S. Environmental Protection Agency 1977c. 
TABLE 34

SUMMARY OF TYPICAL EMISSION MODIFICATIONS

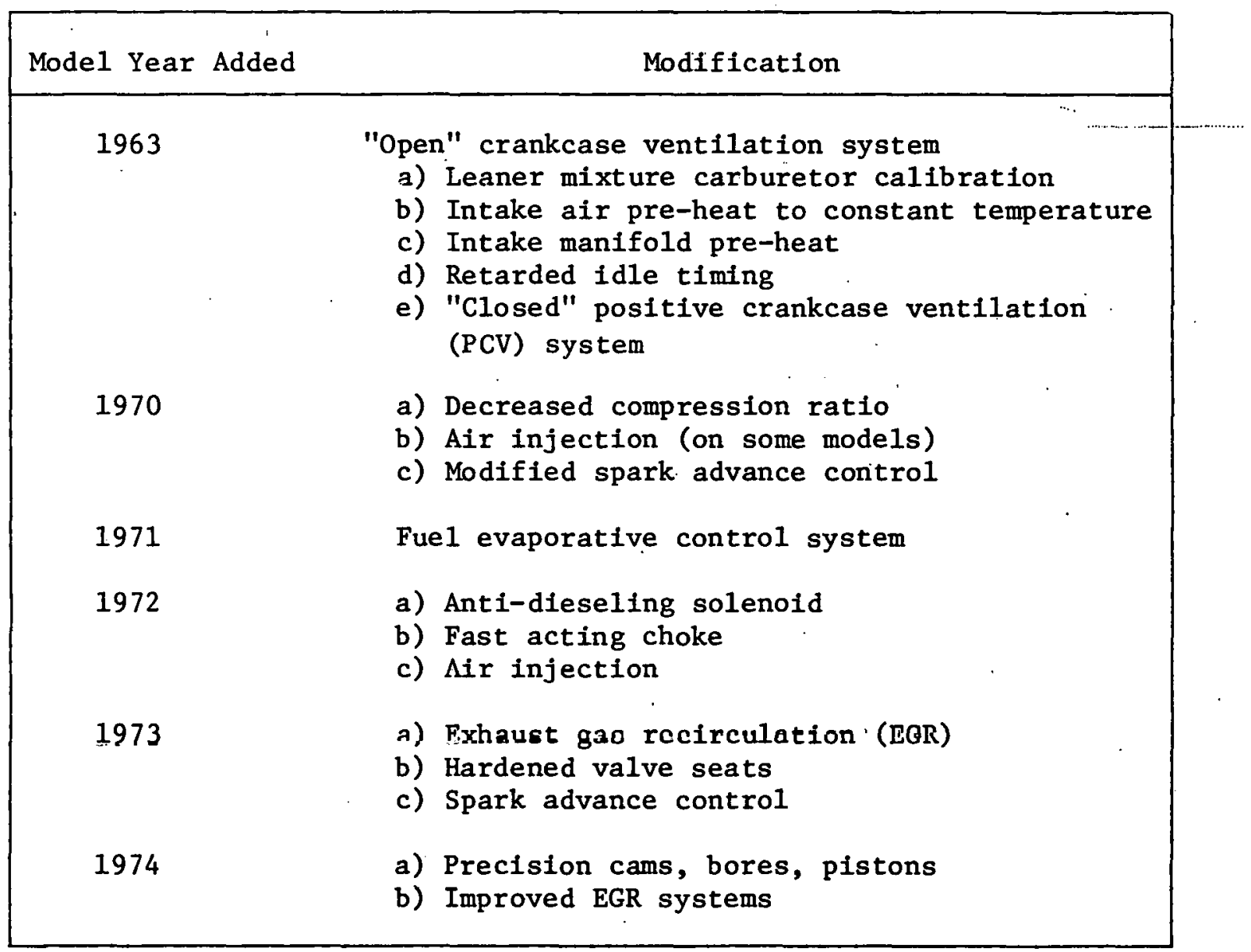

Source: Loftness 1978. 
TABLE 35

PROPOSED AUTOMOBILE EMISSIONS STANDARDS

\begin{tabular}{|c|c|c|c|c|c|c|c|c|c|c|c|}
\hline \multirow[b]{2}{*}{$\begin{array}{l}\text { Emission standard (gramsimile) } \\
\text { Proposal (ef Eective date) }\end{array}$} & \multicolumn{3}{|c|}{ Hydrocarbons } & \multicolumn{3}{|c|}{ Carbon Monoxide } & \multicolumn{5}{|c|}{ Nitrogen Oxides } \\
\hline & 1.5 & 0.9 & 0.41 & 15.0 & 9.0 & 3.4 & 3.1 & 2.0 & .1 .5 & 1.0 & 0.4 \\
\hline $\begin{array}{l}1970 \text { Clean Air Act } \\
\text { Schedule as of January } 1976 \\
\text { EPA proposal (March 5, 1976) } \\
\text { President's proposal (July 28, 1975) } \\
\text { Senate staff proposal (August 8, 1975) } \\
\text { House subcomittee proposal } \\
\text { Senate comnittee bill } \\
\text { House conmittee bill } \\
1977 \text { amendnents }\end{array}$ & $\begin{array}{l}1976 \\
1976-77 \\
1977-79 \\
1976-81 \\
1976-77 \\
1976-77 \\
1976-78 \\
1976-79 \\
1976\end{array}$ & $\begin{array}{c}. \\
1980-81\end{array}$ & $\begin{array}{l}1977 \\
1978 \\
1982 \\
1978 \\
1980 \\
1979 \\
1980 \\
1980\end{array}$ & $\begin{array}{l}1976 \\
1976-77 \\
1977-79 \\
1976-81 \\
1976-77 \\
1976-77 \\
1976-78 \\
1976-79 \\
1976\end{array}$ & $\begin{array}{l}1980-81 \\
1978-79\end{array}$ & $\begin{array}{l}1977 \\
1978 \\
1982 \\
1978 \\
1980 \\
1979 \\
1980 \\
1981\end{array}$ & $\begin{array}{l}1976 \\
1976 \\
1976-81 \\
1976-77 \\
1976 \\
1976 \\
1976\end{array}$ & $\begin{array}{l}1977 \\
1977 \\
1977-81 \\
\\
1977-79 \\
1977-79 \\
1977-80 \\
1977\end{array}$ & & $\begin{array}{c}1978-81^{a} \\
1979^{c}\end{array}$ & $\begin{array}{l}1982 \\
1980^{b} \\
1981^{d}\end{array}$ \\
\hline
\end{tabular}

applies to only 50 percent of vehicles and engines in 1978 and 1979.

b Administrator may grant annual suspensfons based on unavailability of technology or excessive fuel penalties, but interim standards are not to exceed $1.5 \mathrm{gpm} 1 \mathrm{n} 1980-81$ and $1.0 \mathrm{gpm}$ in 1982-84.

CApplies to only 10 percent of vehicles in 1979 and 100 percent in 1980.

Administrator would be able to grant yearly suspension of this requirement. Maximum allowable standards with such suspension would be 2.0 for 1981-82, 1.5 for $1983-84$ and 0.4 for 1985 and beyond.

Source: Counc1l on Environmental Quality 1976, 1977. 
Waste Lubricating 0ils

Automotive, industrial, aviation, and other lubricating oils, when burned or used in various systems, end up as waste oils. It has been estimated that, on the average, 63 percent ( $1 . e ., 1,115 \mathrm{x}$ $10^{6}$ out of $2,234 \times 10^{6}$ gallons) of the oil sold in the U.S. In 1972 ended up as waste oil (U.S. Environmental Protection Agency 1974). In terms of ecological hazards, such a large volume of waste oil is of concern.

Waste automotive lubricants are the drained crankcase oils, transmission fluids, differential gear lubricants, hydraulic oils from automotive and construction equipment, and small quantities of solvents frequently used in servicing automobile equipment. Table 36 lists the synthetic organic additives containing sulfur, nitrogen, oxygen, and different metals that are used to reduce wear, resist oxidation, and inhibit corrosion, and that function as detergents, bactericides, and anhistalic agents. The organic portion of these additives is considered to be susceptible to losses due to combustion and reactions; however, the inorganics concentrate in the waste crankcase oil. The evaporative or volatile components are generally water and fuel. The soluble materials in the waste oil include viscosity index improvers and detergents, while insoluble materials include submicron sized carbon particles, dust, metal particles, and metal oxides, particularly lead oxides originating during fuel combustion. The metal content includes lead, calcium, zinc, phosphorus, barium, iron, vanadium, aluminum, copper, silicon, tin, sodium, and magnesium. Used automotive lubricating oils may also contain appreciable amounts of gasoline introduced through blow-by. Aluminum, copper, iron, lead, silicon, and tin are introduced by means of wear, combustion, and/or corrosion. Sodium, barium, calcium, zinc, and magnesium are added to lubricating oils by the oil manufacturer to impart specific properties to the oll. Use of catalytic converters and unleaded gasoline mandated by the Clean Air Act. Amendments of 1970 reduce the lead and phosphorus content of waste lubricating oils.

It has been stated that virgin lubricating oil contains polynuclear aromatics which have been determined to be carcirogenic. Used oils show a higher percentage of such constituents than virgin oils (U.S. Environmental Protection Agenry 1974). Used motor oils contain 13 percent monoaromatics, 3.52 percent diaromatics, and 62 percent polyaromatics (Whisman et al. 1975). Nitrosamines may also be found in used motor oils since both nitrogen and amine compounds are found in motor oils (Fin and Fan 1976).

The industrial lubricating ofls used in metal industries are heavily contaminated with oxidized lubricating materials, sediment, 
TABLE 36

COMPOSITION OF SOME LUBRICATING OIL ADDITIVES

\begin{tabular}{|c|c|c|}
\hline Additive & Composition & Function \\
\hline $\begin{array}{l}\text { Corrosion } \\
\text { inhibitor }\end{array}$ & $\begin{array}{l}\mathrm{Zn} \text { and } \mathrm{Ba} \text { dithiophosphates, } \\
\text { dithiocarbamates, metal } \\
\text { sulfonates and sulfurized } \\
\text { terpenes }\end{array}$ & $\begin{array}{l}\text { To react with metal } \\
\text { surfaces to form a } \\
\text { corrosion-resistant } \\
\text { film }\end{array}$ \\
\hline $\begin{array}{l}\text { Rust } \\
\text { inhlbitor }\end{array}$ & $\begin{array}{l}\text { Sulfonates, alkylamines, } \\
\text { amine phosphates, alkenyl- } \\
\text { succinic acids, fatty } \\
\text { acids, and acid phos- } \\
\text { phate esters }\end{array}$ & $\begin{array}{l}\text { To react chemically } \\
\text { with steel surfaces } \\
\text { to form an imper- } \\
\text { vious film }\end{array}$ \\
\hline Antioxidant & $\begin{array}{l}\text { Sulfides, phosphites, } \\
\text { amines, phenols, di- } \\
\text { thiophosphates }\end{array}$ & $\begin{array}{l}\text { To inhibit oxidation } \\
\text { of oil }\end{array}$ \\
\hline Detergent & $\begin{array}{l}\text { Sulfonates, phosphonates, } \\
\text { phenates, alkyl substi- } \\
\text { tuted salicylates com- } \\
\text { bined with barium, } \\
\text { magnesium, zinc, and } \\
\text { calcium }\end{array}$ & $\begin{array}{l}\text { To neutralize acids } \\
\text { in crankcase oils } \\
\text { to form compounds } \\
\text { suspended in oil }\end{array}$ \\
\hline Dispersant & $\begin{array}{l}\text { Alkenyl sucinimides, } \\
\text { alkylacrylic polymers, } \\
\text { ashless compounds }\end{array}$ & $\begin{array}{l}\text { To disperse contam- } \\
\text { inants in the } \\
\text { lubricant }\end{array}$ \\
\hline $\begin{array}{l}\text { Metal } \\
\text { deactivator }\end{array}$ & $\begin{array}{l}\text { Organic dihydroxphosphines, } \\
\text { phosphates, and sulfur } \\
\text { compounds }\end{array}$ & $\begin{array}{l}\text { To form protective } \\
\text { film on running } \\
\text { surfaces to inhibit } \\
\text { reaction }\end{array}$ \\
\hline $\begin{array}{l}\text { Color } \\
\text { stabilizer }\end{array}$ & Amine compounds & $\begin{array}{l}\text { To stabilize oil } \\
\text { color }\end{array}$ \\
\hline $\begin{array}{l}\text { Viscosity } \\
\text { index } \\
\text { improver }\end{array}$ & $\begin{array}{l}\text { Isobutylene polymers and } \\
\text { acrylate copolymers }\end{array}$ & $\begin{array}{l}\text { T'o retard loss of vis- } \\
\text { cosity at high } \\
\text { cemperatures }\end{array}$ \\
\hline $\begin{array}{l}\text { Pour point } \\
\text { depressant }\end{array}$ & $\begin{array}{l}\text { Polymethacrylates, poly- } \\
\text { acrylamides, alkylated } \\
\text { naphthalenes, and } \\
\text { phenol.s }\end{array}$ & $\begin{array}{l}\text { To prevent congealing } \\
\text { of oil at low tem- } \\
\text { peratures }\end{array}$ \\
\hline
\end{tabular}


TABLE 36 (Concluded)

\begin{tabular}{|c|c|c|}
\hline Additive & Composition & Function \\
\hline $\begin{array}{l}\text { Extreme } \\
\text { pressure } \\
\text { additive }\end{array}$ & $\begin{array}{l}\text { Organic'compounds with sul- } \\
\text { fur, phosphorus, nitrogen, } \\
\text { halogens, carboxyl or } \\
\text { carboxalate salt }\end{array}$ & $\begin{array}{l}\text { To form low-shear } \\
\text { strength film pro- } \\
\text { viding lubrication } \\
\text { at start-up and at } \\
\text { high bearing loads }\end{array}$ \\
\hline Antiodorant & $\begin{array}{l}\text { Perfumes, formaldehyde } \\
\text { compounds }\end{array}$ & To mask odors \\
\hline Antiseptic & $\begin{array}{l}\text { Alcohols, phenols, chlorine } \\
\text { compounds }\end{array}$ & $\begin{array}{l}\text { To inhibit micro- } \\
\text { organisms }\end{array}$ \\
\hline $\begin{array}{l}\text { Antiwear } \\
\text { additive }\end{array}$ & $\begin{array}{l}\text { Chlorinated waxes, organic } \\
\text { phosphates, lead } \\
\text { naphthenate }\end{array}$ & $\begin{array}{l}\text { To form low-shear } \\
\text { strengh film pro- } \\
\text { viding lubrication }\end{array}$ \\
\hline $\begin{array}{l}\text { Tackiness } \\
\text { agent }\end{array}$ & $\begin{array}{l}\text { Polyacrylates and poly- } \\
\text { butenes }\end{array}$ & $\begin{array}{l}\text { To improve adhesive } \\
\text { qualities of base } \\
\text { oil }\end{array}$ \\
\hline Emulșifier & $\begin{array}{l}\text { Surfactants, sulfonates, } \\
\text { naphthenates and fatty } \\
\text { acid soaps }\end{array}$ & $\begin{array}{l}\text { To reduce interfacial } \\
\text { tension and permit } \\
\text { formation of water- } \\
\text { oil emulsion }\end{array}$ \\
\hline
\end{tabular}

Sources: Swain 1977; Skinner 1976. 
polychlorinated heat transfer and transformer oils, and finely divided, hard-to-filter particles. Other industrial waste oils consist of spent turbine oil, spent transformer oil, mixtures of aviation jet fuel and lubricants, gear box olls from industrial rotary machinery, heat transfer fluids, and railroad lubricants. There are indications that high levels of nitrosamines are present in metalworking fluids (Fin and Fan 1976). Waste metalworking oils may contain substantial amounts of iron, aluminum, copper, $t i n$, and chromium, as well as fatty oils, soaps and emulsifiers, corrosion and rust inhibitors, sulfur, chlorine, and phosphorus compounds (Swain 1977).

The composition of waste ofls from rallroad service centers is similar to that reported for automotive waste ofls, except that lead content is negligible and the flash point may average on the higher side.

Aviation service center waste oll includes jet fuel drain from aircraft, alrcraft sumping, loading facility spills, draining of petroleum based engine and transmission lubricants, synthetic lubricants from the aircraft exterior, and ground support equipment washing and deicing fluids (e.g., ethyl glycol). A significant quantity of waste oils and other compounds appear in aircraft wastewater and storm water sewers. Also included among waste olls are paint strippers, solvents, degreasers, washdown waters, and plating wastes.

\section{Control of Emissions}

Atmospheric emissions of nitrogen oxides, carbon monoxide, sulfur oxides, hydrocarbons, and particulate matter from stationary and mobile source combustion are effectively controlled or reduced with the proper use of engineering controls that are elther retrofitted or built into the combustion process equipment. These control measures are identified in the discussion below.

\section{3tationary Source}

Reduction of air polluting emissions by process, operational, and system control is not only an important adjunct to air and gas cleaning technology and to atmospheric dispersion, but it also is a definitive response to the concept of zero emissions when it can be employed for total control. In general, filtration, electrostatic precipitation, scrubbing, mist elimination, and adsorption are some of the techniques used to control hazardous emissions.

The quantity of sulfur oxides emitted depends on the amount of sulfur present in oll and natural gas that is burned. $\mathrm{SO}_{\mathrm{x}}$ emissions generally are low and are significantly less when compared with 
those from coal-fired bollers. Raw natural gas may contain a significant quantity of hydrogen sulfide, but it is generally removed from the gas before distribution and widespread utilization. Thus, the combustion of natural gas emits only low levels of sulfur oxides.

About 90 to 95 percent of nitrogen oxides are emitted as nitric oxide and the remainder is nitrogen dioxide. Carbon monoxide and gaseous hydrocarbons are emitted as a result of incomplete combustion of the oil and gas. In properly designed and operated units, the quantities of carbon monoxide are less than $100 \mathrm{ppm}$ for gas-fired furnaces and $20 \mathrm{ppm}$ for oll-fired furnaces. However, in poorly designed and operated systems, emissions may be increased by 10 or 100 times (Engdahl and Barrett 1977). Table 37 summarizes the different control measures used to reduce atmospheric emissions from stationary source combustion of ofl and gas. In California these techniques have reduced $\mathrm{NO}_{\mathrm{x}}$ emissions from utility boilers sufficiently to meet emissions standards of $160 \mathrm{ppm}$ for gas-fired and 250 ppm for oil-fired utility boilers.

\section{Mobile Source}

Automobile emissions control, achieved through changes in equipment design or legal constraints, is a compromise involving the superposition of emissions regulations upon an engine that was deve1oped over a period of 60 years with practically no consideration of the composition of the exhaust. Pre-1977 engine design objectives of low cost, high power-to-weight ratio, high power-to-size ratio, good durability, low maintenance, high reliability, and low fuel consumption have put constraints on the additional design objectives of reducing pollutant emissions. Table 37 also summarizes various means and control techniques used to reduce emissions from mobile sources.

The retrofit of emissions controls on in-use vehicles has been successfully accomplished, most notably in California, a state that required installation of retrofit emission controls on 1955 through 1970 model vehicles upon change of ownership. These devices were intended to control exhaust hydrocarbons and nitrogen oxides. Carbon monoxide emissions also were controlled by retrofit devices for 1966 to 1970 models. The U.S. Environmental Protection Agency has specified various retrofit strategies to reduce vehicle pollution in localities with special problems. Installation of emission controls in new motor vehicles after they leave the as sembly line has been successful in special situations. This was accomplished, for example, with the Russian-built Lada vehicle when it was prepared for export to the U.S. and other countries (01son 1977).

Aircraft emissions can be controlled through engine modifications without degrading engine reliabllity or seriously reducing 
TABLE 37

EMISSION CONTROL TECHNIQUES

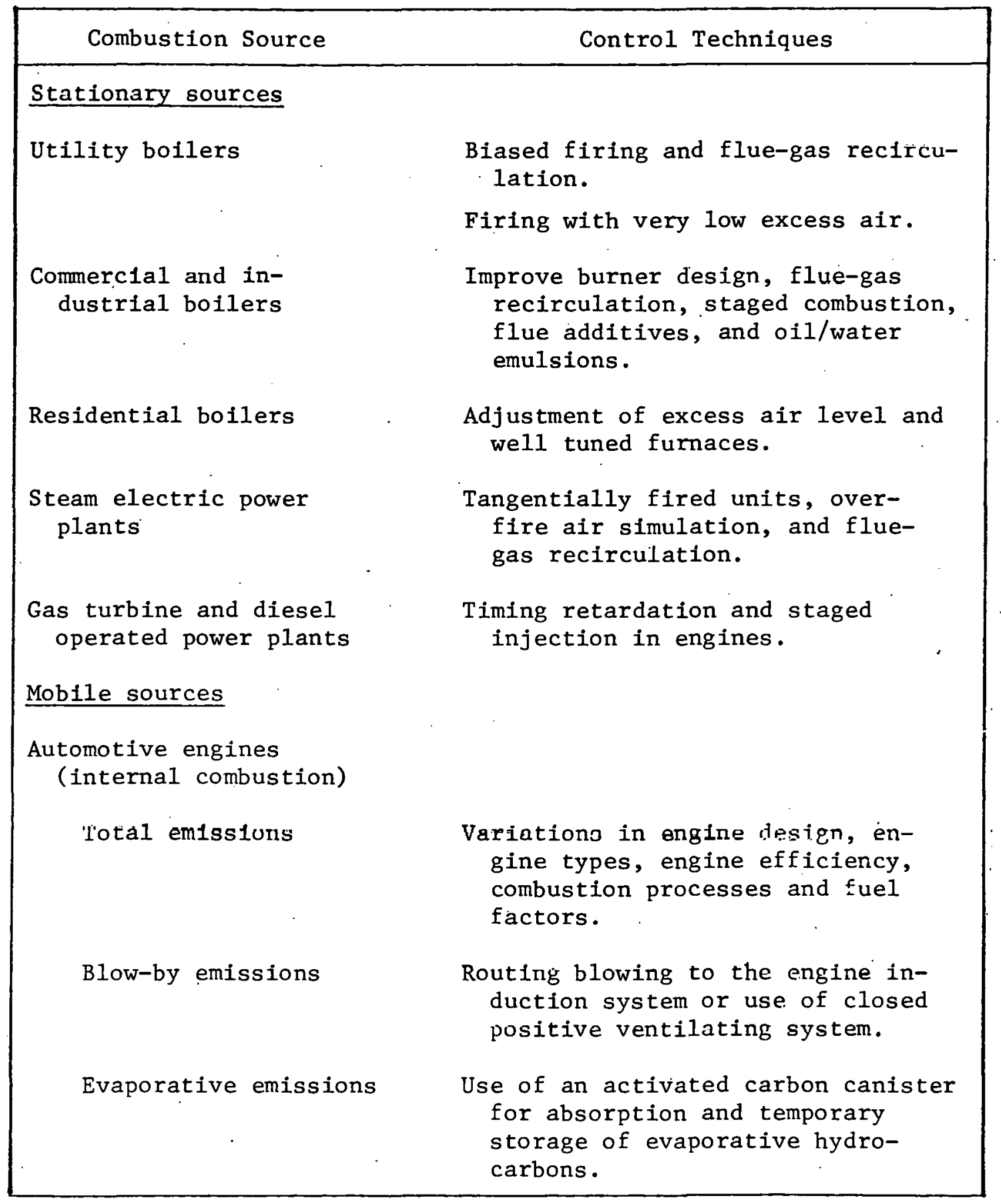


TABLE 37 (Continued)

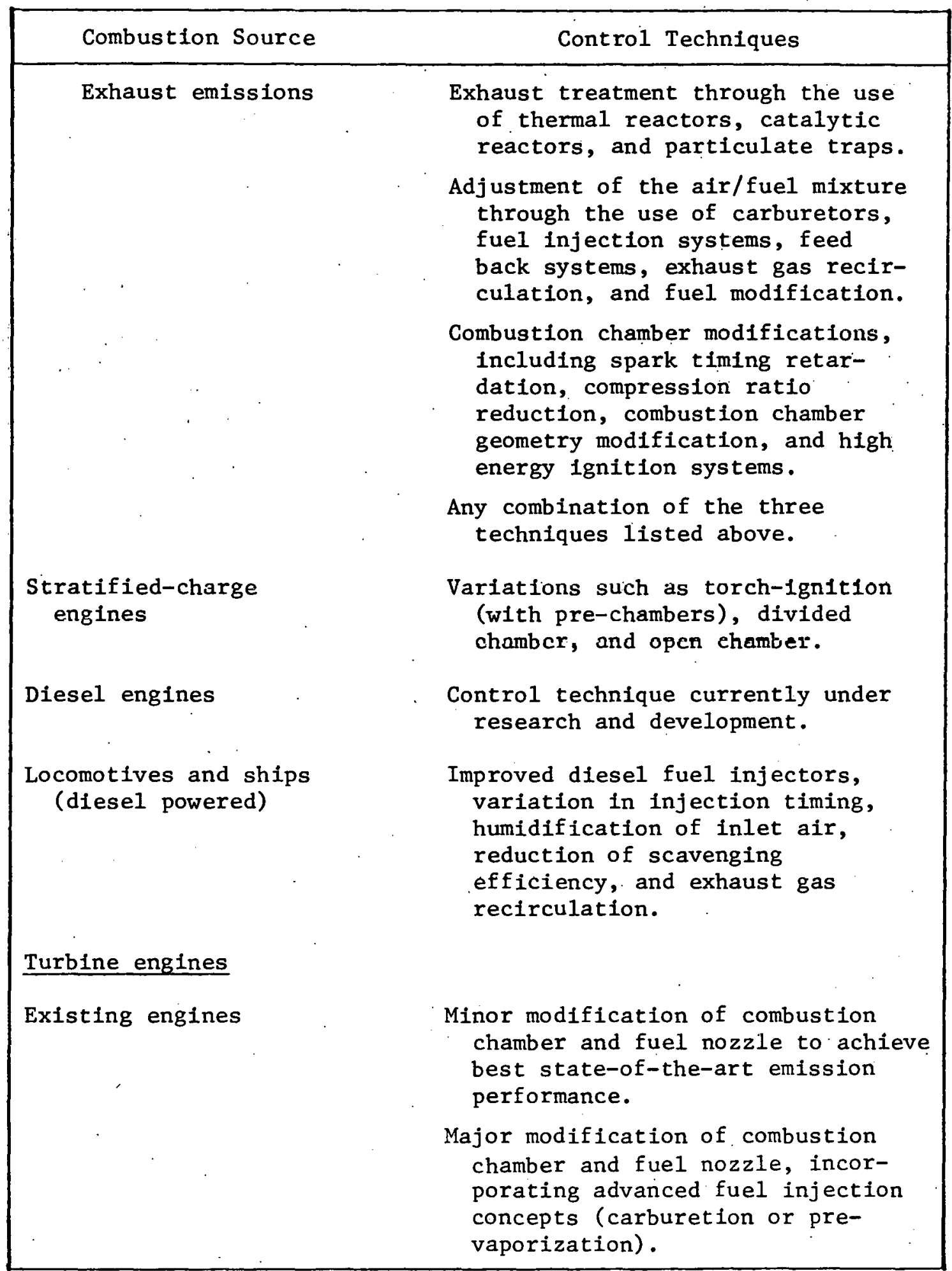


TABLE 37 (Continued)

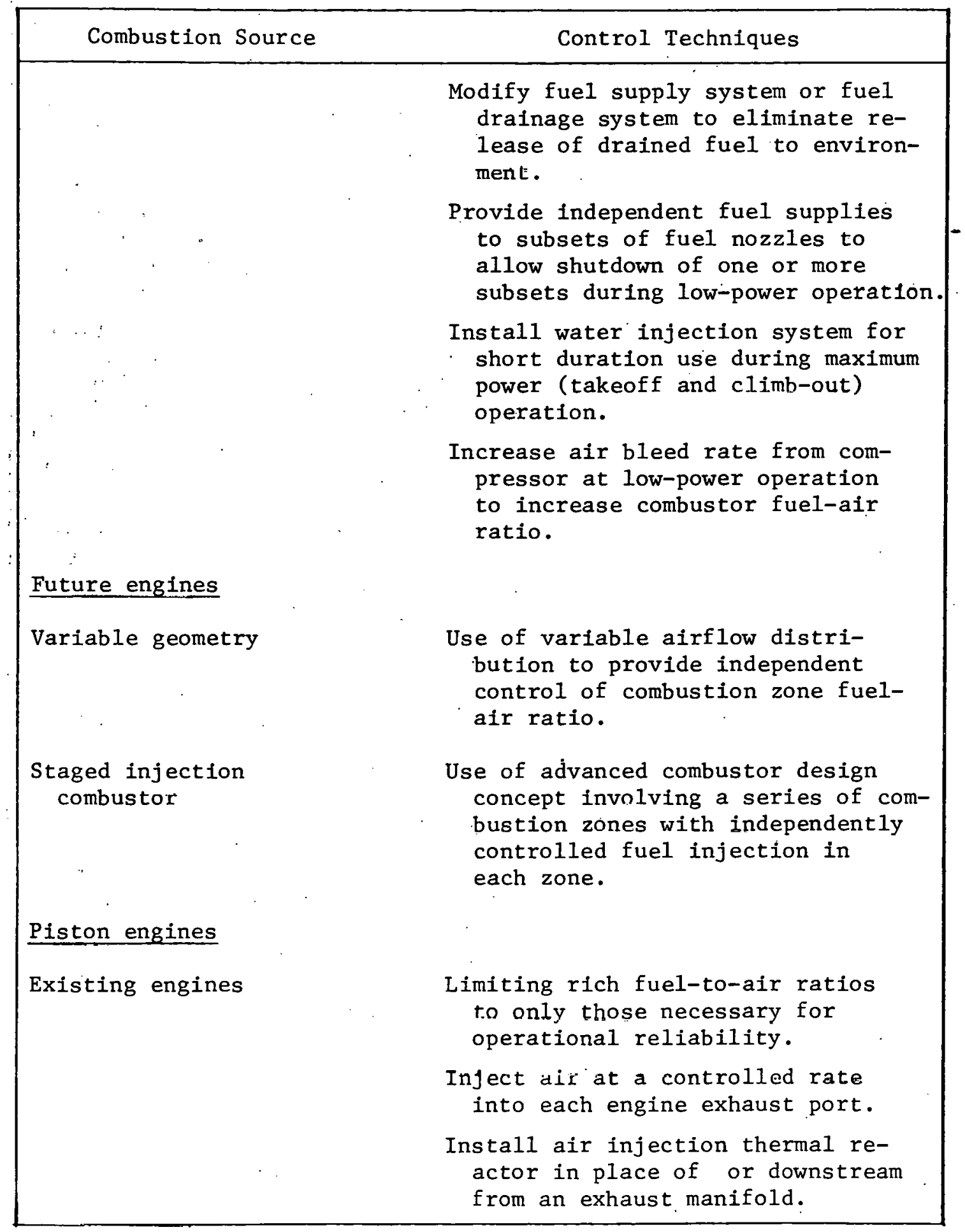


TABLE 37 (Concluded)

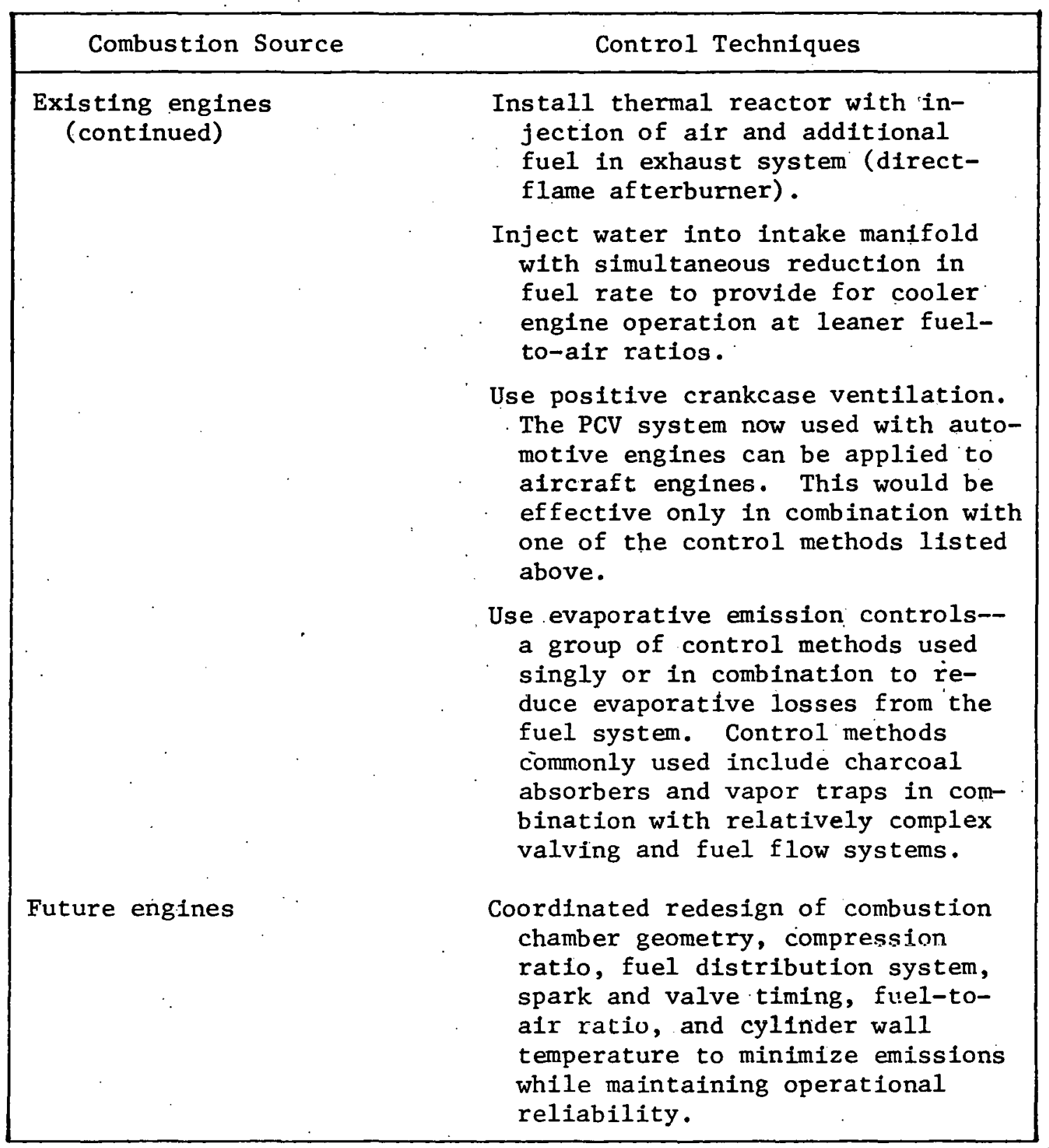

Source: Olson 1977. 
performance. These emissions modifications have been previously discussed (Olson 1977).

Control of carbon monoxide emissions and total hydrocarbons at carrier airports can be accomplished by modifying ground-operation procedures for turbine aircraft. The control methods include: increasing engine speed while reducing the number of engines operating during ldling and taxiling, reducing operating time by controlling departure times from gates, reducing taxiling time by transporting passengers to aircraft and by towing aircraft between runway and gate, and reducing operation of the alrcraft auxilliary power supply by providing a ground-based power supply. These control methods may be difficult to implement at busy general aviation alrports and international alrports such as the Kennedy Alrport in New York, 0'Hare Airport in Chicago, Orly Airport in Paris, and Heatherow in London.

\section{Oxidants}

Photochemical oxidants, called ozone, or PAHs, are rarely emitted directly by sources. Instead, they are secondary pollutants, so control can be achieved only by directing efforts toward controlling precursors, or primary pollutants that contribute to the formation of photochemical oxidants. These precursors are organic compounds, mainly hydrocarbons and nitrogen oxides, predominantly emitted from motor vehicles and stationary combustion sources. The ratio of hydrocarbons to $\mathrm{NO}_{x}$ is critical in order to achieve a substantlal reduction in the ozone level of $0.25 \mathrm{ppm}$ (a common nearmaximum for regions other than Los Angeles). Table 38 presents the results derived from an ozone 1sopleths* model used to calculate the non-methane hydrocarbon (NMHC) and/or $\mathrm{NO}_{\mathrm{x}}$ control requirements needed to reduce $0.25 \mathrm{ppm}$ ozone to $0.16,0.12$, or 0.08 as a function of the $\mathrm{NMHC}-\mathrm{to}-\mathrm{NO}_{\mathrm{x}}$ ratio. Based on this model, the conclusions derived by the Air Management group of the Organization for Econom1c Cooperation and Development (OECD) are 11 sted below (1979):

- Only when the $M M H C-t o-\mathrm{NO}_{x}$ ratio is below 10 is there an 80 percent reduction in hydrocarbon levels (predicted to reduce $0.25 \mathrm{ppm}$ ozone to less than $0.08 \mathrm{ppm}$ ). In all cases greater than 80 percent, control of nitrogen oxides emissions is required to meet this objective.

\footnotetext{
* The ozone isopleths model uses relationships among $\mathrm{sO}_{\mathrm{x}} ; \mathrm{HC}$, and $\mathrm{NO}_{x}$, derived from smog chamber data.
} 
TABLE 38

HYDROCARBON AND/OR NITROGEN OXIDE CONTROL REQUIREMENTS ${ }^{a}$

\begin{tabular}{|c|c|c|c|}
\hline $\begin{array}{c}\text { Reduce } 0.25 \text { ppm } \\
\text { Ozone to: }\end{array}$ & $\begin{array}{c}\text { Reduction of } \\
\text { NMHC } \\
\text { (percent) }\end{array}$ & $\begin{array}{c}\text { Reduction of } \\
\text { NO }_{\mathrm{x}} \\
\text { (percent) }\end{array}$ & $\begin{array}{l}\text { Reduction of } \\
\text { Both NMHC and } \mathrm{NO}_{\mathrm{x}} \\
\text { (percent) }\end{array}$ \\
\hline & $\mathrm{NMH}$ & $o_{x}=5$ & \\
\hline $\begin{array}{l}0.16 \\
0.12 \\
0.08\end{array}$ & $\begin{array}{l}43 \\
51 \\
66\end{array}$ & $\begin{array}{r}71 \\
88 \\
93\end{array}$ & $\begin{array}{l}\text { No advantage }{ }^{b} \\
\text { No advantage } \\
\text { No advantage }\end{array}$ \\
\hline & $\mathrm{NMH}$ & $o_{x}=10$ & \\
\hline $\begin{array}{l}0.16 \\
0.12 \\
0.08\end{array}$ & $\begin{array}{l}63 \\
69 \\
82\end{array}$ & $\begin{array}{r}63 \\
83 \\
89\end{array}$ & $\begin{array}{l}50 \text { each } \\
62 \text { each } \\
80 \text { each }\end{array}$ \\
\hline 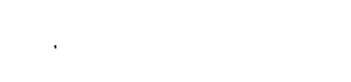 & NMH & $o_{x}=20$ & \\
\hline $\begin{array}{l}0.16 \\
0.12 \\
0.08\end{array}$ & $\begin{array}{l}73 \\
80 \\
90\end{array}$ & $\begin{array}{r}57 \\
79 \\
85\end{array}$ & $\begin{array}{l}49 \text { each } \\
67 \text { each } \\
81 \text { each }\end{array}$ \\
\hline . & NMHC & $0_{x}=30$ & \\
\hline $\begin{array}{l}0.16 \\
0.12 \\
0.08\end{array}$ & $\begin{array}{l}78 \\
84 \\
92\end{array}$ & $\begin{array}{l}54 \\
74 \\
82\end{array}$ & $\begin{array}{l}\text { Little advantage } \\
\text { Little advantage } \\
\text { Little advantage }\end{array}$ \\
\hline
\end{tabular}

${ }^{a}$ Control requirements to reduce $0.25 \mathrm{ppm}$ ozone to $0.16,0.12$, or 0.08 as a function to $\mathrm{NMHC}-$ to-NO$_{\mathrm{x}}$ ratio.

$b_{\text {No }}$ advantage over unilateral HC control

Little advantage over unilateral No control.

Source: Organization for Economic Cooperation and Development 1979. 
- Technical limitations, deterioration in performance of control devices; and accidental, fugitive, natural, and uncontrollable emissions of precursors are constraints that limit hydrocarbon reductions and make it almost impossible to reduce the $\mathrm{NO}_{x}$ level by the desired amount.

- It is advantageous to control both precursors and achieve ratios between 10 and 20 , particularly when less strict air quality goals are to be met.

Different control measures introduced to reduce emissions of hydrocarbons and nitrogen oxides from stationary and mobile sources were discussed earlier. Changes in emissions standards for $\mathrm{NO}_{x}$ and hydrocarbons caused reductions in the emissions of precursors of photochemical oxidants.

$\underline{\text { Lead }}$

Among the lead particles emitted from gasoline combustion, 40 to 75 percent are less than 1 um in diameter. Hence, these emissions are difficult to control with particulate control equipment.

Methods of control include reducing the lead level in gasoline from $1.7 \mathrm{gm}$ per gallon prior to 1979 to $0.5 \mathrm{gm}$ per gallon as of 0ct. 1, 1979, and using lead particulate traps. The first method is expected to reduce lead emissions associated with combustion by approximately 65 percent and the second by more than 90 percent. Lead emissions from waste oil disposal can be controlled by preheating before burning, blending with fuel oll, and/or reducing lead in gasoline. These methods will reduce lead emissions from waste oil and gasoline by 65 percent. Fugitlve lead emissions from boiler and furnace leaks can be controlled by proper maintenance of the equipment such as by sealing furnaces and ductwork.

lotal lead emisstons from automobiles are estimated to be reduced from 140,900 tons in 1975 to 49,500 tons in 1985, assuming a 2 percent annual increase in average consumption. The lead emissions from waste oll disposal are estimated to be reduced from 5,480 tons in 1975 to 2,300 in 1985 (U.S. Environmental Protection Agency 1977b). 
THIS PAGE

\section{WAS INTENTIONALLY \\ LEFT BLANK}

536 
HEALTH EFFECTS OF OIL AND GAS USE

In previous sections, emissions estimates and measurements from stationary and mobile source combustion were presented. Following . control, the magnitude of these emissions may be sizable and may pose a health hazard through chronic, low-level exposure. Table 39 shows the nationwide air pollution emissions by pollutant and source from. 1968 to. 1974. Table 40 summarizes the major alr pollutants and their principal health and environmental effects (Council on Environmental Quality 1975). These effects are discussed in this section along w1th research problems germane to the use of oll and gas.

Outdoor Air Pollution

A concern is the occasional discomfort and long-term alterations in physiological functions experienced by the general population and occupational groups as a result of exposure to levels of air pollutants elevated.above national ambient levels. In terms of emissions per unit of energy released, more inorganic substances ( $\mathrm{NO}_{\mathrm{x}}, \mathrm{SO}_{x}$, and $\mathrm{CO}$ ) are generated from coal, while more hydrocarbons are released from o11. Except for $\mathrm{NO}_{x}$, natural gas is relatively non-polluting when compared to coal and oil. The data below reflect the relative pollutant emission rates of electric power plants using coal, ofl, or natural gas as an energy source (Gartrell 1977).

\begin{tabular}{lccc}
\hline & \multicolumn{3}{c}{ Relative Emission Rates } \\
\cline { 2 - 4 } Pollutant & $\begin{array}{c}\text { Coal } \\
(1 \mathrm{bs} / \mathrm{Btu})\end{array}$ & $\begin{array}{c}\text { Oil } \\
(1 \mathrm{bs} / \mathrm{Btu})\end{array}$ & $\begin{array}{c}\text { Gas } \\
(1 \mathrm{bs} / \mathrm{Btu})\end{array}$ \\
\hline $\mathrm{NO}_{\mathrm{X}}$ & 0.80 & 0.69 & 0.37 \\
$\mathrm{SO}_{2}$ & $3.04^{\mathrm{a}}$ & $2.09^{\mathrm{a}}$ & 0.0004 \\
$\mathrm{SO}_{3}$ & $0.048^{\mathrm{a}}$ & $0.033^{\mathrm{a}}$ & $\mathrm{b}$ \\
$\mathrm{CO}$ & 0.02 & 0.0003 & $\mathrm{~b}$ \\
$\mathrm{HC}$ as methane & 0.008 & 0.021 & $\mathrm{~b}$ \\
Aldehyde as formaldehyde & 0.0002 & 0.004 & 0.0009 \\
Part1culate matter & 0.204 & 0.002 & 0.014 \\
\hline
\end{tabular}

assumes the use of coal with a 2 percent sulfur content. bata unavallable. 
TABLE 39

NATIONWIDE AIR POLLUTION EMISSIONS

BY POLLUTANT AND SOURCE

\begin{tabular}{|c|c|c|c|c|c|}
\hline \multirow{2}{*}{$\begin{array}{l}\text { Pollutants and } \\
\text { Sources }\end{array}$} & \multicolumn{5}{|c|}{ Emissions (millions of tons per year) } \\
\hline & 1968 & 1970 & 1972 & & 1974 \\
\hline \\
\hline $\begin{array}{l}\text { Transportation } \\
\text { Stationary combustion }\end{array}$ & 1.2 & 1.2 & 1.3 & & 1.3 \\
\hline sources $^{b}$ & 8.9 & 8.3 & 7.1 & & 5.9 \\
\hline others $c$ & 18.2 & 18.0 & 14.8 & & 12.3 \\
\hline Total & $\overline{28.3}$ & $\overline{27.5}$ & $\overline{23.2}$ & & $\overline{19.5}$ \\
\hline \multicolumn{6}{|l|}{ Sulfur oxide } \\
\hline Transportation & 0.8 & 0.7 & 0.7 & & 0.7 \\
\hline $\begin{array}{l}\text { Stattonary combustion } \\
\text { sources }\end{array}$ & & & & & 24.3 \\
\hline $\begin{array}{l}\text { sources } \\
\text { Others }\end{array}$ & $\begin{array}{r}24.4 \\
8.0\end{array}$ & $\begin{array}{r}21.0 \\
6.0\end{array}$ & $\begin{array}{r}23.2 \\
6.2\end{array}$ & & $\begin{array}{r}24.3 \\
6.3\end{array}$ \\
\hline Total & 33.0 & 34.3 & 32.6 & & 31.4 \\
\hline \multicolumn{6}{|l|}{ Carbon monoxide } \\
\hline Transportation & 63.8 & 82.3 & 83.4 & & 73.5 \\
\hline Stationary combustion & & & & & \\
\hline sources & 1.9 & 1.1 & 1.0 & & 0.9 \\
\hline Others & 34.4 & 23.9 & 20.5 & & 20.2 \\
\hline Total & $\overline{100.1}$ & $\overline{107.3}$ & $\overline{104.9}$ & & $\overline{94.6}$ \\
\hline \multicolumn{6}{|l|}{ Hydrocarbons } \\
\hline Transportation & 16.6 & 14.7 & 14.1 & & 12.8 \\
\hline \multicolumn{6}{|l|}{ Stationary combustion } \\
\hline sources & 0.7 & 1.6 & 1.7 & & 1.7 \\
\hline Others & 14.7 & 15.8 & 13.5 & $\checkmark$ & 15.9 \\
\hline Total & $\overline{32.0}$ & $\overline{32.1}$ & 31.3 & & 30.4 \\
\hline \multicolumn{6}{|l|}{ Nitrogen oxides } \\
\hline Transportation & 8.1 & 9.3 & 10.5 & & 10.7 \\
\hline \multicolumn{6}{|l|}{ Stationary combustion } \\
\hline Sources & 10.0 & 10.1 & 10.8 & & 11.0 \\
\hline $\begin{array}{l}\text { Others } \\
\text { Total }\end{array}$ & 2.5 & 1.0 & 0.9 & & 0.8 \\
\hline Total & 20.6 & 20.4 . & 22.2 & & 22.5 \\
\hline
\end{tabular}

ancludes automobiles, aircraft, railroads, vesseis, and nonhigiway motor fuel use.

${ }^{b}$ Includes coal, fuel oil, and natural gas.

${ }^{\mathrm{C}}$ Includes industrial processes and solid waste disposal.

Source: Adapted from Lof tness 1978. 
TABI.E 40

major atr pollutants and thelR PRINCtPal- efFects ${ }^{3}$

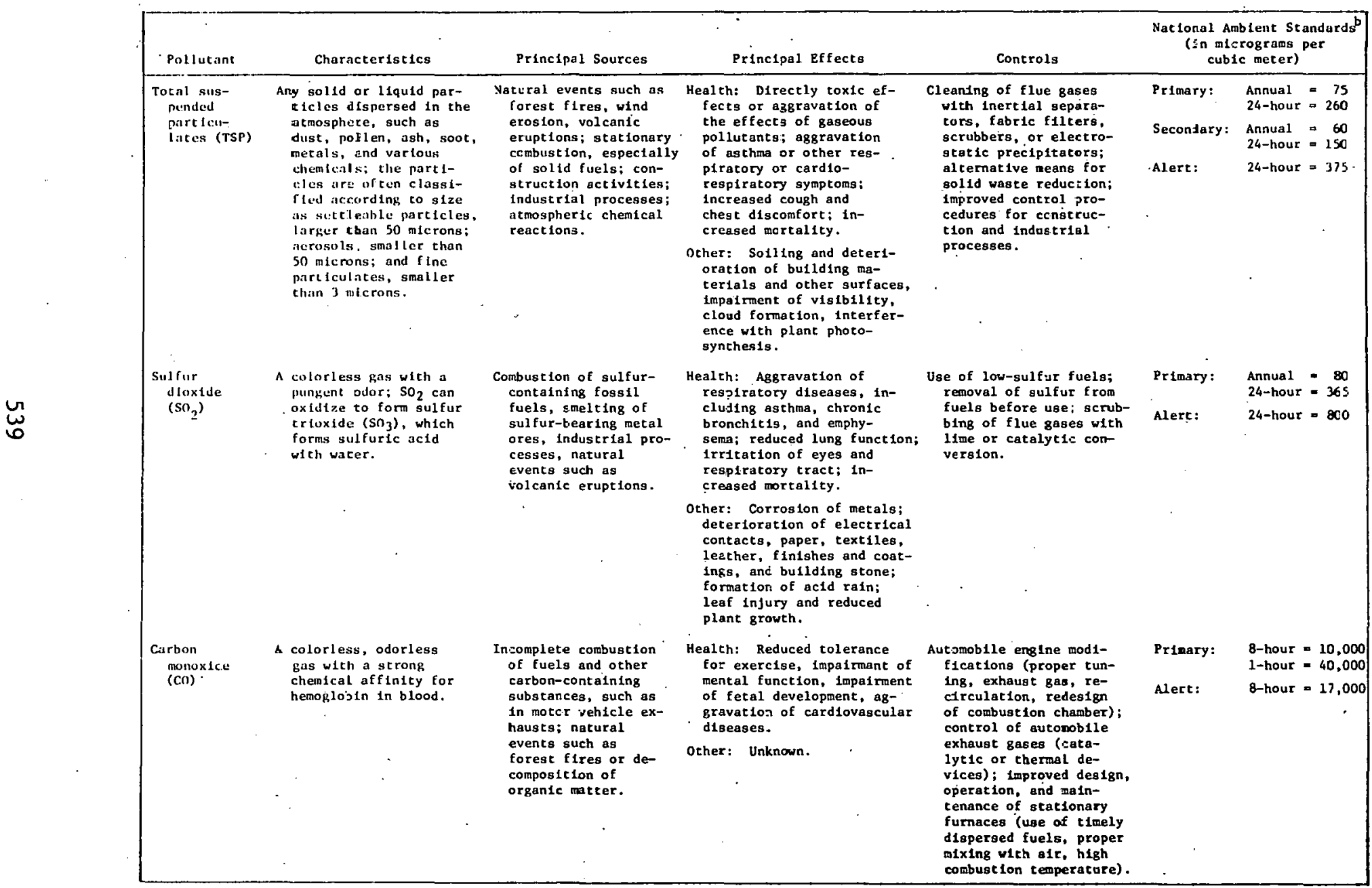


TABLE 40 (Concluded)

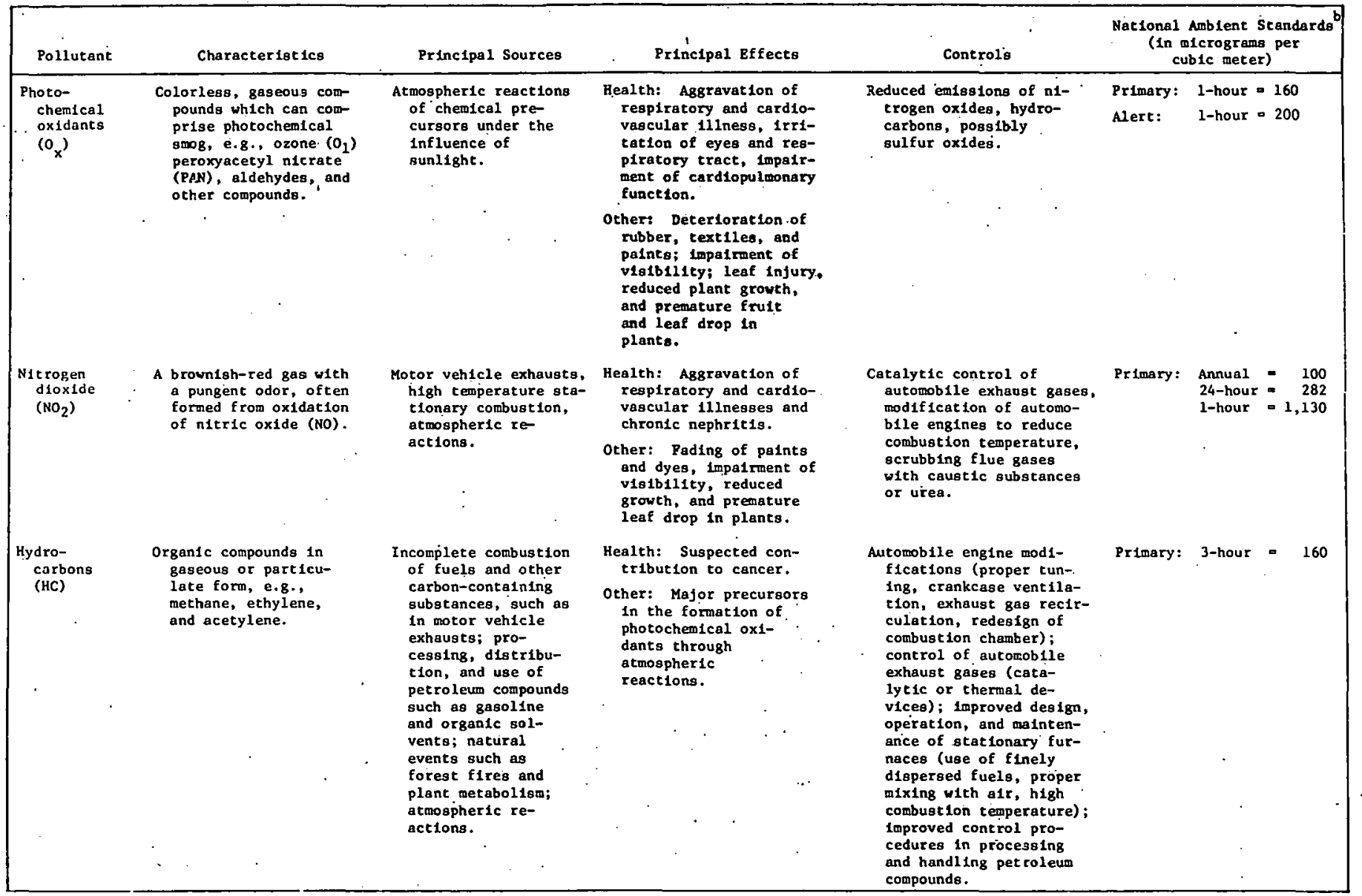

${ }^{a}$ Pollutants for which national amblent alr quality standards have been establisted.

bifmary standards are 1ntended to protect aga1nst adverse effects on human health. Secondary standards are intended to protect against adverse effects on materials, vegetation, and other environaental values. The federal episode criteria specify that reteorological conditions are such that pollutant withtn the next 24 hours unless control actions bre taken.

Source: Counc1l on Envfronmental Quality 1975. 
Projections of electricity generation for 1980 to 2000 suggest that coal use for power generation will increase from $1.1 \mathrm{kWh}$ per year in 1980 to $2 \mathrm{kWh}$ per year in 2000, while ofl and gas consumption for power generation will remain at $0.5 \mathrm{kWh}$ per year for oil and $0.3 \mathrm{kWh}$ per year for gas (Gartrell 1977). From past projections, $1 \mathrm{t}$ is evident that a much smalles quantity of pollutants such as sulfur dioxide, sulfur trioxide, and particulates will be generated from oll and gas than from coal. The data do not reflect the uncertainties associated with 1mplementation of the Energy Security Act of 1980, especially with respect to oll and gas in the form of synthetic fuels. The mobile source emissions of hydrocarbons, carbon monoxide, and nitrogen oxides contribute significantly to the nationwide alr pollutant emissions as seen in Table 39. Hydrocarbon emissions from transportation constitute about 40 to 45 percent of total hydrocarbon emissions, while nitrogen oxides from transportation account for 40 to 48 percent of total $\mathrm{NO}_{\mathrm{x}}$ emissions in the U.S. Carbon monoxide emissions from transportation comprised approximately 76 percent of the total Co emissions in the U.S. during the period reflected by the data.

The effects of these air pollutants on human health may include: acute sickness or death; Insidious or chronic disease, shortening of life, or Impairment of growth or development; alteration of important physiological functions (e.g., ventilation of the lung, transport of oxygen by hemoglobin, sensor acuity, time interval estimation, or other functions of the nervous system); Impairment of performance; sensory irritation such as discomfort, odor, and impalrment of visibility; and bioaccumulation of potentially hazardous materials in the body. In the following paragraphs particular health effects associated with major oil and gas pollutants such as nitrogen oxides; hydrocarbons, carbon monoxide, photochemical smog, and ozone are discussed.

\section{N1trogen Oxides}

The effects of nitrogen oxides on health have been extensively studied in experimental animals as well as in human clinical and epidemiological studies, and are reported in a Federal criteria document (National Institute for Occupational Safety and Health 1976). Comparative toxicity data taken from the document show a direct dose-response relationship: 


\begin{tabular}{|c|c|c|c|c|c|c|}
\hline Pollutant & & & Dosé & & & Effect \\
\hline $\mathrm{NO}_{2}$ & $\begin{array}{l}\vdots . \\
. .\end{array}$ & $\begin{array}{l}1,500 \\
1,200\end{array}$ & $\begin{array}{l}\text { ppm and } \\
\text { ppm }\end{array}$ & more & $\begin{array}{l}100 \% \\
100 \%\end{array}$ & $\begin{array}{l}\text { death } \\
\text { survival }\end{array}$ \\
\hline No. & . & 3,500 & ppm : & 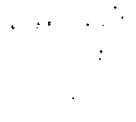 & $100 \%$ & $\begin{array}{l}\text { death in } 4 \text { to } 5 \\
\text { minutes }\end{array}$ \\
\hline $\begin{array}{lll}\cdots & \cdots \\
\cdots & & \\
\therefore & \cdots\end{array}$ & $\therefore$ & $\begin{array}{l}350 \\
320 \\
310\end{array}$ & $\begin{array}{l}\mathrm{ppm} \\
\mathrm{ppm} \\
\mathrm{ppm}\end{array}$ & 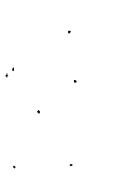 & $\begin{array}{r}100 \% \\
50 \% \\
10 \%\end{array}$ & $\begin{array}{l}\text { death } \\
\text { death } \\
\text { survival following } \\
\text { 8-hr exposure }\end{array}$ \\
\hline
\end{tabular}

It Is apparent that nitric oxide is approximately four times more toxic than nitrogen dioxide. Carcinogenic effects of nitrogen oxides are not conclusive and further work is needed. Evidence of mutagenesis by nitrogen dioxide or its derivatives in animal species has not been found in the literature. However, nitrous acid, which is one of the products of the reaction of nitrogen dioxide with water at normal temperatures, has been shown to have potent mutagenic effects on lower forms of life such as the tobacco mosaic virus and Escherichia col1.

The effects of nitrogen oxides on humans listed below are summarlzed in the criteria document (National Institute for Occupational Safety and Health 1976).

- Initial local irritation; reversible symptoms of breathlessness, cyanosis, vomiting, giddiness, stupefaction, delirium, fainting, cough, mild fever, and unconsciousness;

o. Milder respiratory and gastrointestinal symptoms;

- Shock-1ike illness such as instantaneous asphyxia, convulslons and respiratory arrest;

- Severe methemoglobinemia; and

- Acute and potentially lethal pulmonary edema and/or bronchilitis fibrosa obliterus.

Animal experiments and human studies suggest that the principal direct action of nitric oxide upon humans is the conversion of hemoglobin to methemoglobin (one of the inactive forms of hemoglobin). Nitric oxide poisoning effects are solely due to the hypoxemia which 
is secondary to the methemoglobinemia. No quantitative exposure effect relationship can be made for nitric oxide due to the lack of any measured environmental data on human exposure. Animal studies show a dose-response relationship.

The acute and usually delayed effects of high concentrations of nitrogen dioxide on man are well established. These include an irritant cough, a slight headache, and mild dyspnea before the onset of acute and potentlally lethal pulmonary edema. The critical concentration of $\mathrm{NO}_{2}$ needed to produce acute pulmonary edema or bronchilitis. fibrosa obliteraus is not known. These conditions have even been reported for low, but relatively steady levels of exposure assoclated with the few industrial processes in which oxides of nitrogen are steadily generated and continuously permitted to enter the workplace atmosphere.

Generally, subacute and chronic responses to low levels of nitrogen dioxide are not well defined for humans. Research has not definftely established that methemoglobinemia occurs in man from exposure to $\mathrm{NO}_{2}$. Acute effects of low levels of $\mathrm{NO}_{2}$ in man include a decrease in effective lung compliance, alteration of pulmonary mechanics, and increased airway resistance in chronic bronchitis patients. It is not known whether any or all of these effects are completely reversible following repeated intermittent exposures over an extended period. There has been much speculation as to whether chronic low-level exposure to $\mathrm{NO}_{2}$, among other irritant gaseous air pollutants, may be a contributory cause of chronic obstructive pulmonary disease in man. A variety of other effects of nitrogen dioxide exposures, including changes in puimonary physiology, biochemical changes in the lung, pulmonary surfactant, enzymetric changes in remote organs, changes in macrophage populations and behavior, and immunological changes, have been observed.

Determining whether nitrogen oxides are carcinogenic or mutagenic will require new data. The possibility exists that nitrugen dioxide may act as a co-carcinogen or carcinogenic "promoter;" however, data are insufficient.

Nitrosamines. Oxides of nitrogen have the intrinsic chemical property of reacting with primary and secondary amines present in the body tissues, food, tobacco, water, and in workplace air to form nitrosamines. Effects of nitrosamine exposure in experimental animals are listed below (National Institute for Occupational Safety. and Health 1976). 
Inhalation

Inhalation of relatively high concentrations for a short period
Acutely toxic; polydypsia; loss of appetite; ascites hyperactive liver necrosis; leukopenia; and disruption of normal blood coagulation; hemorrhage into the walls of the gastrointestinal tract, the abdominal cavity, and other tissues.

Liver damage; severe hematologic changes; and carcinoma of the nasal cavity, trachea, and lungs.

No animal data or human epidemiological data have been found indicating chronic effects of long-term exposure to airborne secondary nitrosamines. Further research is needed to establish the potential hazards of nitrosamines for humans.

Occupational Exposure. Under normal, well-maintained conditions, utility, industrial, commercial, and residential boilers and furnaces are unlikely to cause workers and residents to be exposed to nitrogen oxides emissions. Exposure to nitrogen oxides fumes is possible only during accidental leaks, explosions, bursts, and process upsets. Sufficient general ventilation in boiler rooms reduces the impact of such hazards.

Control of nitrogen oxides from indoor vehicular operation is usually dependent upon providing sufficient ventilation. Where work is performed on stationary vehicles (as in repair garages), the room's exhaust system should be attached to or located close to the vehicle tailpipes. This would limit exposure not only to nitrogen dioxide, but also to other contaminants, particularly carbon monox1de. Similar control measures can be applied to gas and diesel engines operated in enclosed areas such as mines and tunnels.

Ambient Exposure. The current Federal standard* for nitrogen dioxtde is $5 \mathrm{ppm}$ as an 8-hour time weighted average (TWA) and the one

* St andard for nitrogen dioxide and nitric oxide established as announcement 29CFR1910.1000 published in the Federal Register 39: 23542, June 27, 1974 . 
for nitric oxide is $25 \mathrm{ppm}$ as an 8-hour TWA. Following a 1976 review of current regulations, scientists concluded that the Federal standard of $5 \mathrm{ppm}$ should be reduced to a celling of $1 \mathrm{ppm}$ to prevent acute irritation of the lungs of workers exposed to $\mathrm{NO}_{2}$ (National Institute for Occupational Safety and Health 1976). They also recommended that, in the absence of conclusive data, the current Federal standard of $25 \mathrm{ppm}$ as an 8-hour TWA should be continued för up to 10 hours per day and 40 hours per week to protect workers from exposure to nitric oxide. Future research may determine the nitric oxide concentrations that impair resplratory or other biological functions so a secondary standard may be promulgated.

Many workers are exposed to nitrogen oxides at ambient air concentrations or at concentrations considerably below recommended occupational limits. However, concern for worker health requires that protective measures be instituted below the enforceable limits to ensure that exposures do not exceed standards. Thus, a working definition of occupational exposure to nitrogen oxides 18: "exposuxe above half the environmental limits, thereby delineating those work situations which do not require the installation of unnecessary controls and the expenditure of health resources for provisions such as environmental and medical monitoring and associated recordkeeping" (National Institute for Occupational Safety and Health 1976).

\section{Hydrocarbons}

Evaporative hydrocarbons contribute to photochemical oxidant formation in the atmosphere, indirectly affecting human health, and also act as irritants or simple asphyxiants. The largest constituents of particulate hydrocarbons are polynuclear aromatic hydrocarbons, and exposure to these results in respiratory tract diseases including cancer. Diesel exhaust emissions, which contain hydrocarbons, are considered below in a special section. The prospect that passenger cars equipped with diesel engines will soon represent a significant portion of new car production raises an important question concerning their possible impact on human health.

Volatile Hydrocarbons. Volatile hydrocarbons emitted from various sources and those identified in ambient air are 1 is ted in Table 41. Evaporative hydrocarbons include allphatic, alicyclic, and aromatic compounds. Based on data available prior to 1970 when the Alr Quality Criteria for Hydrocarbons was published, it was concluded that no obvious health effects directly relate to ambient concentrations of gaseous or volatile hydrocarbons as a pollutant class (U.S. Department of Health, Education, and Welfare 1970). This document was instrumental in developing a nonmethane hydrocarbon air quality standard of $160 \mathrm{ug}$ per m $\mathrm{m}^{3}(0.24 \mathrm{ppm})$ over 3 hours that is not to be exceeded more than once per year. 
TABLE 41

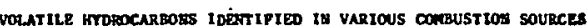

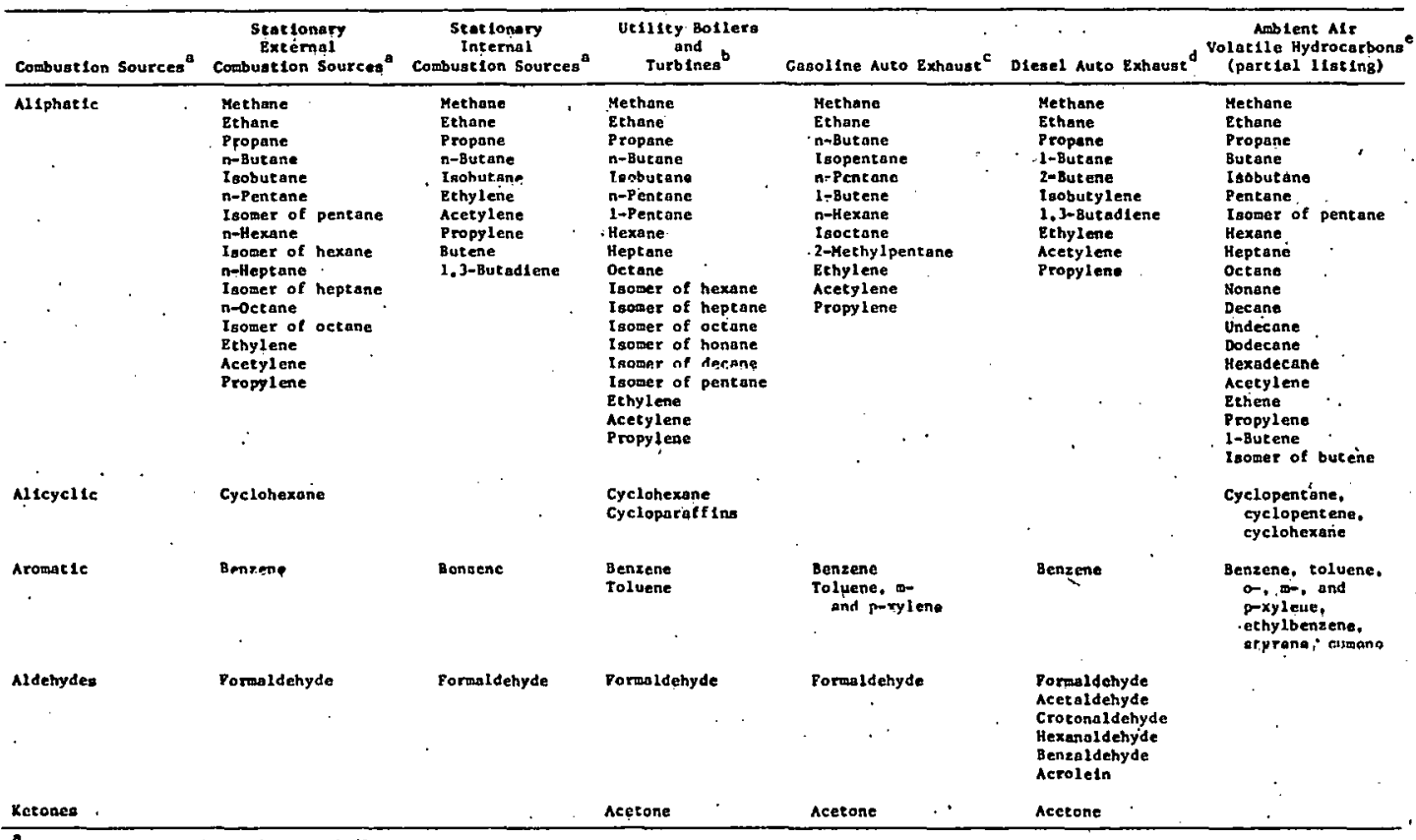

"Soureal Bucon et at. 2970: EPA=450/3-78-119.

bourcet Taback et al. 1978.

Source: National Academy of Sciences 1976b.

SSourcé: Braddock and Gabele 1977.

Source: Craedel 1978. 
Since promulgation of the hydrocarbon standards in 1971, the effects of hydrocarbons on public health have been extensively studied. A review by the author of the literature since 1970 indicates that evaporative hydrocarbons do not present a significant health hazard in the atmosphere at the average nationwide levels. Higher levels near refineries, petrochemical facilities, and storage and handling facilities may represent local health hazards. All of these hydrocarbons should be controlled or restricted to minimize their contribution to photochemical oxidants, namely smog, ozone, and peroxysoyl nitrates.

Toxicological and clinical studies on aliphatic (saturated and unsaturated), alicyclic, and aromatic hydrocarbons that provide the basis for assessing health ef fects are well summarized elsewhere (Gerarde 1963a, b, c). Aliphatic hydrocarbons are toxicologically Inactive at concentrations many times above those generally found in the atmosphere. No obvious effects are observed at levels below 500 ppm for the alkanes and 1,000 ppm for the alkenes. These aliphatic hydrocarbons, when present in high concentrations in the air, act as simple asphyxiants without other significant physiological effects. Any systemlc effects that may be observed are thought to be secondary due to the oxygen-replacing capabilities of these gaseous and/or vapor phase hydrocarbons at extremely high concentrations. Generally, alkanes. as a group show Increasingly strong narcotic properties.

Exposure to only one alkane is infrequent, so the National Institute for Occupational Safety and Health (NIOSH) (1977) has recommended a TWA concentration level of $350 \mathrm{mg}$ per $\mathrm{m}^{3}$ as the occupational limtt for pentane, hexane, laptane, octane, and alkane mixtures. This recommended standard is based on the conclusion that acute intoxication by these alkanes involves a transient central nervous system depression and that chronic intoxication may involve a more persistent effect, polyneuropathy. No strong evidence suggests that any volatile aliphatic hydrocarbon has carcinogenic, mutagenic, or teratogenic effects on humans or experimental animals. On the basis of limited bloassay data, alkanes and alkenes are not considered to be carcinogens.

Like aliphatics, allcyclic hydrocarbons act as general anesthetics and central nervous system depressants. They are generally biochemically inert and are only reactive at concentrations 100 to 1,000 times higher than average levels found in the atmosphere. Allcyclic hydrocarbons (naphthenes), which are present in relatively low concentrations in modern gasoline and gasoline vapors, have not been indicated as hematopoietic toxicants. These compounds are rapidly metabolized and eliminated in the urine, thus eliminating the 
chance of increased body burden upon repeated exposure to low atmospheric concentrations. No occupational or epidemiological evidence is available which indicates that naphthenes have any systemic effect. Naphthene vapors at very high concentrations cause irritation of mucous membranes. No avallable studies indicate a definite human carcinogenic, mutagenic, or teratogenic potential of any alicyclic hydrocarbon.

The primary route of exposure to the levels and kinds of aromatic hydrocarbons that are biochemically and biologically active is by vapor inhalation. Systemic injury can result from the inhalation of aromatic hydrocarbon vapors above a concentration of $22 \mathrm{ppm}$. Acute poisoning by high concentrations of benzene, toluene, and xylene can produce effects on the central nervous system that are usually reversible. The symptoms of acute narcosis include drowsiness, vertigo, nausea, unconsciousness, and death.

The health effects of benzene have been extensively studied. Benzene exposure by inhalation and other routes is strongly implicated in leukemia, pancytonia, and chromosomal aberrations. The more severe long-term hazard is to the hematopoletic system and affected blood parameters include erythrocyte count, hemoglobin, mean corpuscular volume of red blood cells, platelet counts, and leukocyte counts. The carcinogenic potential of benzene has been suggested primarily through the experience of human occupational exposure. In recognition of accumulated clinical and epidemiological ovidence that benzene causes leukemia and probably other severe illnesses, a much more stringent standard for occupational exposure to benzene has been recommended. The proposed occupational standard, setting a maximum of $1 \mathrm{ppm}$ benzene for 60 minutes, was expected to materially reduce the risk of benzene-induced leukemia from that incurred at the present acceptable ceiling of $25 \mathrm{ppm}$. Recently, however, the U.S. Supreme Court blocked enforcement of the lower benzene exposure 1imit.

Other aromatic hydrocarbons such as toluene and xylene are considered to be less toxic and volatile than benzene. Organ-spectfic effects due to toluene exposure involve organs other than hematopoietic systems--the nervous system, liver, kidney, heart, mucous membrane, immune system, and the skin. The reported effects for some of these organs are inconsistent and need further verification. A recommended Federal standard for occupational exposure to toluene is determined as 100 ppm TWA for an 8-hour day, with a celling concentration of $200 \mathrm{ppm}$ (National Institute for Occupational Safety and Health 1973). The only well documented effects that a xylene standard should protect against are the irritating and narcotizing properties of xylene. Recently, xylenes have been shown to produce necrosis of living tissues in experimental animals exposed to high 
concentrations. There are few data available from actual occupational or environmental exposures to xylenes that warrant their consideration as important environmental health hazards for the general public. The.NIOSH xylene standard is $100 \mathrm{ppm}$ as a TWA for up to a 10-hour workday and 40-hour workweek, with a ceiling concentration of 200 ppm (National Institute for Occupational Safety and Health 1975). For additional information on the health effects of volatile hydrocarbons, the reader is referred to the Refinery Operations section of this report.

Nonvolatile Hydrocarbons. The aliphatic nonvolatile hydrocarbons are generally considered to be biologically inactive, but there are indications that parafins from decane to hexdecane may influence the tumorigenicity of carcinogenic hydrocarbons on epithelial tissues. The $C_{10}$ through $C_{16}$ alkanes applied in high concentrations increase the activity of carcinogenic polycyclic aromatic hydrocarbons (PAHs) and may act as weak tumor promoters. On the other hand, alkanes with $\mathrm{C}_{30}$ may inhibit the carcinogenicity of PAHs.

The nonvolatile olefins, following photodecomposition in the atmosphere, produce epoxides and peroxides thar are suspected carcinogens, co-carcinogens, tumor-promoters or both. These decomposition products were shown to be tumorigenic in experimental animals following skin painting and subcutaneous injection. The epoxides; which are oxygenated components of nonvolatile olefins, are known to be clliatoxic and are shown to inhibit the lung clearance mechanism in experimental animals. The exact chemical composition of these nonvolatile olefins is not known and further research is needed. Extensive studies have been carried out on the carcinogentc activity of many epoxides (mono-, di-, and poly-), b-lactones, hydroperoxides, and peroxides in a variety of test systems. These systems include skin application in mice, subcutaneous injection in mice and rats, and intragastric intubation in rats (Van Duuren 1969). Further research is needed to better understand the mode of action of these hydrocarbons. Additional information on these substances may be found in the section of this report concerning refinery operations.

Particulate Hydrocarbons. These constitute approximately 20 to 65 percent of the organic particulate matter present in polluted urban air (Hoffman and Wynder 1977). Polycyclic aromatic hydrocarbon particles are among the most extensively studied compounds found in polluted air. The great interest lies in the facl liat several are known animal carcinogens and some are suspected carcinogens for man. PAHs are the primary mutagenic compounds in crude petroleum and their concentration increases as the boiling range of the petroleum fuels increases. The major potentially carcinogenic PAHs identified with certainty in air pollutants are aromatic hydrocarbons with four, five, and six benzene rings. The relative carcinogenicity of PAHs 
are listed in Table 42 (Hoffman and Wynder 1977). Also Identified in urban air are traces of $11 \mathrm{H}$-benzo(b)fluorene, $5 \mathrm{H}$-benzo(a)fluorene, $7 \mathrm{H}$-benzo(c)fluorene, and benzo(ghi)fluoranthene, which are considered noncarcinogenic. Urban air also contains traces of several alkylated PAHs. (The PAHs emitted from heavy duty diesel- and gasoline-powered engines are discussed above.)

PAHs have been shown to be carcinogenic in various in vivo tests. These tests have included bioassays on mouse skin, subcutaneous mouse tissue, mouse cervix, and newborn mice. Fractionation studies on urban pollutants suggest that PAHs may play an important role in the overall carcinogenicity and tumor-initlating activity of urban pollutants in experimental animals. These effects are under investigation in experimental animals, following exposure via subcut aneous administration, oral administration, inhalation, or bladder implantation.

Benzo(a)pyrene ( $\mathrm{BaP}$ ), a known carcinogen, is the most widely studied PAH. Estimated emissions for BaP in the U.S. are 11sted below (Hof fman and Wynder 1977):

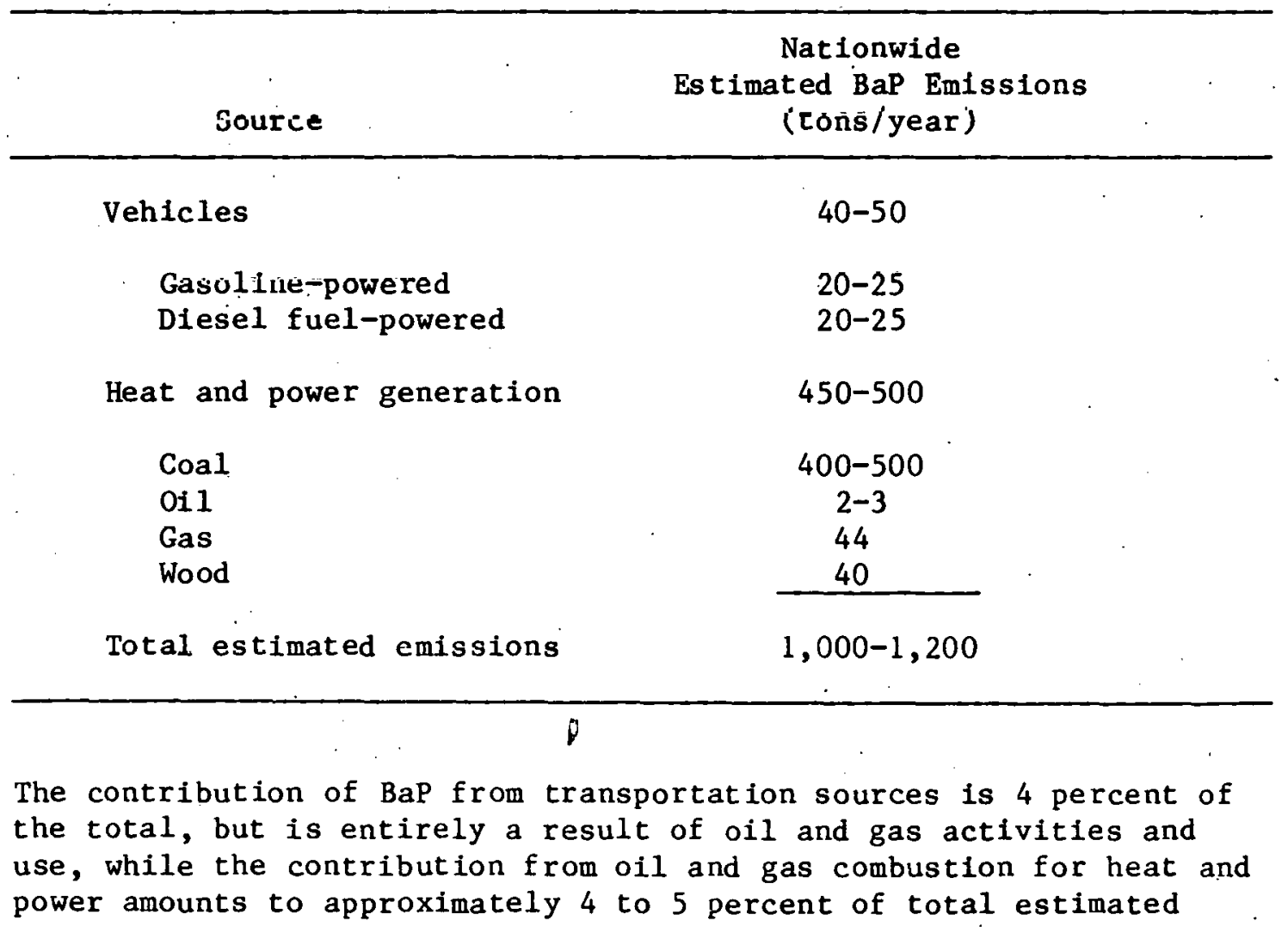


TABLE 42

POLYNUCLEAR AROMATIC HYDROCARBONS FROM VARIOUS SOURCES

\begin{tabular}{|c|c|c|c|c|c|c|}
\hline Name & Structure & Carcinogenicity & $\begin{array}{l}\text { Ambient } \\
\text { Alr }\end{array}$ & $\begin{array}{l}\text { Diese1-b } \\
\text { Engine } \\
\text { Heavy- } \\
\text { Duty }\end{array}$ & $\begin{array}{l}\text { Casoline } \\
\text { Vehicles } \\
\text { American }\end{array}$ & $\begin{array}{l}\text { Diesel }^{d} \\
\text { Vehicle }^{-1}\end{array}$ \\
\hline Benz (a)anthracene & & $\begin{array}{l}\text { very weak } \\
\text { carc1nogen }\end{array}$ & + & $t$ & + & + \\
\hline Chrysene & & $\begin{array}{l}\text { very weak } \\
\text { carcinogen }\end{array}$ & + & $t$ & + & + \\
\hline Pyrene & & no carcinogen & + & + & $t$ & + \\
\hline Fluoranthene & & no carcinogen & + & + & + & + \\
\hline Benzo (a)pyrene & & $\begin{array}{l}\text { strong } \\
\text { carcinogen }\end{array}$ & + & + & + & + \\
\hline Benzo(e)pyrene & & $\begin{array}{l}\text { very weak } \\
\text { carcinogen }\end{array}$ & & + & + & $t$ \\
\hline Perylene & & no carcinogen & + & & + & \\
\hline benz (e') acepheuanili y levie & & $\begin{array}{c}\text { weak } \\
\text { cartinogen }\end{array}$ & + & & & \\
\hline Benzo( $j$ ) fluoranthene & & $\begin{array}{c}\text { moderately strong } \\
\text { carcinogen }\end{array}$ & 十 & & & \\
\hline Benzo(k) Eluoranthene & & no carcinogen & + & & & \\
\hline Benzo (ghl)perylene & & no carcinogen & + & + & + & + \\
\hline
\end{tabular}


TABLE 42 (Concluded)

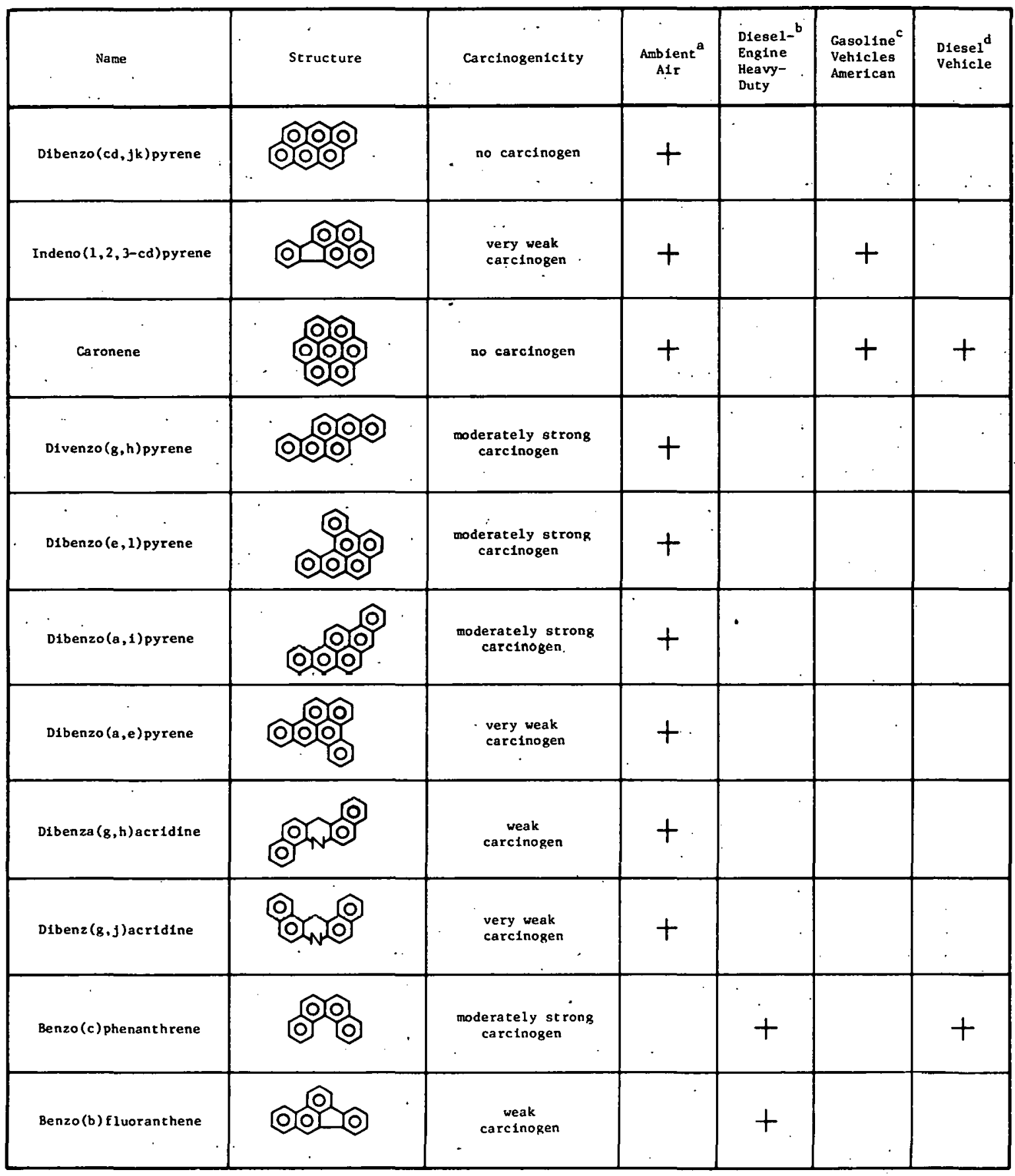

Note: + Indicates relevance to medium/source.

${ }^{a}$ Source: Hoffman and Wynder 1977.

${ }^{b}$ Source: Spindt 1977

cSource: U.S. Environmental Protection Agency 1978c. 
emissions. This reflects the existence of a potentially greater health hazard for individuals exposed to BaP from oil and gas consumption in the transportation sector, compared to using o1l and gas for heat and power in the industrial, commerclal, and utility sectors. BaP emissions from gasoline-powered automobiles have been significantly reduced in the U.S. through the use of newer model cars and implementation of emissions control regulations. The data presented below supports this expected reduction in BaP levels (Hoffman and Wynder 1977):

\begin{tabular}{lc}
\hline Source & $\begin{array}{c}\text { BaP } \\
\text { (ug/gallon fuel consumed) }\end{array}$ \\
\hline $\begin{array}{c}\text { Uncontrolled car } \\
(1956-1964)\end{array}$ & 170 \\
$\begin{array}{l}\text { Uncontrolled car (1966) } \\
\text { Emission controlled } \\
\text { vehicles (1968) } \\
\text { Advanced systems }\end{array}$ & $45-70$ \\
\hline
\end{tabular}

It is estimated that as much as 30 percent of the BaP in exhaust gases can be attributed to BaP in gasoline fuels (Bergman and Colucci 1968). Benzo(a)pyrene production in gasoline-powered automobiles at an air-to-fuel ratio of 20 to 1 is 30 times higher than that at a ratio of 14 to 1 . As vehicles accumulate mileage in normal consumer use, there is an increase in deposits formed in the combustion chamber, which influences total hydrocarbon exhaust emissions. This may reflect a negative differential health hazard for the poor (undocumented), who generally own older and less well-maintalned automobiles, especially in the densely populated low-income sections of urban communities.

The quantity of benzo(a)pyrene emitted from stationary combustion sources is highly dependent on the efficiency of combustion, and not on the fuel. In specific areas, the relative contribution of any given source may dfffer siguiflcantly from that impliod by the nationwide figures (e.g., the vehicular source may be the major contributor in suburban areas where large stationary sources are absent). 
With particulate hydrocarbons, namely PAHs, their effect on human health depends on the particle size. The major source of carcinogenic particulate organic matter in polluted air is controlled combustion that produces particles 0.1 to $10 \mathrm{um}$ in diameter. "Lungdamaging" components are considered to be particles 0.25 to $10 \mathrm{um}$ in diameter. Particles less than 0.25 um are retained to a low degree in the lung, and particles with diameters greater than $10 \mathrm{um}$ lodge in the upper respiratory tract and do not reach the bronchi.

Because practically all combustion leads to the formation of unknown traces of carcinogenic PAHs and the particles generated are primarily 0.1 to $10 \mathrm{um}$ in diameter, it has been assumed that particulate organic matter will be partially deposited in the bronchial tree, especially at the bifurcation (National Academy of Sciences 1972). This thesis has been substantiated by experimentally demonstrating that $\mathrm{BaP}$ and other $\mathrm{PAHs}$ are readily eluted from soot samples recovered from the human lung (Falk et al. 1958).

Polycyclic aromatic hydrocarbons of weak or mild carcinogenic1ty that are present in the polluted air have been suggested to act as co-carcinogenic or anticarcinogenic agents. Whenever two or more agents present in the alr are applied simultaneously or sequentially under experimental conditions, they may interact in a variety of ways so as to alter each other's effects. This modifying nature of carcinogenic and anticarcinogenic agents should be clarified.

The polycyclic aromatic hydrocarbons and heterocyclics, e.g., olefins, constitute a group of known carcinogens, co-carcinogens, or anticarcinogens that are present in the particulate phase of polluted air. However, the extent of their contribution to the incidence or promotion of human lung cancer in particular is unknown. other agents--such as tumor-promoting, co-carcinogenic, and noncarcinogenic, but tumor-initiating agents, and carcinogens other than aromatics (e.g., asbestos, benzene)--probably contribute to the PAHcaused total human health hazard. These agents and their physical and chemical characteristics, modes of action, oxidation products and intermediates, and target organs are poorly understood. Extensive research is being undertaken to investigate the unknowns mentioned above.

In vivo and in vitro carcinogenesis/mutagenesis studies for whole gasoline, diesel fuel, and heating oils are attempting to identify synergistic, additive, and cumulative effects of other gaseous pollutants in the presence of known carcinogens. An example of such research includes a study initiated to study comparative mutagenic activity of organics from combustion sources (Claxton and Hisingh 1979). The results are presented in Table 43. This study demonstrates how bacterial mutation systems can be used to provide relative potency comparisons as well as qualitative comparisons for the 
TABLE 43

SPECIFIC ACTIVITY AND RELATIVE POTENCY

OF VARIOUS COMBUSTION ORGANICS

\begin{tabular}{|c|c|c|c|c|c|c|c|c|}
\hline \multirow{3}{*}{$\frac{\text { Strain }}{\text { TA98 }}$} & \multicolumn{8}{|c|}{ Specific Activity ${ }^{a}$ (Relative Potency) ${ }^{b}$} \\
\hline & \multirow{2}{*}{$\begin{array}{c}\begin{array}{c}\text { Cigarette } \\
\text { Smoke }\end{array} \\
\begin{array}{c}\text { Negative } \\
98.2 \quad(0.3)\end{array}\end{array}$} & \multirow{2}{*}{$\begin{array}{c}\begin{array}{c}\text { Roofing } \\
\text { Tarc }^{c}\end{array} \\
\begin{array}{c}\text { Negative } \\
98.7 \quad(0.3)\end{array}\end{array}$} & \multicolumn{2}{|c|}{$\begin{array}{l}\text { Diesel } \\
\text { Vehicle }\end{array}$} & \multicolumn{2}{|c|}{$\begin{array}{l}\text { Gasoline } \\
\text { Vehicle }\end{array}$} & \multicolumn{2}{|c|}{$\begin{array}{c}\text { Residential } \\
\text { Heater }\end{array}$} \\
\hline & & & $\begin{array}{l}1,225.2 \\
1,367.1\end{array}$ & $\begin{array}{l}(8.9) \\
(4.0)\end{array}$ & $\begin{array}{l}137.8 \\
341.9\end{array}$ & $\begin{array}{l}(1.0) \\
(1.0)\end{array}$ & $\begin{array}{r}90.5 \\
152.5\end{array}$ & $\begin{array}{l}(0.7) \\
(0.4)\end{array}$ \\
\hline TA1538 & $\begin{array}{l}\text { Negative } \\
90.6 \quad(0.6)\end{array}$ & $\begin{array}{l}\text { Negative } \\
34.4 \quad(0.3)\end{array}$ & $\begin{array}{l}347.2 \\
468.0\end{array}$ & $\begin{array}{l}(7.2) \\
(3.2)\end{array}$ & $\begin{array}{r}48.4 \\
144.1\end{array}$ & $\begin{array}{l}(1.0) \\
(1.0)\end{array}$ & $\begin{array}{l}40.2 \\
71.4\end{array}$ & $\begin{array}{l}(0.8) \\
(0.5)\end{array}$ \\
\hline TA1538 & $\begin{array}{l}\text { Negative } \\
\text { Negative }\end{array}$ & $\begin{array}{l}\text { Negative } \\
36.5 \quad(0.5)\end{array}$ & $\begin{array}{l}178.5 \\
206.2\end{array}$ & $\begin{array}{l}(6.0) \\
(2.6)\end{array}$ & $\begin{array}{l}29.8 \\
79.1\end{array}$ & $\begin{array}{l}(1.0) \\
(1.0)\end{array}$ & $\begin{array}{l}18.4 \\
33.0\end{array}$ & $\begin{array}{l}(0.6) \\
(0.4)\end{array}$ \\
\hline TA.1535 & $\begin{array}{l}\text { Negative } \\
\text { Negative }\end{array}$ & $\begin{array}{l}\text { Negative } \\
\text { Negative }\end{array}$ & $\begin{array}{l}\text { Nega } \\
\text { Nega }\end{array}$ & $\begin{array}{l}\text { ive } \\
\text { ive }\end{array}$ & $\begin{array}{l}\text { Neq } \\
\text { Neq }\end{array}$ & $\begin{array}{l}\text { Elve } \\
\text { tive }\end{array}$ & & $\begin{array}{l}\text { tive } \\
\text { tive }\end{array}$ \\
\hline TA100 & $\begin{array}{c}\text { Negative } \\
? \mathrm{~d}\end{array}$ & $\begin{array}{c}\text { Negative } \\
420.0(1.8)\end{array}$ & $\begin{array}{r}1,270.1 \\
881.7\end{array}$ & $\begin{array}{l}(6.5) \\
(3.9)\end{array}$ & $\begin{array}{l}196.6 \\
228.0\end{array}$ & $\begin{array}{l}(1.0) \\
(1.0)\end{array}$ & $\begin{array}{l}200.0 \\
289.2\end{array}$ & $\begin{array}{l}(1.0) \\
(1.3)\end{array}$ \\
\hline
\end{tabular}

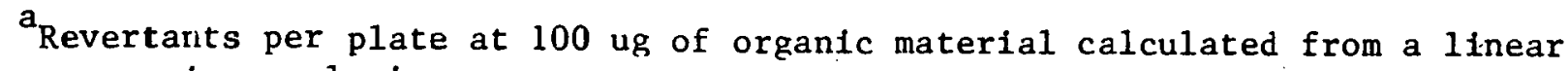
regression analysis.

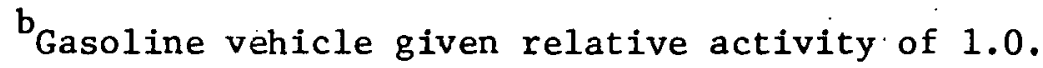

$\mathrm{c}_{\text {From }}$ zetest of organics at lower doses.

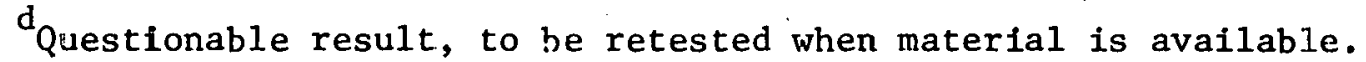

Source: Claxton and Huisinghi 1979. 
evaluation of complex mixtures. In a recent study conducted for the American Petroleum Institute, it was demonstrated that no. 2 home heating oil does not exhibit positive mutagenic response in Salmonella typhimurium. However, in vitro mouse lymphoma array indicated a significant dose-response, with an increase in mutation frequency both in the presence and absence of metabolic activation. The study results concluded that no. 2 home heating oil has the potential to produce mutations in genetic material (Hazelton Laboratories 1979). It should be noted that the relationship of mutagenic potency and carcinogenic potency is not clear at this time and is a controversial issue in toxicology.

Occupational Exposures. Workers in o11- and gas-fired power plants, automobile garages, and service stations, as well as those in jobs involving diesel and jet fuels, mechanics, and workers handling heavy duty engines may be exposed to PAHs in the workplace. Under normal working conditions, exposure to PAHs can be controlled with the use of protective clothing, masks, respirators, and hand creams or gloves. Accidental occupational exposure is a matter of particular concern. Occupational exposures and related hazards suggest exposure through the skin and inhalation.

Epidemiological evidence suggests that dermal exposure to PAHs causes various skin associated ailments. These include nonallergic dermatitis, cell-mediated hypersensitivity (allergic contact dermatitis), phototoxic and photo-allergic reactions, folliculitis, acne, and pigment changes. Nonallergic dermatitis in workers has been caused by materials containing PAHs such as lubricating and cutting oils. The inflammatory response of the skin to irritants and antigenic agents in man is known as an eczematous reaction. The histological features of acute contact dermatitis are intracellular and intercellular epidermal edema, and in chronic contact dermatitis, the epidermis also is thickened. Clinical response is characterized by erythema and edema that persist longer than a primary irritant response. Continuous exposure of mechanics and service station employees to cutting and lubricating oils may cause acne, characterized primarily by lesions involving the pilosebaceous apparatus of the skin.

The relationship between occupational PAHs exposure via inhalation and pulmonary disease such as chronic bronchitis and emphysema has been studied in great detail. Evidence suggests that airborne polycyclic organic compounds are carcinogenic. Studies of occupational PAH exposures and possible respiratory effects among chimney sweeps, petrochemical workers, and coal workers are known, but data are not available which suggest incidences of lung cancer in workers associated with oil and gas combustion and transportation activities. 
Long-term exposure to gasoline and jet fuel has been suggested to cause chronic mental and neurological symptoms. A cross-sectional epidemiological study on jet fuel workers showed intoxication by jet fuel ( 80 percent aliphatic, 20 percent aromatic hydrocarbon) followed by acute symptoms related to the central nervous system: dizziness, drowsiness, nausea, vomiting, pain during inhalation, feeling of suffocation, slight cough, palpitations and thoracic oppression (Knave et a1. 1979). It is not clear what component of the fuel may cause the observed neurasthemic syndrome (1.e., fatigue and emotional instability).

Ambient Exposure. Nonoccupational neoplastic pulmonary effects we re summarized by scient ists as sociated with the Committee on Biological Effects of Atmospheric Pollutants--Particulate Polycycifc. Organic Matter (National Academy of Sciences 1972). Based on reviews of various epidemiological studies of lung cancer, the committee concluded that:

o Lung cancer has emerged as the single greatest cause of cancer death in males and a significant cause of death in females in the United States, and its incidence has increased in the last 30 years.

- $\Lambda$ major etiological factor appears to be clgarette smoking; however, smoking does not completely account for the increased Inctdence of the disease.

- Urban dwellers have approximately twice as high an Incidence of lung cancer as those living in rural areas. Within urban communities, the incidence is greater where more general industrial pollution is present.

- Polycyclic organic matter, found in cigarette smoke in high concentrations, causes cancer of the lung and other organs in experimental animals, is present in the alr in laige quantities in industries whose workers have high lung cancer rates, and is present in the air of urban communities.

- Generally, immigrants have an incidence of lung cancer between that noted for their countries of origin and that of the countries to which they migrate. The higher their ages when they migrate, the closer their rates are to those of their cohorts who remain in the countries of origin. In some of the studies in which the home country had a much higher cancer rate, the rates in persons who left it decreased significantly, even though their cigarette smoking increased. These studies suggest a significant environmental effect operating early in life for lung cancer development. 
- A variety of types of epidemlological studies lead to an estimate of the effect of pollution on the lung cancer death rate of a 5 percent increase per unit increase in urban pollution [as indexed by benzo(a)pyrene with one benzo(a)pyrene unit $=1$ ug of benzo(a)pyrene per $1,000 \mathrm{~m}^{3}$ of air].

In short, these results suggest the feasibility and warrant the desirability of further epidemiological studies on airborne carcinogenesis resulting from hydrocarbons emitted during the use of o1l and gas. One way to assess the impact of particulate hydrocarbon pollution on lung cancer is to see what happens when pollution is reduced. To see whether particulate hydrocarbon pollution contributes to the development of respiratory cancer, trends in cancer deaths from 1950 to 1970 in London, where particulate pollution declined greatly, can be compared with trends in the rest of England and Wales where the decline was not as pronounced (Higgins 1974).

\section{Hydrocarbon Mixtures}

Gasoline. Hydrocarbon mixtures produced and consumed in the U.S. include natural gas, gasoline, kerosene, jet and turbo fuels, and lubricating oils. Gasoline represents the major source of homogeneous hydrocarbons emitted in a mixture of $C_{4}$ to $C_{12}$ hydrocarbons where blend composition* includes paraffins ( 56.8 percent by welght), olefins ( 7.9 percent by weight), naphthenes ( 2.47 percent by welght) and aromatics (benzene 0.12 , toluene 21.8 , and alkyl benzene 7.0 percent by weight) over a bolling range of $79^{\circ}$ to $399^{\circ} \mathrm{F}$ ( $26^{\circ}$ to $204^{\circ} \mathrm{C}$ ). Acute exposure to gasoline vapors will cause symptoms of intoxication similar to heptane exposure. These include uncontrolled hilarity, stupor, loss of appetite, slight nausea, and a taste resembling gasoline. The concentrations of gasoline hydrocarbons that cause mucous membrane irritations will vary with the concentration and degree of branching of the paraffins, and alkyl derivatives of benzene and olefins. The human response to unleaded gasoline vapor inhalation at temperatures below $230^{\circ} \mathrm{F}\left(110^{\circ} \mathrm{C}\right)$ is described below (Machle 1941):

${ }^{\text {aPI standard. }}$ 


\begin{tabular}{|c|c|c|}
\hline Concentration (ppm) & Exposure Time & Response \\
\hline 500 & 1 hour & No effect \\
\hline 900 & 1 hour & $\begin{array}{l}\text { Slight dizziness and } \\
\text { irritation of eyes, } \\
\text { nose, and throat }\end{array}$ \\
\hline 2,000 & 1 hour & $\begin{array}{l}\text { Dizziness, mucous mem- } \\
\text { brane irritation, and } \\
\text { anesthesia }\end{array}$ \\
\hline 10,000 & 20 minutes & $\begin{array}{l}\text { Nose and throat irrita- } \\
\text { tion in } 2 \text { minutes, diz- } \\
\text { ziness in } 4 \text { minutes, } \\
\text { sign of intoxication } \\
\text { in } 4 \text { to } 10 \text { minutes }\end{array}$ \\
\hline
\end{tabular}

Based on the above data, a threshold limit value for gasoline of 500 ppm was recommended (Gerarde 196.3a, b).

Human Inhalation toxicity data for gasoline vapor exposure are very limited. Inhalation of extremely high concentrations of gasoline vapor can cause narcosis, coma, and sudden death. Death upon acute exposure to gasoline fumes generally is attributed to severe central nervous system depression terminating in respiratory paralys1s. Sudden deaths observed in cases of accidental gasoline exposure are attributed to the sensitization of the myocardium to the extent that small quantities of epinephrine may precipitate venticular fibrillation (Chenoweth 1946). Inhalation of milder concentrations of gasoline vapor usually are characterized by nonspecific anesthetic or narcotic effects with symptoms of headache, vertigo, blurred vision, ataxia, tinnitus, nausea, anorexia, and muscular weakness. Table 44 summarizes the effects of gasoline vapors on humans. Chronic gasoline toxicity data and epidemiological studies for occupational exposures to gasoline vapors are limited.

In general, the symptoms of chronic exposure to gasoline vapor are ill-defined. They may consist of fatigue, muscular weakness, nausea, vomiting, abdominal pain, and weight loss. Exposure also is known to have neurological ef fects which include confusion, ataxia, tremor, paresthesias, neuritis, and paralysis of peripheral and cranial nerves (Swinyard 1977). 
TABLE 44

HUMAN EXPOSURE TQ GASOLINE VAPORS

\begin{tabular}{|c|c|c|c|c|}
\hline $\begin{array}{c}\text { Concentration } \\
\text { (ppm) : }\end{array}$ & ": & $\begin{array}{c}\text { Exposure } \\
\text { Time }\end{array}$ & & $\begin{array}{l}\text { Physiological/ } \\
\text { Sensory Effect }\end{array}$ \\
\hline $5,000-16,000$ & & 5 mins & & Lethal \\
\hline 10,000 & $\therefore$ & 10 mins & & $\begin{array}{l}\text { Nose and throat irritation in } \\
2 \text { mins; dizziness in } 4 \text { mins; } \\
\text { signs of intoxication in } \\
4-10 \text { mins, definite in-. } \\
\text { toxication }\end{array}$ \\
\hline 3,000 & & 15 mins & & Dizziness, nausea \\
\hline 2,600 & & $1 \mathrm{hr}$ & & Dizziness \\
\hline 2,000 & & $1 \mathrm{hr}$ & & $\begin{array}{l}\text { Dizziness, mucous membranes } \\
\text { irritated and anesthesia }\end{array}$ \\
\hline 1,000 & & 15 mins & & Drowsiness, dullness, numbness \\
\hline 1,000 & & $1 \mathrm{hr}$ & & Dizziness, headache, nausea \\
\hline 1,000 & & 30 mins & & Fye irritation on $1 y$ \\
\hline$\cdot$ & . & $1 \mathrm{hr}$ & & $\begin{array}{l}\text { Slight dizziness, irritation } \\
\text { of eyes, nose and throat }\end{array}$ \\
\hline 550 . & . & $1 \mathrm{hr}$ & $\vdots$ & Eye irritation \\
\hline 500 & & $1 \mathrm{hr}$ & . & Eye irritation \\
\hline $300-700$ & & 18 mins & ' & No symptoms \\
\hline $160_{7} 270$ & & $8 \mathrm{hrs}$ & . & Eye irritation \\
\hline
\end{tabular}

Source: Chenoweth 1946. 
Cases of repeated, self-induced gasoline intoxication, generally involving higher concentrations of gasoline vapor, could possibly be considered chronic inhalation exposures. Persons engaged in the regular habit of "gasoline sniffing" experience loss of appetite and welght, muscular weakness, and cramps. Other effects reported to result from this practice include abnormal electroencephalograph readings and possible liver and renal damage.

The greatest hazard associated with chronic gasoline Inhalation is exposure to the aromatic hydrocarbons, espectally benzene. As previously noted, chronic benzene intoxication can result in irreversible systemic effects such as encephalopathy, aplastic anemia, and leukemia. The literature lacks information relating chronic gasoline sniffing to fetal pathological conditions such as liver, k1dney, or bone marrow lesions.

The threshold limit value (TLV) for a gasoline is dependent upon the benzene concentration in the gasoline mixtures and the additive or synergistic effect of benzene with other hydrocarbons in gasoline.

Gasoline TLVs were calculated using the American Conference of Industrial Hygienists (ACGIH) method at the former benzene TLV criterion of $10 \mathrm{ppm}$, as well as the new criterion of $1 \mathrm{ppm}$ (Runion 1977). Results indicated that gasoline containing 1 percent benzene, for example, had a TLV of $30 \mathrm{ppm}$, whereas the same gasoline with the proposed benzene standard of $1 \mathrm{ppm}$ would have a TLV of less than 150 ppm.

No serfous at tempt has been made to measure the health risk to the general public as a result of gasoline vapor exposure. Studies have been conducted utilizing large numbers of filling station at tendants, tank-truck drivers, garage mechanics, and gasoline loaders, and they have provided no conclusive evidence of harmful health effects due to low level exposures to gasoline vapors. In these studies, a phenol excretion level is used as an index of benzene absorption. This phenol index is particularly susceptible to individual variations in metabolic rates, nutritional status, smoking habits, and dietary intake. The importance of these confounding factors needs to be explored.

Diesel Exhaust. As seen earlier, emissions of volatile hydrocarbons are lower from diesel than from gasoline engines, but use of an oxidation catalyst can substantially reduce most of these emissions from gasoline engines. However, recent analytical studies have shown that particulate emissions in diesel exhaust can be up to 82 times as much as in gasoline exhaust (Springer and Baines 1977). There are several important reasons why increased exposure to particulate matter derived from diesel engines may constitute a potential health hazard (Schreck 1978). 
- Carbonaceous particles from diesel exhaust are reportedly composed in part of high-molecular-weight polycyclic aromatic hydrocarbons.

- These particles have large surface areas, theoretically enabling them to adsorb large quantities of gaseous exhaust products, most importantly the carcinogenic POMs such as benzo(a)pyrene.

- The particles themselves may be degraded by atmospheric oxidation to yield lower-molecular-welght POMs which are potentially carcinogenic.

- Diesel particulates are primarily in a size range $(0.2$ to 0.3 um mean diameter) which would allow for deposition in the deep lung compartments, and possible retention in the lung.

Diesel exhaust particulates are known to contain the carcinogenic and mutagenic chemical benzo(a)pyrene, among many other potentially hazardous and less well characterized components. The quantities of particulates that may be emitted from both gasoline and diesel cars in 1990 are estimated below (Huisingh et al. 1978):

\begin{tabular}{|c|c|c|}
\hline $\begin{array}{c}\text { Percent } \\
\text { Diesel } \\
\text { New Car Sales } \\
1985-1991 \\
\end{array}$ & $\begin{array}{c}\text { Particulate Emissions } \\
\text { in Tons from Gasoline } \\
\text { Cars by } 1990 \\
\end{array}$ & $\begin{array}{c}\text { Particulate Emissions } \\
\text { in Tons from Light } \\
\text { Diesel Cars by } \\
1990\end{array}$ \\
\hline 0 & 32,000 & 0 \\
\hline 10 & 28,000 & 57,000 \\
\hline 25 & 26,000 & 155,000 \\
\hline
\end{tabular}

The amount of particulate matter that would be emitted from gasoline cars in 1990, if no diesel cars are sold, is estimated at 32,000 tons. In contrast, as much as 155,000 tons could be emitted by diesel cars if they make up 25 percent of car sales. This estimate assumes no emissions controls on diesel passenger cars. The possible impact of rising diesel usage on atmospheric pollution indicates that an increase in diesel use is likely to increase PAHs in ambient air, resulting in a new source and, conceivably, in an additional health hazard. 
In the past few years, diesel exhaust emissions have been extensively characterized. The tests include mutagenicity testing in Salmonella typhimurium, generally taken as strong presumptive evidence for the existence of mutagentc as well as carcinogenic activity. The Ames test has been used to show the relationship between collection and extraction techniques for diesel exhaust emissions, and mutagenic activity of diesel exhausts. Some mutagenic activity was demonstrated in the insoluble basic and acidic fractions of dichloromethane (DCM) extracted particulate samples. However, neutral fractions showed most of the mutagenic activity (U.S. Environmental Protection Agency 1978c).

Direct acting components as well as components requiring metabolic activation were apparent in different fractions, although most of the mutagens were of the direct-acting frameshift type. Studies of direct-acting mutagens are significant because they exclude polycyclic hydrocarbons, which require metabolic activation for expression of mutagenic effects. It was suggested that substituted polynuclear aromat 1cs, namely phenols, ethers, and ketones, were the major components of a neutral fraction.

Investigators in this area have suggested exercising caution before implicating neutral fraction components in diesel exhaust as a major health hazard to man. The results of bacterial mutagenicity assays on diesel and gasoline exhaust have indicated that directacting mutagens are formed during combustion. These mutagens are presumed to be substituted polycyclic aromatic hydrocarbons. The mutagenicity of the diesel exhaust was found to be 10 times higher than that of the gasoline exhaust, although the addition of microsome activation enzymes decreased this activity (Lofroth 1979). Mutagenic activity was enhanced in anseroblc assays, presumably due to the presence of nitro compounds (U.S. Environmental Protection Agency 1978 c).

Varinns in vivo studies undertaken to assess potential hazards of diesel exhaust emissions have concluded that:

- Exposure of rats to diesel particles for 9 months did not result in a toxic effect, although some changes, including a signiflcant 1ncrease in lung welght, were observed (M1s lorowski 1979).

- Inhalation of diesel emissions may lead to emphysema in rats and mice (Bhatneger 1979).

- In comparison to the gasoline engine operating with or without a catalytic converter, the diesel engine produces far greater quantities of carbonaceous particulate materlal. 
These particles are of respirable size and have large surface areas, which allows them to absorb gaseous exhaust products. Among these products are small amounts of irritant gases and, perhaps most significantly, a large portion of potentially carcinogenic polycyclic organic matter, e.g., benzo(a)pyrene. Benzo(a)pyrene has been shown to account for 20 percent of the carcinogenic activity of diesel exhaust condensate observed in skin painting tests with mice (Grimmer 1979).

Schefner (1979) demonstrated that lung cancer appears to be more prevalent and far advanced in diesel-exposed hamsters than in controls. This poses the potential risk of delivery of adsorbed gases into the lung by carrier particles. In turn this may lead to extensive localization of harmful materials in the lung, with the accompanying threat of emphysema and cancer. In addition, fibrotic changes may occur, leading to reduced lung compliance and/or obstruction.

Investigators have for many years attempted to show that exposure to automotive emissions may lead to the development of cancer. Indeed, it was shown several decades ago that both diesel and gasoline engine exhausts contaln carcinogenic polycyclic aromatic hydrocarbons such as benzo(a)pyrene. Since that time, chronic studies have been initiated which involve the inhalation of total diesel emissions by rats and hamsters. Under the conditions employed, these experiments have failed to produce tumors of the respiratory tract. On the other hand, there is evidence of serious damage to respiratory tissues. Rats exposed to diesel exhaust for 20 months displayed extensive particulate accumulations in the lungs, accompanied by vesicular emphysema, and beginning interstitial fibrosis. Hamsters developed similar problems, in addition to the presence of cuboidal metalplasia. It is not known whether such tissue damage is reversible or if it may shorten lives. In addition, a high incidence of skin cancer has been shown to occur in mice following dermal application of the particulate exhaust fraction from diesel and gasoline engines.

A series of in vivo studies with several animal species inhaling diesel exhaust indicated the existence of clearance mechanisms for diesel particulates. Among guinea pigs inhaling diesel exhaust, several exposure-related changes were seen including increased pulmonary flow resistence, increased lung-weight-to-body-weight ratios, sinus bradycardia, and damage to the alveolar walls. The reversibility of these lesions or the degree of functional impairment which accompanies them has not been determined. A series of in vivo mutagenesis studies in progress may provide definitive data on this problem. 
Biochemical and metabolic effects associated with exposure to diesel exhaust emissions are not known. Studies involving DNA bonding, effects on collagen production, and inhibition of BaP metabolism, along with research on uptake, distribution, metabolism and excretion, will provide valuable information to assess diesel exhaust emissions and human health hazards. Work is also underway to measure and identify behavioral and neurophys lological effects in experimental animals.

An objective of the epidemiological investigation of diesel exhaust emissions is to demonstrate that an increased use of diesel vehicles is environmentally acceptable. With recent occupational mortality and.morbidity studies on groups, including railroad workers, truck drivers, miners, heavy duty equipment workers, diesel mechanics, and trash collectors, it has not been possible to isolate diesel emissions as a singular component contributing to the excess deaths and adverse (carcinogentc) health effects occasionally observed. The London Transport study completed in 1957 (Raffle 1957) found no increased cancer incidence among bus garage drivers. This study has been criticized for poor documentation of exposure levels and for poor control regarding the workers' smoking habits. Large population-based studies are just emerging, since large populations that have been exposed to ambient levels of light duty diesel emissions have not previously existed in the U.S. This also is true of well-controlled investigations of worker populations, since quantitative exposure data have not been available. Most studies are conducted with coal miners who are exposed to underground diesel exhaust emissions. One such study concluded that, for coal miners exposed to diesel emissions: there were no relationships between respirable particles and shift changes in pulmonary functions; there were no relationships between $\mathrm{NO}_{2}$ and shift change in pulmonary function; and smokers suffered greater pulmonary function decrements over a workshift then ex-smokers or nonsmokers. Coal miners exposed to diesel emissions in addition to the ordinary mine atmosphere show some decrements in their lung function over a work shift (Reger et al. undated) Another study on coal miners exposed to diesel emissions reported symptoms of persistant cough, phlegm, and exacerbation of cough and phlegm. Aside from dyspnea and wheezing, long-term diesel exhaust exposure was assoclated with a tendency toward deteriorating health for coal miners (Reger and Hancock undated).

There is no way to place in perspective the comparative hazards of diese 1 and overall automobile emissions. Diesel exhaust is a noxious mixture with the potential to produce serious lung disease, behavioral alterations, biochemical changes, and decrements in pulmonary function. Its risk as a human carcinogen, however, is unquantified. When looked upon in light of what we know regarding the potential health effects of noncatalyst-treated gasoline exhaust, the 
impact of diesel fueled emissions remains unclear. Presently, firm data suggesting an increased carcinogenic threat from the substitution of diese1- for gasoline-powered light duty vehicles are not avallable. Further epidemiological research must be pursued and studies with laboratory antmals must be conducted to characterize cause-and-effect relationships and exposure-response parameters.

\section{Carbon Monoxide}

Air emissions of carbon monoxide ( $\mathrm{CO}$ ), resulting from the use of oil and gas in transportation and combustion, accounted for approximately $65,77,80$, and 78 percent of total emissions in 1968, 1970, 1972, and 1974, respectively. This large air pollution burden has been studied in detail and the effects of carbon monoxide pollution are well summarized elsewhere (U.S. Department of Health, Education, and Welfare 1970).

Carbon monoxide is an odorless, colorless gas that of fers no warning before actual poisoning occurs. Thus, severe accidental CO poisoning is falrly common. With increasing concentrations, the usual sequence of signs and symptoms are headache, dizziness, weariness, flickering eyes, ringing in the ears, nausea, vomiting, difficult breathing, muscular weakness, collapse, unconsciousness, and death. No overt signs are to be expected from exposure to carbon monoxide at even the highest concentrations found in the ambient air ( 50 to $100 \mathrm{ppm}$ ). Ilowever, concerin has been expressed regarding the possibility that exposure to ambient concentrations may decrease physical or mental acuity or interfere with the function of an organ already suffering oxygen defictency, such as a diseased heart: With humans, $C O$ has been shown to negatively affect vigilance, reaction time, estimation of time, coordination and tracking, sensory processes, and complex intellectual behavolr.

Co principally interferes with oxygen transport by combining with hemoglobin. Carboxyhemoglobin, thus formed, gradually accumulates, and with time, eventually reaches a plateau or equilibrium unless death occurs. Thus, the level of carboxyhemoglobin in the body is a function of both the concentration of the inhaled gas and duration of exposure. The general population is not continuously exposed to high CO levels, and carboxyhemoglobin diminishes to background when exposed persons leave the area of contamination such as traffic, or when ambient levels subside at night. There is general agreement that, for normal individuals, exposure to low levels is entirely reversible and causes no lasting dysfunction. The relationship between exposure to $C O$ pollution and the resulting carboxyhemoglobin is not immediately obvious because of the time delay between exposure and the buildup of carboxyhemoglobin levels in the blood and its effects on tissues. 
A number of studies have investigated the relationship between cigarette smoking and carbon monoxide exposure. Inhaling clearly increased the smoker's intake of carbon monoxide. In addition, the effects of $\mathrm{CO}$ on cardiovascular disease have been studied extensively in experimental animals and to some extent in human subjects. These studies indicate that carbon monoxide can affect the heart: decreasing the probability of survival of persons who have a myocardial infraction and possibly other cardiovascular diseases; aggravating an existing circulatory condition, particularly anglna pectoris and peripheral arteriosclerosis; and causing unfavorable changes in the healthy person. In addition, evidence suggests it may be a factor in the onset and progression of cardiovascular disease.

Occupational Exposure. Carbon monoxide exposure is possible for automobile mechanics, traf fic controllers, and tunnel construction workers. Signs and symptoms of acute Co poisoning are headaches, dizziness, drowziness, nausea, vomiting, collapse, coma, and death. Loss of consciousness occurs at about the 50 percent carboxyhemoglobin level. Recovery from acute polsoning usually occurs without sequelae unless tissue hypoxia was severe enough to result in brain cell degeneration. Severe $C 0$ poisoning has been reported to permanently damage the extrapyramidal system; Including the basal ganglia.

The present Federal standard $1850 \mathrm{ppm}$ ( $55 \mathrm{mg}$ per $\mathrm{m}^{3}$ ). A standard recommended by the National Institute for Occupational Safety and Health is $35 \mathrm{ppm}$ with a ceiling value of $200 \mathrm{ppm}$. The $35 \mathrm{ppm}$ would limit carboxyhemoglobin formation to 5 percent in a nonsmoker engaged in sedentary activity at a normal altitude. The protective measures that workers can undertake include using gas masks where CO levels are not exceedingly high and using self-contained air ventilation systems in areas with high concentrations.

\section{Photochemical Oxidants}

The photochemical process that forms secondary pollutants through the interaction of primary pollutants and sunlight results in a number of irritating or toxic chemicals. Ozone and peroxyacyl nitrates are toxic when inhaled or absorbed through surface contact. If present in sufficient concentrations in the alr, these gases can cause death. At sublethal concentrations, they cause physiological malfunctions or anatomical lesions.

Investigation of the acute toxicity of ozone began as early as 1904. At first, work was mainly concerned with mortalicy, gross examination of the lung for evidence of inflammation, wet weight-dry weight ratios for evidence of edema, and histopathological examination (Coffin and Stokinger 1977). Brief exposure to ozone at higherthan-ambient concentrations has been known to cause edema and acute 
inflammatory responses. The long-term either continuous or intermittent exposure to ozone appears roughly proportional to the time and dose of the ozone exposure in the experimental animals. Long-term, exposure-related anatomical changes consist of an increase in the number of pulmonary alveolar macrophages; deposition of fibrous elements; changes in the lung elasticity; thickening of the terminal airway and respiratory bronchiolar walls; accumulation of lymphocytes, plasma cells, and fibroblasts in the peribronchiolar tissue; metabolic alterations in the endothelial cells of the interalveolar capillaries; pathological changes such as necrosis, replacement of the respiratory epithelium, reversion of connective tissue to a less cellular appearance in the terminal bronchioles; fibroplastic proliferation; and a flattening and smoothing of the bronchiolar epithelium.

Despite extensive investigation, there is still no generally accepted explanation of the mechanism or mechanisms through which ozone exerts its toxic action. Experimental exposure of human volunteers to ozone has produced symptoms of cough, substernal soreness, pharyngeal irritation, dyspnea, headache, and general discomfort. However, these symptoms do not persist after the exposure.

The systemic effects ascribed to ozone exposure include the following: changes in elements in the clrculating blood, decrease in brain serotonin, increase of the RNA-to-DNA ratio in the 1iver, transitory increase in liver weight and alkaline phosphatase, morphologic alterations of the parathyroid gland, and increased sleeping time from sodium phenobarbitol. Extensive research on possible mutagenic effects has been inconclusive.

Occupational exposure to high levels of ozone in industries using oil and gas is unlikely. Exposure of the general population and related health effects are discussed above.

\section{Sulfur Oxides}

Air emissions of sulfur oxides from transportation and o1l-and gas-fired boilers are negligible. Hence, the health effects of sulfur oxides emissions are not detailed in this section. Briefly, sulfur oxides health effects include aggravation of the respiratory diseases of asthma, chronic bronchitis, and emphysema; reduced lung function; and irritation of eyes and the respiratory tract. These are discussed in the Transportation and Storage section of this report.

\section{Lead}

The major sources of lead exposure are air, food, and water, with an estimated average intake of 0.12 to $0.35 \mathrm{mg}$ per day. The 
important absorption routes for man and animals are ingestion and inhalation. In adults, from 5 to 10 percent of ingested lead and 20 to 50 percent of inhaled lead may be metabolically absorbed into the body (Goldsmith and Friberg 1977). Studies of occupational lead poisoning show that symptoms include loss of appetite, a metallic taste in the mouth, constipation and obstipation, aneuria, pallor, malaise, weakness, insomnia, headache, nervous irritability, muscle and joint pains, fine tremors, encephalopathy, and colic (Mayers 1969). With lead colic, there may be severe abdominal pain and gastrointestinal cramps. Three types of toxicity are documented: gastrointestinal cramps, central and peripheral nervous system effects, and anemia. Kidney disease, excessive frequency of hypertension, and vascular disease have also been reported.

Lead can interfere with the synthesis of heme, thereby altering the urinary or blood concentration of enzymes and intermediates in heme synthesis or their derivatives. Thus, lead poisoning can lead to an accumulation of nonheme iron and protoporphyrin-a in red blood cells; an increase in 1-aminolevulinic actd in blood and urine; an increase in urinary coproporphyrin, uroporphyrin, and porphobilinogen; inhibition of blood aminolevulinic acid dehydratase; and an increased proportion of immature red blood cells. Table 45 summarizes the effects of lead poisoning in humans following exposure to lead either by Inhalation or ingestion.

Various studies have found substantially higher levels of lead in blood samples from urban dwellers than from rural residents. It has been suggested that reducing the amount of lead Inhaled would significantly reduce the body's burden of lead.

Children are more vulnerable to lead exposure than are adults. Their ingestion is distributed to a smaller tissue mass and their gastrointestinal absorption is estimated to be 25 percent, compared to 8 percent for adults (Karhausen 1973). Some children also are exposed to lead when they eat dirt and paint chips. In addition, their more rapid growth rate and metabolism make them more vulnerable to lead poisoning. Urban children have higher blood lead levels than rural children. When children suffer acute lead polsoning, much of the increase in the body's burden of lead and most of the damaging effects to the nervous system are due to lead paint, air pollution (partly as a result of the combustion of leaded gasoline), and the high lead levels of dirt in streets, parks, and other areas where children play. The biological limits proposed to protect children and adults are shown in Table 46 (Zielhuis 1973).

Occupational Exposure. Policemen, flremen, taxi drivers, vehicle tunnel attendants, garage mechanics, and service station at tendants are examples of occupational groups who work out-of-doors, but 
TABLE 45

EFFECTS OF LEAD POISONING

\begin{tabular}{l}
$\begin{array}{c}\text { Disease; Affected } \\
\text { Organ or System }\end{array}$ \\
\hline Anemia \\
Gastrointestinal \\
sequelae (in-- \\
testinal colic) \\
Peripheral and \\
central nervous \\
system
\end{tabular}

Encepha1opathy

\section{Encephalopathy}

Neuropathy

\author{
Phystological Changes
}

Symptoms

Reduced red blood cell life span, reticulocytosis, occurrence of basophilic stippled cells in peripheral blood

No major physiological effects

Peripheral neropathy; extensor muscles of the hand and feet are often involved

Cardiorespiratory arrest following ingestion of lead by children

\section{Absorption of alkyl lead}

Progressive and irreversible loss of kidney function, with progressive azotomia and occasional hyperuricemia with or without gout
Irritability, fatigue, pallor and sallow complexion

Nausea often without vomiting, constipation, and headache before or about the time of onset of collc

Loss of motor function but little loss of sensory function; extensor weakness precedes wrist drop or palsy

Acute effects--seizures, coma and death. Chronic effects--loss of motor skills and of speech, development of behavioral disorders

\section{Psychosis}

Children have developed renal dwarfism, hypertension, marked retention of urea, and low urinary concentration. Faconi syndrome observed in some children. Nephritis in adults 
TABLE 46

PROPOSED LIMTTS FOR LEAD

AND ITS BIOCHEMICAL INDICES ${ }^{a}$

\begin{tabular}{|c|c|c|c|}
\hline & $\begin{array}{l}\text { Individual } \\
\text { Upper Limit }\end{array}$ & $\begin{array}{c}\text { Group } \\
\text { Average }\end{array}$ & Unit \\
\hline \multicolumn{4}{|l|}{ For Adults } \\
\hline Blood lead (PbB) & 40 & 25 & $\mu \mathrm{g} \mathrm{Pb} / 100 \mathrm{ml}$ \\
\hline Urine ALA ${ }^{b}$ & 6 & 3 & mg/11ter urine \\
\hline $\begin{array}{l}\text { Blood ALA } \\
\text { dehydratase }\end{array}$ & 20 & 30 & $\begin{array}{l}\text { Percentage decrease } \\
\text { from } 100 \% \text { at: } 10 \\
\mu g \mathrm{PbB} / 100 \mathrm{ml}\end{array}$ \\
\hline \multicolumn{4}{|l|}{ For Children } \\
\hline Blood lead (PbB) & 35 & 20 & $\mu \mathrm{g} \mathrm{Pb} / 100 \mathrm{ml}$ \\
\hline Urine ALA & 5 & 3 & mg/liter urine \\
\hline $\begin{array}{l}\text { Blood ALA } \\
\text { dehydratase }\end{array}$ & 30 & 40 & $\begin{array}{l}\text { Percentage decrease } \\
\text { from } 100 \% \text { at: } 1 \\
\mu g \mathrm{~Pb} / 100 \mathrm{ml}\end{array}$ \\
\hline
\end{tabular}

a These limits were proposed as guidelines for public health hazard appraisal. They should not be regarded as fine lines discriminating innocuous from harmful environments; however, if the limits are exceeded, the possibility of undue acute effects or chronic sequeale increases. The data for population groups should be interpreted by experts. who can judge the representativeness of the population sample. Single values moderately exceeding upper limits in individuals should cause awareness and caution; the measurement should be repeated.

${ }^{b}$ ALA - amino levulinic acid.

Source: Zlelhuis 1973. 
are nonetheless exposed to lead from the combustion and use of oil and gas products. The primary source of this exposure is the lead salt emitted from internal combustion engines that burn leaded gasoline. A Public Health Service (1965) survey showed that these workers are placed in atmospheres containing varying amounts of lead for their 8-hour workday. Some samples indicated levels that even approach the Federal standard for lead and its inorganic compounds, which is $0.2 \mathrm{mg}$ per $\mathrm{m}^{3}$ as a time weighted average. It is evident, from the results of many blood samples collected from workers and the public, that there is a high rate of lead absorption on the job.

The Federal criteria document recommends that occupational exposures be limited to a time weighted average value of $0.15 \mathrm{mg}$ per $\mathrm{m}^{3}$. This is the level of airborne lead that will result in biochemical indices showing acceptable lead absorption. It also recommends, based on the acceptable urinary lead level of $0.15 \mathrm{mg}$ per liter, a threshold value of $0.10 \mathrm{mg}$ per $\mathrm{m}^{3}$ (National Institute for Occupational Safety and Health 1972).

Blood lead.level is the single sound criterion for interpreting the acceptability of lead absorption. Other indices that are useful in the assessment of worker health include aminolevulinic acid (ALA) and coproporphyrin assays, as well as examination of blood for hemoglobin, reticulocytes, and stippled cells. Blood lead and urine lead are good indices of the momentary absorption of lead, but are not necessarily indications of a body's lead burden. Bone lead is prohably more indicative of total body burden, but it is not feasible to sample bone for a routine lead assay.

Exposure of the general population and workers to lead has been controlled to some extent through the use of unleaded gasoline in motor vehicles as discussed earlier. Exposure of children to the lead in ingested paint scalings and chips can be successfully mitigated by reducing the lead content of paint. For oil processors, handlers, and those in the end use work force, exposure to lead and lead alkyls can be reduced with full body work clothing and caps and the use of dust and fume masks or air respirators.

\section{Nicke1}

Nickel is a trace metal found in crankcase oils and as a persistent metal in waste oils generated at automotive centers. Workers are exposed to nickel through handling lubricating oils in garages, service stations, and waste oil recovery stations. In these cases exposure is through skin contact, and to a lesser extent, inhalation. The Federal standard for nickel metal and its soluble compounds is 1 ug per $\mathrm{m}^{3}$. Nickel is probably carcinogenic, producing an increased incidence of cancer of the lung and nasal passages. Effects on the 
heart muscle, brain, liver, and kidney have been seen in animal studles (National Academy of Sclences 1975).

\section{Add1tives}

Tetraalkyl Lead. Tetraalkyl lead compounds are used as antiknock agents in gasoline and ethylene dibromide is usually added to gasoline along with these lead additives. Tetraethyl and tetramethyl are the most commercially important tetraalkyl lead compounds. The occupational groups susceptible to exposure to these compounds include gas station at tendants, storage tank cleaners, gasoline additive workers, garage mechanics, and alrplane machinists. Public exposure to lead alkyls is negligible.

Tetraalkyl lead may enter the human system in three ways: inhalation, ingestion, and skin contact. Ingestion is of minor significance when workers are aware of the hazard and use ordinary precautions. Inhalation of the vapor and percutaneous absorption of the liquid of such compounds cause the following systemic effects (U.S. Department of Health, Education, and Welfare June 1977). The absorption of a sufficient quantity of tetraethyl lead, whether briefly at a high rate, or for prolonged perlods at a lower rate, may cause acute intoxication of the central nervous system. Mild degrees of intoxication cause headache; anxiety, insomnia, nervous excitation, and minor gastrointestinal symptoms with a metallic taste in the mouth. The most noticeable clinical sign of tetraethyl lead poisoning is encephalopathy, which may give rise to a variety of symptoms including mild anxiety, toxic delirium with hallucinations, delusions, convulsions, and acute toxic psychosis. Physical signs are not prominent, but bradycardia, hypotension, increased reflexes, tremor, and slight welght losses have been reported. No peripheral neuropathy has been observed. When the interval between the termination of (either brief or prolonged) exposure and the onset of symptoms 18 delayed (up to 8 days) the prognosis is guardedly hopeful, but when the time interval is short (a few hours), an early fatal outcome may result. Recovered patients show no residual damage to the nervous system, although recovery may be prolonged.

No cases of poisoning from absorption of tetramethyl lead have been reported. The compound responsible for almost all cases of organic lead poiconing is tetraethyl. lead. Animal experimentation, however, indicates that a similar intoxication can be caused by tetramethyl lead. The Federal. standard for tetraethyl lead is 0.075 $\mathrm{mg}$ per $\mathrm{m}^{3}$ and for tetramethyl lead is $0.07 \mathrm{mg}$ per $\mathrm{m}^{3}$.

Ethylene Dibromide. As mentioned earlier, ethylene dibromide $(E D B)$ is added to gasoline along with lead additives to assist in the removal of lead from the engine after combustion. Of the $33 \times 10^{6}$ 
pounds of EDB produced each year, approximately 80 percent is used with lead gasoline additives (Air/Water Pollution Report 1977). As a component of lead additives, however, it seems likely that EDB will be phased out of gasoline as the lead concentration is reduced. EDB now comprises about 25 percent of the total lead additive mixture. Quantitatively, it would appear that EDB vaporization is negligible from such diluted solutions.

EDB has been shown to be toxic, carcinogenic, mutagenic, and teratogenic, as well as a sterility inducer in numerous animal studies. The National Institute for Occupational Safety and Health has recommended that workplace EDB exposure be limited to a ceiling level of $1 \mathrm{mg}$ per $\mathrm{m}^{3}$ of air, a reduction from the current limit of $20 \mathrm{ppm}$ ( $145 \mathrm{mg}$ per $\mathrm{m}^{3}$ ). Human data on the carcinogenic and sterillzing effects of EDB alone are lacking. However, even the low airborne levels of EDB that may vaporize from gasoline may be associated with some increased risk of adverse health effects.

\section{Indoor Air Pollution}

The health hazard from an indoor pollutant is a function of the following parameters:

o The levels at which it occurs indoors,

o The frequency with which tt occurs indoors,

- The extent to which individuals are exposed to the pollutant, and

- The exposure-effect relationship of the pollutant.

These parameters are potentially quantifiable by monitoring and sampling indoor air pollutant levels. Instruments needed to characterize and measure indoor levels are not available. The instruments that are commercially available to measure and monitor ambient levels of air pollutants and workplace pollutants cannot be used successfully because of various limitations.

Research priorities have only recently focused on indoor air pollution. The results of these studies may indicate that air pollution levels are higher inside than outside. Indoor pollutants of concern include:

- Carbon monoxide, nitrogen oxides, and sulfur oxides;

- Tobacco smoke and its products; 
- Chlorinated hydrocarbons and organophosphates in pesticides;

- Fluorocarbons in propellants;

- Lead, cadmium, arsenic, and aluminium; and

- Radionucilides.

This listing is in order of fmportance, based on the pollutant's ubiquity in nonworkplace indoor environments, the extent to which substantial health hazards have already been identified, and the extent to which the existence of the hazard and a lack of data suggest that further research is needed.

Indoor air pollution issues related to oll and natural gas end uses are primarily associated with the presence of the gaseous pollutants $\mathrm{NO}, \mathrm{NO}_{2}, \mathrm{CO}$, evaporative hydrocarbons, and radioactivity, and to a lesser extent, $\mathrm{SO}_{2}$.

\section{Nitrogen Oxides}

Nitrogen oxides in indoor air may present a human health hazard in light of reported indoor concentrations. The $\mathrm{NO}_{2}$ level in a gas kitchen is significantly higher than in an electric one. Two studies, one in England and the other in the U.S., reported that gas kitchens had $\mathrm{NO}_{2}$ concentrations six to seven times higher (Melia et al. 1978).

This difference between gas and electric kitchens may explain the association between respiratory disease and gas cooking reported for school children in England. The boys and girls from homes in which gas was used for cooking were found to have more coughs, "colds going to the chest," and bronchitis. This "cooking effect" was assumed to be independent of the effects of age, social class, population density, levels of $\mathrm{SO}_{2}$ outdoors, and types of fuel used for heating (Melia et al. 1977).

$\mathrm{NO}_{2}$ principally associated with gas appliance operations has been found within the following range (Melia et al. 1977):

$\begin{array}{ll}\text { Duration } & \mathrm{NO}_{2} \text { Levels (peak) } \\ \begin{array}{c}1-\mathrm{hr} \text { average } \\ 1-\mathrm{hr}\end{array} & 450-950 \mathrm{ug} / \mathrm{m}^{3} \\ & 1,900-2,800 \mathrm{ug} / \mathrm{m}^{3}\end{array}$

These values can be compared with short-term exposure effects studied in the range of 228 to 815 ug per $\mathrm{m}^{3}--1$ evels known to contribute to an excess risk of acute respiratory disease in the absence of 
excessive long-term exposure (Melia et al. 1977). The range of 1-hour average $\mathrm{NO}_{2}$ concentrations given above for gas-fired appliances is within this range of a potential risk of acute respiratory disease. (However, the American Gas Association does not support this relationship.)

A review of published and unpublished data related to Chat tanooga, Tennessee, concludes that (French 1975):

- Exposure to prolonged levels of nitrogen dioxide, ranging from 113 to $395 \mathrm{ug}$ per $\mathrm{m}^{3}$, in combination with short-term exposures of 301 to $1,203^{\prime} \mathrm{ug}$ per $\mathrm{m}^{3}$, may contribute to an excess risk of acute respiratory disease and the residual effects. from this exposure may last for as long as 4 years.

- Repeated short-term exposures at 228 to $815 \mathrm{ug}$ per $\mathrm{m}^{3}$ may contribute to an excess risk of acute respiratory disease in the absence of excessive long-term exposures.

- Prior high short-term and long-term exposures to $\mathrm{NO}_{2}$, coupled with continuous excessive short-term exposures, might trigger the onset of chronic respiratory disease symptoms.

Other studies have compared the incidence of reported respiratory illness in households cooking with gas and electricity, but they fail to conclusively oupport the above relationship. Further field studies to determine the effects of short-term $\mathrm{NO}_{2}$ exposure in houses using gas-fired appliances are needed.

The unvented gas space heater has been shown to contribute $\mathrm{NO}_{2}$ to the indoor air. A study conducted in Florida homes found that gas space heaters contribute $222 \mathrm{ppb} \mathrm{NO}{ }_{2}$, which is above the U.S. Primary Air Quality standard (Palmes and Tomezyk 1979). The Consumer Product Safety Commission proposed banning the heaters in February 1978 because of their ability to produce $\mathrm{CO}$ and to deplete room oxygen. The proposed ban was not related to a possible $\mathrm{NO}_{2}$ hazard.

Another aspect of indoor $\mathrm{NO}_{2}$ pollution is the need to monitor and evaluate nitric acid, nitrates, and nitrosamine concentrations. There is also a need for studies of blood level concentrations of methemoglobin in residents of homes with and without gas-fired appliances.

\section{Carbon Monoxide}

Indoor co levels range from 1,000 to 4,000 $\mathrm{mg}$ per hr (400 to 1,000 mg per Kcal), depending upon stove operation. The carbon monoxide gas is relatively unreactive and decays slowly. It is also 
emitted from gas-fired furnaces during normal operations, from leaky furnaces, and from attached garages.

The special hazards of indoor CO buildup are widely known. Studies have shown that indoor concentrations of carbon monoxide often reach potentially hazardous levels, and smoking is an important contributor. Internal combustion engines used in ice skating rinks and school buses are sources of indoor Co known to have caused symptoms of drowsiness, headaches, and nausea in school children. Carbon monoxide levels greater than $50 \mathrm{ppm}$ have been measured in houses with faulty indoor combustion sources (Cote et al. 1974).

An ad hoc committee, established in 1972 by the Bureau of Community Environmental Management, reviewed the effects of $C O$ on human health with the specific objective of developing recommendations for residential standards. Committee members concluded that continuous exposure should not exceed $15 \mathrm{ppm}$ (resulting in about 2.6 percent at equilibrium in the blood of nonsmokers). This level was considered to allow both for the higher $\mathrm{CO}$ concentration tolerance of smokers and the increased susceptibility of cardiac patients.

Considering the ambient standard to be nine ppm for 8 hours, indoor concentrations should not be allowed to raise the baseline air content by more than six ppm. For comparison, $15 \mathrm{ppm}$ has been proposed as the short-term public limit by the National Academy of Sciences (1970). These results are of particular concern when extrapolated to a large population using stoves and heating systems and space heaters fueled with oil and natural gas.

\section{Sulfur Oxides}

Gaseous emissions of sulfur dioxide from gas ovens under various burner and ventilation conditions have been shown to be in the range of 15 to 110 ug per $\mathrm{m}^{3}$ (Hollowell et al. 1976). No available data suggest respiratory hazards due to exposure to indoor sulfur oxide concentrations. Additional work is necessary to show any causeef fect relat Ionship at indoor levels. Information documented for outdoor levels of $\mathrm{SO}_{x}$ suggest the synergistic effects of $\mathrm{SO}_{2}$ with particulates aud of $\mathrm{SO}_{2}$ with sulfates in producing both acute and long-term respiratory system problems; however, the adverse impacts of $\mathrm{SO}_{2}$ alone at common ambient levels are poorly understood.

Even though $\mathrm{SO}_{2}$ concentrations have been shown to be lower indoors than outdoors, the mechanism of $\mathrm{SO}_{2}$ depletion may be a cause of concern since the process involves the oxidation of $\mathrm{SO}_{2}$ to sulfates with potential hydration to form acid mists: The sulfate particles which tend toward micron- and submicron-sized aerosols may be important indoor air pollutants. These suspended sulfate 
particles may remain indoors for some period of time, presenting a persistent health hazard. Further research is needed to study the chemical composition, concentration, and human uptake and impact of indoor sulfates.

\section{Hydrocarbons}

Evaporative and particulate hydrocarbon emission levels assoclated with oil- and gas-operated household appliances are not well known. Saturated aliphatic hydrocarbons present indoors include: the gaseous methane, propane, and butane; and liquid hydrocarbons from pentanes $\mathrm{C}_{5}$ through $\mathrm{C}_{16}$. Methane, the principal component of natural gas, is biologically inert, while other aliphatics are known asphyxiants or irritants. In general, compounds in the series from propane through octanes show increasingly strong narcotic properties, although the thresholds are high. Based on the composition of natural gas burned during cooking and the length of exposure to combustion products in homes, the following equivalent exposure times are given:

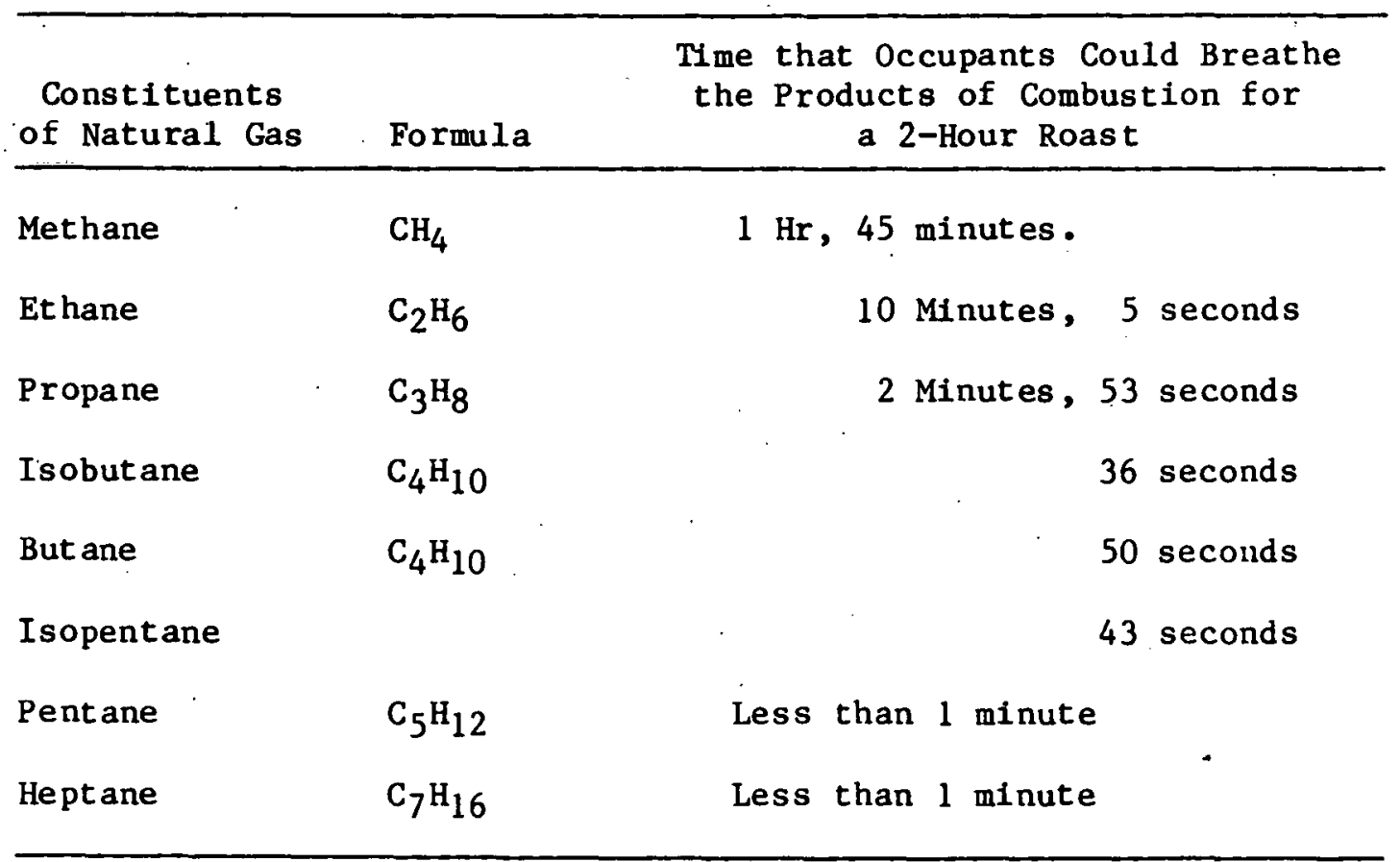

Intermittent, chronic exposure to the products of combustion or partial combustion of these evaporative hydrocarbons could lead to cumulative health effects. The nature and extent of this problem 
should be studied further. The roles of natural gas contaminants such as benzene and metals also are unknown. They could pose potential hazards at long-term, low-level exposures, resulting from the operation of gas appliances. These hydrocarbons, in the presence of indoor nitrogen oxide, may produce secondary pollutants of unknown types and quantities. Aldehydes also may arise from cooking operations and their indoor levels or effects are unknown. All of these problems should be researched.

\section{$\underline{\text { Radioactivity }}$}

The effects of exposure to low levels of lonizing radiation have been studied for many years. Recently, the state of knowledge in this area was summarized in a report of the Committee on the Blological Effects of Ionizing Radiations of the National Academy of Sciences (1980).

The levels of radon released from natural gas combustion in the average home have not been thoroughly quantifled. Presumably they vary from near zero to high levels resulting in over 30 mrem per year (in terms of the dose-equivalent to the bronchial epithelium for persons exposed to radon as a result of natural gas combustion for cooking and space heating). Radon levels in gas presumably vary with the degree of radioactivity strata from which the gas was withdrawn. Since natural gas is transported long distances, this could be a pervasive and serious problem.

The section of this report on indoor pollution lists known emission levels for radon assoclated with oil and gas use. As indoor exposures to radon are known to occur at high levels. from a number of other sources, indoor radon emissions (including those from the use of oil and gas) constitute a national problem that threatens to grow worse. This problem requires immediate steps to assess its full ramifications and to develop control options (Inside Washington Publis hers 1980).

\section{Confounding Factors}

In addition to the effects of pollutants, one must consider the interaction of indoor pollutants with variables such as indoor temperature and humidity. Studies by the Community Health and Environmental Surveillance System (CHESS). of the U.S. Environmental Protection Agency (1978f) and other studies that have been cited imply that ambient air pollutants sause more aggravation of respiratory disease at high temperatures. One study concluded that increasing the relative humidity of occupied spaces from 20 to 50 percent reduces the relative incidence of respiratory conditions among school children (Green 1975). Thus, the use of humidifiers mitigates the ef fects of indoor pollutants. 
Scientists are concerned about human exposure to myrlad organic chemical substances released in the home, such as vapors, liquid phase, dust from aerosol sprays, household cleaners, and insecticides. Based on clinicial observations, it has been suggested that home pollutants affect immune reponse systems, promote collagen, aggravate cardiovascular diseases, and even cause mental illness. More data are needed to conclusively show any relationship among indoor air pollutants generated from oil and gas appliances in the home and other health hazards:

To effectively assess the role and impact of indoor air pollutants, one must await actual exposure measurements performed with proper instruments, and a demonstration of the extent to which exposures overcome physiological defense mechanisms to produce adverse ef fects.

Summary of Research Needs

Several research needs were identified in the discussion above on health effects. There, these were placed in context with supportive documenting justification.

The following summary draws some of this information together, highlighting the research needs.

\section{Stationary Source Combustion}

- Assessment of health effects from air emissions of sulfur, nitrogen, hydrocarbons, and particulates emitted by oil- and gas-fired power plants, as compared to coal-fired power plants (see text for specific information needs).

- Development of an epidemiological information base and monitoring methods for workers exposed to indoor emissions from oil-fired boilers and gas-fired heaters and dryers.

- Development of biological tests for routine medical surveillance of specific hydrocarbon compounds and complex mixtures.

- Development of in vivo tests to study the occupational health effects of inhalation, ingestion, and dermal exposures to distillate and residual heating oils.

- Study of the development of neurobehavioral and reproductive effects following exposure to distillate and residual oil mixtures and fractions in laboratory animals. 
- Study of the long-term health effects of chronic exposure to ambient levels of specific pollutants that accompany the use of o11 and gas.

- Design of clinical studies to test low-level exposures to $\mathrm{SO}_{2}$ and $\mathrm{NO}_{x}$ in volunteer populations.

Mobile Source Combustion

- Study of the toxic effects of exhaust pollutants generated from automobiles fitted with pollution control devices by in vivo and in vitro tests (with emphasis on specific, untreated pollutants).

- Implementation of occupationally-based epidemiological studies to provide morbidity and mortality data regarding gasoline, and diesel exhaust exposure. The sampling should be large enough to detect the low probabilities involved. These should be compounded with the Howard Medical School study of 30,000 rail road workers.

- Initiation of community-based epidemiological studies to provide information on any morbidity and mortality effects of diesel exhaust exposure. These should be compared with the results of occupational studies.

- Design of in vivo and in vitro methods to quantify and compare exposures to diesel and gasoline exhaust (with emphasis on cancer and emphysema).

- Development of biological tests to monitor workers exposed to higher concentrations of gasoline, diesel fuels, and lubricating oils, individually or in groups.

- Development of guidelines for proper fuel use and cleanliness at self service gasoline stations.

- Inftiation of diesel exhaust inhalation exposure studies in animals using various dose levels to detect neurotoxicity, reproductive effects, cardiovascular function impairment, and threshold dose levels for toxic response.

- Evaluation of diesel exhaust mutagenicity by in vivo and in vitro tests that use standard methods precisely and are reproducible.

- Evaluation of carcinogenesis using various fractions of diesel exhausts in in vitro systems. 
- Evaluation of the carcinogenic, co-carcinogenic, and tumor promoting and inhibiting potential of diesel exhaust emissions in laboratory animals following different exposure routes.

- Assessment of the toxic effects of diese1 exhausts in light of variation in fuel and engine operating parameters.

- Development of animal test models to ascertain the fate, clearance, and transport mechanism of inhaled and/or ingested diesel particulate matter.

- Implementation of parallel toxicity studies with diesel and gasoline exhausts to compare relative hazards and public health implications.

- Study of the effects of chronic intoxication in occupationally exposed populations, investigating behavioral, reproductive and cardiovascular hazards.

- Study of the carcinogenic potential of ethylene dibromide, a gasoline additive, at various concentrations.

- Study of olefins, naphthenes, and certain other organic constituents of gasoline to determine their potential toxicity.

- Determination of the effects of benzene with other hydrocarbons and additives in gasoline by in vivo and in vitro studies.

- Quantitative assessment of the health risks due to gasoline vapor exposure.

- Development of tests to study chronic gasoline intoxication in laboratory animals.

- Study of the carcinogenic and dermatosis hazards of lubricating oils via skin contact by skin painting experiments.

- Determination of the neurobehavioral, reproductive, and other systemic effects following inhalation of and dermal exposure to diesel fuels in laboratory animals.

- Study of the synergistic effects of Co and smoking as well as the cumulative effects of carbon monoxide exposure in the workplace.

- Collection of exposure data for defined occupationally exposed populations in automobile and related industries. 
- Study of the blological fate of diesel and gasoline fuels in laboratory animals and the effects of these on biotransformation and detoxification.

Indoor Air Pollution

- Study of the effects on human behavior and health caused by indoor sulfates, oxidants, nitrosamines, dioxins, and nitrates emitted from oil and gas sources or formed from subsequent chemical reactions.

- Determination of effects from short-term $\mathrm{NO}_{2}$ exposures assoclated with effects in home occupants using oil- and gasfired appliances.

- Study of synergistic and/or cumulative health effects of chronic, low-level exposures to indoor pollutants generated from oil- and gas-fired appliances.

- Evaluation of effects of indoor ofl and gas emissions on children, the elderly, the diseased, and persons with preexisting physiological or mental disorders.

- Development of models for calculating human exposure to indoor air pollutants, taking into consideration outdoor and workplace exposures to similar pollutants and individual health histories.

- Design of epidemiological studies and data collection systems to study the morbidity in occupants exposed to oil- and gasgenerated indoor pollutants.

- Development of human exposure standards for indoor pollutants based on exposure levels for both indoor and outdoor sources of oil and gas emissions.

- Design of studies to evaluate effects of air pollution on the public, considering the totality of atmospheric, occupational, and indoor exposures to pollutants emanating from oil and gas use.

- Characterization of household exposure to indoor air pollutants in light of frequency (i.e., continuous, intermittent, infrequent, persistent, etc.) and subsequent effects following different routes of exposures.

- Study of the absorption and inhalation potentials and subsequent fate and deposition of o1l and gas end-use-generated indoor air pollutants in man by in vivo tracer studies. 
- Documentation of the nature and extent of radon radiation from indoor oil and gas use. Sources for study include gas range surface burners and ovens, oil and gas space heaters and furnaces, air conditioning units, dryers, and water heaters.

- Determination of the actual dose-equivalent exposures recelved from all of the above oil and gas related sources in relation to other indoor sources. 
ECOLOGICAL EFFECTS OF OIL AND GAS USE

Ecological effects associated with oil and gas use are less severe than, or perhaps less noticeable when compared with, impacts of other fossil fuel uses (e.g., coal and other facets of the ofl and gas industry). $0 i 1$ and gas end uses primarily impact the ecosystem, particularly vegetation. The effects of end use combustion on aquatic ecosystems are minimal and the aquatic system is covered extensively in other parts of this report, so this subject is not discussed here. However, this section includes a brief discussion of the effects of waste oils on land and water biota.

\section{Effects on Vegetation}

The effects of air pollutants on vegetation generally are discussed in terms of effects on individual plants. These effects are diagnosed to be either highly visible or subtle. Visible effects are identifiable morphologically', while subtle effects can be observed only when growth or physiological changes occur in a plant. Descriptions of injury to vegetation by air pollutants are widely documented in various review articles. Only the significant points in the symptomology are summarized below.

At high concentrations, nitrogen oxides (particularly nitrogen dioxide) affect vegetation by acutely. injuring plants. Low concentrations are known to increase chlorophyll levels, but long-term, low-level exposures may cause early leaf senescence and abscission. Ozone exposure causes a variety of leaf markings, forming stipple, fleck, and necrotic areas on broad leaves, grasses, and conifer needles. Plants sensitive to ozone include oat, petunias, pinto beans, potatoes, radishes, soybeans, sycamores, tobacco, tomatoes, white ash, and white pine. Plants resistant to ozone damage are beets, geraniums, gladiolus, maples, mint, peppers, and rice. Exposure to sulfur dioxide results in visible damage to sensitive plants such as alfalfa, apple, barley, cotton, giant ragweed, pine, squash, and wheat. Plants resistant to sulfur dioxide exposure include cantaloupe, celery, corn, oak, and rhododendron. Peroxyacetyl nitrate sensitive plants are annual bluegrass, petunia, pinto bean, and romaine lettuce, while cesistant plants are broccoli, chrysanthemum, corn, cotton, and sorghum.

The most discussed source of lead enrichment in soils and plants is tetraethyl lead, an antiknock additive in gasoline. The lead content of unwashed plant material from both sides of traffic lanes near major highways is 5 to 10 time that of plants from adjacent fields (Kloke 1975). With stagnant wind conditions, the lead content in roadside plants has increased by as much as 100 times. This contamination has been shown to be external. The lead content of 
plants decreases asymptotically with increasing distance from the traffic lanes and, as a rule, reaches a normal level 100 meters from the highway. The magnitude of the lead content is primarily determined by traffic density, exposure time, wind direction, and specific plant factors. The enrichment of lead on plants is accompanied by lead enrichment in soil and animals such as field mice.

The cadmium content can be increased by diesel vehicles and the use of heating oil in industries, rising from 0.2 to $2 \mathrm{mg}$ per $\mathrm{kg}$. In plants, the increase may be from 0.5 to $1 \mathrm{mg}$ per $\mathrm{kg}$. The cadmium content of $0.22 \mathrm{ppm}$ in the soll at a distance of 32 meters from traffic lanes is increased to $1.45 \mathrm{ppm}$ at a distance of 8 meters (Lagerwerff and Specht 1970). This increase is attributed to the age of the street, traffic density, and wind conditions.

Hydrocarbons historically have been recognized as phytotoxic air pollutants. Ethylene pollution, to a large extent, is attributed to emissions from internal combustion engines. Ethylene has affected vegetation adversely at atmospheric concentrations of $1 \mathrm{ppm}$ or less. A concentration as 1 ow as $0.05 \mathrm{ppm}$ has caused malformation in certain plants--and this concentration is well within the range measured in ambient air. While other unsaturated hydrocarbons such as acetylene, propylene, and butylene produce effects similar to ethylene's, the effects occur at concentrations 60 to 500 times that of ethylene. Naturally produced ethylene serves as a hormone that regulates plant growth and development and other processes such as fruit ripening. Thus, ethylene is unique, serving either as an endogenous plant regulator or a serious phytotoxic air pollutant, depending on its concentration.

In general, rural areas have ethylene levels lower than $5 \mathrm{ppb}$; however, higher levels observed in urban areas are consistent with traffic density and are highly dependent upon topography and meteorological conditions. Peak ethylene concentrations in urban areas have ranged from $<5 \mathrm{ppb}$ to as high as $700 \mathrm{ppb}$, while mean concentrations are considered to be much smaller. With the advent of the catalytic converter, in use on U.S.-built cars since 1975, it is expected that ethylene levels will begin to decrease since the internal combustion engine is responsible for more than 90 percent of the ethylene in ambient air. Ethylene standards have been proposed by various associations, but due to a lack of sufficient data, no standard has been universally adopted. The 1-hour maximum standard recommended by the American Industrial Hygiene Association ranged from 0.25 to $1 \mathrm{ppm}$ ( 287.7 to $1,150 \mathrm{ug}$ per $\mathrm{m}^{3}$ ) and the 8-hour maximum ranges from 0.05 to $0.2 \mathrm{ppm}\left(57.5\right.$ to $230 \mathrm{ug}$ per $\left.\mathrm{m}^{3}\right)$.

Polycyclic organic matter apparently does not induce cancer-like tumors in plant tissues following external exposures. Various investigators have reported absorption of PAHs, such as benzo(a)pyrene, 
pheranthrene, anthracene, pyrene, anthenthrene, benzo(e)pyrene, chrysene, perylene, benzo(a)anthracene, benzo(gh1)perylene, dibenz$(a, h) a n t h r a c e n e$ and coronene, from soll into lettuce, kale, spinach, leeks, and tomatoes (National Academy of Sciences 1972). These hydrocarbons are known to be present in the ambient air and automotive exhaust. (See previous parts of the End Use section for the pervasiveness of these substances with respect to oil and gas end use emissions.) Benzo(a)pyrene also has been detected in various cereal grains. How much of this contamination is due to o1l and gas end use activities or other industrial sources remains undetermined. Also unknown are the long-term exposure effects of massive doses of polycylic compounds on plant growth, development, and reproduction.

\section{Effects on Biota}

Effects on plants and animals are usually not limited to one specific area, but are observed over a great distance because of the nature of oil and gas end use activities (e.g., transportation and combustion). For the oil and gas industry as a whole, these effects are most severe with oil and gas exploration, extraction, refining, and transport and storage activities. Thus, discussion of the effects of hydrocarbon emissions and effluents is contained in the sections of this report dealing with such industrial activities. The potential terrestrial and aquatic hazards due specifically to waste oil disposal are discussed below.

Impacts of Waste 0il Disposal

Waste oils and their proper disposal represent a major area of concern. Indiscriminate disposal of waste oil is potentially detrimental to terrestrial and aquatic ecosystems. Prior to 1972, virtually no information existed on the effects of waste oil on land and in the aquatic environment. Waste oil is introduced in the envirunment primarily through four routes: road oil use (spreading), land disposal, dumping in sewers, and burning.

Recent modification in refinery technology has provided the capability to recycle these oils. Collection, storage, and transportation of these wastes will continue to be constraints until there is some economic incentive favoring recyciling.

Land disposal of used oil is a time-honored practice that affects surface water and land when the discharge is without adequate treatment or proper disposal. The soil is known to be an excellent inedium for growing microorganisms, thus it is capable of assimilating and decomposing organic matter. Soll microbes, with proper application rates and conditions, can assimilate complex organic mixtures 
from waste oils. It is suggested that high molecular weight, viscosity and crystallinity are properties that inhibit biological decomposition. Medium-molecular-welght hydrocarbons such as kerosene and light motor oils oxidize easily, but aromatic hydrocarbons are more resistant.

Adding large amounts of waste oil to land creates anaerobic conditions and the efficiency of decomposition is minimized. Large ofl applications are often toxic to plants. The volatile fractions of these oils have great penetrating power, entering plants and seeds and producing a narcotic effect. This effect is the result of a mechanical obstruction that prevents the plants from obtaining sufficient moisture and air. Land disposal of waste oils has been viewed as a blessing for some types of soils because the long-term effect upon soil is to improve its physical and chemical properties by increasing organic matter and nitrogen content, decreasing its volume-to-weight ratio, and increasing molsture holding capacity (Dotson et al. 1974; U.S. Environmental Protection Agency 1974).

The effects of waste oils in the freshwater medium are studied by determining acute and chronic waste oil toxicity levels for tissue accumulation levels in fish. The studies also characterize virgin oils, waste oils, intermediates, and by-products to identify potential toxic components. The nonvolatile components of waste oils include about 76 percent saturated hydrocabons, 4 percent aromatic hydrocarbons (comprised primarily of alkyl benzenes and polynuclear compounds), 3 percent volatile hydrocarbons, 4 percent polar compounds, and 15 percent particulate material. Metals present include lead (18,500 ug per gm), and zinc (1,350 ug per gm) (Hedtke 1974).

The volatile components of waste oil are alkyl benzenes and naphthalenes, but the freshwater soluble fractions of waste ofl are different, containing 80 percent polar compounds, 3 percent saturated compounds, and 14 percent aromatic compounds. The metal concentrations are as high as 16,000 ug per liter of zinc; 4,400 ug per liter of lead; and 200 ug per liter of molybdenum, selenium, arsenic, chromium, nickel, iron, manganese, copper, and cadmium. Waste ofl is essentially free of chlorinated compounds.

Short-term mortality tests indicate that the approximate level lethal to freshwater fish is 0.1 to 1.1 percent by volume of total oil and a chronic "no effect" level is between 0.08 and 0.35 percent by volume of a water soluble fraction stock solution. Tissue residue analyses indicate a significant accumulation of normal hydrocarbons, zinc, lead, and cadmium; with no accumulation of aromatic hydrocarbons above the ug per gm level. 
Used crankcase oil is demonstrated to be toxic to large marine organisms such as the coot, clam, oyster, and lobster. LD50 concentrations in these organisms range from 1 to $5 \mathrm{ppm}$, while the toxicity to phytoplankton, zookplankton and larval fish ranged from 10 to 50 ppm (Rogerson 1974). Sub-acute studies show that waste crankcase oil causes morphological changes in estuarine fish as well as oysters and scallops.

Studies that characterize sublethal effects and community structure changes are needed before standards can be set to protect marine biota. It has been suggested that fish can produce mutagenic metabolites from PAHs and that used crankcase oils, which are released into the terrestrial and aquatic.environment, may represent a considerable mutagenic threat (Payne et al. 1978). Further research is needed on effects in the following areas: reproductive success of marine organisms, freshwater invertebrates, and more sensitive freshwater fishes; survival and community structure in marine and freshwater field conditions; the sensitivity of organisms to other pollutants or to disease; and the synergistic effects of waste ofl introduced into domestic treatment facilities.

For additional information on the ecological effects of products of oil and gas combustion, of evaporative hydrocarbons, and of waste effluents and leachates, the reader is referred to the Refinery Operations, Transportation and Storage, and Onshore Development sections of this report.

Summary of Research Needs

- Study the biological transport and fate of lead, vanadium, and nickel in soil and their bioaccumulation in plants and food chains, especially with respect to man.

- Determine ways to use waste oils in land forming similar to the way oil is used in refinery sludges. (Technology transfer is needed in this area.)

- Determine the pervasiveness of the automobile owner's clandestine practices for disposing of waste oil and identify mitigating control strategies.

- Identify the extent to which leachates emanate from road surfaces coated with waste oil and their effects on aquatic systems .

- Identify the extent to which evaporative hydrocarbons emanating from road surfaces contaminate nearby crops and other vegetation. 


\section{THIS PAGE \\ WAS INTENTIONALLY \\ LEFT BLANK}

590 
TRANSPORT AND TRANSFORMATION EFFECTS

The air polluting effects of oll and gas use are discussed in this section, since emissions from transportation and oil and gas combustion contribute significantly to total air pollution. The effects of end use activities on water are insignificant when compared with other oil and gas technology sequences such as transportation and storage, refinery operations, and onshore and offshore development. Thus, the sections of this report relating to those technologies discuss water pollution.

The atmospheric emissions from ofl and gas end use activities are subjected to a variety of physical and chemical influences that may lead to the formation of objectlonable products, or the objectionable products may be converted into harmless compounds. The pollutants released from stationary sources and mobile source combustion include primary pollutants (e.g., nitrogen oxides, carbon monoxides, hydrocarbons, sulfur oxides) and secondary products (e.g., photochemical oxidants). Research on air transport and transformation effects is helpful in determining the nature of precursors, the mechanisms of reactions, and the effects of emissions on air quality.

Among the emissions, evaporation of gasoline alone accounts for a mixture of hundrede of species of organic molecules. Even more complicated are the secondary transformation products found in automobile exhausts and emissions from oil- and gas-fired boilers used to generate electricity, process heat, and steam. These products are further exposed to changes through oxidation, ozonation, and photochemical reactions that result in formation of smog, haze, ozone, and peroxyacetyl nitrates. The photochemical air pollution outilined below delineates, in broad terms, the directions that should be taken in collecting data on and researching transformation mechanisms.

Photochemical Air Pollution

When exposed to sunlight, hydrocarbons react with other compounds in the atmosphere, producing ozone and other photochemical oxidants. The chemistry of oxidants formation is described in detail in several publications (National Academy of Sciences 1976b, 1977).

The description presented below is a highly simplified version of the complex chemical reactions leading to photochemical air pollution. It serves to underscore the pivotal role that hydrocarbons and other emissions of end use technologies may have in these processes.

The major photochemical oxidants--ozone $\left(\mathrm{O}_{3}\right)$, nitrogen dioxide $\left(\mathrm{NO}_{2}\right)$, and peroxyacetyl nitrate (PAN)--are secondary pollutants formed in the atmosphere under favorable conditions. Ozone, present 
in the highest concentrations, is the product of a reaction in which common diatomic oxygen $\left(\mathrm{O}_{2}\right)$ reacts with molecular oxygen $(0)$ in the presence of a third molecule or action (M):

$$
\mathrm{O}+\mathrm{O}_{2}+\mathrm{M} \longrightarrow \mathrm{O}_{3}+\mathrm{M} \text {. }
$$

$M$ is usually a nitrogen compound or oxygen. The atomic oxygen (0) reactant is generated largely from the photolysis of nitrogen dioxide $\left(\mathrm{NO}_{2}\right)$ :

$$
\mathrm{NO}_{2}+\mathrm{hv} \rightarrow \mathrm{O}+\mathrm{NO} \text {. }
$$

The reaction mechanism is completed by the reaction of the two reaction products to regenerate nitrogen dioxide and diatomic oxygen:

$$
\mathrm{NO}+\mathrm{O}_{3} \rightarrow \mathrm{NO}_{2}+\mathrm{O}_{2}
$$

The above reactions are the mechanism for atmospheric ozone formation, but alone they do not account for ozone accumulation.

Photochemical hydrocarbon reactions affect the relative rates and the concentrations of products of the above reactions. Modeling and smog-chamber simulations show significant oxidant formation when reactive hydrocarbons are present. Hydrocarbons photochemically regenerate free radicals that react with oxygen to form alkylperoxy and hydroperoxy free radicals. These radicals react with no to form $\mathrm{NO}_{2}$ :

$$
\begin{aligned}
& \mathrm{RH}+\mathrm{O} \longrightarrow \mathrm{Ro}+\mathrm{OHo}, \\
& \mathrm{Ro}+\mathrm{O} 2 \longrightarrow \mathrm{ROOO}, \\
& \mathrm{ROOO}+\mathrm{NO} \longrightarrow \mathrm{NO}_{2}+\mathrm{OHo} .
\end{aligned}
$$

Hydrocarbons are oxidized in the process. These hydrocarbon reactions essentially "pump" the primary reaction of $\mathrm{NO}_{2}$ photolysis by scavenging the reaction's NO product and making available more $\mathrm{NO}_{2}$ reactant. In the process, atomic oxygen is made available for ozone and other oxidant formation. The amount of pumping, and thus the amount of oxidants formed, depends on the concentration and reactivity of the hydrocarbons present.

Table 47 presents a comparison of reactivities of dif ferent types of hydrocarbons. Hydrocarbons are classified with respect to oxidant-related reactivities in urban atmospheres in Table 48. Note that alkenes (olefins), benzene derivatives, and aldehydes have the highest reactivities. Methane, ethane, propane, and benzene do not participate in these reactions. These reactivity data reflect rates 
TABLE 47

COMPARISON OF REACTIVITIES OF DIFFERENT TYPES OF ORGANICS

\begin{tabular}{|c|c|c|c|c|c|c|c|}
\hline \multirow[b]{2}{*}{$\begin{array}{l}\text { Substances of } \\
\text { subclass }\end{array}$} & \multicolumn{7}{|c|}{ Reactivity with respect to designated effects, 0 to 10 scale } \\
\hline & $\begin{array}{l}\text { Ozone or } \\
\text { oxidant }\end{array}$ & $\begin{array}{c}\text { Peroxy- } \\
\text { acyl- } \\
\text { nitrate }\end{array}$ & $\begin{array}{l}\text { Formal- } \\
\text { dehyde }\end{array}$ & Aerosol & $\begin{array}{l}\text { Eye } \\
\text { irrita- } \\
\text { tion }\end{array}$ & $\begin{array}{l}\text { Plant } \\
\text { damage }\end{array}$ & $\begin{array}{l}\text { Overall } \\
\text { reactivity }\end{array}$ \\
\hline$c_{1}-c_{3}$ paraffins & $\mathbf{0}$ & 0 & 0 & 0 & $\mathbf{0}$ & 0 & $\mathbf{0}$ \\
\hline Acetylene & $\mathbf{0}$ & 0 & 0 & $\mathbf{0}$ & 0 & $\mathbf{0}$ & $\mathbf{0}$ \\
\hline Benzene & 0 & 0 & 0 & $\cdots 0$ & 0 & $\mathbf{0}$ & $\mathbf{0}$ \\
\hline$C_{4+}$ paraffins $^{a}$ & $0-4$ & $0^{b}$ & $\mathbf{0}^{b}$ & 0 & $0^{b}$ & 0 & 1 \\
\hline $\begin{array}{l}\text { Toluene (and other } \\
\text { monoal kylbenzenes) }\end{array}$ & 4 & $\mathrm{ND}^{\mathrm{C}}$ & 2 & 2 & 4 & $0-3$ & 3 \\
\hline Ethylene & 6 & 0 & 6 & $1-2$ & 5 & $+b$ & 4 \\
\hline 1-alkenes & $6-10$ & $4-6$ & $7-10$ & 4-8 & 4-8 & $6-8$. & 7 \\
\hline Diolefins & $6-8$ & $0-2$ & $8-10$ & 10 & 10 & $0^{b}$ & 6 \\
\hline $\begin{array}{l}\text { Dialkyl- and trialkyl- } \\
\text { benzenes }\end{array}$ & $6-10$ & $5-10$ & $2-4$ & $+^{e}$ & $4-8$ & $5-.10$ & 6 \\
\hline $\begin{array}{l}\text { Internally dousle- } \\
\text { bonded olefins }\end{array}$ & $5-10$ & $8-10$ & $4-6$ & $6-10$ & $4-8$ & 10 & 8 \\
\hline Aliphatic aldehydes & $5-10$ & $+e^{e}$ & $+e$ & NDC & $+^{e}$ & $+e$ & -- \\
\hline
\end{tabular}

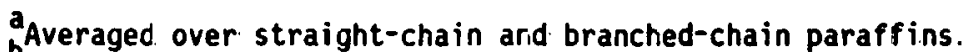

Very small yields or effects may occur after long irradiations.

No experimental data avaialble.

Includes measurements on propylene through 1-hexene, 3-ethyl-1-butene and 2,4,4-trimethyl-1-1-pentene.

Effect noted experimentally, but data insufficient to quantify.

Source: U.S. Environmental Protection Agency 1980. 
TABLE 48

CLASSIFICATION OF ORGANICS WITH RESPECT TO OXIDANT-RELATEO REACTIVITY IN URBAN ATMOSPHERES

\begin{tabular}{|c|c|c|}
\hline $\begin{array}{l}\text { Class I } \\
\text { (Low reactivity) }\end{array}$ & $\begin{array}{l}\text { Class II } \\
\text { (Moderate reactivity) }\end{array}$ & $\begin{array}{l}\text { Class III } \\
\text { (High reactivity) }\end{array}$ \\
\hline $\begin{array}{l}C_{1}-C_{3} \text { paraffins } \\
\text { Acetylene } \\
\text { Benzene } \\
\text { Benzaldehyde } \\
\text { Acetone } \\
\text { Methanol } \\
\text { Isopropanol } \\
\text { Tert-alkyl alcghols }{ }^{a} \\
\text { Methyl acetate } \\
\text { Methyl benzoate } \\
\text { Ethyl amines } \\
\text { N, N-dlmethy } \\
\text { formamide } \\
\text { Perhalogenated } \\
\text { hydrocarbons } \\
\text { Partial ly halogenated } \\
\text { paraffins } \\
\text { Mono, dichlorobenzenes } \\
\text { Methyl ethyl ketone }\end{array}$ & $\begin{array}{l}\text { Tert-monoalkyl benzenes } \\
\text { Cyclic ketones } \\
\text { Tolualdehydes } \\
\text { Tert-alkyl acetates }{ }^{a} \\
\text { 2-Nitropropane } \\
C_{4+} \text { paraffigs, cyclo- } \\
\text { paraffins } \\
\text { Ethanol } \\
\text { Prim, sec } C_{3+\text { alkyl }} \\
\text { N, N-dimetth6t acetamide } \\
\text { n-alkyl } C_{5+} \text {-ketones }\end{array}$ & $\begin{array}{l}\text { Prim-, sec-, monoalkyl } \\
\text { benzenes } \\
\text { Dialkyl benzenes } \\
\text { Styrene } \\
\text { N-Methyl pyrrolidone } \\
\text { Partially halogenated } \\
\text { olefins } \\
\text { Aliphatic olefins } \\
\text { Tri-, tetra-alkyl } \\
\text { benzene } \\
\text { Methyl styrene } \\
\text { Brancher alkyl kotones } \\
\text { Unsaturated ketones } \\
\text { Aliphatic aldehydes } \\
\text { Diacetgne alcohol } \\
\text { Ethers } \\
\text { 2-Ethoxy-ethanol }\end{array}$ \\
\hline
\end{tabular}

${ }^{a}$ Currently classified as not photochemically reactive under Los Angeles County Rule 66 and similar regulations.

Source: U.S. Environmental Protection Agency 1980. 
of formation rather than resulting peak oxidant concentrations. With lesser reactive hydrocarbons, the same reactions occur at a slower rate over a longer period of time.

A number of conditions affect the formation and bulldup of ozone concentrations. Moist air significantly aids ozone formation. In the absence of hydrocarbons, an equilibrium is established among ozone, nitric oxide, and nitrogen oxide. Concentrations of these compounds and reactive hydrocarbons change diurnally in response to available sunlight. Atmospheric particulate components, such as metal oxides and carbon particles, have a catalytic effect on many photooxidation reactions.

Besides $0_{3}$, several other compounds are known photochemical oxidants, including $\mathrm{NO}_{2}$, hydrogen peroxide $\left(\mathrm{H}_{2} \mathrm{O}_{2}\right)$, organic peroxides, organic hydroperoxides, and peroxyacetyl nitrate. Organic peroxides have the general formula ROOH. The major peroxyacyl nitrates are peroxyacetyl nitrate (PAN) and peroxybenzoyl nitrate $(P B N)$. (Actually, this nomenclature is inappropriate for these structures--better names would be acetyl peroxynitrate and benzoyl peroynitrate.)

Atmospheric hydrocarbon measurement data are deficlent. Most available data concern only total hydrocarbon concentrations measured by flame-ionization detectors (FID) (U.S. Environmental Protection Agency 1980b). Nonmethane hydrocarbons (NMHC) are measured by gas chromatographic separation of methane from total hydrocarbons, followed by FID measurement of methane and total hydrocarbons in the air sample. NMHC data are obtained by subtracting methane from total hydrocarbon concentrations. Since the FID responds to organically bound carbon in compounds other than hydrocarbons, the measurement of NMHC may more appropriately be termed nonmethane organic compound (NMOC) measurement (U.S. Environmental.Protection Agency 1980). FID techniques have been associated with high measurement errors and variability. This must be considered when NMHC data are compared with exposure data from toxicity studies and used for air quality monitoring. It is apparent that FID measurements may be inadequate for the complete characterization of hydrocarbons in ambient air.

\section{Single Source Pollution}

Air pollution caused by gaseous effluents from single or small groups of stacks has been extensively studied. It is regarded as a local problem (except that tall stacks contribute to the long dis-. tance transport of pollutants). Primary emission concentrations of concern generally occur at distances ranging from the immediate vicinity of the stack to those on the order of several kilometers. Maximum ground-level concentrations tend to occur within this range 
but not adjacent to the stack. The transport and transformation effects related to a single emission are well described in the refinery operations section of this report. A large number of stack emissions spread over a large urban area produce a different type of air pollution problem. Variables such as wind speed, humidity, and temperature affect the resulting pollutant concentrations.

Ozone formation is not commonly observed in coal-fired power plant plumes. However, dispersed in urban areas, particles released from the combustion of coal may have a direct influence on oxidant formation. Hydrocarbons adsorb onto these particles. In metropolitan areas such as Houston, atmospheric hydrocarbons are paraffinic (least reactive and have minor effects on public health). Irradiation of hydrocarbons adsorbed on these alrborne particles initiates the formation of olefinic hydrocarbons (more reactive than their precursors in terms of photochemical processes). It is possible that there is some synergism between the irradiation and catalytic constituents of the supporting particles (Nahm 1976).

Indoor Pollution

The two major sources of indoor air pollution are infiltration from outdoor amblent air and generation of pollutants in the indoor environment due to activities such as cooking, heating, and smoking. Pollutants entering buildings from outdoor ambient air include $\mathrm{SO}_{2}$, $\mathrm{NO}_{x}, \mathrm{CO}, \mathrm{HC}$, oxldants, and suspeuded particulates. Other pollutants of outdoor origin for which researchers have considered indoor and outdoor concentrations have included the respirable fraction of particles, free metals, blological aerosols, $\mathrm{CO}_{2}$, carbon disulfide, hydrogen sulfide, and peroxyacetyl nitrate. For almost all outdoorgenerated pollutants, researchers have found that indoor concentrations are lower than those outdoors, except in the upper floors of bulldings adjacent to heavily-traveled streets.

The concentration, residence time, and decay rates of indoor pollutants depend on building ventilation and the indoor climate. Apparently, no important research has dealt with indoor chemical formation of secondary pollutants (e.g., sulfates and nitrates).

In general, the area of chemical transformation and fate of indoor pollutants has not been addressed in depth. Data on indoor emissions of criteria pollutants and their distribution and behavior are limited to measurements on the production of carbon monoxide and nitrogen oxide in gas stoves. This scarcity is probably a function of the technological difficulties involved in measuring the fugitive, uncontrolled generation of indoor air pollutants from gas stoves, space heaters, and old, leaky furnaces fueled with oil and gas. 
Sulfur dioxide emissions have been attributed to faulty, oilfueled heating plants in buildings and homes. Various investigators have suggested that the $\mathrm{SO}_{2}$ concentration inside a building is a function of the ambient outdoor concentration. They have found indoor $\mathrm{SO}_{2}$ levels to be lower than outdoor concentrations. This reduced level is attributed to the $\mathrm{SO}_{2}$ adsorption by walls, cellings, and other interior surfaces. The role of higher relative humidity and its affect on $\mathrm{SO}_{2}$ levels inside a house or commercial. building is not known. In addition, the dynamics and the extent of transformation of $\mathrm{SO}_{2}$ to sulfate within a dwelling is essentially unknown. Normally, outdoor transformation is a result of the relatively long reaction time for $\mathrm{SO}_{2}: \mathrm{SO}_{4}$, rather than the short residence time of $\mathrm{SO}_{2}$ in the indoor environment.

Carbon monoxide levels also are suggested to be lower indoors than outdoors. $\mathrm{CO}$ is relatively unreactive and decays much more slowly than $\mathrm{SO}_{2}$. Indoor $\mathrm{CO}$ emissions are likely to be from gasfired appliances, leaky furnaces, and attached garages. Indoor smoking also contributes $C O$, causing the concentration to increase to six or seven times the background level.

The General Electric Company (1972) investigated the Co behavior in two high rise bulldings and reported that indoor co concentrations were lower than those outdoors at heights lower than 100 feet above the roadway; while at higher elevations, Co concentrations were higher indoors than outdoors. This was attributed to the entrapment of $C O$ within the building. It has been demonstrated that carbon monoxide emissions from a gas stove have a significant effect on indoor Co levels (Geomet 1977). Table 49 illustrates the results from one such survey. This table Indicates that co concentrations. we re differentially dependent upon background or outside concentrations and indoor stove use. Lawrence Berkeley Laboratory measurements lend support to this result. In houses where higher $C O$ concentrations were found, the problem was traced to unvented space heaters or heating stoves, to oil- or gas-fired furnaces used for central heating, and to combinations of these sources.

Nitrogen oxide concentrations found indoors are attributed to both infiltration from the outdoor environment and to emissions from gas-fired household heating and cooling systems. In a field study conducted in Hartford, Connecticut, investigators found that more NO than $\mathrm{NO}_{2}$ was generally generated from gas stoves (Cote et al. 1974). NO was found to behave much like monitored $\mathrm{CO}$, with peaks associated with rush hour automobile traffic.

Indoor $\mathrm{NO}$ and $\mathrm{NO}_{2}$ concentrations, to the extent that they arise from outdoor-generated pollution, depend upon a building's 
TABLE 49

SUMMARY OF INDOJR AND OUTDOOR CO DATA

\begin{tabular}{|c|c|c|c|c|c|c|c|c|}
\hline \multirow[b]{2}{*}{$\begin{array}{l}\text { House } \\
\text { Number }\end{array}$} & \multirow[b]{2}{*}{$\begin{array}{l}\text { Sampling } \\
\text { Period }\end{array}$} & \multicolumn{5}{|c|}{$\begin{array}{l}\text { Daily Average Co Concentrątion } \\
\text { in Each Locatio } \lambda \mu \mathrm{g} / \mathrm{m}^{3}\end{array}$} & \multirow{2}{*}{$\begin{array}{c}\text { Total } \\
\text { Stove } \\
\text { (oven plus } \\
\text { burners) } \\
\text { Use } \\
\text { (mins/day) }\end{array}$} & \multirow[b]{2}{*}{$\begin{array}{l}\text { Number of } \\
\text { Days of Valid Data }\end{array}$} \\
\hline & & $\begin{array}{l}\text { Kitchen } \\
\text { Over } \\
\text { Stove }\end{array}$ & $\begin{array}{l}\text { Kitchen } \\
\quad 1 \mathrm{~m} \\
\text { From Stove }\end{array}$ & $\begin{array}{l}\text { Living } \\
\text { Room }\end{array}$ & $\begin{array}{l}\text { Bed- } \\
\text { room }\end{array}$ & Outside & & \\
\hline \multirow[t]{3}{*}{1} & $\begin{array}{l}\text { Spring - } \\
\text { Summer }\end{array}$ & -- & 4,490 & 4,070 & 4,170 & 3,480 & 198 & 9 \\
\hline & $\begin{array}{l}\text { Fall - } \\
\text { Winter } \\
\text { lst half }\end{array}$ & 4,190 & 3,520 & 3,230 & -- & 1,670 & 106 & 4 \\
\hline & $\begin{array}{l}\text { Fall - } \\
\text { Winter } \\
\text { 2nd half }\end{array}$ & 4,790 & 4,210 & -- & 3,830 & 2,310 & $\begin{array}{c}\text { (Unavail- } \\
\text { able) }\end{array}$ & 6 \\
\hline 2 & $\begin{array}{l}\text { Spring - } \\
\text { Summer }\end{array}$ & 3,000 & -- & 3,080 & 2,900 & 2,940 & 43 & 3. \\
\hline \multirow[t]{3}{*}{3} & $\begin{array}{l}\text { Spring - } \\
\text { Summer }\end{array}$ & 4,310 & - & 3,210 & 2,680 & 2,230 & 37 & 13 \\
\hline & $\begin{array}{l}\text { Fal1 - } \\
\text { Winter } \\
\text { lst half }\end{array}$ & $\begin{array}{c}7,820 \\
.\end{array}$ & 6,420 & $\begin{array}{r}5,070 \\
:\end{array}$ & - & 3,380 & 66 & 6 \\
\hline & $\begin{array}{l}\text { Fall - } \\
\text { Winter } \\
\text { 2nd half }\end{array}$ & 7,130 & 6,620 & -- & 5,500 & 2,500 & 115 & 8 \\
\hline 4 & $\begin{array}{l}\text { Fall - } \\
\text { Winter }\end{array}$ & 9,070 & 9,000 & 8,190 & - & 2,410 & 201 & 6 \\
\hline
\end{tabular}

Source: U.S. Environmental Protection Agency 1977d. 
proximity to sources generating the pollutants. No research information is available on indoor mechanisms for determining nitrate and nitrosamine formation.

Hydrocarbon emissions from indoor uses of ofl and gas have not been documented. Unmeasurable, low levels of volatile and particulate hydrocarbons may be emitted during gas stove cooking and o1l- or gas-fired heating. The hydrocarbon transport and transformation effects are not known. Formation of ozone may be possible, provided hydrocarbons and $\mathrm{NO}_{\mathrm{x}}$ are present indoors under favorable conditions. This unknown should be studied in detail.

Indoor air quality monitoring technology is not currently available. For monitoring and characterization purposes there is a strong reliance upon the techniques and instruments developed for ambient air and occupational health monitoring. Adaptation and development of new instrumentation methods would be essential for assessing indoor air quality. Many indoor-generated pollutants are emitted in a "fugitive" manner, i.e., they enter the indoor atmosphere through uncontrolled evaporation from surfaces, leaks from faulty combustion systems, from gas stove burners, or pllot lights on stoves.

Indoor air pollutant levels vary with the following activities of occupants: opening and closing of doors and windows; use of heating, ventilating, and air conditioning systems; and use of household sprays, fumigants, cleaners, and polishes.

Indoor air quality is also affected by various energy conservation measures, including: minimizing heat flow from the building to the outside by insulating, and caulking; making structural changes such as installing storm doors and windows that reduce air change rates; and modifying heating and cooling systems. These indoor activities and conservation measures modify the transport and transformation effects of indoor air pollutants, thus affecting potential pollutant related health hazards. Research to identify the effects of conservation measures is essential and studies in the area of air filtration are underway.

Summary of Research Needs

The following is a brief summary of transport and transformation research needs that would provide clarification and detailed information. 


\section{Effects}

\section{Atmospheric Pollution}

- Development of atmospheric models to study transport mechanisms and the fate of ofl- and gas-generated emissions in the immediate vicinity of and downwind from sources. These should be specific to oll or gas and focus on fugitive emissions.

- Assessment of oil- and gas-generated air pollutants and their behavior relevant to other sources that contribute to total loading. This is important since there will be similar emissions from synthetic fuel facilities and synfuel combustion.

- Development of mathematical reaction models to study ethylene levels in urban areas with increasing traffic density and the rate of reaction product formation (in this era of catalytic converter use) (e.g., perchloroethylene, ethylene dichloride, and ethylene dibromide).

- Collection of data relevant to the photocatalytic processes that can convert innocuous hydrocarbons into polynuclear aromatic species that would be of concern for public health.

- Collection of data on the hydrocarbon species present in aerosol particulate matter emitted in combustion.

- Collection of data on organometallic substances in particulate emissions that may serve as catylysts, solvation agents, or residual valence forces responsible for adsorption.

- Identification of the changes in qualitative profiles of emissions resulting from technology and design changes, fuel conversion, etc., which may affect profiles of ambient hydrocarbon levels.

- Utilization of tracer hydrocarbons such as acetylene to indicate the contribution of hydrocarbons from the combustion of each oll and gas product (gasoline, natural gas liquids, and fuel oils) to total nonmethane hydrocarbon concentrations.

\section{Indoor Pollution}

- Development of models to study pollutant decay and transformation products in homes using oil- and gas-fired furnaces, stoves, and ovens. 
- Identification of products of interactions of indoor air pollutants and of the effects of temperature, humidity, air flow patterns, and number of occupants on such interactions, as well as associated health effects.

- Study of the transport patterns of indoor and outdoor pollutants in and around the house, especially with regard to energy conservation measures such as insulation, and solar heating and cooling.

- Design of indoor standards for $\mathrm{NO}_{\mathrm{x}}, \mathrm{CO}, \mathrm{SO}_{\mathrm{x}}$, and hydrocarbons, taking into consideration oil and gas appliances.

- Study of the potential for the indoor formation of secondary pollutants ( $1 . e .$, sulfates, nitrates, oxidants, nitrosamines).

- Study of indoor/outdoor air exchange patterns in homes and buildings as a function of structural design (e.g., high rise cellings, multi-story stairwells).

- Study of the cumulative effects of indoor pollutants generated from indoor activities considering sources other than oil and gas end uses (e.g., aerosol sprays, solvents, paints). This is critical to an understanding of compounding variables.

\section{Characterization, Measurement, and Monitoring}

\section{Stationary Source Combustion}

- Characterization of fíy ash particles for identifying trace metal compounds emitted from oil-fired power plants and the potential for catalytic activity on the particle surface.

- Development under field conditions of real-time measurement of ambient volatile compounds near heavily traveled streets.

- More extensive determination of the composition and rate of emissions functions of boiler and burner type, fuel characteristics, air/fuel ratio, and fuel load. Much EPA research already has been performed in this area, however, the need for both energy efficiency and purity of combustion requires that this become a major research thrust, especially in light of emerging indoor pollution problems in large industrial and commercial buildings. 
- Study of seasonal variations in emissions levels from distillate oil- and waste oil-fired residential and commercial heating units, especially with respect to indoor and local outdoor pollution episodes.

- Identification of chlorinated hydrocarbons and dioxins in airborne particulates from oll-fired power plants.

- Determination of the potential for olefin formation on particles emitted from coal-fired power plants as a result of the irradiation of absorbed hydrocarbons released from oil and gas combustion.

\section{Mobile Emissions}

- Characterization of exhaust particles from gasoline- and diese1-powered automobiles (see text for details).

- Development of refined methods to measure and monttor automobile exhaust constituents.

- Assessment of interactions among exhaust constituents during collection and storage and identification of reaction products.

- Develupweul of slandardized cechniques for intérp̈reting diesel emisstons source data.*

- Development of an ethylene monitoring system for specific geographic areas, e.g., California (Los Angeles), Colorado (Denver).

- Identification and quantification of suspected carcinogens, nitrosamines, chlorinated dioxins, and other potentially toxic substances in gasoline and diesel exhausts.

- Quantification of polycyclic aromatic hydrocarbons and measurement of the effects of variables on hydrocarbons emitted from light duty vehicles.

\footnotetext{
* In a recent Ford Motor Company study of emissions from diesel engines, chromatographic and mass spectrometric techniques were employed to ascertain that most of the biologically active species were oxidation products. The majority of more than 100 compounds identified were formed during sampling or storage, or during the separation process; therefore, caution is advised in interpreting all diesel emissions source data until standarized techniques are developed. The development of these techniques is a high priority.
} 
- Development of uniform, standardized, and quality controlled data gathering and reporting system. This is necessary to assess hazards related to oll and gas end use.

o Characterization of diesel odor components and development of control methods and materials.

- Development of environmentaily safe substitute additives to be used in diesel and gasoline fuels such as smoke and odor suppressants and antiknock agents (see text for details).

- Determination of hydrocarbons, organic lead vapors, and other toxic constituents of exhaust. In busy garages, bus depots, and service stations.

\section{Indoor Air Pollutants}

- Development of sensitive instruments to measure and detect low levels of Indoor air pollutants generated from 011 and gas appliances.

- Measurement of evaporative hydrocarbon levels when a gas stove and oven are in use, and when only the pilot light is in operation.

0 : Collection of data on the dosages of an indoor alr pollutant that an individual would recelve when exposed to varying concentrations for different lengths of time.

- Comprehensive quantitative measurement of all indoor air pollutants generated from stoves, ovens, and furnaces.

- Development of sensitive instruments and appropriate sensing methods for measuring low levels of indoor radon emissions, especially with regard to natural gas range surface burners and ovens.

- Study of the effects of energy conservation measures on indoor pollutant levels and their residence time.

- Development of monitoring methods to detect and collect information on indoor concentrations of nitric acid, nitrosamines, and nitrate.

- Development of an information base. and exposure inventories together with well designed field measurements for indoor air pollutants. 
- Development of reliable instruments that can continuously monitor indoor emissions over longer periods of time.

- Development of simple, real-time detectors of the toxic indoor concentrations of pollutants.

- Study of the frequency with which $\mathrm{SO}_{2}, \mathrm{CO}$, $\mathrm{NO}_{x}$, sulfates, nitrates, and hydrocarbons occur in the indoor air.

- Determination of chlorinated dioxins in indoor airborne particulates emitted from oil- and gas-fired appliances that could be collected on electrostatic precipitators. 


\section{Part 8}

Unconventional Resources 
Few health and environmental effects studies related to the various unconventional energy technologies have been performed. In this section, relevant research needs are discussed along with effects issues associated with each of the technologies.

of overriding and critical importance with respect to these emerging techologies is the need to exchange information among researchers and project managers associated with technological development. The techniques proposed for recovering oil from U.S. tar sands are also applied to recovery of deep light oils and heavy oils, as well as enhanced recovery of oil shale by in situ techniques. Some heavy oils are produced in California and Texas by the rmal methods (and are included in conventional oil reserve estimates). Gas from geopressured brines, easterm shales, western tight sands, and deep basins is expected to be extracted through the application of fracturing and use of drilling muds--methods that are also employed to recover the resources named above.

The resources discussed in this section are classified by various Federal agencies under different programs, depending upon the. agency's convenience and statutory mandates, pricing categories for the resource, and definitions of conventional versus unconventional resources. As an example, research in support of heavy oil may be categorized as conventional crude oil research by one agency and as support of synthetic fuels development by another (the Energy security Act classifies undeveloped heavy crude as a synthetic fuel). As a result, many duplicative development and research strategies are taking place. Health and environmental research would often apply to several techologies. An information transfor strategy is needed which will enable relevant generic, regional, and process-specific research to be brought to bear on solving similar oil and gas health and environmental effects problems. 
THIS PAGE

\section{WAS INTENTIONALLY \\ LEFT BLANK}


UNCONVENTIONAL RESOURCES

TABLE OF CONTENTS

$\underline{\text { Page }}$

OIL 609

The Sources 609

$0 i 1$ Mining 609

Heavy Crude Oil

612

Tar Sands

614

Health and Environmental Issues and Research Needs

oil. Mining

619

Heavy Crude $0 i 1$

620

Tar Sands

621

Information Transfer

622

624

The Sources

624

Methane-Saturated Brines

624

Eastern Gas Shales (Devonian Shales)

625

Western Gas Sands (Tight Sands)

626

Methane from Coal Seams and Mines

626

Methane Hydrates

628

Gas from Deep Basins

630

Gas from Biomass

631

Health and Environmental Issues and Research Needs

631

Methane-Saturated Brines

631

Eastern Gas Shales (Devonian Shales)

633

Western Gas Sands (Tight Sands)

633

Methane from Coal Seams and Mines

634

Methane Hydrales

635

Gas from Deep Basins

635

Gas from Biưnass

635 
THIS PAGE

\section{WAS INTENTIONALLY \\ LEFT BLANK}




\section{UNCONVENTIONAL RESOURCES}

Within this section, various new sources of oil and gas are discussed. Some of these new sources are already contributing to the domestic oil and gas supply base. These are not treated in as much depth as the conventional oil and gas industry, but are presented as examples of substantial future inputs from non-conventional sources. (Although addressed in other Committee-sponsored reports, synthetic oil and gas from coal and oll shale should be noted as new sources.) As they are developed, these new sources will probably change the character of the oil and gas industry--enhancing its diversity of resources, processes, distribution systems, and marketing patterns.

OIL

In the last 100 years, more than 450 billion barrels of oil have been discovered in the U.S; however, only about 115 billion barrels have been produced. Advances in conventional drilling and well completion technology can allow only for the production (including enhanced recovery) of another 30 billion barrels from these fields, leaving about 305 billion barrels. Another 26 billion barrels of oil are contained in Utah's tar sands; 30 billion barrels of heavy, viscous oil are located in California; and blllions more are located elsewhere in shallow diatomite formations and in tar sands. Much of this oil is recoverable with new oil mining techniques. These new methods and resources are discussed in this section.

The Sources

\section{Oil Mining}

The term "oil mining" encompases several new and innovative processes used primarily to extract thick and heavy oil. These techniques include: (1) removing oil-bearing rock through conventional mining techniques and heat extraction of the crude; (2) excavating huge pits down to the oil bearing formation and applying chemicals to loosen the oil, and (3) the excavation of a series of tunnels underlying the ofl-bearing formation with holes projecting upward to allow oil to collect within the tunnels for recovery.

These processes are attractive because they apply not only to heavy crude, but also to tar sands, and to oil fields of lighter crude where conventionally recoverable supplies of crude have been exhausted. It has been estimated that ofl mining can increase the economically exploitable U.S. oil reserves 10-fold. As the price of oil rises, the mining of it underground or on the surface will become economically more attractive (Smith 1979; Dick and Wimpfen 1980). 
The conventional method of ofl extraction by drilling is highly inefficient, leaving 40 to 60 percent of the oil in the ground, even with the use of enhanced oil recovery techniques. This efficiency of recovery is in contrast to some mineral mining operations that recover up to 90 percent of the ore. Much of the oil left behind after conventional recovery can be mined.

The concept of oil mining is not new. At Macksburg, Ohio, in 1865, a large-diameter shaft was sunk in place of the small drill hole of a well that had begun to yield a small amount of oil and much water. A small quantity of oll was then skimmed from the top of the water in the large hole. In California the following year, a series of tunnels was excavated slanting upward into a natural oil seep area on a mountainside. From each of 30 tunnels, between 1 and 20 barrels of ofl per day were gravity fed at the tunnel mouth. These and other tunnels dug in the 1890 s continued to produce oil for several decades.

In 1932 a. U.S. Bureau of Mines study of oil mining feasibility concluded that the method could bring large financial returns and recover oil that would otherwise be lost in U.S. oil fields (Rice 1932).

011 mining in Europe began in 1735 with the excavation of tunnels into an oil bearing formation in France. By the 1930s the underground tunnel network had been extended to an area covering three square miles. In Germany, oil mining began at Wietze in the late 19 th century and gained some significance in World War I when a shaft 13 feet in diameter was sunk to a depth of 495 feet. 011 skimmed from this shaft totaled 127,000 barrels in 1918 (Dick and Wimpfen 1980).

Currently, oil mining is centered in Canada and the Soviet Union. In Canada, oil mining is utilized in the excavation and removal of oil from tar sands. In western Russia, where only 2 percent of the Yarega oil field could be tapped by conventional drilling and pumping, shafts were sunk to a depth of 500 feet to aid in the recovery of heavy oil. Horizontal gallaries radiate from each shaft. Inclined passages extend from each gallery down into the oil-bearing formation to a production gallery as large as 80 feet in diameter. Uptilted holes radiate from each production gallery for a distance as long as 800 feet. Steam, injected into the reservoir rock from the horizontal galleries, aids in promoting the flow of the heavy oil into the collection holes. It is estimated that the combination of subsurface excavation, lateral drilling from the production galleries, and steam injection will make it possible to recover up to 60 percent of the oil in the reservoir. More than 300 other reservolis of heavy ofl in the Soviet Union are being considered for application of the oil mining technique (Dick and Wimpfen 1980). 
Conoco has been operating a 50-barrel-a-day underground mining plant for the last 3 years on a shallow ofl fleld near Casper, Wyoming. The oil is drained into a 2,000-foot-long horizontal shaft, 180 feet underground. Getty 011 Company is constructing a $\$ 21 \mathrm{~m} 11-$ lion pilot plant at its McKittrick field outs1de Backersfield. The plant is expected to produce 20,000 barrels a day by the late 1980 s. The fleld, under a decline in production, is expected by Getty to produce 400 million barrels, largely through digging and processing the carbon-rich diatomite before the field is mined out. This production will amount to almost twice the total production from the field during the 80 years it has been tapped (Smith 1979). The processing will be performed by two methods which will be evaluated. One is a coal liquefaction process and the other utilizes a solvent proven successful in extracting vegetable oll from soybeans.

The exploitation of the tar sands of Utah, New Mexico, California, Texas, and the eastern states by the emerging U.S. tar sands industry is expected to utilize surface mining to a large extent. Researchers at the University of Utah predict that up to 150,000 barrels a day of o11 can be produced from unt processes that depend upon mining tar sands (Smith 1979; see the section on tar sands below).

The Kern County, California, deposits of heavy o11 are expected to be recovered, largely through ofl mining techniques (see the section on heavy crude oil below).

The concept of ofl mining incorporates surface mining, in situ, and underground mining. Surface strip mining is efficient for deposits at depths down to 180 feet in flat terrain. Open-pit mining is suitable for deposits with irregular surface topography and those that are deeper than 180 feet. Surface terrace mining, a variation of open-pit mining that involves outwardly spiraling strip mining, is applicable to relatively shallow deposits covering a wide area.

Underground mining is relatively inefficlent for oil mining since the ofl bearing rock is brought to the surface much like bituminous coal. Rock formations strong enough to be safe for tunneling have a low oil content. Conversely, when the proportion of oll to rock is high enough to make mining the oil economically attractive, the rock surrounding the tunnels is dangerously weak (Dick and Wimpfen 1980).

The most promising ofl mining method is a modified in situ approach similar to that practiced in the Soviet Union. The operation requires the presence of a structurally sound rock stratum adjacent to and under the oil reservoir. Working in underlying tunnels, miners would drill and extend solid casings up through the water zone 
of the reservolr to the oll zone. Thus, oll would seep through perforations in the end of the casings and drain into a collection system in the tunnels below.

\section{Heavy Crude 011}

Heavy crude, as the name implies, is more dense than conventional crude o1l. Its specific gravity is generally considered to be less than 20 degrees, compared to 34 degrees for the ofl industry's standard, Saudi Arabian 11ght crude oil (Kotkin 1979). It is more expensive to extract and difficult to refine, partly due to its high content of sulfur and other impurities. Often the ofl must be heated to keep it adequately fluid.

The avallabllity of heavy ofl as a major energy source is related, In large measure, to economics. Former President Carter ordered an end to price controls on heavy crude ofl in an attempt to "significantly increase production in American crude oll reserves" and consequent1y add to the nation's energy security (Schram 1979). This action is expected to increase the current production of heavy crude ofl of 250,000 barrels a day to 450,000 by 1985 and 750,000 by 1990. One study predicts an output of 2 million barrels a day by 1985 (Braun 1979).

Most of the heavy-o1l-bearing lands are In Utah and California. To date, most of California's heavy crude has been extracted near Bakersfield while a large reserve is under the clty of Long Beach, California. Conservative estimates say as many as 10 billion barrels of heavy crude exist in the U.S. (Schram 1979; Braun 1979). Other estimates vary from a relątively modest 150 billion barrels in place w1th 30 to 45 billion barrels recoverable (Schurr et al. 1979), to enough heavy oll to allow the U.S. to be "totally independent of the Middle East in 20 years" (Braun 1979).

Huge reserves may exist outside of the U.S., perhaps in at least 60 countries. Most untapped fields are known to be in the Western Hemlsphere from Alaska to the tip of South America. As much as 967 billion barrels of heavy ofl--more than the total of estimated light ofl reserves of the entire Persian Gulf--are expected to be found in the rich tar sand deposits of Alberta, Canada. As many as 2 trillion barrels of heavy crude may lie along the Orinoco River in Venezuela-an amount equal to the petroleum consumed by all countries of the world to date (Braun 1979; Kennedy 1979).

Most of the heavy oil found within the U.S. has been a byproduct of the search for light oil. Since a systematic search specifically for heavy oll has not been made, U.S. reserves are difficult to estimate with accuracy. Exploration and development of 
this resource is expected to depend primarily on anticipated profits. As long as greater financial incentives are associated with extracting and refining light oll, heavy crude is not likely to become a major source of petroleum products.

A new process to improve the recovery of heavy o1l has been developed by the Hop Corporation, a subsidiary of Barber 011 Corporation. The process uses horizontal steam injection into heavy ofl deposits, rather than the conventional method of drilling wells much like regular oil wells for the vertical injection of steam. The company anticipates that the technique will permit the efficient and economical production of heavy oil from reserves that have not been commercially viable (The Wall Street Journal 1979).

Project DEEPSTEAM, A Department of Energy-sponsored effort to develop methods of freelng heavy oll from reserves too deep for conventional techniques, has begun fleld testing near Bakersfield, Callfornia. Sclentists from Sandia Laboratorieg at Albuquerque and from Chevron USA are testing a prototype steam generating system that could eventually enable companfes to tap highly viscous oil deposits as deep as 5,000 to 6,000 feet, roughly twice the depth that is economically practical today. The key to project DEEPSTEAM is a "downhole" steam generator. Injecting steam into a heavy ofl reservolr thins the ofl, making it flow more readily to nearby production wells where $1 t$ can be pumped to the surface. Conventional systems, however, must first produce steam in bollers on the surface, then plpe 1t down the borehole.. The technique is limited to depths of 2,500 feet or less; at deeper levels the steam cools too much to be effectIve (U.S. Department of Energy 1980a).

Using the new concept being tested by Sandla, steam would be generated at the base of the borehole in the oll bearing formation itself, rather than on the surface. This avoids the heat losses commonly encountered in piping the steam, and more of the heat can actually be used to free the o1l. Lowering llie steam generator into the underground formation also may hold some environmental advantages. Conventional generators burn about one barrel of ofl for every three recovered, and the bollers require expensive scrubbers to keep emisslons within air quality standards. Generating steam underground and injecting both 1 ts and the combustion gases into the deep reservolrs could significantly lessen the impact on air quality-while using only $2 / 3$ rds as much fuel as today's methods. Moreover, the carbon dioxide in the combustion gases is expected to help move the oil toward producing wells (U.S. Department of Energy 1980a).

In the current serles of tests, the unit operates on the surface and injects steam and gases into an 800-foot-deep heavy ofl reservoir in the Kern River Field. Then, by monitoring at both the injection 
and production wells, investigators expect to determine how much carbon monoxide, nitrogen oxides, nitrous oxides, and sulfur dioxide (typical combustion gases) escape into the atmosphere. Also, by comparing production from these wells with past production using pure steam injection, it can be determined if the combustion by-products actually boost ofl flow. The tests also will help reveal if particulates from the combustion gases might plug the oll formation and prevent steam from moving away from the infection well (U.S. Department of Energy 1980a).

Steam flooding in relatively shallow heavy ofl reservolrs with high heavy oll content has been performed by the Santa Fe Energy and Getty 0il companies in Californa. Cyclic steam stimulation was used to reduce viscosity and improve mobllity of the oll.

In situ combustion, a process similar to that utflized in the underground gaslfication of coal and oil shale, Involves hightemperature oxidation in the heavy ofl reservolr by continuous infection of air or alr and water. During the process, part of the ofl 18 converted to coke which is then consumed to produce more heat. The water is turned to steam that, in turn, distills some of the o1l in advance of the reaction, causing it to become more mobile and to move readily toward producing wells. Field testing of in situ combustion of heavy oil has been conducted by the Husky 011 Company in

California without success and by the Cities Services 011 Company in Loulsiana, where increases in production have been obtained and where new variations in operation are being tested (U.S. Department of Energy $1980 \mathrm{~b}$ ).

\section{Tar Sands}

Tar sands are characterized by hydrocarbon bearing deposits of rock whose interstices contain highly viscous to semi-solid bitumen (mineral pitch) or crude oll with mobility insufficient for adequate movement to a wellbore. In tar sand, the bitumen is so viscous and immobile that it prevents displacement and production by conventional recovery methods. Generally, tar sand oils have specific gravities of less than 12 degrees, compared to about 15 to 20 degrees for heavy 011 and 34 degrees for Saudi Arabian light crude o11.

Within the U.S., most tar sands are in Utah. Unt11 recently they had been regarded as too remote and inaccessible for recovery to be economically viable. In North America, the largest reserves of tar sands cover about 12,000 square miles of northwestern Alberta, Canada. These deposits are varlously estimated to contain at least 900 billion barrels of ofl--more than the world's proven conventional reserves and enough to supply North America's oil demand for over 100 years. Currently, Canada extracts about 90,000 barrels of ofl a year 
from the deposits. In 1978 a joint venture of four ofl companies and the government of Canada was formed to inftlate a project designed to produce 125,000 barrels of oll a day from the tar sands by 1982 . Because most of the sands are deep ( 200 feet or more below the surface), only about 25 percent of the ofl is recoverable with conventional technology (Canada Today 1979; Time 1979).

In Canada, bucket-wheel excavators are used to remove the sands from shallow deposits to 150-ton trucks that carry the material to processing facilities. The tar is then separated from the sand by heating with hot water, producing a "contaminated asphalt" that is run through a coking and hydrodesulfurization process to produce synthetic crude o11. By-products of the process are coke and sulfur.

Of 500 U.S. tar sand deposits identified in 22 states, only 39 have been meaningfully assessed in terms of resource size. These have been estimated to contain up to 30 billion barrels of oil in place (about equivalent in size to current estimates of conventional petroleum reserves), of which 29.3 billion barrels are estimated to be located in 27 deposits within the state of Utah (U.S. Department of Energy 1980b; Resources for the Future 1979).

So far, U.S. recovery has focused on small-gcale mining of shallow surface deposits to produce tar sand for direct use in road paving. Most of the U.S. deposits lie under overburden material that is too thick for economical surface mining, so in situ recovery will be required. Steam or hot water injection and in situ combustion are the two processes considered for the release of bitumen from deep U.S. tar sand deposits.

Because of the abundance of accessible surface deposits in Alberta, little experience has been gained in the underground recovery of oll from tar sands. Conventional hardrock mining is not feastble due to the structural character of tar sand deposits. However, it may be possible to utilize modified conventional longwall mining techniques to recover tar sands.

Hydraulic mining, a technique proven successful for the underground mining of urantum ore, may be feasible and recently has been tested with tar sands in southern California. In this process, a capsule contalning a high pressure nozzle, a slurry pump, and piping is lowered through a casing into a shaft drilled through the tar sands zone into the underlying formation. The nozzle directs a stream of water agalnst the tar sands deposit, breaking the material into small pieces which are then entrained in the wastewater as a slurry. The slurry drains into the sump in the underlying zone and from there it is pumped to the surface for aboveground processing (Tetra Tech 1977). 
Al though attractive from the standpoint of not requiring huge capital investments for aboveground retorting and separation facilities; from a technical standpoint in situ recovery is a much more complex operation then aboveground processing. Essentially, in situ recovery techniques completely process the tar sands underground, removing only the valuable bitumen and leaving the sand matrix in place. But when these reactions take place far underground, monftoring and controlling become monumental tasks. Even though handling of sand is eliminated, large quantities of recovery fluids must be pumped. Because recovery rates depend on many unknown natural geologic characteristics, recovery efficiencies are usually much lower than those attainable aboveground where such conditions may be controlled. Thus, overall, in situ processing is unlikely to be any less expensive per unit of ofl recovered than aboveground processing, but where deep deposits exist, it is the only recovery technique that can be used (Tetra Tech 1977).

Thermal stimulation has been used by the conventional oil industry for many years for secondary and tertiary recovery in depleted ofl reservolrs. The primary difference in tar sands applications is that the low gravity and high viscosity of bitumen require extremely high displacement pressures to initlate flow. Such processes are Iimited to deep deposits that have enough overburden to contain the high pressures (Tetra Tech 1977).

Cyclic steam injection is a technique developed in Alberta in which steam is injected into tar sands strata and o1l is produced from the same well. As steam is infected, it lowers the viscosity of the bitumen around the well, thereby increasing the permeability. This increased permeability then allows the less viscous bitumen to be removed from the well. Continued injection cycles expand the halo of permeability around each well until the halos of adjacent wells overlap and conventional steam flood may be used.

In a formation with communication established between adjacent wells, the steam flood process may be used. Steam injected at one well site forces bitumen ahead of it toward a production well. This process has been studied by Shell Canada at its Peace River test. site. Rather than using cyclic steam injection to achieve communication between wells, however, Shell used a steam soak process in which steam was constantly injected unt1l breakthrough. This breakthrough required 2 years in a tar sands zone about 2,000 feet deep. While maintaining steam injection, backpressure was increased over a 6month period until the desired pressure of about 1,000 psi was obtained. Next, the steam pressure was maintained for about $1-1 / 2$ years until the entire zone was heated; then the pressure was lowered to about 250 to 500 psi for a production period of about $1-1 / 2$ 
years. Shell officlals sald this process was developed for use specifically in the geology in the Peace River deposit and would have to be changed if different geological conditions were encountered (Tetra Tech.1977).

In the early 1960s, Shell Canada conducted tar sands recovery tests based on injection of steam and sodium hydroxide. The tests Indicated that horizontal fractures can be induced in tar sands to establish communication between infection and production wells. Once these fractures are formed, emulsifying fluids can be introduced. According to She11, 50 to 70 percent of the bitumen in place can be extracted with less than three barrels of water injected per barrel of bitumen produced.

A modified steam or hot water technique involves the use of solvent extraction. Unlike kerogen, the hydrocarbon constituent in oil shale, the bitumen in tar sands is soluble in a varlety of organic solvents. This property, along with the relatively high permeability of some zones, allows tar sands deposits to be tapped by in situ solvent extraction processes. However, because solvents are usually valuable products in themselves, the loss of relatively small amounts of these materials in the waste sand can offset the gains of recovering large quantities of raw bitumen. For this reason, the solvent recovery step is the key to the cconomic success of any solvent extraction process.

In in situ solvent extraction processes, a solvent fluid is circulated through the impregnated zone. As bitumen 1 s dissolved into the solvent, it is pumped to the surface. The permeability of the bitumen-free sand matrix then increases, providing passageways through which the solvent can flow to attack new areas of bitumen. Varlations on this basic procedure may require heating the solvent or fracturing the impregnated zone. Two of the many processes that have been devised for solvent extraction of tar sands were patented by Texaco. In the first process, two wells are drilled into the base of the tar sands zone, one an injection well and the other a production we11. Communication between wells is established by fracturing. Hot water or steam is then injected and allowed to flow between the wells. A solvent such as carbon disulfide $\left(\mathrm{CS}_{2}\right)$ is then injected along with the heating fluid. Since the bolling point of the $\mathrm{CS}_{2}$ is lower than the temperature of the heating fluld, the $\mathrm{CS}_{2}$ becomes vapor upon entering the 1mpregnated zone, and diffuses into the tar sands zone, dissolving the bitumen. Once its temperature has been lowered the $\mathrm{CS}_{2}$ condenses. As it drains back into the stream of heating fluid, it carries quantities of dissolved bitumen with it (Tetra Tech 1977). 
In another process patented by Texaco, both surface mining and solvent extraction operations are used. After the overburden layer has been stripped off the tar sands zone, the pit is filled with water. Then carbon disulfide is injected into the tar sands zone Immedlately below the water. Carbon disulfide is used because it does not react with water and its density is greater than that of water. As the solvent removes the bitumen from the sand matrix, the water from the pit above replaces it. More $\mathrm{CS}_{2}$ is injected and it contacts deeper levels of bitumen-rich sand. As the water level of the pond drops, more water is added to keep the cavity full. Once the bitumen has been removed, the cavity is pumped dry (except for the water remaining in the sand) and the pit is backfilled to minimize environmental damage (Tetra Tech 1977).

With respect to in situ combustion in the process of forward combustion, some of the tar sands deposit is burned to recover the hydrocarbon product from the remainder. Combustion is started in the tar sands zone near the injection well and is maintained through continued injection of air. At first, bitumen is consumed in the combustion process, but as the ore ahead of the combustion zone becomes heated, the bitumen will be driven toward the production well, leaving behind carbon residue and heavy ends as a fuel source for the combustion process. This process depends on the natural permeability of the deposit to enable the vapors produced to be recovered at the production well. If this natural permeability is not adequate, 1t may be necessary to fracture the zone before Ignition. Regardless of the source of permeabllity, elther natural or induced, it is vital that it be uniform throughout the vertical extent of the zone. If permeability is greater in one horizontal plane than another, the air injected w111 tend to create a path through that zone, causing the combustion front to finger into the path rather than to progress uniformly through the zone. Another problem with forward combustion is the plugging of pores as the hydrocarbon vapors pass through the cooler parts of the tar sands zone on the way to the production well. Even if the Initial permeability of the zone were adequate to allow for the flow of vapors, condensing vapors might well plug these pathways and cause production to stop (Tetra Tech 1977).

Reverse combustion is based on the same concept as forward combustion, except the combustion zone progresses from the production well to the injection we11. Because the hydrocarbon vapors that are produced pass through a heated area on their way to the production wel1, plugging is minimized. Furthermore, because of the high tem- peratures which the vapors encounter on the way to the production well, some thermal cracking occurs, leading to the production of an upgraded product. 
A combination of in situ combustion and water infection processes have been tested in Canada. The first step in the process was fracturing the formation to achieve communication between injection and production wells. Forward combustion was then started and maintalned. After an initial heating period, water was injected along with the combustion air. As water vaporized in the combustion zone it diffused to the surrounding tar sands and heated them to approximately $200^{\circ} \mathrm{F}\left(93^{\circ} \mathrm{C}\right)$. At this temperature, the bitumen was les 8 viscous and could be moved by the air-water drive to a production well. Tests indicated that, if mechantcal problems had not been encountered, recovery of in-place bitumen would have been close to 50 percent (Tetra Tech 1977).

\section{Health and Environmental Issues and Research Needs}

\section{Mining}

Safety hazards common to all underground mining (coal and ore extraction) also apply to the excavation, maintenance, and use of shafts, tunnels, galleries, and drill holes associated with oll min1ng. In addition, with ofl mining the potential for ofl hydrocarbon and gas leakage poses the risk of fires and explosions. The potential for flooding from the overlying water zones also exists. Moreover, the workforce can suffer dermal and inhalation exposure to the toxic components of crude o11.

Environmental issues center on four maln areas of concern: the land disturbance, reclamation, and leaching assoclated with storage and disposal of overburden and mine wastes; disposal of spent solvents and other process chemicals; subsidence; and groundwater contamination from in situ leaching and surface leaching from solid wastes. Most water produced as a result of the process can be reinfected into the ofl reservolr.

Although surface mining is generally safer than modified in situ mining, its environmental impact may be greater. Methane gas, hydrogen sulfide, other gases, dust, and noxlous odors may be expected near the mines. Overburden and tailings may impair scenic vistas while causing substantial disposal problems.

Currently, the Bureau of Mines of the U.S. Department of Interfor is undertaking a detalled study intended to identify and quantify the environmental problems assoclated with ofl mining and to identify control and abatement actions (Dick and Wimpfen 1980). 


\section{Heavy Crude 011}

Health and environmental issues associated with the extraction of heavy oils focus on mine-assisted steam flooding. The issues relate to occupational health and safety, degradation of air and water quality, and on water availability (U.S. Department of Energy 1979a).

Occupational health and safety concerns relate to the potential danger of fire and explosions assoctated with methane and hydrocarbon vapors; exposure to asphyxiating gases such as sulfur and nitrogen oxides, hydrogen sulfide, and carbon monoxide; dermal and inhalation exposure to toxic components in the ofls and process chemicals; dangerous high temperature and pressure operating conditions; nolse; and transportation accidents.

Atr quality concerns relate to emissions of sulfur and nitrogen oxides and particulate matter from the operation of direct-fired bollers used in steam production. The venting of hydrogen sulfide is also a concern. The U.S. Department of Energy is conducting a study to determine the feasibility of reinfecting combustion gases with the steam as a mitigating measure to reduce air pollution.

Water quality concerns relate to the contamination of surface waters or aquifers by stored saline water accumulated during the extraction process and by toluene which is used in connection with the steam infection process. After storage, most wastewaler is reinjected. The steam flooding process requires large amounts of water and 1 ts withdrawal from the surface waters in the semi-arid areas of the western U.S. may pose a severe Impact on the maintenance of natural stream blota and on the amount of water avallable for domestic and industrial use.

W1th regard to occupational safety and health, bioassays are needed, along with dose-response studies, and specific safe handing procedures for the chemficals used in the various technologies. Research areas under study include. developing screening tests for hydrocarbon carcinogeniclty and mutagenicity, analysis of molecular processes involved in the carcinogenic action of polycyclic aromatic hydrocarbons, and evaluation of the influence of inhaling acid aerosols and particulate matter.

The major problem with mine-assisted steam flooding will be safely drilling horizontal wells from the mine shafts, and little experience is avallable in this area. Insufficlent sand control could result in well plugging. Mining the horlzontal shafts through oll and water zones also w11l be difficult and may require 
modification of existing technology or development of entirely new methods for shaft slnking under these conditions (U.S. Department of Energy 1979a).

With regard to environmental issues, resarch needed in the air quality area includes improved alr-monitoring procedures, evaluation of air quality near factlities, and development of improved atmospheric transport models to predict fate and dose to man and the ecosystem. Work is in progress to develop remote and in situ instruments that will detect toxic substances, suspended particulate matter, carcinogenic vapors in ambient atmospheres, polycylic hydrocarbons, and other organic pollutants. Needed research efforts in the water quality area include examination of environmental control technology for improved brine control, improved characterization of aqueous effluents from oll refining sources, study of the blodegradation of chemical compounds discharged from refinerles, and study of the effects of mixed petroleum hydrocarbons on marine fish. Some of this research is being intlated (U.S. Department of Energy 1979a).

\section{Tar Sands}

About 2.2 tons of tar sands must be mined and heated in aboveground retorts to yield one barrel of thick bitumen which can be refined by conventional technology into o11. In Canada, the cold $\left(-4^{\circ} \mathrm{F}\right)$ winter temperatures make year-round operations difficult and the expansion of the volume of the sand (brought about by expansion of vold volume) during extraction creates an environmental disposal problem. However, from an environmental standpoint in the U.S., in situ techniques have many drawbacks. (Because only 10 percent of U.S. tar sands are recoverable by surface mining, in situ techniques or underground mining methods must be developed to allow tar sands to become an important energy source.) Removal of bitumen can cause surface subsidence and carcinogentc combustion products can leach into groundwater and pollute water supplies. The disposal of waotc sand containing mineral hydrocarbons and spent process solvents may cause serious environmental problems.

Air emissions of sulfur oxides occur from steam bollers and sulfur removal equipment. Hydrocarbons can be emitted from storage tanks required for the tar sand ofl feed, the naptha and gas ofl intermediates, products, blowdown systems, process drains, cooling towers, and leakage from valves, flanges, and seals. Particulate matter can be emitted from coke and steam plants. Nitrogen oxides also can be emitted from steam bollers. It is envisioned that facilitles used to upgrade tar sand ofl would pose environmental impacts similar to those associated with the coking and hydrotreating processes of an ofl refinery. From the viewpoint of resource utilization, production by surface mining methods (where economically and 
technically feasible) is preferred. However, from an environmental point of view, even in light of the aforementioned impacts, in situ production of tar sands is preferred by some scientists (Frazier et a1. 1976).

Research needs related to an emerging U.S. tar sands industry are many and diverse. They are similar in many ways to those for in situ coal and oil shale processes, recovery of crude from new heavy oll deposits, and enhanced oil recovery techniques applied to depleting or abandoned oil wells. The reader is referred to other reports of the Interagency Committee for a listing of research needs related to emerging synfuel technologies. The major thrust of tar sands research should be utilizing information gained from researching these other technologies. This creates a need to transfer information, which ts the subject of. the following section.

\section{Information Transfer}

As mentioned above, all of the techniques proposed to recover oil from U.S. tar sands are also used in the recovery of deep light oils and heavy oils, the enhanced recovery of oil from old fields, and the recovery of liquids from coal and oil by in situ techniques. Some heavy oils are produced in California and Texas by thermal methods (and are included in conventional oil reserve estimates). Extraction of heavy oils is expected to accelerate through some kind of an enhanced oil recovery method (perhaps by adopting successful in situ combustion or steam injection techniques). 'Ihese techniques are also expected to be utilized for U.S. tar sands and in situ recovery is a major component of the process for developing synthetic fuels from coal and oil shale.

These resources are classified by various Federal agencies under different programs depending upon the agency's convenience, mandates, pricing categories for the resource(s), and its definition of conventional versus unconventional resources. As a result, in one case heavy oils may be treated as a conventional crude oil resource or as a synthetic fuel (Energy Security Act, PL 96-294). Petroleum substitutes and chemical feedstocks produced from the chemical and physical transformation of coal, shale, and tar sands are defined as synthetic fuels. These energy resources are treated under separate programs within and among different agencies. As a result, many duplicative development and research strategies are taking place. In terms of health and environmental research, much is applicable across the technologies, especially with regard to generic and region-specific research.

An information transfer strategy is needed that will enable common health and environmental effects problems and related research 
needs to be reallzed. Such a category would bring approprlate and avallable information to bear upon newly developing resources, while at the same time improving research efficlency and eliminating duplication of effort. 
Reserves of unconventional sources of gas are largely so 111defined that their true potential is unknown. These will need to be explored for, defined, and developed much like commerclal deposits of oll and gas. In the U.S., large resources of methane are known to exist in Devonian shales, coal seams, tight gas formations in various parts of the country (particularly in the West), and in geopressured brines along the Gulf Coast.

There is some commercial gas production from Devonian shales (0.1 Tcf per year) and tight sand formations (1 Tcf per year). Recently, considerable attention has been pald to potentially large gas reserves in deep sedimentary basins. There is uncertainty concerning both the size of the resource in place and the potential supply-price curve for methane from each type of deposit. Industry has regarded these resources as high-risk compared to conventional o11 and gas reserves. However, it is now believed that considerable quantities of unconventional methane could be obtained at a lower cost than methane produced from coal or imported liquefled natural gas (Resources for the Future 1979; Booz-Allen \& Hamilton 1979).

For these reasons, these potential new sources of gas are briefly discussed below. As a result of the lack of attention paid to the development of these resources in the past, there is little understanding of the health and environmental issues and research needs associated with these potential new sources of gas.

\section{The Sources}

\section{Methane-Saturated Brines}

It is generally recognized that a vast amount of natural gas is dissolved in the underground water, both onshore and offshore, of the sedimentary basin paralleling the coasts of Texas, Loulsiana, Mississippi, Alabama, and the Florida panhandle. Much of this is in hydrostatic-pressurized (hydropressured) water in an abundance that has long been recognized. The amount in the deeper geopressurized water* is largely unknown. Estimates of the amount of natural gas dissolved in waters of the Gulf and in sandstone and shale sediments along the Coast range from 4 to 60 quadrillion cublc feet (Hocott 1979; Hodgson 1978).

*With geopressurized water, the pressure of surrounding rock from below is greater than that of the hydrostatic head. 
Since this area has been heavily drilled for conventional ofl and gas, work has focused on mapping to define the most promising areas for methane recovery, and on identifying sand thickness, porosity (permeability), temperature, and dissolved methane content. Energy development of the geopressured waters has focused on the production of electricity, with methane recovery being a by-product. Th1s emphasis has led to controversy in terms of priorities. That 1s, some sclentists belleve that much more energy can be acquired by placing emphasis on methane recovery without restricting pressure release to drive turbines. (A substantial drop in reservoir pressure would release large amounts of dissolved gas to accumulate in an underground gas cap) (Adams 1979; Hodgson 1978).

Although, as much as 60 quadrillion cubic feet are estimated to exist in solution along the Gulf Coast, about 90 percent may be in shale strata having permeability too low for production. Thus, the actual resource may be about 6 quadrillion cubic feet. If only 5 percent of brine and dissolved gas in place can be produced before natural flow ceases (not including gas cap pumping), only about 300 trillion cubic feet may be producible without excessive pumping costs. It has been estimated (subjectively) that 10 percent of methane-saturated brine is in sandstone reservoirs large enough to recover drilling costs. Thus, no more than 30 trillion cublc feet may be economically recoverable (still a sizeable amount) (Randolph 1979).

\section{Eastern Gas Shales (Devonian Shales)}

U.S. gas contained in Devonian and some Mississtpplan shales is mostly in the East, in an area bounded on the north by a line between Michigan and lower New York State, and on the south by northern Alabama. The amount of gas in the reserve may be about $1 / 2$ to 1 quadrilition cubic feet--an amount over three times the proven reserves of conventional natural gas. Ten percent of the gas can be recovered by modern methnds (Hodgson 1978; Resourcee for the Future 1979; U.S. Department of Energy $1979 \mathrm{~b}$ ).

The U.S. natural gas industry began in 1821 with a well drilled into a shale formation in Fredonia, New York. The well had a low, but constant productivity (only a few thousand cublc feet a day), and a long life (35 years)--characteristics typical of the existing 10,000 shale wells.

Berause flow rates associated with conventional shale wells liave been too low to make them economically attractive, Federal efforts have been directed toward developing fracture stimulation and dri11ing techniques to connect more gas-containing natural and induced fractures connected to the borehole. In areas of high fracture 
density, liquid chemical explosives and cryogenic fracturing have been demonstrated to be improvements over conventional explosives. In areas of low fracture density, hydraulic fracturing with gelled water and sand is an improvement over explosive stimulation. Laboratory experiments have shown that mixtures of water and carbon dioxIde appear to increase permeability, porosity, and surface area of the shale (termed gas fracturing). These and other experiments are aimed at developing low-cost fracturing methods and fracturing fluids. Sometimes fracturing does not work, but when it does, usually the output per well is still lower than that typlcally found in conventional natural gas wells (U.S. Department of Energy 1979b; Stobaugh and Yergin 1979; Technology Forecasts 1979).

\section{Western Gas Sands (Tight Sands)}

In the western U.S., there are thick layers of strongly cemented sand that have low porosity and permeability. These areas, largely In the Rocky Mountain states of Wyoming, Colorado, and Utah, are estimated to contain as much as 730 trilion cubic feet of gas-inplace. Small quantities of gas are produced in these areas, but only where natural fracturing of the sandstone occurs. About $1 / 4$ th to $1 / 3$ rd of the gas in place 1 s expected to be economically recovered (American Gas Association 1979a; Mankin 1979; U.S. Department of Energy 1979d).

Major tcchnological improvements in fracturing and formation definition are required before the full potential of the sands can be realized. Massive hydraulic fracturing, a large-scale application of fracturing techniques where the length of the fracture may be in thousands of feet and the height in hundreds of feet, is the most promising technique for tight sands. The technique opens and ma1ntains (by filling with sand) artificial fractures which penetrate deep into the sandstone. This provides condults for gas to migrate to the borehole.

Methane from Coal Seams and Mines

Methane, the major component of natural gas, is a by-product of many of the natural anaerobic digestion and metamorphic processes associated with coal formation. This methane often escaped by permeation and diffusion during the millions of years in which flora was transformed into coal. Frequently, the low permeability of strata associated with coalbeds limited the escape of the gas, causing its entrapment in high concentrations. Several studies lend support to an estimate that the recoverable quantity of methane from U.S. coal seams is 250 trillion cubic feet, an amount approximately equal to the known conventional U.S. natural gas reserves (TRW 1977). The total amount of methane in U.S. coal seams has been estimated at 
700 to 1,000 trillion cubic feet at depths as great as 6,000 feet (Hodgson 1978). By tapping coal seams for methane, possibly 1 trillion cubic feet per year could be produced by 1985 , the equivalent of 40 million tons of coal* (Hodgson 1978).

Several other gases are associated (although in small amounts) with methane in coal. These are hydrogen, water vapor, nitrogen, carbon dioxide, and helium. The gas content of a coal seam is primarily influenced by depth, moisture, and coal rank. Generally, at greater depths and concurrent h1gher pressures, a greater volume of gas is held within the coal. Molsture reduces the capacity of coal to absorb methane. Higher rank coals such as anthracite, especially with low molsture content, tend to contain higher levels of methane. The release of methane from coal is controlled largely by porosity, permeability, and gas pressure. As gas at greater depths exists under higher pressure, it is released in larger amounts in deeper mines (Iannacchione and Puglio 1979).

The extraction of methane from coal seams prior to mine development can minimize the poisonous atmosphere or explosion potential associated with a new underground coal mine. Recent experiments have shown that in-mine methane emissions can be reduced by as much as 40 percent when methane is drained from coal seams prior to coal extraction (U.S. Department of Energy 1978).

The techniques being investigated for capturing methane from coalbeds include drilling vertical or directional wells into coal seams in advance of a mine's working face, and drilling horizontal boreholes into virgin coalbeds from a central shaft. Innovative methods include using liquids to fracture seams, a process that can increase gas flow 8- to 20-fold (Hodgson 1978). Such gas removal methods substantially reduce the ventilation requirements necessary to maintain gas concentrations at a safe level and at the same time improve mining productivity by reducing the downtime caused by hazardous levels of methane. Gas withdrawal from previously mined areas may be accomplished through vertical wells that provide mixtures of gas and air. Mines in the Pittsburgh coal seam currently vent over 100 million standard cubic feet of methane each day. At present, no commercial use is being made of this resource (U.S. Department of Energy 1979d).

When cleaned, methane withdrawn from coal seams can be utilized in a variety of ways, such as direct pipeline injection, production of liquified natural gas (LNG), on-site power generation, heating,

\footnotetext{
*U.S. coal production in 1978 was about 650 million tons.
} 
and as a petrochemlcal feedstock. The cleaning process includes removing sand and coal particles.

This resource holds the promise of protecting the health and safety of coal miners, while serving as a significant new source for methane (and helium if filtering devices are modified for pipeline gas). Barriers to its development, other than technology, involve constraints in the eastern U.S. where few coal companies have clear title to the gas. Since the market value of a ton of coal has been about 100 times the value of the methane contained within the coal, coal mining companies have had little interest in the gas-derived revenues relative to their primary objective of coal production. The recovery methods have not yet been sufficiently demonstrated to attract private investment. However, economics are becoming more favorable for commercial exploitation of this resource. For coal companies, recent interest in gas recovery is primarily due to the enhancement of coal production. The methane-derived revenues remain secondary in importance.

Methane can be recovered from both minable and unminable coalbeds, thus utilizing an entire coal seam as an energy resource. In addition, methane can be recovered from gob piles. The Bureau of Mines has an extensive program of research designed to identify the extent of methane in coalbeds and to develop control measures (U.S. Department of the Interior 1979, 1980). Methane gas is also recognized as a hazard and an energy resource in salt mines and other non-coal mines (lead and zinc, gold and sllver, copper, iron, silicates, marble, uranium, limestone, oil, oil shale, and trona).

One drawback to methane recovery from coal seams is the accumulation of coal and sand particles in the well. The most promising recovery technique involves drilling and using a nitrogen-charged foam and sand solution to open natural underground fractures in the coal seam, allowing trapped methane to reach surface wells. This technique is essentially the same as hydraulic fracturing used for recovering methane from eastern gas shale and western gas sands.

\section{Methane Hydrates}

Methane or gas hydrates are solid, ice-like compounds in which gas molecules are trapped and bound to water molecules. Detected in the mid-1960s, the hydrates exist under cold temperature and high pressure beneath permafrost and in deep-ocean sediments. Soviet scientists estimate that a 30,000-year world supply--or 1.7 million trillion cubic feet of gas--lies trapped in the form of hydrates (American Gas Association 1979a; Hodgson 1978). 
The physical chemistry of gas hydrates has been studied extensively and is well understood, in part because of the problems with gas transmission created by their formation in pipelines (see. Liquefled Energy Gases and Transportation and Storage sections). A tendency exists for gas hydrates to form when conditions of low temperature and moderately high pressure are present and gas is avallable at saturation concentration. These conditions can be present in oceanfloor sediments at water depths of more than a few hundred meters (or even shallower in very cold water) and beneath permafrost. Formation of gas hydrates in sediments causes a radical decrease in permeability, as indicated both by laboratory studies and by attempts to produce gas in conditions where hydrates were forming (D111on 1980).

Gas hydrate-cemented layers may be effectlve seals, forming gas traps in marine sediments at water depths of a few hundred to a few thousand meters. If such traps exist, they would occur at very sha1low subbottom depths, only about $4 / 5 \mathrm{ths}$ of a mile $(1 / 2 \mathrm{~km})$ from the surface. However, drilling through the gas hydrate-cemented layer may require new engineering techniques to provide a seal around the casing. Exploration of such traps in the marine environment may be attempted first in the Blake Ridge area off North Carolina for three reasons: the gas hydrates seem to be well developed there, the area is controlled by the U.S., and 1 t is near U.S. ports and markets (D111on 1980).

Gas hydrate deposits appear to be well developed not only off North Carolina, but also off South Carolina and beneath the Beaufort Sea north of Alaska. These deposits may explain the large quantities of methane observed at hundreds of locations since 1968 by the Deep Sea Drilling Project sponsored by the National Science Foundation.

U.S. onshore development of gas hydrate reserves is 11 kely to focus on the shallow and accessible permafrost. Such development. fs unlikely until after the conventional deposits of Alaskan gas are depleted. The production of deep-sea gas hydrates is dependent upon the development of new offshore drilling technology. One production technology under development is the circulation of light hydrocarbon fluids to dissolve the gas for subsequent recovery. However, the injection of saline formation waters might be a less expensive, more environmentally acceptable and effective way of decomposing gas hydrates held in potentially producible marine reservolr formations (American Gas Association 1979a; Hodgson 1978; Tiratsoo 1979). 
Gas from Deep Basins

Recently, attention has focused on the potential for extensive reserves of natural gas to be discovered and extracted from relatively extreme depths in the earth's crust, as measured by trad1tional drilling practices. Within the U.S., as much as 360 trillion cubic feet of natural gas may occur below 25,000 feet in the Anadarko Basin of western Oklahoma. Th1s basin, where more than 30 successful deep wells exist ( $t$ wo of them below 30,000 feet), has 22,000 cublc miles of sediments below 15,000 feet, with only 1 percent of 1 t explored. Other deep reserves may lie in the Permian and Delaware Basins in Texas, the Appalachian Basin in the East; the Mississippi Embayment in the South; and the Arkoma Basin in Oklahoma and Arkansas (Mankin 1979; Hodgson 1978).

Drilling a well today in the Anadarko Basin, similar to those completed to depths of 30,050 and 31,441 feet a few years ago, would cost about $\$ 10$ million In 1979 dollars. Although th1s cost may seem high, it is far lower than the inftial capital investment required for a synthetic fuel facility, particularly a coal gasification plant. One deep well completed in May 1978 produces 20 million cublc feet of gas a day. A proposed coal gasification plant in Mercer County, North Dakota, is expected to cost $\$ 1$ billion and would produce 125 million cubic feet of high-Btu coal gas dally. A simflar investment in the development of deep gas could yield over 2 billion cublc feet of gás a day (Rothberg et a1. 1979; U.S. Senate 1979; Hodgson 1978).

W1 th expenditures of about $\$ 16$ billion, gas from deep basins could supply a trillion cubic feet by 1982 and as much as 4 trillion cublc feet of gas to U.S. markets by 1991. (To place these quant1tles in perspective, in 1978 total U.S. natural gas production was about 20 trillion cubic feet.) Such expectations indicate that development of this resource would be highly profitable (MacDonald 1979; Hodgson 1978). Technological problems that are being overcome include extremely high pressures (as great as 19,000 psi), which crush ordinary well casings, and supercorrosive hydrogen sulfide.

Tapping gas at depths below 30,000 feet may provide deep-earth gas belleved to be of nonblological origin. Such gas, normally released in volcanic emissions, consists of water, carbon dioxide, carbon monoxide, methane, ammonia, molecular hydrogen, hydrogen sulfide, and other gases. Some methane may be oxidized to carbon dioxide as it reaches the surface through hot volcanic lava at low pressure. Deep gas methane can enter the atmosphere through cold faults, mainly during earthquakes. The phenomena of flames shooting out of the ground, "earthquake lights," fierce bubbling in bodies of 
water, sulfurous air, and loud explosive and hissing sounds assoclated with earthquakes are probably attributable to the release of methane and hydrogen (Gold and Soter 1980).

\section{Gas from Blomass}

In the broadest sense, biomass includes all living plant material and assoclated wastes, residues, and by-products. These can be converted into solid, liquid, and gaseous fuels. Dry blomass (1.e., ready to burn) includes logs, twigs, dry straw, and the stumps of trees. Wet blomass (1.e., at least 50 percent molsture), such as manure and munlclpal garbage, also can be burned, but together with wetted dry blomass it can be made to produce methane gas.

Renewable sources of marine or land biomass or organic and municlpal wastes can be converted to gaseous fuels using either thermal decomposition (creating a synthetic fuel) or by anaerobic digestion, i.e., the blological breakdown of organic matter into methane (and other materials) by bacterial action in the absence of oxygen.

Biogas production techniques are many and diverse. Several ut1$11 z e$ anaerobic digesters. The natural, oxygen-free fermentation of manure produces a burnable gaseous mixture that is 60 percent methane and 40 percent carbon dioxide. Water effluents from such a process contain nitrogen which can be used as a fertilizer.

The technology for producing gas from biomass has existed for many years and holds a great potential for future development, with possible techniques including the recovery of methane from landfills (Ham et a1. 1979; Industrial Research/Development 1979). How great a contribution biomass will make as an energy resource depends on the extent to which technology will increase its productive potential. Cropland, with its high yleld potential, would have to account for more than 50 percent of the output. Thus, emphasis is on improving blomass yleld through such means as higher biomass-ylelding food and feed crops and on recovering energy from food and fiber after it has been put to its primary use, 1.e., energy recovery from sewage, manure, and urban solld wastes (Yeck 1979).

Health and Environmental Issues and Research Needs

\section{Methane-Saturated Brines}

Most of the projected health and environmental impacts associated with the development of geopressured-geothermal energy are expected to occur with development of the Gulf Coast pressured brines. These Include potential impacts on land by surface modifications (construction of wells, pipelines, and power plants), subsidence, and 
selsmic activity. In some cases, the water discharge may be of low salinity and usable as an agricultural water supply. In most instances, disposal of such a large volume of saline water will require reinjection, canaling to a saline body of water, or reinfection to a low pressure area. Ammonta, boron, dissolved sollds, and trace elements such as manganese and 1ron may be released in aqueous aerosols. The key environmental issues are possible land subsidence caused by high volume brine production, and possible tectonic activity and man-induced minor earth tremors caused by the withdrawal or reinjection of brines. Occupational health and safety issues relate to worker exposure to potentlally hazardous substances, such as hydrogen sulfide (although more prevalent with hydrothermal energy recovery) and process chemicals, and to nolse and accidental blowouts. All significant lmpacts are expected to be localized in the immediate vicinity of a wellhead and processing facility (Nguyen et al. 1980; Wilson et al. 1977).

Additional research is needed on the chemistry of geopressured and hydropressured waters. To date, only a few wells have been sampled; however, enough is known to suspect that high concentrations of trace metals and other pollutants are not ubiquitous.

Since the source of the rocks surrounding the sallne reservolis is sedimentary, there is reason to believe that radioactivity may be a problem in waste materials and pipeline quality gas. Radon emissions in the home resulting from the natural gas combustion are now recognized as a serlous problem warranting substantial research. (See the discussion of indoor air pollution in the End Use section.) Radioactive emissions associated with the combustion of geopressurized gas could compound an existing health hazard.

It should be noted that potential pollutants associated with drilling oil and gas wells also would be present (see Onshore section). These include residual sludges from air and water treatment, scale, cuttings, and drilling muds. The transfer of information from research on the health and environmental effects related to conventional oil and gas drilling is needed. This also holds true for transferring information from research on health and environmental problems associated with the development of geothermal energy.

Since geopressured reservolrs are more susceptible to subsidence than hydrothermal reservolrs, subsidence monttoring methods, including guidelines for field data acquisition and analysis, should be refined for use in Gulf Coast areas subject to the extraction of methane-saturated brines. 
Negligible research has been conducted on the impact of methanesaturated brines and reinjection on the hydrological alteration of hot springs and other areas of freshwater upwelling in the Gulf Coast reglon. Many of these springs are prime recreational areas and tourist attractions that support unique populations of flora and fauna. The impact upon these ecologically and socially significant areas caused by the extraction of methane-saturated brines should be de termined.

\section{Eastern Gas Shales (Devonian Shales)}

Environmental concerns related to the development of eastern gas shales include: the land use and blotic habitat impacts associated with the siting and construction of gathering lines and larger longdistance pipelines and roads; pollution of underground and surface waters due to hydraulic fracturing operations and residues from chemlcal explosions; and high water withdrawal rates from aquifers and surface waters. Occupational safety concerns focus on the accidental mixing or 1mproper handling of explosives. Concern for public health focuses on contamination of the gas from by-products of chemical explosions and residues of hydraulic fracturing. In addition, potential alr pollution from diesel engtnes and turbines required in hydraulic fracturing can result in the release of large amounts of nitrogen oxides and particulate matter (U.S. Department of Energy 1979a).

Essentially all of the above concerns are being addressed by current research (U.S. Department of Energy 1979c). One concern not addressed, but of Importance to public health (see Indoor Alr Pollution in the End Use section) is contamination of natural gas by radon and other radioactive materlals. Some gas shales can have an average uranium concentration of 60 parts per million. When these shales are fractured, radon can be released, resulting in the enhancement of naturally occuring radloactivity and contamination of pipeline gas. Research is required to assess the nature and extent of radioactive materials in shale deposits and possible strategles to minimize the transmittal of such materials in pipeline gas.

\section{Western Gas Sands (Tight Sands)}

Health and environmental concerns related to the development of western gas sands are essentially the same as those associated with eastern gas shales. Only the severity of impact may be different. The siting and construction of extensive support networks of new pipelines to transport gas over semi-arid areas and water avallability are major issues particularly assoclated with the development of western tight sands. Research needs are also the same as those for eastern gas shales. 
011 shale development is planned for many of the same geographical areas where western tight sands may be expected (e.g., Green River Formation, Piceance Basin, Uinta Basin). Consequently, the information data base being amassed in relation to oll shale development should actively be made available and there should be coordination of research efforts on health and environmental problems related to the two technologies. In addition, since tight sands are sedimentary in origin, the gas from these formations should be screened for radioactive materials.

\section{Methane from Coal Seams and Mines}

Many coal seams contaln substantlal amounts of methane that are released continuously or sporadically, of ten with.catastrophic results, during mining. The gas is a major safety problem and its removal and use prior to mining would decrease worker mortality and injury, while at the same time increasing the size of the energy resource base.

Methane can be withdrawn from many different mines (see description of the resource) to minimize the probability of explosion and provide an energy resource: The health and environmental issues and research needs assoclated with recovering methane from eastern gas shales and western gas sands also are essentlally applicable to the recovery of methane from coal seams and other sedimentary deposits. Since recovery often involves draining existing mines, or draining methane in front of a working face, the control of the level of methane in the work atmosphere is important to assure that workers are safe from the risk of explosions.

Recently, flve men were killed in a methane gas mine explosion that traglcally underscored the need for rellable methods of forecasting methane hazards in mines and other areas where workers are exposed to methane. The explosion occurred on June 9, 1979, in a Louisiana salt mine. As a result of this explosion, the mine and three other salt mines have been reclassified as gassy by the Mine Safety and Health Administration (MEAS) (U.S. Department of the Interfor 1979, 8392).

The methane concentration in the return air in the mine was 90 ppm. Currently, a 100-ppm concentration is recommended by the Bureau of Mines as a simple and convenient guideline for forecasting the methane hazard in a mine, whether or not the mine is classifled as gassy (a classification requiring compliance with stringent safety standards--see Code of Federal Regulations, 30 CFR 57.21-1). 
The information and reclassifications that resulted from the explosion suggest that a guideline of about $70 \mathrm{ppm}$ may be more approprlate (U.S. Department of the Interfor 1979, 8392). New assessments are needed to establish the most appropriate concentration for a guideline.

\section{Methane. Hydrates}

Studies of health and environmental 1ssues assoclated with the development of gas hydrates have not taken place, nor have the 18sues themselves been defined. Even studies related to the nature and extent of the resource are few in number (American Gas Association $1979 \mathrm{~b})$.

One mechanism for recovering hydrate gas would be tapping a free-gas zone underlying a hydrate layer, but this may cause a problem. The produced free gas would cause a pressure drop that would cause the hydrates to melt, perhaps leading to melting of the permafrost which could cause frost leaves, permafrost 1nstab1lity, and creation of surface cracks and fissures. Once started, such discontinulties can propagate in an uncontrolled manner. This problem should be studied in detall before test wells are drilled.

\section{Gas from Deep Basins}

Considerable research is needed in the fundamental field of geophysics and geochemistry, especially with respect to deep gas reservoirs. An incidental benefit of such research may be finding new approaches to earthquake prediction. Other than the potentlal for catastrophic releases of hydrogen sulfide and the creation of a channel for the exit of hot flutds, few health and environmental concerns can be identifled prior to a more defined characterization of the resource potential.

\section{Gas from Biomass}

Sludge remaining after anaerobic digestion is separated into a liquid effluent and solid waste material. Both are potentially dangerous if not carefully treated. The liquid effluent contains toxic materials, disease organisms, suspended solids, and undigested organic material. The suspended solids can increase the turbidity of surface waters, while the leachate from digested solids used in landfill can cause additional ground and surface water pollution. The solids contain unknown quantities of toxic chemicals, such as pestic1des and trace metals, as well as pathogenic microorganisms. The large amounts of water required for anaerobic digestion could aggravate water shortages in areas already experlencing a shortage of water (Energy Research and Development Administration 1977). 
The potential contamination of $8011 \mathrm{~s}$ and water sources can adversely impact plant and animal 11fe. Bacterla remaining in the water after digestion would grow, depleting the oxygen supply and adversely Impacting aquatic 11fe. Increased turbidity of streams would interfere with photosynthesis and could also be harmful to aquatic, blota. The possible biological contamination of solls and water sources could create serlous health hazards for humans.

Environmental impacts resulting from increased employment and resultant 1mmigration are similar to those described above. Concomitant social and economic impacts are well known, but mitigative measures are not well understood.

The various potential environmental impacts mentioned above suggest frultful areas for research. In addition, a coordinated and cooperative information transfer program should be initiated which will exchange health and environmental data among varlous processes. Currently, processes for producing methane by anaeroblc digestion operate on a small scale and use a varlety of blomass sources (e.g., manure, urban refuse, logging and wood manufacturing residues, agr 1cultural crops and food wastes, Industrlal wastes, municipal sewage, and solid wastes). 
Part 9

Basic Effects Issues 
Broad issues and research needs related to many facets of the oil and gas industry are discussed in this section, including hydrocarbons. These are in the nature of basic research. A basic research theme that is not addressed in this section is treated in depth in other sections of this report. This theme is the need for increased research emphasis on the characterization, monitoring, and chemistry of hydrocarbons of significant health concerm that are in the ambient environment, such as polynuclear aromatic hydrocarbons and amines. Attention should focus on the Gulf Coast, Southern California, northeasterm industrialized areas, and other industrialized regions to utilize the available research resources effectively.

With respect to basic research, naturally occurring atmospheric hydrocarbons are derived from many sources, but their effects are not well understood and presumably may be beneficial due to the adaptability of biotic organisms. This warrants further study. To characterize atmospheric hydrocarbons, a more accurate and reliable replacement for the flame-ionization detector is needed. A nationally coordinated methane monitoring program is needed to provide data for a number of different energy focused assessment studies. Also within this section, the broad subject of the role of hydrocarbons in the atmosphere is discussed. This dicusssion provides background information for many sections of the report. 
THIS PAGE

\section{WAS INTENTIONALLY LEFT BLANK}


BASIC EFFECTS ISSUES

TABLE OF CONTENTS

$\underline{\text { Page }}$

NATURAL HYDROCARBON EMISSIONS $\quad .641$

MEASUREMENT OF PHOTOCHEMICAL OXIDATION $\quad 642$

$\begin{array}{ll}\text { METHANE MONITORING } & 644\end{array}$

APPENDIX ROLE OF HYDROCARBONS IN THE ATMOSPHERE 
THIS PAGE

\section{WAS INTENTIONALLY \\ LEFT BLANK}


The following discussion covers a few health and environmental effects issues.related to many facets of the oil and gas industry. The issues discussed are not covered in detail within any of the preceding sections. Certain broad issues, relating to many facets of the industry that have been treated in depth elsewhere* are not discussed in this section. Since many of the basic effects of hydrocarbons relate to airborne emissions, a general discussion of the known role of hydrocarbons in the atmosphere is provided in an appendix to this section.

\section{NATURAL HYDROCARBON EMISSIONS}

Within the last decade the presence in the atmosphere of natural hydrocarbons, including methane, has been well documented. Although most of these hydrocarbons arise from biological sources, small and highly localized quantities of methane and other lower-molecularwelght hydrocarbons have been associated with emissions from geothermal areas, coal fields, natural gas and petroleum fields (including natural seafloor seeps), and forest and brush fires. Recently, methane of nonbiological origin, associated with the release of gases from deep in the earth's mantle during earthquake and volcanic activity, also has been identified as a natural emission.

Most of these natural hydrocarbon emissions occur during the natural decomposition of organic matter in both land and water (swamps, marshes, and sediments). Volatile terpenes and isoprenes are also a major constituent of natural hydrocarbon emissions. These compounds have been associated with plant metabolism and contribute to the blue haze of the Appalachian Mountain region. They also can play a significant role in photochemical aerosol formation.

Ambient methane concentrations appear to be uniform and ubiquitous except for localized anomalies (e.g., swampy areas, tectonic fissures). Mẹsurements of other low-molecular-weight hydrocarbons such as ethane, ethene, ethylene, butane, terpense and isoprenes have been few in number, especially in nonurban areas. Estimates of the average life of these compounds in the atmosphere are varied and range from a few years to 20 years for methane, and on the order of

\footnotetext{
*For a discussion of the efferts of hydrocarbons on humans and ulher biota, see the Onshore, offshore, Refinery Operations, and Transportation and Storage sections; for the effects of evaporative emissions on air quality, see Refinery Operations, Transportation and Storage, and End Use sections; and for the effects associated with oil and gas combustion products, see the End Use section.
} 
days to months for higher-molecular-welght hydrocarbons. About 43 percent of these emissions occur during summer (June, July, and August) and almost half occur in southern states (U.S. Department of Health, Education, and Welfare 1970; first external review draft of Facts and Issues Assoclated with the Need for a Hydrocarbon Criterla Document, see Federa1 Register, March 10, 1980; pp. 15262-15263).

The role of natural hydrocarbon emissions with respect to alr quality and related biotic effects is not well understood. Some of these emissions may be beneficlal owing to evolutionary adaptation of biotic mechanisms to natural emissions. If this is true, land clearing and water pollution may be responsible for decreased ambient levels of these hydrocarbons and their biotic value may be partially replaced by hydrocarbons from technological sources. Thts 18 an area where research is needed.

\section{MEASUREMENT OF PHOTOCHEMICAL OXIDATION}

Hydrocarbons react with other compounds in the atmosphere on exposure to sunlight, producing ozone and other photochemical oxidants. The chemistry of oxidants formation is described in detall by the National Academy of Sclences (1976, 1977). The description presented below is a highly simplified version of the complex chemical reactions leading to photochemical alr pollution that underscores. the pivotal role hydrocarbons may play in these processes.

The major photochemical oxidants--ozone $\left(\mathrm{O}_{3}\right)$, nitrogen dioxide $\left(\mathrm{NO}_{2}\right)$, and peroxyacetyl nitrate (PAN)--are secondary pollutants formed from other pollutants in the atmosphere under favorable cond1tions. Ozone, present in the highest concentrations, is the product of a reaction in which common diatomic oxygen $\left(\mathrm{O}_{2}\right)$ reacts with molecular oxygen $(0)$ in the presence of a third molecule $(M)$, where $M$ is usually a nitrogen compound or oxygen:

$$
0+O_{2}+M=O_{3}+M \text {. }
$$

The atomic oxygen $(0)$ reactant is generated largely from the photolysis of nitrogen dioxide $\left(\mathrm{NO}_{2}\right)$ :

$$
\mathrm{NO}_{2}+\mathrm{hv}=\mathrm{O}+\mathrm{NO} \text {. }
$$

The reaction mechanism is completed by the reaction of the two nonozone reaction by-products to regenerate nitrogen dioxide and diatomic oxygen:

$$
\mathrm{NO}+\mathrm{O}_{3}=\mathrm{NO}_{2}+\mathrm{O}_{2} \text {. }
$$


These reactions are the mechanism for atmospheric ozone formation, but alone they do not account for ozone accumulation. Photochemical hydrocarbon reactions affect the relative rates and the concentrations of reaction products. Modeling and smog-chamber simulations show significant oxidant formation when reactive hydrocarbons are present. Hydrocarbons photochemically regenerate free radicals that react with oxygen to form alkylperoxy- and hydroperoxy-free radicals. These radicals react with $\mathrm{NO}$ to form $\mathrm{NO}_{2}$ :

$$
\mathrm{KH}+\mathrm{O}=\mathrm{Ro}+\mathrm{OHo} ; \mathrm{Ro}+\mathrm{O}_{2}-\mathrm{ROOO} ; \mathrm{ROOO}+\mathrm{NO}-\mathrm{NO}_{2}+\mathrm{OHo} \text {. }
$$

Hydrocarbons are oxidized in the process. These hydrocarbon reactions essentially "pump" the primary reaction of $\mathrm{NO}_{2}$ photolysis by scavenging this reaction's NO product and making avallable more $\mathrm{NO}_{2}$ reactant. In the process, atomic oxygen is made avallable for ozone and other oxidants formation. The amount of "pumping," and thus the amount of oxidants formed, depends on the. concentration and reactivity of the hydrocarbons present.

Hydrocarbons are classified with respect to oxidant-related reactivities in urban atmospheres. Alkenes (olefins), benzene derivatives, and aldehydes have the highest reactivities. Methane, ethane, propane, and benzene essentially do not participate in these reactions. These reactivity data reflect rates of formation rather than resulting peak oxidant concentrations. The same reactions occur with lesser reactive hydrocarbons at a slower rate over a longer period of time.

A number of conditions affect the formation and bulldup of ozone concentrations. Moist air significantly aids ozone formation. In the absence of hydrocarbons an equilibrium is established among ozone, nitric oxide, and nitrogen oxide. Concentrations of these compounds and reactive hydrocarbons change diurnally in response to available sunlight and darkness. Atmospheric particulate components, such as metal oxides and carbon particles, have a catalytic effect on many photooxidation reactions.

Besides ozone $\left(\mathrm{O}_{3}\right)$, a number of other compounds are photochemical oxidants--nitrogen dioxide $\left(\mathrm{NO}_{2}\right)$, hydrogen peroxide $\left(\mathrm{H}_{2} \mathrm{O}_{2}\right)$, organic peroxides, organic hydroperoxides, and peroxyacyl nitrate. Organic peroxides have the general formula ROOR. Organic hydroperoxides have the formula ROOH. The major peroxyacyl nitrates are peroxyacetyl nitrate (PAN) and peroxybenzoyl nitrate (PBN). (Actually, this nomenclature is inappropriate for these structures-better names would be acetyl peroxynitrate and benzoyl peroynitrate.) 
The comprehensiveness of atmospheric hydrocarbon measurement data is deficient. Most avallable data concerns only total hydrocarbon concentrations measured by flame-ionization detectors (FID). Nonmethane hydrocarbons (NMHC) are measured by gas chromatographic separation of methane from total hydrocarbons followed by FID measurement of methane and total hydrocarbons in the air sample. NMHC data are obtalned by subtracting methane from total hydrocarbon concentrations. Since the FID responds to organically bound carbon in compounds other than hydrocarbons, the measurement of NMHC may more appropriately be termed nonmethane organic compound (NMOC) measurements.

FID techniques have been associated with high measurement errors and variablity. This must be kept in mind when NMHC data are compared with exposure data from toxicity studies and air quality monitoring. It is apparent that FID measurements are inadequate for the complete characterization of hydrocarbons in ambient air. There is a need for continued development and refinement of accurate, reliable field instruments for measuring NMHC--individually and collectively--in ambient air and in source emissions. For the measurement of individual compound, emphasis should be placed on standardizing chromatographic techniques for qualitative and quantitative measurement. This is needed both for an 1mproved understanding of atmospheric hydrocarbon chemistry and from a public risk perspective.

\section{METHANE MONITORING}

Monitoring ambient concentrations of methane is necessary to identify the resources and fugitive emissions associated with both unconventional and conventional sources of natural gas. Knowledge of the sources and sinks of methane is a central topic of interest in the research disciplines of geochemistry, ecology, and atmospheric chemistry.

The atmospheric chemistry community has speculated that the stratosphere is a sink for methane and that this sink mechanism is connected with the earth's ozone layer, which acts as a protective shield against excessive ultraviolet radiation. The oxidation of methane may contribute to a decrease in ozone levels. A smaller, but extremely important phenomenon; the oxidation of methane in the troposphere is also of great interest in the study of the photochemistry of the troposphere (Crutzen et al. 1976; Heidt and Pollock 1976).

Oceanographers and ecologists are interested in monitoring methane generated by anaerobic processes on land and in swamps, marshes, lakes, estuaries, and the ocean. Such sources of methane tend to obscure the contribution of urban pollutant plumes. Methane monitoring also can be useful in other areas, including: tracing the 
flow of carbon through the ecosystem (useful to the understanding of the global $\mathrm{CO}_{2}$ cycle); searching. for natural gas sources; identifying leaks from natural gas development fields including geopressurized fields, western tight sands, deep gas, coal seams, and in situ combustion, as well as leaks from transmission lines; and identifying potential locations of earthquake activity.

A nationally coordinated atmospheric methane monitoring program is needed, covering local, reglonal, and global monitoring. This program could support the research needs of these various areas through the development of a common data base. 


\section{THIS PAGE \\ WAS INTENTIONALLY \\ LEFT BLANK}




\section{APPENDIX}

\section{ROLE OF HYDROCARBONS IN THE ATMOSPHERE}

The degree of alrborne transport by petroleum pollutants is a function of both the physical and chemical characteristics of the pollutants and any other processes (e.g., atmospheric phenomena) acting upon them. It is the combination and interaction of various components within each of these two areas that determine how, and to what extent, individual or mixed pollutants are transported.

Alrborne pollutants may be envisioned as consisting of two broad classes: particles and gases. These classes are not necessarily discrete, $1 . e .$, they can exh1b1t varying degrees of interactions both with each other, and also with other non-pollutant atmospheric constituents. In this context, alrborne particles may be pollutants themselves or be non-pollutant particles on which pollutants are adsorbed. Pollutant vapors that are emftted to the atmosphere may remaln unchanged, undergo complex photochemical reactions, condense on particulate matter, or form aerosols.

In the area of atmospheric particulate pollution, aerosols-especially these contalning polycyclic organic matter-are of great Importance from the standpoint of human health (National Research Council 1972). It is in the form of aerosols that many organic pollutants, both particulate and vaporous, are transported to and through the atmosphere. (For this discussion, an aerosol can be considered to be a gaseous suspension of ultramicroscopic particles of a liquid or solld.)

Among the most important physical factors affecting aerosol transport are the size and shape of the constituent particles. The size range of such particles is large; values ranging from $6.7 \mathrm{x}$ $10^{-4}$ to $6.7 \times 10^{-3}$ yds $\left(6 \times 10^{-4}\right.$ to $\left.10^{-3} \mathrm{~m}\right)$ for urban and natural aerosols have been cited (Corn 1976). In addition to s1ze, the shapes of such particles are highly varlable, but may be categorized as spherical, irregular, cubical, flake, fibrous, and condensation forms. The shape of such a particle in an atmospheric aerosol will be a function of the temperature, pressure, fuel, and other factors associated with the local emission source from which it was derived (Corn 1976). Other attendant physical characteristics defining transport capability for such aerosols are density and surface area. In the context of particle size as it affects the properties of atmospheric aerosols, the following factors have been cited: the resistance of the medium, the rate of evaporation, the rate of cooling, the predominance of diffusion or settling, and vapor pressure (Fuchs 1964). 
Until the last few years, only a few data were available on many aspects of airborne particles, especially polycyclics and their relative size and welght distribution within aerosols (National Research Council 1972). For example, one study (Demaio and Corn 1966) indicated that 75 percent by weight of a group of polycyclics analyzed were associated with aerosol particles less than 2.5 um in radius. Another study, however, examining the specific distribution of benzo(a)pyrene per unit weight of soot aerosol found the distribution of the pollutants to be constant (Thomas et al. 1968). In general, few studies have been performed on the mechanics of adsorption of polycyclic organics onto particle surfaces (National Research Council 1972) and, as mentioned in the End Use section of this report, considerable research is needed in this area, especially with respect to adsorption onto particles emitted from coal combustion. The recent state of knowledge, especially with regard to airborne particles, has been summarized by the National Research Council (1979).

In addition to heavier pollutants that are adsorbed onto pollutant or non-pollutant particles, there are organic pollutants that are initially vapors and which subsequently condense. The presence of solid particles in the atmosphere (whatever their nature) promotes the condensation of vapor onto them, and consequently affects their transport capabilities. Particles with a radius smaller than $0.1 \mathrm{um}$ are referred to as condensation nuclei (Corn 1976). The general term, Aitken nuclei, is of ten used to refer to such microscopic particles that are the foci of vapor condensation. These nuclei aro generated from many sources, especially combustion processes, and they are often pollutants since they may be formed from reactions between various hydrocarbons and nitrogen oxides (Corn 1976).

In addition to the physical and chemical characteristics of the pollutants, extraneous terrestrial and meterological factors also modify airborne transport. A major terrestrial factor is the topography of the terrain over which pollutants are transported. Terrain that is not flat, or that has various large scale natural or artificial structures on it, may modify the transport of airborne pollutants. Burr and Clymer (1976) have enumerated some of the following meterological effects that rough, complex terrains may have on the dispersion of airborne pollutants:

- Channeling of wind by valleys;

- Boundary layer instability effects;

- Increased turbulence aloft due to surface roughness;

- Downflow of colder air into a valley; 
Literature Cited 
- Irregular distribution of updraft due to insolation of rough terrain;

- Turbulence due to wind shear;

o Nonuniform wind speed and direction due to flow over rough terrain; and

- Elevation of a "cloud" of pollution caused by inflow of cooler, cleaner alr below.

The above list is not meant to serve as a definitive array of factors affecting airborne transport over rough terrain, but it indicates some of the attendant difficulties in predicting the transport and location of such pollutants.

In addition to factors affecting transport, there are transformations that emitted pollutants undergo, elther among themselves or with other atmospheric constituents. Such constituents may be particulate, vaporous, or gaseous in nature and may or may not, by themselves, be pollutants. Complex chemlcal transformations among mixtures of these various components may produce pollutants differing in both nature and amount from the kind originally emitted to the atmosphere.

Perhaps the key or at least a major factor inftiating, contro1ling, and terminating atmospheric pollutant reactions, especially with regard to hydrocarbons, is light energy. From this perspective, the broadest view may be taken on how various vapor or particulate organic pollutants, may interact with themselves and other atmospheric constituents.

For chemical reactions to occur in the atmosphere, it is necessary to have energy input. Atmospheric temperatures generally are not sufficient tor this purpose. Light, however, may provide the necessary energy even to initiate reactions subsequently completed in the dark (Haagen-Smit and Wayne 1976). When atmospheric molecules, petroleum-derived organic pollutants, or natural constituents become dissoclated due to light energy, they form highly reactive chemical species termed free atoms or radicals. These highly reactive, electrically imbalanced species are of major importance in atmospheric transformations (Haagen-Smit and Wayne 1976). Both organic pollutants and inorganic atmospheric constituents may, under the influence of absorbed light, be converted into these active chemical species. These chemical species then, in a myriad of intermediate reactions, may be transformed into different compounds; or in a series of reactions, they may produce other highly reactive free radicals as products. These in turn may, in a chain reaction, continue the process 
(Haagen-Sm1t and Wayne 1976). Among the classes of organics which can undergo such photodissoclation are: aldehydes; ketones; alky1-, acyl-, and peroxyacyl nitrates; and organic peroxides (Haagen Smit and Wayne 1976). Such large classes of organics all contaln pollutants assoclated with oll or gas production.

It is important to note that this photooxidation of organic pollutants is not confined to compounds that may exist only as a vapor. Photooxidation of adsorbed aromatic hydrocarbons also may occur. It is postulated that the chemical reactivity of hydrocarbons adsorbed on particles is greater than that of hydrocarbons in solution (National Research Counc11 1972). In experimental studies, such organics as anthracene, naphthacene, benz(a)anthracene, and benzo(a)pyrene have been oxidized under the influence of room or ultraviolet light while in an adsorbed condition (National Research Counc11 1972).

Rather than attempt to assemble a list of specific organic pollutants and the myriad number of actual or potential products that are, or might be formed from them, this section attempts to delineate some of the more important aspects of atmospheric pollutant chemistry. As a concluding note, some effort has been made to rank organics in terms of their reactivity in relation to their rate of consumption due to photooxidation. ThIs "reactivity" ranking places . internally double-bonded olefins as highly reactive; polyalkyl benzenes and monoalkyl ethylenes as moderately reactive; ethylene, monoalkyl benzenes and alkanes as of low reactivity; and benzene, acetylene, methane, ethane, and propane of negligible reactivity (Haagen-SmIt and Wayne 1976). 
Energy Insider. 1980. DOE Rostrum (excerpts from major speeches), Jan. 7, 1980, p. 4 .

Hale, D. 1980. Industry Peak-shaving Capacity Greatest Ever for 1980-1981 Winter. Pipeline and Gas Journal 207(13):17-20.

Hammett, D. 1980. What 1s Industry's Deepwater Capability? Ocean Industry $15(11): 65-68$

Hodgson, B. 1978. Natural Gas: The Search Gocs On. National Geographic, November 1978, pp. 632-651.

King, R. 1980. What 1s Industry's Deepwater Capab1lity? Ocean Industry $15(11): 65-68$.

Maier, R.W., et a1. 1979. Refinery Energy Profile. OR0-5262-5. National Technical Information Service, Springfield, Virginia.

Newsweek. 1980. Higher 011 Prices, Deeper Drilling. March 31, 1980 , p. 60 .

0'Toole, T. 1980: 011 Firm Unveils Advance in Refining. The Washington Post, Apri1 1, 1980, p. A-6.

Technology Forecasts. 1979. Appalachlans: New Energy Treasure Trove. August 1979, pp. 9-10.

U.S. News and World Report. 1980. Hunt for 011, Gas Quickens All Across U.S. September 15, 1980, p. 51 . 


\section{THIS PAGE}

\section{WAS INTENTIONALLY \\ LEFT BLANK}

652 


\section{ONSHORE DEVELOPMENT \\ LITERATURE CITED}

Ahokas, J.T., O. Pelkonen, and N.T. Karki. 1974. Metabolism of Polycyclic Hydrocarbons by a Highly Active Aryl Hydrocarbon Hydroxylase System in the Liver of a Trout Species. Biochem. and Biophys. Res. Comm. 63(3):635-641.

Alber, P., and R. Szaro. 1976. The Effects of Petroleum Hydrocarbons on Aquatic Birds. In Sources, Effects, and Sinks of Hydrocarbons in the Aquatic Environment; American Institute of Biological Sclences Symposium, pp. 437-446.

Allen, T.0., and A.P. Roberts. 1978. Production Operations: Well Completions, Workover, and Stimulation, vols, 1 and 2.011 and Gas Consultants International, Inc., Tulsa, Oklahoma.

Alpin, J.A. 1977. The Effect of Explosives on Marine Life. California Fish and Game 55:23-27.

Altshuller, A.P., and J.U. Bufalin1. 1971. Photochemical Aspects of Alr Pollution: A Review. Env. Sc1. Tech. 5:39-64.

American Institute of Mining Englneers. 1975. Petroleum Production and the Environment. Soclety of Petroleum Eng1neers, American Inst1tute of Mining Engineers, Dallas, Texas.

American Petroleum Insitute. 1953. Selected Values of Physical and Thermodynamic Properties of Hydrocarbons and Related Compounds. Carnegie Press, Pittsburgh, Pennsylvania.

American Petroleum Institute. 1976. Primer of 011 and Gas Production, 3rd ed. Dallas, Texas.

American Petroleum Institute. 1979a. Summary of Occupational InjurIes and Illnesses in the Petroleum Industry. Statistics Department, Washington, D.C.

American Petroleum Institute. 1979b. Review of Fatal Injurles in the Petroleum Industry for 1978. Statistics Department, Washington, D.C.

Anderson, J.W. 1973. Uptake and Depuration of Petroleum Industry for 1978. American Petroleum Institute, Statistics Department, Washington, D.C. 
LITERATURE CITED (Onshore Development, Continued)

Antizzo, J., and A. Lawrence. 1976. EDP for Enhanced 011 and Gas Recovery. WP-12895, series 8. The MITRE Corporation, Metrek Division, McLean, Virginia.

Ayres, S.M., and M.E. Buehler. 1970. The Effects of Urban Pollution on Health. Clin. Pharmacol. Ther. 11:271-332.

Battelle Pacific Northwest Laboratories 1973. Effects of 011 and Chemically Dispersed 011 on Selected Marine Blota--A Laboratory Study. Pub. no. 4191. American Petroleum Institute, Washington, D.C.

Be11, D.L. 1971. The Toxic1ty and Biological Effects of 011 Po1lution. Memo to Environmental Protection Agency, Office of Water Programs, Washington, D.C.

Bestougelf, M.A. 1967. Petroleum Hydrocarbons. In Fundamental Aspects of Petroleum Geochemistry, eds. B-Nagy and $\bar{U}$. Colombo, pp. 109-175. Elsevier Publishing Co., New York.

Blumer, M., and J. Sass. 1972. The West Falmouth 011 Spil1. Rep't. no. WHOI-72-19. Woods Hole Oceanographic Institution, Woods Hole, Massachusetts.

Boehm, P.D., and J.G. Quinn. 1973. Solubilization of Hydrocarbons by the Dissolved Organic Matter in Sea Water. Geochem. Cosmochem. Acta 37:2459-2475.

Boesch, D.F., C.H. Hershner, and J.D. M1lgram. 1974. 011 Spills and the Marine Environment. Ballinger Publishing Company, Cambridge, Massachusetts.

Britt, D., et a1. 1976. Balanced Program Plan. In Energy Technology Focus, vol. 2. MTR-7174. The MITRE Corporation, Metrek Div1sion, McLean, Virginia.

Brockson, R.W., and H.T. Balley. 1973. Respiratory Response of Juvenile Chinook Salmon and Striped Bass Exposed to Benzene, A WaterSoluble Component of Crude 011. In Proceedings, Joint Conference on Prevention and Control of $011 \mathrm{Spi} \overline{11}$. American Petroleum Institute, Washington, D.C.

Brown, R.A., and H.L. Huf fman. 1976. Hydrocarbons in Open Ocean Waters. Science 191:847-849. 
LITERATURE CITED (Onshore Development, Continued)

Brown, R.D. 1976. Considerations in the Establishment of Discharge Standards for Petroleum Refinery Effluents. Conference on the Management of Petroleum Refinery Wastewaters, Tulsa, Oklahoma.

Brown, R.D. 1977. Control of Air Quality from 011 Tankers. Unpublished information prepared in support of a Federal initiative dealing with the regulation of offihore oil pollution. The MITRE Corporation, McLean, Virginia.

Brown, V.M. 1976. Aspects of Heavy Metals Toxiclty in Freshwaters. In Toxicity to Blota of Metal Forms in Natural Water, eds. R.W.

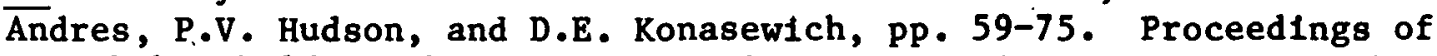
a workshop held by the International Jolnt Commission on Great Lakes, Duluth, Minnesota, Oct. 7-8, 1975.

Burr, J.C., and A.B. Clymer. 1976. Alr Modeling in Ohio: EPA. In Proceedings of the EPA Conference on Environmental Modeling and Simulation, ed. W.R. Off, pp. 82-85. EPA 600/9-76-016. Office of Research and Development and office of Planning and Management, Washington, D.C.

Button, D.K. 1976. The Influence of Clay and Bacteria on the Concentration of Dissolved Hydrocarbon in Saline Solution. Geochem. Cosmochem. Acta 40:435-550.

Card, J.D., P.V. Ponce, and W.C. Srider. 1975. Tankship Accidents and Resulting 011 Outflows, 1963-1973. Proceedings of the Conference on Prevention and Control of 011 Pollution, San Francisco, California. Sponsored jointly by the American Petroleum Institute, the U.S. Environmental Protection Agency, and the U.S. Coast Guard.

Case, L.C. 1970. Water Problems In 011 Production, 2nd ed. Petroleum Publishing Company, Tulsa, Ohlahoma.

Chesapeake Blological Laboratory. 1948. Effects of Underwater. Explosions on Oysters, Crabs, and Fish. Chesapeake Blological Laboratory Publication 70:1-43.

Clark, J., J. Zinn, and C. Terrel1. 1978. Environmental Planning for offshore 011 and Gas. Recovery Technology, vol. 1. FWS/OBS-77-12. U.S. Fish and Wildife Service, Biological Services Program, Washington D.C.

Coffeen, J.A. 1978. Seismic Exploration Fundamentals. Petroleum Publishing Company, Tulsa, Oklahoma. 
LITERATURE CITED (Onshore Development, Cont1nued)

Council on Environmental Quality. 1973. Energy and the Environment. Electric Power. Council on Environmental Quality, Washington, D.C.

Comotto, R.M., P.A. Kimerle, and R.D. Swisher. 1979. Bloconcentration and Metabolism of Linear Alkylbenzene Sulfonate by Daphnids and Fathead Minnows. In Aquatic Toxicology, Proceedings of the Second Annual Symposium on Aquatic Toxicology, eds. L.L. Marking and R.A. Kimerle, p.p. 232-258. ASTM special technical pub. no. 667. American Society, for Testing and Materisals, Philadelphia, Pennsylvania.

Corn, M. 1976. Properties of Nonviable Particles in Air. In Air Poliutants, Their Transformation and Transport; vol. 1, ed. $\bar{A} \cdot \mathrm{C}$. Stern, pp. 78-168. Academic Press, New York.

Council on Environmental Quality. 1974. OCS 011 and Gas--An Environmental Assessment, vol. 1. U.S. Government Printing Office, Washington, D.C.

Counc1l on Environmental Quality. 1976. Environmental Quality, Seventh Annual Report. Council on Environmental Quality, Washington, D.C.

DeMaio, L.', and M. Corn. 1966. Polynuclear Aromatic Hydrocarbons Associated with Particulates in Pittsburgh Air. J. Air Pollut. Cont. Assoc. 16:67-71.

Dieter, M.P. 1976. The Effects of Petroleum Hydrocarbons on Aquatic Birds. In Sources, Effects, and Sinks of Hydrocarbons in the Aquatic Environment, American Institute of Blological Sciences Symposium, pp. 437-446. Washington, D.C.

Encyclopedia Britannica. 1975. Petroleum and Gas Extraction, vol. 14, pp. 175-179.

Farrington, J.W. 1977. 011 Pollution in the Coastal Environment. Estuarine Pollution Control and Assessment, vol. 2, pp. 385-400. EPA 440/1-77-007. U.S. Environmental Protection Agency, Washington, D.C.

Filby, R.H., and K.R. Shah. 1975. Neutron Activation Methods for Trace Elements in Crude 0ils. In The Role of Trace Metals in Petroleum, ed. T.F. Yen. Ann Arbor Science Publishers, Ann Arbor, Michigan. 
LITERATURE CITED (Onshore Development, Continued)

Forrest, R.M., and S.F. McKetta. 1978. Investigation of Hydraulic Fracturing Technology in Tight Gas Reservolrs. In Enhanced 011 and Gas Recovery and Improved Drilling Methods, vol. 2, pp. G-2 G-14. Fourth Annual Department of Energy Symposium, Tulsa, Oklahoma.

Fox, G.A., et al. 1975. Herring Gull Productivity and Toxic Chem1cals in the Great Lakes in 1975. Manuscript Reports no. 34, pp. 134. Toxic Chemicals Division, Canadian Wildiffe Service.

Fuchs, N.A. 1964. The Mechanics of Aerosols. Pergamon Press, Oxford, England.

Gage, S.J. 1977. Accidents and Unscheduled Events Associated with Non-Nuclear Resources and Technology. U.S. Environmental Protection Agency, Washington, D.C.

Goldberg, E.D. 1978. Ocean Pollution Research, Development, and Monitoring Needs--Review and overview. Presented at a workshop in Estes Park, Colorado, July 10-14. National Oceanic and Atmospheric Administration, Rockville, Maryland.

Gowanloch, J.N., and J.E. McDougal. 1945. Effects from the Detonation of Explosive on Certain Marine Life. 011 4:13-16.

Hammer, D.I., et al. 1974. The Los Angeles Student Nurse Study. Arch. Environ. Health 28:255-260.

Hanson, M.E., et al. 1978. Theoretical and Experimental Research on Hydraulic Fracturing, vol. 2, pp. E-6 - E-27. In Enhanced 011 and Gas Recovery and Improved Drilling Methods. Fourth Annual Department of Energy Symposium, Tulsa, Oklahoma.

Harris, L.M. 1972. An Introduction to Deepwater Floating Drilling Operations. The Petroleum Publishing Company, Tulsa, Oklahoma.

Huff, J.R. 1976. Study Analyses: Offshore Rig Casualties. 011 and Gas Journal 74:71-86.

Hutchinson, T.C., et al. 1980. The Correlation of the Toxicity to Algae of Hydrocarbons and Halogenated Hydrocarbons with The1r Physical-Chemical Properties. In Hydrocarbons and Halogenated Hydrocarbons in the Aquatic Environment, pp. 577-588. Plenum Press, New York. 
LITERATURE CITED (Onshore Development, Continued)

IMCO, FAO, UNESCO, WMO, WHO, IAEA, UN: 1971. Joint Group of Experts on the Scientific Aspect of Marine Pollution. Impact of 0il on the Marine Environment. Food and Agriculture Organization of the United Nations, Rome. Rep. Stud. GESAMP, 6.

Kalas, L., A. Mudroch, and F.I. Onuska. 1980. Bloaccumulation of Arene and Organochlorine Pollutants by Cipangopaludina Chinensis (Gray, 1834, Mollusca: Gastropoda) from ponds in the Royal Botanical Gardens, Hamilton, Ontario. In Hydrocarbons and Halogenated Hydrocarbons in the Aquatic Environment, pp. 567-576. P1enum Press, New York.

Kosh, D.E., et al. 1973. Energy Under the Oceans: A Technology Assessment of Outer Continental Shelf 011 and Gas Operations. University of Oklahoma Press, Norman, Oklahoma.

Laskin, S., M. Kuschner, and R.T. Drew. 1970. Studies in Pulmonary Carcinogenesis. In Inhalation Carcinogenesis, eds. M.G. Hanna, Jr., P. Nettesheim and J.R. Gilbert, pP. 321-350. AEC symposium series, no. 18. U.S. Atomic Energy Commission, Washington, D.C.

Lawrence, A. 1976. EDP for Conventional 011 and Gas. WP 12985, series 5. The MITKE Corporation, Metrek Dlvislun, McLean, Virginia.

Leck1e, J.0., and R.0. James. 1976. Contro1 Mechan1sms for Trace Metals in Natural Waters. In Aqueous-Environmental Chemistry of Metals, ed. A.J. Rubin, pp. 1-76. Ann Arbor Sclence Publishers, Inc., Ann Arbor, Michigan.

Leggett, N., and T. Willlams. 1979. Natural Gas Processing. The MITRE Corporation, Metrek Division, McLean, Virginia.

Maki, A.W. 1979. Respiratory Activity of Fish as a Predictor of Chronic Fish Toxicity Values for Surfactants. In Aquatic Toxicology, eds. L.L. Marking and R.A. Kimerle, pp. 77-95. Proceedings of the Second Annual Symposium on Aquatic Toxicology. ASTM special technical pub. no. 667. American Society for Testing and Materials, Philadelphia, Pennsylvania.

Malins, D.C. 1977. Metabolism of Aromat1c Hydrocarbons in Marine Organisms. In Aquatic Pollutants and Biologic Effects with Emphasis. on Neoplas1s, vol. 298, eds. H.F. Kraybill, C.J. Dawe, J.C.

Harshbarger and R.G. Tardiff, pp. 482-496. Annals of the New York Academy of Sciences, New York. 


\section{LITERATURE CITED (Onshore Development, Continued)}

McAuliffe, C.D. 1977. Dispersal and Alteration of 011 Discharged on a Water Surface. In Fate and Effects of Petroleum Hydrocarbons in Marine Organisms and Ecosystems, ed. D.A. Wolfe, pp. 19-35.

McAuliffe, C.D., et al. 1979. The Chevron Main Pass Block 41011 Sp111: Chemical and Biological Investigations. Proceedings of the 1975 Conference on Prevention and Control of 011 Pollution, pp. 555-566. American Petroleum Institute, Washington, D.C.

McCauley, R.N. 1966. The Biological Effects of 0il Pollution in a River. Limul. Oceanogr. (11):475-486.

Meler, V. 1978. 011 Well Operation and Salt-water Intrusion: Policy Implications. Industrial Wastes (24):42-45.

Melancon, M.J., Jr., and J.J. Lech. 1979. Uptake Blotransformation, Disposition, and Elimination of 2-Methylnapthalene and Napthalene in Several Fish Species. In Aquatic Toxicology, eds. L.L. Marking and R.A. Kimerle, pp. 5-22. Proceedings of the Second Annual Symposium on Aquatic Toxicology. ASTM special technical pub. no. 667. American Society for Testing and Materials, Philadelphia, Pennsylvania.

Moore, S.F. 1973. Towards a Model of the Effects of 011 on Marine Organisms. National Academy of Sciences Workshop on Inputs, Fates and Effects of Petroleum in the Marine Environment. Washington, D.C.

Moore, S.F., R.L. Dwyer, and A.M. Katz. 1973. A Preliminary Assessment of the Environmental Vulnerability of Machias Bay, Maine, to 011 Supertankers. Ralph M. Parsons Laboratory for Water Resources and Hydrodynamics. Rep't. no. 162. Department of Civil Engineering, School of Engineering, Massachusetts Institute of Technology, Cambridge, Massachusetts.

National Academy of Sciences. 1972. Biologic Effects of Atmospheric Pollutants: Particulate Polycyclic Organic Matter. National Academy of Sciences, Washington, D.C.

National Academy of Sciences. 1975. Petroleum in the Marine Environment. National Academy of Sciences, Washington, D.C.

National Petroleum Council. 1976. EOR, An Analysis of the Potential for Enhanced $0 i 1$ Recovery from Known Fields in the Jnited States-1976 to 2000. National Petroleum Council, Washington, D.C. 
LITERATURE CITED (Onshore Development, Continued)

Nelson-Smith, A. 1973. 011 Pollution and Marine Ecology. Plenum Press, New York.

Office of Technology Assessment. 1978. Enhanced 011 Recovery Potential in the United States. U.S. Department of Energy, Washington, D.C.

Patton, C.C. 1977. Ollfleld Water Systems. Campbell Petroleum Series, 2nd ed. Norman, Oklahoma.

Payne, J.F., and W.R. Penrose. 1975. Induction of Anyl Hydrocarbon (Benzo(a)pyrene) Hydroxylase in Fish by Petroleum. Bull. Environ. Contam. Toxicol. (14):112-116.

Pedersen, M.G., W.K. Hershberger, and M.R. Juchau. 1978. Metabolism of 3,4-Benzpyrene in Ralnbow Trout (Salmo galrdneri). Bull. Environ. Contam. Toxico1. (12):481-486.

Plckering, Q.H., and C. Henderson. 1966. Acute Toxicity of Some Important Petrochemicals to Fish. J. Water Po1l. Cont. Fed. $38(9): 1419-1429$.

Plmlott, D.H., D. Brown, and K.r. Sam. 1976. OL1 Under the Iec. Canadian Arctic Resources Committee, Ottawa, Ontario.

Rahme, H. 1978. Enhanced 011 Recovery. WP-13465, The MITRE Corporation, Metrek Division, McLean, Virginia.

Ranney, M.W. 1979. Offshore O11 Technology: Recent Developments. Noyes Data Corporation, Park Ridge, New Jersey.

Renzett1, N.A., and R.J. Bryan. 1961. Atmospheric Sampling for Aldehydes and Eye Irritation in Los Angeles Smog--1960. J. Air Pollut. Cont. Assoc. 11:421-424.

Rice, S.D. 1973. Toxicity and Avoldance Tests with Prudhoe Bay 011 and Pink Salmon Fry. In Proceedings of the Joint Conference on Prevention and Control of 011 Spi11s, pp. 667-670. American Petroleum Institute, Washington, D.C.

Rice, S.D., J.W. Short, and J.F. Karinew. 1976. Toxicity of Cook Inlet Crude $0 i 1$ and No. 2 Fuel 011 to Several Alaskan Marine Fishes and Invertebrates. In Sources, Effects, and Sinks of Hydrocarbons in the Aquatic Environment, pp. 305-406. American Institute of Biological Sciences Symposium. 
LITERATURE CITED (Onshore Devlopment, Continued)

Richards, N.L. 1979. Effects of Chemicals Used in 011 and Gas WellDrilling in Aquatic Environments. Paper presented at Fourth National Conference Interagency Energy/Environment R\&D Program. U.S. Environmental Protection Agency, Washington, D.C.

Schumacher, M.M., ed. 1978. Enhanced 011 Recovery: Secondary and Tertiary Methods. Noyes Data Corporation, Park Ridge, New Jersey.

Silvestro, E., and A. Desmara1s. 1980. Toxicity of Chemical Compounds Used for Enhanced 011 Recovery. DOE/BC/10014-5. National Technical Information Service, Springfield, Virginia.

Sittig, M. 1978. Petroleum Transportation and Production, 0il Spill and Pollution Control. Noyes Data Corporation, Park Ridge, New Jersey.

Stokes, P., and T.C. Hutchinson. 1976. Copper Toxicity to Phytoplankton as Affected by Organic Ligands, Other Cations and Inherent Tolerance of Algae to Copper. In Toxicity To Blota of Metal Forms in Natural Water, eds. R.W. Andrew, P.B. Hodson, D.E. Konasewich, pp. 159-185. Proceedings of a Workshop held by the International Joint Commission on the Great Lakes, Oct. 7-8, 1975, Duluth, Minnesota.

Stokinger, H.E., and D.L. Coffin. 1968. Blologic Effects of Air Pollutants. In Air Pollution and Its Effects, 2nd ed., vol. 1, ed. A.C. Stern, pp. 445-546. Academic Press, New York.

Straunghan, D. 1972. Factors Causing Environmental Changes After an Oil Spill. Journal of Petroleum Technology 24:250-254.

Tarzwe11, C.M. 1971. Toxicity of 011 and 011 dispersant Mixtures to Aquatic Life. In Water Pollution by 0il, ed. Peter Hepple, pp. 263-

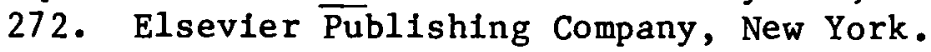

Taylor, R.W., and R.B. Krakl. 1976. Outer Continental Shelf Safety in $0 i 1$ and Gas Operations. United States Geological Survey Annual Report, Fiscal Year 1976. Reston, Virginia.

Thomas, J.F., M. Mulkai, and B.D. Tebbens. 1968. Fate of Airborne Benzo(a)pyrene. Env. Sc1. Tech. 2:33-39.

Thompson, J.A. 1958. Biological Effects of the Ripple Rock Explosion. Progress Report Pacific Coast Station, Fish Research Board, Canada $111: 3-8$. 
LITERATURE CITED (Onshore Development, Continued)

Tinsley, I.J. 1979. Chemical Concepts in Pollutant Behavior. John Wiley \& Sons, New York.

Tubb, M. 1980. 1979-80 Directory of Marine Drilling Rigs. Ocean Industry $14(9): 20-176$.

U.S. Department of Energy. 1978. Environmental Readiness Document, Enhanced 011 Recovery Commercialization Phase III Planning. Washington, D.C.

U.S. Department of Energy. 1979. Fossil Energy Program Summary. DOE/ET-0087. Washington, D.C.

U.S. Department of the Interior. 1972. Final Environmental Impact Statement (EIS) on Proposed Trans-Alaska Pipeline, vol. 4.

Washington, D.C.

U.S. Department of Transportation. 1976. Summary of Liquid Pipeline Accidents, Reported on DOT Form 7000-1 from January 1, 1975 December 31, 1975. Washington, D.C.

U.S. Environmental Protection Agency. 1972. Water Quality Criteria 1972: A Report of the Commictees on Waler Quallty Criteria by tho National Academy of Sclences. U.S. Environmental Protection Agency, Washington, D.C.

U.S. Environmental Protection Agency. 1976. Development Document for Interim Final Effluent Limitations Guidelines and Proposed New Source Performance Standards for the 011 and Gas Extraction Point Source Category. EPA-440/9-76-023. Washington, D.C.

U.S. Environmental Protection Agency. 1977. The Report To Congress: Waste Disposal Practices and Their Effects on Groundwater (Executive Summary). SH-656. Washington, D.C.

U.S. Geological Survey. 1976. Final Environmental Impact Statement: 011 and Gas Development in the Santa Barbara Channel Outer Continental Shelf off California, vol. 1. U.S. Geological Survey, Department of the Interior, Reston, Virginia.

U.S. Office of Management and Budget. 1972. Standard Industrial Classification Manual. Statistical Policy Division, Washington, D.C.

University of Oklahoma. 1975. Energy Alternatives: A Comparative Analysis. PB-246-365. National Technical Information Service, Springfield, Virginia. 


\section{LITERATURE CITED (Onshore Development, Concluded)}

Valkovic, V. 1978. Trace Elements in Petroleum, Petroleum Publishing Company, Tulsa, Oklahoma.

Wilkins, G.E. 1977. Industrial Process Profiles for Environmental Use. 011 and Gas Production Industry, chapt. 2. EPA-600/2-77-023b. Radian Corporation, Austin, Texas.

Young, G.A. 1973. Guidelines for Evaluating the Environmental Effects of Underwater Explosion Tests. Naval Ordnance Laboratory, White Oak, Maryland. 


\section{THIS PAGE}

\section{WAS INTENTIONALLY \\ LEFT BLANK}


OFFSHORE DEVELOPMENT

LITERATURE CITED

Albright, J.L. 1973. Seismic Charts Gas Seeps. Offshore, May, pp. 122-128.

Alexander, J.E., T.T. White, K.E. Turgeon, and A.W. Blizzard. 1977. Rig Monitoring, vol. 6. Gaseline Monitoring Studies, MAFLA, OCS, 1975-76. Final Report to the U.S. Department of the Interior, Bureau of Land Management Outer Continental Shelf office, Washington, D.C.

Alpin, J.A. 1977. The Effect of Explosives on Marine Life. Calffornia Fish and Game 55:23-27.

Altshuller, A.P., and J.J. Beualini. 1971. Photochemical Aspects of Air Pollution: A Review. Envi. Sci. Tech. 5:39-64.

American Petroleum Institute. 1953. Selected Values of Physical and Thermodynamic Properties of Hydrocarbons and Related Compounds. Carnegie Press, Pittsburgh.

American Petroleum Institute. 1979a. Summary of Occupational Injuries and Illnesses in the Petroleum Industry. Statistics Department, Washington, D.C.

American Petroleum Institute. 1979b. Review of Fatal Injuries in the Petroleum Industry for 1978. Statistics Department, Washington, D.C.

Anderson, J.W. 1973. Uptake and Depuration of Petroleum Hydrocarbons by Marine Organisms. U.S. Department of the Interior, hearings, Santa Barbara, California, Oct. 2-4.

Ayers, R.C. 1980a. Comment on the Fate and Effects of Drilling Discharges in the Marine Environment. Appendix B, American Petroleum Institute statement before the Joint Hearing Committee on Commerce, Science, and Transportation, Subcommittee on Energy Resources and Materials Production of the United States regarding Senate Bill S-2119, Georges Bank Protection Act. Washington, D.C. March 25.

Ayers, R.C., Jr. 1980b. Personal communication by telephone on Aug. 6. Rcsearch Associate, Exxon Production Research Company, Houston, Texas. 
LITERATURE CITED (Offshore Development, Continued)

Ayers, R.C., Jr., G. Bowers, R.P. Meek, and T.C. Sauer, Jr. 1980. An Environmental Monitoring Study to Assess the Impact of Drilling Discharges in the Mid-Atlantic. I. Quantity and Fate of Discharges. In Symposium on Environmental Fate and Effects of Drilling Fluids and Cuttings, Jan. 21-24, Lake Buena Vista, Florida (in press).

Ayres, S.M.', and M.E. Buehler. 1970. The Effects of Urban Pollution on Health. Clin. Pharmacol. Ther. 11:271-332.

Battelle Pacific Northwest Laboratories. 1973. Effects of 011 and Chemically Dispersed Oil on Selected Marine Biota--A Laboratory Study. 4191. American Petroleum Institute, Washington, D.C.

Bel1, D.L. 1971. The Toxicity and Biological Effects of 011 Pollution. Memo to Environmental Protection Agency, Office of Water Programs, Washington, D.C.

Blumer, M., and J. Sass. 1972. The West Falmouth 0il Spill. WHOI-72-19. Woods Hole Oceanographic Institution, Woods Hole, Massachuset ts.

Boehm, P.D., and J.G. Quinn. 1973. Solubilization of Hydrocarbons by the Dissolved Organic Matter in Sea Water. Geochem. Cosmochem. Acta $37: 2459-2475$.

Boesch, D.F., C.H. Hershner, and J.H. Milgram. 1974. 011 Spills and the Marine Environment. Ballinger Publishing Company, Cambridge, Massachuset ts.

Bolton, S. 1980. Personal communtcation by telephone on Aug. 11 . Marine Biologist, Ocean Programs Branch, Office of Water and Waste Management, U.S. Environmental Protection Agency, Washington, D.C.

Boyne, I. 1980. North Sea Waters Most Dangerous for 011 Workers. Byline circa April 1, 1980. Field News Service (formerly Chicago Dally News Service), Chicago, Illinois.

Brandsma, M.G., L.R. Davis, R.C. Ayers, Jr., and T.C. Sauer, Jr. 1980. A Computer Model to Predict the Short-Term Fate of Drilling Discharges in the Marine Environment. In Symposium on Environmental Fate and Effects of Drilling Fluids and Cuttings, Jan. 21-24. Lake Buena Vista, Florida (in press). 


\section{LITERATURE CITED (Offshore Development, Continued)}

Brannon, A.C., and K.R. Rao. 1979. Barium, Strontium, and Calcium Levels in the Exoskeleton, Hepatopancress, and Abdominal Muscle of the Grass Shrimp, Palaemonetes puglo: Relation to Molting and Exposure to Barite. Comparative Biochemistry and Physlology, vol. 63A, pp. 261-274.

Bright, T.B., and R. Rezak. 1978a. Northwestern Gulf of Mexico Topographic Features Study. Final Report to the U.S. Department of the Interfor, Bureau of Land Management, Outer Continental Shelf office, New Orleans, Louisiana.

Bright, T.B., and R. Rezak. 1978b. South Texas Topographic Features Study. Final Report to the U.S. Department of the Interior, Bureau of Land Management, Outer Continental Shelf office, New Orleans, Loulsiana.

Brown, C.L., Jr., and R.H. Smlth. 1972. Effects of Underwater Demolition on the Environment in a Small Tropical Marine Cove. 4459. Naval Underwater Systems Center. New London Laboratorles, New London, Connecticut.

Brown, R.A., and H.L. Huffman. 1976. Hydrocarbons in Open Ocean Waters. Sclence 191:847-849.

Brown, R.D. 1977. Control of Alr Quality from 011 Tankers. Unpublished information prepared in support of a Federal iniative dealing with the regulation of offshore oil pollution. The MITRE Corporation, McLean, Virginia.

Burke, T.E. 1980. Personal Communication during meetings on July 31, Aug. 3-4. Oceanographer, Branch of Environmental Studies, Bureau of Land Management, U.S. Department of the Interior, Washingtoin, D.C.

Button, D.K. 1976. The Influence of Clay and Bacteria on the Concentration of Dissolved Hydrocarbon in Saline Solution. Geochem. Cosmochem. Acta 40:435-440.

Calder, J. 1980. Personal Communication by Telephone on August 11. Bering Sea Regional Studies Manager, National Oceanic and Atmospheric Administration (NOAA), Juneau, Alaska.

Card, J.C., P.V. Ponce, and W.C. Snider. 1975. Tankship Accidents and Resulting Oil Outflows, 1963-1973. Proceedings of the Conference on Prevention and Control of 011 Pollution, San Francisco, California. Jointly sponsored by the American Petroleum Institute, U.S. Environmental Protection Agency, and the U.S. Coast Guard. 


\section{LITERATURE CITED (Of fshore Development, Continued)}

Chesapeake Blological Laboratory. 1948. Effects of Underwater Explosions on Oysters, Crabs, and Fish, pp. 1-43. CBL pub. 70.

Clark, J., J. Zinn, and C. Terrel1. 1978. Environmental Planning for Offshore 011 and Gas. Recovery Technology, vol. 1. The Conservation Foundation. Washington, D.C. FWS/OBS-77/12. U.S. Fish and Wildlife Service, Biological Services Program.

Conklin, P.J., D.G. Doughtie, and K.R. Rao. 1980. Effects of Barite and Used Drilling Muds on Crustaceans, with Particular Reference to the Grass Shrimp, Palaemonetes pugio. In Sumpostum on Research on Environmental Fate and Effects of Drilling Fluids and Cuttings. Jan. 21-24. Lake Buena Vista, Florida (in press).

Council on Environmental Quality. 1973. Energy and the Environment. Electric Power. Washington, D.C.

Council on Environmental Quality. 1974. OCS $0 i 1$ and Gas--An Environmental Assessment, vol. l. U.S. Government Printing office, Washington, D.C.

Council on Environmental Quality. 1976. Environmental Quality, Seventh Annual Report of the Council on Environmental Quality, Washington, D.C.

Crutchfield, J.A. 1969. Effects of Mineral and Petroleum Extraction on Living Resources of Continental Shelf Waters. Gulf Carib. Fish Inst. Proc., 21 st Annual Session.

Dames and Moore. 1978. Drilling Fluid Dispersion and Biological Effects Study for the Lower Cook Inlet C.O.S.T. Well. Conducted for Atlantic Richfield Company, Los Angeles, Callfornia.

Dietsch, D. 1980. Loop...Bringing the P1peline System to the Supertanker. Pipeline 52(3):43-44, 46,.63.

Downie, L. 1980. Search for Survivors Ends with 123 Lost in North Sea. The Washington Post, March 30, 1980, p. A20.

Ecomar, Inc. 1978. Tanner Bank Mud and Cuttings Study. Conducted for Shell oil Company, Goleta, California.

Falk, M.R., and M.J. Lawrence. 1973. Seismic Exploration: Its Nature and Effect on Fish. Technical rep't, series no. CEN/T. 73-9. Resources Management Branch, Fish and Marine Service Central Region, Fisheries Operations Directorate, Winnipeg, Ontario, Canada. 


\section{LITERATURE CITED (Offshore Development, Continued)}

Farrington, J.W. 1977. Oil Pollution in the Coastal Environment. In Estuarine Pollution Control and Assessment, vol. 2. EPA 440/177-007. U.S. Environmental Protection Agency, Washington, D.C.

Fitch, J.E., and P.H. Young. 1948. Use and Effect of Explosives in California Coastal Waters. California Fish and Game 34(2):53-70.

Gillan, L. 1980a. Human Fallures are Frequently Responsible for Offshore 0il Drilling Rig Accidents. Houston Chronicle, sect. 2., March 31, 1980.

Gillan, L. 1980b. Few Bad Apples in offshore Drilling Spoiling Safety Reputation for All. Houston Chronicle, sect. 3, March 30 , 1980 , p. 21 .

Goldberg, E.D. 1978. Ocean Pollution Research, Development and Monitoring Needs. Review and Overview. Report on a Workshop, Estes Park, Colorado, July 10-14.

Gowanloch, J.N., and J.E. McDougal1. 1945. Effects from the Detonation of Explosives on Certain Marine Life. 0il 4:13-16.

Green, J.J., and G.M. Davidson. 1969. Explosive Tests of Under-. water Ordnance by the Naval Ordnance Laboratory in Maryland Tidal Waters. NOLTR 69-33. Naval Ordnance Laboratory, Solomons, Maryland.

Groover, R.D., ed. 1977. Environmental Studies, South Texas Outer Continental Shelf, RIg Monttoring Program. Final Report to the U.S. Department of the Interior, Bureau of Land Management, Outer Continental Shelf office, Washington, D.C.

Harris, L.M. 1972. An Introduction to Deepwater Floating Driliing Operations. The Petroleum Publishing Company, Tulsa, Oklahoma.

Hoffman, D. 1980. Baltimore Canyon Crude. The Washington Post Magazine, Aug. 24, 1980, pp. 18-28.

Hubbs, C.L., and A.B. Rechnitzer. 1952. Report on Experiments Designed to Determine Effects of Underwater Explosions on Fish Life. California Fish and Game 38(3):333-366.

Huff, J.R. 1976. Study Analysis--Offshore Rig Casualties. 011 and Gas Journal 74:71-86. 


\section{LITERATURE CITED (Offshore Development, Continued)}

IMCO, FAO, UNESCO, WMO, WHO, IAEA, UN. 1977. Joint Group of Experts on the Scientific Aspect of Marine Pollution. Impact of 0il on the Marine Environment. Food and Agriculture Organization of the United Nations, Rome, Italy. Rep. Stud. FESAMP 6.

Jacoff, F.S., ed. 1979. A Small 011 Spill at West Falmouth. EPA Decision Series 600/9-79-007. Office of Research and Development, U.S. Environmental Protection Agency, Washington, D.C.

Kash, D.E., I.L. White, K.H. Bergey, M.A. Chartock, M.D. Devine, R.L. Leonard, S.N. Solomen, and H.W. Young. 1973. Energy Under the Oceans: A Technology Assessment of Outer Continental Shelf 011 and Gas Operations. University of Oklahoma Press, Norman, Oklahoma.

Laskin, S., M. Kuschner, and R.T. Drew. 1970. Studies in Pulmonary Carcinogenes 1s. In Inhalation Carcinogenesis, eds. M.G. Hanna, Jr., P. Nettesheim, and J.R. Gilbert. AEC symposium series no. 18., pp. 321-350. Washington, D.C.

Leggett, N., and T. Williams. 1979. Natural Gas Processing. The International Research Technology Corporation. The MITRE Corporation, Metrek Division, McLean, Virginia.

Liss, R.G., F. Knox, D. Wayne, and T.R. Gilbert. 1980. Avallability of Trace Elements in Drilling Fluids to the Marine Environment. In Symposium on Research on Environmental Fate and Effects of Drilling Fluids and Cuttings, Jan. 21-24, Lake Buena Vista, Florida (in press).

Longley, W.L., and R.G. Jackson. 1980. Managing Impacts of Petroleum Development in Brackish Marshes. In Proceedings of the Gulf of Mexico Coastal Ecosystems Workshop. FWS/OBS-80/30. Fish and ivildlife Service, U.S. Department of the Interior, Washington, D.C.

Mariani, G.M., L.V. Sick, and C.C. Johnson. 1980. An Environmental Monitoring Study to Assess the Impact of Drilling Discharges in the Mid-Atlantic, III. Chemical and Physical Alterations in the Benthic Environment. In Symposium on Environmental Fate and Effects of Drilling Fluids and Cuttings, Jan. 21-24, Lake Buena Vista, Florida (in press).

Mathews, J. 1980. Chinese Press Assails 0il Rig Deaths. The Washington Post, July 23, 1980. 


\section{LITERATURE CITED (Offshore Development, Continued)}

McAuliffe, C.D. 1977. Dispersal and Alteration of 011 Discharged on a Water Surface. In Fate and Effects of Petroleum Hydrocarbons in Marine Organisms and Ecosystems; ed. D.A. Wolfe, pp. 19-35.

McAuliffe, C.D., A.E. Smalley, R.D. Groover, W.M. Welsh, W.S. PIckle, and G.E. Jones. 1979. The Chevron Main Pass Block $410 i 1$ Spill:

Chemical and Biological Investigations. In Proceedings of the 1975 Conference on Prevention and Control of $0 \overline{11}$ Pollution. American Petroleum Institute, Washington, D.C.

McLeod, G.C., T.R. Gllbert, R. Stune, and N. Riser. 1980. Indices of Sublethal Stress in Bivalve Molluscs Exposed to Drilling Muds: An Overview. In Symposium on Environmental Fate and Effects of Drilling Fluids and Cuttings, Jan. 21-24, Lake Buena Vista, Florida (in press).

Meek, R.P., and J.P. Ray. 1980. Induced Sedimentation, Accumulation, and Transport Resulting from Exploratory Drilling Discharges of Drilling Flulds and Cuttings. In Symposium on Environmental Fate and Effects of Drilling Fluids and Cuttings, Jan. 21-24, Lake Buena Vista, Florida (in press).

Menzie, C.A., D. Mauer, and W. Leatham. 1980. An Environmental Monitoring Study to Assess the Impact of Drilling Discharges in the Mid-Atlantic, IV. The Effects of Drilling Discharges on the Benthic Communty. In Symposium on Environmental Fate and Effects of Drilling Fluids and Cuttings, Jan. 21-24, Lake Buena Vista, Florida (in press).

Moore, S.F. 1973. Towards a Model of the Effects of Oil on Marine Organisms. National Academy of Sclences Workshop on Inputs, Fates and Effects of Petroleum in the Marine Environment. Washington, D.C.

Moore, S.F., R.L. Dwyer, and A.M. Katz. 1973. A Preliminary Assessment of the Environmental Vulnerability of Machias Bay, Maine, to 011 Supertankers. Ralph M. Parsons Laboratory for Water Resources and Hydrodynamics. Rep't no. 162. Department of Civil Engineering, School of Engineering, Massachusetts Institute of Technology, Cambridge, Massachusetts.

Morbidity and Mortality Weekly Report. 1980. Occupational Mortality in the 0il Industry 29(20):230-231. U.S. Department of Health and Human Services, Washington, D.C. 


\section{LITERATURE CITED (Offshore Development, Continued)}

National Academy of Sciences. 1975. Petroleum in the Marine Environment. Washington, D.C.

Neff, J.M. 1980. Review of the Toxicity and Blological Effects of Used offshore Drilling Fluids to Marine Animals. Appendix C, American Petroleum Institute statement before the Joint Hearing Committee on Commerce, Science, and Transportation, Subcommittee on Energy Resources and Materials Production of the United States regarding Senate Bill S-2119, Georges Bank Protection Act, Washington, D.C. March 25.

Ocean Industry. 1978. Trends in Subsea Production Systems. $13(7): 19-20$.

Ocean Industry. 1980. A World First. 15(4):111.

Offshore Rig Data Services. 1980. Accidents: Offshore Mobile Drilling Units, 1955 to Present. Offshore Rig Data Service, Research Consulting Division, Houston, Texas.

Page, D.S., E.S. Gilfillan, R.P. Gerber, B.T. Page, and J.B. Hotham. 1980. Bloavallability of Toxic Constituents of Used Drilling Muds. In Symposium on Environmental Fate and Effects of Drilling Fluids and Cuttings, Jan. 21-24, Lake Buena Vista, Florida (in press).

Petroleum Equipment Suppliers Association. 1980. Chemical Components and Uses of Drilling Fluids, Appendix A, American Petroleum Institute statement before the Joint Hearing Commltee on Commerce, Science, and Transportation, Subcommittee on Energy Resources and Materials Production of the United States regarding Senate Bill S-2119, Georges Bank Protection Act, Washington, D.C. March 25.

Pipeline and Gas Journal. 1980. The Gulf Coast's First Onshore Deep-Draft 011 Terminal. Pipeline and Gas Journal, August, p. 2.

Ranney, M.W. 1979. Offshore O1I Technology: Recent Developments. Noyes Data Corporation, Park Ridge, New Jersey.

Ray, J.P., and R.P. Meek. 1980. Water Column Characterization of Drilling Fluids Dispersion from an offshore Exploratory Well on Tanner Bank. In Symposium on Environmental Fate and Effects of Drilling Flulds and Cuttings, Jan. 21-24, Lake Buena Vista, Florida (in press). 


\section{LITERATURE CITED (Offshore Development, Continued)}

Richards, N.L. 1979. Effects of Chemicals Used in 011 and Gas WellDrilling Operations in Aquatic Environments. In Energy/Environment: Proceedings of the Fourth National Conference $\overline{\text { on }}$ the Interagency Energy/Environment R\&D Program, pp. 171-181. EPA 600/9-79-040. U.S. Environmental Protection Agency, Office of Research and Development, Washington, D.C.

Richards, N.L. 1980. Offshore Drilling. In Research Highlights 1979, pp. 75-76. EPA 600/9-80-005. U.S. Environmental Protection Agency, Office of Research and Development, Washington, D.C.

Shinn, E.A., J.H. Hudson, D.M. Robbin, and C.K. Lee. 1980. Drilling Mud Plumes from offshore Drilling Operations: Implications for Coral Survival. In Symposium on Environmental Fate and Effects of Drilling Fluids and Cuttings, Jan. 21-24, Lake Buena Vista, Florida (in press).

Sittig, M. 1978. Petroleum Transportation and Production, 011 Spill and Pollution Control.. Noyes Data Corporation, Park Ridge, New Jersey.

Smith, D.R. 1979. Techniques Involved in Drilling Well in Deepest Water. Ocean Industry 14(6):37-39.

Sprague, J.B. 1973. The ABC's of Pollutant Bioassay Using Fish. In Blological Methods for the Assessment of Water Quality, eds. J. Cairns, Jr., and K.L. Dickson, pp. 6-30. ASTM STP 528. American Society for Testing and Materials, Philadelphia, Pennsylvania.

Steering Committee for the International symposium on Driling Fluids and Cuttings. In press. Proceedings of the Symposium on Research on Environmental Fate and Effects of Drilling Fluids and Cuttings, Jan. 21-24, Lake Buena Vista, Florida. $1629 \mathrm{~K}$ St., N.W., Suite 700, Washington, D.C. 20006 .

Stokinger, H.E. and D.L. Coffin. 1968. Biologic Effects of Air Pollutants. In Air Pollution, 2nd ed., vol. 1, ed. A.C. Stern. Academic Press Inc., New York.

Straunghan, D. 1972. Factors Causing Environmental Changes After an Oil Spill. Journal of Petroleurn Technology 24:250-254.

Taylor, R.W., and R.B. Krahl. 1976. Outer Continental Shelf Safety in 011 and Gas Operations. U.S. Geological Survey Annual Report, Fiscal Year 1976. Reston, Virginia 
LITERATURE CITED (Offshore Development, Continued)

Thompson, J.A. 1958. Biological Effects of the Ripple Rock Explosion. Prog. Rep. Pacif. Coast Sta., Fish Res. Bd. Canada 111:3-8.

Thompson, J.H., Jr. 1979. Effects of Drilling Mud on Seven Species of Reef-Bullding Corals as Measured in Field and Laboratory. Final Report to the U.S. Geological Survey, Reston, Virginia.

Thompson, J.H., Jr., and T.J. Bright. 1977. Effect of Drilling Mud on Sediment Clearing Rates of Certain Hermatypic Corals. In Proceedings of the 0il Spill Conference (Prevention, Behavior, Control, Cleanup), pp. 495-498. March 8-10, 1977, New Orleans, Louisiana. Jolntly sponsored by the American Petroleum Institute, the U.S. Environmental Protection Agency, and the U.S. Coast Guard.

Tillery, J.B. 1980. Long Term Fate and Effects of Heavy Metal Contamination from Petroleum Production in the Gulf of Mexico. In Symposium on Environmental Fate and Effects of Drilling Fluids and Cuttings, Jan. 21-24, Lake Buena Vista, Florida (in press).

Trafford, A. 1980. 1980-81 Directing of Marine Drilling Rigs. Ocean Industry 15(9): 19-168.

Tubb, M. 1979. 1979-80 Dlreccory of Marine Drilling Rigs. Ocean Industry $14(9): 19-176$.

U.S. Department of the Interior. 1979. Final Environmental Impact Statement, OCS Sale No. 48. Appendix J. Bureau of Land Management, Washington, D.C.

U.S. Department of Transportation. 1976. Summary of Liquid Pipeline Accidents Reported on DOT form 7000-1 from January 1, 1975 - December 31, 1975. Washington, D.C.

U.S. Environmental Protection Agency. 1977. Accidents and Unscheduled Events Associated with Non-Nuclear Energy Resources and Technology. EPA-600/7-77-016. Office of Research and Development, Washington, D.C.

U.S. Environmental Protection Agency. 1978. Energy/Environment Fact Book. EPA-600/9-77-041. Office of Research and Development, Washington, D.C.

U.S. Environmental Protection Agency. 1980. Research Program Information Prepared for the Marine Program Review, May 13-15, Washington, D.C. Environmental Research Laboratory, Gulf Breeze, Florida. 


\section{LITERATURE CITED (Offshore Development, Concluded)}

U.S. Geological Survey: 1976. Final Environmental Impact Statement: O11 and Gas Development in the Santa Barbara Channel Outer Continental Shelf off California, vol. 1. U.S. Department of the Interior, Reston, Vírginia.

U.S. Geological Survey 1980. Outer Continental Shelf Statistics. Conservation Division, Reston, Virginia.

U.S. News and World Report. 1980. No End to Peril in offshore Drilling. April 7, p. 13.

U.S. Office of Management and Budget. 1972. Standard Industrial Classification Manual. Statistical Policy Division, Washington, D.C.

University of Oklahoma. 1975. Energy Alternatives: A Comparative Analysis. NTIS PB-246 365. National Technical Information Service, Springfield, Virginia.

The Washingtion Post: 1980. Offshore Rig Explodes. June 9, p. A5.

The Washington Post Magazine. 1980. Balt1more Canyon Crude. Aug. 24, Pp. 18-28.

Wilkins, G.E. 1977. Industrial Process Profiles for Environmental Use. Oil and Gas Production Industry, chap. 2. EPA-600/2-77-023b. Radian Corporation, Austin, Texas .

Young, G.A. 1973. Guidelines for Evaluating the Environmental Effects of Underwater Explosion Tests. Naval Ordnance Laboratory, White Oak, Maryland. 
THIS PAGE

\section{WAS INTENTIONALLY \\ LEFT BLANK}

676 
REFINERY OPERATIONS

LITERATURE CITED

Aalund, L.R. 1980a. Refining Report: Octane Emphasized in Refining-Capacity Gains. 011 and Gas Journal, March 24, pp. 75-79. Aalund, L.R. 1980b. Sour Crude Technology Set for '80's. 011 and Gas Journal, March 24, pp. 78-79.

American Chemical Society. 1980a. Phenylenediamines Added to TSCA Priorities. Chemical and Engineering News, June 9, p. 13.

American Chemical Society. 1980b. Low-Level $\mathrm{SO}_{2}$ Causes Asthma Attacks. Chemical and Englneering News, May 26, p. 23.

American Petroleum Institute. 1971. Petroleum Facts and Figures. Washington, D.C.

American Petroleum Institute. 1974. Reported Fire Losses in the Petroleum Industry. Washington, D.C.

American Petroleum Institute. 1975. Reported Fire Losses in the Petroleum Industry. Washington, D.C.

American Petroleum Institute. 1977. Manual on Disposal of Refinery Wastes, Volume on Atmospheric Emissions. Pub. no. 931. Washington, D.C.

American Petroleum Institute. 1978. Analysis of Refinery Wastewaters for the EPA Priority Pollutants (Interim Report and Revisions). 4926. Washington, D.C.

Ameriran Petroleum Inet1tute. 1979a. Eummary of Oecupational Injuries and Illnesses. Washington, D.C.

American Petroleum Institute. 1979b. Review of Fatal Injuries in The Petroleum Industry for 1978. Washington, D.C.

Argonne National Laboratory. 1977. Water Pollution Impacts of the National Energy Plan. ANL/IAPE/TM-78-4. Energy Research and Deve1opment Administration.

Arthur D. Little, Inc. 1976. Environmental Consideration of Selected Energy Conserving Manufacturing Process Options. Petroleum Refining Industry Report, vol. 4. PB-264-270. National Technical Information Service, Springfield, Virginia. 
LITERATURE CITED (Refinery Operations, Continued)

Aviado, D.M., S. Zakhari, and T. Watanabe. 1977. Non-Fluorinated Propellants and Solvents for Aerosols. CRC Press, Cleveland, Ohio.

Baker, J.M. 1973. Biological Effects of Refinery Effluents. In Proceedings of the Joint Conference on Prevention and Control of 0il Spills, March 13-15. American Petroleum Institute, Washington, D.C.

Barber, D.H. 1975. Safety in Petroleum Refinery Operations. Proceedings of the World Petroleum Congress 6:133-132.

Barrett, K., and A. Goldfarb. 1979. A Review of Standards of Per= formance for New Stationary Sources--Petroleum Refineries. MTR-7825. The MITRE Corporation, McLean, Virginia.

Beliles, R.P. 1975. Metals. In Toxicology: The Basic Science of Poisons, chapt. 18, pp. 454-502. MacMillan, New York.

Bingham, E., R. Trosset, and D. Warshawski. 1980. Carcinogenic Potential of Petroleum Hydrocarbons: A Critical Review of the Literature. Journal of Environmental Pathology and Toxicology 3:483563.

Birmingham, D.J. 1978. Occupational Dermatoses. In Patty's Industrial Hyglene and Toxicology, 3rd ed., chapt. $\overline{8,}$ ed. G.D. Clayton and F.E. Clayton, Pp. 203-235. Wiley, New York.

Bliss, C., P. Clifford, G. Goldgraben, E. Graf-Webster, K. Krickenberger, H. Mahar, and N. Zimmerman. 1976. Accidents and Unscheduled Events Associated with Non-Nuclear Energy Resources and Technology . M76-68. The MITRE Corporation, McLean, Virginia.

Blot W.J., L.A. Brinton, J.F. Fraumeni, and B.J. Stone. 1977. Cancer Mortality in U.S. Countries with Petroleum Industries. Science 298(4312):51-53.

Bogovsky, P., and E.A. Walker. 1975. N-Nitroso Compounds in the Environment. International Agency for Research on Cancer, Lyon, France.

Bombaugh, K.J., E.C. Cavanaugh, J.C. Dickerman,. S.L. Keil, T.P. Nelson, M.L. Owen, and D.D. Rosebrook. 1976. Sampling and Analytical Strategies for Compounds in Petroleum Refinery Streams. EPA600/2-76-0126. Office of Research and Development, U.S. Environmental Protection Agency, Washington, D.C. 


\section{LITERATURE CITED (Refinery Operations, Continued)}

Bowen, J.H. 1978. Statistics on Fires and Explosions at Refineries In Canvey: An Investigation of Potentlal Hazards from Operations In the Canvey Island/Thurrock Area. Health and Safety Executive. Her Majesty's Stationery Office, London, England.

Brief, R.S., F.S. Venable, and R.S. Ajemian. 1965. Nickel Carbonyl: Its Detection and Potential for Formation. Amer. Ind. Hyg. Assoc. J. $26(1): 72-76$.

Brief, R.S., J.W. Blanchard, R.A. Scala, and J.H. Balcker. 1971. Metal Carbonyls in the Petroleum Industry. Arch. Environ. Health 23:372-384.

Brltt, D.L., and J.M. Hushon. 1976. Blological Effects, Criterla and Standards for Hazardous Pollutants Associated w1th Energy Technologies. MTR-7283. The MITRE Corporation, McLean, Virginia.

Brock, G.H. 1977. Hydrocarbons: A Viable Alternative Aerosol Propellant. Aeropress Corporation.

Brown, R.: 1977. Control of A1r Qual1ty from 011 Tankers. The MITRE Corporation, McLean, Virginia.

Brown, R., and A. Witter. 1979. Health and Environmental Effects of Coal Gasification and Liquefaction Technologies. MTR-79W00137. The MITRE Corporation, McLean, Virginia.

Burlingame, A.L. 1977. Assessment of the Trace Organlc Molecular Composition of Industrial and Municipal Wastewater Constituents by Capillary Gas Chromatography/Real Time High Resolution Mass Spectrometry: A Preliminary Report. Ecotoxicology and Environmental Safety $1: 111-150$.

Cantrell, A. 1980. Annual Refining Survey: 011 and Gas Journal, March 24, pp. 130,135, 136, 138, 143-148, 151-160.

Carry, C.W. 1976. Public Law 92-500: Technology Assessment Technical Volume. National Technical Information Service, Springfield, Virginia.

Chemical and Engineering News. 1980a, Brain Timnr/Petrochomical Link rrobed. Nov. 3, 1980, p. 6.

Chemical and Engineering News: 1980b. Brain Tumor Risk in Petrochemlcal Workers. Nov. 10, 1980, pp. 33, 34, 36. 
LITERATURE CITED (Refinery Operations, Continued)

Chemical Industry Institute of Toxicology. 1977. CIIT Status Report No. 1: n-Hexane. Research Triangle Park, North Carolina.

Chemical Week. 1980. Health, Safety Budgets on Rise. Chemical Week, May 28, p. 25.

Cheremisinoff, P.N., and A.C. Morres1. 1977. Petroleum Refinery Environmental Assessment. In Environmental Assessment \& Impact Statement Handbook, pp. 297-332. Ann Arbor Sclence Publishers, Ann Arbor, Michigan.

Chlorinated Dioxin Task Force. 1978. The Trace Chemistries of Fire--A Source of and Routes for the Entry of Chlorinated Dioxins into the Environment. Dow Chemical Corporation, Midland, Michigan.

Council on Environmental Quality. 1974. OCS 011 and Gas--An Environmental Assessment. U.S. Government Printing office, Washington, D.C.

Counc1l on Environmental Quality. 1979. Environmental Quality-1979. U.S. Government Printing office, Washington, D.C..

Cralley, L.V., P.R. Alklus, L.J. Cralley, and G.D. Clayton. 1975. Industrial Environmental Health. Academic Press, New York.

Crow, P. 1979. Big Problems Still Rein Growth of U.S. Refining. Oil and Gas Journal, March 12, pp. 23-28.

Cuddington, K.S. 1980. High Sulfur Content Associated with Largest Petroleum Reserves. Oil and Gas Journal, March 24, pp. 95, 96, 100.

Cummings, G.H. 1973. The Petroleum/Petrochemical Industry and the Ecological Challenge. American Institute of Chemical Engineers, New York.

Cunningham, J.M., and J. Lom. 1979. Development Document for Proposed Effluent Limitations Guidelines, New Source Performance Standards, and Pretreatment Standards for the Yetroleum Reflnluy Puint Source Category. EPA 400/1-79/014-6. U.S. Environmental Protection Agency, Washington, D.C.

Darby, G.H., A. Dukich, C.W. Hargens, H.G. Hil1, S. Hsiao, D. LissSuter, R. Mason, and L.M. Miller. 1978. Information Profiles on Potential Occupational Hazards. Final Report: National Institute for Occupational Safety and Health, Rockville, Maryland. 


\section{LITERATURE CITED (Refinery Operations, Continued)}

Deane, M., and G. Sanders. 1978. Annoyance and Health Reactions to Odor from Refineries and other Industries in Carson, California. Environmental Research 15:119-132.

De Nora, V., and J.A. King. 1967. Chemicals and Catalysts. In Petroleum Processing Handbook, eds. W.F. Bland, and R.L. Davidson. McGraw-H111, New York.

Dickerman, J.C., T.D. Raye, J.D. Colley, and R.H. Parsons. 1977. Industrial Process Profiles for Environmental Use. In Petroleum Refining Industry, chapt. 3. EPA-600/2-77-023C. Of fice of Research and Development, U.S. Environmental Protection. Agency.

Dipple, A. 1976. Polynuclear Aromatic Carcinogens. In Chemfcal Carcinogens, ed., C.E. Searle, pp. 245-314. American Chemical Society, Washington, D.C.

Ember, L.R. 1980. Nitrosamines: Assessing the Relative Risks. Chemical and Engineering News, March 31, pp. 20-16.

Energy Information Administration. 1979. Petroleum Refineries In the United States and U.S. Territories. U.S. Department of Energy, Washington, D.C. June 28 .

Engineering Science, Inc. 1975. Water Pollution Abatement Technology: Costs and Capabilities, Petroleum Refining Industry. PB-243830. National Technical Information Service, Springfield, Virginia.

Enviro Control, Inc. 1979. Industrial Hyglene Characterization of Petroleum Refineries (draft). Rockville, Maryland.

Fnvirnnmental Protection Scrvice. July 1979. Status Report on Abatement of Water Pollution from the Canadian Petroleum Refining Industry--1977. EN-43-3/79-5. Minister of Supply and Services, Ot tawa, Canada.

Environmental Quality Systems, Inc. 1976. Petroleum Refining. In Disposal of Wastewater Residuals, Appendix A.4, pp. A-29-A-41. PB-251-371-02. National Technical Information Service, Springfield, Virginia. March.

Esposito, J.S. 1970. Task Force Report on Air Pollution. Center for Study of Responsive Law, Washington, D.C. 


\section{LITERATURE CITED (Refinery Operations, Continued)}

Federal Energy Administration. 1976. Strategic Petroleum Reserve, Draft Environmental Impact Statement. National Technical Information Service, Springfield, Virginia.

Fernandes, S. 1978. Proceedings: Symposium/Workshop on Petroleum Refining Emissions Held at Jekyll Island, Georgia, April 1978. PB-287-900. National Technical Information Service, Springfield, Virginia.

Filby, R.H., and K.R. Shah. 1975. Neutron Activation Methods for Trace Elements in Crude 0ils. In the Role of Trace Metals in Petroleum, ed. T.F. Yen, pp. 89-1 10. Ann Arbor Press, Ann Arbor, Mi chigan.

Frank, A. 1978. Oil Refinery Sludge: An Industry Looks to Land Cultivation. Sludge Magazine, May-June, pp. 26-31.

Fryer, L.S., G.D. Kaiser, and B.C. Walker. 1978. The Escape of 1,000 Tons of Anhydrous Ammonia from a Pressure Storage Tank. In Canvey: An Investigation of Potential Hazards from Operations in the Canvey Island/Thurruck Area. Her Majesty's Stationery office, London, England.

Galloway, J. 1979. Refinery Waste Disposal Screening Study. Radian Corporation. National Technical Information Service, Springfield, Virginia.

General Accounting office. 1979. U.S. Refining Capacity: How Much is Enough? EMD-78-77. Comptroller General, Washington, D.C. January 15.

General Accounting Office. 1979. The United States Refining Policy in a Changing World Oil Environment. EMD-79-59. Comptroller General, Washington, D.C. June 29.

Ghassemi, M., D. Strehler, K. Crawford, and S. Quinlivan. 1978. Applicability of Petroleum Refinery Control Technologies to Coal Conversion. EPA-600/7-78-190. U.S. Environmental Protection Agency, Washington, D.C.

Gordon, J. 1976. Air Pollution Assessment of Cresols. MTR-7227. The MITRE Corporation, McLean, Virginia.

Gordon, R.J., and R.J. Bryan. 1973. Patterns in Airborne Polynuclear Hydrocarbon Concentrations at Four Los Angeles Sites. Env. Sci. Tech. 7(11):1050-1053. 
LITERATURE CITED (Refinery Operations, Continued)

Grosjean, D., K.V. Cauwenberghe, J. Schmid, and J.R. Pitts . 1977. Formation of Nitrosamines and Nitramines by Photooxidation of Amines Under Simulated Atmospheric Conditions. In Fourth Joint Conference on Sensing of Environmental Pollutants, pp. 196-199. American Chemical Society, Washington, D.C.

Gsellman, L., W. Park, and T. Kornreich. 1976. Strateg1c Petroleum Research Distribution Study. MTR-7384. The MITRE Corporation, McLean, Virginia.

Gulf Publishing Company. 1978. Refining Process Handbouk. Hydrocarbon Processing 57(9):97-224.

Habib, Y.H. 1975. Odor Emission Sources in the Chemical and Petroleum Industries. In Industrial Odor Technology Assessiment, chapt. 12, eds. P.N. Cheremisinoff and R.A. Young, PP. 189-201. Ann Arbor Press, Ann Arbor, Michigan.

Hakansson, H., and A. Jernelov, 1977. Petroleum and Petrochemicals. Swedish Water and Air Pollution Research Laboratory, Stockholm.

Hale, D. 1978. Peakshaving Supplies Reach All Time High for '78-'79 Winter. Pipeline and Gas Journal 205(13):20-25.

Hanis, N.M., K.M. Stravraky, and L.J. Fowler. March 1979. Cancer Mortality in 011 Refinery Workers. Journal of Occupational Medicine $21(3): 167-174$.

Harrison, P.R. 1978. Detection and Classification of of Fugitive Component Leaks. In Proceedings: Symposium/Workshop on Petroleun Refining Emissions Held at Jekyll Island, Georgia, Apri1, pp. 54-71. PB-287-900. National Technical Inforwation Service, Springfield, Virginia.

Health and Safety Executive. 1978. Canvey: An Investigation of Potential Hazards from Operations in the Canvey Island/Thurrock Area. Her Majesty's Stationery Office, London, England.

Hervin, R.L, R. Rivera, and J.P. Flesch. 1973. Health Hazard Evaluation Report. 72-91-37. National Institute for Occupational Safety and Health, Cincinnati, Ohio.

Hobson, G.D. 1974. Modern Petroleum Technology, 4th ed. Wiley, New York. 


\section{LITERATURE CITED (Refinery Operations, Continued)}

Huddleston, R., and L. Cresswell. 1976. The Disposal of Oily Wastes by Land Farming. In Proceedings of the Open Forum on Management of Petroleum Refinery Wastewaters, ed. F. Manning. University of Tulsa, Tulsa, Oklahoma.

Hustvedt, K.C., and R.A. Quaney. 1978. Control of Volatile Organic Compound Leaks from Petroleum Refinery Equipment. PB-286-158. National Technical Information Service, Springfield, Virginia.

Hustvedt, K.C., and Weber, R.C. 1978. Detection of Volatile Organic Compound Emissions from Equipment Leaks. In Proceedings: Symposium/ Workshop on Petroleum Refining Emission Held at.Jekyll Island, Georgia, April 1978, ed. S.R. Fernandes, pp. 75-86. PB-287-900. National Technical Information Service, Springfield, Virginia.

Illinols Institute for Environmental Quality. 1974. Determination of Maximum Permissible Levels of Selected Chemicals that Exert Toxic Effects on Plants of Economic Importance in Illinois. PB-237-654. National Technical Information Service, Washington, D.C.

Inside Washington Publishers, Inc. 1980. EPA Tabs 150 Chemicals as Carcinogens; Labeling to Apply to About 100. Inside EPA Weekly Report $1(13): 1,4-5$.

Kincannon, C.B. 1976. Oily Waste Disposal by Soil. Cultivation. In Proceedings of Open Forum on Management of Petroleum Refinery Wastewaters, Jan. 26-29, ed. F.S. Manning, pp. 257-272. American Petroleum Institute, Washington, D.C.

Kipling, M.D. 1976. Soots, Tars, and 0ils as Causes of Occupational Cancer. In Chemical Carcinogens, ed. C.E. Searle, pp. 385-323. American Chemical Society, Washington, D.C.

Kneese, A.V., and B.T. Bower. 1979. Environmental Quality and Residuals Management. Johns Hopkins University Press, Baltimore, Maryland.

Kornreich, M.R. 1976. Coal Conversion Processes: Potential Carcinogenic Risk. MTR-7155, 2nd revision. The MITRE Corporation, McLean, Virginia.

Kornrelck, M.R. 1980. A Preliminary Assessment of the Problem of Carcinogens in the Atmosphere. MTR-6874. The MITRE Corporation, McLean, Virginia. 


\section{LITERATURE CITED (Refinery Operations, Continued)}

Kuna, R.A., and R.W. Kapp. 1981. The Embryotoxic/Teratogenic Potential of Benzene Vapor in Rats. Toxicology and Applied Pharmacology $57(1): 1-7$.

Lang, D. 1979. U.S. Industry Facing St111 Larger Numbers in 1979. Q11 and Gas Journal 29:107-114, 119-125.

Laster, L.L. 1973. Atmospheric Emissions from the Petroleum Refining Industry. PB-225-040. National Technical Information Service, Springfield, Virginia.

Lebowitz, H., S. Tam, G. Smithson, H. Nack, J. Oxley, G. Cavanaugh, C. Burklin, and J. Dickerman. 1975. Potentially Hazardous Emissions from the Extraction and Processing of Coal and Oil. PB-241-803. National Technical Information Service, Springfield, Virginia.

Lewis, R.J. 1979. Registry of Toxic Effects of Chemical Substances. U.S. Government Printing office, Washington, D.C.

Magee, P.N., R. Montesano, and R. Preussmann. 1976. N-Nitroso Compounds and Related Carcinogens. In Chemical Carcinogens, ed. C.E. Searle. American Chemical Society, Washington, D.C.

Maggard, M.G. 1980. Detecting Internal Hydrogen Attack. 011 and Gas Journal 10:90-94.

Maier, R.W., W.P. Ovent, D.L. Brandt, and T.G. Golden. 1979. Refinery Energy. Profile. ORO-5262-5. National Technical Information Service, Springfield, Virginia.

Manahan, S.E. 1975. Environmental Chemistry, 2nd ed. Willard Grant Press, Boston, Maseachusetts.

Mat thews, J.E., and L.H. Myers. 1976. Acute Toxic Effects of Petroleum Refinery Wastewaters and Redear Sunfish. PB-262-913. National Technical Information Service, Springfield, Virginia.

Medical Research Council. 1968. The Carcinogenic Action of Mineral 0ils: A Chemical aud Blological Study. Her Majesty's Stationery Office, London, England.

Menck, H.R. 1974. Industrial Air Pollution: Possible Effects on Lung Cancer. Science 183:210-212. 
LITERATURE CITED (Refinery Operations, Continued)

Miller, D.W. 1980. Waste Disposal Effects on Ground Water, pp. 260262. Premier Press, Berkeley, California.

The MITRE Corporation. 1978. Initiatives With Potentials for Reducing Imports of $0 i 1$ and Gas. M78-34. McLean, Virginia.

National Academy of Sciences. 1972. Biological Effects of Atmospheric Pollutants--Particulate Polycyclic Organic Matter. National Academy of Sciences, Washington, D.C.

National Academy of Sciences. 1972. Water Quality Criteria. National Academy of Engineering. U.S. Government Printing office, Washington, D.C.

National Academy of Sclences. 1975. Petroleum in the Marine Environment. Washington, D.C.

National Air Pollution Control Administration. 1970. Air Quality Criteria for Hydrocarbons. U.S. Government Printing Office, Washington, D.C.

National Commission on Water Quality. 1976. Disposal of Wastewater Rosiduals. PB-251-371-02. National Technical Information Service, Springfield, Virginia.

National Institute for Occupational Safety and Health. 1974. Criteria. for a Recommended Standard... Occupational Exposure to Ammonia. U.S. Goverument Printing Office, Washington, D.C.

National Institute for Occupational Safety and Health. 1975a. Criteria for a Recommended Standard... Occupational Exposure to Xylene. U.S. Government Printing office, Washington, D.C.

National Institute for Occupational Safety and Health. 1975b. Health and Safety Guide for Bulk Petroleum Plants. U.S. Government Printing office, Washington, D.C. November.

National Institute for Occupational Safety and Health. 1976. Criteria for a Recommended Standard... Occupational Exposure to Phenol. 76-96. Rockville, Maryland.

National Institute for Occupational Safety and Health. 1977a. Criteria for a Recommended Standard... Occupational Exposure to Alkanes. U.S. Government Printing Office, Washington, D.C. March. 


\section{LITERATURE CITED (Refinery Operations, Continued)}

National Institute for Occupational Safety and Health. 1977b. Criteria for a Recommended Standard...occupational Exposure to Hydrogen Sulfide. U.S. Government Printing Office, Washington, D.C. May.

National Institute for Occupational Safety and Health. 1978. Criteria for a Recommended Standard... Occupational Exposure to n-Alkane Mono Thiols, Cyclohexanethiol, and Benzenethiol. U.S. Government Printing office, Washington, D.C. September.

Oil and Gas Journal. 1980. New Process Could Boost Gasoline Yield. April 7, pp. 42-43.

0il Companies International Marine Forum. 1974. International 011 Tanker and Terminal Safety Guide, 2nd ed. Wiley, New York.

Parrot, J., R. Herbert, A. Saindelle, and F. Ruff. 1969. Platinum and Platinosis: Allergy and Histamine Release Due to Some Platinum Salts. Arch. Environ. Health 19:685-691.

Patrick, R., and W. Whipple. 1974. Petroleum Industry in the Delaware Estuary: A Proposal Submitted to the National Science Foundation. Rutgers University, New Brunswick, New Jersey.

Peer, E.L., and F.V. Marsik. 1975. Trends in Refinery Capacity and Utilization. Federal Energy Administration, Washington, D.C.

Pellizzari, E.D. 1978. Identification of Components of EnergyRelated Wastes and Effluents. Research Triangle Institute. National Technical Information Service, Springfield, Virginia.

Pfeiffer, F.M. 1979, 1977 Screening Survey for Measurement of Organic Priority Pollutants in Petroleum Refinery Wastewaters. In Measurement of Organic Pollutants in Water and Wastewater, ed. C.E. Van Hall, American Society for Testing and Materials. Philadelphia, Pennsylvania.

Price, S., S. Rifkin, M. Drabkin, and J. Watson. 1980. Handbook on Fine Particulates. MTR-79W00297. The MITRE Corporation, McLean, Virginia.

Radian Corporation. 1977. Preliminary Draft: The Impact of the Clean Air Act on Expansions of Petroleum Refinery, Petroleum Storage, and Selected Petrochemical Feedstock Facilities, vol. 1. U.S. Environmental Protection Agency, Washington, D.C. 


\section{LITERATURE CITED (Refinery Operations, Continued)}

Radian Corporation. 1978. Analysis of Refinery Wastewaters for the EPA Priority Pollutants: Interim Report with Revisions. American Petroleum Institute, Washington, D.C.

Ranney, M.W. 1978. Fuel Additives for Internal Combustion Engines. Noyes Data Corporation, Park Ridge, New Jersey.

Roller, P.P., and L.K. Keefer. 1975. Catalysis of Nitrosation Reactions by Electrophilic Species. In N-Nitroso Compounds in the environment, eds. P. Bogovski and E.A. Walker; pp. 86-90. International Agency for Research on Cancer, Lyon, France.

Rosenberg, D.G., R.J. Lofty, H. Cruse, E. Weisberg, and B. Beutler. 1976. Assessment of Hazardous Waste Practices in the Petroleum Refining Industry. PB-259-097. National Technical Information Service, Springfield, Virginia.

Rushton, L., and M. Alderson. 1980. The Influence of Occupation on Health--Some Results from a Study in the UK 01l Industry. Carcinogenes is $1: 739-743$.

Scala, R.A. 1976. Hydrocarbon Neuropathy. Ann. of Occup. Hyg. $19: 293-299$.

Schweinsberg, F. 1975. Catalysis of Nitrosamine Synthesis. In N-Nitroso Compounds in the Environment, eds. P. Bogovski and E.A. Walker, pp. 80-85. International Agency for Research on Cancer, Lyon, France.

Seta, J.A. 1980. Chemical and Physical Agents Observed in the Petroleum Refining Industry During the Field Investigation Phase of National Occupational Health Survey. National Institute for Occupational Safety and Health, Cincinnati, Ohio.

Sims, A. 1974. Field Surveillance and Enforcement Guide for Petroleum Refineries. PB-236-669. National Technical Information Service, Springfield, Virginia.

Singh, N.P., and W.F. Pickup. 1975. Metallic and Non-metallic Po1lutants in the Discharge Water of Varieties of Industries. Bull. Environ. Contam. Toxicol. 14(2):225-232.

Sittig, M. 1978. Petroleum Refining Industry: Energy Saving and Environmental Control. Noyes Data Corporation, Park Ridge, New Jersey. 
LITERATURE CITED (Refinery Operations, Continued)

Sittig, M. 1979. Hazardous and Toxic Effects of Industrial Chemicals. Noyes Data Corporation, Park Ridge, New Jersey.

Singer, P.C. 1973. Trace Metals and Metal-Organic Interactions in Natural Waters. Ann Arbor Press, Ann Arbor, Michigan.

Smith, I.C., T.L. Ferguson, and G.L. Carson. 1975. Metals in New and Used Petroleum Products and By-Products: Quantities and Consequences. In The Role of Trace Metals in Petroleum, ed. T.F. Yen,

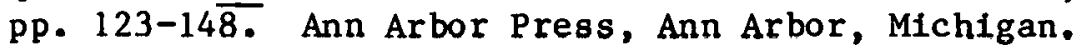

Spillane, L.J., and H.P. Leftin. 1970. Refining Petroleum for Chemicals. American Chemical Society, Washington, D.C.

Statistics Department. 1979. Review of Fatal Injuries in the Petroleum Industry for 1978. American Petroleum Institute, Washington, D.C.

Stedman, D.H., D.A. Hikade, R. Pearson, and E.D. Yalvac. 1980. Nickel Carbonyl: Decomposition in Air and Related Kinetic Studies. Science, May 30, pp. 1029-1031.

Taback, H.J. 1978. Petroleum Refinery Fugitive Emissions: Measurement Emission Factors and Profiles. In Proceedings: Symposium/Workshop on Petroleum Refining Emissions, April 1978, Jekyll Island, Georgia, ed. S.R. Fernandes, pp. 14-38. PB 287-900. National Technical Information Service, Springfield, Virginia.

Taylor, R.J. 1978. Industrial Impact in Northern Whatcom County, Washington. Water, Air and So11 Pollution 10:199-213.

Theriault, G., and L. Goulet. 1979. A Mortality Study of 011 Refinery Workers $21(5): 367-370$.

Thoman, D., and J. Hushon. 1979. Survey of Energy Related and Carcinogenic Pollutants Detected in Water. WP-79W00314. The MITRE Corporation, McLean, Virginia.

Tischler, L.F. 1976. Inherent Variability in Wastewater Treatment. In Proceedings of Open Forum on Management of Petroleum Refinery Wastewaters, Jan. 16-19, ed. F.S. Manning, pp. 413-432. American Petroleum Institute, Washington, D.C.

U.S. Army Corps of Engineers. 1977. Final Environmental Impact

Statement: Hampton Roads Energy Company, Portsmouth, Virginia. U.S. Army Fingineer District, Washington, D.C. 


\section{LITERATURE CITED (Refinery Operations, Continued)}

U.S. Army Corps of Engineers. 1978. Final Supplement to Final Environmental Impact Statement: Hampton Roads Energy Company's Portsmouth Refinery and Terminal, Portsmouth, Virginia (Permit Action). Office of the Chief of Engineers, Washington, D.C.

U.S. Army Medical Bloengineering Research and Development Laboratory. 1976. Problem Definition Studies on Potential Environmental Pollutants, IV: Physical, Chemical, Toxicological, and Biological Properties of Benzene; Toluene; Xylenes; and p-Chlorophenyl Methyl Sulfide, Sulfoxide, and Sulfone. AD-A040435. National Technical Information Service, Springfield, Virginia.

U.S. Bureau of Labor Statistics. 1979. Technological Change and Its Labor Impact in Five Energy Industries. Government Printing office (Bureau of Labor Statistics Bulletin 2005), Washington, D.C.

U.S. Bureau of Labor Statist1cs. 1980. Small 011 Refineries Yield to Union Demands. Monthly Labor Review, April, p. 63.

U.S. Department of Energy. 1978a. Final Environmental Impact Statement: Strategic Petroleum Reserve: Texoma Group Salt Domes. National Technical Information Service, Springfield, Virginia.

U.S. Department of Energy. 1978b. Expansion of the Strategic Petroleum Reserve: Amendment No. 2. U.S. Government Printing office, Washington, D.C.

U.S. Department of Energy. 1978c. Final Environmental Impact Statement: Strategic Petroleum Reserve: Seaway Group Salt Domes. National Technical Information Service, Springfield, Virginia.

U.S. Department of Energy. 1978d. Strategic Petroleum Reserve: Seaway Group. Salt Domes. DOE/EIS-0021. National Technical Information Service, Springfield, Virginia.

U.S. Department of Energy. 1978e. Energy Data Report. International Petroleum Annual 1978. DOE/EIA-0042(78). Energy Information Administration. Washington, D.C.

U.S. Environmental Protection Agency. 1974. Development Document for Effluent Limitations Guidelines and New Source Performance Standards for the Petroleum Refining Point Source Category. U.S. Government Printing office, Washington, D.C. April. 
LITERATURE CITED (Refinery Operations, Continued)

U.S. Environmental Protection Agency. 1977a. Economic Analysis of Interim Final Pretreatment Standards for the Petroleum Refining Industry. EPA-440/1-77-002. Office of Water Planning and Standards, Washington, D.C.

U.S. Environmental Protection Agency. 1977b. Interim Final Supplement for Pretreatment to the Development Document for the Petroleum Refining Industry Existing Point Source Category. U.S. Environmental Protection Agency, Washington, D.C.

U.S. Environmenta1 Protection Agency. 1978. Candidate List of Chemical Substances, Addendum I, Generic Terms Covering Petroleum Refinery Process Streams. Washington, D.C. January.

U.S. Environmental Protection Agency. 1979a. Petroleum Refining: Point Source Category Effluent Limitations Guidelines, Pretreatment Standards, and New Source Prevention Standards. Federal Register, December 21, pp. 75926-75949.

U.S. Environmental Protection Agency. 1979b. Development Document for Proposed Effluent Limitation Guidelines, New Source Performance Standards, and Pretreatment Standards for the Petroleum Refining Point Source Category. EPA-440/1-79-014b. Washington, D.C. December.

U.S. Environmental Protection Agency. 1980a. Facts and Issues Associated with the Need for a Hydrocarbon Criteria Document (Draft). Research Triangle Park, North Carolina. February.

U.S. Environmental Protection Agency. 1980b. Proposed Effluent Guidelines: Rulemaking for the Petroleum Refining Point Source Category. Office of Water and Waste Management, Washington, D.C.

U.S. Environmental Protection Agency. 1980c. Fugitive Emissions. In Research Highlights 1979. EPA-600/9-80-005. Office of Research and Development, Washington, V.C.

II.S. Puhlic Health Service. 1970. Air Quality Critcria for Hydrocarbons. AP-64. Washington, D.C.

Vandervort, R., and J.B. Lucas. 1974. Health Hazard Evaluation Report 72-77-109. National Institute for Occupational Safety and Health, Cincinnati, Ohio. 


\section{LITERATURE CITED (Refinery Operations, Concluded)}

Venable, F.S. 1975. Skin and Respiratory Exposure to Polynuclear Aromatics from Delayed Coking Units. Medical Bulletin (Exxon) $35: 120-128$.

Walker, H.M. 1970. Product Opt1mization in the Petrochemical Refinery. In Refining Petroleum for Chemicals, eds. L.J. Spillane and H.P. Leftin, pp. 137-152. American Chemical Society, Washington, D.C.

Walker, P. 1976. Air Pollution Assessment of Benzene. MTR-7188. The MITRE Corporation, McLean, VA.

Walker, P., J. Gordon, L. Thomas, and R. Ouellette. 1976. Environmental Assessment of Atmospheric Nitrosamines. MTR-7152. The MITRE. Corporation, McLean, Virginia.

Wallace, L. 1977. Personal Air Quality Monitors: Past Uses and Present Prospects. In Fourth Jolnt Conference on Sensing of Environmental Pollutants, pp. 390-394. American Chemical Society, Washington, D.C.

Westaway, M.T., and G.J. Brocklis. Petroleum. In Industrial Air Pollution Handbook, chapt. 13, pp. 363-388.

Wetherold, R., and L. Provost. 1979. Emission Factors and Frequency of Leak Occurrence for Fittings in Refinery Process Units. EPA-600/ 279-044. National Technical Information Center Service, Washington, D.C.

Williamson, H.J., and L.P. Provost. 1978. Statistical Analysis of Fugitive Emission Change Due to Refinery Expansion. EPA-600/2-78195. U.S. Environmental Protection Agency, Washington, D.C.

Wilson, F.W. 1976. Toxicology of Petroleum Naphtha Distillate Vapors. Journal of Occupational Medicine 8(12):821.

Windholz, M. 1976. Merck Index. An Encyclopedia of Chemicals and Drugs, 9 th ed. Merck and Company, Inc., Rathway, New Jersey.

World Health Organization. 1978. Nitrates, Nitrites, and N-Nitroso Compounds. Geneva, Switzerland.

Yen, T.F. 1975. The Role of Trace Metals in Petroleum. Ann Arbor Press, Ann Arbor, Michigan. 


\title{
LIQUEFIED ENERGY GASES \\ LITERATURE CITED
}

\author{
American Gas Association. 1973. Introduction to LNG Personnel \\ Safety. Washington, D.C. \\ American Gas Association. 1977. LNG Fact Book. Arlington, \\ Virginia.
}

Brown, R.D., and R.M. Helfand, 1977. Environmental Issues Associated with Alaskan Natural Gas Transportation. WP-12451. The MITRE Corporation, McLean, Va.

Chat terjee, N. and J.M. Geist. 1972. The Effects of Stratification on Boiloff Rates in LNG Tanks. Presented at the Distribution Conference, Atlanta, Georgia, May 8-10, 1972. Sponsored by the American Gas Association, Washington, D.C.

Clapp, M.B., and L.F. Litzinger. 1972. Refrigerated Terminals for LNG and LPG. Ocean Industry, November 1972, pp. 37-38.

Drake, E.', and R. Reid. 1977. The Importation of Liquefied Natural Gas. Scientific American 236(4):22-29.

Federal Power Commission. 1973. National Gas Survey, vol. 2 . Washington, D.C.

General Accounting Office. 1978. Liquefied Energy Gases Safety, vol. 1. Comptroller General of the United States, Washington, D.C.

Hale, D. 1980. Developments Proceed Slowly in World LNG Industry. Pipeline and Gas Journal 207(3):17-19.

Hari, 0., A. Antonelli, and G. Boeri. 1974. Beneficial Uses of Waste Heat. Report of the Study Group on the Release of Thermal Effluents of Nuclear Power Plants and its Environmental Impact. RT/PROT(74)10. Comitato Nazionale Energia Nucleare, Rome, Italy.

Kalberer, W. 1980. Do Power Plants Mean Trouble for Fish? Virginia Polytechnic Institute and State University. Sea Grant Today 10(1): 7-9.

Kirscheke, R.H., K. Singh, and C. Chen. 1976. Capital Cost Variation Experience in Power Plant Construction. Power Engineering $80(2): 60-63$. 


\section{LITERATURE CITED (LIquefied Energy Gases, Continued)}

Maher, J.B., and L.R. Van Gelder. 1972. Understanding Ro11-Over and Thermal Overfill in the Flat Bottom LNG Tanks. Presented at the Distribution Conference, Atlanta, Georgia, May 8-10, 1972. Sponsored by the American Gas Association, Washington, D.C.

National Academy of Sclences. 1972. LNG Water Explosions. Washington, D.C.

Office of Technology Assessment. 1977. Transportation of Liquefied Natural Gas. U.S. Congress, Washington, D.C. September.

Sarsten, J.A. 1972. LNG Operating Experiences at La Spazla, Italy. Presented at the Distribution Conference, Atlanta, Georgla, May 8-10, 1972. Sponsored by the American Gas Assoclation, Washington, D.C.

Scorecard. 1980. U.S. and Canadian LNG Peakshaving Facility and International Baseload LNG Liquefaction Facilities. P1peline and Gas Journal 207(3):20-22.

Strobaugh, R., and D. Yerg1n, eds. 1979. Energy Future: Report of the Energy Project at the Harvard Business School. Random House, New York.

Tiratsoo, E.N. 1979. Natural Gas. Gulf Publishing Company, Houston, Texas.

Tutko, T.J. 1979. How to Design an Integrated Security System for an LNG Factlity. Pipeline and Gas Journal 207(8):50-62.

U.S. Department of Energy. 1979. Monthly Energy Review. DOE/EIA $0035 / 12$ (79). Energy Information Administration, Washington, D.C. December.

U.S. Department of the Interior. 1970. Natural Gas Liquids: A Review of their Role in the Petroleum Industry. Information Circular 8441. Bureau of Mines, Washington, D.C.

U.S. Department of the Interfor. 1977. Report of the Interagency Task Force on Environmental Issues (Related to the Alaskan Gas Transportation System). Office of the Secretary, Washington, D.C. July 1 . 


\section{LITERATURE CITED (Liquefied Energy Gases, Concluded)}

U.S. Department of the Interfor. 1978. Minerals Yearbook 1976, vol. 1, Metals, Minerals, and Fuels. Bureau of Mines, Washington, D.C.

U.S. Environmental Protection Agency. 1977. Accidents and Unscheduled Events Assoclated with Non-Nuclear Energy Resources and Technology. EPA-600/7-77-016. Office of Research and Development, Washington, D.C. February.

University of Maine. 1979. Power Plant Waste Heat Ut1lization in Aquatic Systems. Malne Sea Grant Publications, Ira C. Darling Center, Walpole, Maine.

University of Oklahoma. 1975. Energy Alternatives: A Comparative Analysis. The Science and Public Pollcy Program of the University, Norman, Oklahoma.

Van Horn, A.J., and R. W11son. 1976. L1quefled Natural Gas: Safety Issues, Public Concerns, and Decision Making. Energy and Environmental Polfcy Center, Harvard University, Cambridge, Mass. 


\section{THIS PAGE \\ WAS INTENTIONALLY \\ LEFT BLANK}

696 


\section{TRANSPORTATION AND STORAGE \\ LITERATURE CITED}

Adams, R.S., and R. Ellis. 1960. Some Physical and Chemical Changes in the Soil Brought About by Saturation with Natural Gas. Proc. Soil Sci. Soc. Amer. 24:41-44.

Ahokas, J.T., 0. Pelkonen, and N.T. Karki. 1974. Metabolism of Polycyclic Hydrocarbons by a Highly Active Aryl Hydrocarbon Hydroxylase System in the Liver of a Trout Species. Biochem. and Biophys. Res. Comm. 63(3):635-641.

Alber, P., and R. Szaro, 1976. The Effects of Petroleum Hydrocarbons on Aquatic Birds. In Sources, Effects and Sinks of Hydrocarbons in the Aquatic Environment; American Institute of Biological Sciences Symposium, pp. 437-446.

Allen, T.0., and A.P. Roberts. 1978. Production Operations Well Completions, Workover, and Stimulation, vols. 1 and 2 . $0 i 1$ and Gas Consultants International, Inc., Tulsa, Oklahoma.

Altshuller, A.P., and J.U. Bufalini. 1971. Photochemical Aspects of Air Pollution: A Review. Env. Sci. 'lech. 5:39-64.

American Institute of Mining Engineers. 1975. Petroleum Production and the Environment. Society of Petroleum Engineers, American Institute of Mining Engineers, Dallas, Texas.

American Petroleum Institute. 1975. Crude Oil Pipeline Map of the United States and Southern Canada. Washington, D.C.

American Petroleum Institute. 1976. Primer of 0il and Gas Production, 3rd ed. American Petroleum Inotitutc, Dallas, Texas.

American Petroleum Institute. 1979a. Sumnary of Occupational Injuries and Illnesses in the Petroleum Industry. Statistics Department, Washington, D.C.

American Petroleum Institute. 1979b. Review of Fatal Injuries in the Petroleum Industry for 1978. Statistics Department, Washington, D.C.

Antibus, R.K., and A.E. Linkins. 1978. Ectomycorrhizal Fungi of Salix Rotundifolia Trauto. I. Impact of Surface Applied Prudhoe Bay Crude oil on Mycorrhizal Structure and Composition. Arctic 31(3): 366-380. 
LITERATURE CITED (Transportation and Storage, Continued)

Antizzo, J., and A. Lawrence. 1976. EDP for Enhanced 011 and Gas Recovery. WP-12895, series 8. The MITRE Corporation, McLean, Virginia.

Ayres, S.M., and M.E. Buehler. 1970. The Effects of Urban Pollution on Health. Clin. Pharmacol. Ther. 11:271-332.

Bestougeff, M.A. 1967. Petroleum Hydrocarbons. In Fundamental Aspects of Petroleum Geochemistry, eds. B-Nagy and U. Colombo, pp. 109-175. Elsevier Publishing Co., New York.

Bliss, C. 1977. Accidents and Unscheduled Events Associated with Non-Nuclear Energy Resources and Technology. EPA-600/7-77-016. U.S. Environmental Protection Agency, Washington, D.C.

Bouwer, H. 1978. Groundwater Hydrology • McGraw-Hill Book Company, New York.

Britt, D. 1976. Balanced Program Plan. Energy Technology Focus, vol. 2. MTR-7174. The MITRE Corporation, McLean, Virginia.

Brockson, R.W., and H.T. Bailey. 1973. Respiratory Response. of Juvenile Chinook Sälmon and Strlyed Basss Expoocd to Bonzene, a WaterSoluble Component of Crude 011. Proceedings of the Jolnt Conference on Prevention and Control of Oil Spills. American Petroleum Institute, Washington, D.C.

Brown, R.D., and R.M. Helfand. 1977a. Review of Environmental Issues of the Transportation of Alaskan North Slope Crude 0il. EPA-600/7-77/046. Of fice of Research and Development, U.S. Environmental Protection Agency, Washington, D.C.

Brown, R.D., and R.M. Helfand. 1977b. Alaskan 011 Transportation Issues. EPA-600/9-77-019. Office of Research and Development, U.S. Environmental Protection Agency, Washington, D.C.

Brown, R.D. 1978. Alaskan Gas Transportation Issues. WP-13357: The MITRE Corporation, McLean, Virginia.

Brown, V.M. 1976. Aspects of Heavy Metals Toxicity in Freshwaters. In Toxicity to Biota of Metal Forms in Natural Water, eds. R.W. Andres, P.V. Hudson and D.E. Konasewich, pp. 59-75. Proceedings of a workshop held by the International Joint Commission on Great Lakes, Duluth, Minnesota, Oct. 7-8, 1975. 


\section{LITERATURE CITED (Transportation and Storage, Continued)}

Bryant, R.D. 1975. A Progress Report on the Effects of Methanol on the Microflora of Arctic Soils. Prepared for Canadian Arctic Gas Study Limited. Northern Engineering Services Company Limited, Calgary, Alberta, Canada.

Burklin, C.E., et al. 1976. Background Information on Hydrocarbon Emissions from Marine Terminal Operations. Radian Corporation, Austin, Texas.

Case, L.C. 1970. Water Problems in 011 Production, 2nd ed. Petroleum Publishing Company, Tulsa, Oklahoma.

Cavanaugh; E.C., et al. 1975. Environmental Problem Definition for Petroleum Refineries, Synthetic Gas Plants, and Liquefied Natural Gas Plants. Radian Corporation, Austin, Texas.

Coffeen, J.A. 1978. Selsmic Exploration Fundamentals. Petroleum Publishing Company, Tulsa, Oklahoma.

Comotto, R.M., P.A. Kimerle, R.D. Swisher. 1979. Bioconcentration and Metabolism of Linear Alkylbenzene Sulfonate by Daphnids and Fathead Minnows. In Aquatic Toxicology, eds. L.L. Marking and R.A. Kimerle, pp. 232-258. Proceedings of the Second Annual Symposium on Aquatic Toxicology. ASTM spectal technical publication no. 667. American Society for Testing and Materials, Philadelphia, Pennsylvania.

Dieter, M.P. 1976. The Effects of Petroleum Hydrocarbons on Aquatic Birds. In Sources, Effects and Sinks of Hydrocarbons in the Aquatic Environment. American Institute of Biological Sciences, Symposium, pp. 437-446.

Dyas, N. 1972. North Alaska OH1 and Related Issues. Congressional Research Service, Library of Congress, Washington, D.C.

Filby, R.H., and K.R. Shah. 1975. Neutron Activalion Methods for Trace Elements in Crude Oils. In The Role of Trace Metals in Petroleum, ed. T.F. Yen. Ann Arbor Science Publishers, Ann Arbor, Michigan.

Flagg, J. 1980. The National Ocean Survey's Strategic Petroleum Reserve. Sea Technology 21(6):28-30. 


\section{LITERATURE CITED (Transportation and Storage, Continued)}

Forrest, R.M., and.S.F. McKetta. 1978. Investigation of Hydraulic Fracturing Technology in Tight Gas Reservoirs. In Enhanced 011 and Gas Recovery and Improved Drilling Methods, vol. 2 , pp. G-2 - G-14. Fourth Annual DOE Symposium, Tulsa, Oklahoma.

Fox, G.A. 1975. Herring Gull Productivity and Toxic Chemicals in the Great Lakes in 1975. Manuscript Reports no. 34, pp. 1-34. Toxic Chemicals Division, Canadian Wildife Service.

Hale, D. 1980. Over 11,000 Miles 011 Pipeline Planned for U.S., Canada. Pipeline \& Gas Journal 297(7):17-19.

Hammer, D.I., V. Hasselblad, B. Portnoy, and P.F. Wehrle. 1974. The Los Angeles Student Nurse Study. Arch. Environ. Health 28:255-260.

Hanson, M.E. 1978. Theoretical and Experimental Research on Hydrau11c Fracturing. In Enhanced 011 and Gas Recovery and Improved Drilling Methods, vol. 2, pp. E-6 - E-27. Fourth Annual DOE Symposium, Tulsa, Oklahoma.

Hellebust, J.A., B. Hanna, R.G. Sheath, M. Gerg1s, and T.C. Hutchinson. 1y/b. Experimental Ciude 0il Spillo on a Smal1. Suharctic Lake in The Mackenzie Valley, N.W.T.: Effects on Phytoplankton, Periphyton, and Attached Aquatic Vegetation. In Proceedings of Conference on Prevention and Control of 011 Pollution, San Francisco, California.

Hershaft, A. 1976. Critical Review of Alr Pollution Dose-Effect Functions. Council on Environmental Quality, Washington, D.C.

Hunt, P.G., W.E. Rickard, F.R. Kontz, and R.P. Murrman. 1973. Biological Effects of Terrestrial 0il Spills in Alaska: Environmental Effects and Recovery. In Proceedings of the Joint Conference on Prevention and Control of $0 i 1$ Spills. U.S. Environmental Protection Agency, Washington, D.C.

Hut chinson, T.C., and W. Freedman. 1975. Effects of Experimental Crude 0il Spills on Taiga and Tundra Vegetation of the Canadian Arctic. In Proceedings of Conference on Prevention and Control of Oil pollution, San Francisco, California.

Hutchinson, T.C. 1980. The Correlation of the Toxicity to Algae of Hydrocarbons and Halogenated Hydrocarbons with Their PhysicalChemical Properties. In Hydrocarbons and Halogenated Hydrocarbons in the Aquatic Environment, PP. 577-588. Plenum Press, New York. 


\section{LITERATURE CITED (Transportation and Storage, Continued)}

International Agency for Research on Cancer. 1972-1979. IARC Monographs on the Evaluation of the Carcinogenic Risk of Chemicals to Humans, vols . 1-19.

Jenkins, T.F., L.A. Johnson, C.M. Collins, and T.T. McFadden. 1978. The Physical, Chemical and Biological Effects of Crude 0il Spilis on Black Spruce Forest, Interior Alaska. Arctic 31(3):305-323.

Kalas, L., A. Murdoch, and F.I. Onuska. 1980. Bioaccumulation of Arene and Organochlorine Pollutants by Cipangopaludina Chinensis (Gray, 1834, Mollusca: Gastropoda) from Ponds in the Royal Botanical Gardens, Hamilton, Ontario. In Hydrocarbons and Halogenated Hydrocarbons in the Aquatic Environment, pp. 567-576. Plenum Press, New York.

Katz, D. 1980. Underground Storage of Gases. University of Michigan, Ann Arbor, Michigan.

Koike, H. 1961. The Ef fects of Fumigants on Nitrate Production in Soil. Proc. Soil Sc1. Soc. Amer. 25:204-206.

Laskin, S., M. Kuschner, and R.T. Drew. 1970, Studies in Pulmonary Carcinogenesis. In Inhalation Carcinogenesis, eds. M.G. Hanna, Jr., P. Nettesheim, and J.R. Gilbert, pp. 321-350. AEC Symposium Series, no. 18. U.S. Atomic Energy Commission, Washington, D.C.

Lawrence, A. 1976. EDP for Conventional Dil and Gas. WP 12985, series 5. The MITRE Corporation, McLean, Virginia.

Leckie, J.0., and R.0. James. 1976. Control Mechanisms for Trace Metals in Natural Waters. In Aqueous-Environmental Chewistry of Metals, ed. A.J. Rubin, pp. $1-76$. Ann Arbor Science Publishers, Inc. Ann Arbor, Michigan.

Leggett, N., and T. Williams. 1979. Natural Gas Processing. The MITRE Corporation, McLean, Virginia.

Ti.inkins, A.F., R.M. Atlas, and P. Gustil. 1978. Effect of Surface Applied Crude $0 i 1$ on Soil and Vascular Plant Root Respiration, Soil Cellulose, and Hydrocarbon Hydroxylase at Barrow, Alaska. Arctic $31(3): 355-365$.

Mackison, F.W., ed. 1978. NIOSH/OSHA Pocket Guide to Chemical Hazards. Department of Health, Education, and Welfare pub. no. 78-210. National Institute for Occupational Safety and Health, Rockville, Maryland. 
LITERATURE CITED (Transportation and Storage, Continued)

Macropaedia. 1975. Petroleum and Gas Extraction. Encyclopedia Britannica, vol. 14, pp. 175-179.

Maki, A.W. 1979. Respiratory Activity of Fish as a Predictor of Chronic Fish Toxicity Values for Surfactants. In Aquatic Toxicology, eds. L.L. Marking and R.A. Kimerle, pp. 77-95. Proceedings of the Second Annual Symposium on Aquatic Toxicology. ASTM special technical publication no. 667. American Society for Testing and Materials, Philadelphia, Pennsylvania.

Malins, D.C. 1977. Metabolism of Aromatic Hydrocarbons in Marine Organisms. In Aquatic Pollutants and Blologic Effects with Emphasis on Neoplasis, eds. H.F. Kraybill, C.J. Dawe, J. C. Harshbarger and R.G. Tardiff. Annals of the New York Academy of Sciences, vol. 298, pp. 482-496.

McCauley, R.N. 1966. The Blological Effects of Oil Pollution in a River. Limnol. Oceanogr. 11:475-486.

Meier, V. 1978. Oil Well Operation and Salt-Water Intrusion: Policy Implications. Industrial Wastes, vol. 24, March/April.

Melancon, M.J., Jr., and J.J. Lech. 1979. Uptake Biotransformation, Disposition and Elimination of 2-Methylnaphthalene and Naphthalene in Several Fish Species. In Aquatic Toxicology, eds. L.L. Marking and R.A. Kimerle, pp. 5-22. Proceedings of the Second Annual Symposium on Aquatic Toxicology. ASTM special technical publication no. 667 . American Society for Testing and Materials, Philadelphia, Pennsylvania.

Middleton, J.T., E.F. Darley, and P.F. Brewer. 1958. Damage to Veget ation from Polluted Atmospheres. J. Air Pollut. Cont. Assoc. $8: 9-15$.

Middleton, J.T. 1961. Photochemical Air Pollution Damage to Piants. Ann. Rev. Plant Physiol. 12:431-448.

Miller, 0.K., A.E. Linkins, and M.A. Chmielewski. 1978. Fungal Biomass Responses in 011 Perturbated Tundra at Barrow, Alaska. Arctic 31(3):394-406.

National Petroleum Council. 1976. EOR, an Analysis of the Potential for Enhanced 0il Recovery from Known Fields in the United States--1976 to 2000. Washington, D.C. 
LITERATURE CITED (Transportation and Storage, Continued)

Nelson-Smith, A. 1973. Oil Pollution and Marine Ecology, Plenum Press, New York.

Office of Technology Assessment. 1978. Enhanced 011 Recovery Potential in the United States. U.S. Department of Energy, Washington, D.C.

Parkinson, D., R. Gossen, S. Visser, and L. Nelson. 1974. A Preliminary Report on the Effects of Methanol on the Microflora of Arctic Solls. Prepared for Canadian Arctic Gas Study Limited. Northern Engineering Services Company Limited, Calgary, Alberta, Canada.

Patton, C.C. 1977. O1lfield Water Systems. Campbell Petroleum Series, 2nd ed. Norman, Oklahoma.

Payne, J.F., and W.R. Penrose. 1975. Induction of Anyl Hydrocarbon (Benzo(a)pyrene) Hydroxylase in Fish by Petroleum. Bull. Environ. Contam. Toxicol. (14):112-116.

Pedersen, M.G., W.K. Hershberger, and M.R., Juchau. 1974. Metabolism of 3,4-Benzpyrene in Ra1nbow Trout (Salmo gairdner1). Bull. Environ. Contam. Toxicol. (12):481-486.

Petroleum Extension Service. 1966. Introduction to the 011 P1peline. Industry. The University of Texas, Austin, Texas

Petroleum Extension Service: 1978. 011 P1peline Construction and MaIntenance. The University of Texas, Austin, Texas.

Plckering, Q.H., and C. Henderson. 1966. Acute Toxictity of Some Importanc Petrochemicals to F1sh. Water Pollut. Cont: Fed. 38(9): 1419-1429.

Polasek, T. 1980. Bureaucrats Are Training Big Guns on Crude Product Pipelitnes. Pipeline \& Gas Journal 297(7):20-22.

Rahme, H. 1978. Enhanced 011 Recovery. WP-13465: The MITRE Corporation, McLean, Virginia.

Renzett1, N.A., and R.J. Bryan. 1961. Atmospheric Sampling for Aldehydes and Eye Irritation in Los Angeles Smog--1960. J. Afr Pollut. Cont. Assoc. 11:421-424. 


\section{LITERATURE CITED (Transportation and Storage, Continued)}

Rice, S.D. 1973. Toxicity and Avoidance Tests with Prudhoe Bay 011 and Pink Salmon Fry. In Proceedings of Joint Conference on Prevention and Control of oil Spills, pp. 667-670. American Petroleum Institute, Washington, D.C.

Rice, S.D., J.S. Short, and J.F. Karinew. 1976. Toxicity of Cook Inlet Crude 011 and No. 2 Fuel 011 to Several Alaskan Marine Fishes and Invertebrates. In Sources, Effects and Sinks of Hydrocarbons in the Aquatic Environment, pp. 305-406. American Institute of Blological Sciences Symposium.

Richards, N.L. 1979. Effects of Chemicals Used In 011 and Gas Well-Drilling in Aquatic Environments. Paper presented at Fourth Nat Ional Conference Interagency Energy/Environment R\&D Program. U.S. Environmental Protection Agency, Washington, D.C.

Rode, L.J., and J.W. Foster. 1965. Gaseous Hydrocarbons and the Germination of Bacterial Spores. Proc. Nat. Acad. Sci. 53:31-38.

Schumacher, M.M:, ed. 1978. Enhanced 011 Recovery: Secondary and Tertiary Methods. Noyes Data Corporation, Park Ridge, New Jersey.

Sexstone, A., K. Everett, T. Jenkins, and R. At las. 1978. Fate of Crude and Refined Oils in North Slope Solls. Arctic 31(3):339-347.

Sparrow, E.B., C.V. Davenport, and R.C. Gordon. 1978. Response of Microorganisms to Hot Crude 011 Spills on a Subarctic Taiga Soil. Arctic 31(3):324-338.

Stephens, E.R., and W.E. Scott. 1962. Relative Reactivity of Various Hydrocarbons in Polluted Atmospheres. Proc. Amer. Petrol. Inst. 42 (Section III Refinery):665-670.

Stokes, P., and T.C. Hutchinson. 1976. Copper Toxicity to Phytoplankton as Affected by Organic Ligands, Other Cations and Inherent Tolerance of Algae to Copper. In Toxicity to Biota of Metal Forms in Natural Water, eds. R.W. Andrew, P.B. Hodson, D.E. Konasewich., pp. 159-185. Proceedings of a Workshop held by the International Joint Commission on the Great Lakes, Oct. 7-8, 1975, Duluth, Minnesota.

Stokinger, H.E., and D.L. Coffin. 1968. Biologic Effects of Air Pollutants. In Air Pollution and Its Effects, 2nd ed., vol. 1, ed. A.C. Stern, pp. 445-546. Academic Press, New York. 
LITERATURE CITED (Transportation and Storage, Continued)

Tarzwe11, C.M. 1971. Toxic1ty of $0 i 1$ and 011 Dispersant Mixtures to Aquatic Life. In Water Pollution by 0il, ed. Peter Hepple, pp. 263272. Elsevier Publishing Company, New York.

Tayior, 0.C. 1969. Importance of Peroxyacetyl Nitrate (PAN) as Phytotoxic Air Pollutant. J. Air Pollut. Cont. Assoc. 19:347-351.

Tingey, D.T. 1977. Ozone Induced Alterations in Plant Growth and Metabolism. In Proceedings of the International Confference on Photochemical Oxidant Pollution and Its Control. EPA 600/3-77-001b. U.S. Environmental Protection Agency, Washington, D.C.

Tinsley, I.J. 1979. Chemical Concepts in Pollutant Behavior: Wiley, New York.

U.S. Department of Energy. 1978. Environmental Readiness Document, Enhanced 011 Recovery Commercialization Phase III Planning. Washington, D.C.

U.S. Department of Energy. 1979. Fossil Energy Program Summary Document. DOE/ET-0087. Washington, D.C.

U.S. Department of Health, Education, and Welfare. 1977. Registry of Toxic Effects of Chemical Substances, vols. 1 and 2. Washington, D.C.

U.S. Department of the Interior. 1972. Final Environmental Impact Statement (EIS) on Proposed Trans-Alaska Pipeline, vol. 4. Washington, D.C.

U.S. Department of the Interior. 1976. Nlaoka Natural Gas Transportation System Final Environmental Impact Statement. Washington, D.C.

U.S. Department of the Interior. 1977. Report of the Interagency Task Force on Environmental Issues, July 1, 1977. Office of the Secret ary, Washington, D.C.

U.S. Environmental Protection Agency. 1972. Water Quality Criteria 1972. A Report of the Committees on Water Quality Criteria by the National Academy of Sciences for the U.S. Environmental Protection Agency, Washington, D.C.

U.S. Environmental Protection Agency. 1975. Vapor-Phase Organic Pollutants--Volatile Hydrocarbons and Oxidation Products. EPA 600/1-75-005. Health Effects Research Laboratory, Research Triangle Park, North Carolina. 


\section{LITERATURE CITED (Transportation and Storage, Continued)}

U.S. Environmental Protection Agency. 1976a. Development Document for Interim Final Effluent Limitations Guidelines and Proposed New Source Performance Standards for the 011 and Gas Extraction Point Source Category. EPA-440/9-76-023. Washington, D.C.

U.S. Environmental Protection Agency. 1976b. Quality Criteria for Water. EPA-440/9-76-023. Washington, D.C.

U.S. Environmental Protection Agency. 1977. The Report to Congress on Waste Disposal Practices and Their Effects on Groundwater (Executive Summary). SH-656. Washington, D.C.

U.S. Environmental Protection Agency. 1978. Alr Quality Criteria for Ozone and Other Photochemical 0xidants. EPA-600/8-78-004. Washington, D.C.

U.S. Environmental Protection Agency. 1979. A Small 0il Spill at West Falmouth. EPA 600/9-79-007. Office of Research and Development, Washington, D.C.

U.S. Office of Management and Budget. 1972. Standard Industrial Classification Manual. GPO 041-001-00066-6. U.S. Government Printing office, Washington, D.C.

University of Oklahoma. 1975. Energy Alternatives: A Comparative Analysis. PB-246-365. National Technical Information Service, Springfield, Virginia.

University of Oklahoma. 1979. Energy from the West. EPA-600-7-790601. Office of Research and Development, U.S. Environmental Protection Agency, Washington, D.C.

Valkovic, V. 1978. Trace Elements in Petroleum. Petroleum Publishing Company, Tulsa, Ọlahoma.

Wensley, R.N. 1953. Microblological Studies of the Action of Some Selected Soil Fumigants. Can. J. Bot. 31:277-308.

Wilkins, G.E. 1977. Industrial Process Profiles for Environmental Use, Oil and Gas Production Industry, chapt. 2. EPA-600/2-77-023b. Radian Corporation, Austin, Texas. 
LITERATURE CITED (Transportation and Storage, Concluded)

Z1tko, V. 1976. Structure-Activity Relations and the Toxicity of Trace Elements to Aquatic Biota. In Toxicity to Biota of Metal Forms In Natural Water, eds. R.W. Andrew, P.V. Hodson, D.E. Konasewich, Pp. 9-32. Proceedings of a workshop held in Duluth, Minnesota, Oct. 7-8, 1975. International Jo1nt Commission on the Great Lakes. 


\section{THIS PAGE \\ WAS INTENTIONALLY \\ LEFT BLANK}


END USE

LITERATURE CITED

Air/Water Pollution Report. 1977. EPA to study EDB in Response to Petition. EDF calls for Regulation Under Toxic Act. 15(36):356.

American Gas Association. 1974. Gas Facts--A Statistical Record of the Gas Utility Industry in 1974. Department of Statistics, Arlington, Virginia.

American Gas Association. 1975. Gas Facts--A Statistical Record of the Gas Utility Industry. Arlington, Virginia.

Andersen, I. 1972. Relationship Between Outdoor and Indoor Air Pollution. Atmos. Env. 6:275-278.

Ayres, S.M., S. Giannell1, and H. Mueller. 1970. Effects of Low Concentrations of Carbon Monoxide. Ann. N.Y. Acad. Sci. 174:268-293.

Bahr, D.W. 1971. Control and Reduction of Aircraft Turbine Engine Exhaust Emissions. In Emissions from Continous Combustion Sources. Plenum Press, New York.

Baum, F. 1972. Carbon Monoxide Emissions from Home-Heating Furnaces. Staub Reinhaltung Luft. 32(2):54-59.

Begeman, D.R., and J.M. Colucci. 1968. Benzo(a)pyrene in Gasoline Partially Persists in Automobile Exhaust. Science 161:271.

Benson, F.B., J.J. Henderson, and D.E. Caldwell. 1972. IndoorOutdoor Air Pollution Relationships: A Literature Review. Pub. no. AP-112. U.S. Environmental Protection Agency, Washington, D.C.

Bhatnagar, R.S. 1979. Evidence Suggesting that Exposure to Diesel Emissions May Lead to Emphysema. Presented at the International Symposium on Health Effects of Diesel Engine Emissions. December 3-5. Cincinnati, Ohio.

Biersteker, K., M. de Graff, and A.G. Nass. 1965. Indoor Air Pollution in Rotterdam Homes. International Journal of Air and Water Pollution 9:343-350.

Black, F.M., and L.E. High. 1978. Diesel Hydrocarbon Emissions, Particulate and Gas Phase. Symposium on Diesel Particulate Measurement Characterization, Ann Arbor, Michigan. May 17-19. 
LITERATURE CITED (End Use, Continued)

Black, F.M., and L.E. High. 1979. Methodology for Determining Particulate and Gaseous Diesel Hydrocarbon Emissions. SAE Technical Paper Series Publication No. 790422. Society of Automotive Engineers, Inc., Warrendale, Pennsylvania.

Boyer, K.W., and H.A. Laitinen. 1975. Automobile Exhaust Particulates: Properties and Environmental Significance. Env. Sci. Tech. $9: 457-469$.

Braddock, J.N., and P.A. Gabele. 1977. Emission Patterns of Diese1Powered Passenger Cars. Part II Presented at Society of Automotive Engineers Automotive Engineering Congress and Exposition. Detroit, Mil chigan. February 28 - March 4. SAE Paper No. 770168.

Breslin, J.A., A.J. Strazisar, and R.L. Stein. 1976. Size Distribution and Mass Content of Particulates from Diesel Engine Exhausts. Bureau of Mines Report of Investigations. No. RI8141r. U.S. Department of the Interior, Washington, D.C.

Bucon, H.W., J.F. Macko, and H.J. Taback. 1978. Volatile Organic Compound (VOC) Species Data Manual. EPA-450/3-78-119. U.S. Environmental Protection Agency, Research Triangle Park, North Carolina. December.

Budiansky, S. 1980. Diesel Exhaust Regulations and Health Effects. Env: Sci. Tech. 14(2):135-137.

Cadle, S.H., and P.A. Mulawa. 1980. Low Molecular Welght Aliphatic Amines in Exhaust from Catalyst-Equipped Cars. Env. Sci. Tech. $14(6): 718-723$.

Cancer Assessment Group. 1978. Assessment of Human Exposures to Atmospheric Benzene. U.S. Environmental Protection Agency, Washington, D.C.

Cațo, G.A., H.J. Buening, C.C. DeVivo, B.G. Morton, and J.M. Robinson. 1974. Field Testing--Application of Combustion Modification to Control Pollutant Emissions from Industrial Boilers--Phase I. EPA-650/2-74-078a. U.S. Environmental Protection Agency, Washington, D.C.

Chass, R.L., P.S. Tow, R.G. Lunche, and N.R. Shaffer. 1960. Total Air Pollution Emission in Los Angeles County. J. Air Pollut. Cont. Assoc. 10:351-366. 


\section{LITERATURE CITED (End Use, Continued)}

Chenoweth, M. 1946. Venticular Fibrilation Induced by Hydrocarbons and Epinephrine. J. Ind. Hyg. Toxico1. 28:151-158.

Claxton, L., and J.L. Huisingh. 1979. Comparative Mutagenic Activity of Organics from Combustion Sources. Prepared for the Proceedings of the Symposium on Pulmonary Toxicology of Respirable Particles. Health Effects Research Laboratory, U.S. Environmental Protection Agency, Research Triangle Park, North Carolina.

Coffin, D.L., and H.E. Stokinger. 1977. Biological Effects of Air Pollutants. In Air Pollution, 3rd ed., vol. II, ed: A.C. Stern, pp. 232-345. Academic Press, New York.

Cote, W.A., W.A. Wade III, and J.E. Yocom. 1974. A Study of Indoor Air Quality. EPA-650/4-74-042. U.S. Environmental Protection Agency, Washington, D.C.

Council on Environmental Quality. 1975. Sixth Annual Report of the Council on Environmental Quality, Washington, D.C.

Council on Environmental Quality. 1976. Seventh Annual Report of the Council on Environmental Quality, Washington, D.C.

Council on Environmental Quality. 1977. Eighth Annual Report of the Council on Environmental Quality, Washington, D.C.

Council on Environmental Quality. 1979. Environmental Quality: The Tenth Annual Report of the Council on Environmental Quality, Washington, D.C.

Dotson, G.K., R.B. Dean, W.B. Cooke, and B.A. Kenner. 1974. Land Spreading: A Conserving and Non-polluting Method of Disposing Oily Wastes. Appendix A. In Waste 0il Study--Report to the Congress, pp. 146-160, Apri1. U.S. Environmental Protection Agency, Washington, D.C.

Dow Chemical Company. 1978. The Chlorinated Dioxin Task Force, The Trace Chemistries of Fire--A Source of and Rnutes for the Entry of Chlorinated Dioxin into the Environment. Midland, Michigan.

Eacon, W.C., C.M. Shy, J.F. Finklea, J.N. Howard, R.M. Burton, F.B. Benson, and G.H. Ward. 1972. A Preliminary Study of Indoor Air Pollution in a Home Using a Gas Stove. Part I: Oxides of Nitrogen, Part II: Condensation Nuclei. U.S. Environmental Protection Agency, Washington, D.C. 
LITERATURE CITED (End Use, Continued)

Energy and Environmental Analysis, Inc. 1978. Draft Report to the Environmental Protection Agency, Atmospheric POM: Sources and Population Exposure Estimate. The MITRE Corporation, McLean, Virginia.

Engdahl, R.B.; and R.E. Barrett. 1977. Fuels and Their Utilization. In Air Pollution, 3rd ed., vol. 4, ed. A.C. Stern, pp. 380-424. Academic Press, New York.

Falk, H.L., P. Kotin, and I. Markul. 1958. The Disappearance of Carcinogens from Soot in Human Lungs. Cancer 11:482-489.

Fin, D., and R.Y. Fan. 1976. Report to the National Science Foundation, Washington, D.C. September 16.

Fisher, M. 1980: Fuels of the Future. In The Energy Consumer (September 1980), Office of Consumer Affairs, U.S. Department of Energy, Washington, D.C.

French, J.G. 1975. Recent Epidemiologic Studies on Health Effects Related to Exposure to $\mathrm{NO}_{x}$. EPA-600/9-75-003. Presented at Sc1entific Seminar on Automotive Pollutants. Thomas Jefferson Memorial Auditorium, Washington, D.C., February 11 .

Gartrell, F.E. 1977. Power Generation. In Air Pollution, 3rd ed. vol. IV, ed. A.C. Stern, pp. 465-529. Academic Press, New York.

General Electric Company. 1972. Indoor-Outdoor Carbon Monoxide PolIution Study. NTIS no. PB220428. National Technical Information Service, Springfield, Virginia.

Geomet, Inc. 1977. The Status of Indoor Air Pollution Research 1976. Geomet, Inc., Gaithersburg, Maryland.

Gerarde, H.W. 1963a. The Aliphatic Hydrocarbons. In Industrial Hygiene and Toxicology, vol. 2, ed. F.A. Patty. Interscience Publishers, Inc., New York.

Gerarde, H.W. 1963b. The Alicyclic Hydrocarbons. In Industrial Hygiene and Toxicology, vol. 2, ed. F.A. Patty. Interscience Publishers, Inc., New York.

Gerarde, H.W. 1963c. The Aromatic Hydrocarbons. In Industrial Hygiene and Toxicology, vol. 2, ed. F.A. Patty. Interscience Publishers, Inc., New York. 


\section{LITERATURE CITED (End Use, Continued)}

Gerarde, H.W. 1963d. Hydrocarbon Mixtures. In Industrial Hygiene and Toxicology, vol. 2, ed. F.A. Patty, pp. 1199-1201. Interscience Publishers, Inc., New York.

Goldsmith, J.R., and L.T. Friberg. 1977. Effects on Human Health. In Air Pollution, 3rd ed., vol. 2, ed. A.C. Stern, pp. 533-558. Academic Press, New York.

Graedel, T.E. 1978. Chemical Compounds in the Atmosphere. Academic Press, New York.

Gredischnik, H.K. 1972. Air Pollution Due to Heating Systems. Gras. Umweltschulz Staedtcreinig (Vienna) 9(9):202-206. (In German, abstract in English.)

Green, G.H. 1975. The Effect of Indoor Relative Humidity on Absenteeism and Colds in Schools. Journal American Society Heat Refrig. Air Condition Eng. 17(1):57-62.

Grimmer, G. 1979. Tumor-Producing Effect of Diesel Exhaust Condensate and Automobile Exhaust Condensate After Epicutaneous Application to Mice. Presented at the International Symposium on Health Effects of Diesel Engine Emissions, December 3-5, Cincinnati, Ohio.

Grobman, J.S. 1971. Effects of Operating Variables on Pollutant Emissions from Aircraft Turbine Engine Combustor. Symposium on Emissions from Continuous Combustion Systems held at General Motors Research Institute, Warren, Michigan, pp. 279-303.

Gross, G.P. 1972. The Effect of Fuel and Vehicle Variables on Pnlynuclear Aromatic Hydrocarbons and Phenol Emissions, paper no. 720210. Presented at the SAE Automotive Engineering Congress and Exposition, Detroit, Michigan.

Habibi, K., E.S. Jacobs, W.G. Kunz, Jr., and D.L. Pastell. 1970. Characterization and Control of Gaseous and Particulate Emissions from Vehicles. Presented at the Air Pollution Control Association Fifth Technological Meeting, San Francisco. Available from E.I. DuPont de Nemours and Co., Wilmington, Delaware.

Hangebrauck, R.P., D.J. VonLehmden, and J.E. Meeker. 1967. Sources of Polynuclear Hydrocarbons in the Atmosphere. Public Health Service no. 999-AP-33. 


\section{LITERATURE CITED (End Use, Continued)}

Hazelton Laboratories. 1979. In Vitro and In Vivo Mutagenicity Studies: No. 2 Home Heating 0il, Final Report. Submitted to American Petroleum Institute, Washington, D.C.

Heck, W.W., and C.S. Brandt. 1977. Effects on Vegetation: Native, Crops, Forests. In Air Pollution, 3rd ed., vol. 2, ed. A.C. Stern, pp. 158-220. Academic Press, New York.

Hedtke, S.F. 1974. The Ef fects of Waste 011 on Freshwater Aquatic Life. Appendix C. In Waste 0il Study--Report to the Congress, pp. 213-266. U.S. Environmental Protection Agency. April.

Helfand, R. 1977. Study to Obtain Data Necessary for the Development of Standards of Performance for Oil- and Gas-fired Domestic Space Heaters. MTR-7641. The MITRE Corporation, McLean, Virginia.

Henry, W.M., and K.T. Knapp. 1980. Compound Forum of Fossil Fuel Fly Ash Emissions. Env. Sc1. Tech. 14(4):450-456.

Hess, L.Y. 1979. Reprocessing and Disposal of Waste Petroleum Oils. Noyes Data Corporation, Park Ridge, New Jersey.

Higgins, I.T.T. 1974. Trends In Respiratory Cáncèr Morcaltity. Arch. Environ. Health 28:121-129.

Hinkamp, J.B., M.E. Griffing, and D.W. Zutut. 1971. Aromatic Aldehydes and Phenols in the Exhaust from Leaded and Unleaded Fuels. Presented at Division Petroleum Chemical, Inc., ACS, Los Angeles Meeting, March 28 - April 2.

Hof fman, D., and E.L. Wynder. 1977. Organic Particulate Pollutants. In Air Pollution, 3rd ed., vol. 2, ed. A.C. Stern, pp. 362-445.

Academic Press, New York.

Hollowell, C.D., R.J. Budnitz, G.D. Case, and G.W. Traynor. 1976. Combustion-Generated Indoor Air Pollution, 1-- Field Measurements 8/75-10/75. R'pt no. 4416. Lawrence Berkeley Laboratory, Berkeley, California.

Homolya, J.B., and J.L. Cheney. 1978. An Assessment of Sulfuric Acid and Sulfate Emissions from the Combustion of Fossil Fuels. U.S. Environmental Protection Agency, Environmental Services Research Laboratory, Research Triangle Park, North Carolina. 


\section{LITERATURE CITED (End Use, Continued)}

Huisingh, J.L., R. Bradow, R. Jungers, L. Claxton, R. Zweidinger, S. Tejada, J. Bumgarner, F. Duffield, and M. Waters. 1978. Application of Bioassay to the Characterization of Diese1 Particle Emissions. In Application of Short Term Bioassays in the Fractionation and Analysis of Complex Environmental Mixtures. EPA-600/9-78-027. U.S. Environmental Protection Agency, Washington, D.C. September.

Hurn, R.W. 1968. Mobile Combustion Sources. In Air Pollution, 2nd ed., vol. 3, ed. A.C. Stern, pp. 55-95. Academic Press, New York.

Inside Wash1ngton Publishers, Inc. 1980. Interagency Group Labels Radon National Problem Needing Quick Attention. Inside EPA Weekly Report 1(28):1-2.

Irwin, W.A. and R.A. Liroff. 1974. Used Oil Law in the United States and Europe. EPA-600/5-74-025. U.S. Environmental Protection Agency, Washington, D.C. July.

Karhausen, L. 1973. Environmental Health Aspects of Lead. In Commission of the European Communities and the U.S. Environmental Protection Agency, pp. 427-440. Published by the Commission of the European Communities Directorate General for Dissemination of Knowledge. Center for Information and Documentation, Luxembourg, Belgium.

Kloke, A. 1975. Lead-Zinc-Cadmium Enrichment in Soils and Plants. VDI--Berichte Nr. 203:69-73.

Knave, B., P. Mindus and G. Struwe. 1979. Neurasthetic Symptoms in Workers Occupationally Exposed to Jet Fuels. Acta. Psychtat. Scand. $60: 39-49$.

Koga1, S. 1976. On the Indoor $\mathrm{NO}_{2}$ Ef fect (Public Nuisance) 12(8):789-793. $\mathrm{NO}_{2}$ in Yoru Okuna1 Osen No Jitta1 Ni Tsuite. (In Japanese, abstract in English.)

Kunz, W.G., E.S. Jacobs and A.J. Pahnke. 1975. Design and Performance of Muffler Lead Traps for Vehicles. Proconted to the Untun Intersyndicale de l'Industrie du Petrole, Paris, France. January.

Lagerwerff, J.V. and A.W. Specht. 1970. Occurrence of Environmental Cadmium and Zinc and their Uptake by Plants. U.S. Soil Laboratory USDA-ARS-SWC, Beltsville, Maryland. 
LITERATURE CITED (End Use, Continued)

Laity, J.L., M.D. Malbin, W.W. Heskell, and W.I. Doty. 1973. Mechanism of Polynuclear Aromatic Hydrocarbon Emissions from Automotive Engines. No. 730835. Society of Automotive Engineers, Inc., Warrendale, Pennsylvania.

Arthur D. Little. 1975. An Impact Assessment of ASHRAE Standard 90-75. In Energy Conservation in New Building Design. Report to. Federal Energy Administration, Cambridge.

Lofroth, G. 1979. Salmonella/Microsome Mutagenicity Assay of Exhausts from Diesel and Gasoline Powered Motor Vehicles. Presented at International Symposium on Health Effects of Diesel Engine Emissions. December 3-5, Cincinnati, Ohio.

Loftness, R. 1978. Energy Handbook. Van Nostrand Reinhold Co. New York, New York.

Lyons, M.J. 1962. Comparison of Aromatic Polycyclic Hydrocarbons from Gasoline Engines and Diesel Engine Exhausts, General Atmospheric Dust, and Cigaret te Smoke Condensate. Mono. no. 9 NCI 193-199. National Cancer Institute, Bethesda, Maryland.

Machle, W. 1941. Gasoline Intoxication. J. Amer. Med. Assoc. $117: 1965-1971$.

Mayers, M.R. 1969. Occupational Health--Hazards of the Work Environment, pp. 69-70, 444. Williams, \& Wilkins Co., Baltimore, Maryland.

Melia, R.J.W., C. Du V. Florey, D.G. Altman, and A.V. Swan. 1977. Association Between Gas Cooking and Respiratory Disease in Children. Brit. Medical Journal 2:149-152.

Melia, R.J.W., C. Du V. Florey, S.C. Darby, E.D. Palmes, and B.D. Goldstein. 1978. Differences in $\mathrm{NO}_{2}$ levels in Kitchens with Gas or Electric Cookers. Atmospheric Environment 12:1379-1381.

Menster, M., and A.G. Sharkey. 1977. Chemical Characterization of Diesel Exhaust Particulates. PERC/RI-77/5. National Technical Information Service, Springfield, Virginia.

Misiorowski, R.L., K. Strom, and M. Schvapil. 1979. Lung Biochemistry of Rats Chronically Exposed to Diesel Particulates. Presented at the International Symposium on Health Effects of Diesel Engine Emissions, December 3-5, Cincinnati, Ohio. 
LITERATURE CITED (End Use, Continued)

The MITRE Corporation. 1977. Study to Obtain Data Necessary for the Development of Standards of Performance for $0 i 1$ and Gas Fired Domestic Heaters. MTR7641. McLean, Virginia. November.

Mueller, P.K. 1970. Characterization of Particulate Lead in Vehicle Exhaust--Experimental Techniques. Env. Sci. Tech. 4:248-251.

Nahm, J. 1976. Measurements of Photodegraded $\mathrm{C}_{2}-\mathrm{C}_{5}$ Hydrocarbons from Aerosol Particulates Collected in Houston, Texas. In Ozone/ Oxidants--Interactions with the Total Environment. The Air Pollution Control Assoclation, Pittsburgh, Pennsylvania.

National Academy of Sciences. 1970. Proceedings of a Conference on Biological Effects of Carbon Monoxide. Washington, D.C.

National Academy of Sciences. 1972. Particulate Polycyclic Organic Matter. Washington, D.C.

National Academy of Sciences. 1975. Nickel. Washington, D.C.

National Academy of Sciences. 1976a. Chlortne and Hydrogen

Chloride. Washington, D.C.

National Academy of Sciences. 1976b. Vapor-Phase Organic

Pollutants. Washington, D.C.

National Academy of Sclences. 1977. Ozone and Other Photochemical

Oxidants. Washington, D.C.

National Academy of Sciences. 1980. The Effects on Populations of Exposure to Low Levels of Ionizing Radiation (known as the BEIR III report). Washington, D.C.

National Council on Radiation Protection and Measurements. 1977. Radiation Exposure from Consumer Products and Miscellaneous Sources. NCRP Rep't no. 56. Washington, D.C.

National Council on Radiation Protection and Measurements. $197 \mathrm{~b}$. Natural Background Radiation in the United States. NCRP Rep't no. 45. Washington, D.C.

National Institute for Occupational Safety and Health. 1972. Criteria for a Recommended Standard--Occupational Exposure to Inorganic Lead. U.S. Department of Health, Education, and Welfare. 


\section{LITERATURE CITED' (End Use, Continued)}

National Institute for Occupational Safety and Health. 1975. Criteria for a Recommended Standard--Occupational Exposure to Toluene. U.S. Department of Health, Education, and Welfare.

National Institute for Occupational Safety and Health. 1976a. Criteria for a Recommended Standard--Occupational Exposure to Oxides of Nitrogen (Nitrogen Dioxide and Nitric Oxide). U.S. Department of Health, Education, and Welfare, Public Health Service Center for Disease Control, National Institute for Occupational Safety and Heal th.

National Institute for Occupational Safety and Health. 1976b. Revised Recommendations for an Occupational Exposure Standard for Benzene. U.S. Department of Health, Education, and Welfare, Cincinnati, Ohio. August.

National Institute for Occupational Safety and Health. 1977. Criteria for Recommended Standard--Occupational Exposure to Alkanes $\left(\mathrm{C}_{5}-\mathrm{C}_{8}\right)$. Pub. no. 77-151. U.S. Department of Health, Education, and Welfare. Cincinnati, Ohio. March.

Natinnal Institute for Occupational Safety and Health. 1978. The Use of Diesel Equipment in Ünderground Cual Minco, Workgrnip Reports from NIOSH Workshop, September 19-23, Morgantown, West Virginia. February.

National Petroleum Council. 1971a. Environmental Conservation. The $0 i 1$ and Gas Industries, vol. 1. Washington, D.C.

National Petroleum Council. 1971b. The 0il and Gas Industries. A Report of the National Petroleum Council's Committee on Environmental Conservation, June. W.W. Keeler, Chairman. National Petroleum Council, Washington, D.C.

O'Donnell, A., and A. Dravnieks. 1970. Chemical Species in Engine Exhaust and Their Contribution to Exhaust Odors. Rep't ro. IIT RIC6183-5. Prepared for NAPCA and CRC. November.

Office of Program Coordination. 1980. International Environmental Memo 2(8):7. Office of the Environment, U.S. Department of Energy, Washington, D.C.

Offen, G.R., J.B. Kessen1ring, K. Lee, G. Doe, and K.J. Wolfe. 1976. Control of Particulate Matter from Oil Burners of Boilers. EPA-450/3-76-005. U.S. Environmental Protection Agency, Washington, D.C. 
LITERATURE CITED (End Use, Continued)

01son, D.R. 1977. The Control of Motor Vehicle Emission. In Air Pollution, 3rd ed., vol. 4, ed. A.C. Stern, pp. 596-652. Academic Press, New York.

Organization for Economic Cooperation and Development. 1979. Photochemical Oxidants and Their Precursors in the Atmosphere--Effects, Formation, Transport and Abatement. Paris, France.

Palmes, E.D., and C. Tomezyk. 1979. Relationsh1p of Indoor $\mathrm{NO}_{2}$ Concentrations to Use of Unvented Gas Appliances. J. Air Pollut. Cont, Assoc. 29(4):392-393.

Payne, J.F., I. Martins, and A. Rahimtüla. 1978. Crankcase 0ils: Are They a Major Mutagenic Burden in the Aquatic Environment? Science 200:329.

PEDCO Environmental. 1978. Air Quality Assessment of Particulate Emissions from Diese1-powered Vehicles. Prepared for U.S. Environmental Protection Agency, Research Triangle Park, North Carolina. March.

Petroleum Analytical Research Corporation. 1973. Study on Use of Waste Lubricating 011 as Fuel, Report to the American Petroleum Institute, Washington, D.C.

Public Health Service. 1965. Survey of Lead in the Atmosphere of Three Urban Communities. Public Health Service Publication 999-AP-12. U.S. Department of Health, Education, and Welfare.

Raffle, P. 1957. The Health of the Worker. British Journal of Industrial Medicine 14:73-80.

Reger, R., and J. Hancock. Undated. On Respiratory Health. Coal Miners Exposed to Diesel Exhaust Emissions. Appalachian Laboratory for Occupational Safety and Health, Morgantown, West Virginia.

Reger, R., J. HankInson, and J. Merchant. Undated. Ventilatory Function Changes Over a Work Shift for Coal Miners Exposed to Diesel Emissions. Appalachian Laboratory for Occupational Safety and Health, Morgantown, West Virginia.

Rogerson, P. 1974. Effects of Emulsified Waste Crankcase 0il on Selected Marine Blota. In Waste 011 Study--Keport to the Congress, pp. 268-185. Apr11. 
LITERATURE. CITED (End Use, Continued)

Runion, H.E. 1977. Benzene in Gasoline II. Amer. Ind. Hyg. Assoc. J. 38:391-393.

Sampson, R.E., and G.S. Springer. 1973. Effects of Exhaust Gas Temperature and Fuel Composition on Particulates from Spark Ignition Engines. Env. Sci. Tech. 7:55-60.

Sawicki, E., J.E. Meeker, and M. Morgan. 1965. Polynuclear Aza Compounds in Automotive Exhaust. Arch. Environ. Health 11:773-775.

Schefner, A.M. 1979. Carcinogenicity of Diesel-Exhaust Particles by Intratracheal Instillation Range Studies. Presented at the International Symposium on Health Effects of Diesel Engine Emissions, December 3-5, Cincinnati, Ohio.

Schreck, R.M. 1978. Health Effects of Diesel Exhaust. Biomedical Science Department, General Motors Research Laboratories, Warren, Michigan.

Schreck, R.M., J.J. McGrath, S.J. Swarin, W.E. Hering, P.J. Groblicki and J.S. MacDonald. 1978. Characterization of Diesel Exhaust Particulate for Mutagenic Testing. Rep't no. 78-33.5. General Motors Research Laboratories, Warren, Michigan.

Skinner, D.J. 1976. Preliminary Review of Used Lubricating Oils in Canada. Rep't no. EPS 3-WP-74-4. Prepared for Canada Environmental Protection Service, Ottawa, Canada. June 1975, revised January.

Spicer, C.W., and A. Levy. 1975. The Photochemical Reactivity of Diesel Exhaust Organics. PB244166. Battelle Columbus Laboratories. National Technical Information Service, Springfield, Virginia.

Springer, K.J., and T.M. Baines. 1977. Emissions from Diesel Versions of Production Passenger Cars. Society of Automotive Engineers, Passenger Car Meeting, Detroit, Michigan.

Stara, J.F., W. Moore, and A.W. Breidenbach. 1974. Toxicology of Atmospheric Pollutants Resulting from Fuel Additives and Emissions Associated with the Use of Automobile Catalytic Converters. In Recent Advances in the Assessment of the Health Effects of Environmental Pollutants, vol. II, Pp. 521-772. Proceedings of an International Symposium, June 24-28, Paris, France.

Staub, B.F. 1972. Carbon Monoxide Emissions from Home-Heating Furnaces. Reinhaltung Luft 32(2):54-59. (In German, abstract in Englis h.) 
Storment, J.0., C.D. Wood, and R.J. Mathis. 1975. A Study of Fuel Economy and Emission Reduction Methods for Marine and Locomotive Diesel Engines. Prepared for U.S. Department of Transportation and U.S. Coast Guard, Washington, D.C.

Swatn, J.W. 1977. Assessment in Industrial Hazardous Was te Management Petroleum Re-Refining Industry. PB272267. U.S. Environmental Protection Agency, Office of Solid Waste Management Programs. National Technical Information Service, Springfield, Virginia. June.

Swinyard, E.A. 1977. Noxlous Gases and Vapors. In The Pharmacological Basis on Therapeutic, 4th ed., eds. L.S. Goodman and A. Gilman, pp. 930-943. MacMillan Co., Toronto, Canada.

Taback, H.J., T.W. Sonnichsen, N. Brunetz, and J.L. Stredler. 1978. Control of Hydrocarbon Emissions from Stationary Sources in the California South Coast Air Basin. PB283486. National Technical Information Service, Springfield, Virginia. June.

U.S. Department of Health, Education, and Welfare. 1970. Air Quality Criteria for Carbon Monoxide. AP-62. Public Health Service Series. Washington, D.C.

U.S. Department of Health, Education, and Welfare. 1977. Occupational Diseases: A Guide to Their Recognition, revised ed., eds. Marcus M. Key, Austin, F. Henschel, J. Butler, Robert N. LIgo, and Irving . . Tabershaw. Pub. no. 77-181. National Institute for Occupational Safety and Health, Washington, D.C. June.

U.S. Environmental Protection Agency. 1974. Report to Congress: Waste 0il Study. Washington, D.C. April.

U.S. Environmental Protection Agency. 1976. National Air Quality and Emissions Trend Report. Office of Air and Waste Management, Research Triangle Park, North Carolina.

U.S. Environmental Protection Agency. 1977a. Compilation of Air Pollutant Emission Factors, 2nd ed. AP-42. Washington, D.C.

U.S. Environmental Protection Agency. 1977b. Control Terhniques for Lcad Air Euissions, vol. 1, chapt. 1-3. EPA-450/2-77-012. December.

U.S. Environmental Protection Agency. 1977c. National Air Quality, Monitoring, and Emission Trends Report. EPA-450/2-78-052. Research Triangle Park, North Carolina. December. 


\section{LITERATURE CITED (End Use, Continued)}

U.S. Environmental Protection Agency: 1977d. The Status of Indoor Air Pollution Research--1976. PB272597. Geomet Inc., Environmental Monitoring and Support Laboratory, Research Triangle Park, North Carolina. National Technical Information Service, Springfield, Virginia.

U.S. Environmental Protection Agency. 1978a. Advanced O11 Processing/Utilization Environmental Engineering: EPA Program Status Report. EPA-600/7-78-007. Office of Research and Development, Washington, D.C. May.

U.S. Environmental Protection Agency. 1978b. Environmental Assessment for Residual 011 Utilization--Second Annual Report. EPA-600/778-175. Environmental Research Laboratory, Research Triangle Park, North Carolina. September.

U.S. Environmental Protection Agency. 1978c. Health Effects Associated with Diesel Exhaust Emissions: Literature Review and Evaluation. EPA-600/1-78-063. EPA Health Effects Research Laboratory, Research Triangle Park, North Carolina. November.

II.S. Finvironmental Protection Agency. 1978d. Mobile Source Emission Factors. EPA-400/9-78-005. NTIS no. PB295672, Springfield, Virginia. March.

U.S. Environmental Protection Agency. 1978e. National Air Quality, Monitoring, and Emissions Trend Report. EPA-450/2-78-052. Research Triangle Park, North Carolina. December.

U.S. Environmental Protection Agency. 1978f. Research Outlook 1979. EPA 600/9-78-001. Office of Research and Development, Washington, D.C. June.

U.S. Environmental Protection Agency. 1979a. Draft report on the Population and Characteristics of Industrial/Commercial Bcilers. Industrial Environmental Research Laboratory, Research Triangle Park, North Carolina. May.

U.S. Environmental Protection Agency. 1979b. Overview of Pollution from Combustion of Fossil Fuels in Bollers of the United States, EPA-600/7-79-233. Washington, D.C. October.

U.S. Environmental Protection Agency. 1980. Facts and Issues Associated with the Need for a Hydrocarbon Criteria Document (draft). Washington, D.C. February. 
Urone, P. 1976. The Primary Alr Pollutants--Gaseous, Their Occurrences, Source and Effects. In Air Pollution, 3rd ed., vol. 1, ed. A.C. Stern, pp. 23-75. Academic Press, New York.

Van Duuren, B.L. 1969. Carcinogenic Epoxides, Lactones, and Haloethers and Their Mode of Action. Ann. N.Y. Acad. Sc1. 163:633-651.

Whisman, N.L., et al. 1975. Waste Lubricating 011 Research: Geographic and Seasonal Variations in Used Lubricating 011 Base Stock Composition, pt. 2. BERC/RI-75/11. U.S. Energy Research and Development Administration, Bartlesville Energy Research Center, Bartlesville, Oklahoma. December.

Wilson, W.E., L.L. Spiller, T.G. Ellestad, P.G. Lamothe, T.G. Dzubay, R.K. Stevens, E.C. Maclas, R.A. Fletcher, J.D. Husar, R.B. Husar, K.T. Whitby, D.B. Kittelson, and B.K. Cantrell. 1977. General Motors Sulfate Dispersion Experiments: Summary of EPA Measurement. J. Air Pollut. Cont. Assoc. 27:46-51.

Yocum, J.E., W.L. Clink, and W.A. Cote. 1971. Indoor/Outdoor Air Quality Relationship. J. Air Pollut. Cont. Assoc. 21(5):251-259. May.

Yocum, J.E., W.A. Cote, and W.L. Clink. 1974. Measurement of Alr Pollution Penetration into Bullding Interiors. Anal. of Instrumentation, no. 9.

Zielhuis, R.L. 1973. Environmental Health Aspects of Lead. In Commission of the European Communities and the United States Environmental Protection Agency; pp. 631-653. Published by the Commission of the European Communities Directorate General for Dissemination of Knowledge, Centre for Infurmation and Documentation, Luxembourg, Belgium. 


\section{THIS PAGE WAS INTENTIONALLY LEFT BLANK}


UNCONVENTIONAL RESOURCES

LITERATURE CITED

Adams, J.R. 1979. Popping the Cork on Natural Gas. The Wall Street Journal, May 30, p. 24.

American Gas Association. 1970. Diary of an Industry. Arlington, Virginia.

American Gas Association. 1979a. New Technologies for Gas Energy Supply and Efficient Use. F00716. Arlington, Virginia.

American Gas Association. 1979b. Gas Hydrates Occurring in Nature: A B1bllography 1968-1978. H54979. Arlington, Virginia.

Booz-Allen \& Hamilton. 1979. Analysis of Economic Incentives to Stimulate a Synthetic Fuels Industry. In Synthetic Fuels. Report by the Subcommittee on Synthetic Fuels of the Committee on the Budget. U.S. Senate, Washington, D.C. Sept. 27 .

Braun, J. 1979. Hidden Resource--Our Heavy O11. Parade Magazine, Sept. 9, pp. 7-12.

Brown, R.D. 1978. Alaskan Gas Transportation Issues. WP 13357. The MITRE Corporation, McLean, Virginia.

Canada Today/d'aujoral' hui. 1979. Tar Sands. 10(2):4-5.

Dick, R., and S. Wimpfen. 1980. O1l Mining. Scientific American $243(4): 182-189$.

Dillon, W.P. 1980. Unconventional Gas Hydrate Seals May Trap Gas Off Southeast U.S. Oil and Gas Journal, Jan. 7, pp. 124-130.

Energy Research and Development Administration. 1977. Alternative Fuels Demonstration Program: Final Environmental Impact Statement. ERDA-1547. Washington, D.C.

Frazier, N.A., D.W. Hissong, W.E. Ballantyne, and E.J. Mazey. 1976. Production and Processing of U.S. Tar Sands: An Environmental

Assessment. U.S. Environmental Protection Agency, Industrial Environmental Research Laboratory, Cincinnat1, Ohio.

Gold, T., and S. Soter. 1980. The Deep-Earth-Gas Hypothesis. Scientific American 242(6):154-161. 
LITERATURE CITED (Unconventional Resources, Continued)

Ham, R.K., K.K. Hekimian, S.L. Kathen, W.J. Lockman, R.J. Loby, D.E. McFaddin, and E.J. Daley. 1979. Recovery, Processing, and Ut1lization of Gas from Santtary Landfills. EPA-600/2-79-001. Municipal Environmental Research Laboratory, U.S. Environmental Protection Agency, Washington, D.C.

Hocott, C.R. 1979. Unconventional Sources of Gas. Presentation at the 38th Annual Meeting of the Inst1tute of Gas Technology, Chicago, I111nols.

Hodgson, B. 1978. Natural Gas: The Search Goes On. National Geograph1c, November, pp. 632-651.

Iannacchione, A.T., and D.G. Pug110. 1979. Geology of the Lower Kittanning Coalbed and Related Mining and Methane Emission Problems In Cambria County, $\mathrm{Pa}$. Report of Investigations 8354. U.S. Bureau of Mines, Washington, D.C.

Industria1 Research/Development. 1979. Landf111 Site W111 Create Methane. December, p. 66.

Kennedy, T. 1979. New Interest Shown in Canada's Tar Sands. The Washington Post, June 2ú, pp. C7-c8.

Kotkin, J. 1979. California, Rich in Heavy Crude 011, Sees a Boom Coming. The Washington Post, Aug. 28, p. A2.

Lewis, J., ed. 1979. Registry of Toxic Effects of Chemical Substances. National Institute for Occupational Safety and Health, Cincinnati, Ohio.

MacDonald, G.J. 1979. Future of Natural Gas. MP79W00021. The MITRE Corporation, McLean, Virginia.

Mankin, C.J. 1979. Gas Resources and Reserves. Environment $21(1): 25-28$.

Nguyen, V.T., J.F. Caskey, R.T. Pfundstein, and S.B. Rifikin. 1980. Geothermal Energy: Environmental Problems and Control Methods. MTR80W108. The MITRE Corporation, Metrek Division, McLean, Virginia.

Petroleum Extension Service. 1966. Introduction to the 011 Pipeline Industry. 


\section{LITERATURE CITED (Unconventional Resources, Continued)}

Randolph, P. 1979. Unconventional Sources of Gas. Presentation at the 38th Annual Meeting of the Institute of Gas Technology, Chicago, Illinols.

Resources for the Future. 1979. Energy: The Next Twenty Years. Ballinger Publishling Company, Cambridge, Massachusetts.

Rice, G. 1932. Mining for Petroleum by Underground Methods. U.S. Bureau of Mines Bulletin 351. U.S. Department of Commerce, Washington, D.C.

Rothberg, P., L. Crane, R. Trumbule, M. Simmons, A. Kaufman, and S. Bodilly. 1979. Synthetic Fuels from Coal: Status and Outlook of Coal Gasification and Liquefaction. Rept. no. 79-134 SPR. Congressional Research Service, Library of Congress, Washington, D.C.

Schram, M. 1979. Price Controls Lifted on Heavy Crude. The Washington Post, Aug. 18, pp. Al, A4.

Schurr, S., J. Darmstadter, H. Perry, W. Ramsay, and M. Russell. 1979. Energy In America's Future: The Chotces Before Us. Resources for the Future, Inc., Washington, D.C.

Sm1th, J.P. 1979. O11 Mining May Increase U.S. Supply Dramat1cally. The Washington Post, Dec. 3, pp. Al, A4.

Stobaugh, R., and D. Yerg1n, eds. 1979. Energy Future: Report of the Energy Project of the Harvard Business School. Random House, New York.

Technology Forecasts. 1979. Battelle Studies Gas Fracturing Fluid for Shale. August, pp. 14-15.

Tetra Tech., Inc. 1977. Energy Fact Book--1977. TT-A-642-77-306. Arlington, Virginia.

Time. 1979. Energy: Fuels of the Future. June 11, pp. 72-76.

T1ratsoo, E.N. 1979. Natural Gas. Gulf Publishing Company, Houston, Texas.

TRW. 1977. Methane Produced from Coalbeds, vol. 1. Energy Systems Group, Energy Systems Planning Division, McLean, Virginia.

U.S. Department of Energy. 1978. Methane--Dreaded by Coal Miners-Could Become a Source of Energy. Energy Insider 1(29): 3. 
LITERATURE CITED (Unconventional Resources, Concluded)

U.S. Department of Energy. 1979a. Environmental Issues Relating to Fossil Energy Technology Options. DOE/EV-0065. Office of Environment, Washington, D.C.

U.S. Department of Energy. 1979b. Semiannual Report for the Unconventional Gas Recovery Program (period ending Sept. 30, 1978). Morgantown Energy Technology Center, Morgantown, West Virginia.

U.S. Department of Energy. 1979c. Environmental Unconventional Gas Recovery (Enhanced Gas Recovery). DOE/EDP-0049. Washington, D.C.

U.S. Department of Energy. 1979d. Fossil Energy Program: Summary Document. DOE/ET-0087. Washington, D.C.

U.S. Department of Energy. 1979e. Environmental Readiness of Emerging Energy Technologies: Summary Report. DOE/ERD-0022. Washington, D.C.

U.S. Department of Energy. 1980a. Project DEEPSTEAM: DOE: Sandia Field Testing Steam to Free Heavy 011 from Deep Reservoir. Energy Insider $3(8): 4$.

U.S. Department of Energy. 1980b. Fossil Energy Program: Summary Document, FY 1981. Washington, D.C.

U.S. Department of the Interior. 1979. Reports of Investigations (RI): Numbers $8354,8359,8380,8392,8406,8407$. Bureau of Mines, Washington, D.C.

U.S. Department of the Interior. 1980. Reports of Investigations (RI): Numbers $8424,8459,8829$. Bureau of Mines, Washington, D.C.

U.S. Senate. 1979. Synthetic Fuels. Subcommittee on Synthetic Fuels, Committee on the Budget, Washington, D.C. Sept. 27.

The Wall Street Journal. 1979. New Process to Extract Heavy Crude. July $16, p \cdot 14$.

Wilson, J.S., J.R. Hamilton, J.A. Manning, and P.E. Muehlbert. 1977. Environmental Assessment of Geopressured Waters and Their Projected Uses. EPA-600/7-77-039. U.S. Environmental Protection Agency, Industrial Environmental Research Laboratory, Cincinnati, Ohio.

Yeck, R. 1979. Methane From Biomass. Environment 21(1):28-29. 


\section{BASIC EFFECTS ISSUES \\ LITERATURE CITED}

Burr, J.C., and A.B. Clymer. 1976. A1r Modeling in Oh1o, EPA. In: Proceedings of the EPA Conference on Environmental Modeling and SImulation, ed. W.R. Off, pp. 82-85. EPA 600/9-76-016. Office of Research and Development and Office of Planning and Management. Washing ton, D.C.

Corn, M. 1976. Properties of Nonviable Part1cles in A1r. In A1r Pollutants, Their Transformation and Transport, vol. 1, ed. A.D. Stern, pp. 78-168. Academic Pres8, New York.

Crutzen et al. 1976. A Numerical Investigation of Tropospher1c Photochemistry Using a One-Dimensional Model. Paper presented at the Non-Urban Tropospheric Symposium, Hollywood, Florida, Nov. 10-12, 1976.

DeMa1o, L., and M. Corn. 1966. Polynuclear Aromatic Hydrocarbons Assoclated with Particulates in P1ttsburgh Alr. J. Alr Pollut. Cont. Assoc. 16:67-71.

Fuchs, N.A. 1964. The Mechanics of Aerosols. The Pergamon Press, New York.

Haagen-Smit, A.J., and L.G. Wayne. 1976. Atmospheric Reactions and Scavenging Processes. In Alr Pollution, 3rd ed., vol. 1, edited by A.C. Stern. Academic Press, New York.

Heidt, L.E., and W.H. Pollock. 1976. Measurements of $\mathrm{N}_{2} \mathrm{O}, \mathrm{CH}_{4}{ }^{\circ}$ $\mathrm{H}_{2}, \mathrm{CO}$, and $\mathrm{CO}_{2}$ in the Non-Urban Troposphere. Paper presented at the Non-Urban Tropospheric Symposium, Hollywood, Florida, Nov. 10-12, 1976.

National Academy of Sclences. 1976. Vapor-Phase Organlc Pollutants. Washington, D.C.

National Academy of Sclences. 1977. Ozone and Other Photochemical Oxidants. Washington, D.C.

National Research Counc11. 1972. Particulate Polycyclic Organic Matter. National Academy of Sclences, Washington, D.C.

National Research Counc11. 1979. Alrborne Particles. University Park Press, Balt1more, Maryland. 
LITERATURE CITED (Basic Effects, Concluded)

Thomas, J.F., M. Mulka1, and B.D. Tebbens. 1968. Fate of Alrborne Benzo(a) pyrene. Env. Sc1. Tech. 2:33-39.

U.S. Department of Health, Education, and Welfare. 1970: Air Qua1ity Criteria for Hydrocarbons. Washington, D.C. 